Universidade de São Paulo-UsP

Escola de Engenharia de São Carlos

Departamento de Engenharia Elétrica e de Computação Programa de Pós-Graduação em Engenharia Elétrica

\author{
Juliano Coêlho Miranda
}

\title{
Segurança Cibernética com Hardware Reconfigurável em Subestações de Energia Elétrica Utilizando o Padrão IEC 61850
}





\section{Juliano Coêlho Miranda}

\section{Segurança Cibernética com Hardware Reconfigurável em Subestações de Energia Elétrica Utilizando o Padrão IEC 61850}

Tese de doutorado apresentada ao Programa de Engenharia Elétrica da Escola de Engenharia de São Carlos como parte dos requisitos para a obtenção do título de Doutor em Ciências.

Área de concentração: Sistemas Elétricos de Potência

Orientador: Prof. Tit. Denis Vinicius Coury

São Carlos 
AUTORIZO A REPRODUÇÃO TOTAL OU PARCIAL DESTE TRABALHO, POR QUALQUER MEIO CONVENCIONAL OU ELETRÔNICO, PARA FINS DE ESTUDO E PESQUISA, DESDE QUE CITADA A FONTE.

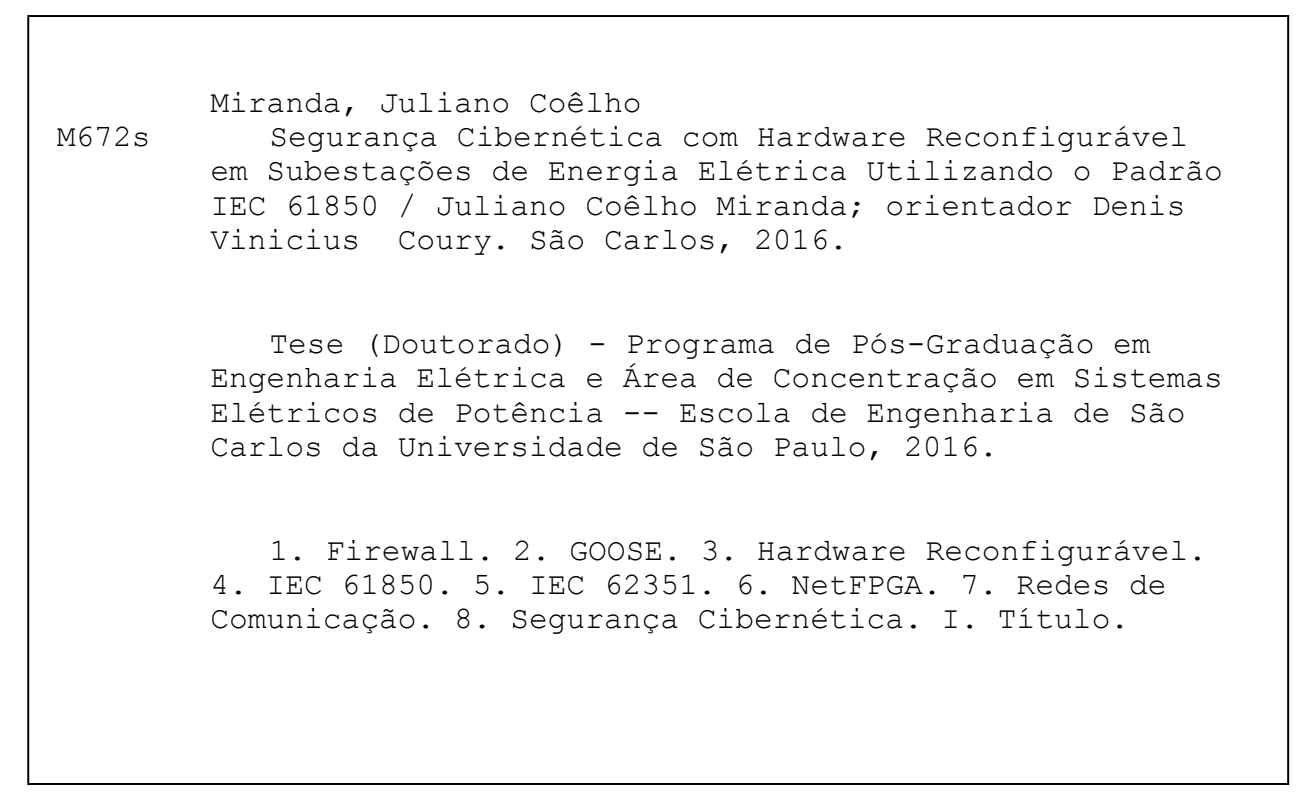




\section{FOLHA DE IULGAMENTO}

Candidato: Licenciado JULIANO COÊLHO MIRANDA.

Título da tese: "Segurança cibernética com hardware reconfigurável em subestações de energia elétrica utilizando o padrão IEC 61850".

Data da defesa: 20/09/2016.

Comissão Julgadora:

Prof. Titular Denis Vinicius Coury

(Orientador)

(Escola de Engenharia de São Carlos/EESC)

Prof. Dr. José Carlos de Melo Vieira Junior

(Escola de Engenharia de São Carlos/EESC)

Prof. Associado Ivan Nunes da Silva

(Escola de Engenharia de São Carlos/EESC)

Prof. Dr. Cesar Augusto Cavalheiro Marcondes

(Universidade Federal de São Carlos/UFSCar)

Prof. Dr. Eduardo Lorenzetti Pellini

(Escola Politécnica/EP-USP)
Resultado:

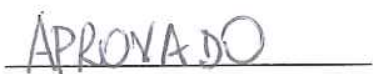

APROVADO

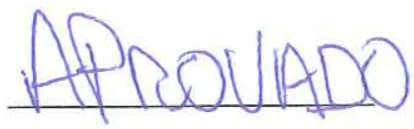

APROVAOO

APROVADO

Coordenador do Programa de Pós-Graduação em Engenharia Elétrica: Prof. Associado Luis Fernando Costa Alberto

Presidente da Comissão de Pós-Graduação:

Prof. Associado Luis Fernando Costa Alberto 

Dedico este trabalho à Viviane e aos nossos queridos filhos, Luiz Felipe e Júlia, pois é preciso amor para poder pulsar. Aos meus pais, Antônio e Roseli, e meu irmão Pedro Paulo, pois é preciso serenidade e exemplos para poder seguir. Aos meus avós Antônio e Arildo, e às minhas avós Mescias e Margarida, pois é preciso amparo e inspiração para viver. 



\section{Agradecimentos}

A Deus, pela indelével inquietação em meu espírito, pelo anseio incontido de buscar novos horizontes, além do horizonte. À minha família, cujos valores transcendem o tempo e o espaço, pelos cuidados, as orações e o amor. A todos que têm auxiliado em favor dos meus filhos, com dedicação, esforço e exemplos, envolvendo-os em carinho.

Ao Professor Tit. Denis Vinicius Coury, da Escola de Engenharia de São Carlos (EESC), Universidade de São Paulo (USP), por compartilhar de forma consciente, dedicada e sincera suas experiências profissionais, e de meus ideais acadêmicos, oportunizar o conhecimento e as facilidades materiais imprescindíveis na estruturação e no desenvolvimento das atividades do Laboratório de Sistemas de Energia Elétrica (LSEE). Pela orientação amiga, pontual e competente.

Ao amigo, Mateus de Freitas Andrade, pelo apoio em todas as atividades que envolveram esta pesquisa. Pelas madrugadas de trabalho com a NetFPGA, Verilog, Mensagens GOOSE, Filtro, Autenticação... Obrigado!

Ao amigo, Guilherme Vitor Vitorino Mendonça, pelo auxílio com a sintaxe abstrata e as regras de codificação, e dedicação durante todo processo de desenvolvimento do módulo ASN.1/BER GOOSE.

Ao amigo, Caio Felipe Zanatelli, pelo apoio e dedicação durante o processo de desenvolvimento do módulo ASN.1/BER GOOSE. Pelas madrugadas de programação em Java, C e Verilog, que resultaram no aplicativo VMG e no módulo de criptografia.

Ao amigo, e companheiro de doutorado, Lázaro Eduardo da Silva que, com chuva, sol, frio ou calor, nas constantes viagens ou nas intermináveis noites de trabalho, esteve sempre disposto a ajudar.

Ao amigo, André Luís Silva Pessoa (EESC/USP), pelas sugestões, a troca de informações e o auxílio na formatação do capítulo de resultados.

Ao amigo Dr. Renato Machado Monaro (EESC/Escola Politécnica/USP) por partilhar continuamente sua competência profissional e conhecimento no que tange aos sistemas elétricos de potência, sistemas de comunicação e linguagem de programação.

Ao Professor Dr. Eduardo Marques (ICMC/USP), pelas sugestões concedidas nas 
disciplinas de Introdução aos Sistemas Embarcados e Pesquisa Científica em Sistemas Embarcados, Evolutivos e Robóticos, e pela preciosa indicação da plataforma NetFPGA.

Ao Professor Dr. Cesar Augusto Cavalheiro Marcondes (DECOM/UFSCar), por compartilhar, de forma pontual e competente, seus conhecimentos pertinentes à plataforma NetFPGA e por permitir o acompanhamento de algumas aulas de Comunicação de Dados. Pelas orientações na defesa da tese.

Ao Professor Dr. Vanderlei Bonato (ICMC/USP), pelas sugestões ministradas durante as disciplinas de Introdução aos Sistemas Embarcados e Computação Reconfigurável.

Ao Professor Dr. Eduardo Nobuhiro Asada (EESC/USP), pelas dicas durante o processo de qualificação.

Aos Professores Dr. Mário Oleskovicz e Dr. José Carlos de Melo Vieira Júnior (EESC/USP), pela postura, dedicação e objetividade com que tratam os assuntos, promovendo facilidade de entendimento e de trabalho. Ao Professor Dr. José Carlos de Melo Vieira Júnior, por aceitar ministrar sua avaliação no que tange a defesa desta tese.

Ao Professor Dr. Eduardo Lorenzetti Pellini (Escola Politécnica/USP), pela minuciosa leitura, pelos questionamentos e valiosas orientações durante os processos de qualificação e defesa.

Ao Professor Dr. Ivan Nunes da Silva (EESC/USP), por propor aulas vivas e condições desafiantes, leia-se facilitadoras, a construção do conhecimento. Pelas oportunas orientações na defesa da tese.

A Professora Dra. Vilma Alves de Oliveira e o Professor Dr. Ricardo Quadros Machado (EESC/USP) pelo empréstimo eventual de um osciloscópio do Laboratório de Controle (LAC).

Aos senhores Mauricio Kobayashi e Rodrigo Maygton Vicentini da Keysight Technologies Brasil, pelo suporte e empréstimo de alguns osciloscópios de alta precisão.

Ao amigo, Carlos Magno B. Araújo, pelas informações compartilhadas e apoio com o osciloscópio.

Ao Professor Ms. Douglas Machado Tavares (CEFET/MG), pela introdução à Linguagem Python.

Aos profissionais, Aparecida Antunes de Souza, César Domingues, Daniel Rogério Manjini, Fernanda Ribeiro Destro de Souza Lima, João Paulo Brognoni Casati, José Carlos de Oliveira, Jussara Ramos Zoia, Marisa Helena R. V. Fortulan, Murilo Rodrigues Moretti, Odair da Silva, Petrussio Gonçalves da Silva, Roseli Ribeiro, Rosenberg Julio da Silva e Rui Bertho pelo atendimento cordial, competente e respeitoso no Departamento de Engenharia Elétrica e Computação (EESC/USP).

Aos amigos do LSEE Rafael Marsolla, Ulisses, Athila, Rui, Guacira, Thais, Gerson, Daniel Motter, Eduardo, Fabricio, Vinícius, Rogério, Jáder, Rodrigo, Ricardo, Leandro, Jeovane, Luiz, Gustavo, Rodolfo, Luciano, Fernando, Carlos, Evandro e a todos que já compartilharam o café das $16 \mathrm{~h}$. 
Ao Centro Federal de Educação Tecnológica de Minas Gerais (CEFET/MG), Unidade Varginha/MG, em especial aos amigos do Departamento de Mecatrônica (DMCVG). Pelo empréstimo de alguns osciloscópios do Laboratório de Automação e Sistemas Embarcados (LASE).

Ao Professor Dr. Paulo Henrique Cruz Pereira (CEFET/MG), por dilatar no meu horizonte o espantoso mundo da Automação e Robótica Industrial. Pela confiança, apoio e amizade.

Ao Professor Dr. Carlos Alberto Carvalho Castro (CEFET/MG), pela orientação compartilhada de trabalhos de iniciação científica, envolvendo a plataforma NetFPGA.

Aos Professores Dr. Fernando Teixeira Filho (in memoriam), Ms. Daniel Soares de Alcântara, Ms. José Eduardo Silva Gomes e Dr. Wanderley Xavier Pereira, pelo apoio e facilidades no harmonizar de minhas atividades profissionais no CEFET/MG.

A Professora Ms. Marlene Carolina de Souza, pelo apoio e revisão gramatical do texto.

Aos amigos do coração Clovis José, Arthur, Fábio Magrini, Jessica, Bela, Bruno, Fabi, Maristela, Roseane, José Donizete e Érika Kress.

À Fundação de Amparo à Pesquisa do Estado de São Paulo, FAPESP, pelo apoio financeiro concedido para a estruturação do Laboratório de Sistemas de Energia Elétrica (LSEE).

Ao CEFET/MG, por meio da Diretoria de Planejamento e Gestão e da Coordenação Geral de Desenvolvimento de Recursos Humanos, pelo apoio financeiro à capacitação de servidores do quadro permanente na realização de cursos de Pós-Graduação. 

Com a força de um moinho que trabalha devagar, vou buscar o meu caminho... 



\title{
Resumo
}

\author{
MIRANDA, Juliano Coêlho. Segurança Cibernética com Hardware Reconfi- \\ gurável em Subestações de Energia Elétrica Utilizando o Padrão IEC 61850. \\ 259 p. Tese de doutorado - Escola de Engenharia de São Carlos, Universidade de São \\ Paulo, 2016.
}

Com a tecnologia digital, as redes de comunicação têm sido de fundamental importância para o bom funcionamento das subestações de energia elétrica. Criado em 2002, o padrão IEC 61850 busca harmonizar a diversidade de equipamentos e fabricantes, e possibilitar a integração de dados para que o máximo de benefícios possa ser extraído. Nesse contexto, o protocolo GOOSE (Generic Object Oriented Substation Event), pertinente ao padrão IEC 61850, é um datagrama multicast concebido para funcionar na rede local ou de longa distância que interliga as subestações de energia elétrica. Nos ambientes de longa distância, o tráfego de dentro para fora, e vice-versa, deveria passar por um firewall. Porém, a tecnologia de firewall atual não é capaz de inspecionar as mensagens GOOSE reais ou originadas a partir de um ataque, e afeta o tempo de transferência das mesmas, que, no enlace de comunicação, não deve exceder $5 \mathrm{~ms}$. Dessa forma, o objetivo deste trabalho é desenvolver um firewall em hardware reconfigurável, por meio da plataforma NetFPGA, de modo que o incremento no tempo de propagação de uma mensagem GOOSE, Tipo 1A (Trip), ao transpor o dispositivo de segurança, não ultrapasse $20 \%$ do tempo total destinado ao enlace de comunicação. Por ter a capacidade de ser um acelerador, construído por meio de hardware reconfigurável FPGA (Field Programmable Gate Array), a NetFPGA conduz enlaces Gigabit, e torna possível examinar e estabelecer regras iniciais de autorização ou negação para o tráfego de mensagens GOOSE, manipulando os campos do quadro ISO/IEC 8802-3. O incremento no tempo máximo de propagação de uma mensagem com 1518 bytes foi de $77,39 \mu$ s, com $77,38 \mu$ s de tempo médio. Um algoritmo de criptografia e outro de autenticação também foram testados e mensagens falsas não conseguiram transpor o firewall. No momento atual da pesquisa, concluiu-se que o firewall 
em NetFPGA, pertinente ao conjunto de recursos de hardware e software destinados a garantir a segurança de uma rede, é capaz de rejeitar mensagens GOOSE falsas e fornecer segurança aos dispositivos ativos de uma subestação, sem atrasos adicionais superiores a $1 \mathrm{~ms}$.

Palavras-chave: Firewall. GOOSE. Hardware Reconfigurável. IEC 61850. IEC 62351. NetFPGA. Redes de Comunicação. Segurança Cibernética. 


\section{Abstract}

MIRANDA, Juliano Coêlho. Cyber Security with Reconfigurable Hardware in Power Substations Using the IEC 61850 Standard. 259 p. Ph.D. Thesis - São Carlos School of Engineering, University of São Paulo, 2016.

With the digital technology, the communication networks have been of fundamental importance for the good performance of power substations. Created in 2002, the IEC 61850 standard seeks for harmonization of the different equipment and manufacturers, enabling the integration of data for maximum performance. In this context, the GOOSE (Generic Object Oriented Substation Event) message, concerning the IEC 61850 standard, is a multicast datagram, designed to operate in LAN or WAN that connects power substations. In the long-distance environment, the propagation time in the communication link must not exceed 5ms. The current firewall technology is not able to differ true GOOSE messages from the ones originated from an attack, and it affects the transfer time of messages. The objective of this research is to develop a reconfigurable firewall hardware, using the NetFPGA platform, so that the increase in propagation time of a GOOSE message, Type 1A (Trip), does not exceed $20 \%$ of the total time allocated to the link communication. Due to the ability of NetFPGA of being an accelerator, and having been built by using reconfigurable FPGA (Field Programmable Gate Array) leading to Gigabit links, it was possible to examine and establish initial rules of authorization or denial of GOOSE messages by manipulating some of the fields from the table ISO/IEC 8802-3. The increase in the maximum propagation time of a message of 1518bytes was $77,39 \mu \mathrm{s}$, with the average of $77,38 \mu \mathrm{s}$. Fake messages failed to cross the firewall. Results from a process of authentication and encryption were also presented. At the present study, it has been concluded that the firewall using NetFPGA, concerning the hardware and software in order to ensure the security of a network, is able to reject false GOOSE messages and provide security to devices of a power substation without time increments greater than $1 \mathrm{~ms}$. 
Keywords: Cyber Security. Firewall. GOOSE. IEC 61850. IEC 62351. NetFPGA. Network Communications. Reconfigurable Hardware. 


\section{Lista de ilustrações}

Figura 1 Topologia de rede típica com firewalls . . . . . . . . . . . . . . . 42

Figura 2 Número de publicações envolvendo o tema IEC 61850, Web of Science ${ }^{\circledR} 49$

Figura 3 Níveis e interfaces lógicas no Sistema de Automação da Subestação (SAS) 52

Figura 4 Noção de conexão e Logical Node (LN) . . . . . . . . . . . . . . . . . . 53

Figura 5 Modelo de dados . . . . . . . . . . . . . . . . . . 54

Figura 6 Nó lógico XCBR . . . . . . . . . . . . . . . . . 56

Figura 7 Estrutura da linguagem de configuração da subestação $\quad$. . . . . . . . . 58

Figura $8 \quad$ Fragmento de um arquivo Substation Configuration Language (SCL) . . 58

Figura 9 Método de comunicação ACSI . . . . . . . . . . . . . . . . . . . . 60

Figura 10 Estrutura do LN, tipo de informação e atributos . . . . . . . . . . . . . . 62

Figura 11 Representação simplificada da pilha de protocolos IEC 61850 . . . . . . 65

Figura 12 A mensagem GOOSE e o conceito de descentralização autônoma . . . . 68

Figura 13 Pilha de comunicação da mensagem GOOSE . . . . . . . . . . . . . . . 69

Figura 14 Formas de codificação . . . . . . . . . . . . . . . . . . . . . 71

Figura 15 Código do identificador de tipo . . . . . . . . . . . . . . . . . . . 72

Figura 16 Codificação de tamanho - (a) Forma curta (b) Forma longa . . . . . . . 72

Figura 17 Visão geral do quadro ISO/IEC 8802-3 para GSE-GOOSE . . . . . . . 73

Figura 18 Exemplo dos campos de um quadro ISO/IEC 8802-3 - Mensagem GOOSE 78

Figura 19 Transmissão de mensagens GOOSE . . . . . . . . . . . . . . . . . . . . 79

Figura 20 Arranjo para geração das mensagens GOOSE aleatórias . . . . . . . . . . 81

Figura 21 Objetivos definidos para as classes GOOSE e allData . . . . . . . . . . 81

Figura 22 Codificadores definidos . . . . . . . . . . . . . . . . . 82

Figura 23 Exemplo de uma mensagem GOOSE gerada pelo RGGM . . . . . . . . 83

Figura 24 Total de incidentes reportados ao CERT.br . . . . . . . . . . . . . . . 86

Figura 25 Tipos de ataques reportados $(\%)(2015) \ldots \ldots$. . . . . . . . . . . . 88

Figura 26 Origem dos ataques reportados . . . . . . . . . . . . . . . . . . . 88

Figura 27 Pontos básicos de vulnerabilidade de uma subestação . . . . . . . . . . . 90 
Figura 28 Modelo para segurança de rede . . . . . . . . . . . . . . . . . . . . 92

Figura 29 Conceito de aplicação do firewall . . . . . . . . . . . . . . . . . . . . . 95

Figura 30 Arquitetura dual-homed host . . . . . . . . . . . . . . . . . . . . 97

Figura 31 Arquitetura sreened host . . . . . . . . . . . . . . . . . 98

Figura 32 Arquitetura screened subnet . . . . . . . . . . . . . . . . . . . 99

Figura 33 Modelo simplificado da criptografia convencional . . . . . . . . . . . 100

Figura 34 Criptografia de chave assimétrica . . . . . . . . . . . . . . . . . 103

Figura 35 MsAC criado pelo emissor e verificado pelo receptor . . . . . . . . . . . 104

Figura 36 Conceito geral do HMAC . . . . . . . . . . . . . . . . . 105

Figura 37 Autenticação das mensagens/protocolos GOOSE e SMV . . . . . . . . 109

Figura 38 Diagrama simplificado de blocos da plataforma NetFPGA . . . . . . . 114

Figura 39 Identificação dos componentes da NetFPGA-V2 . . . . . . . . . . . . . 116

Figura 40 Estrutura modular da plataforma NetFPGA-V2 . . . . . . . . . . . . 118

Figura 41 Formato interno dos quadros Ethernet na plataforma NetFPGA . . . . 119

Figura 42 Pipeline de referência . . . . . . . . . . . . . . . . . . . 120

Figura 43 Sinais pertinentes à interface de comunicação entre módulos . . . . . . 122

Figura 44 Reutilização de módulos para um projeto . . . . . . . . . . . . . . . . . 123

Figura 45 Organização interna de uma FIFO stack . . . . . . . . . . . . . . . . . 124

Figura 46 Ponteiros da FIFO . . . . . . . . . . . . . . . . . . . . . 124

Figura 47 Módulos que compõem o decodificador ASN.1/BER GOOSE . . . . . . 125

Figura 48 Formato do quadro ISO/IEC 8802-3 dentro da NetFPGA-V2 . . . . . . 126

Figura 49 Modelo e exemplo utilizado para a decodificação . . . . . . . . . . . . . 127

Figura 50 Diagrama do fluxo de dados do modelo . . . . . . . . . . . . . . . . 129

Figura 51 Design dos módulos GFIXED e GPDU (As linhas pontilhadas são exclusivas do módulo GPDU) . . . . . . . . . . . . . . . . . . . . . 130

Figura $52 \quad$ FSM do módulo goose_fixed . . . . . . . . . . . . . . . . . . 131

Figura 53 Simulação de captura dos campos Destination Address até o Reserved

2, para a mensagem GOOSE que compõe a Figura 49(b) . . . . . . . . 132

Figura $54 \quad$ FSM do módulo goose_PDU . . . . . . . . . . . . . . . . 133

Figura 55 Exemplo da captura de um trecho do campo flexível gocbRef . . . . . . 135

Figura 56 Leitura dos campos da matriz . . . . . . . . . . . . . . . . 136

Figura 57 Sumário de utilização e distribuição lógica do design- Projeto ASN.1/BER

GOOSE (Route 1 e 2) . . . . . . . . . . . . . . . . . 137

Figura 58 Topologia de ensaio - Estrutura laboratorial . . . . . . . . . . . . . . 139

Figura 59 Dispositivos reais da topologia de ensaio - LSEE/EESC/USP (\#1) . . 140

Figura 60 Trechos das telas do VMG . . . . . . . . . . . . . . . . . . 142

Figura $61 \quad$ User Data Path Módulo Filter. . . . . . . . . . . . . . . . . . . . 145

Figura 62 Modelo de filtragem do quadro ISO/IEC 8802-3 . . . . . . . . . . . . 147 
Figura 63 Exemplos de filtros que podem ser configurados . . . . . . . . . . . . 148

Figura 64 FSM do módulo Filter . . . . . . . . . . . . . . . . . . . . . . . . . . . 149

Figura 65 Lógica de atuação do estado Fixed_Field para 2 filtros . . . . . . . . . . 150

Figura 66 Lógica de atuação do estado Wait para 2 filtros . . . . . . . . . . . . . 151

Figura 67 Lógica de atuação do estado Verify para 2 filtros . . . . . . . . . . . . 151

Figura 68 Exemplo de um Filtro para o campo Destination Address . . . . . . . . 153

Figura 69 Sumário de utilização e distribuição lógica do design - Projeto Filter

(Route 1 e 2) . . . . . . . . . . . . . . . . . 153

Figura 70 Operação XOR para criptografia de um texto claro . . . . . . . . . . . 154

Figura 71 Representação geral do algoritmo de encriptação DES . . . . . . . . . . 155

Figura $72 \quad$ User Data Path Módulo Crypto . . . . . . . . . . . . . . . . . . . . . . 156

Figura 73 Formato do quadro ISO/IEC 8802-3 criptografado . . . . . . . . . . . . 157

Figura $74 \quad$ FSM geral do sistema Crypto . . . . . . . . . . . . . . . . . . . 158

Figura 75 Exemplo da criptografia XOR - Chave 0x53179bdf02468ace . . . . . . . 159

Figura 76 Exemplo da criptografia DES - Chave 0x53179bdf02468ace . . . . . . . 160

Figura 77 Tela de configuração do módulo Crypto . . . . . . . . . . . . . . . . . . 160

Figura 78 Sumário de utilização e distribuição lógica do design - Projeto XOR (Route 1 e 2) . . . . . . . . . . . . . . . . . . . 161

Figura 79 Sumário de utilização e distribuição lógica do design - Projeto DES (Route 1 e 2) . . . . . . . . . . . . . . . . . 161

Figura 80 User Data Path módulo Authentication $T X$ e $R X$, respectivamente . . 163

Figura 81 FSM sumarizada do módulo Authentication $T X \ldots 164$

Figura 82 Resultado da autenticação com SHA-3 512 bits . . . . . . . . . . . . . 165

Figura 83 FSM sumarizada do módulo Authentication_RX . . . . . . . . . 165

Figura 84 Sumário de utilização e distribuição lógica do design - Projeto Authentication_TX (Route 1) . . . . . . . . . . . . . 167

Figura 85 Sumário de utilização e distribuição lógica do design - Projeto Authentication_RX (Route 1) . . . . . . . . . . . . . 167

Figura 86 Arranjo do ensaio com os módulos Authentication TX e RX . . . . 168

Figura 87 Resultado da autenticação e do ataque . . . . . . . . . . . . . . . . . 170

Figura 88 Dispositivos reais da topologia de ensaio - LSEE/EESC/USP (\#2) . . 171

Figura 89 Diagrama de blocos em alto nível dos sinais RGMII - PHY . . . . . . . 174

Figura 90 Medida do tempo de transferência/latência (LIFO) . . . . . . . . . . . 174

Figura 91 Boxplot do tempo de transferência por tamanho da mensagem, considerando todos os módulos . . . . . . . . . . . . . . . . . . 178

Figura 92 Gráfico de barras do tempo de transferência médio por tamanho da mensagem, com barras de erro representando o mínimo e o máximo, considerando todos os módulos . . . . . . . . . . . . . . . . . . . . 179 
Figura 93 Boxplot do tempo de transferência por módulo, considerando todos os tamanhos da mensagem . . . . . . . . . . . . . . . . . . 181

Figura 94 Gráfico de barras, representando a média do tempo de transferência por módulo, com barras de erro representando o mínimo e o máximo, considerando todos os tamanhos da mensagem . . . . . . . . . . . . . 182

Figura 95 Gráfico de linhas das médias do tempo de transferência entre os tamanhos da mensagem e os módulos . . . . . . . . . . . . . . . . . 183

Figura 96 Gráficos de barras do valor máximo (a) e da amplitude (b) do tempo de transferência, por tamanho da mensagem estratificada para o módulo 1183

Figura 97 Gráficos de barras do valor máximo (a) e da amplitude (b) do tempo de transferência, por tamanho da mensagem estratificada para o módulo 2184

Figura 98 Gráficos de barras do valor máximo (a) e da amplitude (b) do tempo de transferência por, tamanho da mensagem estratificada para o módulo 3184

Figura 99 Gráficos de barras do valor máximo (a) e da amplitude (b) do tempo de transferência por, tamanho da mensagem estratificada para o módulo 4185

Figura 100 Gráficos de barras do valor máximo (a) e da amplitude (b) do tempo de transferência por, tamanho da mensagem estratificada para o módulo 5185

Figura 101 Gráficos de barras do valor máximo (a) e da amplitude (b) do tempo de transferência por, tamanho da mensagem estratificada para o módulo 6186

Figura 102 Gráficos de barras do valor máximo (a) e da amplitude (b) do tempo de transferência por, tamanho da mensagem estratificada para o módulo 7186

Figura 103 Gráficos de barras do valor máximo (a) e da amplitude (b) do tempo de transferência por, tamanho da mensagem estratificada para o módulo 8187

Figura 104 Gráficos de barras do valor máximo (a) e da amplitude (b) do tempo de transferência por, tamanho da mensagem estratificada para o módulo 9187

Figura 105 Gráficos de barras do valor máximo (a) e da amplitude (b) do tempo de transferência por, tamanho da mensagem estratificada para o módulo 10188

Figura 106 Gráfico de linhas das médias do tempo de transferência entre os módulos e os tamanhos da mensagem . . . . . . . . . . . . . . . 190

Figura 107 Gráficos de barras do valor máximo (a) e da amplitude (b) do tempo de transferência, por módulo estratificado para o tamanho da mensagem de 69B . . . . . . . . . . . . . . . . . . . . 190

Figura 108 Gráficos de barras do valor máximo (a) e da amplitude (b) do tempo de transferência, por módulo estratificado para o tamanho da mensagem de 128 B . . . . . . . . . . . . . . . . . . . . . . . 191

Figura 109 Gráficos de barras do valor máximo (a) e da amplitude (b) do tempo de transferência, por módulo estratificado para o tamanho da mensagem

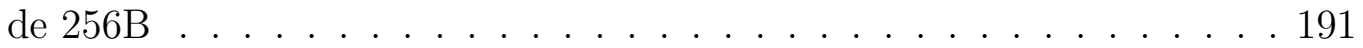


Figura 110 Gráficos de barras do valor máximo (a) e da amplitude (b) do tempo de transferência, por módulo estratificado para o tamanho da mensagem de 409B . . . . . . . . . . . . . . . . . . . . . . . . 192

Figura 111 Gráficos de barras do valor máximo (a) e da amplitude (b) do tempo de transferência, por módulo estratificado para o tamanho da mensagem de 512B . . . . . . . . . . . . . . . . . . . . . 192

Figura 112 Gráficos de barras do valor máximo (a) e da amplitude (b) do tempo de transferência, por módulo estratificado para o tamanho da mensagem de $768 \mathrm{~B}$

Figura 113 Gráficos de barras do valor máximo (a) e da amplitude (b) do tempo de transferência, por módulo estratificado para o tamanho da mensagem de 1024B

Figura 114 Gráficos de barras do valor máximo (a) e da amplitude (b) do tempo de transferência, por módulo estratificado para o tamanho da mensagem de $1280 \mathrm{~B}$

Figura 115 Gráficos de barras do valor máximo (a) e da amplitude (b) do tempo de transferência, por módulo estratificado para o tamanho da mensagem de $1500 \mathrm{~B}$

Figura 116 Gráficos de barras do valor máximo (a) e da amplitude (b) do tempo de transferência, por módulo estratificado para o tamanho da mensagem de $1518 \mathrm{~B}$

Figura 117 Gráficos de barras do valor máximo (a) e da amplitude (b) do tempo de transferência, por tamanho da mensagem estratificada pela soma dos módulos M1 e M1

Figura 118 Gráficos de barras do valor máximo (a) e da amplitude (b) do tempo de transferência, por tamanho da mensagem estratificada pela soma dos módulos M2 e M2

Figura 119 Gráficos de barras do valor máximo (a) e da amplitude (b) do tempo de transferência, por tamanho da mensagem estratificada pela soma dos módulos M3 e M3

Figura 120 Gráficos de barras do valor máximo (a) e da amplitude (b) do tempo de transferência, por tamanho da mensagem estratificada pela soma dos módulos M4 e M4 . . . . . . . . . . . . . . . . . . . . . . . . . . . 199

Figura 121 Gráficos de barras do valor máximo (a) e da amplitude (b) do tempo de transferência, por tamanho da mensagem estratificada pela soma dos módulos M5 e M5 . . . . . . . . . . . . . . . . . . . . . 200

Figura 122 Gráficos de barras do valor máximo (a) e da amplitude (b) do tempo de transferência, por tamanho da mensagem estratificada pela soma dos módulos M6 e M6 
Figura 123 Gráficos de barras do valor máximo (a) e da amplitude (b) do tempo de transferência, por tamanho da mensagem estratificada pela soma dos módulos M7 e M8 . . . . . . . . . . . . . . . . . . . . . . . . . . 201

Figura 124 Gráficos de barras do valor máximo (a) e da amplitude (b) do tempo de transferência, por tamanho da mensagem estratificada pela soma dos módulos M9 e M10 . . . . . . . . . . . . . . . . . . . . . . . . 201

Figura 125 Gráficos de barras do valor máximo (a) e da amplitude (b) do tempo de transferência, por tamanho da mensagem estratificada pela soma dos módulos M3, M6 e M9 . . . . . . . . . . . . . . . . . . . . . 203

Figura 126 Gráficos de barras do valor máximo (a) e da amplitude (b) do tempo de transferência, por tamanho da mensagem estratificada pela soma dos módulos M3, M7 e M9 . . . . . . . . . . . . . . . . . . . . . . . . . 203

Figura 127 Gráficos de barras do valor máximo (a) e da amplitude (b) do tempo de transferência, por tamanho da mensagem estratificada pela soma dos módulos M4, M6 e M9 . . . . . . . . . . . . . . . . . . . . . 204

Figura 128 Gráficos de barras do valor máximo (a) e da amplitude (b) do tempo de transferência, por tamanho da mensagem estratificada pela soma dos módulos M4, M7 e M9 . . . . . . . . . . . . . . . . . . . . . 204

Figura 129 Gráficos de barras do valor máximo (a) e da amplitude (b) do tempo de transferência, por tamanho da mensagem estratificada pela soma dos módulos M5, M6 e M9 . . . . . . . . . . . . . . . . . . . 205

Figura 130 Gráficos de barras do valor máximo (a) e da amplitude (b) do tempo de transferência, por tamanho da mensagem estratificada pela soma dos módulos M5, M7 e M9 . . . . . . . . . . . . . . . . . . 205

Figura 131 Gráficos de barras do valor máximo (a) e da amplitude (b) do tempo de transferência, por tamanho da mensagem estratificada pela soma dos módulos M3, M6 e M10 . . . . . . . . . . . . . . . . . . 206

Figura 132 Gráficos de barras do valor máximo (a) e da amplitude (b) do tempo de transferência, por tamanho da mensagem estratificada pela soma dos módulos M4, M6 e M10 . . . . . . . . . . . . 206

Figura 133 Gráficos de barras do valor máximo (a) e da amplitude (b) do tempo de transferência, por tamanho da mensagem estratificada pela soma dos módulos M5, M6 e M10 . . . . . . . . . . . . . . . . . . 207

Figura 134 Gráficos de barras do valor máximo (a) e da amplitude (b) do tempo de transferência, por tamanho da mensagem estratificada pela soma dos módulos M3, M8 e M10 . . . . . . . . . . . . . . . 207

Figura 135 Gráficos de barras do valor máximo (a) e da amplitude (b) do tempo de transferência, por tamanho da mensagem estratificada pela soma dos módulos M4, M8 e M10 . . . . . . . . . . . . . . . . . . . . 208 
Figura 136 Gráficos de barras do valor máximo (a) e da amplitude (b) do tempo de transferência, por tamanho da mensagem estratificada pela soma dos módulos M5, M8 e M10 . . . . . . . . . . . . . . . . . . 208

Figura 137 Medida do Throughput entre módulos estratificado por TM . . . . . . . 209 



\section{Lista de tabelas}

Tabela 1 Documentos básicos que definem o padrão IEC 61850 . . . . . . . . . . 51

Tabela 2 Grupo de LN . . . . . . . . . . . . . . . . . . 55

Tabela 3 Arquivos de configuração da SCL . . . . . . . . . . . . . . . . . 57

Tabela 4 CDCs citadas no padrão IEC 61850 parte $7.3 \ldots$. . . . . . . . . . 61

Tabela 5 Exemplo de definição dos tipos de atributos . . . . . . . . . . . . 63

Tabela 6 Anatomia de uma classe de proteção ativa (ACT), funcionalidade de

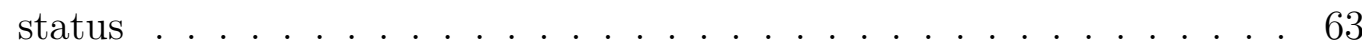

Tabela 7 Anatomia do nó lógico (XCBR), Disjuntor . . . . . . . . . . . . . 64

Tabela 8 Combinações de serviços dos protocolos . . . . . . . . . . . . . 66

Tabela 9 Tipos de mensagem e classes de desempenho . . . . . . . . . . . . . . 67

Tabela 10 Tipos de dados básicos ASN.1 . . . . . . . . . . . . . . . . . 71

Tabela 11 Tipos de dados ASN.1 para mensagens GOOSE . . . . . . . . . . . . 73

Tabela 12 Descrição dos campos fixos . . . . . . . . . . . . . . . . . . . . 74

Tabela 13 Descrição dos campos flexíveis - GOOSE Header . . . . . . . . . . . . 75

Tabela 14 Exemplo de endereço multicast recomendado . . . . . . . . . . . . . 80

Tabela 15 Lista de vulnerabilidades e riscos envolvidos no acesso remoto (nível de bay) . . . . . . . . . . . . . . . . . . . . 91

Tabela 16 Iniciativas em segurança cibernética para o sistema de energia elétrica 107

Tabela 17 Identificação das portas Gigabit Ethernet no OS . . . . . . . . . . . . . 121

Tabela 18 Sinais da interface do módulo, com o barramento de pacotes . . . . . . 122

Tabela 19 Descrição do tempo de transferência (ms) entre os tamanhos da mensagem, considerando todos os módulos . . . . . . . . . . . . . . 177

Tabela 20 Comparação do tempo de transferência (ms) entre os tamanhos da mensagem, considerando todos os módulos . . . . . . . . . . . . . 178

Tabela 21 Descrição do tempo de transferência (ms) entre os módulos, considerando todos os tamanhos da mensagem . . . . . . . . . . . . . 180 
Tabela 22 Comparação do tempo de transferência (ms) entre os módulos, considerando todos os tamanhos da mensagem . . . . . . . . . . . . . 180

Tabela 23 Regressão Gama para o tempo de transferência, a partir da interação entre o tamanho da mensagem e os módulos . . . . . . . . . . . . . 196

Tabela 24 Exemplo de 7 itens do allData com o tipo "dado_1" . . . . . . . . . 229

Tabela 25 Exemplo de itens do allData com o tipo "dado_2" . . . . . . . . . . 231

Tabela 26 Exemplo de itens do allData com o tipo "dado_3" . . . . . . . . . . 231

Tabela 27 Tamanho da amostra por módulo, em cada tamanho de mensagem, variando o nível de significância e o poder do teste . . . . . . . . . . . 234

Tabela 28 Descrição do tempo de transferência (ms) entre os tamanhos da mensagem, estratificada por módulo . . . . . . . . . . . . . . . . 235

Tabela 29 Comparação do tempo de transferência (ms) entre os tamanhos da mensagem estratificada por módulo . . . . . . . . . . . . . . . 238

Tabela 30 Descrição do tempo de transferência (ms) entre os módulos, estratificados por tamanho da mensagem. . . . . . . . . . . . . . . . . . . . . . 241

Tabela 31 Comparação do tempo de transferência (ms) entre os módulos, estratificados por tamanho da mensagem . . . . . . . . . . . . . . . . 243

Tabela 32 Descrição do tempo de transferência (ms) entre os tamanhos da mensagem estratificada pela soma dos módulos 2 a 2 . . . . . . . . . . . 247

Tabela 33 Comparação do tempo de transferência entre os tamanhos da mensagem, estratificada pela soma dos módulos 2 a 2 . . . . . . . . . . . . . 249

Tabela 34 Descrição do tempo de transferência (ms) entre os tamanhos da mensagem estratificada, pela soma dos módulos 3 a 3 . . . . . . . . . . 253

Tabela 35 Comparação do tempo de transferência (ms) entre os tamanhos da mensagem estratificada pela soma dos módulos 3 a 3 . . . . . . . . 256 


\section{Lista de algoritmos}

1 Trecho da codificação ASN.1 - Mensagem GOOSE . . . . . . . . . . . . . 70

2 Trecho da codificação ASN.1 - Campo allData . . . . . . . . . . . . . . . . 77

3 Número de registradores que compõe o campo . . . . . . . . . . . . . . . . 128

4 Passos para validar o módulo Filter . . . . . . . . . . . . . . . . . . . . . 152

5 Passos para validar o módulo Crypto . . . . . . . . . . . . . . . . . 158

6 Pseudocódigo do RGGM . . . . . . . . . . . . . . . . . . . . . . 230 



\section{Lista de siglas}

ACL Access Control List

ACSI Abstract Communication Service Interface

ACT Protection Activation Information

ANEEL Agência Nacional de Energia Elétrica

APDU Application Protocol Data Unit

APPID Application Identifier

ASIC Application Specific Integrated Circuit

ASN.1 Abstract Syntax Notation One

BER Basic Encoding Rules

CAD Computer Aided Design

CBR Circuit Breaker

CDC Commom Data Classes

CFI Canonical Format Identifier

CID Configured Intelligent Electronic Device (IED) Description

CIP Critical Infrastructure Protecion

CPU Central Processing Unit

CSI Computer Security Institute

CSMA/CD Carrier Sense Multiple Access/Collision Detection

CSWG Cyber Security Working Group 
DBM Debugger of the Message

DDR2 Double Data Rate

DES Data Encryption Standard

DMZ DeMilitarized Zone

DNP Distributed Network Protocol

DoS Denial of Service

DRAM Dynamic Random Access Memory

EESC Escola de Engenharia de São Carlos

EPRI Eletric Power Research Institute

FBI Federal Bureau of Investigation

FC Functional Constraints

FCS Frame Check Sequence

FDDI Fiber Distributed Data Interface

FIFO First-In First-Out

FIPS Federal Information Processing Standard

FPGA Field Programmable Gate Array

FSM Finite State Machine

GFIXED Message GOOSE Fixed

GOOSE Generic Object Oriented Substation Event

GM GOOSE Message

GoCB GOOSE Control Block

GPDU Protocol Data Unit GOOSE

GSE Generic Substation Events

GSSE Generic Substation State Events

HDL Hardware Description Language

HMAC Hash-based Message Authentication Code 
HSR High-availability Seamless Redundancy

ICCP Inter-Control Center Communications Protocol

ICD IED Capability Description

IDE Integrated Development Environment

IDS Intrusion Detection Systems

IEC International Electrotechnical Commission

IEC TC Technical Committee

IEC TR Technical Report

IED Intelligent Electronic Device

IEEE Institute of Electrical and Electronics Engineers

IP Internet Protocol

IP Core Intellectual Property Core

IPv4 Internet Protocol version 4

ISA International Society of Automation

ISO International Organization for Standartization

I/O Input/Output

JTAG Joint Test Action Group

LC Logical Connections

LD Logical Devide

LIFO Last-In First-Out

LN Logical Node

LSEE Laboratório de Sistemas de Energia Elétrica

LUT Look-up Table

MAC Media Access Controllers

MGIO Multi-Gigabit I/O

MMS Manufacturing Message Specification 
MsAC Message Authentication Code

NBS National Bureau of Standards

NERC North American Electric Reliability Corporation

nGM no GOOSE Message

NIC Network Interface Card

NIST National Institute of Standards and Technology

NWIP New Work Item Proposal

OS Operating System

OSI Open Systems Interconnection

PC Physical Connections

PCB Printed Circuit Board

PCI Peripheral Component Interconnect

PD Physical Devices

PDU Protocol Data Unit

PHY Physical Layer Devices

PRP Parallel Redundancy Protocol

PSRC Power Systems Relay Committee

PTP Precision Time Protocol

QE Qualidade de Energia

RGGM Random Generator GOOSE Messages

RGMII Reduced Gigabit Media Independent Interface

RISI Repository of Industrial Security Incidents

RM-OSI Reference Model - Open Systems Interconnection

SAS Sistema de Automação da Subestação

SATA Serial Advance Technology Attachment

SCADA Supervisory Control and Data Acquisition 
SCD Substation Configuration Description

SCL Substation Configuration Language

SCPI Standard Commands for Programmable Instruments

SCSM Specific Communication Service Mapping

SDRAM Synchronous Dynamic Random Access Memory

SEP Sistema Elétrico de Potência

SFD Start Frame Delimiter

SGIP Smart Grid Interoperability Panel

SHA-1 Secure Hash Algorithm 1

SMV Sampled Measured Values

SNTP Simple Network Time Protocol

SRAM Static Random Access Memory

SSD System Specification Description

STO Security Through Obscurity

SV Sampled Values

TA Automation Technology

TC Transformador de Corrente

TCI Tag Control Information

TCP Transmission Control Protocol

TCP/IP Transmission Control Protocol/Internet Protocol

TI Tecnologia da Informação

TP Transformador de Potencial

TPID Tag Protocol Identifier

TrgOp Trigger Option

UCA Utility Communications Architecture

UDP User Datagram Protocol 
USP Universidade de São Paulo

UTP Unshielded Twisted Pair

WAN Wide Area Network

WIP Work in Progress

Verilog Verilog Hardware Description Language

VID VLAN Identifier

VLAN Virtual Local Area Network

VMG Validator GOOSE Messages

XML eXtender Markaup Language 


\section{Sumário}

1 Introdução $\quad 39$

1.1 Contextualização do Problema . . . . . . . . . . . . . . . . . . . . . . . . 40

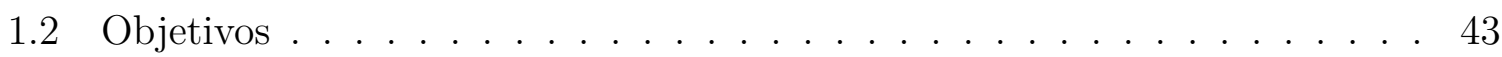

1.3 Contribuições da Pesquisa . . . . . . . . . . . . . . . . . . . . . 43

1.4 Limitações da Pesquisa . . . . . . . . . . . . . . . . . . . . . . . . . . . 44

1.4.1 Formato do Quadro . . . . . . . . . . . . . . . . 44

1.4 .2 Casos de Uso . . . . . . . . . . . . . . . . . . . . . . 45

1.5 Organização do Texto . . . . . . . . . . . . . . . . . . . 45

$2 \quad$ O Padrão IEC 61850 e o Protocolo GOOSE $\quad 47$

2.1 Histórico IEC $61850 \ldots \ldots$. . . . . . . . . . . . . . . . . . 47

2.2 Revisão Bibliográfica . . . . . . . . . . . . . . . . . . . . 48

2.3 Composição e Objetivo . . . . . . . . . . . . . . . . . . . . . . 50

2.4 Requisitos de Comunicação . . . . . . . . . . . . . . . . . . . . . . . 50

2.4 .1 Nó Lógico, LN . . . . . . . . . . . . . . . . . . . . . . . 53

2.4.2 Grupo de Nós Lógicos . . . . . . . . . . . . . . . . . . . . . . . 54

2.5 Linguagem de Configuração . . . . . . . . . . . . . . . . . . . . . . . . 56

2.6 Estrutura de Comunicação . . . . . . . . . . . . . . . . . . . . . 59

2.6.1 Serviço de Interface de Comunicação Abstrata, ACSI . . . . . . . . 59

2.6.2 Classe Comum de Dados, CDC . . . . . . . . . . . . . . . . 61

2.6.3 Compatibilidade entre Nós Lógicos e Classes de Dados . . . . . . . 62

2.7 Mapeamento de Serviços Específicos de Comunicação . . . . . . . . . . . 64

2.7.1 Tipos de Mensagem . . . . . . . . . . . . . . . 66

2.7.2 A Mensagem GOOSE . . . . . . . . . . . . . . . 67

2.8 Gerador RGGM-61850 . . . . . . . . . . . . . . . . 80

3 Concepções de Segurança nas Subestações $\quad 85$

3.1 A Subestação como Ponto Vulnerável do Sistema Elétrico . . . . . . . . . 89 
3.2 Modelo de Referência de Segurança . . . . . . . . . . . . . . . . . . . 92

3.3 Firewall . . . . . . . . . . . . . . . . . . . . . . . 94

3.3.1 Tipos de Firewalls . . . . . . . . . . . . . . . . . . . . . . . 95

3.3 .2 As Arquiteturas de Firewalls . . . . . . . . . . . . . . . . . . . 97

3.4 Criptografia e Autenticação . . . . . . . . . . . . . . . . . . . . . . . . . 99

3.4.1 O Processo de Criptografia . . . . . . . . . . . . . . . . . . 99

3.4 .2 O Processo de Autenticação . . . . . . . . . . . . . . . . . 103

3.5 Organizações e Padrões . . . . . . . . . . . . . . . . . . . . . 106

3.6 O Padrão IEC $62351 \ldots \ldots$. . . . . . . . . . . . . . . . 106

3.6.1 Histórico e Composição do Padrão IEC 62351 . . . . . . . . . . . . 106

3.6.2 IEC 62351-6, Perfil de Segurança para IEC 61850 . . . . . . . . . . 108

4 Decodificador ASN.1/BER GOOSE $\quad 111$

4.1 Definição do Problema . . . . . . . . . . . . . . . . . . . . . 111

4.2 Revisão Bibliográfica . . . . . . . . . . . . . . . . . . . . . . . 112

4.3 A Plataforma NetFPGA . . . . . . . . . . . . . . . . . . . . . 112

4.3 .1 Início do Projeto e Objetivo . . . . . . . . . . . . . . . . . 113

4.3 .2 NetFPGA Versão 1 . . . . . . . . . . . . . . . . . . . . . 114

4.3 .3 NetFPGA Versão 2 . . . . . . . . . . . . . . . . . . 115

4.3.4 Estrutura Modular da NetFPGA-V2 . . . . . . . . . . . . . . . 118

4.4 O Módulo de Decodificação . . . . . . . . . . . . . . . . . . . . . . . . . . 124

4.5 O Formato da Mensagem GOOSE dentro do Módulo . . . . . . . . . . . . 125

4.6 Modelo do Decodificador . . . . . . . . . . . . . . . . . 126

4.7 Fluxo de Dados do Modelo . . . . . . . . . . . . . . . . . . . . 128

4.8 O Design dos Módulos . . . . . . . . . . . . . . . . . . . . . . 130

4.8.1 A FSM do Módulo Message GOOSE Fixed (GFIXED) . . . . . . . 130

4.8.2 A FSM do Módulo Protocol Data Unit GOOSE (GPDU) . . . . . 132

4.9 Ocupação do Hardware - Módulo ASN.1/BER GOOSE . . . . . . . . . . 137

4.10 Sistema de Ensaio ASN.1/BER GOOSE . . . . . . . . . . . . . . . . . 138

4.10.1 Softwares Utilizados pelo ASN.1/BER GOOSE . . . . . . . . . . . 138

4.10.2 Ensaios Realizados ASN.1/BER GOOSE . . . . . . . . . . . . . . 142

4.10 .3 Resultados ASN.1/BER GOOSE . . . . . . . . . . . . . . . . 143

$5 \quad$ Firewall em Hardware Reconfigurável 145

5.1 O Módulo Filter . . . . . . . . . . . . . . . . . . . . . . . . . . . . . . 145

5.1 .1 Modelo do Filtro . . . . . . . . . . . . . . . . 146

5.1 .2 O Design do Filter . . . . . . . . . . . . . . . . . . . . . . 148

5.1.3 Ensaios Realizados com o Filter . . . . . . . . . . . . . . 150

5.2 O Módulo Crypto . . . . . . . . . . . . . . . . . . 154

$5.2 .1 \quad$ A Cifra XOR . . . . . . . . . . . . . . . 154 
$5.2 .2 \quad$ A Cifra DES . . . . . . . . . . . . . . . . 155

5.2.3 O Módulo Crypto . . . . . . . . . . . . . . . . . . 156

5.2 .4 O Design da Crypto . . . . . . . . . . . . . . . 156

5.2.5 Ensaios Realizados com a Crypto . . . . . . . . . . . . 158

5.3 O Módulo Authentication . . . . . . . . . . . . . . . . . . . . . 162

5.3.1 Função Hash . . . . . . . . . . . . . . . . . . . . . . . . . . . . . . 162

5.3.2 Authentication_TX e Authentication_RX . . . . . . . . . 162

5.3.3 O Design do Módulo Authentication . . . . . . . . . . . . . . . . 163

5.3.4 Ensaios Realizados com o Authentication . . . . . . . . . . . 166

6 Resultados e Discussões 173

6.1 A Metodologia para Medição . . . . . . . . . . . . . . . . . . . . . . 173

6.2 Os Módulos Utilizados . . . . . . . . . . . . . . . . . . . . . . . 175

6.3 A Metodologia Estatística . . . . . . . . . . . . . . . . . 175

6.4 Comparação do TT entre os TMs . . . . . . . . . . . . . . . . . . . . . 177

6.5 Comparação do TT entre os Módulos . . . . . . . . . . . . . . . . . . . . 179

6.6 Comparação do TT entre os TMs Estratificada por Módulo . . . . . . . . 180

6.7 Comparação do TT entre os Módulos Estratificados por TM . . . . . . 189

6.8 Análise do Crescimento do TT, quando se Aumenta o TM . . . . . . . . . 196

6.9 Comparação do TT entre os TMs Estratificada pela soma dos Módulos 2

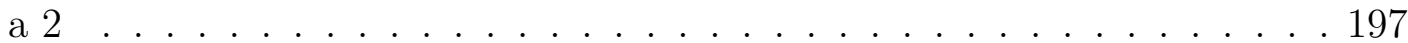

6.10 Comparação do TT entre os TMs Estratificada pela Soma dos Módulos 3

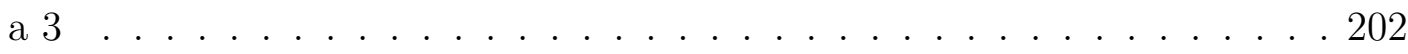

6.11 Throughput entre Módulos Estratificado por TM . . . . . . . . . . . . 209

7 Conclusões $\quad 211$

7.1 Pontos de Continuidade da Pesquisa . . . . . . . . . . . . . . . . 213

Referências $\quad 215$

$\begin{array}{ll}\text { Apêndices } & 227\end{array}$

$\begin{array}{llll}\text { APENDICE A } & \text { Pseudocódigo do RGGM } & 229\end{array}$

APÊNDICE B Tamanho da Amostra para os Testes Estatísticos Realizados 233

B.1 Definições . . . . . . . . . . . . . . . . . . . . . 233

B.1.1 Poder do Teste . . . . . . . . . . . . . . . . . . 233

B.1.2 Nível de Significância . . . . . . . . . . . . . . . . . . . . 233

B.1.3 Tamanho do Efeito . . . . . . . . . . . . . . . . . . . 233 
B.2 Método para Calcular o Número de Amostras . . . . . . . . . . . . . . . 234

B.3 Cálculo do Número de Amostras Ideal . . . . . . . . . . . . . . . . . . . . 234

APÊNDICE C Tabelas Referentes ao TT entre os TM, Estratificadas por Módulo

APÊNDICE D Tabelas Referentes ao TT entre os Módulos, Estratificados por TM

APENNDICE E Tabelas Referentes ao TT entre os TM, Estratificadas pela Soma dos Módulos 2 a 2

APÊNDICE F Tabelas Referentes ao TT entre os TM, Estratificadas pela Soma dos Módulos 3 a 3 


\section{Introdução}

A automação de subestações de energia elétrica demanda a implantação de uma rede de comunicação de dados e computadores, envolvendo telecomunicações e computação, para conectar dispositivos com funções de medição, controle e proteção. O foco desta junção de áreas é consolidar e disseminar, de forma rápida e precisa, informações provenientes do Sistema Elétrico de Potência (SEP).

Com a tecnologia digital, as medições, sinalizações e comandos são encapsulados em quadros de dados que trafegam sobre uma rede local de subestação, utilizando-se de protocolos de comunicação, responsáveis por coordenar e assegurar o transporte de informações, pertinentes às operações do SEP.

No ambiente das subestações, o elevado número de protocolos, proprietários e não proprietários têm representado um desafio para a conexão entre equipamentos de fabricantes distintos. Imersos neste cenário, e diante da necessidade de uma solução de integração não-proprietária, padronizada e que apresentasse um protocolo de alta velocidade, em 1994, os Grupos de Trabalho, WG11 e WG12 do Comitê Técnico 57 do IEC (International Electrotechnical Commission) iniciaram o desenvolvimento do padrão internacional IEC 61850 - Redes de Comunicação e Sistemas para Automação de Concessionárias de Energia.

Dentre os perfis de comunicação descritos pelo padrão IEC 61850, o protocolo de interesse para esta pesquisa é o GOOSE (Generic Object Oriented Substation Event), que é responsável por possibilitar aos IEDs (Intelligent Electronic Device) acesso aos recursos da rede de comunicação e prover a troca de serviços. Um exemplo é a possibilidade de distribuição rápida em todo sistema de uma mensagem GOOSE do Tipo 1A ( Trip $^{1}$ ), que apresenta classe de performance P1 e P2 e tempo de tranferência com classe TT5 e TT6 (IEC/TR-61850-5, 2013). A classe de desempenho P1 é muito utilizada para mensagens dentro da subestação ou qualquer outro sistema local, já a classe P2 é pertinente para mensagens entre subestações. A classe TT5 descreve um tempo de transferência menor ou igual a $10 \mathrm{~ms}$ e a classe TT6, um tempo menor ou igual a $3 \mathrm{~ms}$.

\footnotetext{
${ }^{1}$ Trip, sinal de desligamento enviado por um relé (MARDEGAN, 2010).
} 


\subsection{Contextualização do Problema}

Apesar de sua importância, os protocolos de comunicação raramente incorporam quaisquer medidas de segurança, incluindo a segurança contra erros involuntários, mau funcionamento de equipamentos do sistema de energia, falhas dos equipamentos de comunicação, ou sabotagem deliberada (IEC/TS-62351-6, 2007). Em 2002, no lançamento da primeira edição do padrão IEC 61850, não houve recomendações de segurança para o protocolo GOOSE. A vulnerabilidade foi considerada baixa, uma vez que as mensagens eram transmitidas em redes confinadas, protegidas pelo isolamento físico das subestações. Contudo, novas aplicações com troca de mensagens GOOSE entre subestações para esquemas de proteção são descritas pela IEC/TR-61850-90-1 (2010) e fomentam uma preocupação quanto à segurança cibernética em cada porção do SEP, porque, neste âmbito, estão presentes esquemas de controle e proteção, planejados para assegurar a continuidade e a qualidade no fornecimento de energia elétrica.

Em fevereiro de 2011, um relatório publicado pela McAfee ${ }^{\circledR}$ alertou para diferentes tentativas de ataques a empresas de energia elétrica, gás e óleo por meio de ferramentas de administração remota (MCAFEE, 2011; LIU et al., 2012). De acordo com a Schweitzer Engineering Laboratories (2013), um estudo solicitado pelo Departamento de Energia dos Estados Unidos da América apontou uma tendência de crescimento dessas ameaças. As causas são o aumento da exposição, da interconexão e da complexidade das redes de comunicação, aliado ao uso de tecnologias computacionais existentes e à necessidade de cada vez mais automação nos processos desse setor.

A atualização dos sistemas de controle e comunicação para as redes de energia apresenta novos desafios de segurança que, segundo Amin e Giacomoni (2012), devem ser tratados antes da implantação de tecnologias de Smart Grid em larga escala. A digitalização de tais sistemas pode permitir ataques remotos originados de qualquer lugar em estações locais.

De acordo com um alerta de segurança da NCCIC/ICS-CERT ( National Cybersecurity and Communications Integration Center/Industrial Control Systems - Cyber Emergency Response Team), em 23 de dezembro de 2015, as empresas de energia ucranianas experimentaram um ataque cibernético sem precedentes, o que provocou a falta de energia para mais de 225.000 clientes. Estes ataques foram realizados remotamente, aproveitando credenciais legítimas obtidas a partir de meios desconhecidos e operando remotamente disjuntores para desligar a alimentação (NCCIC/ICS-CERT, 2016).

No que tange ao padrão IEC 61850, Hoyos, Dehus e Brown (2012) demonstraram consequências devastadoras sobre a confiabilidade da rede por meio de um ataque prático, explorando fraquezas da mensagem GOOSE. O experimento descreveu o potencial para interrupção generalizada na distribuição de energia após um ataque, que consistiu na publicação de mensagens GOOSE falsas, aceitas pelo IED receptor como mensagens válidas. Os autores citam que o setor de energia elétrica trabalha com uma tecnologia 
que apresenta vulnerabilidades.

Hong, Liu e Govindarasu (2014b) descrevem que um invasor pode ser capaz de acessar a rede da subestação, capturar, modificar e retransmitir mensagens GOOSE de forma a operar os disjuntores em uma subestação. O atacante também pode construir e enviar mensagens para outras subestações inibindo a operação de um disjuntor.

Tais observações justificam a realização desta pesquisa, uma vez que a interrupção no fornecimento de energia elétrica, causada por distúrbios ou um ataque à rede de comunicação de dados influencia na Qualidade de Energia (QE). Mesmo que por alguns ciclos, a interrupção do fornecimento de energia pode causar prejuízos como paradas de máquinas, perda de dados ou mau funcionamento de equipamentos. Martinho (2007) explicita que cerca de $15 \%$ dos prejuízos com matéria prima, durante uma interrupção de energia elétrica, são causados nos primeiros minutos, chegando a $60 \%$ dos custos na primeira hora parada. Oliveira e Sanhueza (2006) mostram que o custo estimado de prejuízos em situações de interrupção de energia em até um minuto pode chegar até 400 mil dólares (instalação de uma indústria têxtil).

De forma mais perturbadora, mensagens GOOSE falsas podem afetar o sistema de proteção, prejudicando sua capacidade de atenuar os efeitos dos distúrbios ou condições anormais e de assegurar a continuidade de alimentação dos usuários, bem como salvaguardar o material e as instalações da rede elétrica (COURY; OLESKOVICZ; GIOVANINI, 2007).

Neste contexto, Anderson e Kipp (2010) descrevem a topologia típica do ambiente de redes da subestação, utilizando firewalls nas suas bordas, conforme ilustra a Figura 1. Os autores explicitam que as subestações modernas deveriam ter no mínimo um firewall para filtrar as comunicações de ingresso, prevenindo ataques de fontes externas, e filtrar comunicações egressas para evitar o vazamento de informações sigilosas.

Salah, Elbadawi e Boutaba (2012) e Marçula e Filho (2005) descrevem o firewall como a primeira linha de defesa contra ameaças externas e internas ao sistema de computadores, às redes e às informações críticas. Para Forouzan e Fegan (2007), o firewall é um dispositivo projetado para encaminhar alguns pacotes e filtrar (não encaminhar) outros, conforme suscita a Figura 1. Dada à sua importância, Stallings e Brown (2008) apontam o firewall como a tecnologia de segurança mais utilizada pelas organizações, com $98 \%$ de adesão.

A segurança da rede requer que todas as entidades recebam tratamento de proteção, porém, a maioria dos firewalls disponíveis é projetada para operar apenas em ambiente TCP/IP (Transmission Control Protocol/Internet Protocol), limitando sua aplicação nas redes industrais e de controle com protocolos distintos (GALLO; HANCOCK, 2001). Adicionalmente, Weiss e Delson (2007) declaram que a tecnologia de firewall é limitada a informações de endereço, não sendo capaz de inspecionar os quadros de dados para um sistema de controle. 


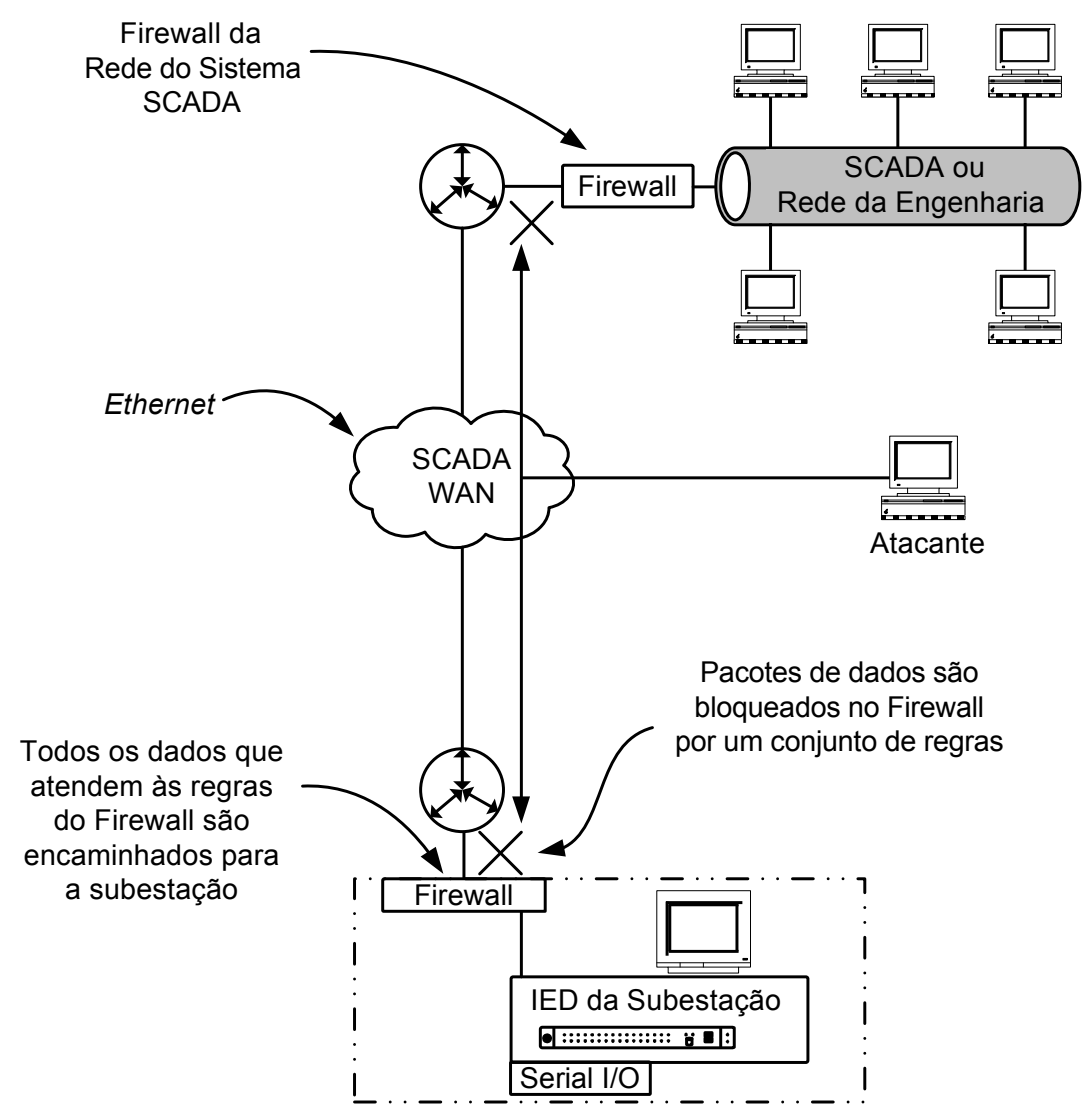

Figura 1: Topologia de rede típica com firewalls

Fonte: Anderson e Kipp (2010)

Considerando o exposto e visando a contribuir para a melhoria da segurança pertinente ao padrão IEC 61850 e, por conseguinte, a troca de mensagens do protocolo GOOSE, esta pesquisa propõe um firewall em hardware reconfigurável para restringir o tráfego de mensagens GOOSE às funções de proteção do SEP. Dessa forma, estabelece-se a questão principal da pesquisa: é possivel utilizar um firewall como um encaminhador de mensagens, capaz de auxiliar contra ameaças à segurança da rede de uma subestação de energia elétrica, sem depreciar demasiadamente o tempo de transferência das mensagens GOOSE?

O tempo de transferência se apoia nas restrições do tempo de propagação envolvendo o enlace ou canal de comunicação de dados entre subestações. Conforme descreve a norma IEC 60834-1² citada pelo padrão IEC 61850 (IEC 61850-90-1 ${ }^{3}$ ), este tempo deve ocupar até $5 \mathrm{~ms}$.

Para alcançar tempos de propagação que permitam a utilização do firewall como um encaminhador de mensagens GOOSE, o hardware tem como suporte a plataforma

\footnotetext{
${ }^{2}$ Teleprotection equipment of power systems - Performance and testing - Part 1: Command systems.

${ }^{3}$ Communication networks and systems for power utility automation - Part 90-1: Use of IEC 61850 for the communication between substations.
} 
NetFPGA, um acelerador construído por meio de hardware reconfigurável FPGA (Field Programmable Gate Array) que permite a construção de protótipos funcionais de rede de alta performance.

O desenvolvimento em hardware reconfigurável tem como meta "proporcionar as vantagens da lógica sob medida sem os custos associados. A lógica programável combina um tempo reduzido de desenvolvimento à manutenção de uma elevada escala de integração, acrescentando ainda a possibilidade de permitir alterações em fases avançadas do desenvolvimento"(COSTA; MESQUITA; PINHEIRO, 2011).

Vahid (2007) destaca que os FPGAs são "muito mais rápidos do que um software em um microprocessador, em parte porque os FPGAs podem efetivamente implementar operações em pipelining, em nível de bit e concorrentes".

\subsection{Objetivos}

O objetivo do presente trabalho é o desenvolvimento de um firewall em hardware reconfigurável, por meio da plataforma NetFPGA, de modo que o incremento no tempo de propagação de uma mensagem GOOSE Tipo 1A, ao transpor o dispositivo de segurança, não ultrapasse $20 \%$ do tempo total destinado ao enlace de comunicação entre IEDs ou subestações de energia elétrica. O firewall deve ser capaz de decodificar e filtrar quadros ISO/IEC 8802-3, para restringir o tráfego na rede da subestação às funções de proteção do SEP.

Além da filtragem de conteúdo, outros serviços de segurança foram desenvolvidos e avaliados como módulos do firewall para a prova de conceito: dois algoritmos clássicos de criptografia e um algoritmo para autenticação da mensagem GOOSE.

Para a efetivação deste propósito foi necessário alcançar alguns objetivos secundários, tais como:

- Caracterizar as concepções de segurança pertinentes às subestações de energia elétrica e conhecer o estado da arte da plataforma de hardware reconfigurável NetFPGA;

- A proposição de uma metodologia para avaliação da latência na plataforma NetFPGA;

- O desenvolvimento de diversos scripts para os principais testes de validação, por exemplo: composição de um banco de mensagens GOOSE aleatórias, identificação das mensagens que não conseguiram transpor o módulo de decodificação, validação das mensagens GOOSE capturadas pela NetFPGA e composição de um banco de filtros.

\subsection{Contribuições da Pesquisa}

Com este trabalho, espera-se contribuir nos seguintes aspectos: 
- Na melhoria da segurança cibernética, pertinente à troca de mensagens GOOSE no nível de $b a y^{4}$;

- No fornecimento de um modelo para a decodificação de mensagens GOOSE, utilizando o quadro ISO/IEC 8802-3;

- Na oferta de um firewall para filtragem de quadros ISO/IEC 8802-3;

- No fomento da utilização da plataforma NetFPGA como hardware de rede de alta performance;

- Com uma metodologia para a medição do tempo de transferência das mensagens GOOSE na rede de comunicação da subestação;

- Com subsídios estatísticos para análise do tempo de transferência das mensagens GOOSE;

- Com um gerador de mensagens GOOSE aleatórias e um ambiente em software para validar a composição das mensagens GOOSE.

\subsection{Limitações da Pesquisa}

O firewall é apenas uma parte de um conjunto de componentes pertinentes a um sistema de segurança necessário para a proteção de uma subestação. O acesso a serviços legítimos, como as mensagens GOOSE advindas de um IED e concernente ao sistema de proteção e controle da subestação, deve ocorrer quando requisitado. Em seguida, a segurança não depende mais do firewall, mas dos próprios serviços legítimos. Análises para evitar ataques de dentro da subestação se tornam essenciais, da mesma forma que um sistema de detecção de intrusão (NAKAMURA; GEUS, 2007).

Embora Gallo e Hancock (2001) explicitem que num ambiente corporativo padrão, a norma é empregar entre 3 e 18 conjuntos de protocolos, o foco central de investigação é a metodologia para captura dos campos e filtragem de quadros pertinentes ao protocolo GOOSE.

\subsubsection{Formato do Quadro}

Este trabalho considera o formato do quadro ISO/IEC 8802-3 com tamanho máximo de 1518 bytes para as mensagens GOOSE (IEC/TR-61850-8-1, 2011), sem a presença dos campos opcionais HSR (High-availability Seamless Redundancy) e PRP (Parallel Redundancy Protocol), que são pertinentes a métodos de redundância para redes de automação de subestações, operando na camada de enlace (IEC-62439-3, 2016).

\footnotetext{
${ }^{4}$ Onde estão localizadas as unidades de controle e proteção, por exemplo, relés digitais.
} 


\subsubsection{Casos de Uso}

O firewall e os algoritmos de criptografia e autenticação, considerados neste trabalho, podem ser utilizados para a segurança de mensagens GOOSE na troca de sinais entre IEDs, em vias de comunicação internas a uma subestação ou na comunicação entre os IEDs das barras adjacentes de uma linha de transmissão. Os casos de uso do firewall envolvem o emprego de várias técnicas como, por exemplo, (IEC/TR-61850-90-1, 2010; KINDERMANN, 2014):

- Sistema de Bloqueio por Comparação Direcional ou Sistema de Comparação Direcional por Bloqueio;

- Sistema de Comparação Direcional por Desbloqueio;

- Sistema de Transferência de Disparo Direto por Subalcance;

- Sistema de Transferência de Disparo Permissivo por Subalcance;

- Sistema de Transferência de Disparo por Sobrealcance.

Existem vários sistemas de proteção que podem utilizar os esquemas anteriores ou suas variantes em conjunto com as ferramentas de segurança mencionadas anteriormente. Outros casos de uso podem ser observados na IEC/TR-61850-90-1 (2010).

\subsection{Organização do Texto}

O Capítulo 1 apresentou a contextualização do problema, objeto deste trabalho, o objetivo, as contribuições e limitações da pesquisa.

O Capítulo 2 apresenta uma visão geral do padrão IEC 61850 e um delinear de tópicos para apoiar o desenvolvimento de um sistema em hardware para a decodificação de mensagens GOOSE. Alguns dos tópicos abordados são o protocolo GOOSE, o quadro ISO/IEC 8802-3, a linguagem ASN.1 (Abstract Syntax Notation One) e as regras básicas de codificação (BER). Um script para a geração de mensagens GOOSE, com campos aleatórios, é descrito no findar do capítulo.

Os avanços tecnológicos não só têm apresentado significativos benefícios operacionais, como também aumentaram a exposição das subestações, dos sistemas de proteção e de controle para os problemas relacionados à segurança cibernética. Nesse contexto, o Capítulo 3 alerta sobre as vulnerabilidades pertinentes às subestações de energia elétrica e aborda, também, três tecnologias de segurança da informação que podem ser utilizadas: o firewall, a criptografia e a autenticação.

Já no Capítulo 4, destacam-se as características da plataforma de hardware reconfigurável NetFPGA, cujo objetivo é servir para o desenvolvimento dos módulos de segurança propostos neste trabalho. 
Com o intuito de desenvolver um firewall de quadros para a troca de mensagens GOOSE, o Capítulo 4, também apresenta um modelo para segmentar, identificar, delimitar e fornecer para manipulação os campos da mensagem GOOSE, denominado ASN.1/BER GOOSE. Para validar o módulo, um software foi desenvolvido em linguagem Java e permitiu comparar os campos originais de uma mensagem com os valores capturados pela NetFPGA.

Com o intuito de melhorar a segurança cibernética para a troca de mensagens GOOSE, o Capítulo 5 apresenta o desenvolvimento de três módulos em hardware, baseados no ASN.1/BER GOOSE: um filtro para o quadro ISO/IEC 8802-3, dois algoritmos clássicos para a criptografia de mensagens GOOSE, e um algoritmo para autenticação das mensagens.

Uma metodologia para a medição do tempo de transferência das mensagens GOOSE, e uma análise estatística para cada um dos módulos, é apresentada em detalhes no Capítulo 6.

As considerações finais e as recomendações para a continuidade da pesquisa são apresentadas no Capítulo 7. 


\section{O Padrão IEC 61850 e o Protocolo GOOSE}

As redes de comunicação de dados surgiram para viabilizar o compartilhamento de hardware, software e dados. Em geral, esses recursos são sistemas heterogêneos: equipamentos de fabricantes diferentes, com características distintas, que utilizam softwares com propriedades específicas (CARVALHO, 1997). No sistema elétrico, essa heterogeneidade gerou um elevado número de protocolos, proprietários e não proprietários, que tem representado um desafio para a interconexão de IEDs e, por conseguinte, a manipulação de dados.

Para tornar possível a interligação de tais equipamentos, um novo padrão fez-se necessário. Trata-se do IEC 61850 - Redes de Comunicação e Sistemas para Automação de Concessionárias de Energia. Nesse contexto, o capítulo apresenta uma visão geral do padrão e um delinear de tópicos como: a modelagem de dados, a pilha de protocolos e os tipos de mensagem. Além, disso mostra o desenvolvimento de um script para geração de mensagens GOOSE. Estas mensagens foram utilizadas para validar os módulos desenvolvidos em hardware reconfigurável, que serão descritos em capítulos posteriores.

\subsection{Histórico IEC 61850}

Em 1988 o EPRI (Eletric Power Research Institute) iniciou atividades para definição de uma arquitetura de comunicação para concessionárias de energia elétrica, UCA (Utility Communications Architecture). Com base nestes estudos, o relatório técnico TR1550, 1999, definindo dois contextos de comunicação, foi publicado pelo IEEE (Institute of Electrical and Electronics Engineers) (OLIVEIRA et al., 2003):

- Comunicação entre centros de controle;

- Comunicação entre dispositivos de campo. 
Paralelamente, a IEC (International Electrotechnical Commission) reconheceu a necessidade de normalizar as interfaces para os dispositivos de telecontrole, a partir da série de normas IEC 60870-5, por meio dos comitês técnicos IEC TC57 e IEC TC95 (RODRIGUES, 2005).

Em 1994, reconheceu-se a necessidade de uma padronização mais geral para cobrir redes de comunicação e sistemas em subestações, assim, foram criados os grupos de trabalho WG1O, WG11 e WG12, conectados ao Comitê Técnico IEC TC57 (IEC/TR-61850-1, 2013). Esses três grupos reuniram especialistas de vários países com experiência nos protocolos, segundo a norma IEC 60870-5 e a UCA 2.0. A IEC e o EPRI concordaram então em ter uma única normalização, o padrão IEC 61850, que se refere às Redes de Comunicação e Sistemas em Subestações, estabelecendo o modelo de dados e a pilha de protocolos para troca de informações (RODRIGUES, 2005).

\subsection{Revisão Bibliográfica}

Diversos artigos expostos até o momento fazem menção aos principais fundamentos e potencialidades disponibilizadas pelo padrão IEC 61850 e explicitam como seu surgimento influenciou os processos de engenharia de automação das subestações. Recentemente, algumas pesquisas têm apontado para os procedimentos que comprovam toda a capacidade do referido padrão bem como as eventuais dificuldades na implementação de lógicas e esquemas de controle e proteção. Elas manifestam também as experiências e resultados adquiridos na configuração de alguns projetos.

A primeira publicação na biblioteca digital do IEEE Xplore ${ }^{\circledR}$, que aborda o padrão IEC 61850 data de abril de 2001. Shephard, Janssen e Schubert (2001) fornecem detalhes de como alcançar interoperabilidade com o uso da série IEC 61850 "Redes e Sistemas de Comunicação em Subestações". O artigo examina temas como: a origem do padrão IEC 61850, o escopo dos principais documentos para formação de sua arquitetura, o estado da arte (no ano em referência, 2001), além de descrever alguns projetos pilotos. Nesta vertente, foram desenvolvidos os trabalhos de Schubert e Wong (2003), Hoga e Wong (2004), Bastos e Castro (2005), Mackiewicz (2006), Gurjão, Souza e Carmo (2007) e Pereira et al. (2007), que também apresentam a pilha de protocolos e tipos de mensagens previstas pelo padrão. Preiss e Wegmann (2003), Kostic, Preiss e Frei (2005), Ozansoy, Zayegh e Kalam (2009a), Ozansoy, Zayegh e Kalam (2009b), Zhu, Shi e Duan (2011) e Gonzalez-Redondo et al. (2016) apresentam um breve histórico do padrão, o modelo de dados embutido num IED (Intelligent Electronic Device) - dados, classes de dados, nós lógicos e dispositivos lógicos, a linguagem de descrição formal da subestação SCL (Substation Configuration Language) baseada em XML (eXtender Markaup Language), que visa a padronizar atributos de configuração. Os artigos também manifestam os benefícios de utilização do padrão, e soluções de engenharia com a utilização de dispositivos intercambiávies. 
Os impactos, perspectivas e exigências do padrão IEC 61850 são explicitados por Apostolov e Tholomier (2006), Hossenlopp (2007), Sun e Redfern (2009) e Clavel et al. (2015). Os artigos dos referidos autores abordam os benefícios do padrão, a definição de arquiteturas físicas e lógicas, o sistema de configuração e a interoperabilidade entre IEDs. Adicionalmente, Apostolov e Tholomier (2006) tratam das exigências de desempenho para a proteção por meio das estampas de tempo envolvidas nos módulos de uma aplicação distribuída. Os autores contemplam também as vantagens da utilização do sistema de mensagens GOOSE, em vez da comunicação com entradas e saídas digitais e cabeamento de cobre convencionais.

Trabalhos recentes descrevem que o padrão IEC 61850 permite a execução de tarefas críticas como funções de proteção (GIUSTINA et al., 2015), o gerenciamento de fontes renováveis de energia (ANDRÉN; BRÜNDLINGER; STRASSER, 2014), as medições sincronizadas (WENGE et al., 2014) e as aplicações de monitoramento compartilhado pela rede de comunicação (MAZUR; ENTZMINGER; KAY, 2016). Giustina et al. (2013), Georg et al. (2013) e Cavalieri e Regalbuto (2016) explicitam que as arquiteturas, baseadas no IEC 61850, podem ser consideradas como a base das redes inteligentes (Smart Grids).

A Figura 2 mostra o número de publicações envolvendo a temática IEC 61850 nos periódicos e anais de conferência, exceto patentes, pertinentes à base de dados Web of Science ${ }^{\circledR}$. Os percentuais apontam 2013 e 2014 como os anos mais férteis nas publicações envolvendo o tema. Nos próximos anos será possível analisar se a diminuição ocorrida em 2015 aponta um amadurecimento da temática ou uma oscilação normal, como ocorreu em 2007 e 2010.

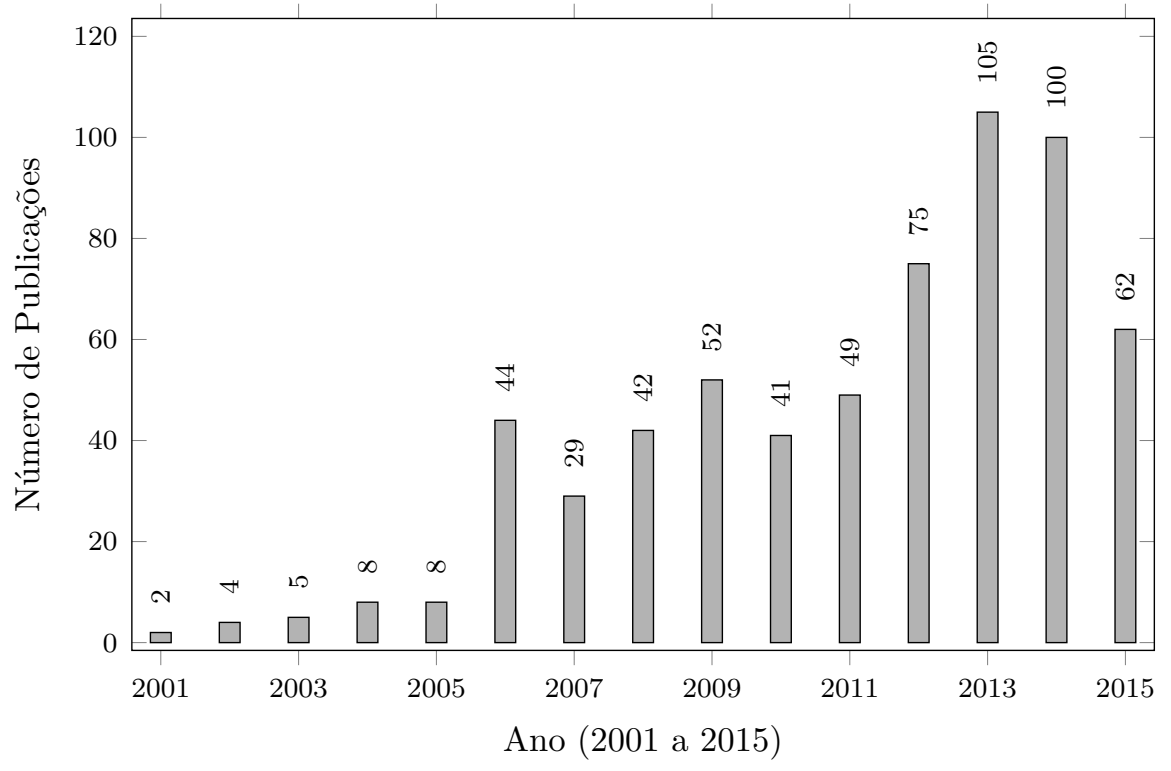

Figura 2: Número de publicações envolvendo o tema IEC 61850, Web of Science ${ }^{\circledR}$ 


\subsection{Composição e Objetivo}

O padrão IEC 61850 foi organizado em 10 partes, todas aprovadas e com status de padrão internacional, conforme descreve a Tabela 1.

A parte 1 do padrão IEC 61850 (IEC/TR-61850-1, 2013) descreve como premissa a interoperabilidade na troca de informações entre dispositivos de fabricantes distintos, como, por exemplo, IEDs, uma vez que a comunicação deve suportar as funções operativas das subestações e garantir, dentre outras, as seguintes características:

- A comunicação baseada no perfil já existente (IEC, IEEE, ISO (International Organization for Standartization), OSI (Open Systems Interconnection));

- A utilização de protocolos abertos e dispositivos que contenham informações sobre a sua configuração. Deve ser possível a adição de novas funcionalidades;

- A utilização de uma estrutura de dados (data object), que representem informações específicas, relacionados às necessidades da indústria de energia elétrica;

- A sintaxe e semântica das informações devem basear-se no uso de objetos de dados comuns, relativos ao SEP;

- Suportar futuros desenvolvimentos tecnológicos.

Adicionalmente, as operadoras do sistema de energia elétrica também requerem a intercambialidade entre IEDs de fabricantes distintos, ou seja, a substituição de equipamentos de um fabricante por outro, sem necessidade de alteração nos demais dispositivos constituintes do sistema.

Mackiewicz (2006) esboça que a estrutura do padrão IEC 61850 utiliza o conceito de definição abstrata para acepção de dados e serviços, isto é, objetos e serviços são criados independemente de qualquer outro protocolo, permitindo neste ínterim, mapeá-los para diversas regras de comunicação que atendam aos dados e serviços requeridos.

\subsection{Requisitos de Comunicação}

O padrão IEC 61850, parte 5, especifica os requisitos para a comunicação das funções implementadas nos diversos níveis do SAS (Sistema de Automação da Subestação).

As funções referem-se a tarefas que devem ser executadas na subestação, por exemplo, controle, monitoração e proteção dos equipamentos da subestação. E podem ser logicamente alocadas nos três diferentes níveis hierárquicos de uma subestação (nível de processo, bay e estação), conforme descreve a Figura 3.

As trocas de dados entre estes níveis ocorrem nas seguintes interfaces (IF1, IF2, ..., IF10): 
Tabela 1: Documentos básicos que definem o padrão IEC 61850

\begin{tabular}{|c|c|c|c|}
\hline Característica & Parte & Descrição & Edição \\
\hline \multirow{5}{*}{ Aspectos do Sistema } & 1 & Introdução e visão geral & $2.0(03 / 2013)$ \\
\hline & 2 & Glossário & $1.0(08 / 2003)$ \\
\hline & 3 & Requisitos gerais & $1.0(01 / 2002)$ \\
\hline & 4 & Gerenciamento de sistema e projeto & $2.0(04 / 2001)$ \\
\hline & 5 & $\begin{array}{l}\text { Requisitos de comunicação para fun- } \\
\text { ções e modelos de dispositivos }\end{array}$ & $2.0(01 / 2013)$ \\
\hline Configuração & 6 & $\begin{array}{l}\text { Linguagem de Configuração para } \\
\text { IEDs de subestações elétricas (SCL) }\end{array}$ & $2.0(12 / 2009)$ \\
\hline Estrutura de & 7.1 & Princípios e modelos & $2.0(07 / 2011)$ \\
\hline \multirow[t]{6}{*}{ Comunicação } & 7.2 & $\begin{array}{l}\text { Serviço de Interface de Comunicação } \\
\text { Abstrata (ACSI) }\end{array}$ & $2.0(08 / 2010)$ \\
\hline & 7.3 & Classe de Dados Comum (CDC) & $2.0(12 / 2010)$ \\
\hline & 7.4 & $\begin{array}{l}\text { Classes de Nós Lógicos e de dados } \\
\text { compatíveis }\end{array}$ & $2.0(03 / 2010)$ \\
\hline & 7.410 & $\begin{array}{l}\text { Estrutura de comunicação básica - } \\
\text { As usinas hidroelétricas - Comunica- } \\
\text { ção para monitoramento e controle }\end{array}$ & $2.0(10 / 2012)$ \\
\hline & 7.420 & $\begin{array}{l}\text { Estrutura de comunicação básica } \\
\text { - Recursos energéticos distribuídos } \\
\text { Nós Lógicos }\end{array}$ & $1.0(03 / 2009)$ \\
\hline & 7.510 & $\begin{array}{l}\text { Estrutura de comunicação básica - } \\
\text { As usinas hidroelétricas - Conceitos } \\
\text { de modelagem e diretrizes }\end{array}$ & $1.0(03 / 2012)$ \\
\hline \multirow[t]{2}{*}{$\begin{array}{l}\text { Mapeamento de Servi- } \\
\text { ços de Comunicação }\end{array}$} & 8.1 & $\begin{array}{l}\text { Mapeamento para MMS (ISO/IEC } \\
9506 \text { Parte } 1 \text { and Parte 2) e para } \\
\text { ISO/IEC } 8802-3\end{array}$ & $2.0(06 / 2011)$ \\
\hline & 9.2 & $\begin{array}{l}\text { Mapeamento Específico de Serviço } \\
\text { de Comunicação (SCSM) - Valores } \\
\text { Amostrados sobre ISO/IEC 8802-3 }\end{array}$ & $2.0(09 / 2011)$ \\
\hline \multirow[t]{6}{*}{ Ensaios } & 10 & Testes de conformidade & $2.0(12 / 2012)$ \\
\hline & 80.1 & $\begin{array}{l}\text { Orientação para troca de informa- } \\
\text { ções a partir de um modelo de dados } \\
\text { baseado em CDC usando IEC } 60870- \\
5-101 \text { ou IEC } 60870-5-104\end{array}$ & $1.0(12 / 2008)$ \\
\hline & 90.1 & $\begin{array}{l}\text { Uso do IEC } 61850 \text { para a comunica- } \\
\text { ção entre subestações }\end{array}$ & $1.0(03 / 2010)$ \\
\hline & 90.4 & Diretrizes de engenharia de rede & $1.0(08 / 2013)$ \\
\hline & 90.5 & $\begin{array}{l}\text { Uso do IEC } 61850 \text { para transmi- } \\
\text { tir informações de sincrofasores de } \\
\text { acordo com a IEEE C } 37.118\end{array}$ & $1.0(05 / 2012)$ \\
\hline & 90.7 & $\begin{array}{l}\text { Modelos de objeto para conversores } \\
\text { de potência em sistemas com Recur- } \\
\text { sos Energéticos Distribuídos (DER) }\end{array}$ & $1.0(02 / 2013)$ \\
\hline
\end{tabular}

Fonte: IEC/TR-61850-1 (2013) 


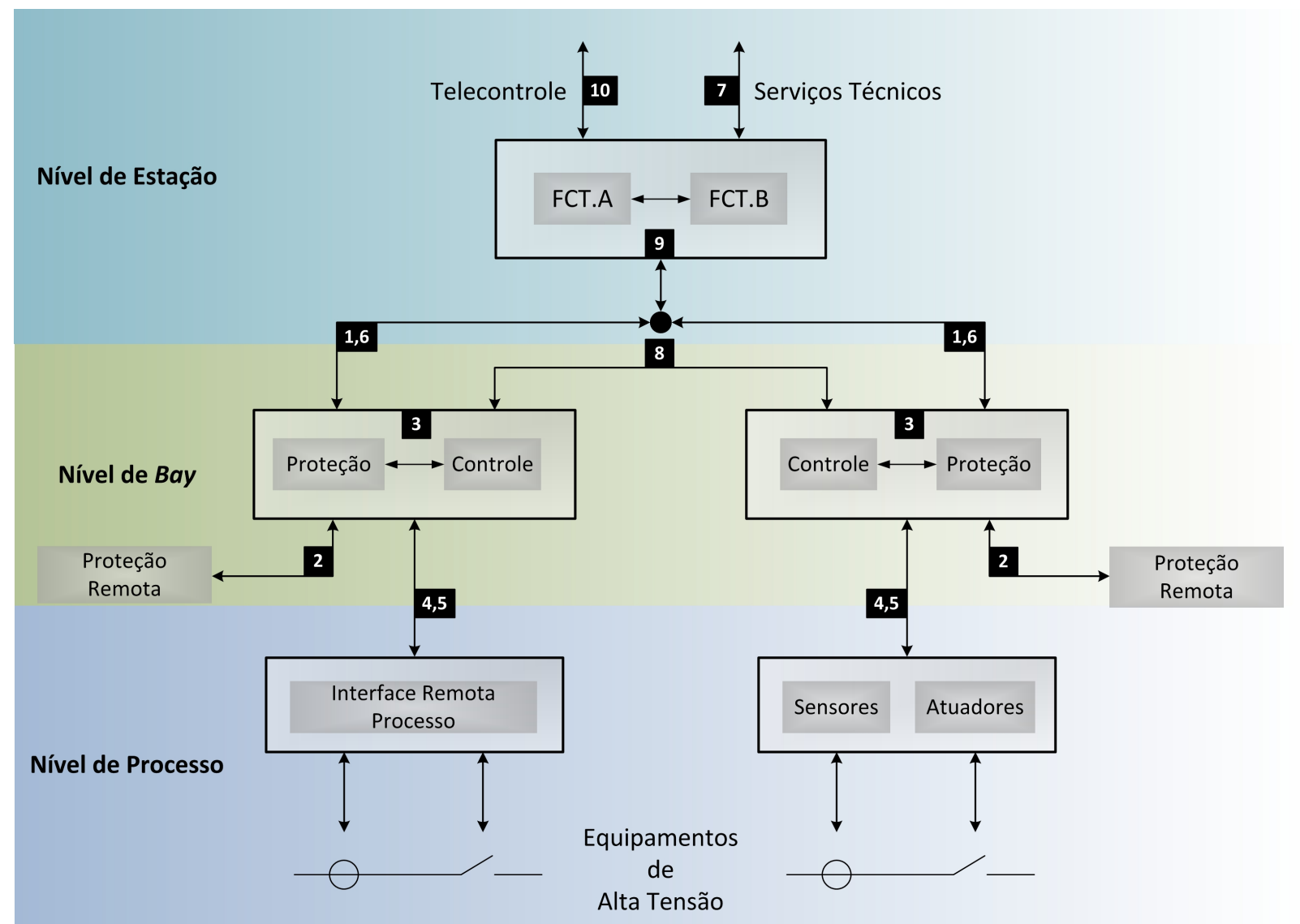

Figura 3: Níveis e interfaces lógicas no SAS

Fonte: IEC/TR-61850-5 (2013)

- IF1: troca de dados de proteção entre os níveis de bay e estação;

- IF2: troca de dados de proteção entre os níveis de bay e proteção remota;

- IF3: troca de dados no nível de bay;

- IF4: troca de dados instantâneos de Transformador de Corrente (TC) e Transformador de Potencial (TP) entre os níveis de processo e bay;

- IF5: troca de dados de controle entre os níveis de processo e bay;

- IF6: troca de dados de controle entre os níveis de bay e estação;

- IF7: troca de dados entre a subestação e o local de trabalho da engenharia;

- IF8: troca de dados entre os bays, especialmente para funções rápidas como intertravamento;

- IF9: troca de dados no nível da estação; 
- IF10: troca de dados de controle entre os dispositivos da subestação e o centro de controle remoto.

Apesar da similaridade lógica, não há uma forma única para que as funções sejam atreladas a dispositivos físicos. O mapeamento é dependente, por exemplo, da disponibilidade e desempenho requeridos, restrição de custos e estado da arte da tecnologia.

Neste contexto, o objetivo do padrão IEC 61850 é fornecer interoperabilidade entre os IEDs de diferentes fabricantes ou, mais precisamente, entre as funções desempenhadas nos níveis hierárquicos da subestação, que estão localizados em dispositivos físicos distintos (IEC/TR-61850-5, 2013).

Conforme mostra a Figura 4, diferentes funções, F (Functions), são implementadas em vários dispositivos físicos, PD (Physical Devices), a partir da divisão em subfunções, ou nós lógicos (LN), que podem trocar informações necessárias à implementação das funções por meio de conexões lógicas, LC (Logical Connections), e físicas, PC (Physical Connections).

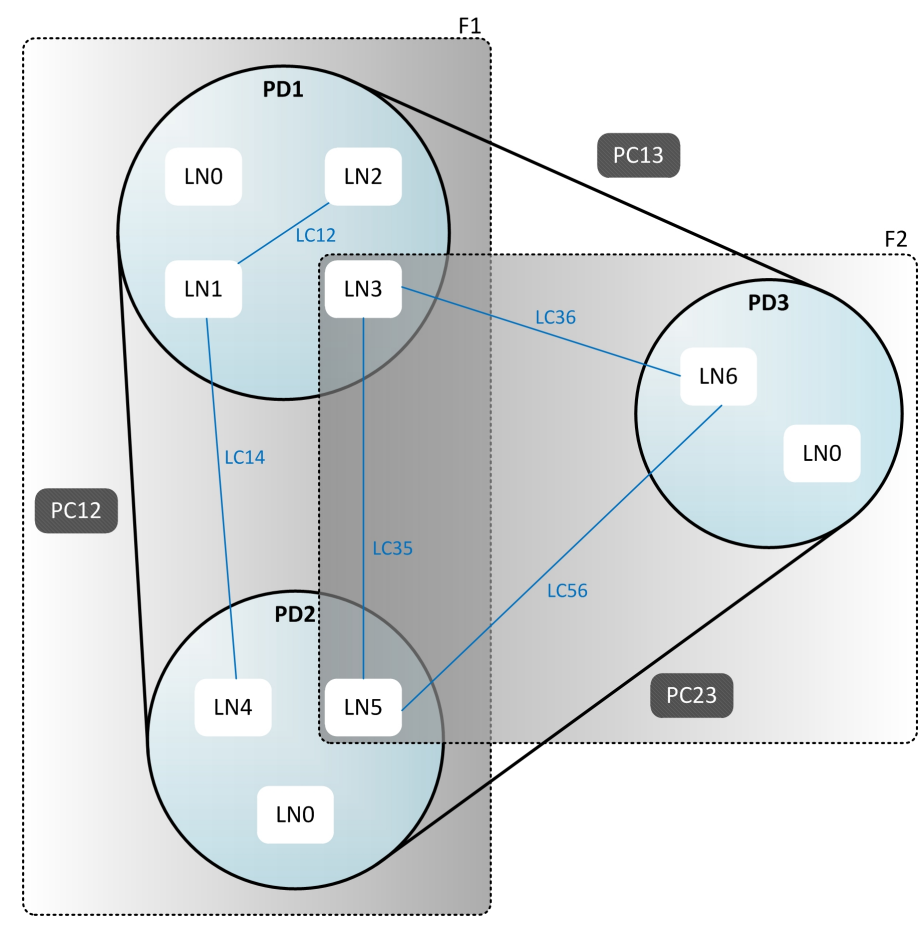

Figura 4: Noção de conexão e LN

Fonte: IEC/TR-61850-5 (2013)

\subsubsection{Nó Lógico, LN}

Na automação de uma subestação, os protocolos normalmente definem como os dados serão transmitidos, utilizando um conceito orientado aos sinais, pelo qual, cada mensagem representa um ponto de dados como, por exemplo, uma informação de status ou um valor 
numérico (FAY; ECKL, 2003). Isto requer que o engenheiro de sistemas configure e mapeie os sinais manualmente, elemento por elemento, endereço por endereço.

Em contraste com o modelo orientado aos sinais, o padrão IEC 61850 utiliza o conjunto de conhecimentos de orientação a objeto para enunciar as características essenciais e específicas de uma modelagem de dados orientada à informação e não ao dispositivo. Dessa forma, consegue-se harmonizar atributos e funções dos equipamentos físicos de uma subestação ou usina do sistema elétrico, de forma a garantir a consistência e o intercâmbio dos dados, independente da marca ou do fabricante.

Um IED que forneça o padrão IEC 61850 é formado, inicialmente, por um hardware que se conecta ao sistema de comunicação de dados, por meio de um endereço de rede (físico e lógico), e o conjunto de funções que caracterizam seu comportamento.

As funções de um SAS, como supervisão, controle e proteção dos dispositivos primários e do próprio SEP foram identificadas e separadas em subfunções, que são descritas como um grupo de dados e serviços, associados em classes, formando um nó lógico LN. Por sua vez, um conjunto de LNs forma um dispositivo lógico, LD (Logical Devide), que está no dispositivo físico (IED), conforme ilustra a Figura 5 (MACKIEWICZ, 2006; GURJÃO; SOUZA; CARMO, 2007).

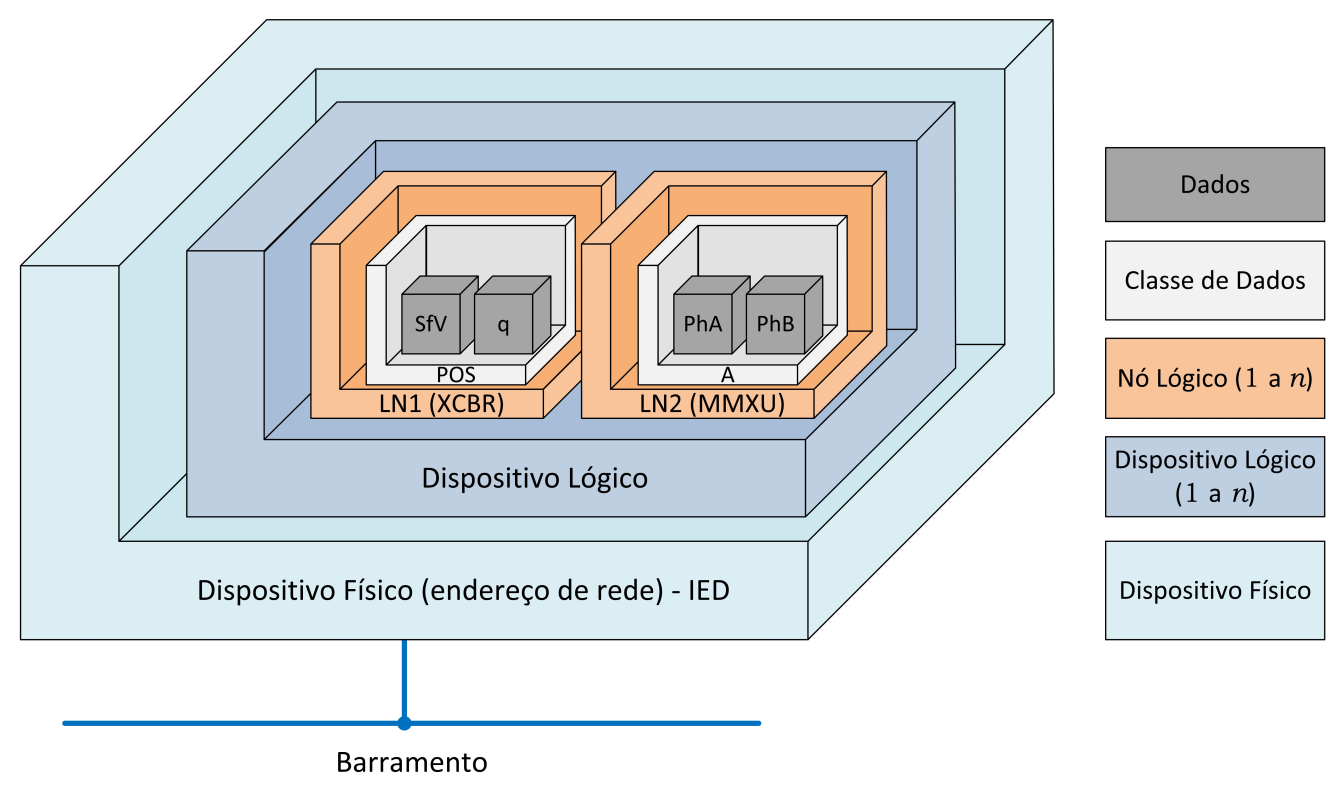

Figura 5: Modelo de dados

Fonte: Gurjão, Carmo e Souza (2006)

\subsubsection{Grupo de Nós Lógicos}

Os nós lógicos são congregados em grupos que, por sua vez, são identificados por indicadores, conforme a Tabela 2 .

Cada LN possui uma denominação, iniciada pelo grupo indicador, como, por exemplo: 
Tabela 2: Grupo de LN

\begin{tabular}{cl}
\hline Grupo Indicador & Grupo de Nós Lógicos \\
\hline A & Controle Automático \\
C & Controle Supervisionado \\
G & Função Genérica \\
I & Interfaces e Arquivamento \\
L & Sistema de Nó Lógico \\
M & Contador e Medição \\
P & Função de Proteção \\
R & Função Relacionada à Proteção \\
S & Sensores e Monitoramento \\
T & Transformador de Instrumento \\
X & Disjuntor e Chave Seccionadora \\
Y & Transformador de Potência e Funções Relacionadas \\
Z & Equipamentos Adicionais do SEP \\
\hline
\end{tabular}

Fonte: IEC/TR-61850-7-4 (2010)

- RREC - Religamento automático;

- CSWT - Controlador de chaveamento;

- MMXU - Medição operativa e indicativa;

- MMTR - Contador;

- MHAI - Medição de harmônicos e inter-harmônicos;

- MDIF - Medição diferencial;

- PDIS - Proteção de distância;

- XCBR - Chave disjuntora;

- XSWI - Chave seccionadora;

- TCTR - Transformador de corrente.

Um sufixo pode ser utilizado para o nome do nó para possibilitar a diferenciação de nós lógicos com o mesmo nome. Como exemplo, Mackiewicz (2006) supõe a existência de duas entradas de medição em um equipamento para aferir dois alimentadores trifásicos. $\mathrm{O}$ nome padronizado para um nó lógico de medição é MMXU. Para diferenciar as medições de cada um dos alimentadores, o IEC 61850 adiciona o sufixo 1 e 2 aos nomes, procedendo à identificação como MMXU1 e MMXU2.

Os nós lógicos mantêm sob controle uma relação de dados concernentes à sua função, com atributos que dizem respeito a cada nó em particular. Cada elemento de dados tem 
um nome único, sendo que sua representação tem sentido definido nas funcionalidades e características do SEP.

Tais pontos lógicos permitem criar modelos de informação de um dispositivo real, como, por exemplo, a representação de um disjuntor ser denominada XCBR, indicador X (disjuntor e seccionadora) e Circuit Breaker (CBR), conforme ilustra a Figura 6.

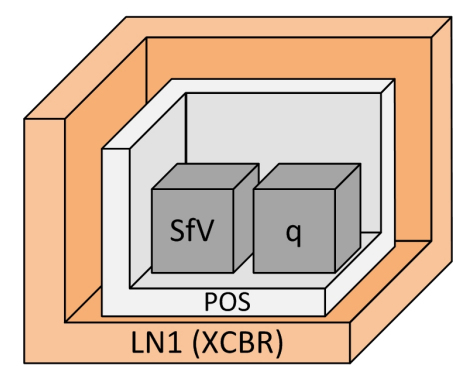

Figura 6: Nó lógico XCBR

Este dispositivo contém uma diversidade de dados associados (classe de dados), tais como:

- Pos: posição;

- OpCnt: contador de operações;

- BlkOpn: bloqueado para um comando de abertura;

- BlkCls: bloqueado para um comando de fechamento;

- CBOpCap: disponibilidade de operação;

- LOC: bloqueado.

O elemento de dado associado, Pos, é diferente de um simples ponto de estado do disjuntor. Segundo Gurjão, Souza e Carmo (2007), Pos apresenta vários atributos de controle, substituição, configuração, descrição e extensão, como Pos.ctlVal, que representa um controle e pode ser um comando de abertura ou fechamento. O Pos.stVal representa a posição real de um disjuntor, podendo assumir os seguintes estados: transição, abertura, fechamento ou defeito.

Para que os requisitos de comunicação sejam mapeados, faz-se necessária a identificação de todas as funções, o que gera a descrição e divisão das funções em LNs e a definição das subfunções e seus atributos.

\subsection{Linguagem de Configuração}

Diante de possibilidades distintas de uso dos nós lógicos em diferentes dispositivos, faz-se necessária uma estratégia para definir o caminho que a informação deve seguir. 
A definição desta estrutura está descrita na parte 6 do padrão IEC 61850, que especifica uma linguagem de descrição formal de configuração para sistemas de automação de subestações, conhecida como SCL (Substation Configuration Language).

Tal linguagem permite uma descrição das relações entre o sistema de automação da subestação e os equipamentos de pátio, ou seja, a configuração dos IEDs com seus respectivos parâmetros, além de configuração de funções das subestações, de acordo com o IEC 61850-5 e IEC 61850-7x.

A SCL é composta por arquivos (em linguagem XML) que contêm dados da subestação, das relações dos equipamentos de manobra, da funcionalidade dos IEDs e de todos os serviços de comunicação, permitindo a troca de informações de configuração entre ferramentas de fabricantes distintos (GURJÃO; SOUZA; CARMO, 2007), conforme Tabela 3.

Tabela 3: Arquivos de configuração da SCL

\begin{tabular}{cl}
\hline \multicolumn{1}{c}{ Arquivo } & Descrição \\
\hline System Specification Description (SSD) & Descreve o diagrama e a funcionalidade da auto- \\
mação da subestação associados aos nós lógicos. \\
Substation Configuration Description (SCD) & Descreve a configuração completa da subestação, \\
& incluindo a rede de comunicação e as informações \\
& sobre o fluxo de dados. \\
IED Capability Description (ICD) & Descreve as capacidades e pré-configurações dos \\
& IEDs. \\
Configured IED Description (CID) & Descrição da configuração de um IED específico, \\
& ou seja, dos dados que serão fornecidos pelos nós \\
& lógicos de cada IED.
\end{tabular}

Fonte: IEC/TR-61850-6 (2009)

Estes arquivos são descritos em formato texto, o que permite sua criação e manutenção em qualquer editor. A Figura 7 ilustra a estrutura da SCL deliberada pelo padrão.

Com base na descrição de Rein Jr. (2006), a Figura 8 descreve um trecho de arquivo SCL da subestação (LSEE), que contém um bay Q1, alimentação E1, um disjuntor QA1 e uma seccionadora QB1, ambos conectados ao nó L1. O disjuntor está associado ao LN XCBR1, da classe XCBR, e a seccionadora está associada ao LN XSWI2.

A SCL, em toda a sua extensão, descreve modelos, citados por Gurjão, Souza e Carmo (2007), tais como:

- A estrutura do sistema primário de potência: traça como os equipamentos estão conectados e quais as suas funções;

- O sistema de comunicações: estabelece como os IEDs serão conectados nas redes e sub-redes, e quais os pontos de acesso de comunicação; 


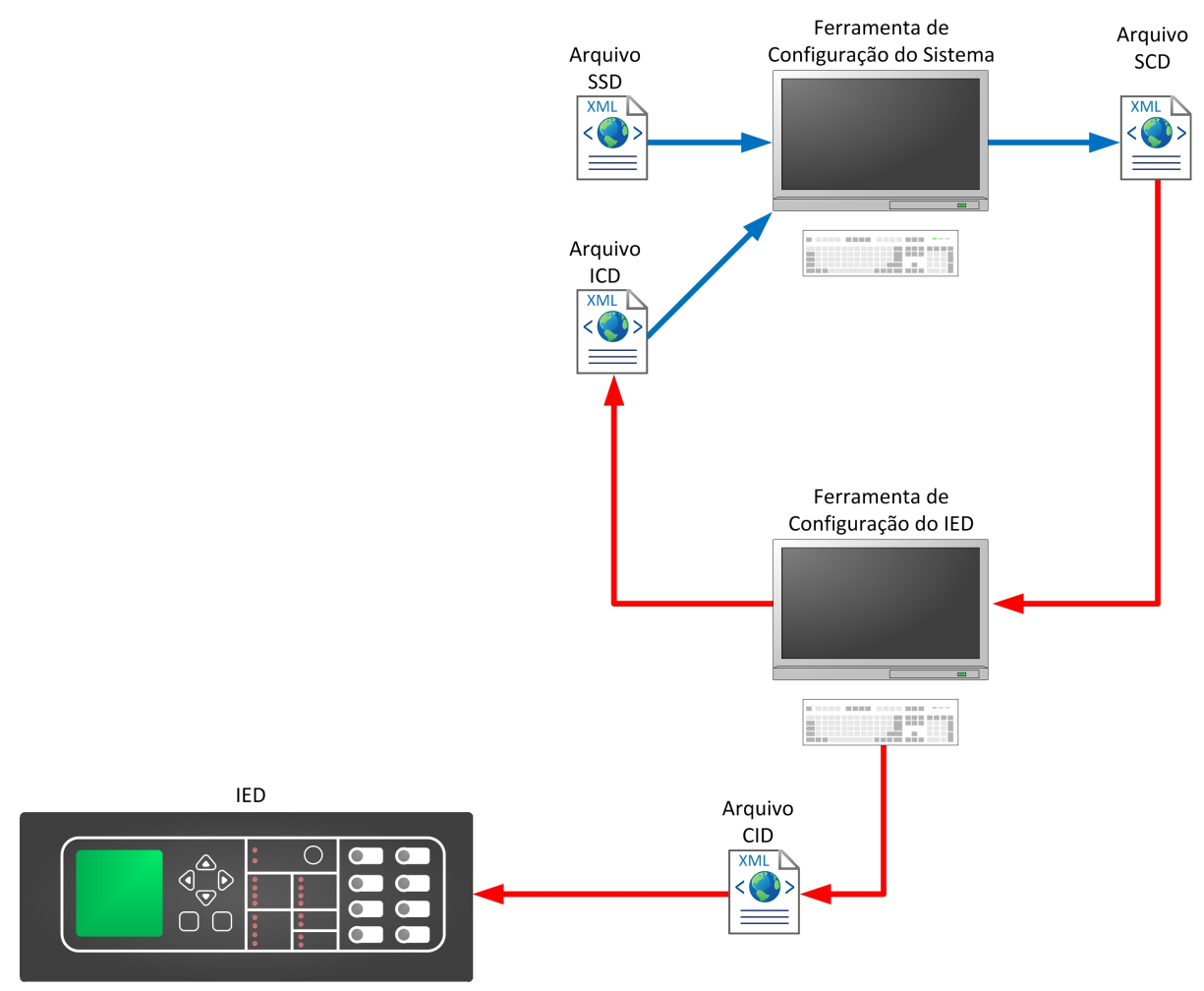

Figura 7: Estrutura da linguagem de configuração da subestação

Fonte: Paulino (2006)

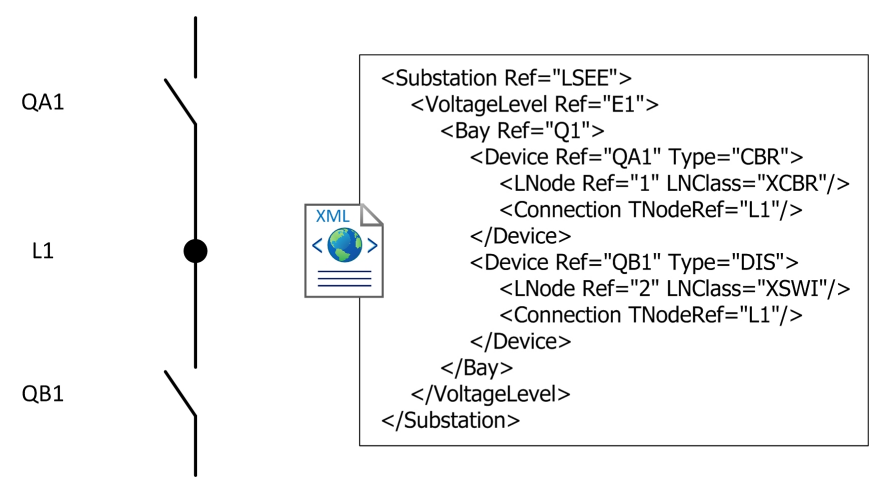

Figura 8: Fragmento de um arquivo SCL

Fonte: Rein Jr. (2006)

- O nível de aplicação das comunicações: mostra como os dados serão agrupados para o envio e como os IEDs os disparam;

- A configuração de cada dispositivo lógico, como nós lógicos com suas classes e tipos pertencentes a cada dispositivo lógico;

- Definições de tipo para cada instância de nó lógico;

- Relacionamento entre cada instância de nó lógico e o IED hospedeiro. 
Os principais benefícios da SCL, conforme Mackiewicz (2006), são:

- Disponibilizar ferramentas de desenvolvimento off-line para gerar os arquivos necessários à configuração automática dos IEDs, reduzindo custos e, se não todas, a maioria das tarefas de configuração manual;

- Possibilitar que os arquivos de configuração sejam padronizados e utilizados por vários usuários e, assim, reduzir inconsistências e equívocos na configuração do sistema. Os usuários podem fornecer seus próprios arquivos SCL para seus respectivos fornecedores e receberem seus IEDs já adequadamente configurados;

- Permitir que as configurações sejam feitas off-line, sem a necessidade de o IED estar conectado à rede.

\subsection{Estrutura de Comunicação}

A estrutura de comunicação do padrão IEC 61850 utiliza o conceito de "definição abstrata" para acepção de dados e serviços, permitindo mapeá-los para quaisquer protocolos que atendam aos dados e serviços requeridos. A parte 7.1 especifica os princípios e modelos necessários para compreender as seções posteriores (IEC/TR-61850-7-1, 2011). As partes 7.2 e 7.4 do padrão definem os serviços e os objetos de dados abstratos, respectivamente.

Conforme Mackiewicz (2006), os objetos de dados são compostos de partes comuns, tais como: status, medições e controle. O conceito de CDC (Commom Data Classes) foi desenvolvido, utilizando-se de blocos comuns, para compor objetos de dados maiores, de acordo com a parte 7.3 do padrão.

\subsubsection{Serviço de Interface de Comunicação Abstrata, ACSI}

A parte 7.2 do padrão IEC 61850 define o ACSI (Abstract Communication Service Interface) como um modelo de classe hierárquica, contendo todas as informações que podem ser acessadas e trocadas.

O ACSI dispõe das seguintes interfaces abstratas, conforme exemplifica a Figura 9:

- A interface abstrata que descreve a comunicação entre um cliente e um servidor remoto, para:

- Acesso e recuperação de dados em tempo real;

- Controle do dispositivo;

- Registro de eventos e login;

- Editor (Publisher) e Assinante de informações (Subscriber);

- Autodescrição do dispositivo; 
- Arquivo de transferência.

- A interface de comunicação para sistemas, cujo tempo na troca de dados é um fator crítico, por exemplo, na troca de dados entre IEDs utilizados para a proteção do SEP.

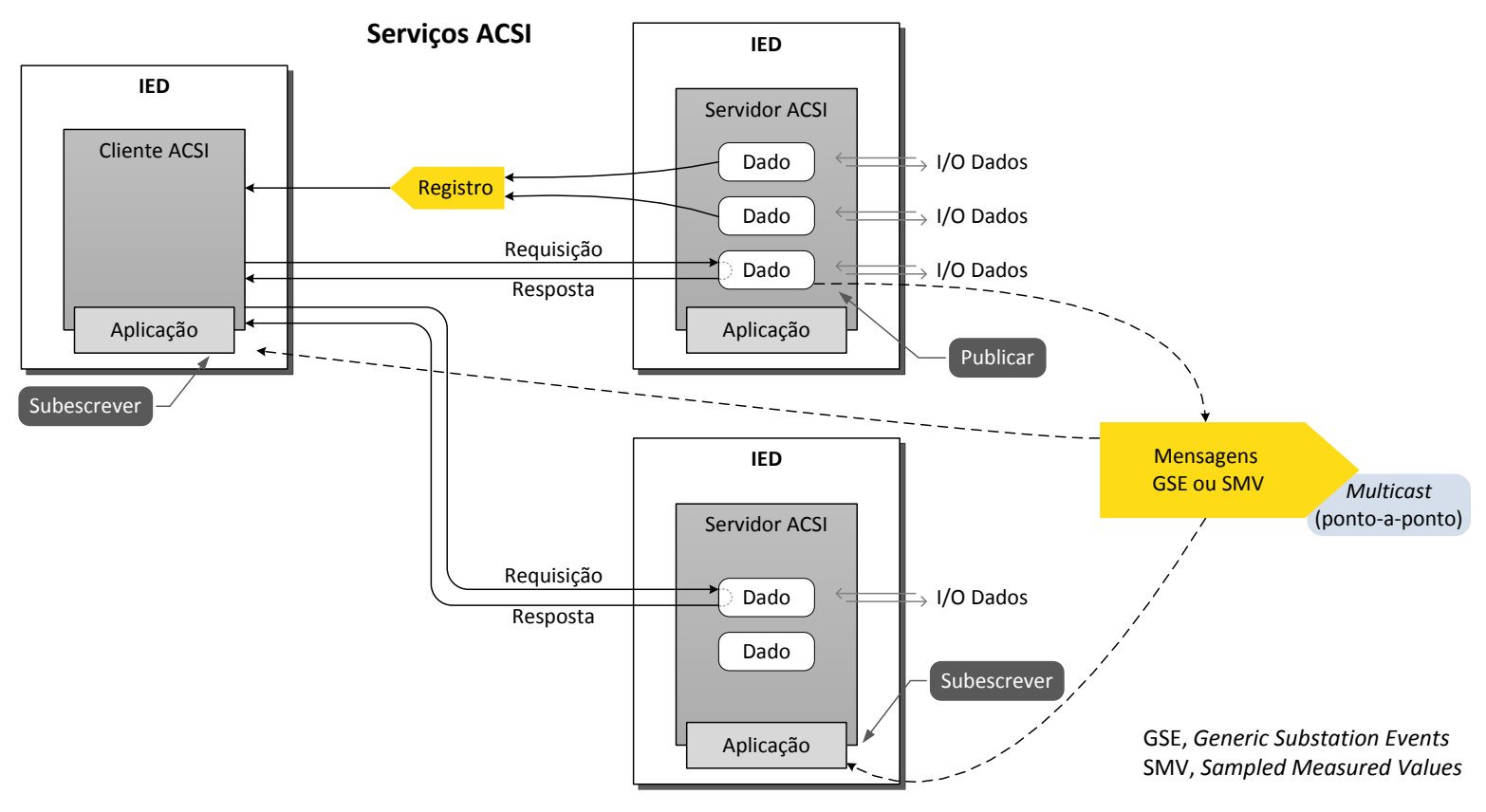

Figura 9: Método de comunicação ACSI

Fonte: IEC/TR-61850-7-1 (2011)

Esta parte do padrão IEC 61850 também pode ser aplicada para descrever modelos de dispositivos e funções para atividades adicionais, tais como (IEC/TR-61850-7-2, 2010):

- Troca de informações entre subestações;

- Troca de informações entre subestações e centros de controle;

- Troca de informações entre o ambiente de campo e o centro de controle;

- Troca de informações para medição.

A parte 7.2 descreve os modelos de classe hierárquica que constroem domínios específicos de informações, para serem acessadas e trocadas, tais como:

- Logical Node: contém as informações produzidas e consumidas por domínios específicos, por exemplo, a função de proteção 59 (sobretensão);

- Data Set: agrupamento de dados e atributos utilizados para acesso direto entre IEDs; 
- File Transfer: define a troca de grandes blocos de dados, tais como programas, oscilografias e registro de eventos;

- Control: define os serviços de controle para o sistema e seus dispositivos;

- Time and time synchronization: define a base de tempo para o sistema e seus dispositivos.

\subsubsection{Classe Comum de Dados, CDC}

O elemento de dados característico de um nó lógico é definido de acordo com a especificação de uma CDC (Commom Data Classes), descrita no padrão IEC 61850, parte 7.3. Cada CDC tem um nome definido e determina o tipo de estrutura dos dados, dentro de um nó lógico, como, por exemplo, informação de status, medição, parametrização ou controle (Tabela 4).

Tabela 4: CDCs citadas no padrão IEC 61850 parte 7.3

\begin{tabular}{|c|c|c|}
\hline Nome & Tipo da Informação & Descrição \\
\hline $\mathrm{ACT}$ & Status & Proteção ativa \\
\hline $\mathrm{ACD}$ & Status & Proteção direcional ativa \\
\hline SEC & Status & Contador de violações \\
\hline SPS & Status & Ponto simples \\
\hline DPS & Status & Ponto duplo \\
\hline INS & Status & Inteiro \\
\hline BCR & Status & Contador binário \\
\hline MV & Medição & Valor real \\
\hline CMV & Medição & Valor complexo \\
\hline SAV & Medição & Valor amostrado \\
\hline WYE & Medição & Valor fase-terra de sistema trifásico em estrela \\
\hline SEQ & Medição & Sequência de fases \\
\hline HMV & Medição & Valor de harmônica \\
\hline HWYE & Medição & Valor de harmônica para ligação em estrela \\
\hline HDEL & Medição & Valor de harmônica para ligação em triângulo \\
\hline $\mathrm{SPC}$ & Controle & Posição única controlável \\
\hline $\mathrm{DPC}$ & Controle & Posição dupla controlável \\
\hline INC & Controle & Posição inteira controlável \\
\hline $\mathrm{BSC}$ & Controle & Informação binária de controle de posição de passos \\
\hline ISC & Controle & Informação inteira de controle de posição de passos \\
\hline $\mathrm{APC}$ & Controle & Informação do valor de referência \\
\hline $\mathrm{SPG}$ & Parametrização & Parâmetros de um ponto de medição \\
\hline ING & Parametrização & Parâmetros de valores inteiros \\
\hline ASG & Parametrização & Parametrização analógica \\
\hline CURVE & Parametrização & Parametrização de curva \\
\hline DPL & Supervisão & Identificador do dispositivo \\
\hline LPL & Supervisão & Identificador do Nó Lógico \\
\hline CSD & Supervisão & Descrição do formato da curva \\
\hline
\end{tabular}

Fonte: IEC/TR-61850-7-3 (2010) e Santos et al. (2007) 
A Figura 10 esboça a modelagem de um nó lógico XCBR, que é composto de dados estruturados, tais como, Pos e BlkOpn (seção 2.4.2). Pode-se verificar que Pos não se restringe apenas a indicar a posição do disjuntor, ou seja, o estado aberto ou fechado, mas um conjunto de atributos, separados pelo tipo de informação que representam, como controle e indicação dentre outros.

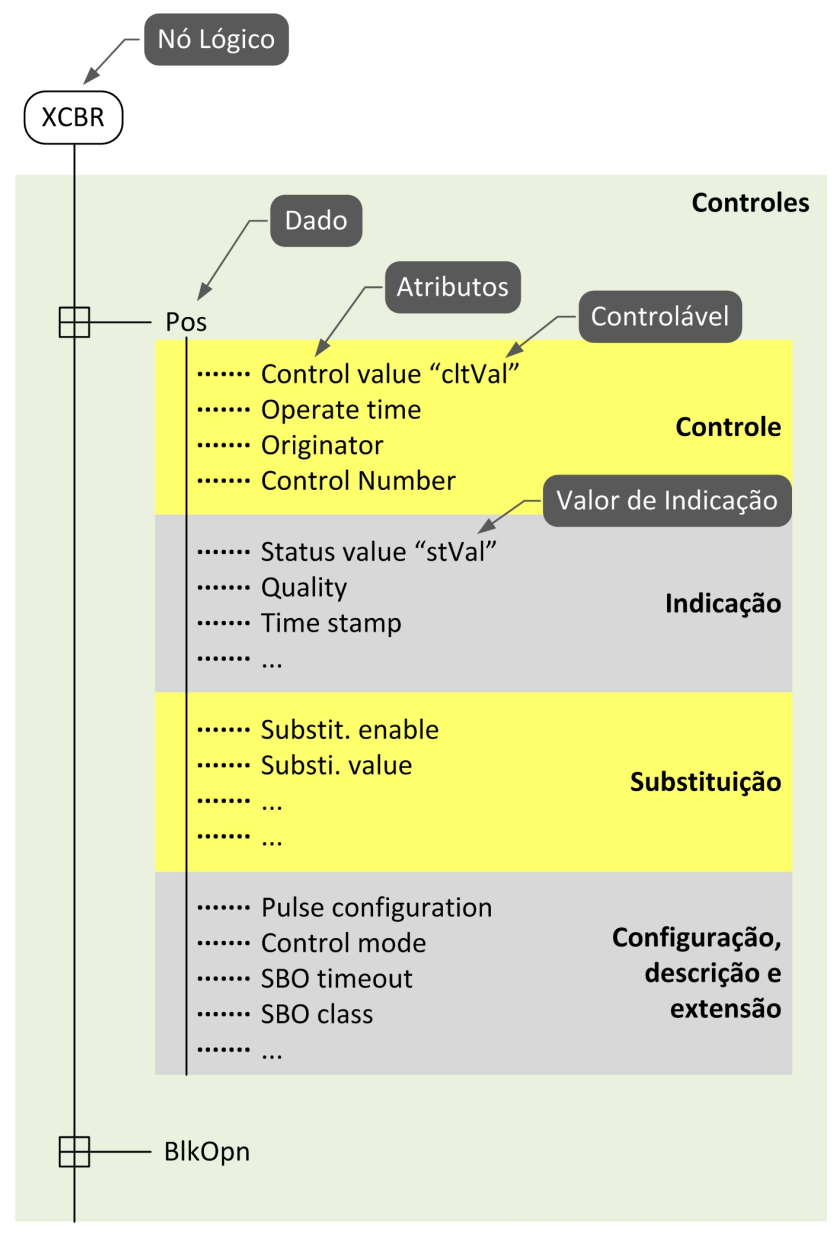

Figura 10: Estrutura do LN, tipo de informação e atributos

Fonte: IEC/TR-61850-7-3 (2010)

Para o arranjo das CDCs são definidos vários tipos de atributos, conforme trecho do padrão descrito na Tabela 5.

Como exemplo de anatomia, a Tabela 6 expõe a CDC ACT (Protection Activation Information). Detalhes dos atributos podem ser observados na IEC/TR-61850-7-3 (2010).

\subsubsection{Compatibilidade entre Nós Lógicos e Classes de Dados}

A parte 7.4 do padrão IEC 61850 (IEC/TR-61850-7-4, 2010) especifica os modelos de informação dos dispositivos e funções relacionadas, para aplicações em subestações. Em especial, estabelece a compatibilidade dos nomes dos nós lógicos e o nome dos dados para comunicação entre IEDs, possibilitando a interoperabilidade na comunicação. 
Tabela 5: Exemplo de definição dos tipos de atributos

\begin{tabular}{|c|c|c|}
\hline $\begin{array}{l}\text { Definição do Tipo } \\
\text { de Atributo }\end{array}$ & $\begin{array}{l}\text { Tipo de } \\
\text { Atributo }\end{array}$ & Descrição \\
\hline Qualidade & validity & $\begin{array}{l}\text { A validade da informação deve ser boa, ques- } \\
\text { tionável ou inválida. }\end{array}$ \\
\hline Valores Analógicos & FLOAT32 & $\begin{array}{l}\text { Valores analógicos representados no formato } \\
\text { float. }\end{array}$ \\
\hline Configuração de Range & $\min , \max$ & $\begin{array}{l}\text { Representam respectivamente o mínimo e o } \\
\text { máximo para a variável do processo. }\end{array}$ \\
\hline Posição de Passo & pos Val & Indicação de posição. \\
\hline $\begin{array}{l}\text { Configuração de Pulso } \\
\text { Booleano }\end{array}$ & $\begin{array}{l}\text { cmdQual } \\
\text { stVal }\end{array}$ & $\begin{array}{l}\text { Indica se o comando é pulsado ou persistente. } \\
\text { Define o estado de valor do dado. }\end{array}$ \\
\hline Qualidade & $q$ & $\begin{array}{l}\text { Qualidade do atributo(s) representando o va- } \\
\text { lor de um dado. }\end{array}$ \\
\hline
\end{tabular}

Fonte: IEC/TR-61850-7-3 (2010)

Tabela 6: Anatomia de uma classe de proteção ativa (ACT), funcionalidade de status

\begin{tabular}{|c|c|c|c|c|c|}
\hline \multicolumn{6}{|l|}{ ACT class } \\
\hline Attribute Name $^{a}$ & Attribute Type ${ }^{b}$ & $\mathbf{F C}^{c}$ & $\operatorname{TrgOp}{ }^{d}$ & Value/Value Range $^{e}$ & $\mathbf{M} / \mathrm{O} / \mathbf{C}^{f}$ \\
\hline DataName & \multicolumn{5}{|c|}{ Inherited from Data Class (see IEC 61850-7-2) } \\
\hline \multicolumn{6}{|l|}{ DataAttribute } \\
\hline \multicolumn{6}{|c|}{ status } \\
\hline general & BOOLEAN & ST & dchg & & M \\
\hline phsA & BOOLEAN & $\mathrm{ST}$ & dchg & & $\mathrm{O}$ \\
\hline phsB & BOOLEAN & $\mathrm{ST}$ & dchg & & $\mathrm{O}$ \\
\hline phsC & BOOLEAN & $\mathrm{ST}$ & dchg & & $\mathrm{O}$ \\
\hline neut & BOOLEAN & $\mathrm{ST}$ & dchg & & $\mathrm{O}$ \\
\hline q & Quality & $\mathrm{ST}$ & dchg & & M \\
\hline $\mathrm{t}$ & TimeStamp & ST & & & M \\
\hline \multicolumn{6}{|c|}{ configuration, description and extension } \\
\hline $\mathrm{d}$ & VISIBLE STRING255 & $\mathrm{DC}$ & & text & $\mathrm{O}$ \\
\hline $\mathrm{dU}$ & UNICODE STRING255 & $\mathrm{DC}$ & & & $\mathrm{O}$ \\
\hline $\mathrm{cdcNs}$ & VISIBLE STRING255 & EX & & & AC_DLNDA_M \\
\hline cdcName & VISIBLE STRING255 & EX & & & $\mathrm{AC}$ _DLNDA_M \\
\hline dataNs & VISIBLE STRING255 & EX & & & $\overline{A C} \_D L N \_\bar{M}$ \\
\hline
\end{tabular}

\footnotetext{
${ }^{a}$ Nome do Atributo;

${ }^{b}$ Tipo do Atributo;

${ }^{c}$ Functional Constraints (FC) indica que o atributo só se aplica a determinados serviços específicos, tais como: Estado (ST, status); Medição de valores analógicos (MX); Controle (CO); Valor amostrado (SV); Configuração (CF); Descrição (DC); Parâmetros de ajuste de grupos (SG); e Definição do espaço para nomes (EX).

${ }^{d}$ Trigger Option (TrgOp) influencia nas possibilidades de mudar parâmetros de um relatório;

${ }^{e}$ Value Range define o conjunto de valores permitidos para um determinado atributo;

${ }^{f} \mathrm{M} / \mathrm{O} / \mathrm{C}$ informa se o atributo é mandatário, opcional ou condicional.
} 
São apontados os detalhamentos de cada LN, isto é, o nome dos dados e atributos, as CDCs utilizadas, o tipo de informação e demais elementos, conforme ilustra a Tabela 7 para o LN XCBR.

Tabela 7: Anatomia do nó lógico (XCBR), Disjuntor

\begin{tabular}{|c|c|c|c|}
\hline \multicolumn{4}{|c|}{ XCBR class } \\
\hline Attribute Name $^{a}$ & Attribute Type $^{b}$ & Explanation $^{c}$ & $\mathbf{M} / \mathbf{O}^{d}$ \\
\hline LNName & & $\begin{array}{l}\text { Shall be inherited from Logical-Node Class (see } \\
\text { IEC 61850-7-2 }\end{array}$ & \\
\hline \multicolumn{4}{|c|}{ 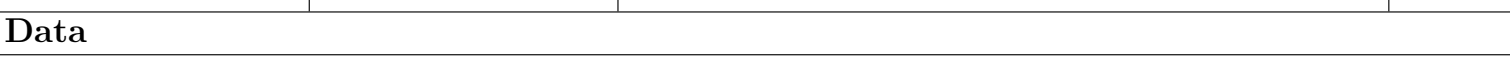 } \\
\hline \multicolumn{4}{|c|}{ Commom Logic Node Information } \\
\hline Loc & SPS & $\begin{array}{l}\text { LN shall inherit all Mandatory Data from Com- } \\
\text { mon Logical Node Class } \\
\text { Local Operation (Local means without substation } \\
\text { automation communication, hardwired direct con- } \\
\text { trol) }\end{array}$ & $\mathrm{M}$ \\
\hline EEHealth & INS & External equipament health & $\mathrm{O}$ \\
\hline EEName & DPL & External equipament name plate & $\mathrm{O}$ \\
\hline OpCnt & INS & Operation counter & M \\
\hline \multicolumn{4}{|l|}{ Controls } \\
\hline Pos & $\mathrm{DPC}$ & Switch position & M \\
\hline $\mathrm{BlkOpn}$ & $\mathrm{SPC}$ & Block opening & M \\
\hline $\mathrm{BlkCls}$ & $\mathrm{SPC}$ & Block closing & M \\
\hline ChaMotEna & $\mathrm{SPC}$ & Change motor enabled & M \\
\hline \multicolumn{4}{|l|}{ Metered Values } \\
\hline SumSwARs & BCR & Sum of Switched Amperes, resetable & $\mathrm{O}$ \\
\hline \multicolumn{4}{|l|}{ Status Information } \\
\hline CBOpCap & INS & Circuit break operating capability & $\mathrm{M}$ \\
\hline POWCap & INS & Point On wave switching capability & $\mathrm{O}$ \\
\hline MaxOpCap & INS & $\begin{array}{l}\text { Circuit break operating capability when fully char- } \\
\text { ged }\end{array}$ & $\mathrm{O}$ \\
\hline
\end{tabular}

${ }^{a}$ Nome dos Dados e Atributos;

${ }^{b}$ Classe Comum de Dados, CDC;

${ }^{c}$ Descrição do dado relacionado a um LN, e como ele é utilizado;

${ }^{d} \mathrm{M} / \mathrm{O} / \mathrm{C}$, informa se o atributo é mandatário, opcional ou condicional.

Fonte: IEC/TR-61850-7-4 (2010)

Santos et al. (2007) salientam que o padrão não se restringe apenas aos LNs previstos, mas também suporta novos LNs, que podem ser criados por usuários, seguindo os padrões estabelecidos na parte 4 .

\subsection{Mapeamento de Serviços Específicos de Comuni- cação}

A parte 8.1 do padrão IEC 61850 fornece instruções quanto aos mecanismos e regras necessárias para implementar os serviços, os objetos e algoritmos descritos nas partes 7.2, 
7.3 e 7.4. Os serviços são mapeados para os protocolos de aplicação: MMS (Manufacturing Message Specification ${ }^{1}$ ), SNTP (Simple Network Time Protocol), GOOSE e SV (Sampled Values), conforme ilustra a Figura 11.

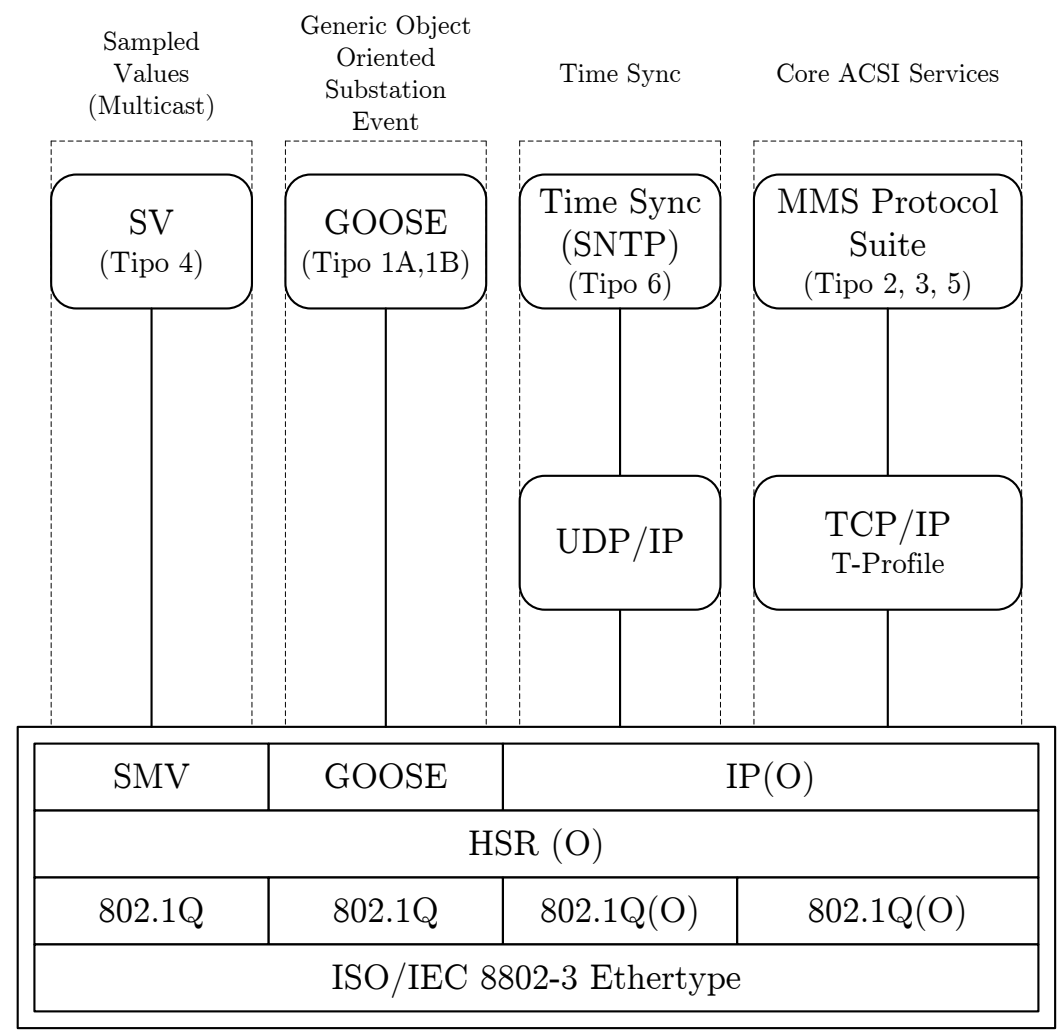

(O) - Opcional

Figura 11: Representação simplificada da pilha de protocolos IEC 61850

Fonte: IEC/TR-61850-8-1 (2011)

Para implementar estes protocolos, foram definidos dois perfis (profiles), ou conjuntos de padrões, dividindo as sete camadas do modelo RM-OSI (Reference Model - Open Systems Interconnection) em dois grupos: o "Application Profile (A-Profile)", que engloba as três camadas superiores que correspondem à aplicação, apresentação e sessão, e o "Transport Profile (T-Profile)", que conglomera as quatro camadas inferiores restantes, transporte, rede, enlace e física (IEC/TR-61850-8-1, 2011). Várias combinações de A-Profile e T-Profile podem ser executadas com o intuito de permitir a troca de determinados tipos de informações e serviços que, conforme especifica a parte 8.1 do padrão IEC 61850, são mapeados em quatro diferentes combinações:

\footnotetext{
${ }^{1} \mathrm{O}$ serviço de aplicação MMS (Manufacturing Message Specification) (Padrão ISO 9506) tem como objetivo possibilitar a interconexão de sistemas computacionais de fabricantes distintos em um ambiente de automação. O MMS é baseado no modelo cliente-servidor, onde as funções de cliente e servidor são exercidas, respectivamente, por um computador hospedeiro e algum dispositivo de campo (CARVALHO, 1997). Os serviços e o protocolo MMS são especificados para operar sobre as camadas do modelo OSI e são compatíveis com os perfis de comunicação do TCP/IP.
} 
- Cliente/Servidor: núcleo de serviços ACSI, utilizando o conjunto de protocolos MMS;

- Time Sync: fornece sincronismo de tempo dentro de uma rede com o protocolo SNTP (Simple Network Time Protocol);

- SV: valores amostrados, como corrente e tensão de transformadores;

- GOOSE/ GSSE (Generic Substation State Events): mensagens pertencentes à classe GSE (Generic Substation Events).

Para cada combinação, a Tabela 8 explicita as camadas do modelo RM-OSI, que estão presentes em cada protocolo.

Tabela 8: Combinações de serviços dos protocolos

\begin{tabular}{cccccc}
\hline $\begin{array}{c}\text { A ou T } \\
\text { Profile }\end{array}$ & $\begin{array}{c}\text { Camada do } \\
\text { modelo RM-OSI }\end{array}$ & SV & GOOSE & $\begin{array}{c}\text { Time } \\
\text { Sync } \\
\text { (UDP/IP) }\end{array}$ & $\begin{array}{c}\text { MMS } \\
\text { Cliente/Servidor } \\
\text { (TCP/IP) }\end{array}$ \\
\hline \multirow{2}{*}{ A } & Aplicação & $\bullet$ & $\bullet$ & $\bullet$ & $\bullet$ \\
& Apresentação & $\bullet$ & $\bullet$ & & $\bullet$ \\
\hline \multirow{2}{*}{ Tessão } & Transporte & & & $\bullet$ & $\bullet$ \\
& Rede & & & $\bullet$ & $\bullet$ \\
& Enlace & $\bullet$ & $\bullet$ & $\bullet$ & $\bullet$ \\
\hline
\end{tabular}

Fonte: IEC/TR-61850-8-1 (2011)

Observa-se, na Tabela 8, que somente três camadas, a física, a de enlace e a de aplicação são comuns a todos os serviços e a suas respectivas mensagens, sendo que na camada física, todos utilizam dados do tipo Ethernet. As células em branco, colunas Time Sync, SV e GOOSE, não apresentam protocolos estabelecidos pelo padrão IEC 61850.

\subsubsection{Tipos de Mensagem}

Para permitir diferentes exigências no ambiente das subestações, as diversas mensagens normalizadas pelo IEC 61850, parte 5, são classificadas conforme o desempenho. Existem dois grupos independentes, um para controle e proteção, outro para medições e aplicações de qualidade de energia. A Tabela 9 descreve os tipos de mensagem, as classes de desempenho, o tempo de transferência e os protocolos aos quais tais mensagens estão vinculadas, como mostra a Figura 11.

As mensagens do Tipo 1 apresentam restrições críticas de tempo, como, por exemplo, o comando de abertura de um disjuntor de alta tensão, e necessitam de maior prioridade 
Tabela 9: Tipos de mensagem e classes de desempenho

\begin{tabular}{|c|c|c|c|c|}
\hline Tipo & Identificação & $\begin{array}{c}\text { Classe de } \\
\text { Desempenho (P) }\end{array}$ & $\begin{array}{c}\text { Tempo de } \\
\text { Transferência(TT) }\end{array}$ & Protocolo \\
\hline $1 \mathrm{~A}$ & Trip & $\mathrm{P} 1, \mathrm{P} 2$ & TT6,TT5 & GOOSE \\
\hline $1 \mathrm{~B}$ & Outras mensagens rápidas & P3 & TT4 & GOOSE \\
\hline 2 & Mensagem de média velocidade & $\mathrm{P} 4$ & TT3 & MMS \\
\hline 3 & Mensagens lentas & $\mathrm{P} 5, \mathrm{P} 6$ & TT2, TT1 & MMS \\
\hline 4 & Dados em rajada (raw data) & P7, P8 & TT6, TT5 & SV \\
\hline 5 & Funções de transferência de arquivo & P9 & TT0 & MMS \\
\hline 6 & Mensagens de sincronismo de tempo & $\mathrm{P} 10, \mathrm{P} 11, \mathrm{P} 12$ & TT2, TT1, TT0 & Time Sync \\
\hline \multicolumn{5}{|c|}{ Exemplos de $(\mathrm{P})$ e $(\mathrm{TT})$ : } \\
\hline \multicolumn{5}{|c|}{$\begin{array}{l}\text { - P1, O tempo total de transmissão deve ser inferior a ordem de } 1 / 4 \text { de ciclo; } \\
\text { - P2, O tempo total de transmissão deve ser da ordem de } 1 / 2 \text { ciclo; } \\
\text { - P3, O tempo total de transmissão deve ser da ordem de } 1 \text { ciclo; } \\
\text { - TT4, O tempo de transferência deve ser } \leq 20 \mathrm{~ms} \\
\text { - TT5, O tempo de transferência deve ser } \leq 10 \mathrm{~ms} \\
\text { - TT6, O tempo de transferência deve ser } \leq 3 \mathrm{~ms}\end{array}$} \\
\hline \multicolumn{5}{|c|}{ Os demais valores para (P) e (TT) podem ser observados no padrão IEC/TR-61850-8-1 (2011). } \\
\hline
\end{tabular}

Fonte: IEC/TR-61850-5 (2013)

para acessar a camada física. Já as mensagens do tipo 2, 3 e 5 permitem a utilização de toda a pilha do protocolo em troca de maiores funcionalidades incluídas pelo MMS, operando, por exemplo, sobre o TCP/IP. As do tipo 4 são utilizadas em transmissão de valores amostrados e as do tipo 6 buscam a sincronização entre IEDs por meio de mensagens de sincronismo de tempo, enviadas pela rede de comunicação, utilizando o protocolo SNTP (Simple Network Time Protocol) sobre o UDP (User Datagram Protocol)/IP (Internet Protocol).

\subsubsection{A Mensagem GOOSE}

O modelo GSE prevê a possibilidade de distribuir informações de um IED de forma rápida para todo o SAS. Este modelo fornece um método que permite a entrega simultânea de uma mesma informação para mais de um dispositivo físico. As mensagens GOOSE e GSSE são pertencentes à classe GSE. Pereira et al. (2007) citam que nas mensagens GOOSE, a informação é configurável e pode utilizar um grupo de dados, Data Set, que permite a um receptor tomar ciência de que um estado foi modificado e o instante de sua alteração. Já as mensagens GSSE somente suportam uma estrutura fixa de informação de estado, a qual é publicada e disponibilizada na rede (IEC/TR-61850-8-1, 2011).

Ali, Thomas e Gupta (2012) e Bastos e Castro (2005) descrevem que a mensagem GOOSE foi implementada como um datagrama ISO, multicast, não orientado à conexão, contendo em seu cabeçalho as informações de endereço e nome do emissor, tempo do 
evento que disparou a mensagem GOOSE e o tempo esperado para a nova mensagem. Cada IED da rede de comunicação, ao receber essa mensagem, deve determinar o emissor da mensagem e se o dado recebido é de seu interesse, conforme ilustra a Figura 12.

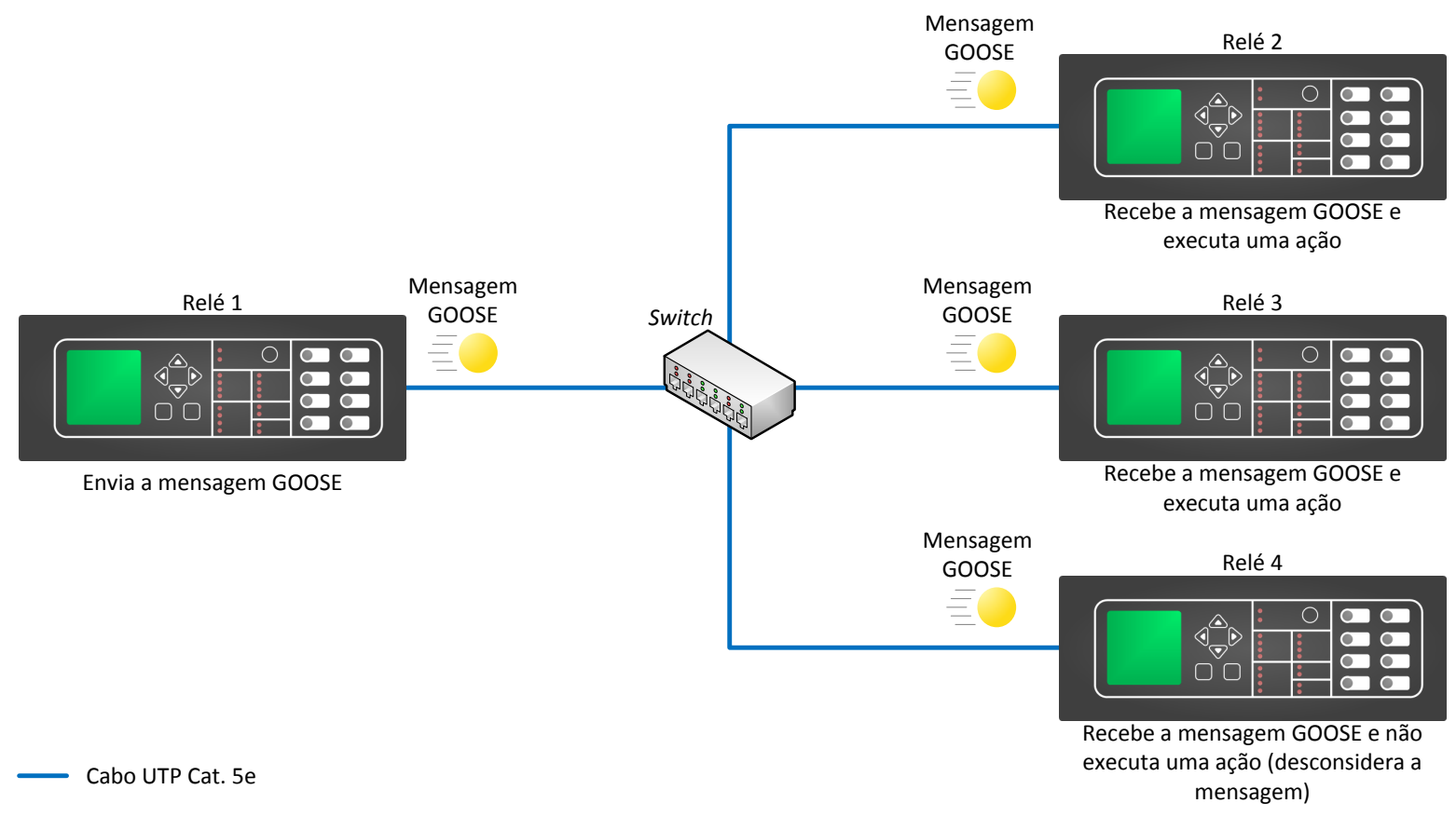

Figura 12: A mensagem GOOSE e o conceito de descentralização autônoma

Na Figura 12, somente os relés digitais 2 e 3 consideram a mensagem GOOSE enviada pelo relé digital 1, por ser de interesse para ambos. Assim, uma mensagem GOOSE enviada pode ser recebida e utilizada por um ou mais dispositivos da rede. A reação do receptor depende de sua configuração e funcionalidade.

O intercâmbio de mensagens GOOSE tem como base um mecanismo denominado publisher/subscriber. O publisher escreve os valores que serão enviados em uma memória local do IED transmissor. Após receber uma mensagem, o subscriber lê os valores de uma memória local do IED receptor.

\subsubsection{A Pilha de Comunicação GOOSE}

De acordo com o A-Profile e o T-Profile (Tabela 8), a pilha de comunicação do protocolo GOOSE consiste em quatro camadas do Modelo RM-OSI: aplicação, apresentação, enlace de dados e física. Conforme ilustra a Figura 13, as mensagens são mapeadas diretamente da camada de apresentação para a camada de enlace de dados (GUO; BAO; FENG, 2014). Sato et al. (2015) descrevem que a característica mais importante desta estrutura é o baixo atraso das informações na rede. 


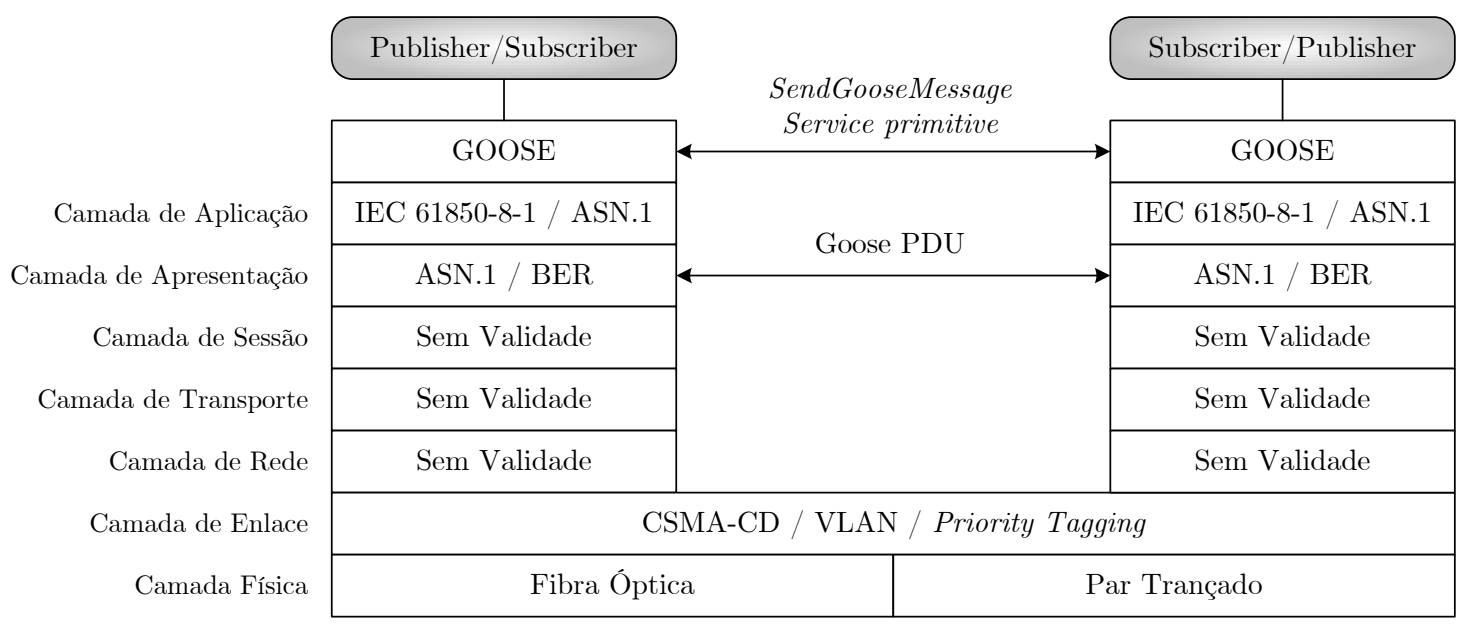

Figura 13: Pilha de comunicação da mensagem GOOSE

Fonte: Sato et al. (2015)

Na camada de aplicação, do protocolo GOOSE, é estabelecida a sintaxe abstrata por meio da qual são definidos os tipos e os valores dos dados a serem transferidos, independentemente das características dos sistemas envolvidos. De acordo com Carvalho (1997), a comunicação dessa camada com aquela de apresentação dá-se em termos da sintaxe abstrata, neste caso, a ASN.1 (Abstract Syntax Notation One).

Já a camada de apresentação codifica a informação por meio da sintaxe abstrata, em bytes, que podem ser transferidos para a camada de enlace. A maneira como é realizada essa codificação é definida a partir de uma sintaxe de transferência. No caso do GOOSE, a tradução entre a sintaxe abstrata e a de transferência é realizada mediante regras de codificação BER (Basic Encoding Rules), que especificam a representação dos valores de cada tipo de dado.

A linguagem ASN.1 e as regras de codificação BER são definidas, respectivamente, pelas normas ISO-8824 e ISO-8825.

A camada de enlace é responsável pela implementação do mecanismo de controle de acesso ao meio físico de transmissão CSMA/CD (Carrier Sense Multiple Access/Collision Detection), a identificação de uma VLAN (Virtual Local Area Network) ${ }^{2}$ e da prioridade das mensagens (Priority Tagging).

Para a camada física, que tem por objetivo realizar a transmissão das unidades de dados por meio de um canal de comunicação que conecta os IEDs, o padrão IEC/TR61850-8-1 (2011) menciona a utilização das tecnologias Ethernet: 10Base-T, 100Base-T e 1000Base-LX.

\footnotetext{
${ }^{2}$ VLAN (IEEE 802.1Q) "(...) é um grupo de nós da rede, cujo tráfego, inclusive as difusões, é isolado dos outros nós. Isso significa a impossibilidade de transmissão de quadros com base em endereços da camada de enlace de dados entre diferentes redes virtuais"(OLIFER; OLIFER, 2006). Mais detalhes sobre as VLANs podem ser encontrados em Forouzan e Fegan (2007).
} 
Em conformidade com Moura et al. (1986), o nome das unidades de dados trocadas pelas camadas de aplicação e apresentação é mensagem; pela camada de enlace é quadro; e pela camada física é bit. Nesse contexto, o padrão IEC 61850 trata dos tipos de mensagem $1 \mathrm{~A}$ e 1B, descritas na Seção 2.7.1, como mensagens GOOSE.

\subsubsection{Notação de Sintaxe Abstrata}

O serviço de envio da mensagem GOOSE utiliza a ASN.1. Carvalho (1997) relata que esta notação é um padrão genérico utilizado nas camadas de aplicação e apresentação para a definição de uma PDU (Protocol Data Unit) e algumas informações referenciadas ou utilizadas pelas aplicações. O Algoritmo 1 ilustra um trecho da codificação ASN.1, que forma a PDU pertinente a uma mensagem GOOSE.

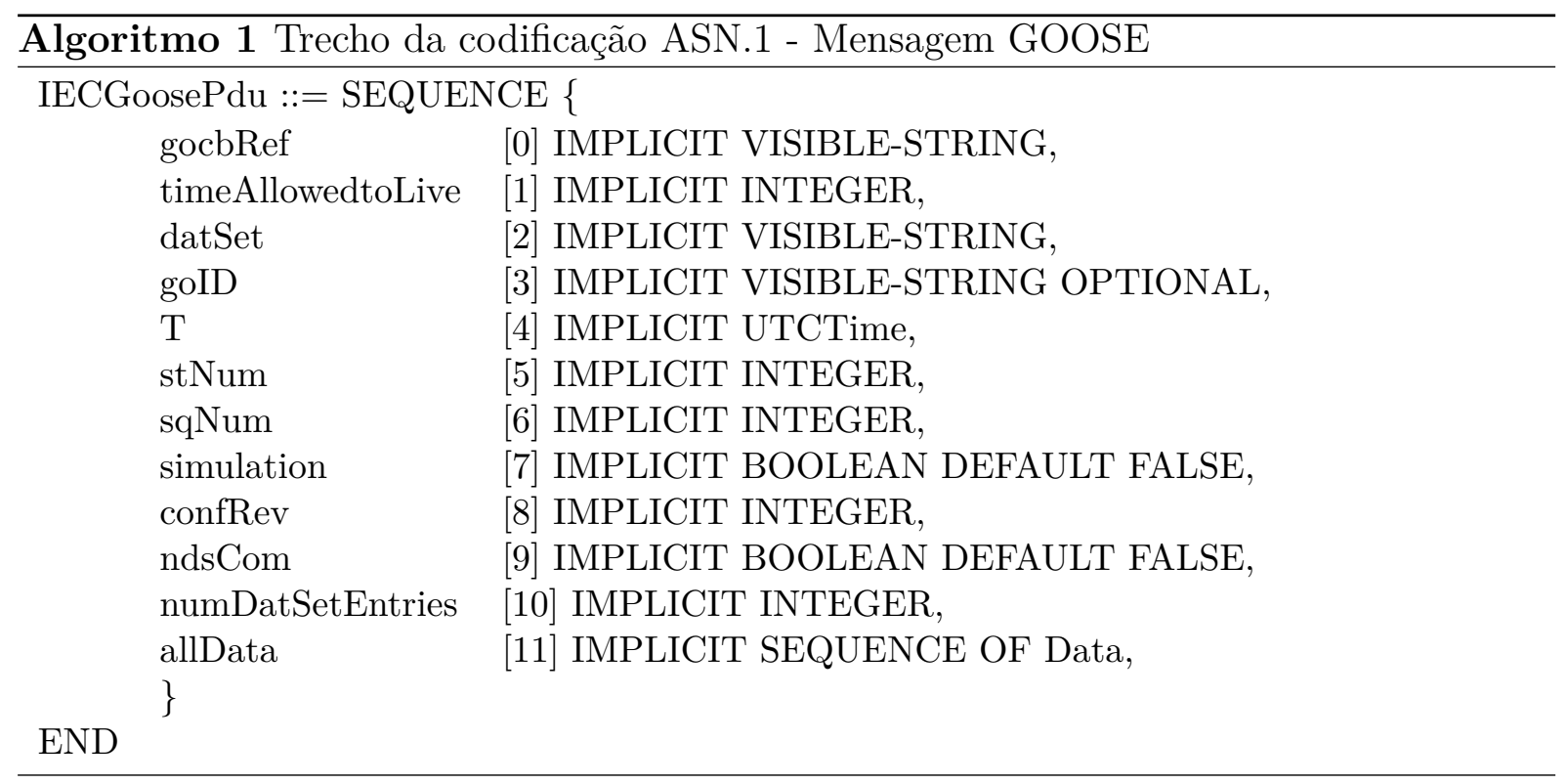

Fonte: IEC/TR-61850-8-1 (2011)

A Tabela 10 mostra alguns tipos de dados definidos pela ASN.1 e utilizados pelo Algoritmo 1. Um estudo da linguagem ASN.1 pode ser encontrado em Dubuisson (2001) e Larmouth (2000).

\subsubsection{Notação de Sintaxe de Transferência}

Além de fornecer uma linguagem de descrição de dados, a ASN.1 oferece regras básicas de codificação (BER), que especificam como instâncias de objetos, utilizando a linguagem de descrição de dados ASN.1, devem ser enviadas pela rede (KUROSE; ROSS, 2012).

O princípio que orienta as regras básicas de codificação é o de que todos os valores transmitidos, tanto primitivos quanto construídos, consistem essencialmente em um identificador (tipo ou tag), no tamanho do campo de dados (em bytes) e no campo de dados. As regras estão baseadas em uma abordagem de codificação denominada TLV - 
Tabela 10: Tipos de dados básicos ASN.1

\begin{tabular}{ll}
\hline Tipo & Descrição \\
\hline BITSTRING & Lista de um ou mais bits \\
BOOLEAN & O valor é Verdadeiro ou Falso \\
INTEGER & Pode assumir valores cardinais \\
OCTET STRING & Lista de um ou mais bytes \\
SEQUENCE OF & Lista de elementos do mesmo tipo ASN.1 \\
UTCTime & Contém data e hora \\
VISIBLE-STRING & Cadeia de caracteres \\
\hline
\end{tabular}

Type, Lenght e Value (FOROUZAN; FEGAN, 2007; DUBUISSON, 2001), conforme ilustra a Figura 14.

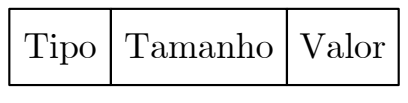

Codificação Primitiva

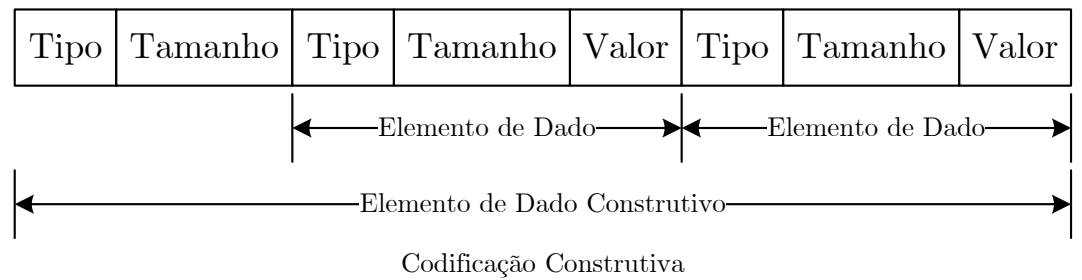

Figura 14: Formas de codificação

Fonte: Carvalho (1997)

Codificação do Identificador de Tipo Na codificação do identificador de campo são utilizados um ou mais bytes, conforme mostra a Figura 15. Tanenbaum (1996) descreve que os 2 bits mais significativos identificam o tipo da tag. O próximo bit informa se o valor é primitivo ou construtivo. Os 5 bits restantes podem ser utilizados para codificar o valor da tag.

Codificação de Tamanho Das regras para codificação, em bytes, do tamanho do conteúdo do dado a ser transmitido, serão abordadas as formas denominadas curta e longa, respectivamente (DUBUISSON, 2001; LARMOUTH, 2000; TANENBAUM, 1996):

- Quando o tamanho do conteúdo for menor ou igual a 127 bytes, o tamanho do campo será diretamente codificado em 1 byte, cujo bit mais significativo é 0, como mostra a Figura 16(a);

\footnotetext{
${ }^{3}$ As regras básicas de codificação podem consistir, também, de uma flag de detecção de final de conteúdo, caso o tamanho dos dados seja desconhecido (TANENBAUM, 1996).
} 


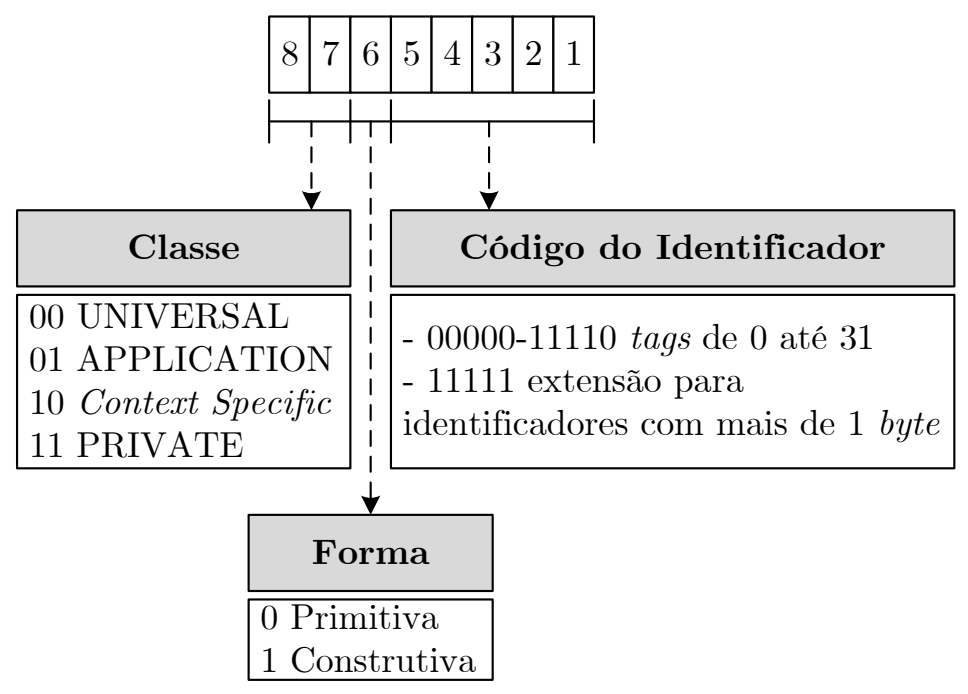

Figura 15: Código do identificador de tipo

- Os campos maiores utilizam diversos bytes, com o primeiro deles contendo nível lógico 1 no bit mais significativo e o campo de tamanho (até 127 bytes) nos 7 bits menos significativos, como pode ser visto na Figura 16(b).

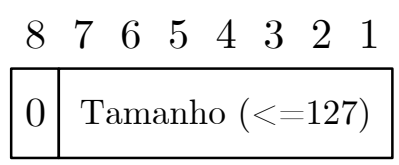

(a)

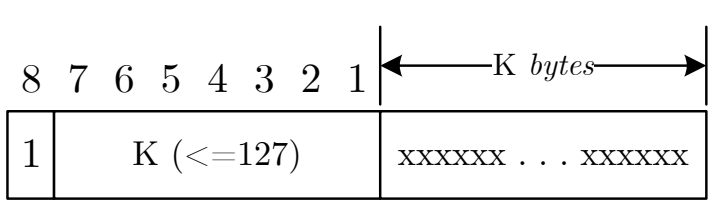

(b)

Figura 16: Codificação de tamanho - (a) Forma curta (b) Forma longa Fonte: Carvalho (1997)

Codificação de Conteúdo A codificação do conteúdo é feita sempre em uma sequência completa de bytes e depende do valor do tipo de dado que for gerado (CARVALHO, 1997). Alguns dos tipos de dados para as mensagens GOOSE podem ser observados na Tabela 11.

\subsubsection{O Quadro e os Campos da Mensagem}

Embora os modelos abstratos sejam um passo importante para a interoperabilidade, estes só podem ser utilizados com base em um protocolo real (OZANSOY, 2010). Neste contexto, a mensagem GOOSE é mapeada para Ethernet (XIAO, 2013), em quadros ISO/IEC 8802-3.

Conforme ilustra a Figura 17, todo quadro é precedido do Preâmbulo e do SFD (Start Frame Delimiter). O Preâmbulo contém 7 bytes compostos por bits 0 e 1 alternados que alertam o receptor sobre o quadro que está chegando e o habilita a sincronizar seu clock 
Tabela 11: Tipos de dados ASN.1 para mensagens GOOSE

\begin{tabular}{l|c|c|l}
\hline Tipo de Dado & Tag & Bytes & Conteúdo \\
\hline Boolean & 0x83 & 1 & 8 Bit set to 0 FALSE; anything else = TRUE \\
INT8 & 0x85 & 2 & 8 Bit Big Endian; signed \\
INT16 & 0x85 & 3 & 16 Bit Big Endian; signed \\
INT32 & 0x85 & 5 & 32 Bit Big Endian; signed \\
INT64 & 0x85 & 9 & 64Bit Big Endian; signed \\
INT8U & 0x86 & 2 & 8 Bit Big Endian; unsigned \\
INT16U & 0x86 & 3 & 16 Bit Big Endian; unsigned \\
INT32U & 0x86 & 5 & 32 Bit Big Endian; unsigned \\
FLOAT32 & 0x87 & 4 & 32 Bit IEEE Floating Point (IEEE 754) \\
ENUMERATED & 0x85 & 2 & 8 Bit Big Endian; signed equivalent to INT8 \\
CODED ENUM & 0x84 & 2 & Bit-string; depending on CODED ENUM definition \\
OCTET STRING & 0x89 & 20 & 20 Bytes ASCII Text, Null terminated \\
VISIBLE STRING & 0x8a & 35 & 35 Bytes ASCII Text, Null terminated \\
TimeStamp & 0x91 & 8 & 64 Bit TimeStamp \\
Quality & 0x84 & 3 & Bit-string \\
\hline
\end{tabular}

Fonte: IEC/TR-61850-8-1 (2011)

de entrada. Estes bits, na realidade, são adicionados à camada física e, formalmente, não fazem parte do quadro (FOROUZAN; FEGAN, 2007). O SFD é uma sequência de bits que anuncia o início de um quadro (1 byte: 10101011(2) $)$.

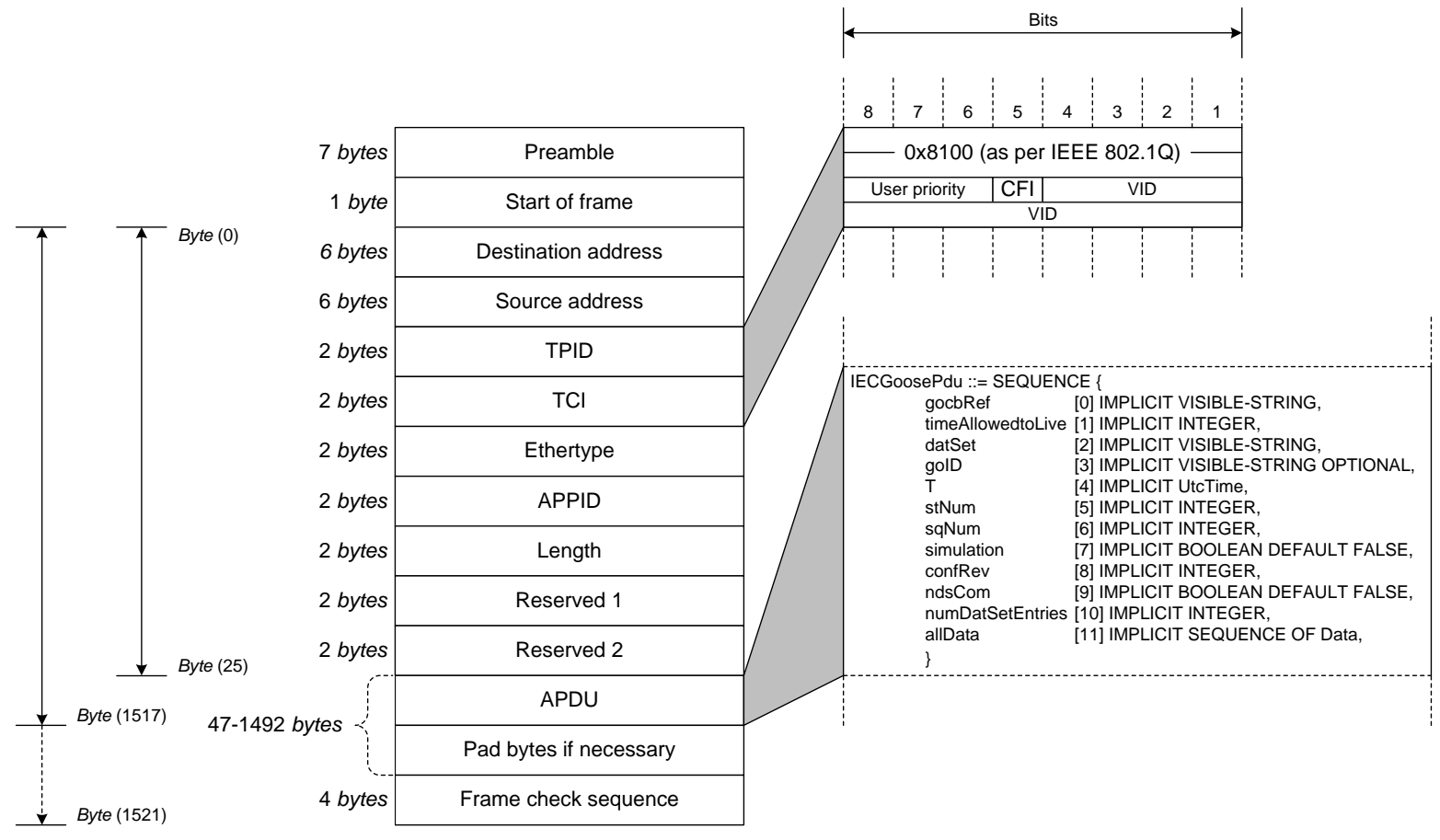

Figura 17: Visão geral do quadro ISO/IEC 8802-3 para GSE-GOOSE 
Os campos que formam o quadro ISO/IEC 8802-3 serão classificados neste trabalho como: fixos e flexíveis. Para os campos fixos não é necessário definir os limites, uma vez que o tamanho do campo em si já é utilizado como delimitador. Os campos fixos são: Destination Address, Source Address, TPID, TCI, Ethertype, APPID, Lenght, Reserved 1 e Reserved 2 (IEC/TR-61850-8-1, 2011).

Já as informações flexíveis do quadro ISO/IEC 8802-3 formam uma APDU (Application Protocol Data Unit) com os seguintes campos (IEC/TR-61850-8-1, 2011): gocbRef, timeAllowedtoLive, datSet, goID, T, stNum, sqNum, simulation, confRev, ndsCom, numDatSetEntries e allData (Figura 17). Para delimitar estes campos é utilizada a abordagem de codificação TLV do BER (PATNAIK; XIAOLONG, 2013).

A descrição dos campos fixos e flexíveis, que formam o quadro da mensagem GOOSE, podem ser observados nas Tabelas 12 e 13, respectivamente. Mais detalhes são encontrados no padrão IEC 61850, Partes 7.2 e 8.1 - Specific Communication Service Mapping (SCSM) (IEC/TR-61850-7-2, 2010; IEC/TR-61850-8-1, 2011).

Cada quadro é encerrado com o campo FCS (Frame Check Sequence), que é uma sequência de verificação, com 4 bytes, que detecta os erros que podem ocorrer durante uma transmissão.

Tabela 12: Descrição dos campos fixos

\begin{tabular}{|c|c|c|}
\hline Campo: Destination Address & Tamanho: & 6 bytes \\
\hline \multicolumn{3}{|c|}{$\begin{array}{l}\text { Endereço físico do IED de destino que receberá a mensagem GOOSE, endereço MAC } \\
\text { (Media Access Controllers). }\end{array}$} \\
\hline Campo: $\quad$ Source Address & Tamanho: & 6 bytes \\
\hline \multicolumn{3}{|c|}{ Endereço físico do IED remetente (endereço MAC). } \\
\hline Campo: & Tamanho: & 2 bytes \\
\hline
\end{tabular}

Para armazenar o número de uma rede virtual (VLAN), o padrão IEEE 802.1Q (tag Protocol) fornece um cabeçalho adicional de quatro bytes (Figura 17). Os dois primeiros bytes formam o Tag Protocol Identifier (TPID) e sempre contêm o valor 0x8100, pelo qual os equipamentos de rede devem reconhecer que esse é um quadro Ethernet com identificação tag.

Campo: TCI Tamanho: 2 bytes

Nesse campo, 12 bits são utilizados para armazenar o número da VLAN (o campo VLAN ID), e 3 bits são alocados para armazenar a prioridade do quadro definida no padrão IEEE 802.1q. Um bit, conhecido como CFI (Canonical Format Identifier), foi introduzido para proporcionar a possibilidade de se distinguir quadros Ethernet dos Token Ring. Em quadros Ethernet, esse bit deve ser configurado como 0. O campo de 12 bits VLAN Identifier (VID) possibilita a criação de até 4096 redes virtuais. 
Tabela 12 - Continuação da página anterior

Campo: Ethertype Tamanho: 2 bytes

Define o protocolo da camada superior: 0x88B8 - GOOSE Tipo 1A ou 1B.

Campo: APPID Tamanho: 2 bytes

O Application Identifier (APPID) é usado para distinguir a aplicação associada. O intervalo de valores reservados para GOOSE Tipo 1B é 0x0000 até 0x3FFF, para o Tipo GOOSE 1A ( Trip), a gama de valores reservado é 0x8000 até 0xFFFF. Se nenhum APPID for configurado, o valor padrão será 0x0000, o que indicará falta de configuração.

Campo: Lenght Tamanho: 2 bytes

É o número de octetos do cabeçalho da PDU até o final da APDU. Portanto, o valor do comprimento deve ser de $8+\mathrm{m}$, onde m é o comprimento da APDU e m é menor que 1492 bytes.

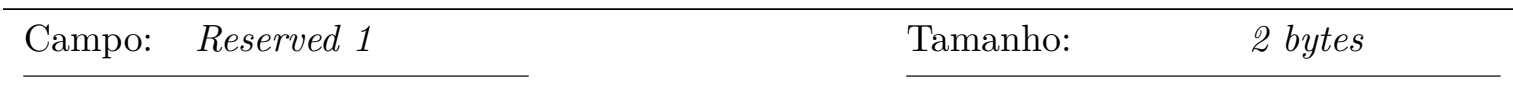

Apresenta bits que indicam quando a mensagem GOOSE foi encaminhada por um equipamento de teste, bits reservados para aplicações futuras e outros para indicar quando uma mensagem com requisitos de segurança é transmitida.

\begin{tabular}{lll}
\hline Campo: Reserved 2 & Tamanho: & 2 bytes \\
É um campo definido pelo padrão IEC 62351-6 e deve ser utilizado quando uma mensagem \\
com requisitos de segurança é transmitida.
\end{tabular}

Fonte: IEC/TR-61850-7-2 (2010) e IEC/TR-61850-8-1 (2011)

Tabela 13: Descrição dos campos flexíveis - GOOSE Header

\begin{tabular}{lllllll}
\hline Campo: gocbRef & ASN.1 tag: & 0x80 & & Tamanho Máximo: & 129 bytes \\
\cline { 1 - 1 } Contém o Objeto de & Referência do & GoCB & (GOOSE & Control & Block $).$ \\
Ex:D60LDInst/LLNOGOgcb01 & & & & \\
\hline Campo: timeAllowedtoLive & ASN.1 tag: & 0x81 & & Tamanho Máximo: & 5 bytes
\end{tabular}

Paramêtro que informa para o destinatário (subscriber) o tempo de espera até a próxima retransmissão da mensagem. Ex: 4500(ms)

\begin{tabular}{llll}
\hline Campo: datSet & ASN.1 tag: $0 \times 82$ & Tamanho Máximo: 129 bytes \\
\end{tabular}

Agrupamento de dados e atributos utilizados para o acesso direto entre IEDs. Ex: D60LDInst/LLNO\$GOOSE1

Campo: goID ASN.1 tag: $0 \times 83 \quad$ Tamanho Máximo: 65 bytes

Este atributo é a referência do GoCB. Ex:GOOSEOut_1 
Tabela 13 - Continuação da página anterior

\begin{tabular}{lllll}
\hline Campo: $T$ & ASN.1 tag: $0 \mathrm{x} 84$ & Tamanho Máximo: 8 bytes \\
\cline { 3 - 4 } &
\end{tabular}

Indica o tempo quando o campo stNum foi incrementado. Ex: Jun 28, 2013 08:59:28.974334955 UTC

Campo: stNum ASN.1 tag: 0x85 $\quad$ Tamanho Máximo: 5 bytes

O stNum contém um contador que é incrementado cada vez que uma mensagem for enviada com sucesso e houver uma alteração no valor de um atributo de dados dentro do datSet de referência.

\begin{tabular}{llll}
\hline Campo: & sqNum & ASN.1 tag: $0 \times 86$ & Tamanho Máximo: 5 bytes \\
\cline { 3 - 4 }
\end{tabular}

O sqNum aponta o número sequencial de cada mensagem gerada e enviada pelo GoCB. A primeira mensagem recebe o valor 1, a segunda o valor 2, e assim por diante. Este campo é zerado quando ocorre uma mudança no campo stNum.

\begin{tabular}{llll}
\hline Campo: simulation & ASN.1 tag: $0 \times 87$ & Tamanho Máximo: 1 bytes \\
\cline { 3 - 4 }
\end{tabular}

Se definido como verdadeiro, indica que o conteúdo da mensagem não é para fins operacionais.

Campo: confRev ASN.1 tag: 0x88 Tamanho Máximo: 5 bytes

Este atributo representa o número de vezes que a configuração do conjunto de dados referenciado pelo datSet foi alterada.

\begin{tabular}{|c|c|c|c|}
\hline$n d s C o m$ & ASN.1 tag: 0x89 & Tamanho Máximo: & 1 bytes \\
\hline \multicolumn{4}{|c|}{$\begin{array}{l}\text { O atributo } N d s C o m \text { deve apresentar valor } T R U E \text {, se o GoCB exigir uma configuração } \\
\text { adicional (necessidade de comissionamento). }\end{array}$} \\
\hline numDatSetEntries & ASN.1 tag: $0 \mathrm{x} 8 \mathrm{a}$ & Tamanho Máximo: & 5 bytes \\
\hline
\end{tabular}

Especifica o número de membros no campo allData.

Campo: allData ASN.1 tag: 0xab $\quad$ Tamanho Máximo: 1492 bytes

Valores pertinentes aos atributos de dados do datSet. O campo allData contém uma lista de informações definidas pelo usuário, por exemplo, informações de status, com base no padrão MMS (IEC/TR-61850-8-1, 2011). Um trecho da codificação ASN.1 deste campo pode ser observada no Algoritmo 2.

Fonte: IEC/TR-61850-7-2 (2010), IEC/TR-61850-8-1 (2011) e Ozansoy (2010) 


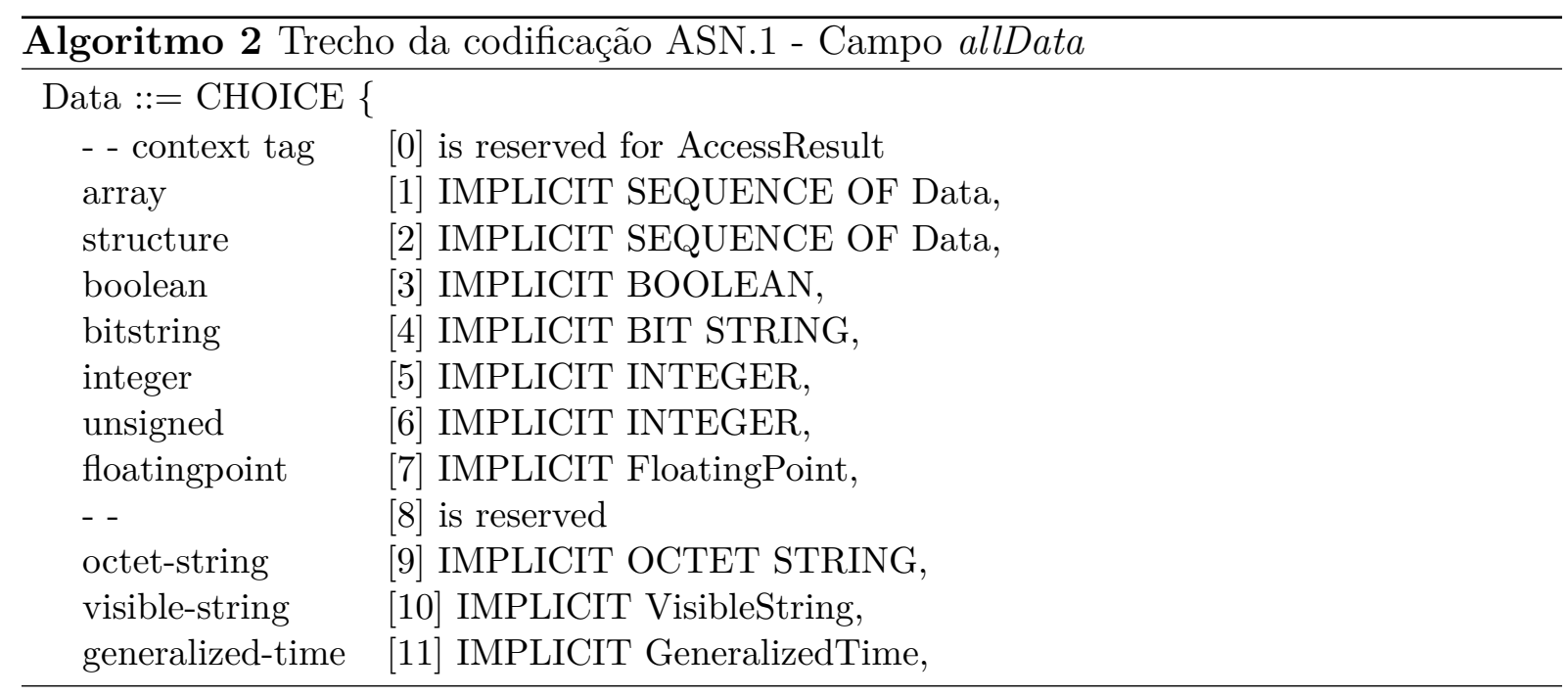

Fonte: Schwarz (2004)

\subsubsection{Exemplo de Mapeamento do Quadro ISO/IEC 8802-3}

A Figura 18 exemplifica o mapeamento de uma mensagem GOOSE para o quadro ISO/IEC 8802-3. No nível da camada de aplicação, a mensagem GOOSE é composta pelos tipos, modelos e serviços abstratos descritos no padrão IEC 61850, partes 7-1, 7-2, 7-3, 7-4 e 7-5. A partir da notação de sintaxe abstrata (ASN.1) e da notação de sintaxe de transferência (BER), a mensagem é mapeada como um quadro de dados e transmitida na rede de comunicação.

Na Figura 18, é possível observar os campos fixos e flexíveis, as tags, os tamanhos e a codificação dos conteúdos:

- A tag 0x61 identifica o início dos campos flexíveis e a quantidade de bytes 0x81a2, que envolvem a codificação de tamanho em sua forma longa;

- A tag 0x80 identifica o campo gocbRef, o seu tamanho 0x1f (31 bytes), e a codificação dos dados: 0x54454d504c4154454346472f4c4c4e3024474f24476f6f73654453657 43133;

- A tag 0xab identifica o campo allData;

- A tag 0xa2 é referente a um tipo de dado que define uma lista dentro do campo allData (structure), ou seja, uma codificação construtiva. 
Mensagem GOOSE (.hex)

Quadro ISO/IEC 8802-3

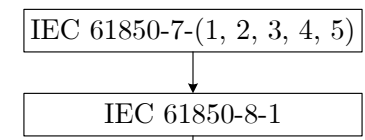

010ccd01000708606eda3a208100800188b8100700ad00000000 6181a2801f54454d504c4154454346472f4c4c4e3024474f24476f6 f7365445365743133810103821754454d504c4154454346472f4c4 c4e3024445365743133830853756232426179318408554bb09ee5 6046008502017f8601008701008801018901008a010cab3c 83010 $0830100830100830100830100830100830100830100 \mathrm{a} 207870508$ 44e8e000a20787050844e80000a20787050844e80000a20787050 $844 \mathrm{e} 74000$

Significado de alguns campos

Frame 1: 191 bytes on wire (1528 bits)

Encapsulation type: Ethernet (1)

Frame Length: 191 bytes (1528 bits)

[Protocols in frame: eth:ethertype:vlan:ethertype:goose]

Ethernet II, Src: AsustekC da:3a:20 (08:60:6e:da:3a:20),

Dst: Iec-Tc57 01:00:07 (01:0c:cd:01:00:07)

Destination: Iec-Tc57 01:00:07 (01:0c:cd:01:00:07)

Source: AsustekC_da:3a:20 (08:60:6e:da:3a:20)

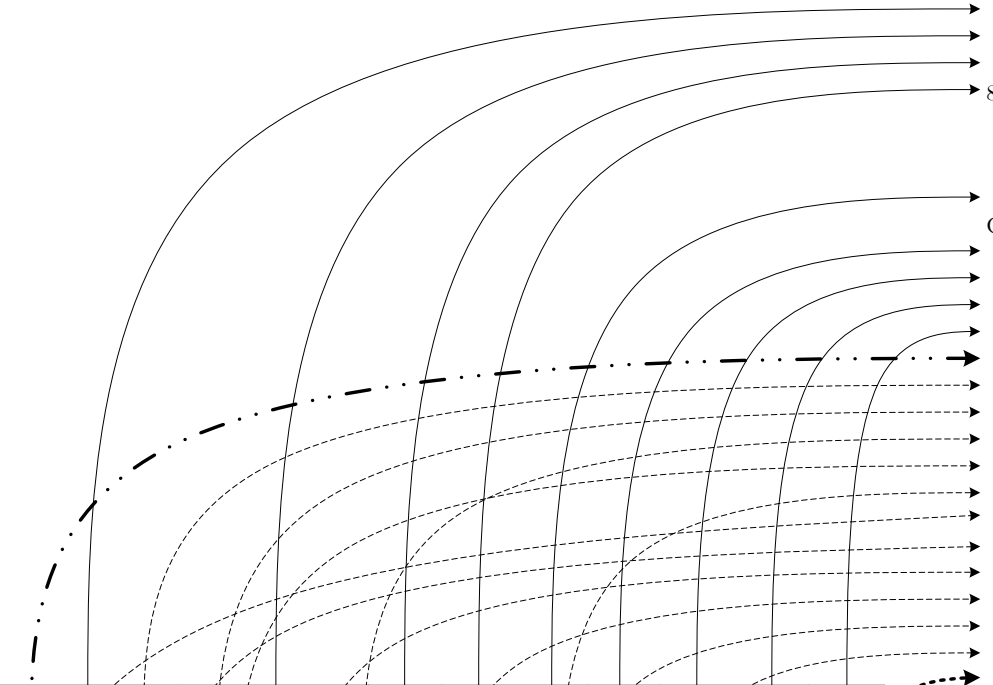

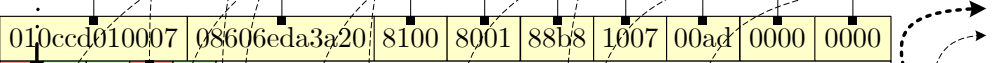
61 81 a2 80 ㅅ $54454 \mathrm{~d} 504 \mathrm{c} 4154454346472 \mathrm{f} 4 \mathrm{c} 4 \mathrm{c} 4 \mathrm{e} 3024474 \mathrm{f} 24476 \mathrm{f} 6 \mathrm{f} 73$ Type: 802.1Q Virtual LAN (0x8100)

802.1Q Virtual LAN, PRI: 4, CFI: 0, ID: 100. ........... = Priority: Controlled Load (4)

$0 \ldots \ldots \ldots=$ CFI: Canonical $(0)$

$000000000001=$ ID: 1

Type: IEC $61850 /$ GOOSE (0x88b8) GOOSE

APPID: 0x1007 (4103)

Length: 173

Reserved 1: 0x0000 (0)

Reserved 2: 0x0000 (0)

goosePdu

gocbRef: TEMPLATECFG/LLN0\$GO $\$$ GooseDSet13

timeAllowedtoLive: 3

datSet: TEMPLATECFG/LLN0\$DSet13

goID: Sub2Bay1

t: May 7, 2015 18:36:14.896000266 UTC

stNum: 383

sqNum: 0

test: False

confRev: 1

ndsCom: False

numDatSetEntries: 12

allData: 12 items

Data: boolean (3)

boolean: False

Data: boolean (3)

boolean: True

\begin{tabular}{ll|l|l|l|l|l|l}
65445365743133 & 81 & $\underline{10}$ & 03 & 82 & $\underline{17}$ & $54454 d 504 c 4154454346472 f 4 c 4 c 4 e 30$
\end{tabular}

\begin{tabular}{|l|l|l|l|l|l|l|}
\hline 24445365743133 & 83 & $\underline{08}$ & 5375623242617931 & 84 & 08 & $554 b b 09 e e 5604600$.
\end{tabular}

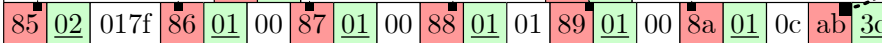

\begin{tabular}{|l|l|l|l|l|l|l|l|l|l|l|l|l|l|l|l|l|l|l|l|l|}
83 & $\underline{01}$ & 00 & 83 & $\underline{01}$ & 01 & 83 & $\underline{01}$ & 00 & 83 & $\underline{01}$ & 00 & 83 & $\underline{01}$ & 00 & 83 & $\underline{01}$ & 00 & 83 & $\underline{01}$ & 00 \\
\hline
\end{tabular}

Data: structure $(2)$

structure: 1 item

Data: floating-point (7)

floating-point: $0844 \mathrm{e} 8 \mathrm{e} 000$

\begin{tabular}{lllllllllll|l|l|l|l|l|l|l}
83 & $\underline{01}$ & 00 & $\mathrm{a} 2$ & $\underline{07}$ & 87 & $\underline{05}$ & $0844 \mathrm{e} 8 \mathrm{e} 000$ & $\mathrm{a} 2$ & $\underline{07}$ & 87 & $\underline{05}$ & $0844 \mathrm{e} 8 \mathrm{e} 000$ & a2 2 & $\underline{07}$
\end{tabular}

\begin{tabular}{llll|l|l|l|l|l|l}
87 & $\underline{05}$ & $0844 \mathrm{e} 8 \mathrm{e} 000$ & $\mathrm{a} 2$ & $\underline{07}, 87$ & 05 & $0844 \mathrm{e} 74000$
\end{tabular}

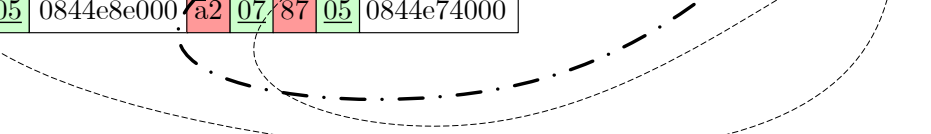

Detalhes do Quadro ISO/IEC 8802-3 (.hex)

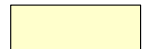

Campos Flexíveis

$\longrightarrow$ Campos Fixos

Abordagem

T $\quad$ L $\quad$ V

- - - - Tag da goosePdu - Início dos Campos Flexíveis

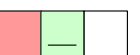

a............. Tag do allData

- $\rightarrow \rightarrow$ Tag de um tipo de dado que define uma lista dentro do allData (Algoritmo 2)

Figura 18: Exemplo dos campos de um quadro ISO/IEC 8802-3 - Mensagem GOOSE 


\subsubsection{Transmissão das Mensagens GOOSE}

Patel (2011) descreve que, enquanto não ocorre alteração nos dados, uma dada mensagem GOOSE é transmitida periodicamente, de acordo com uma variável de tempo denominada MaxTime (T0). Quando um ou mais atributos de dados de um Data Set muda de valor, a primeira transmissão de dados com os valores atualizados é encaminhada dentro do menor tempo configurado, MinTime (T1), conforme exemplifica a Figura 19. Após a primeira transmissão, a mesma mensagem é retransmitida um determinado número de vezes, conforme a política de publicação de cada fabricante, até que seja alcançado o tempo de estabilidade (T0). Valores para o MinTime e o MaxTime são específicos da aplicação, e ajustáveis pelo usuário, por exemplo, 10ms e 1000ms.

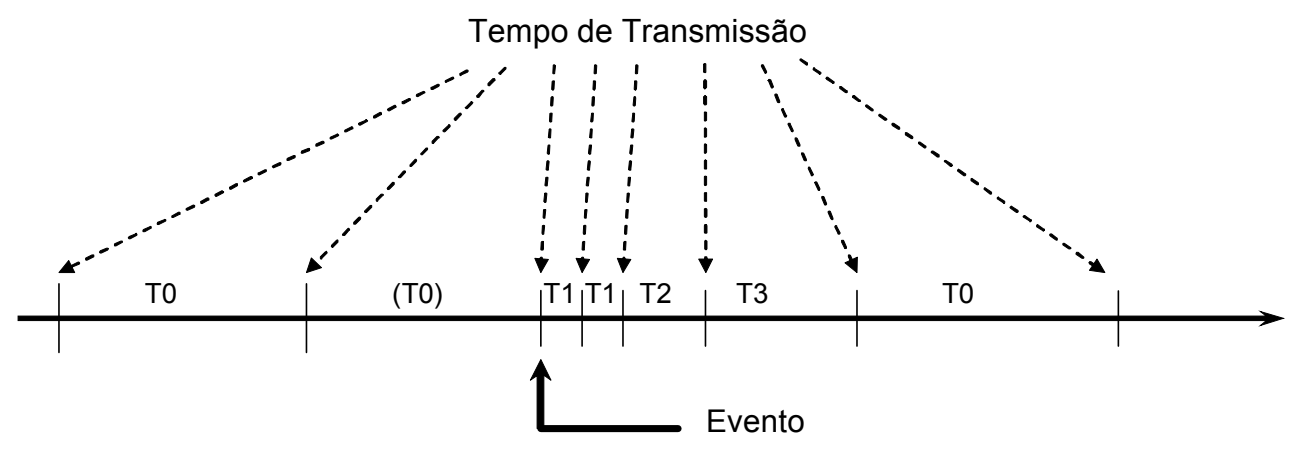

Figura 19: Transmissão de mensagens GOOSE

Fonte: IEC/TR-61850-8-1 (2011)

T2 e T3 são tempos de retransmissão até o retorno de T0.

\subsubsection{Seleção de Endereço Multicast}

A fim de aumentar o desempenho de recepção das mensagens multicast (por exemplo, GOOSE e SV), pode-se realizar uma filtragem pelo endereço MAC (Media Access Controllers).

Os endereços multicast utilizados pelo padrão IEC 61850 têm a seguinte estrutura:

- Os três primeiros bytes (em hexadecimal) são atribuídos pelo IEEE como sendo: 01-0C-CD;

- O quarto byte será 01 para mensagens GOOSE, 02 para mensagens GSSE e 04 para mensagens de valores amostrais (SV);

- Os últimos dois bytes devem ser utilizados como endereços individuais atribuídos pelo intervalo definido na Tabela 14. 
Tabela 14: Exemplo de endereço multicast recomendado

\begin{tabular}{ccc}
\hline \multirow{2}{*}{ Serviço } & \multicolumn{2}{c}{ Gama de endereços a serem distribuídos } \\
\cline { 2 - 3 } & Início do endereço (Hexadecimal) & Fim do Endereço (Hexadecimal) \\
\hline GOOSE & 01-0C-CD-01-00-00 & 01-0C-CD-01-01-FF \\
GSSE & 01-0C-CD-02-00-00 & 01-0C-CD-02-01-FF \\
SV & 01-0C-CD-04-00-00 & 01-0C-CD-04-01-FF \\
\hline
\end{tabular}

Fonte: IEC/TR-61850-8-1 (2011)

\subsection{Gerador RGGM-61850}

Com base no Scapy, que é um framework para manipulação de quadros, escrito em Python por Philippe Biondi (SINGH; SINGH; JOSEPH, 2008), foi desenvolvido um gerador de mensagens GOOSE, denominado RGGM (Random Generator GOOSE Messages), que utiliza os cabeçalhos e tipos de dados descritos pelo padrão IEC 61850 parte 8.1 (Algoritmo 1), e utiliza também o formato de codificação dos bytes do quadro ISO/IEC 8802-3 (Figura 17).

O objetivo do RGGM para este trabalho foi gerar mensagens aleatórias para o processo de validação do módulo decodificador ASN.1/BER GOOSE, implementado em hardware, que será detalhado no Capítulo 4.

O RGGM envia, a cada mensagem gerada, um quadro de dados para uma interface de rede do computador hospedeiro, com Sistema Operacional Linux, conforme configuração no script. Como mostra a Figura 20, este quadro deve ser capturado por um sniffer de rede, por exemplo, o Wireshark ${ }^{\circledR}$ (WIRESHARK, 2016). O Algoritmo 6, no Apêndice A, apresenta o pseudocódigo do RGGM (versão 1.0).

A intenção não foi criar informações que tivessem vínculo com qualquer modelo de equipamento ou fabricante, mas utilizar toda a faixa permitida de valores.

O Scapy fornece suporte para ASN.1/BER por meio de classes e métodos. Nesse contexto, novos objetos ASN.1 foram definidos para criar uma PDU GOOSE, conforme exemplifica a Figura 21. Para a codificação dos dados foram utilizados codificadores BER, conforme é possível observar em diversas linhas do Algoritmo 6 (Apêndice A) e na Figura 22.

A Figura 23 mostra os detalhes de uma mensagem GOOSE gerada pelo RGGM. 


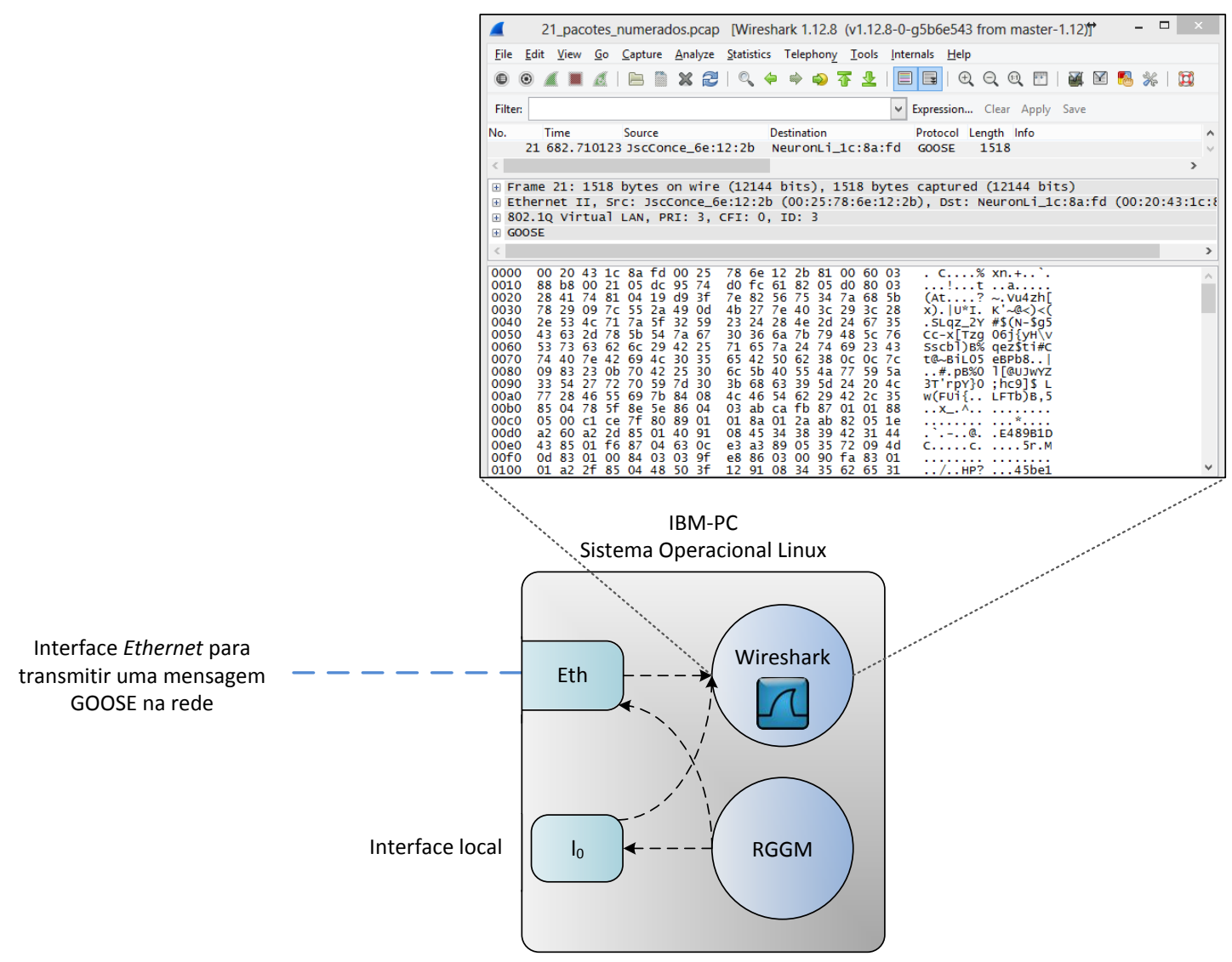

Figura 20: Arranjo para geração das mensagens GOOSE aleatórias

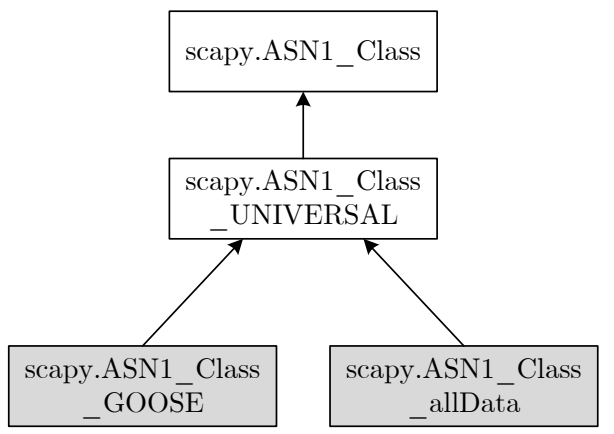

class
ASN1_Class_GOOSE(ASN1_Class_UNIVERSAL):
name="IECGoosePdu"
gocbRef $=0 \times 80$
timeAllowedToLive $=0 \times 81$
datSet $=0 \times 82$
goID $=0 \times 83$
T $=0 \times 84$
stNum $=0 \times 85$
sqNum $=0 \times 86$
simulation $=0 \times 87$
confRev $=0 \times 88$
ndsCom $=0 \times 89$
numDatSetEntries $=0 \times 8 \mathrm{a}$

\begin{tabular}{|l|} 
class \\
ASN1_Class_ALLDATA(ASN1_Class_UNIVERSAL): \\
name="IECGooseAllData" \\
boolean $=0 \mathrm{x} 83$ \\
int $8=0 \mathrm{x} 85$ \\
int $16=0 \mathrm{x} 85$ \\
int32 $=0 \mathrm{x} 85$ \\
int $64=0 \mathrm{x} 85$ \\
int8u $=0 \mathrm{x} 86$ \\
int16u $=0 \mathrm{x} 86$ \\
int32u $=0 \mathrm{x} 86$ \\
float32 $=0 \mathrm{x} 87$ \\
enumerated $=0 \mathrm{x} 85$ \\
codedenum $=0 \mathrm{x} 84$ \\
octetstring $=0 \mathrm{x} 89$ \\
visiblestring $=0 \mathrm{x} 8 \mathrm{a}$ \\
timestamp $=0 \mathrm{x} 91$ \\
quality $=0 \mathrm{x} 84$ \\
\end{tabular}

Figura 21: Objetivos definidos para as classes GOOSE e allData 


\begin{tabular}{|c|c|}
\hline Codificadores para o cabeçalho GOOSE & Codificadores para allData \\
\hline $\begin{array}{l}\text { class BERcodec_gocbRef(BERcodec_ISO646_STRING): } \\
\text { tag = ASN1_Class_GOOSE.gocbRef }\end{array}$ & $\begin{array}{l}\text { class BERcodec_boolean(BERcodec_BOOLEAN): } \\
\text { tag = ASN1_Class_ALLDATA.boolean }\end{array}$ \\
\hline $\begin{array}{l}\text { class BERcodec_timeAllowedToLive(BERcodec_INTEGER): } \\
\text { tag = ASN1_Class_GOOSE.timeAllowedToLive }\end{array}$ & $\begin{array}{l}\text { class BERcodec_int8(BERcodec_INTEGER): } \\
\text { tag = ASN1_Class_ALLDATA.int8 }\end{array}$ \\
\hline $\begin{array}{l}\text { class BERcodec_datSet(BERcodec_ISO646_STRING): } \\
\text { tag = ASN1_Class_GOOSE.datSet }\end{array}$ & $\begin{array}{l}\text { class BERcodec_visiblestring(BERcodec_STRING): } \\
\text { tag = ASN1_Class_ALLDATA.visiblestring }\end{array}$ \\
\hline $\begin{array}{l}\text { class BERcodec_goID(BERcodec_ISO646_STRING): } \\
\text { tag = ASN1_Class_GOOSE.goID }\end{array}$ & $\begin{array}{l}\text { class BERcodec_timestamp(BERcodec_UTC_TIME): } \\
\text { tag = ASN1_Class_ALLDATA.timestamp }\end{array}$ \\
\hline$\{\ldots$ continua $\}$ & $\{\ldots$ continua $\}$ \\
\hline
\end{tabular}

Figura 22: Codificadores definidos 
Frame 9: 897 bytes on wire (7176 bits), 897 bytes captured (7176 bits)

Ethernet II, Src: Personal_11:88:89 (00:c0:c6:11:88:89), Dst: Broadata_52:fc:e5 (00:19:ca:52:fc:e5) 802.1Q Virtual LAN, PRI: 6, CFI: 0, ID: 9

GOOSE

APPID: 0x5534 (21812)

Length: 879

Reserved 1: 0x1715 (5909)

Reserved 2: 0x17a5 (6053)

goosePdu

gocbRef: $\backslash \mathrm{r} \# \$ \mathrm{jp}=5 \mathrm{kKq}$ ?2W56

timeAllowedtoLive: 102402070

datSet: $\left.\backslash \mathrm{t}^{\wedge} \backslash \mathrm{f} 7: \mathrm{LW}\right] \backslash \mathrm{vj}(. \backslash \mathrm{r} \backslash \backslash \mathrm{nIZ},\{$ ee $1 \mathrm{Upj} \backslash \mathrm{r}$

goID: $K^{*} \mathrm{n}>$ D9ii\&dU $\backslash \mathrm{I} \backslash \mathrm{fHn}$ 'bRJFr|-aK'a $\backslash$ ppbm $<$ \}N\$w (] $4 \mathrm{V7}$ `

t: Dec 5, 1989 18:43:12.051640629 UTC

stNum: 212316202

sqNum: 1616321409

test: False

confRev: 1448788789

ndsCom: False

numDatSetEntries: 27

allData: 27 items

Data: structure (2)

structure: 1 item

Data: structure (2)

structure: 5 items

Data: integer (5)

integer: -1064613988

Data: unsigned (6) unsigned: 1778730822

Data: utc-time (17) utc-time: Oct 9, 2022 05:59:33.200764060 UTC

Data: integer (5) integer: -100

Data: bit-string (4)

Padding: 3

bit-string: 28

Data: structure (2)

structure: 2 items

Data: structure (2)

structure: 7 items

Data: utc-time (17)

utc-time: Sep 22, 1995 22:23:33.212469398 UTC

Data: boolean (3)

boolean: False

Data: utc-time (17) utc-time: Apr 4, 1997 18:11:46.188281595 UTC

Data: unsigned (6)

unsigned: 238

Data: floating-point (7)

floating-point: 00a00e07b7

$\{\ldots$ continua $\}$

Figura 23: Exemplo de uma mensagem GOOSE gerada pelo RGGM 


\section{Concepções de Segurança nas Subestações}

A segurança dentro das subestações de energia elétrica passou por mudanças importantes nas últimas décadas. Até 1990, "os equipamentos de automação e proteção de subestações, que já tinham se tornado microprocessados, ainda estavam fora das redes de computadores e compunham soluções isoladas, sem conexão física com a rede mundial" (SCHWEITZER, 2010). As concepções de segurança estavam limitadas à proteção física dos recursos, ou seja:

- O controle de acesso de veículos e pessoas aos recursos da subestação, por meio automático ou de pessoas designadas para a função;

- A proteção dos recursos da subestação contra incêndios;

- O dimensionamento correto do sistema de energia elétrica para alimentar as áreas de processamento e comunicação de dados;

- A climatização dos ambientes, mantendo a temperatura adequada ao funcionamento dos equipamentos da subestação.

Weiss e Delson (2007) explicitam que as preocupações tradicionais das concessionárias de energia elétrica, em relação aos ativos das subestações, concentravam-se na proteção de ameaças físicas, naturais e humanas. E, com exceção de países com conflitos civis, creditava-se as principais ameaças humanas a funcionários descontentes, clientes irritados, ou vandalismo com motivações políticas. No caso de todas as ameaças, o malfeitor tinha que estar dentro das subestações ou próximo a elas para causar danos a esses ativos.

Com a recente introdução dos sistemas distribuídos, o uso de redes de computadores e os recursos de comunicação de dados na automação de subestações, os problemas de 
segurança pertinentes às redes de computadores tornaram-se também parte integrante do sistema elétrico.

O Guia para Segurança Física e Eletrônica de Subestações do Sistema de Potência, IEEE 1402-2000 (IEEE, 2000), descreve que a introdução dos sistemas de computação com acesso online às informações da subestação é significativo. Os sistemas de aquisição de dados, de controle e de proteção podem estar expostos às mesmas vulnerabilidades de todos os demais sistemas computacionais.

Nesse contexto, a quantidade de eventos reportados pelo CERT.br ${ }^{1}$ deve integrar, de um modo geral, as preocupações dos profissionais de TI (Tecnologia da Informação) e, também, os profissionais de TA (Automation Technology) no ambiente de redes de comunicação do SEP, conforme ilustra a Figura 24.

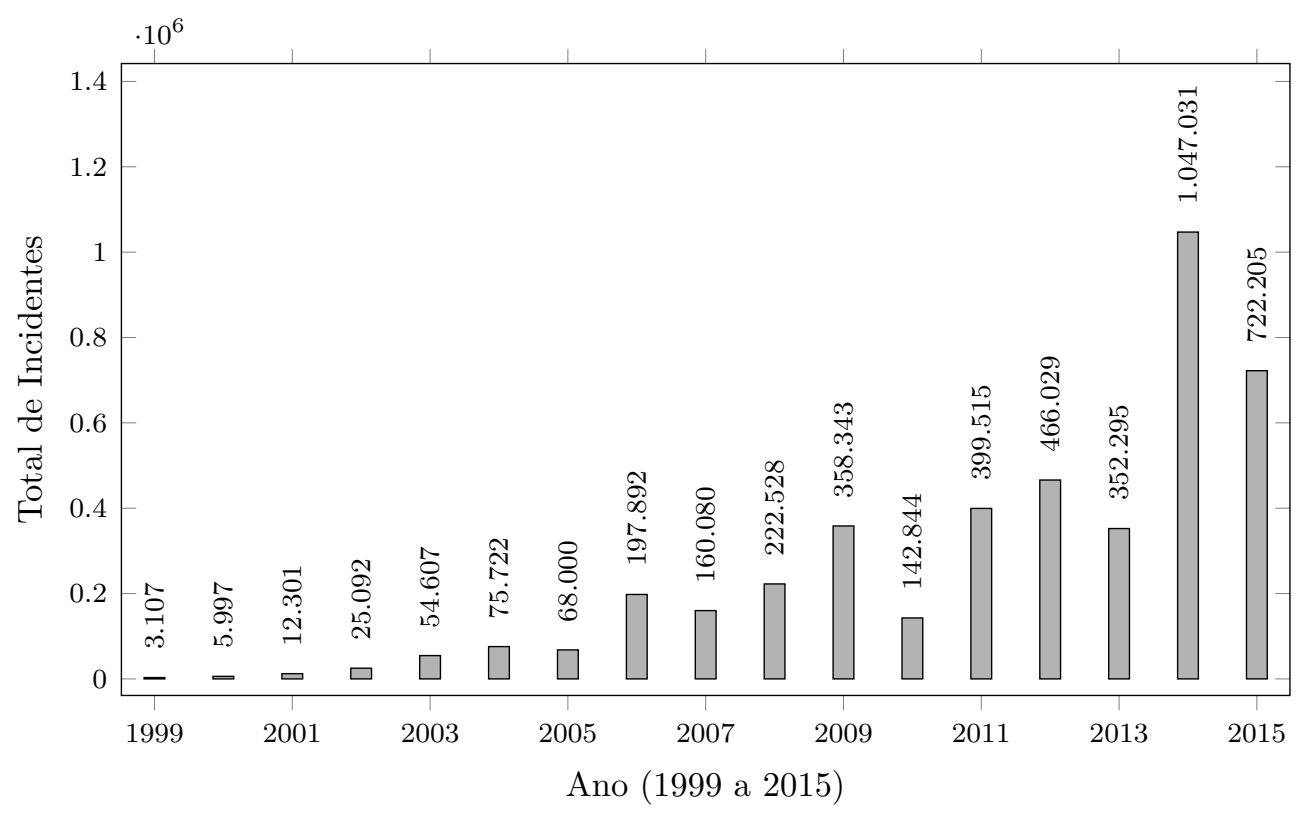

Figura 24: Total de incidentes reportados ao CERT.br

Fonte: CERT.br (2016b)

Na Figura 24, é possível observar que as ameaças relacionadas a problemas de segurança estão mais presentes. Segundo o CERT.br (2016b), a quantidade de incidentes reportados entre 2014 e 2015 foi maior que nos 5 anos anteriores.

Quanto aos tipos de ataques, o CERT.br utiliza a seguinte classificação (CERT.BR, 2016a):

- DoS (Denial of Service): notificações de ataques de negação de serviço. Para realização do ataque, o invasor utiliza um computador ou um conjunto de computadores para tirar de operação um serviço ou uma rede, promovento uma sobrecarga nestes;

\footnotetext{
${ }^{1}$ Grupo de Resposta a Incidentes de Segurança para a Internet brasileira, mantido pelo NIC.br (Núcleo de Informaçãa e Coordenação do Ponto BR), do Comitê Gestor da Internet no Brasil.
} 
- Invasão: um ataque bem sucedido que resulte no acesso não autorizado a um computador ou rede;

- Scan: notificações de varreduras em redes de computadores, com o intuito de identificar quais computadores estão ativos e quais serviços estão sendo disponibilizados por eles. É amplamente utilizado por atacantes para identificar potenciais alvos, pois permite associar possíveis vulnerabilidades aos serviços habilitados em um computador;

- Fraude: esta categoria engloba as notificações de tentativas de fraudes, ou seja, de incidentes em que ocorre uma tentativa de obter vantagem (phishing);

- Worm: notificações de atividades maliciosas relacionadas com o processo automatizado de propagação de códigos maliciosos na rede;

- Web: um caso particular de ataque visando, especificamente, ao comprometimento de servidores $W e b$ ou desfigurações de páginas na Internet;

- Outros: notificações de incidentes que não se enquadram nas categorias anteriores.

Já Stallings (2016) classifica os ataques à segurança como passivos ou ativos:

Ataques Passivos: o objetivo destes ataques é obter informações que estão sendo transmitidas, eles podem se caracterizar como um vazamento de conteúdo ou uma análise do tráfego de dados. Os dois casos são difíceis de se detectar, pois não envolvem qualquer alteração dos dados.

Ataques Ativos: envolvem alguma modificação do fluxo de dados ou a criação de um fluxo falso. O autor subdivide-os em quatro categorias:

- O disfarce: quando o invasor finge ser outro;

- O repasse ou interceptação: envolve a captura de uma unidade de dados e posterior retransmissão dos mesmos;

- A modificação de mensagens: quando alguma parte de uma mensagem legítima é alterada, para produzir um efeito inesperado; e

- A negação de serviço: este ataque impede ou inibe o uso ou gerenciamento normal das instalações.

Nesse contexto, o CERT.br destaca que 54,17\% dos incidentes reportados durante o ano de 2015, totalizando 722.205, constituíram-se de ataques de reconhecimento, Scans, seguidos pelas Fraudes com 23,37\%. A Invasão foi o incidente com menor percentual dos relatos, apresentando $0,34 \%$ do total, o que corresponde a, aproximadamente, 2.455, 
como mostra a Figura 25. Com base nesses dados, é possível visualizar que a maioria dos ataques tem iniciado pela busca de vulnerabilidades e, depois, por outros tipos de violação.

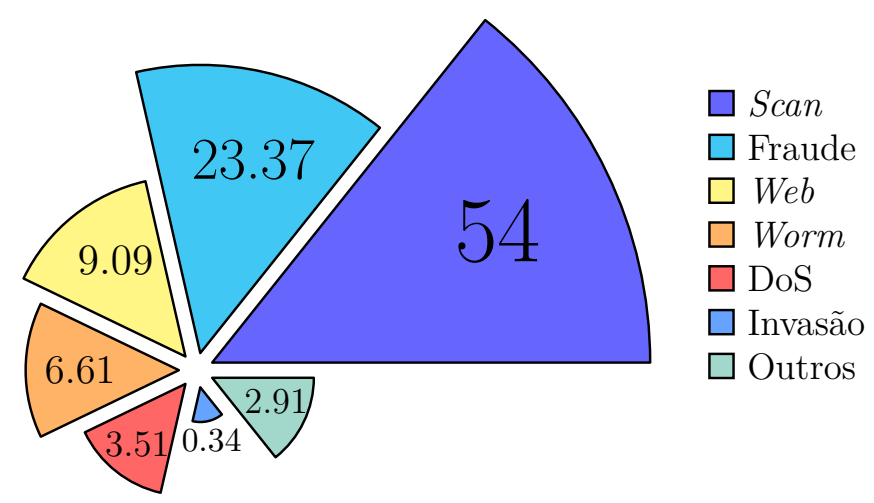

Figura 25: Tipos de ataques reportados (\%) (2015)

Fonte: CERT.br (2016a)

A maior parte dos incidentes reportados tem como origem o próprio Brasil, seguido por Estados Unidos e China (Figura 26).

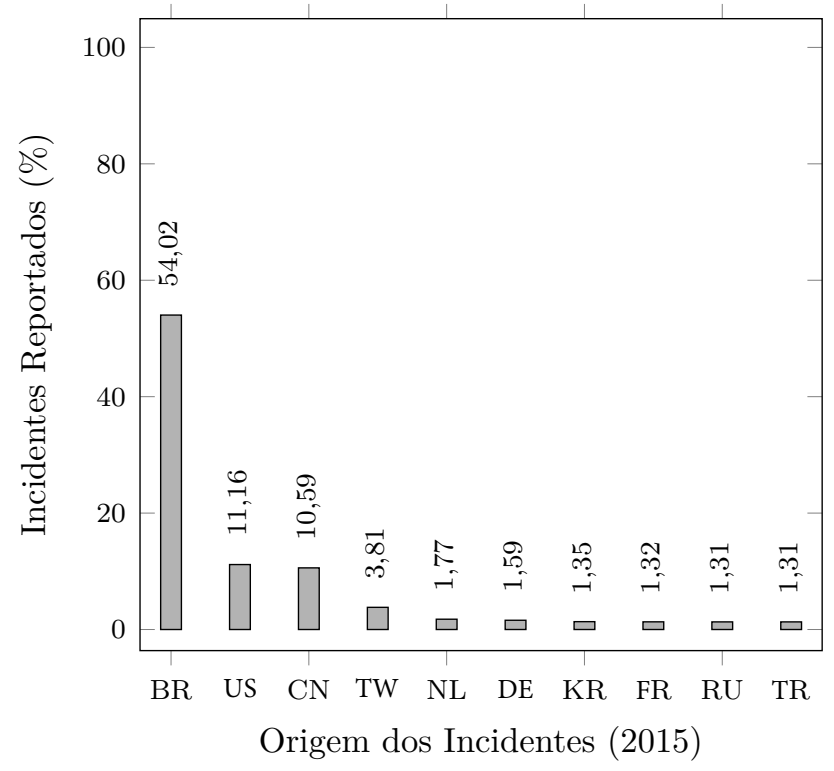

Figura 26: Origem dos ataques reportados

Fonte: CERT.br (2016b)

Estes tipos de ataque são mencionados por Rashid et al. (2014), ao tratarem da segurança cibernética em redes que utilizam mensagens pertinentes ao padrão IEC 61850. De acordo com Premaratne et al. (2010), o efeito de um ataque DoS pode levar à indisponibilidade de dispositivos e de serviços da subestação. Hong, Liu e Govindarasu (2014a) 
citam a possibilidade de abertura de disjuntores por meio de ataques de interceptação (sniffing) e modificação de campos da mensagem GOOSE (spoofing).

Branquinho et al. (2014) destacam o RISI (Repository of Industrial Security Incidents), como um banco de dados de incidentes de segurança que afetam o controle de processos e sistemas SCADA (Supervisory Control and Data Acquisition). Tais dados são coletados de relatórios privados, por intermédio de empresas, e também de pesquisas em reportagens que os tornaram públicos. De acordo com os autores, o RISI destaca que o incidente mais comum em redes de automação é o ataque por malware ${ }^{2}$, que corresponde a $68 \%$ dos incidentes externos em sistemas de controle, seguidos pelos de sabotagem e de invasão de sistemas, com $13 \%$ cada. De acordo com os dados, $6 \%$ dos inicidentes são relativos a ataques de DoS.

Como exemplo de malware, Branquinho et al. (2014) descrevem que o Stuxnet "foi a primeira arma cibernética desenvolvida especificamente para afetar sistemas de controle. Ele foi o primeiro grande indício de que os sistemas de automação seriam os próximos alvos dos atacantes cibernéticos". O Stuxnet (2010) foi projetado para atacar o sistema SCADA (Supervisory Control and Data Acquisition), utilizado para controlar as centrífugas de enriquecimento de urânio iranianas. Aproximadamente 1000 centrífugas foram afetadas por causa do aumento da velocidade de rotação.

Nos dados supracitados, não é possível particularizar os números e tipos de incidentes envolvendo o SEP, tampouco, o padrão IEC 61850. Segundo Melo (2010), os diversos agentes do setor elétrico, envolvendo geração, transmissão e distribuição de energia, resistem em compartilhar informações de incidentes envolvendo a segurança da informação, implementando a estratégia de segurança pela obscuridade, $\mathrm{STO}^{3}$ (Security Through Obscurity).

O ambiente da Internet é diferente do sistema de energia, por exemplo, na tentativa de isolamento da rede de comunicação, porém, as estatísticas elencadas alertam para as ameaças de segurança que envolvem qualquer ambiente de redes.

\subsection{A Subestação como Ponto Vulnerável do Sistema Elétrico}

Como as subestações de energia elétrica tornaram-se mais interligadas e automatizadas, as vulnerabilidades cibernéticas cresceram, conforme ilustra a Figura 27. Conse-

\footnotetext{
2 "Comumente conhecido e generalizado como vírus, o malware agrupa todo software ou programa criado com a intenção de abrigar funções para penetrar em sistemas, quebrar regras de segurança, roubar informações e servir de base para as demais operações ilegais ou prejudiciais" (BRANQUINHO et al., 2014).

${ }^{3}$ Security Through Obscurity (STO): é a ideia de que algo é seguro simplesmente porque não é óbvio, anunciado ou interessante (AHMAD et al., 2002).
} 
quentemente, existe a necessidade de segurança dos ativos da rede de comunicação, para a continuidade no fornecimento de energia elétrica.

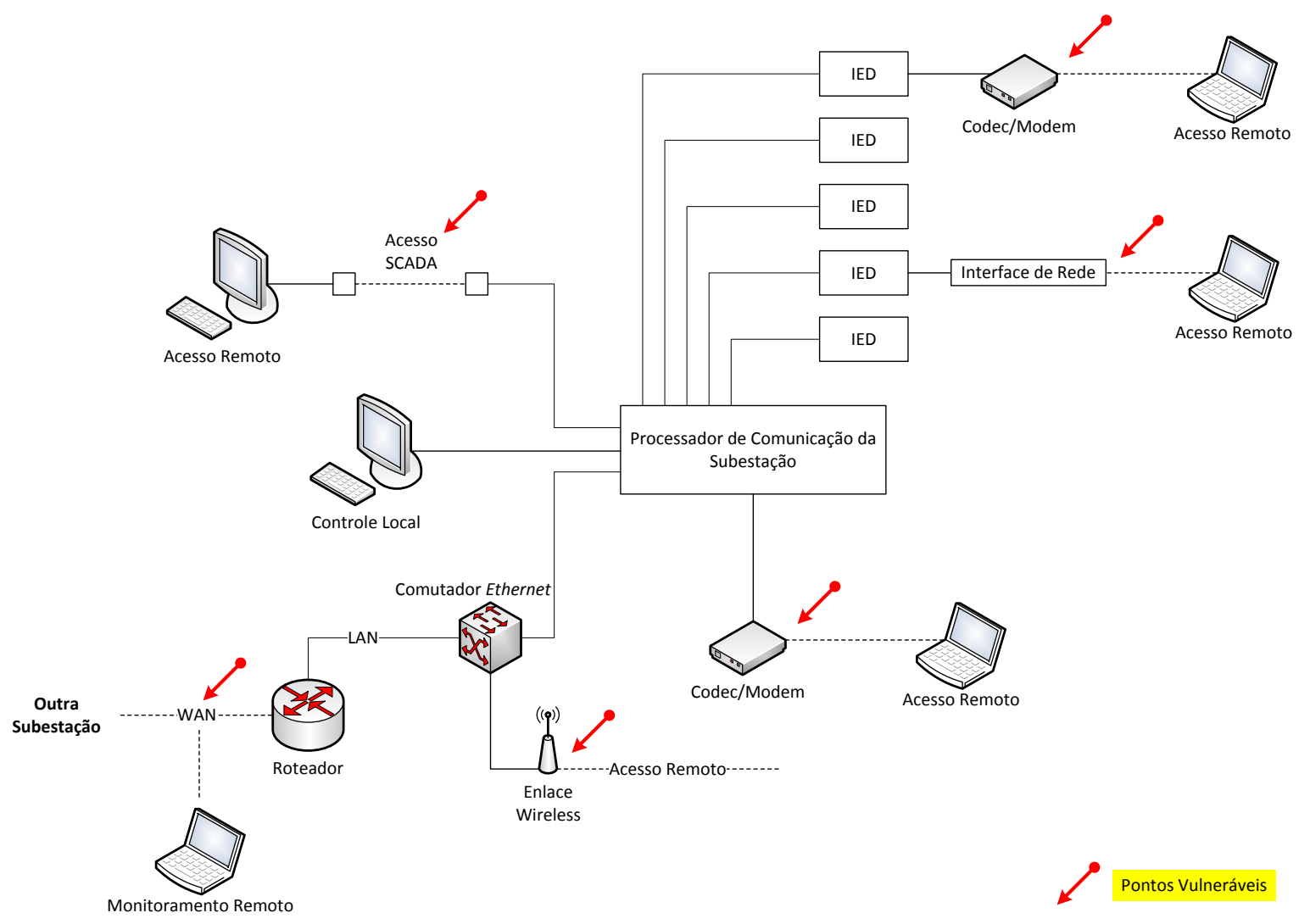

Figura 27: Pontos básicos de vulnerabilidade de uma subestação

Fonte: Schweitzer (2010), Oman, Schweitzer e Roberts (2001) e Hoyos, Dehus e Brown (2012)

A natureza da ameaça mudou porque o dispositivo (IED) responsável por monitorar e controlar dispositivos da subestação, é frequentemente conectado por meio de enlaces de comunicação de dados numa rede WAN ( Wide Area Network), potencialmente acessível ao público em geral. Como consequência, um indivíduo que procura danificar bens públicos pode fazê-lo a partir de locais distantes, assim como o impacto resultante pode envolver várias subestações de forma simultânea (WEISS; DELSON, 2007).

Na Figura 27, é possível observar a vulnerabilidade nos pontos com acesso remoto a IEDs, processadores de comunicação, sistemas SCADA, roteadores e enlaces Wireless. Estes IEDs incluem relés digitais, registradores de faltas, oscilógrafos, unidades de aquisição e controle, controladores programáveis, servidores da subestação e interfaces de comunicação (SCHWEITZER, 2010).

A intrusão típica neste ambiente envolve as seguintes etapas:

- Identificação de pontos de acesso;

- A penetração na rede por meio destes pontos de acesso; 
- A determinação do sistema que será alvo do ataque;

- Execução do ataque.

A realização de um ataque cibernético (Cyber attack) que gere danos aos dispositivos de uma subestação requer planejamento e conhecimento em profundidade. Quando uma intrusão ocorre, por exemplo, em um relé digital, é possível presumir que o invasor sabe como configurar, alterar ou desativar funcionalidades pertinentes aos ajustes deste dispositivo, abrir ou fechar disjuntores e chaves seccionadoras (ZHANG et al., 2015). Neste ínterim, os resultados de um ataque podem danificar os ativos da subestação e gerar a descontinuidade no fornecimento da energia elétrica, com abrangência regional ou nacional.

A Tabela 15 apresenta uma lista de vulnerabilidades e riscos envolvidos no acesso remoto aos equipamentos de proteção em nível de bay.

Tabela 15: Lista de vulnerabilidades e riscos envolvidos no acesso remoto (nível de bay)

\begin{tabular}{|c|c|c|}
\hline Dispositivo & Ponto de acesso vulnerável & Risco \\
\hline \multirow{2}{*}{$\begin{array}{l}\text { Dispositivos de proteção sem } \\
\text { acesso remoto (por exemplo, } \\
\text { relés digitais, controladores } \\
\text { programáveis, religadores) }\end{array}$} & $\begin{array}{l}\text { O acesso local aos dispositivos } \\
\text { de proteção }\end{array}$ & $\begin{array}{l}\text { Equipamentos de proteção acidental- } \\
\text { mente ou deliberadamente danificados }\end{array}$ \\
\hline & $\begin{array}{l}\text { O acesso local para as configu- } \\
\text { rações de proteção }\end{array}$ & $\begin{array}{l}\text { Configurações de proteção acidental- } \\
\text { mente ou deliberadamente alteradas }\end{array}$ \\
\hline \multirow[t]{2}{*}{$\begin{array}{l}\text { Dispositivos de proteção com } \\
\text { acesso remoto por linha dis- } \\
\text { cada (dial-up) }\end{array}$} & $\begin{array}{l}\text { Acesso aos dispositivos de pro- } \\
\text { teção via modem ou codec }\end{array}$ & $\begin{array}{l}\text { Número de discagem acessível por meio } \\
\text { de engenharia social ou varredura auto- } \\
\text { matizada }\end{array}$ \\
\hline & Acesso aos ajustes de proteção & $\begin{array}{l}\text { O controle de acesso contornado por } \\
\text { ataque de senha (Força Bruta) } \\
\text { Configurações de proteção acidental- } \\
\text { mente ou deliberadamente alteradas }\end{array}$ \\
\hline \multirow[t]{5}{*}{$\begin{array}{l}\text { Dispositivos de proteção com } \\
\text { acesso remoto por rede }\end{array}$} & $\begin{array}{l}\text { Acesso aos dispositivos de pro- } \\
\text { teção por meio de endereço ou } \\
\text { porta de rede }\end{array}$ & $\begin{array}{l}\text { Endereço de rede acessível via engenha- } \\
\text { ria social ou varredura automatizada de } \\
\text { endereços e portas de rede }\end{array}$ \\
\hline & Acesso aos ajustes de proteção & $\begin{array}{l}\text { O controle de acesso contornado por } \\
\text { ataque de senha (Força Bruta) }\end{array}$ \\
\hline & Acesso aos pacotes de dados & $\begin{array}{l}\text { Configurações de proteção acidental- } \\
\text { mente ou deliberadamente alteradas }\end{array}$ \\
\hline & $\begin{array}{l}\text { Equipamentos vulneráveis a } \\
\text { ataques de negação de serviço } \\
\text { (DoS) }\end{array}$ & $\begin{array}{l}\text { Os pacotes de dados visíveis na rede } \\
\text { sem autenticação ou criptografia }\end{array}$ \\
\hline & & $\begin{array}{l}\text { Equipamento inacessível e, possivel- } \\
\text { mente, não funcional, durante os ata- } \\
\text { ques (sendo necessário um reset manual } \\
\text { ou atuação do watchdog timer) }\end{array}$ \\
\hline
\end{tabular}


Uma descrição análoga, relativa aos equipamentos pertinentes aos sistemas SCADA, pode ser observada em Oman, Schweitzer e Roberts (2001).

Segundo Costa (2016), preocupadas com a vulnerabilidade do sistema elétrico nacional a ataques virtuais, "as empresas do setor elétrico querem mudar uma regra na ANEEL (Agência Nacional de Energia Elétrica) e passar a destinar recursos de pesquisa e desenvolvimento a projetos de segurança cibernética. A avaliação do setor é que a segurança é frágil e a atual regulamentação não incentiva as empresas a investir no seu reforço".

\subsection{Modelo de Referência de Segurança}

Um modelo para segurança de rede é proposto por Stallings (2013) e exposto na Figura 28. Nele, uma mensagem deve ser transferida de uma parte para outra por meio de uma rede de comunicação. As entidades principais nessa transação precisam cooperar para que a troca ocorra. Um canal de comunicação é estabelecido, definindo-se uma rota da origem ao destino e o uso cooperativo de protocolos pelas entidades principais.

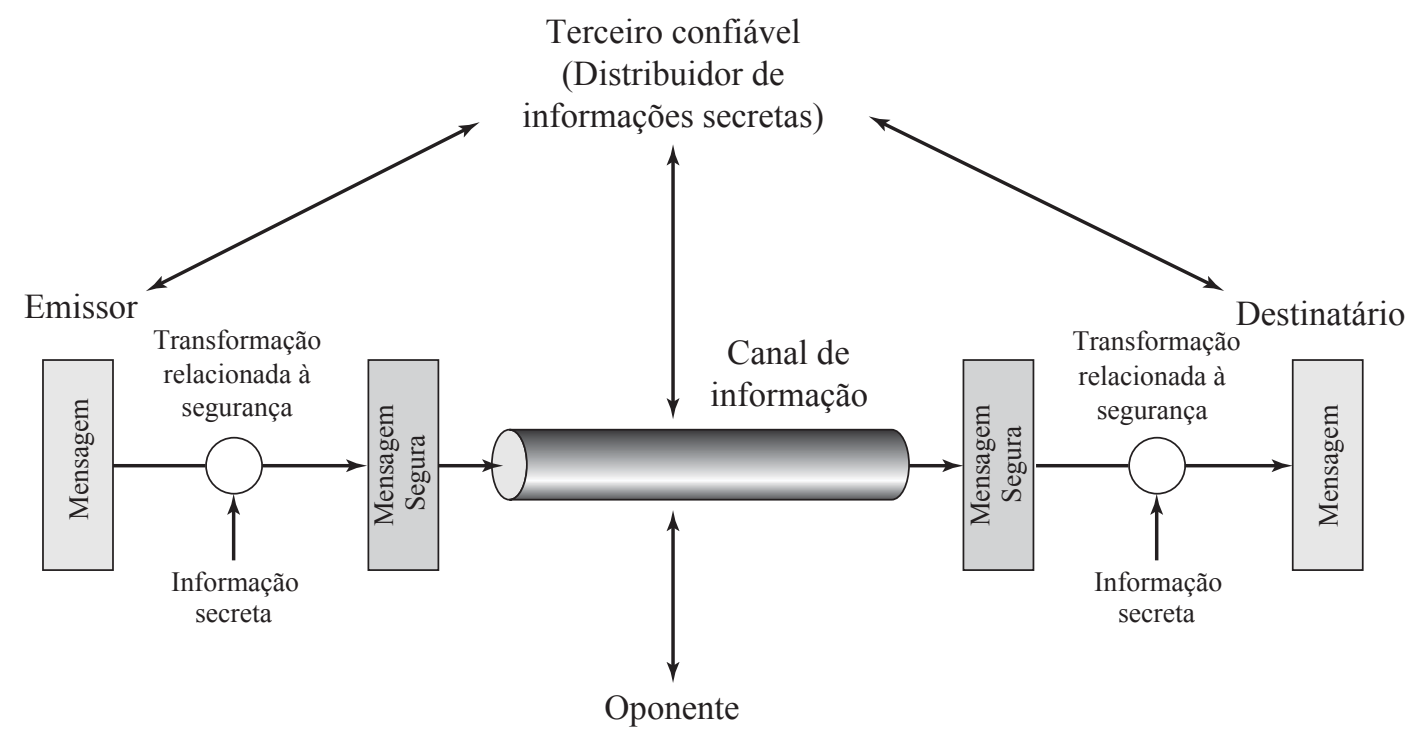

Figura 28: Modelo para segurança de rede

Fonte: Stallings (2013)

Os aspectos de segurança são necessários para proteger a transmissão das informações de um oponente que possa representar uma ameaça à confidencialidade e autenticidade da informação. Um terceiro ente, confiável, pode ser necessário para se conseguir uma transmissão segura, sendo responsável, por exemplo, por distribuir a informação secreta às entidades principais, enquanto a protege contra qualquer oponente (STALLINGS, 2013).

A definição do nível de segurança deste modelo envolve o discernimento dos serviços de segurança que o sistema implementa. Para Stallings e Brown (2008), Moraes (2010), Carissimi, Rochol e Granville (2009) e IEC/TS-62351-1 (2007), os principais serviços são: 
- Integridade: consiste na garantia de que a informação permaneça íntegra, o que significa que ela não sofreu nenhuma espécie de modificação durante a sua transmissão ou armazenamento, sem a autorização do emissor. A integridade é fundamental e crítica em sistemas, tais como: de controle de tráfego aéreo; sistemas financeiros; comércio eletrônico e sistemas de infraestrutura básica, como fornecimento de energia elétrica, água e gás;

- Confidencialidade: proteger a informação em sistemas, recursos e processos, para que estes não sejam acessados por pessoas ou dispositivos não autorizados;

- Não repúdio: é a capacidade de identificar de forma indubitável a origem de um determinado serviço. Consiste em técnicas e métodos para que o emissor da informação não possa negar, no futuro, o envio de uma mensagem;

- Disponibilidade: é a garantia de que o sistema sempre estará disponível quando o usuário precisar;

- Auditoria: serviço que permite a criação de registros, denominados logs, nos quais as ações ocorridas na rede permaneçam registradas e possam ser auditadas no futuro para verificação de irregularidades.

De acordo com Moraes (2010), este modelo de segurança é uma arquitetura de rede confíavel, que implementa uma política de segurança ${ }^{4}$, sendo constituída pelos seguintes componentes:

- Equipamentos de rede: roteadores, switches, gateways e servidores de comunicação;

- Sistemas de segurança: firewalls e criptografia;

- Sistemas de autenticação: assinatura digital, certificação digital e biometria;

- Sistemas de auditoria;

- Informações e mensagens trocadas no sistema de cunho reservado, confidencial, restrito ou livre para divulgação.

Cabe referenciar, dentre os componentes mencionados, a infraestrutura de telecomunicações, que fornece redes de transporte e estruturas para a comunicação de dados, a partir de fibras ópticas, rádio, satélites, sistemas multiplex, e de comutação, dentre outros.

Em consonância com os sistemas mencionados e a concepção de segurança das subestações, este trabalho tem como objetivo o desenvolvimento de um firewall que seja capaz de filtrar mensagens GOOSE, além de avaliar dois algoritmos de criptografia e um algoritmo de autenticação. Nesse contexto, o restante do capítulo dará subsídio ao desenvolvimento destes sistemas em hardware reconfigurável.

\footnotetext{
${ }^{4}$ Consiste em uma série de regras, procedimentos, autorizações e negações, que buscam garantir a manutenção da segurança e da confiabilidade da rede.
} 


\title{
$3.3 \quad$ Firewall
}

A pesquisa de segurança Computer Crime and Security Survey conduzida pelo CSI (Computer Security Institute)/FBI (Federal Bureau of Investigation) indica que o firewall é a tecnologia de segurança mais utilizada pelas organizações contra ameaças no ambiente computacional e de redes. Sendo utilizada em 98\% das organizações (GORDON et al., $2006)^{5}$.

A popularização desta tecnologia de segurança decorre de uma série de fatores (STALLINGS; BROWN, 2008):

- A maturidade avançada da tecnologia de segurança;

- Os administradores do ambiente computacional e de redes estão familiarizados com os produtos que envolvem esta tecnologia, e confiantes na sua efetividade;

- Os custos são considerados razoáveis;

- A interface é considerada amigável;

- A tecnologia é uma das mais significantes para os administradores de segurança.

Segundo Nakamura e Geus (2007), a mais antiga definição para firewalls foi dada por Cheswick, Bellovin e Rubin (1994): "o firewall é um ponto entre duas ou mais redes, no qual circula todo o tráfego". Para Stallings (2013), "os firewalls podem ser um meio eficaz de proteger um sistema local ou um sistema de redes contra ameaças de segurança baseadas em rede e, ao mesmo tempo, podem garantir acesso ao mundo exterior por meio de redes de longa distância e da Internet".

Já Kurose e Ross (2012) exprimem que "um firewall é uma combinação de hardware e software que isola a rede interna de uma organização da Internet em geral, permitindo que alguns pacotes passem e bloqueando outros". Segundo Moraes (2010),

\begin{abstract}
o firewall (...) é um sistema que atua como um ponto único de defesa entre a rede privada e a rede pública. Ele pode ainda controlar o tráfego entre as sub-redes de uma rede privada. Basicamente, todo o tráfego de entrada e saída da rede deve passar obrigatoriamente por esse sistema de segurança. O firewall pode autorizar, negar, além de registrar tudo o que está passando por ele.
\end{abstract}

Partindo dessas definições clássicas Nakamura e Geus (2007) enunciam que o firewall "é um ponto entre duas ou mais redes, que pode ser um componente ou um conjunto de componentes, por onde passa todo o tráfego, permitindo que o controle, a autenticação e os registros de todo o tráfego sejam realizados", conforme ilustra a Figura 29.

De acordo com Moraes (2010) as principais funções do firewall são:

\footnotetext{
${ }^{5}$ Outras tecnologias foram citadas pelos autores (GORDON et al., 2006), por exemplo, um software antivírus, uma lista para controle de acesso, um IDS (Intrusion Detection Systems), Biometria, dentre outras.
} 


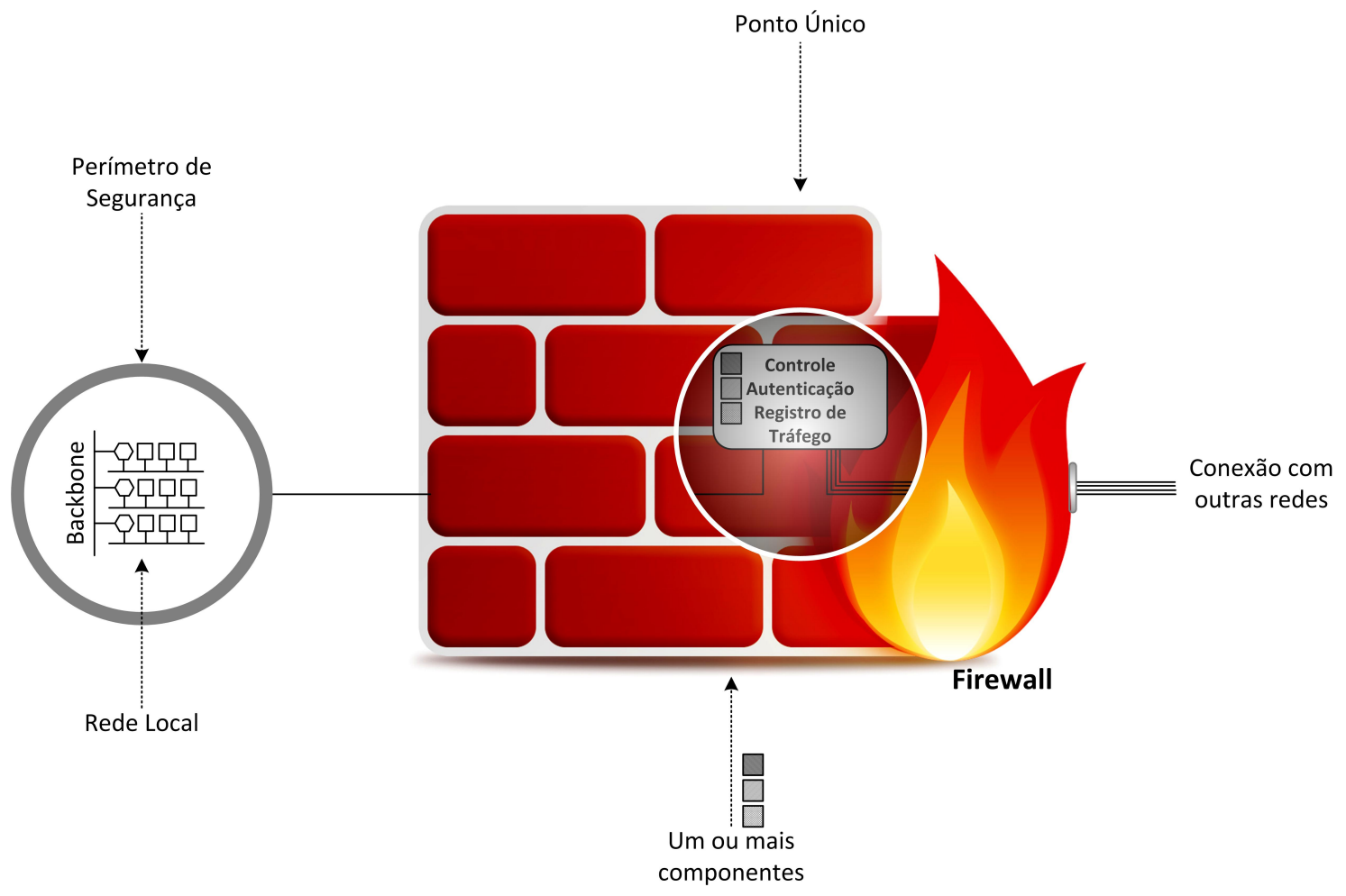

Figura 29: Conceito de aplicação do firewall

Fonte: Tanenbaum (1996)

- Estabelecer um perímetro de segurança;

- Separar as redes e controlar os acessos;

- Ser um elemento central de controle e aplicação de políticas de segurança;

- Proteger sistemas vulneráveis de rede;

- Aumentar a privacidade;

- Logar e gerar estatísticas do uso da rede e acessos indevidos.

A configuração padrão de um firewall é barrar todo o fluxo de dados, a partir da política denominada Default Deny. O administrador da rede, a partir da definição de uma política de segurança, deve configurar regras no firewall para liberar o(s) fluxo(s) permitido(s). Cabe ressaltar que a política inversa é denominada Default Permit (STATO FILHO, 2009).

\subsubsection{Tipos de Firewalls}

Há seis tipos geralmente aceitos de firewalls utilizados em conexões de rede e Internet (GALLO; HANCOCK, 2001): filtragem de quadros, filtragem de pacotes, gateways de cir- 
cuito, filtragem baseada em estados, gateways de aplicação ou proxy e híbrido. A seguir, apresenta-se uma descrição breve de cada tipo.

Firewalls de Filtragem de Quadros: têm a habilidade de filtrar, no nível de bit, o formato e o conteúdo de um quadro de rede local, como, por exemplo, Ethernet IEEE 802.3, Token Ring IEEE 802.5, FDDI (Fiber Distributed Data Interface) e outros. Pelo provimento de filtro neste nível, os quadros que não pertencem à rede autorizada são rejeitados antes de chegar a qualquer ponto valioso, mesmo ao firewall (GALLO; HANCOCK, 2001).

Firewalls de Filtragem de Pacotes: são roteadores com habilidade de filtragem de pacotes ou dispositivos dedicados que fazem filtragens. Eles trabalham com uma lista de controle de acesso (Access List), que é verificada antes de um pacote ser encaminhado para a rede (MORAES, 2010).

Firewalls Gateway de Circuito: nesse caso, o firewall é o gateway em nível de circuito. Um gateway em nível de circuito não permite uma conexão TCP (Transmission Control Protocol) de ponta a ponta; em vez disso, o gateway prepara duas conexões TCP, uma entre ele mesmo e um usuário TCP em um dispositivo interno e uma entre ele mesmo e um usuário TCP em um dispositivo externo (STALLINGS, 2013).

Firewalls de Estado: os firewalls baseados em filtros de pacotes dinâmicos (Dynamic Packet Filter), também conhecidos como filtros baseados em estados (Stateful Packet Filter), tomam as decisões de filtragem, tendo como referência as informações dos cabeçalhos dos pacotes de dados e uma tabela de estados, que guarda estados de todas as conexões. As conexões são monitoradas a todo instante, permitindo que a ação do firewall seja definida de acordo com o estado de conexões anteriores mantidas em sua tabela (NAKAMURA; GEUS, 2007).

Firewall Gateway de Aplicação ou Proxy: este firewall atua como um intermediário na comunicação entre um dispositivo cliente e um servidor. Assim, o cliente realiza uma conexão com o firewall, que estabelece uma conexão com o servidor. O firewall gateway de aplicação ou proxy é responsável pelo monitoramento e controle de tráfego (MARÇULA; FILHO, 2005). Um firewall gateway de aplicação garante proteção no nível de aplicação e utiliza programas personalizados para cada aplicação protegida. Se uma aplicação que requer proteção é adicionada à rede, um novo programa tem que ser escrito e adicionado ao conjunto de aplicativos que estão no firewall (GALLO; HANCOCK, 2001).

Firewall Híbrido: corresponde àquele que mistura os elementos de três categorias apresentadas anteriormente, de modo a garantir a proteção dos proxies para os serviços 
que exigem alto grau de segurança e a segurança do filtro de pacotes, ou do filtro de pacotes com base em estados, para os serviços em que o desempenho é o mais importante (SHINN; SHINN, 2005; NAKAMURA; GEUS, 2007).

Outros tipos de firewall podem ser observados em Nakamura e Geus (2007) e Zwicky, Cooper e Chapman (2000).

\subsubsection{As Arquiteturas de Firewalls}

A arquitetura de um firewall é a forma de juntar componentes e funcionalidades para atender às necessidades de segurança de uma organização. As arquiteturas clássicas são apresentadas por Zwicky, Cooper e Chapman (2000).

\subsubsection{Dual-homed host}

É a arquitetura formada por um dispositivo com duas interfaces físicas de rede, em que uma está conectada à rede interna e outra na rede externa, e funciona como um separador entre duas redes, conforme ilustra a Figura 30.

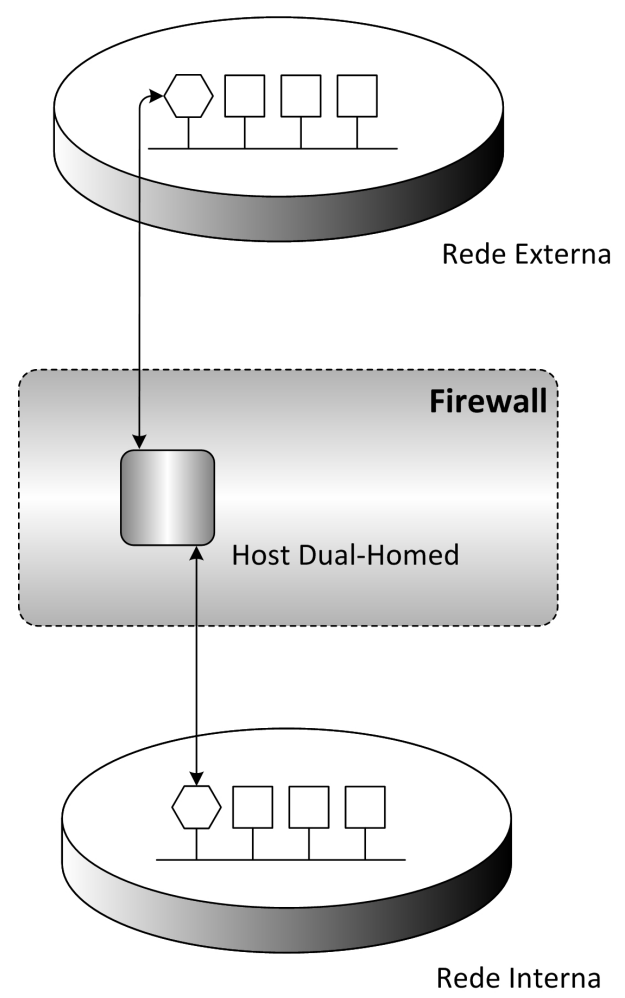

Figura 30: Arquitetura dual-homed host

Fonte: Nakamura e Geus (2007) e Stallings (2013)

Os sistemas internos têm de ser conectados ao Dual-homed host para que possam se comunicar com os sistemas externos e vice-versa, mas nunca diretamente (NAKAMURA; GEUS, 2007). 


\subsubsection{Screened host}

Essa arquitetura é formada por um Bastion Host $^{6}$ e um filtro de pacotes (Figura 31).

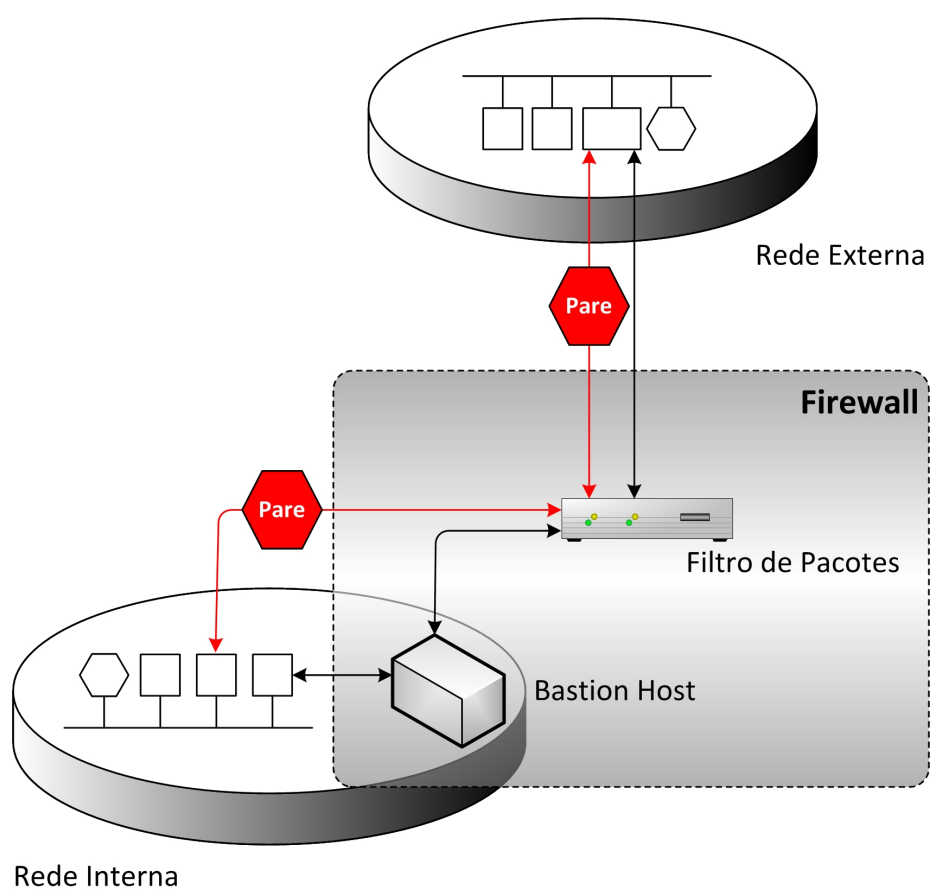

Figura 31: Arquitetura sreened host

Fonte: Nakamura e Geus (2007) e Stallings (2013)

O filtro de pacotes é configurado de forma que somente aceite conexões originadas do Bastion Host, que deve oferecer os serviços necessários para a rede interna. O Bastion Host fica situado na rede interna e é o único dispositivo da rede interna pelo qual a rede externa pode abrir conexões. A rede externa terá que passar pelo filtro de pacotes do firewall. Caso a conexão seja permitida, o pacote será encaminhado para o Bastion Host (NAKAMURA; GEUS, 2007; STALLINGS, 2013).

\subsubsection{Screened subnet}

Nessa arquitetura, o Bastion Host fica na DMZ (DeMilitarized Zone) e adiciona uma área de perímetro, ou uma zona de confinamento, entre a rede externa e a rede interna, que fica entre dois filtros (Figura 32).

Para que um ataque chegue à rede interna, deve-se passar pelo filtro externo, pelo Bastion Host e pelo filtro interno (STATO FILHO, 2009; NAKAMURA; GEUS, 2007).

Variações destas arquiteturas podem ser observadas em Zwicky, Cooper e Chapman (2000).

${ }^{6}$ Bastion Host são os dispositivos em que são instalados os serviços a serem oferecidos para a rede pública. 


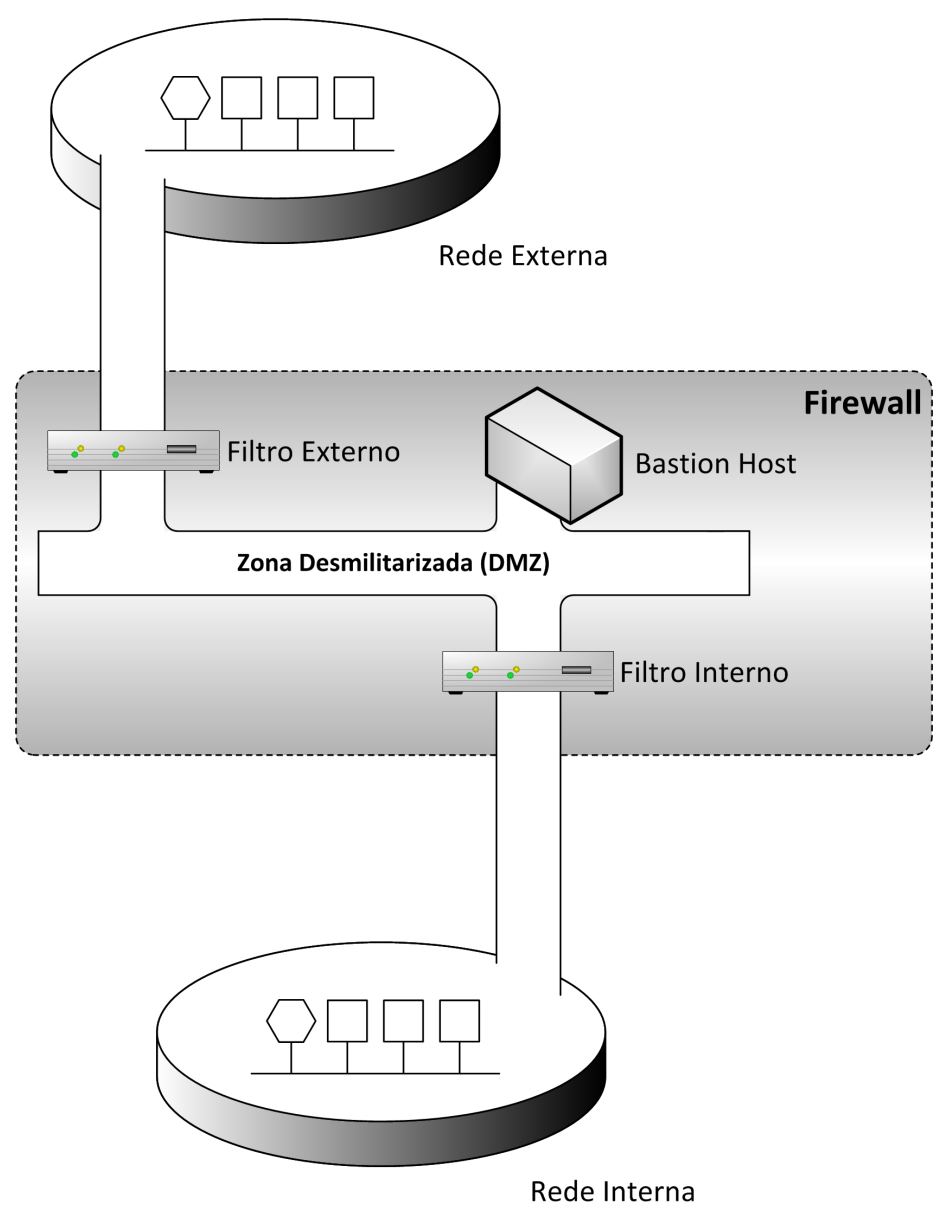

Figura 32: Arquitetura screened subnet

Fonte: Nakamura e Geus (2007) e Stallings (2013)

\subsection{Criptografia e Autenticação}

Além da utilização do firewall, outros serviços de segurança da rede, como criptografia e autenticação, foram incorporados ao SAS (Sistema de Automação da Subestação), principalmente após o advento do conceito de Smart Grid. Vaidya, Makrakis e Mouftah (2013), Lu et al. (2011), Nicanfar, Jokar e Leung (2011) e Kang et al. (2011) caracterizam a reunião destas tecnologias.

\subsubsection{O Processo de Criptografia}

A raiz etimológica da palavra criptografia é instrutiva. A palavra cripto origina-se da palavra grega kryptos. Kryptos descreve qualquer coisa oculta, encoberta, velada, secreta ou misteriosa. A palavra grafia é derivada de graphia, que significa escrita. Portando, criptografia é a arte de escrever segredos (MAXIMUM..., 2003).

Segundo Moraes (2010) a criptografia pode ser usada para: 
- Garantir a confidencialidade da mensagem, para que usuários não autorizados não tenham acesso a ela;

- Garantir que a mensagem enviada é autêntica;

- Validar a origem da mensagem;

- Manter a integridade da mensagem;

- Garantir que a mensagem não seja modificada no encaminhamento;

- Não repúdio;

- Provar o envio.

A Figura 33 mostra os componentes envolvidos na criptografia.

$\begin{array}{lc}\text { Chave secreta } & \text { Chave secreta } \\ \text { compartilhada pelo } & \text { compartilhada pelo } \\ \text { emissor e receptor } & \text { emissor e receptor }\end{array}$

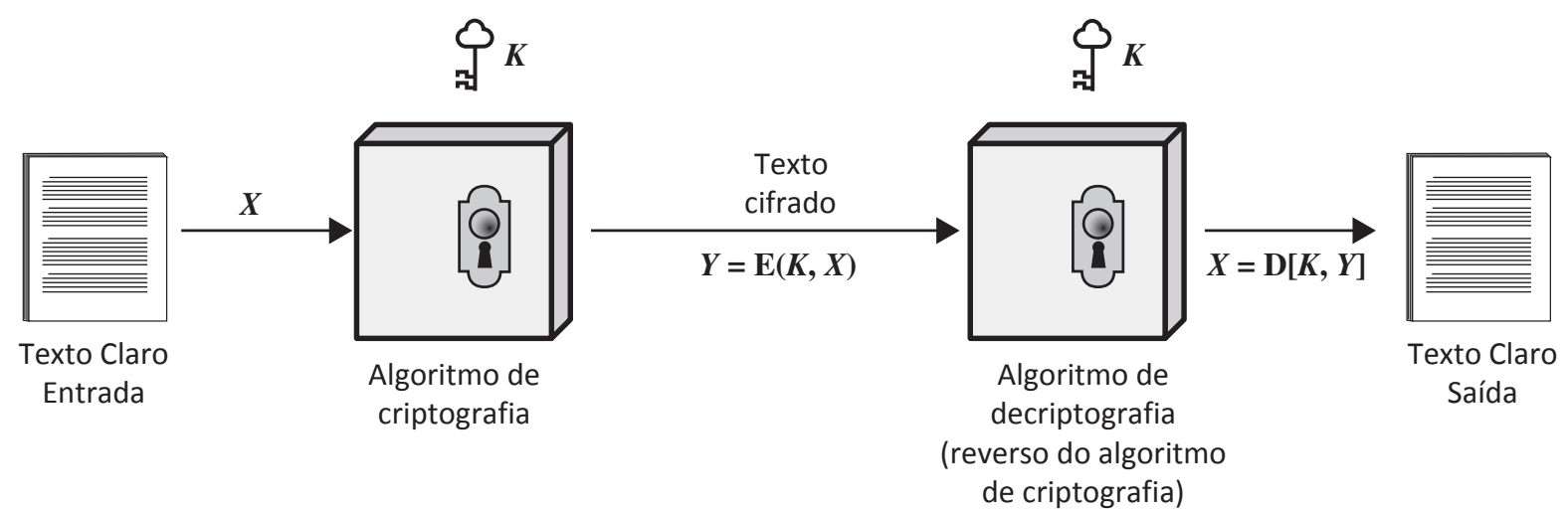

Figura 33: Modelo simplificado da criptografia convencional

Fonte: Stallings (2013)

De acordo com Forouzan e Fegan (2007):

Texto Claro e Texto Cifrado: a mensagem original, antes de ser transformada, é denominada texto claro e, após a transformação, texto cifrado. Um algoritmo de criptografia transforma o texto claro em texto cifrado; um algoritmo de descriptografia transforma o texto cifrado novamente em texto claro.

Cifra: são os algoritmos de criptografia e decriptografia.

Chave: é um número, ou conjunto de números, sobre o qual a cifra opera. 
Emissor, Receptor e Intruso Emissor é aquele que precisa enviar dados seguros. O Receptor recebe os dados cifrados e executa a decriptografia. Intruso é aquele que, de alguma forma, interfere na comunicação entre emissor e receptor.

Na Figura 33, o emissor produz uma mensagem em texto claro, $X=\left[X_{1}, X_{2}, \ldots, X_{M}\right]$. Os $M$ elementos de $X$ são caracteres ou valores binários $\{0,1\}$. Para a criptografia, uma chave na forma $K=\left[K_{1}, K_{2}, \ldots, K_{J}\right]$ é gerada. Se a chave for gerada na origem da mensagem, ela também precisará ser fornecida ao receptor, por meio de um terceiro ou de um canal seguro.

Com a mensagem $X$ e a chave de criptografia $K$ como entrada, o algoritmo de criptografia forma o texto cifrado $Y=\left[Y_{1}, Y_{2}, \ldots, Y_{N}\right]$, conforme a expressão:

$$
Y=E(K, X)
$$

Embasada em Stallings e Brown (2008), essa notação indica que $Y$ é produzido utilizando o algoritmo de criptografia $E$ como função de texto claro $X$, com a função específica determinada pelo valor da chave $K$. O receptor pretendido, de posse da chave, é capaz de inverter a transformação:

$$
X=D(K, Y)
$$

Onde $D$ é o algoritmo de decriptografia.

A implementação de sistemas criptográficos via software é mais barata, entretanto, o resultado é mais lento, mais fácil de ser modificado e forjado. Em hardware, a implementação é executada em chips e microprocessadores dedicados que são mais rápidos (Hardware Crypto Engine), entretanto, menos flexíveis (MORAES, 2010).

\subsubsection{Chaves criptográficas}

A chave é um valor independente do texto claro e do algoritmo. Algumas características da chave são (MORAES, 2010):

1. Tamanho: é o número de bits/bytes da chave;

2. Espaço: é a coleção de combinações matemáticas que apresentam o mesmo tamanho da chave;

3. Mecanismo de gerenciamento:

a) Geração: o padrão de geração de chaves não pode ser de conhecimento público, é preciso utilizar algoritmos randômicos que gerem números aleatórios;

b) Distribuição da chave: a distribuição da chave pode ser manual, automática ou uma combinação das duas; 
c) Armazenamento da chave: As chaves não devem ser acessíveis. Porém, em caso de armazenamento para recuperação da chave, este ambiente deve ser controlado e seguro;

d) Troca de chaves: mecanismo a ser utilizado para que as duas partes envolvidas na comunicação tenham conhecimento das chaves criptográficas. No algoritmo criptográfico de Diffie-Hellman, a chave pode ser trocada quando necessário, utilizando envelopes digitais. Mais detalhes podem ser obtidos em Stallings e Brown (2008).

4. Sistema de chave secreta: baseia-se no conhecimento entre as partes da comunicação de uma chave secreta;

5. Sistema de chave pública: utiliza uma chave pública, conhecida por ambas as partes, e uma chave privada que é mantida em segredo para encriptar os dados, ou seja, emissor e receptor necessitam gerar um par de chaves: uma pública e uma privada.

\subsubsection{Tipos de criptografia}

Os algoritmos de criptografia, as cifras, são divididos em dois grupos: algoritmos de criptografia de chave simétrica, chave secreta, e algoritmos de criptografia assimétrica, chave pública.

Na criptografia de chave simétrica, a chave é usada pelo emissor, para criptografia; e pelo receptor, para decriptografia. A chave é compartilhada, como mostrou a Figura 33.

$\mathrm{Na}$ criptografia de chave pública ou assimétrica, existem duas chaves (FOROUZAN; FEGAN, 2007): uma privada e uma pública. Enquanto uma é utilizada para encriptação, a outra é utilizada para decriptação. Na criptografia/decriptografia de chave pública, a chave pública, utilizada para criptografia, é diferente da chave privada, utilizada para decriptografia. A chave pública está disponível para o público em geral; a chave privada fica disponível apenas para um indivíduo, ou dispositivo, conforme ilustra a Figura 34.

Em conformidade com Stallings (2013), o emissor produz uma mensagem em texto claro, $X=\left[X_{1}, X_{2}, \ldots, X_{M}\right]$. Os $M$ elementos de $X$ são caracteres ou valores binários $\{0,1\}$. O receptor gera um par de chaves: uma chave pública, $P U_{b}$, e uma chave privada, $P R_{b} . P R_{b}$ é conhecida apenas pelo receptor, enquanto $P U_{b}$ está disponível publicamente e, portanto, acessível para o emissor.

Com a mensagem $X$ e a chave de criptografia $P U_{b}$ como entrada, o emissor forma o texto cifrado $Y=\left[Y_{1}, Y_{2}, \ldots, Y_{N}\right]$, conforme a expressão:

$$
Y=E\left(P U_{b}, X\right)
$$

O receptor a quem se destina a mensagem, de posse da chave privada correspondente, é capaz de inverter a transformação: 


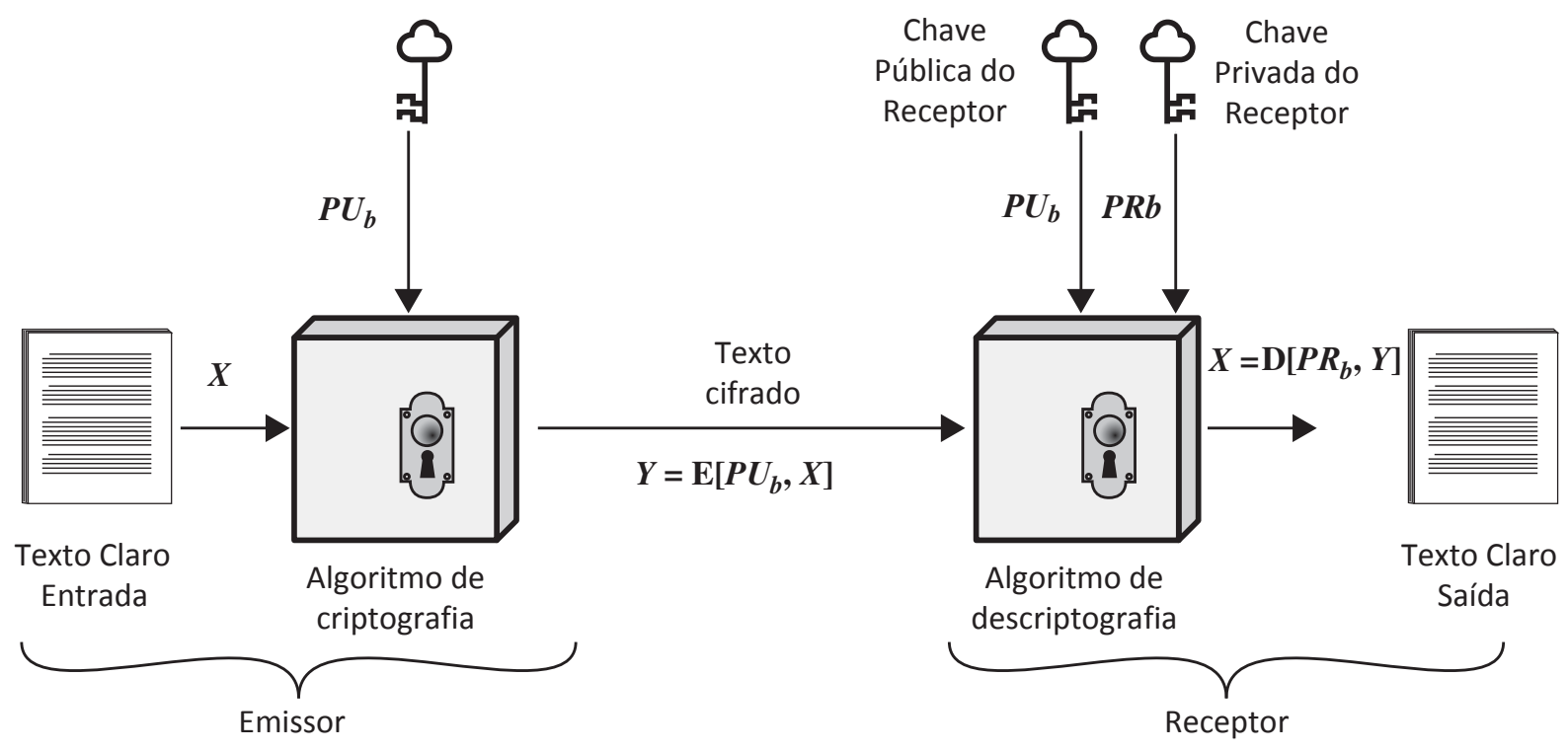

Figura 34: Criptografia de chave assimétrica

Fonte: Stallings (2013)

$$
X=D\left(P R_{b}, Y\right)
$$

Onde $D$ é o algoritmo de decriptografia.

\subsubsection{O Processo de Autenticação}

O processo de autenticação é caracterizado pela confirmação da identidade de algo, ou alguém, em uma comunicação. Stallings (2013) esclarece que a autenticação de mensagens é um mecanismo utilizado para verificar a integridade delas. É a garantia de que os dados recebidos sejam exatamente iguais aos enviados, ou seja, que não contenham modificação, inserção, exclusão ou repetição.

Para Tanenbaum (2011), a autenticação determina se o usuário está ou não se comunicando com um processo específico.

Existem vários métodos de autenticação, todos baseados em três linhas (MORAES, 2010; NAKAMURA; GEUS, 2007):

- Autenticação por meio de algo que o usuário, ou dispositivo, saiba: baseia-se no conhecimento de um login, que é o identificador de um usuário, e de uma senha;

- Autenticação por meio de algo que o usuário, ou dispositivo, tenha: baseia-se na posse de algum objeto (por exemplo, um token, cartão ou smart card) para realizar a autenticação;

- Autenticação por algo que o usuário (ou dispositivo) seja: utiliza alguma característica física ou de comportamento do usuário, como o reconhecimento de voz, a 
impressão digital, a geometria das mãos, o reconhecimento da retina, o reconhecimento da íris e o reconhecimento digital de assinaturas.

\subsubsection{Autenticação de mensagens}

Para oferecer autenticação de mensagens, o transmissor precisa dar evidências de que ele está enviando a mensagem, e não um impostor. Ele precisa utilizar um MsAC (Message Authentication Code) ${ }^{7}$.

Um MsAC, também conhecido como soma de verificação (checksum) criptográfica, é gerado por uma função C na forma (STALLINGS, 2013):

$$
M s A C=C(K, M)
$$

Em que $M$ é uma mensagem de comprimento variável, $K$ é uma chave secreta compartilhada apenas pelo emissor e receptor e $C(K, M)$ é um autenticador de comprimento fixo. A Figura 35 mostra como o emissor utiliza a função com chave para autenticar sua mensagem e como o receptor pode verificar sua autenticidade.

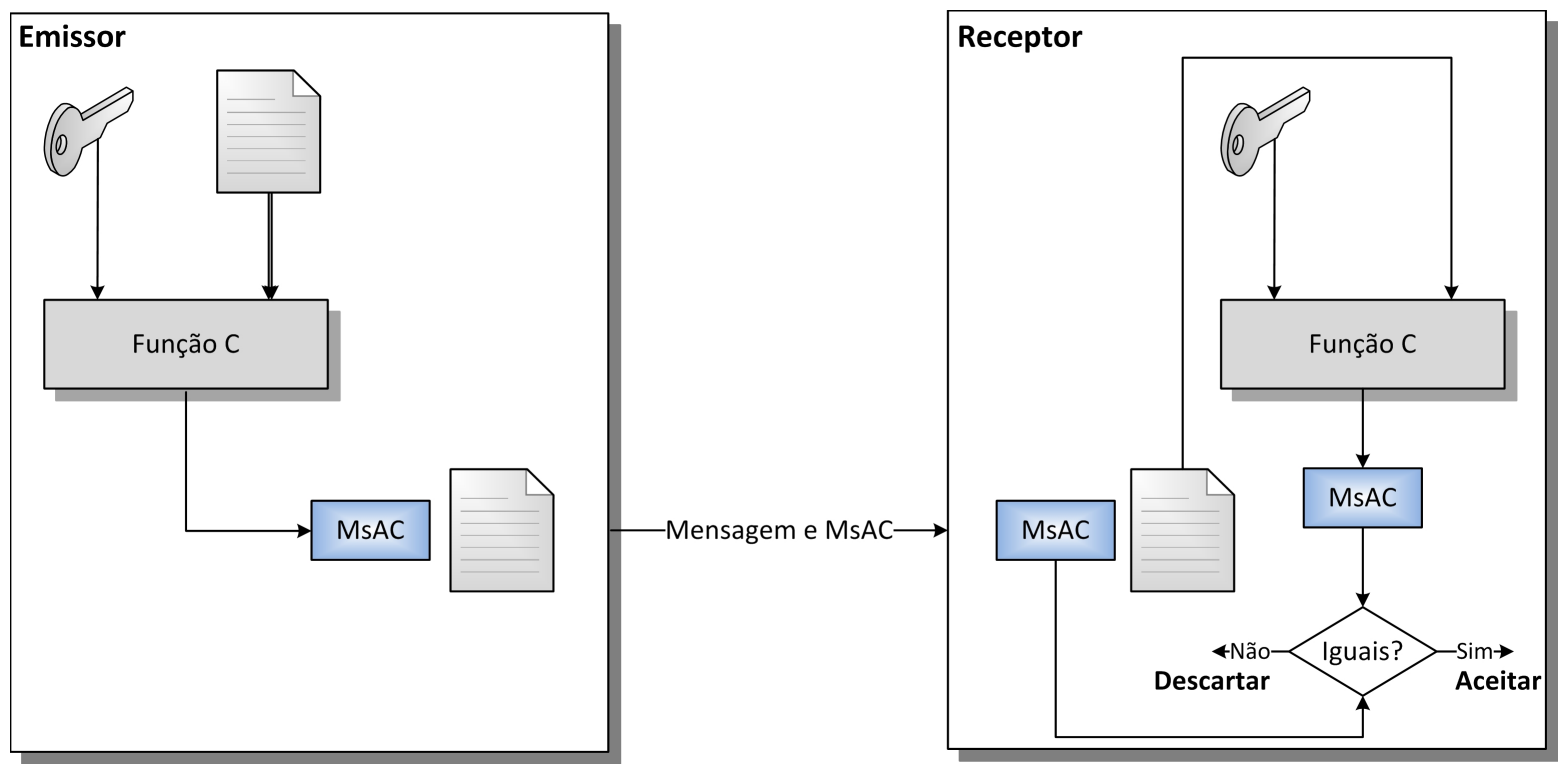

Figura 35: MsAC criado pelo emissor e verificado pelo receptor

Fonte: Forouzan e Fegan (2007)

O emissor utilizando a chave simétrica $(K)$ com o receptor e uma função $C$ com chave, gera um MsAC. Em seguida, concatena o MsAC com a mensagem original e envia ambas para o receptor. O receptor obtém a mensagem e o MsAC e separa uma da outra. Em seguida, aplica a mesma função $C$ à mensagem utilizando a chave simétrica $K$ para obter

\footnotetext{
${ }^{7} \mathrm{Na}$ bibliografia de segurança, a abreviatura utilizada para Message Authentication Code é MAC. Para não ocorrer incoerência com o termo Media Access Controllers, neste trabalho, a abreviatura utilizada para Message Authentication Code será MsAC.
} 
um novo MsAC. Depois disso, o emissor compara o MsAC enviado com o MsAC recémgerado. Se os dois MsACs forem idênticos, a mensagem não foi modificada e o emissor da mensagem é, definitivamente, do originador.

A função $C$ é uma função Hash, cuja finalidade é produzir uma impressão digital da mensagem, arquivo ou bloco de dados. Embora tenham sido desenvolvidos vários algoritmos hash, o mais comum é o SHA-1 ${ }^{8}$ (Secure Hash Algorithm 1). Descrições da função hash e do algoritmo SHA-1 podem ser encontradas em Forouzan e Fegan (2007) e Stallings (2013).

\subsubsection{HMAC}

Segundo Forouzan e Fegan (2007), nos últimos anos, foram desenvolvidos MsACs que se baseiam em funções hash sem chaves, como o SHA-1. Esse conceito é denominado HMAC (Hash-based Message Authentication Code). "O HMAC cria um MsAC alinhado, aplicando uma função hash sem chaves à concatenação da mensagem e a uma chave simétrica". A Figura 36 ilustra o conceito geral.

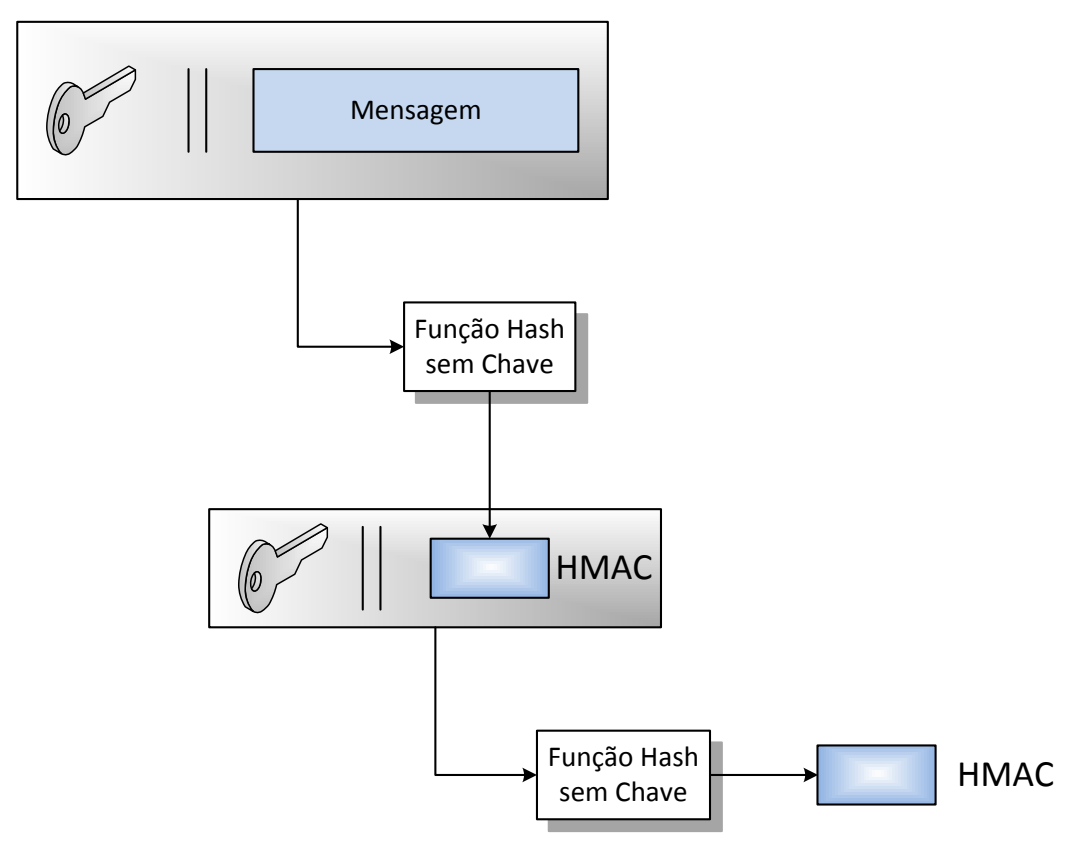

Figura 36: Conceito geral do HMAC

Fonte: Forouzan e Fegan (2007)

\footnotetext{
${ }^{8}$ SHA-1 (Secure Hash Algorithm 1) é uma versão revisada do SHA desenvolvida pelo NIST (National Institute of Standards and Technology). Foi publicada pela primeira vez como um FIPS (Federal Information Processing Standard).
} 


\begin{abstract}
Anexa-se uma cópia de chave simétrica à mensagem. Aplica-se um hash a essa combinação, por meio de uma função hash sem chaves. O resultado é um HMAC intermediário que é, novamente, anexado à chave (a mesma), e é aplicado um hash outra vez ao resultado, utilizando o mesmo algoritmo. O resultado final é o HMAC. O receptor, por sua vez, recebe esse HMAC final e a mensagem, cria seu próprio HMAC da mensagem recebida e compara os dois HMACs para validar a sua integridade e autenticar a origem dos dados (FOROUZAN; FEGAN, 2007).
\end{abstract}

\title{
3.5 Organizações e Padrões
}

As diretrizes de segurança de redes aos fabricantes, fornecedores, órgãos do governo e outros provedores de serviços buscam garantir a interconectividade necessária no mercado atual, propondo sugestões ou medidas de comportamento. A Tabela 16 identifica algumas das organizações e padrões envolvidos com o estabelecimento de regulamentos, diretrizes, ou documentos de melhores práticas de segurança. Outras iniciativas em segurança para o sistema elétrico podem ser vislumbradas em Hull et al. (2012).

\subsection{O Padrão IEC 62351}

Segurança e confiabilidade sempre foram temas importantes no projeto e operação de sistemas no setor de energia elétrica. Neste quesito, a segurança da informação está se tornando cada vez mais importante. O mercado desverticalizado ${ }^{9}$ impôs novas ameaças como o conhecimento dos ativos de um concorrente e a operação do seu sistema. Além disso, as ações deliberadas podem ser tão prejudiciais quanto ações involuntárias (por exemplo, catástrofes naturais) (IEC/TS-62351-1, 2007).

Neste ínterim, o escopo da série IEC 62351 é a segurança da informação para as operações de controle do sistema elétrico. O principal objetivo é realizar o desenvolvimento de normas para a segurança dos protocolos de comunicação definidos pelo IEC TC 57, e relatórios técnicos sobre questões de segurança fim-a-fim (do ponto de origem ao ponto de destino), não abrangendo os requisitos de segurança interna, por exemplo, políticas de segurança (IEC/TS-62351-1, 2007).

\subsubsection{Histórico e Composição do Padrão IEC 62351}

Em 1997, o comitê técnico IEC TC 57 reconheceu que a segurança seria necessária para diversos protocolos. Neste momento foi estabelecido pela primeira vez um grupo temporário para estudar as questões de segurança. Este grupo publicou a IEC TR ( Technical Report) 62210 que aborda requisitos de segurança. Uma das recomendações da IEC TR 62210 era formar um grupo de trabalho para desenvolver padrões de segurança para os protocolos do Technical Committee (IEC TC) 57.

\footnotetext{
${ }^{9} \mathrm{O}$ mercado brasileiro de energia elétrica perdeu a estrutura de governança essencialmente federal.
} 
Tabela 16: Iniciativas em segurança cibernética para o sistema de energia elétrica

\begin{tabular}{|c|c|c|}
\hline Padrão & & Descrição \\
\hline NIST SGIP-CSWG & $\begin{array}{l}\text { Smart Grid Interoperabi- } \\
\text { lity Panel - Cyber Security } \\
\text { Working Group }\end{array}$ & $\begin{array}{l}\text { NISTIR } 7628 \text {, é um relatório do NIST (National } \\
\text { Institute of Standards and Technology) elaborado } \\
\text { pelo CSWG (Cyber Security Working Group) - SGIP } \\
\text { (Smart Grid Interoperability Panel) que aborda pro- } \\
\text { blemas, objetivos e requisitos de segurança em comu- } \\
\text { nicações de redes elétricas inteligentes (Smart Grid) } \\
\text { (CSWG, 2010). }\end{array}$ \\
\hline NERC CIP & $\begin{array}{l}\text { Cyber Security Regulation for } \\
\text { North American Power Utili- } \\
\text { ties }\end{array}$ & $\begin{array}{l}\text { O NERC (North American Electric Reliability Cor- } \\
\text { poration) define normas cuja missão é incrementar a } \\
\text { confiabilidade do sistema de energia elétrica na Amé- } \\
\text { rica do Norte. O CIP (Critical Infrastructure Pro- } \\
\text { tecion) representa um dos programas de implemen- } \\
\text { tação das recomendações propostas pelo NERC no } \\
\text { sentido de orientar tanto os fabricantes quanto os } \\
\text { usuários dos sistemas de energia elétrica para miti- } \\
\text { gar problemas de segurança física e virtual (NERC, } \\
\text { 2013). }\end{array}$ \\
\hline IEC 62351 & $\begin{array}{l}\text { Data and Communications Se- } \\
\text { curity }\end{array}$ & $\begin{array}{l}\text { A série de padrões IEC 62351, Communication } \\
\text { Network and System Security, define mecanismos de } \\
\text { segurança para protocolos de comunicação (IEC/TS- } \\
62351-1,2007 \text { ). }\end{array}$ \\
\hline IEEE PSRC/H13 & $\begin{array}{l}\text { Cyber Security Requirements } \\
\text { for Substation Automation, } \\
\text { Protection and Control Sys- } \\
\text { tems }\end{array}$ & $\begin{array}{l}\text { O PSRC (Power Systems Relay Committee) WG-H13 } \\
\text { prepara um padrão com requisitos de segurança para } \\
\text { sistemas de controle, proteção e automação de subes- } \\
\text { tações (PES, 2013). }\end{array}$ \\
\hline IEEE 1686 & $\begin{array}{l}\text { IEEE Standard for Substation } \\
\text { IEDs Cyber Security Capabili- } \\
\text { ties }\end{array}$ & $\begin{array}{l}\text { Define as funções e características a serem fornecidas } \\
\text { em IEDs para atender à CIP (Critical Infrastructure } \\
\text { Protecion) (WGC1, 2013). }\end{array}$ \\
\hline IEEE 1402 & $\begin{array}{l}\text { IEEE Guide for Electric Power } \\
\text { Substation Physical and Elec- } \\
\text { tronic Security }\end{array}$ & $\begin{array}{l}\text { São relacionadas questões relativas à intrusão hu- } \\
\text { mana e eletrônica em subestações de energia elétrica } \\
\text { (WGE7, 2013). }\end{array}$ \\
\hline ISA S99 & $\begin{array}{l}\text { Industrial Automation and } \\
\text { Control System Security }\end{array}$ & $\begin{array}{l}\text { A ISA (International Society of Automation) é um co- } \\
\text { mitê de desenvolvimento que reúne especialistas em } \\
\text { segurança cibernética para sistemas de controle e au- } \\
\text { tomação industrial (ISA, 2013). }\end{array}$ \\
\hline
\end{tabular}

Portanto, em 1999 formou-se o grupo de trabalho WG 15, Power system control and associated communications - Data and communication security, sua finalidade é realizar o desenvolvimento de normas para a segurança dos protocolos de comunicação definidos pelo IEC TC 57, especificamente as séries IEC 60870-5, IEC 60870-6, IEC 61850, IEC 61970 e IEC 61968 .

A série IEC 62351 foi organizada em 11 partes (IEC/TR-62351-10, 2012):

- IEC 62351-1: Introdução e Visão Geral (Edição 1.0, 05/2007) ${ }^{10}$;

- IEC 62351-2: Glossário de Termos (Edição 1.0, 08/2008);

\footnotetext{
${ }^{10}$ Dados da versão pertinente ao LSEE em outubro de 2013.
} 
- IEC 62351-3: Perfil incluindo TCP/IP (abrange os perfis utilizados pelo ICCP (Inter-Control Center Communications Protocol), IEC 60870-5-104, DNP (Distributed Network Protocol) 3.0 sobre TCP/IP, e IEC 61850 sobre TCP/IP) (Edição 1.0, 06/2007);

- IEC 62351-4: Perfil incluindo MMS (abrange os perfis utilizados pelo ICCP e IEC 61850) (Edição 1.0, 06/2007);

- IEC 62351-5: Segurança para IEC 60870-5 e Derivados (abrange ambos os perfis seriais e de rede utilizados pela IEC 60870-5 e DNP) (Edição 2.0, 04/2013);

- IEC 62351-6: Segurança para perfis da IEC 61850 (abrange os perfis IEC 61850 que não são baseadas em TCP/IP - GOOSE, GSSE e SMV (Sampled Measured Values)) (Edição 1.0, 06/2007);

- IEC 62351-7: Modelos abstratos de objetos de dados para o gerenciamento de redes e sistemas (Edição 1.0, 07/2010);

- IEC 62351-8: Controle de acesso baseado em funções para a gestão de sistemas de energia (Edição 1.0, 09/2011);

- IEC 62351-9: Gerenciamento de chaves, WIP (Work in Progress);

- IEC 62351-10: Diretrizes da arquitetura de segurança (Edição 1.0, 09/2011);

- IEC 62351-11: Segurança para arquivos XML (eXtender Markaup Language), NWIP (New Work Item Proposal).

\subsubsection{IEC 62351-6, Perfil de Segurança para IEC 61850}

A parte 6 da IEC 62351 especifica as mensagens, procedimentos, e algoritmos para segurança operacional dos protocolos baseados ou derivados do padrão IEC 61850 (IEC/TS62351-6, 2007).

Para as mensagens rápidas, Tipo 1A, a IEC 62351 não recomenda a utilização de algoritmos de criptografia, pois são técnicas que podem afetar as taxas de transmissão. A autenticação através de uma assinatura digital é a única medida de segurança incluída pela IEC/TS-62351-6 (2007).

Alguns dos elementos principais das medidas de segurança para as mensagens GOOSE, foco deste trabalho, são (IEC/TS-62351-1, 2007):

- A autenticação é a medida de segurança primária;

- A criptografia deve ser evitada pois adiciona atrasos no tempo de transferência das mensagens; 
- Uma vez que a segurança pode ser aplicada ao longo do tempo, um cliente GOOSE não protegido pode ignorar uma mensagem GOOSE segura;

- A renegociação de chaves não é suportada pois poderia interromper uma informação de alta velocidade com fluxo crítico;

- Por razões de compatibilidade, um campo reservado do quadro que forma a mensagem GOOSE é agora utilizado para informar o comprimento de uma extensão adicionada ao final da mensagem. Esta extensão contém o valor de autenticação (Assinatura Digital HMAC), conforme ilustra a Figura 37. Clientes GOOSE não seguros devem simplesmente ignorar esta extensão.

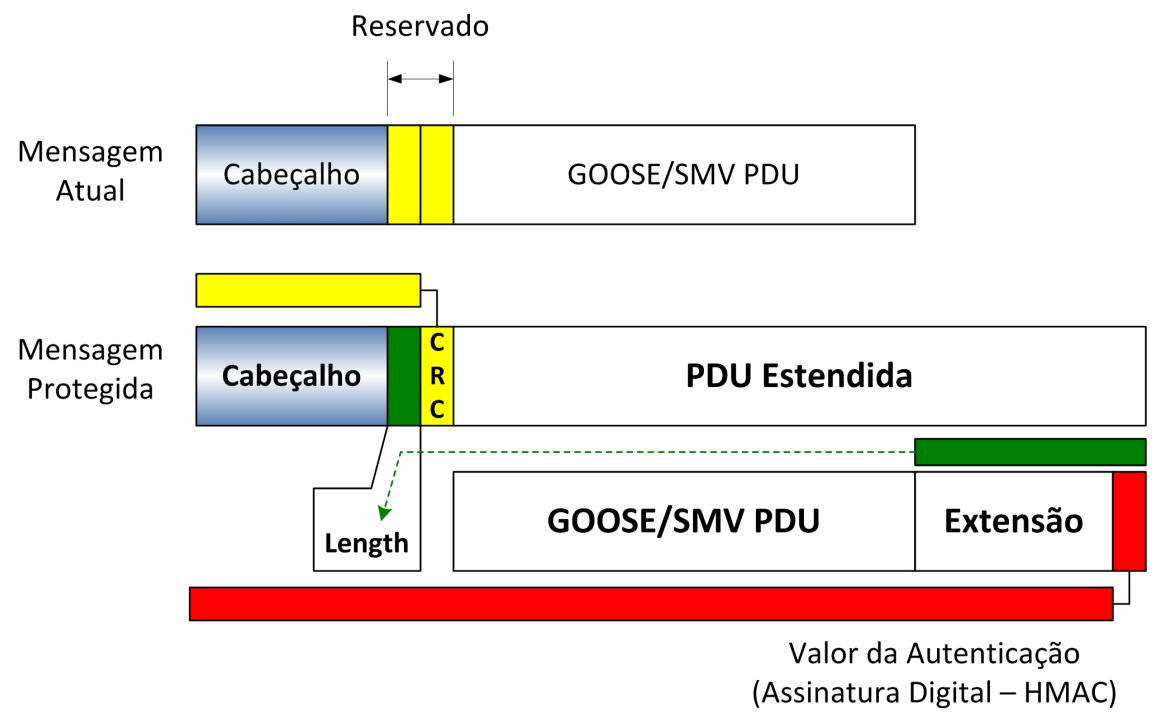

Figura 37: Autenticação das mensagens/protocolos GOOSE e SMV

Fonte: IEC/TS-62351-1 (2007)

- A IEC 62351-6 explicita que as mensagens GOOSE devem ser marcadas com uma etiqueta ( $t a g$ ) de VLAN (Virtual Local Area Network), padrão IEEE 802.1Q (VLAN tagging), para terem os seus requisitos de tempo crítico respeitados. 


\section{Decodificador ASN.1/BER GOOSE}

A composição de sistemas em hardware, para monitorar e controlar a troca de mensagens GOOSE, necessita de um processo para segmentar, identificar, delimitar e fornecer para manipulação os campos do quadro Ethernet. O objetivo deste capítulo é descrever o modelo de decodificação de mensagens GOOSE, denominado ASN.1/BER GOOSE, com foco no quadro ISO/IEC 8802-3. Em virtude das restrições críticas de tempo da mensagem GOOSE, uma nova abordagem é proposta utilizando hardware reconfigurável. Alguns aplicativos de software foram desenvolvidos para validar a decodificação das mensagens. Os ensaios avaliaram um vasto número de mensagens, utilizando todas as estruturas e dados pertinentes ao modelo abstrato e às regras básicas de codificação, conforme descrito no Capítulo 2.

Hauck e DeHon (2010) descrevem que pacotes de rede em hardware não sofrem a perda de desempenho causados pelo processamento de dados sequencial. Neste contexto, para alcançar tempos de propagação que permitam monitorar e controlar mensagens GOOSE, o hardware reconfigurável será baseado na plataforma NetFPGA, um acelerador construído através de hardware reconfigurável FPGA (Field Programmable Gate Array) que permite a construção de protótipos funcionais de rede de alta performance.

\subsection{Definição do Problema}

O desenvolvimento de sistemas, com a capacidade de monitorar e controlar a interatividade entre os dispositivos que processam mensagens GOOSE, apresenta os seguintes problemas:

- Embora o desenvolvimento de aplicativos baseados em software tenha excelente flexibilidade, o seu processamento é limitado devido à natureza sequencial de execução das instruções (VAHID, 2007);

- O tempo de processamento não pode sobrecarregar demasiadamente o tempo de transferência de uma mensagem; e 
- É necessário conhecer a formatação do quadro de dados GOOSE. Este estágio, refere-se ao processo de segmentar uma sequência de bits em unidades discretas ou blocos de dados (GALLO; HANCOCK, 2001).

Conforme exposto no Capítulo 2, tais blocos de dados podem ser de tamanho fixo ou flexível. Na análise de blocos de tamanho fixo, não existe a necessidade de definir os limites dos blocos. O tamanho do bloco em si já é usado como delimitador, assim, o problema está na análise de blocos de tamanho flexível, pois são necessários métodos para definir o final de um bloco e o início do seguinte. Para as mensagens GOOSE, as informações flexíveis do quadro ISO/IEC 8802-3 formam a APDU (Application Protocol Data Unit).

\subsection{Revisão Bibliográfica}

Diversos artigos fazem menção aos principais fundamentos e potencialidades do padrão IEC 61850 e das mensagens GOOSE nos processos de automação das subestações de energia elétrica (MACKIEWICZ, 2006; APOSTOLOV; THOLOMIER, 2006; HOSSENLOPP, 2007; SUN; REDFERN, 2009). No entanto, são escassos os trabalhos que envolvem a decodificação de mensagens GOOSE.

Kriger, Behardien e Retonda-Modiya (2013) realizam uma avaliação detalhada dos campos que formam uma mensagem GOOSE, e relatam que a codificação não é rigorosamente baseada na ASN.1/BER original, porém, uma adaptação da ASN.1/BER para MMS (Manufacturing Message Specification).

Utilizando-se a biblioteca Winpcap, que permite a captura e transmissão de pacotes em rede, desenvolvida pelo NetGroup no Instituto Politécnico de Turim (BLUM, 2003), Du e Liu (2012) descrevem a decodificação de uma mensagem GOOSE, utilizando um aplicativo de software e como hardware um computador. No entanto, não foi detalhado o tempo para decodificação das mensagens.

Um estudo inicial, envolvendo a decodificação em hardware, pode ser observado em Yan, Wu e Li (2015).

Contudo, a decodificação em hardware de toda estrutura atribuída a uma mensagem GOOSE, com a execução de ensaios que validem a decodificação e a descrição dos tempos de transferência envolvidos, é uma lacuna que este trabalho busca eliminar.

\subsection{A Plataforma NetFPGA}

A NetFPGA é uma plataforma desenvolvida pela Universidade de Stanford que permite a estudantes e a grupos de pesquisa projetar e construir protótipos de rede de alto desempenho (GIBB et al., 2008). Trata-se de um acelerador em hardware construído por 
meio de hardware reconfigurável FPGA, conduzindo enlaces de rede Gigabit (MCKEOWN et al., 2007).

O projeto da NetFPGA permite o desenvolvimento de diversos tipos de sistemas de rede baseados em Ethernet, como roteadores, switches e firewalls, com capacidade de processar pacotes dos enlaces Gigabit com baixa latência, na taxa da linha (line-rate), permitindo a implementação experimental em redes reais (CASADO; WATSON; MCKEOWN, 2005; NAOUS; BOLOUKI, 2008).

Sua arquitetura abriga uma FPGA programável pelo usuário em linguagem HDL (Hardware Description Language), memórias SRAM (Static Random Access Memory) e DRAM (Dynamic Random Access Memory), e quatro portas Ethernet Gigabit (NETFPGA, 2016c). Uma interface PCI (Peripheral Component Interconnect) permite a inclusão da plataforma em um computador do tipo IBM-PC para configuração e integração entre software e hardware, conforme ilustra a Figura 38.

A plataforma NetFPGA não é composta apenas pela placa, mas também pelo ambiente e fontes de desenvolvimento disponíveis para prototipagem rápida de projetos de hardware, utilizando linguagem Verilog (Verilog Hardware Description Language).

Três projetos básicos foram implementados na NetFPGA e servem como ponto inicial de estudo da plataforma (GIBB et al., 2008):

- Uma NIC (Network Interface Card) com quatro portas Gigabit;

- Um switch Ethernet;

- Um roteador IPv4 (Internet Protocol version 4).

\subsubsection{Início do Projeto e Objetivo}

Em 2001, um grupo de pesquisadores e professores do Departamento de Engenharia Elétrica da Universidade de Stanford iniciou os trabalhos com o projeto NetFPGA. John W. Lockwood, Greg Watson, Nick Mckeown e Martin Casado vislumbraram a possibilidade de utilizar esta ferramenta em sala de aula (REFORGIATO; BATTAGLIA, 2012).

Em diversas instituições de ensino, os alunos constroem conhecimento dos sistemas de rede apenas com aplicativos de software. A relação deles com as camadas, por exemplo, física e de enlace de rede são limitadas a exposições teóricas. Na Universidade de Stanford, os professores observaram que os estudantes adquirem experiência prática quando há manipulação de mais níveis da pilha de rede (REFORGIATO; BATTAGLIA, 2012).

O objetivo foi possibilitar ao aluno entender o processamento de pacotes no hardware e, por conseguinte, executar a rápida prototipação de dispositivos de rede de alta velocidade (LOCKWOOD et al., 2007; WATSON; MCKEOWN; CASADO, 2006).

NICs, roteadores, switches e firewalls comerciais apresentam projetos complexos, com código proprietário e inadequados para as alterações que a experimentação exige. Nesse 


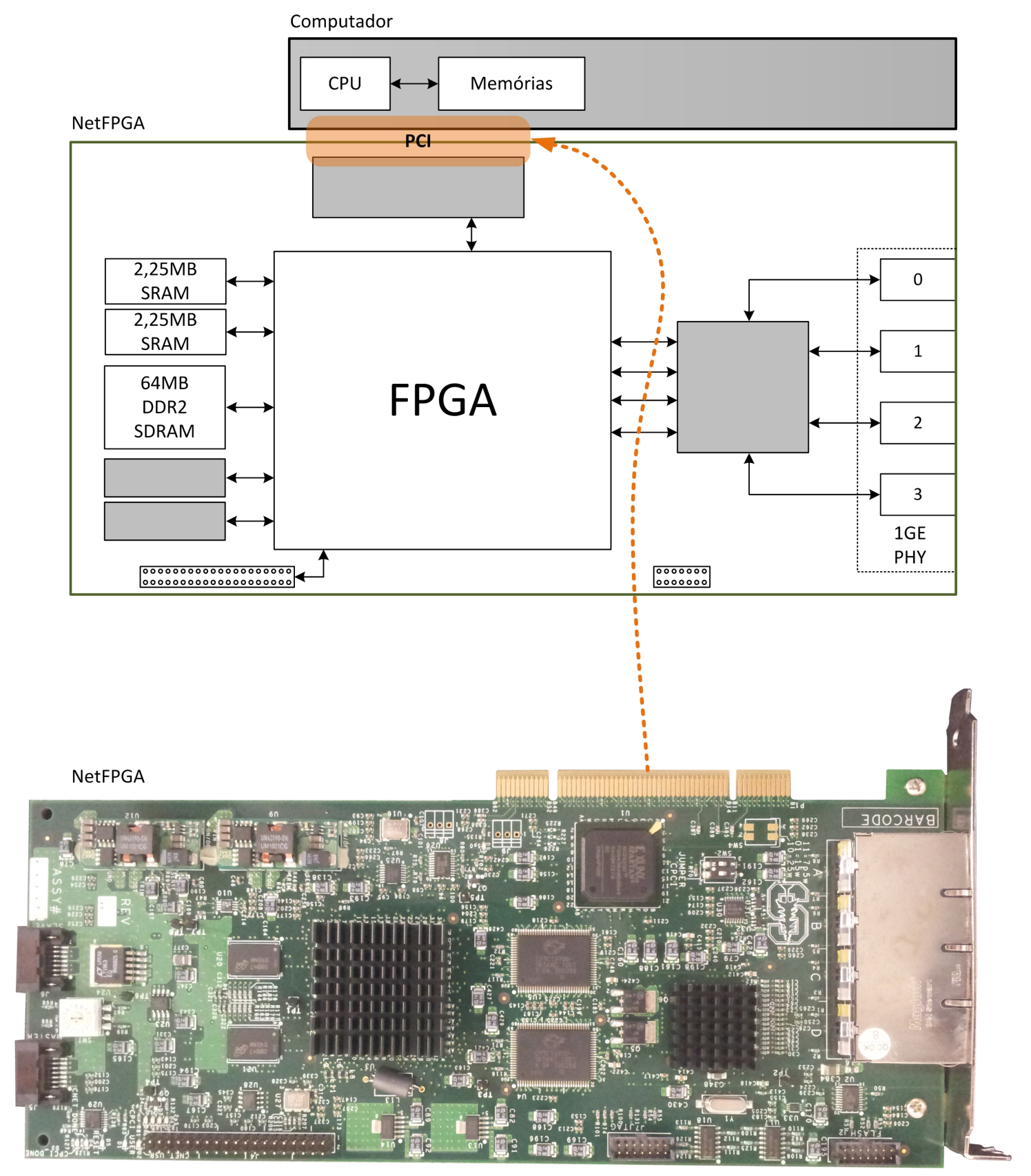

Figura 38: Diagrama simplificado de blocos da plataforma NetFPGA

contexto, o objetivo principal da NetFPGA é possibilitar a construção de sistemas de rede reais, de modo que os desenvolvedores de todo o mundo possam contribuir e reutilizar módulos e projetos para o benefício da comunidade como um todo.

\subsubsection{NetFPGA Versão 1}

A primeira versão do hardware (NetFPGA-V1) foi concebida no final de 2001, para apoiar o ensino de uma disciplina de redes (CS344 Build an Internet Router, Stanford), com base em Ethernet de 10Mbps e protótipos foram utilizados em uma disciplina da 
pós-graduação da Universidade de Stanford em 2003.

A ideia original era disponibilizar um rack com placas NetFPGA-V1 localizadas em Stanford. Os alunos não tinham acesso físico às placas, porém executavam upload e depuração dos projetos remotamente. O objetivo no longo prazo era sediar placas e disponibilizá-las para outras instituições.

Durante os anos de uso, foram identificadas as seguintes limitações (REFORGIATO; REITANO; TORRISI, 2011):

- O formato da placa de circuito impresso, PCB (Printed Circuit Board), exigia um rack específico;

- A velocidade das portas (10Mbps) era insuficiente para muitas pesquisas;

- A falta de uma CPU (Central Processing Unit) on-board não possibilitava a utilização plena da capacidade de software para controle da plataforma;

- A necessidade de expansão dos OSs (Operating System) utilizados pela plataforma de desenvolvimento, inicialmente, Linux e Solaris.

\subsubsection{NetFPGA Versão 2}

No verão de 2004, a Universidade de Stanford começou a resolver as limitações da NetFPGA-V1 mencionados na seção 4.3.2. A segunda versão da plataforma (NetFPGAV2), utilizando Ethernet Gigabit, foi desenvolvida entre 2005 e 2006 (LOCKWOOD et al., 2007).

A NetFPGA-V2 consiste em uma placa PCI (Peripheral Component Interconnect) que pode ser instalada em qualquer computador. Implementações de referência e amostra de material didático foram disponibilizadas no endereço eletrônico do projeto (NETFPGA, 2016b). A placa hospeda uma FPGA Virtex-II PRO da Xilinx ${ }^{\circledR}$, Memórias SRAM, DRAM, e quatro portas Ethernet de 1 Gbps.

A programação e administração da placa de desenvolvimento são executadas pelo PC por meio do barramento PCI, permitindo aos usuários desenvolver e implantar projetos remotamente.

\subsubsection{Especificação da NetFPGA-V2 - Hardware}

A NetFPGA-V2 utiliza duas FPGAs Xilinx ${ }^{\circledR}$, uma Virtex II Pro XC2VP50 para processar o design de rede do usuário, com base em códigos em Verilog e IP Cores (Intellectual Property Core) da Xilinx ${ }^{\circledR}$, e uma Spartan II XC2S200, que implementa a lógica de controle para a interface PCI (Figura 39). A frequência de clock para a Virtex II Pro pode ser configurada pelo programador para $62,5 \mathrm{MHz}$ ou $125 \mathrm{MHz}$, enquanto que a Spartan II possui uma frequência de clock fixa de 62,5MHz (GUO et al., 2012; NETFPGA, 2016a). 


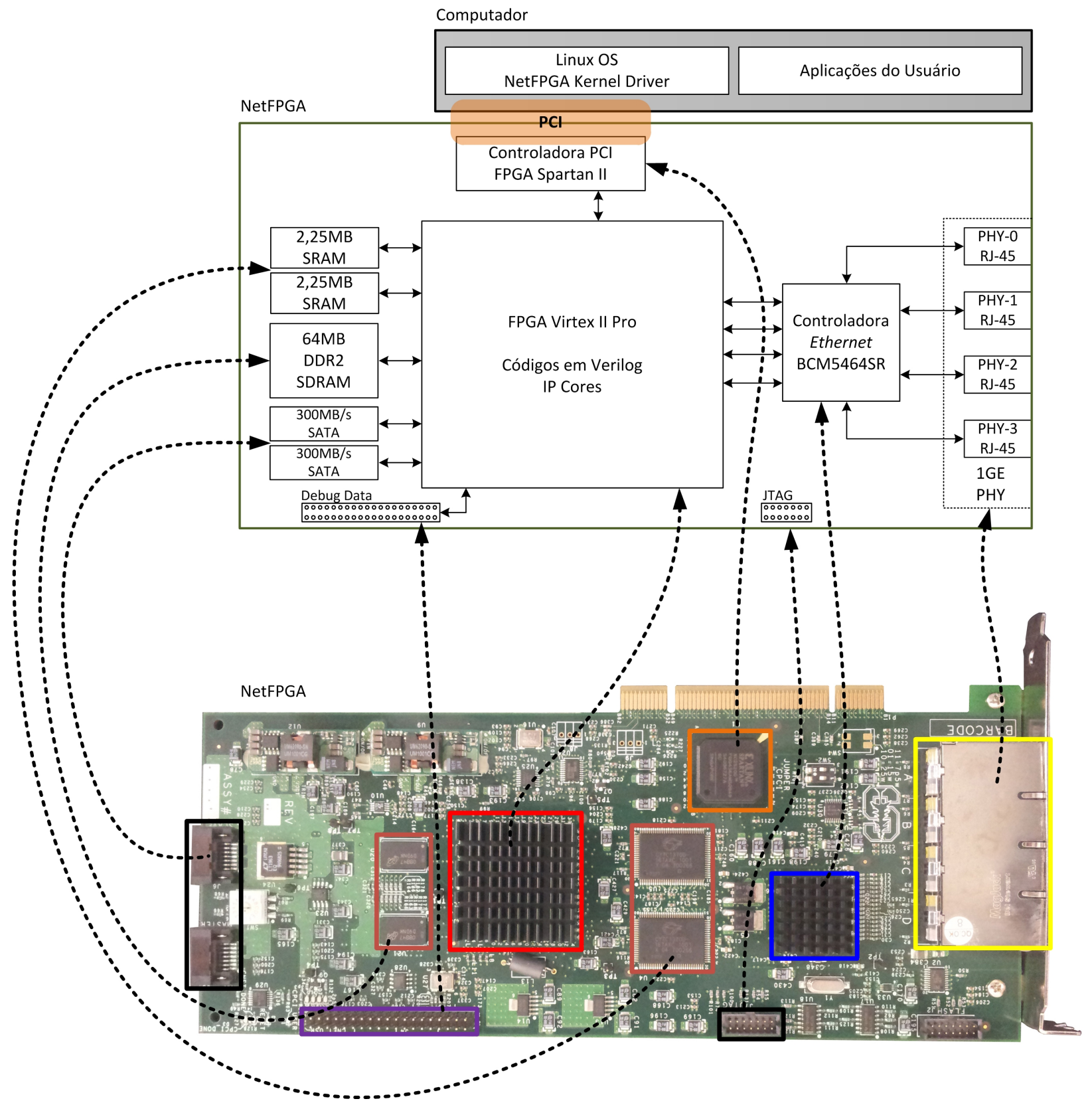

Figura 39: Identificação dos componentes da NetFPGA-V2

Pertinente ao nível de memória, a NetFPGA-V2 apresenta duas memórias SRAM externas e uma memória DDR2 (Double Data Rate) SDRAM (Synchronous Dynamic Random Access Memory) (NETFPGA, 2016a):

- As memórias SRAM: são adequadas para o armazenamento de dados pertinentes, como, por exemplo, a tabela de encaminhamento de pacotes, fornecem uma capacidade total de 4,5MB;

- A memória DDR2 SDRAM: é indicada para o armazenamento de pacotes e apresenta uma capacidade total de 64MB. 
As interfaces de Input/Output (I/O) estão divididas em quatro portas Gigabit Ethernet, uma PCI, duas interfaces Multi-Gigabit, uma JTAG (Joint Test Action Group) e uma barra de pinos para acesso e inserção de sinais digitais (NETFPGA, 2016a):

- Quad-PHY ${ }^{\mathrm{TM}}$ (Physical Layer Devices), BCM5464SR, é um circuito integrado (Controlador Ethernet) da Broadcom ${ }^{\circledR}$, contendo quatro transceptores que executam as funções de interface de camada física para redes 1000BASE-T (Gigabit Ethernet), utilizando cabeamento UTP (Unshielded Twisted Pair) Categorias 5, 5e e 6, e conectores externos RJ-45. Os quatro Gigabit Ethernet MACs (Media Access Controllers) são instanciados como um soft core ${ }^{1}$ na FPGA Virtex II Pro;

- Uma interface PCI, com transferência de dados em 32 bits com velocidade de $33 \mathrm{MHz}$, permite instalar a placa NetFPGA-V2 em um computador do tipo IBM PC, configurar a FPGA Virtex II Pro por meio de arquivos binários (bitfiles) e executar algoritmos em linguagens de programação de alto nível com troca de dados, utilizando registradores entre software e hardware;

- Dois conectores estilo SATA (Serial Advance Technology Attachment), para interfaces MGIO (Multi-Gigabit I/O), podem ser utilizados na interligação direta de NetFPGAs-V2, sem a utilização do barramento PCI, com taxa de transferência de dados de $300 \mathrm{MB} / \mathrm{s}$;

- Uma interface JTAG destinada a testes e programação padronizada que provê maneiras de assegurar a integridade de componentes eletrônicos individuais e as suas interconexões em placa de circuito impresso (COSTA; MESQUITA; PINHEIRO, 2011);

- Interface (Debug Data) baseada em uma barra de pinos para acesso e inserção de sinais digitais diretamente na FPGA Virtex II Pro.

Especificações complementares da NetFPGA-V2 podem ser encontradas no site NetFPGA (2016a).

\subsubsection{Especificação da NetFPGA-V2 - Software}

O grupo de pesquisa da Universidade de Stanford fornece suporte na utilização da distribuição Linux Fedora ${ }^{\circledR}$ como Sistema Operacional do computador que recebe a NetFPGA. No início do projeto o CentOS ${ }^{\circledR}$, uma variação livre da distribuição RedHat ${ }^{\circledR}$, foi utilizada, porém, o suporte para este sistema operacional foi descontinuado. A utilização de outros sistemas operacionais é possível, porém não existe suporte pela equipe de Stanford.

\footnotetext{
${ }^{1}$ Um bloco de lógica digital que é projetado para ser implementado em um chip ASIC (Application Specific Integrated Circuit) ou FPGA.
} 
Para implementar e simular os projetos na NetFPGA-V2, é necessária a utilização de ferramentas de CAD (Computer Aided Design):

- Códigos na linguagem Verilog são sintetizados, utilizando a IDE (Integrated Development Environment) ISE ${ }^{\mathrm{TM}}$, versão sugerida 10.1 SP3 da Xilin ${ }^{\circledR}$, para a geração dos bitfiles;

- Os designs são simulados utilizando o aplicativo Modelsim ${ }^{\text {TM }}$, versão $6.2 \mathrm{G}$ da Mentor Graphics ${ }^{\circledR}$, para verificar a operação correta das lógicas implementadas.

Especificações complementares de software podem ser observados em Gibb et al. (2008).

\subsubsection{Estrutura Modular da NetFPGA-V2}

A divisão do hardware em módulos dentro da FPGA é uma característica da plataforma NetFPGA. Todos os projetos seguem a mesma estrutura modular, conforme ilustra a Figura 40.

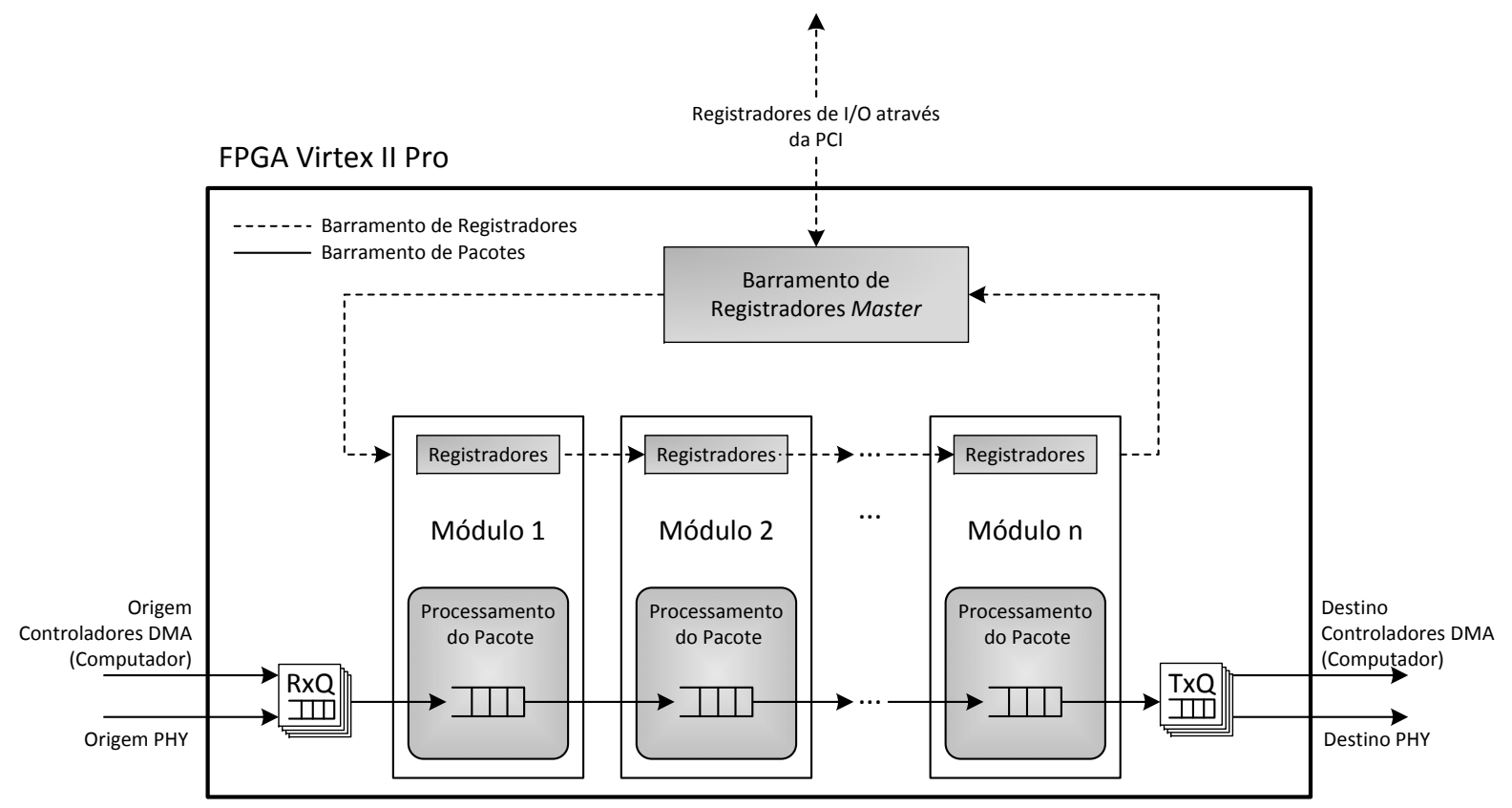

Figura 40: Estrutura modular da plataforma NetFPGA-V2

Fonte: Naous e Bolouki (2008)

Os módulos são interligados por meio de dois barramentos, um para pacotes, Barramento de Dados e Controle, e outro para configurar e ler os registradores dos módulos a partir do Barramento de Registradores (COVINGTON et al., 2009b): 
- Barramento de Pacotes: encaminha dados entre os módulos e é formado por um barramento de dados, uma série de palavras de 64 bits, que consiste no cabeçalho e na carga útil dos pacotes, aqui denominadas fatias, e um barramento de controle que possui 8 bits (NAOUS; BOLOUKI, 2008).

- Barramento de Registradores ${ }^{2}$ : permite a troca de informações entre módulos, o acesso e as alterações nos registradores em hardware por meio de chamadas ioctl $^{3}$, via software.

Quando os quadros Ethernet ingressam no barramento de pacotes, têm o formato definido pela plataforma NetFPGA, conforme ilustra a Figura 41.

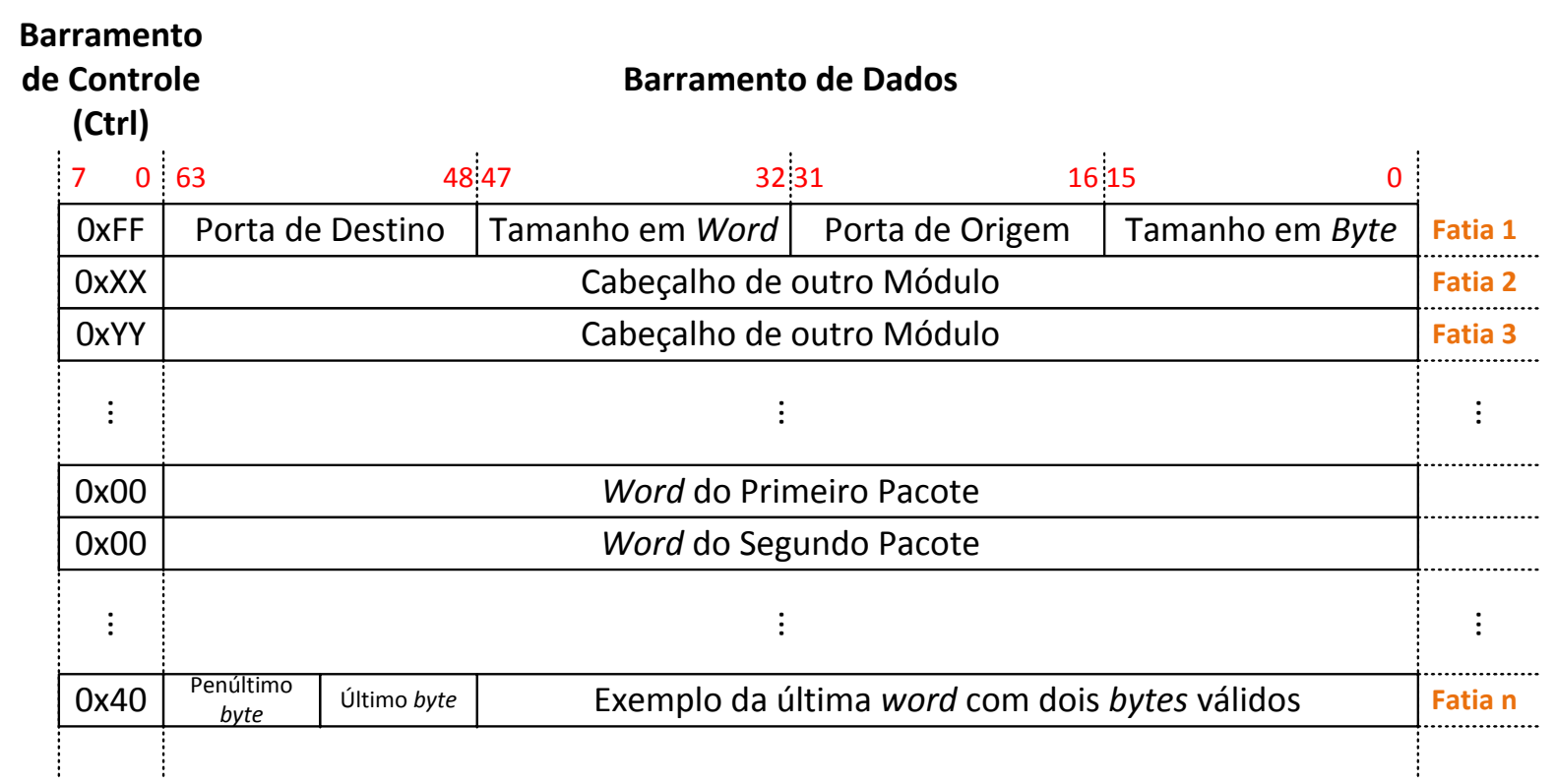

Figura 41: Formato interno dos quadros Ethernet na plataforma NetFPGA Fonte: Naous e Bolouki (2008)

A primeira fatia apresenta um cabeçalho, identificado com o byte de controle 0xFF, e as seguintes informações:

- A porta de destino;

- O tamanho em words;

- A porta de origem;

- O tamanho em bytes.

\footnotetext{
${ }^{2}$ Memórias rápidas, disponíveis para o armazenamento temporário de dados.

${ }^{3} \mathrm{O}$ método ioctl (input output control) é uma chamada no sistema que possibilita a transferência de dados do módulo para o espaço do usuário (COOPERSTEIN, 2009).
} 
Adcionalmente, é possível a inserção de mais cabeçalhos, definidos pelos módulos.

Conforme Seclen (2011), os dados do quadro são identificados com a palavra de controle 0x00. O fim do quadro é demarcado, designando-se com um dos bits de controle, a posição do último byte do quadro. No exemplo da Figura 41, o último byte do quadro se encontra no segundo byte mais significativo. Portanto, a palavra de controle da última fatia é 0x40 (0b01000000).

\subsubsection{Pipeline de Referência}

O design descrito na seção 4.3 .4 é um pipeline $e^{4}$, no qual cada estágio é um módulo separado. O diagrama do design de referência da NetFPGA-V2 é apresentado na Figura 42.

Rx Queues

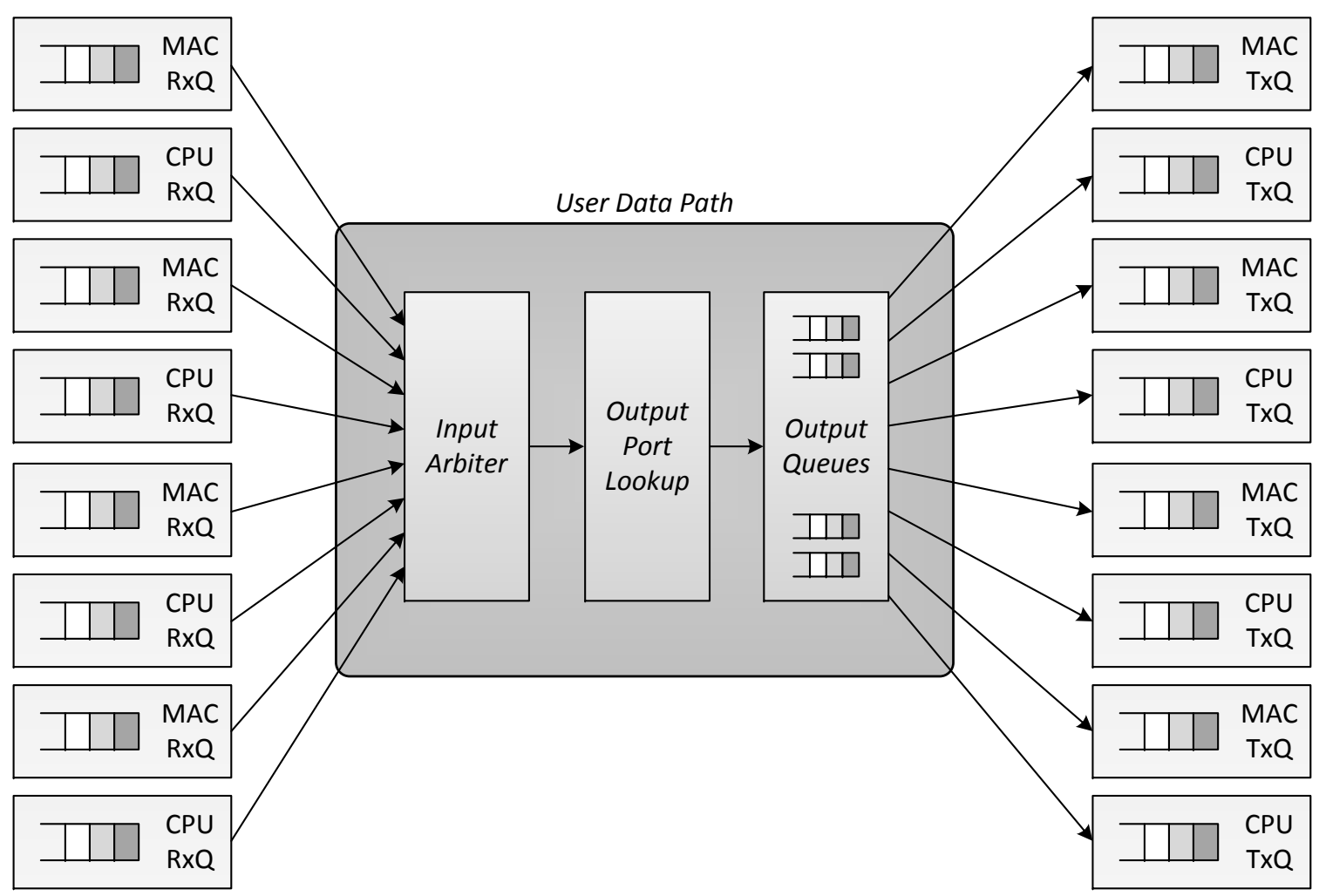

Figura 42: Pipeline de referência

Fonte: Gibb et al. (2008)

Seclen (2011) denomina esta estrutura como a parte operativa, o caminho pelo qual os quadros de dados circulam. Os módulos são descritos como blocos que permitem a configuração da parte operativa e a interação com a CPU (Central Processing Unit) externa.

O primeiro estágio do pipeline consiste em filas, denominadas Rx Queues (fila de entrada), que recebem pacotes de dados das portas de entrada da NetFPGA. Tais pacotes

\footnotetext{
${ }^{4}$ Uma analogia com a canalização que mantém o fluxo de instruções por um processador.
} 
podem ser originados nas interfaces Gibabit Ethernet, identificadas como $M A C R x Q$ ou $C P U R x Q$.

Para o OS (Operating System) pertinente ao computador que recebe a placa NetFPGAV2, as portas Gigabit Ethernet são identificadas conforme explicita a Tabela 17.

Tabela 17: Identificação das portas Gigabit Ethernet no OS

\begin{tabular}{cc}
\hline Porta da NetFPGA & Identificação no OS \\
\hline Porta 0 & nf2c0 \\
Porta 1 & nf2c1 \\
Porta 2 & nf2c2 \\
Porta 3 & nf2c3 \\
\hline
\end{tabular}

Tais portas são conectadas em um invólucro denominado User Data Path, Caminho de Dados, que compreende os módulos de processamento.

No User Data Path o primeiro módulo na passagem dos pacotes é o Input Arbiter, Árbitro de Entrada, que decide qual Rx Queues deve ser encaminhada para o módulo seguinte (Output Port Lookup), baseado em um algoritmo de escalonamento.

O Output Port Lookup, Pesquisador da Porta de Saída, é incumbido de encontrar a porta ou as portas de saída para cada pacote que ingressa na NetFPGA e, se necessário, modificar o pacote. Depois que a decisão é tomada, o pacote é entregue ao módulo Output Queues, Filas de Saída, que armazena o pacote na fila correspondente à porta de saída, 4 filas para as interfaces Ethernet e 4 filas para as interfaces CPU, até que a fila de transmissão (TX Queues) esteja pronta para aceitar o pacote a ser transmitido.

\subsubsection{Troca de Sinais entre os Módulos}

A comunicação entre os módulos do User Data Path utiliza os sinais de interface descritos na Tabela 18.

Observando a Tabela 18 e a Figura 43, que mostram quando um módulo $(i)$ precisa enviar dados para outro módulo $(i+1)$, o módulo $i$ inspeciona o estado do sinal out_rdy (ready), advindo do sinal in_rdy, módulo $i+1$. Se o módulo $i+1$ estiver pronto para receber dados (in_rdy $=1$ ), então, o módulo $i$ ativa o sinal out_wr (write) e envia os dados pelos sinais out_data e out_crtl do módulo $i$. Todos os sinais são síncronos com o sinal de clock, que opera com uma frequência de $125 \mathrm{MHz}$.

Os nomes dos sinais descritos na Tabela 18 e a determinação do tipo, entrada ou saída, são baseados no projeto de referência Reference NIC (NETFPGA, 2016b). Existem outros sinais como, por exemplo, os destinados à interface com o barramento de registradores, além de outros que podem ser criados. 
Tabela 18: Sinais da interface do módulo, com o barramento de pacotes

\begin{tabular}{lcl}
\hline Sinal & Tipo & Descrição \\
\hline out_data [63:0] & Saída & Saída de dados para o barramento de dados \\
out_crtl [7:0] & Saída & Saída de dados para o barramento de controle \\
out_wr & Saída & Sinal de controle para os sinais de saída out_data e out_crtl \\
out_rdy & Entrada & Indica que o módulo $i+1$ pode receber dados \\
in_data [63:0] & Entrada & Entrada de dados para o barramento de dados \\
in_crtl [7:0] & Entrada & Entrada de dados para o barramento de controle \\
in_wr & Entrada & Sinal de controle para os sinais de entrada in_data e in_crtl \\
in_rdy & Saída & O módulo $i+1$ indica ao módulo $i$ que pode receber dados \\
\hline
\end{tabular}

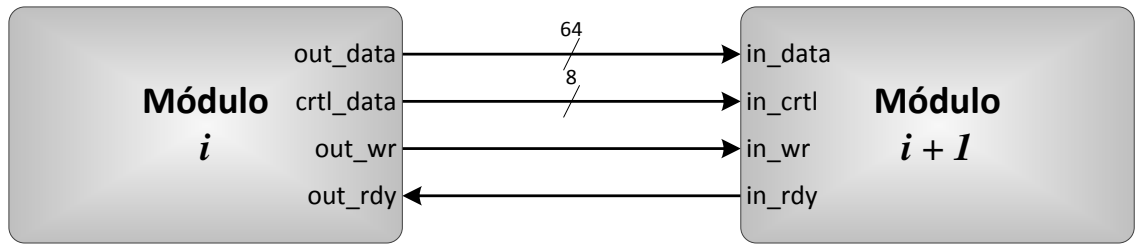

Figura 43: Sinais pertinentes à interface de comunicação entre módulos

\subsubsection{Um Novo Projeto}

Os desenvolvedores que utilizam a plataforma NetFPGA-V2 trabalham com projetos e módulos. Projetos são designs completos, consistindo de componentes de hardware, testes de simulação e regressão ${ }^{5}$ e componentes de software associados (REFORGIATO; BATTAGLIA, 2012). Já os módulos são unidades de hardware reutilizáveis, que podem ser incorporados em diferentes projetos (COVINGTON et al., 2009b).

O componente de hardware para um projeto é tipicamente construído pela interconexão de módulos reutilizáveis, por exemplo, Input Arbiter, Output Port Lookup, Output Queues, e alguns códigos HDL específicos do projeto, conforme exemplifica a Figura 44.

\subsubsection{FIFO}

Diversos módulos, utilizados em projetos da NetFPGA, fazem uso de filas do tipo FIFO (First-In First-Out) como, por exemplo, as denominadas small FIFOs.

Ciletti (1999) explana que um buffer ${ }^{6}$ FIFO é uma memória dedicada a empilhar dados, formada por uma matriz de registradores controlada. É utilizado como uma interface entre uma fonte de dados de alta velocidade e um processador mais lento. O buffer recebe e armazena informações (dados) e, em seguida, fornece estas informações por meio

\footnotetext{
${ }^{5}$ Testes de regressão utilizam o hardware em loop.

${ }^{6} \mathrm{Um}$ espaço de armazenamento.
} 


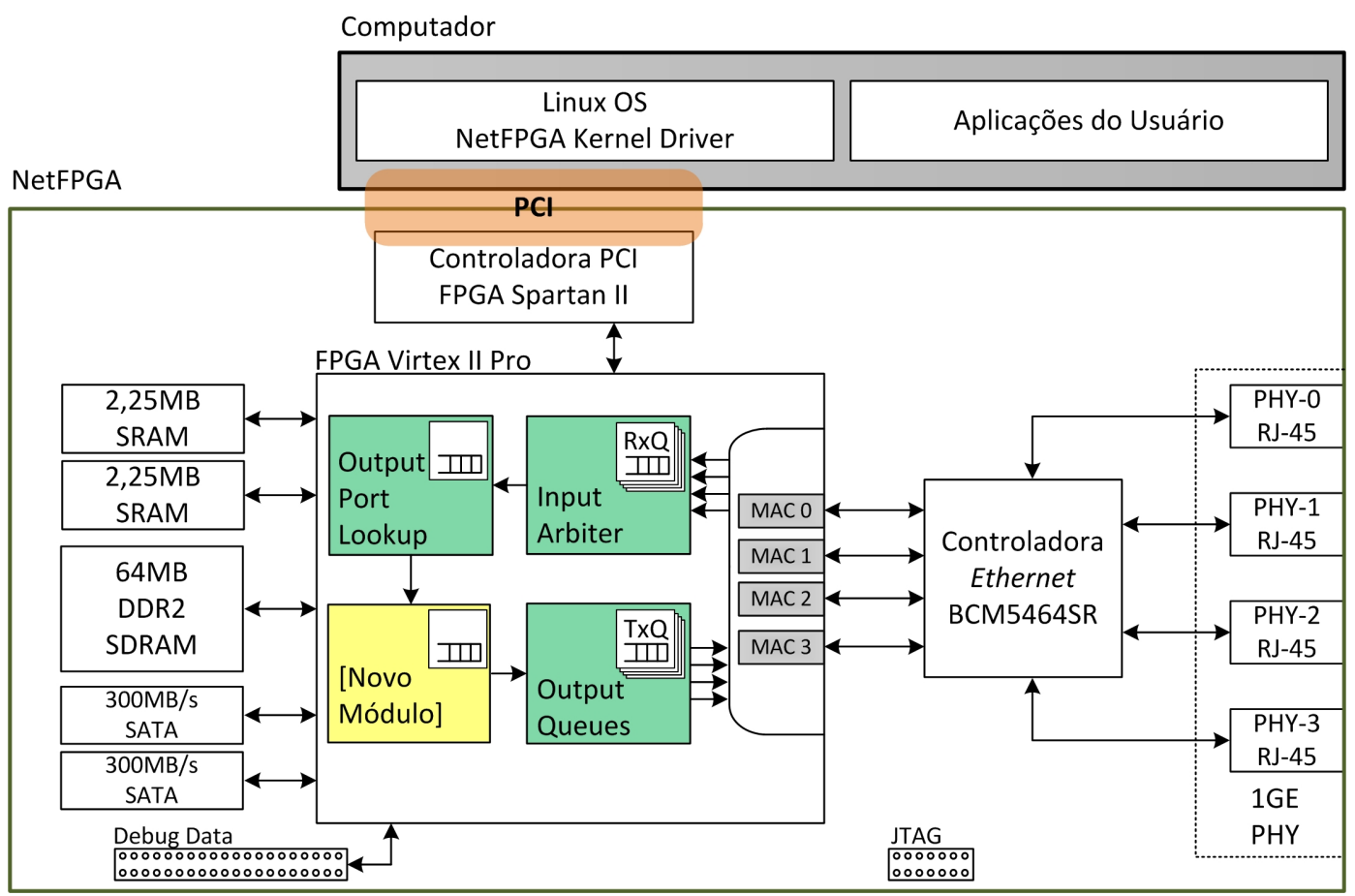

Figura 44: Reutilização de módulos para um projeto

da condução de um controlador. O tamanho da pilha, para uma aplicação específica, é determinado por meio de simulação.

Os registradores da pilha operam de forma síncrona com um (clock) e estão sujeitos a um reset (rst), como mostra a Figura 45. A pilha tem dois ponteiros, endereços, um apontando para a próxima palavra de dados que será escrita, e outro para a próxima que deverá ser lida. A FIFO tem um caminho de dados de entrada e de saída. Três linhas de bit servem como flags para indicar o estado da pilha, quase cheio, cheio e vazio; almost_full, full or empty.

A FIFO escreve a palavra de dados em Data_in para a memória, se a pilha não está cheia, e o sinal write_to_stack é colocado em nível lógico um (1). Ela também executa a leitura de uma palavra na memória, se ela não está vazia, e o sinal read_from_stack é colocodo em nível lógico um (1). A largura e altura da pilha são parametrizadas para estender a utilidade do modelo (Figura 45).

A Figura 46 mostra mais detalhes da pilha. Dois ponteiros, write_ptr e read_ptr, apontam para a célula de memória para a qual os dados serão escritos, e a célula a partir da qual, os dados serão lidos. 


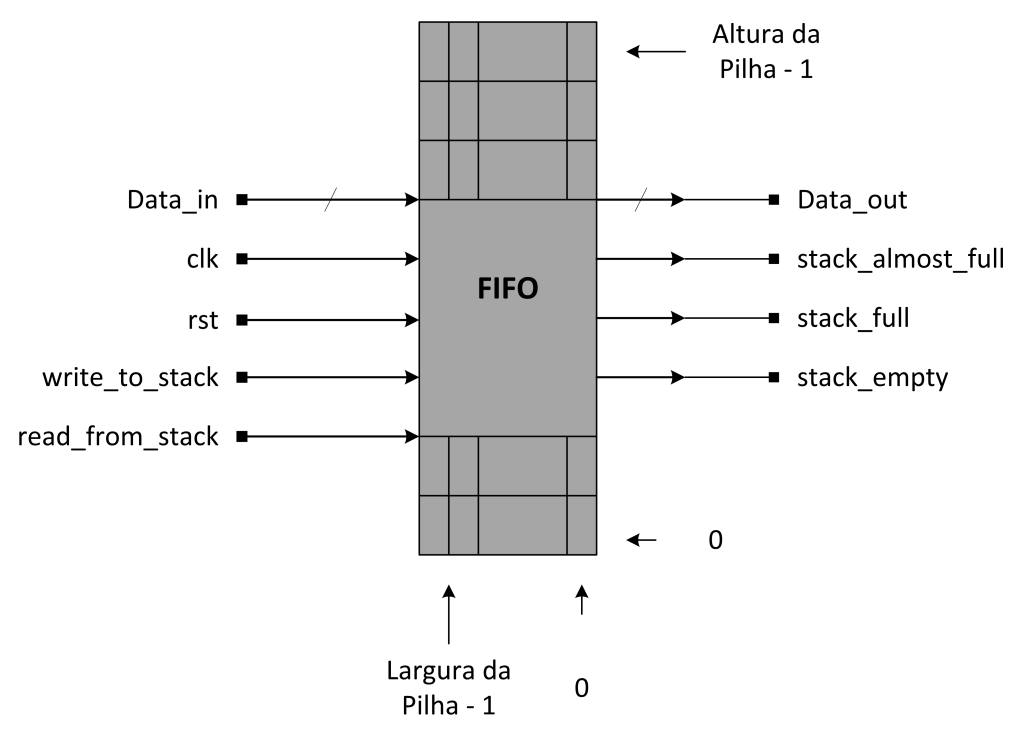

Figura 45: Organização interna de uma FIFO stack

Fonte: Ciletti (1999)

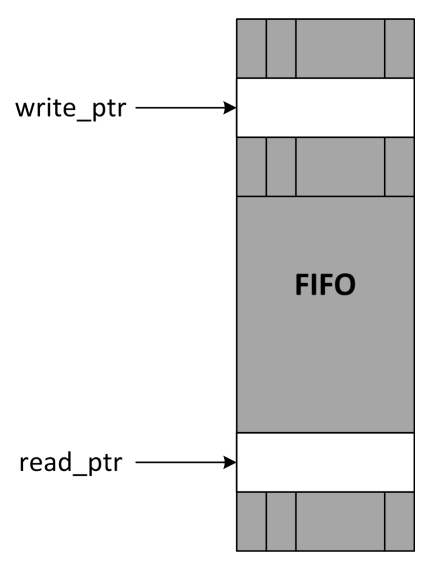

Figura 46: Ponteiros da FIFO

Fonte: Ciletti (1999)

\subsection{O Módulo de Decodificação}

O módulo de decodificação ASN.1/BER GOOSE utiliza o componente de hardware formado pela interconexão dos módulos GFIXED (Message GOOSE Fixed) e GPDU (Protocol Data Unit GOOSE), conforme mostra a Figura 47. Este módulo opera com dois fluxos de bits $^{7}$, distintos em modo simplex:

- Route 1: fluxo entre a Porta 0 e a Porta 1 da NetFPGA ( $\mathrm{P}_{0}$ para $\left.\mathrm{P}_{1}\right)$;

- Route 2: fluxo entre a Porta 1 e a Porta 0 da NetFPGA ( $\mathrm{P}_{1}$ para $\left.\mathrm{P}_{0}\right)$.

\footnotetext{
${ }^{7}$ Sequência de 0s e 1s da mensagem GOOSE.
} 
FPGA Virtex II Pro

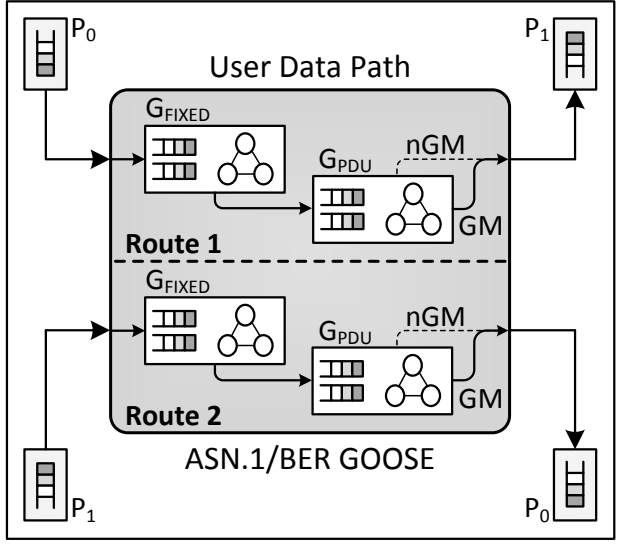

Figura 47: Módulos que compõem o decodificador ASN.1/BER GOOSE

Quando um quadro de dados chega na $\mathrm{P}_{0}$, é direcionado para o módulo GFIXED do Route 1, que tem a função de aquisição e armazenamento dos campos fixos. Posteriomente, o quadro é direcionado ao módulo GPDU, para aquisição e armazenamento dos campos flexíveis. No Route 1, a saída ocorre por meio da $\mathrm{P}_{1}$. Caso o quadro seja uma mensagem GOOSE, com o campo Ethertype igual a 0x88b8, o quadro é encaminhado para a $\mathrm{P}_{1}$ após analise dos campos flexíveis (vide a identificação GM (GOOSE Message), na Figura 47). Se o campo Ethertype for diferente de 0x88b8, o quadro é encaminhado para a saída sem avaliação ou armazenamento dos campos flexíveis, identificação nGM (no GOOSE Message). O mesmo fluxo de dados ocorre entre $\mathrm{P}_{1}$ e $\mathrm{P}_{0}$.

A utilização simultânea dos Routes 1 e 2 permite a interligação de dois segmentos de rede em modo de operação full duplex.

\subsection{O Formato da Mensagem GOOSE dentro do Mó- dulo}

Quando o quadro ISO/IEC 8802-3 ingressa no barramento de dados da NetFPGA-V2, por meio da $\mathrm{P}_{0}$ ou $\mathrm{P}_{1}$, ele passa a ter o formato definido pela plataforma, conforme ilustra a Figura 48(a).

A primeira fatia com 64 bits é um cabeçalho interno da NetFPGA, com as seguintes informações: se o quadro é uma mensagem GOOSE; se o quadro contém dados da VLAN; o tamanho do quadro em words; a porta de origem e o tamanho do quadro em bytes. Para identificação deste cabeçalho são inseridos 8 bits de controle com o valor 0xFF.

Os dados do quadro são identificados com a palavra de controle 0x00, e o fim do quadro é demarcado, designando-se, com um dos bits de controle, a posição do último byte.

Por exemplo, o campo Destination Address está na Fatia 2, entre os bits 16 e 63 (representação: [63:16]). Nesse caso, o byte de controle tem valor igual a 0x00. 


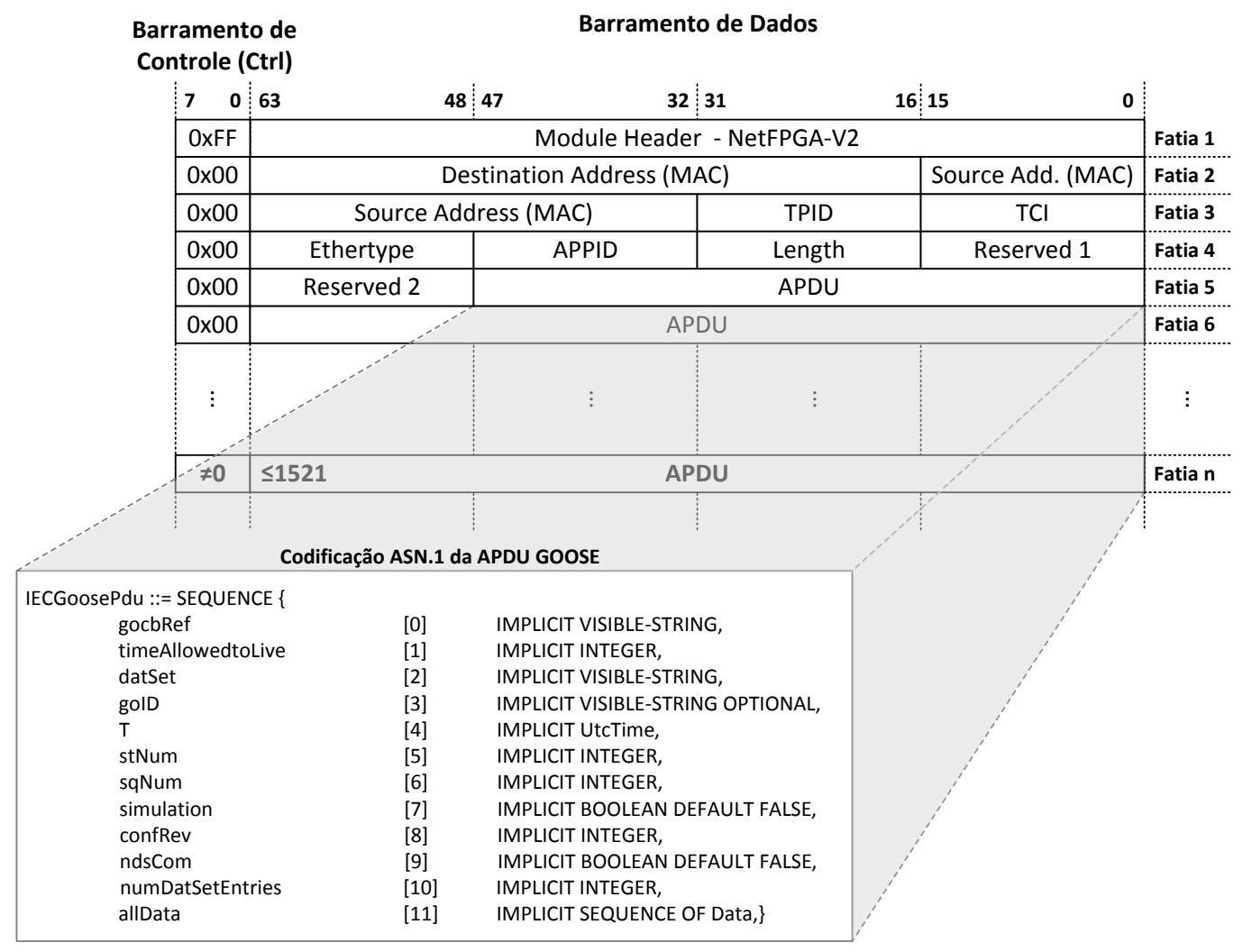

(a)

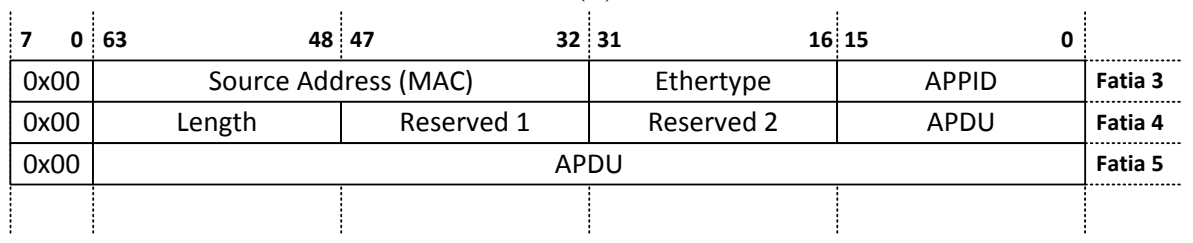

(b)

Figura 48: Formato do quadro ISO/IEC 8802-3 dentro da NetFPGA-V2

É possível visualizar a presença dos demais campos fixos entre as fatias 2 e 5 , caso a mensagem contenha os campos TPID e TCI (Tag Control Information). Ou entre as Fatias 2 e 4, se os campos TPID e TCI estiverem ausentes. Caso a mensagem GOOSE não contenha estes campos, os demais herdam as posições, conforme exemplifica a Figura 48(b).

Também é possível visualizar, na Figura 48(a), a codificação ASN.1 que forma os campos da APDU de uma mensagem GOOSE. Eles estão em ordem, porém a localização binária pode ser alterada, conforme o tamanho dos campos. Os bytes de um campo podem estar em fatias distintas e uma mesma fatia pode conter diversos campos.

\subsection{Modelo do Decodificador}

Para favorecer a localização dos campos flexíveis, os bytes da mensagem GOOSE são reordenados em uma matriz de registradores, que apresentam a mesma quantidade de 
bytes, de forma a padronizar a localização dos campos, conforme ilustra a Figura 49(a).

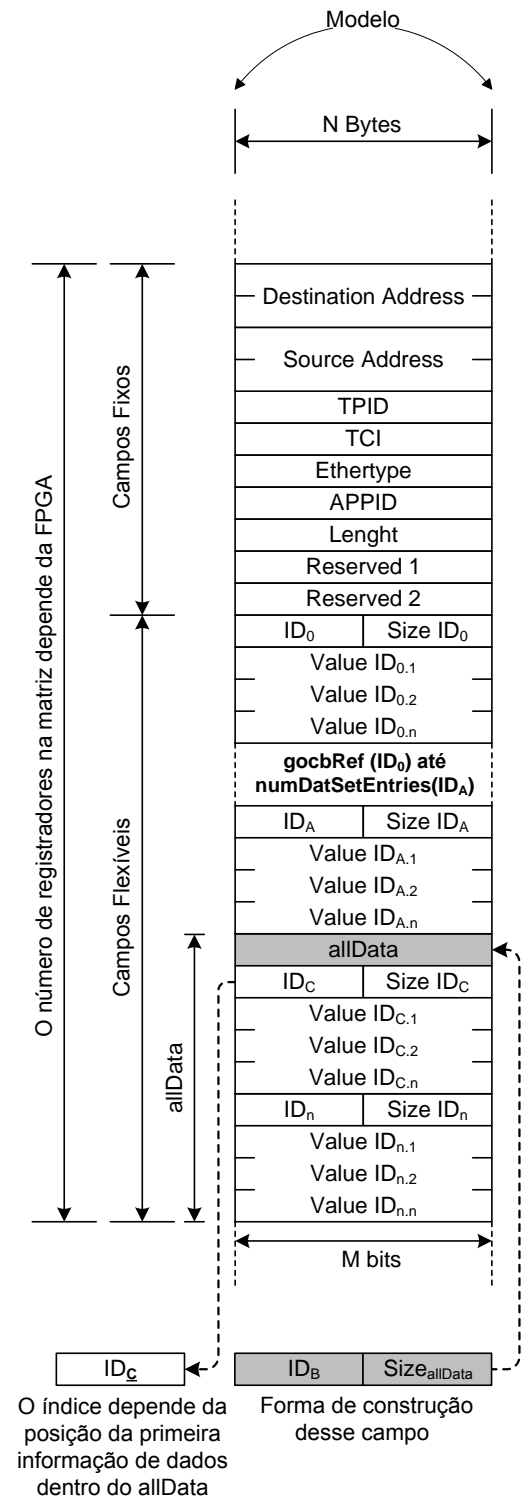

(a)

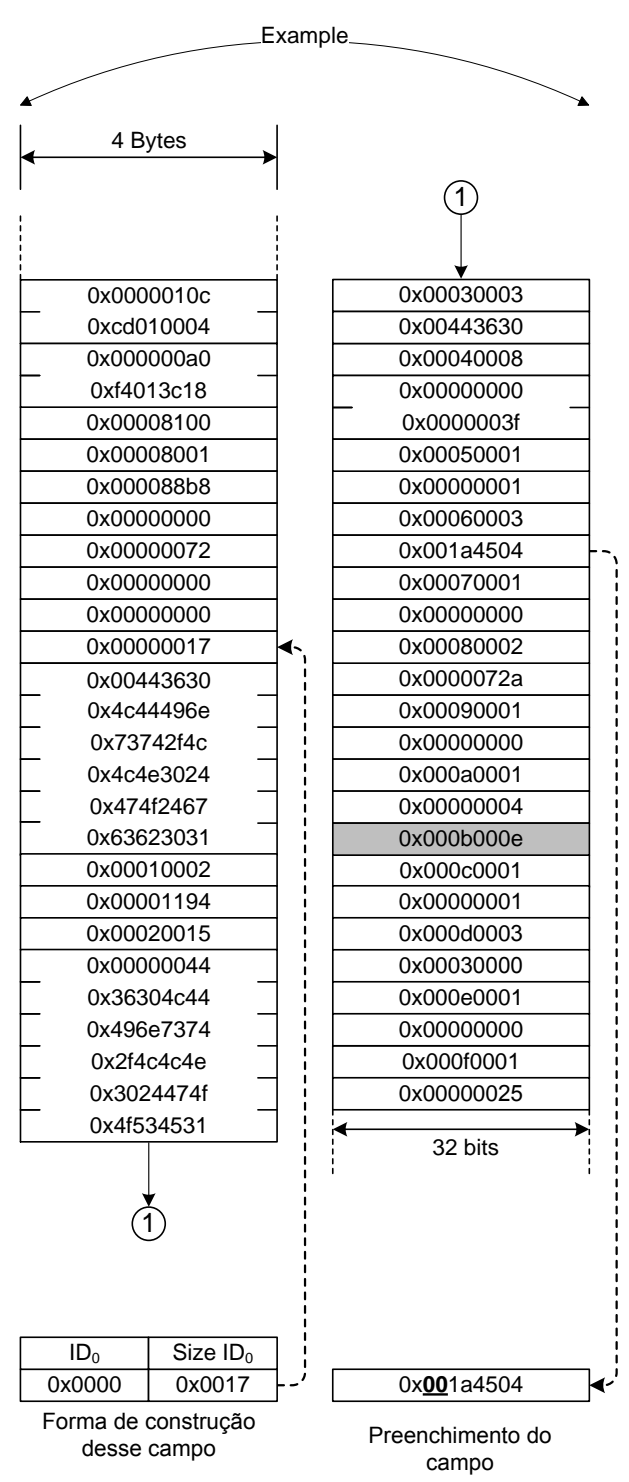

(b)

Figura 49: Modelo e exemplo utilizado para a decodificação

Os primeiros 11 registradores são destinados aos campos fixos (Destination Address até o Reserved 2). Os campos flexíveis (gocbRef até o allData) têm início no $12^{\circ}$ registrador da matriz (ou seja, o $1^{\circ}$ registrador, posição 0, da parte flexível).

No modelo, cada campo flexível é precedido por um registrador que apresenta um identificador (ID) e o seu tamanho (em bytes). Com o número de bytes, é possível determinar o número de registradores necessários para compor o campo, conforme ilustra o Algoritmo 3. Quando não existem bytes suficientes para compor os registradores de um determinado campo, estes são preenchidos com bytes em zero (0).

Após o campo numDatSetEntries, com $\mathrm{ID}_{A}$, o ID 0x000b identifica que o próximo registrador apresenta o ID e o tamanho da primeira informação de dados pertinentes ao campo allData. 


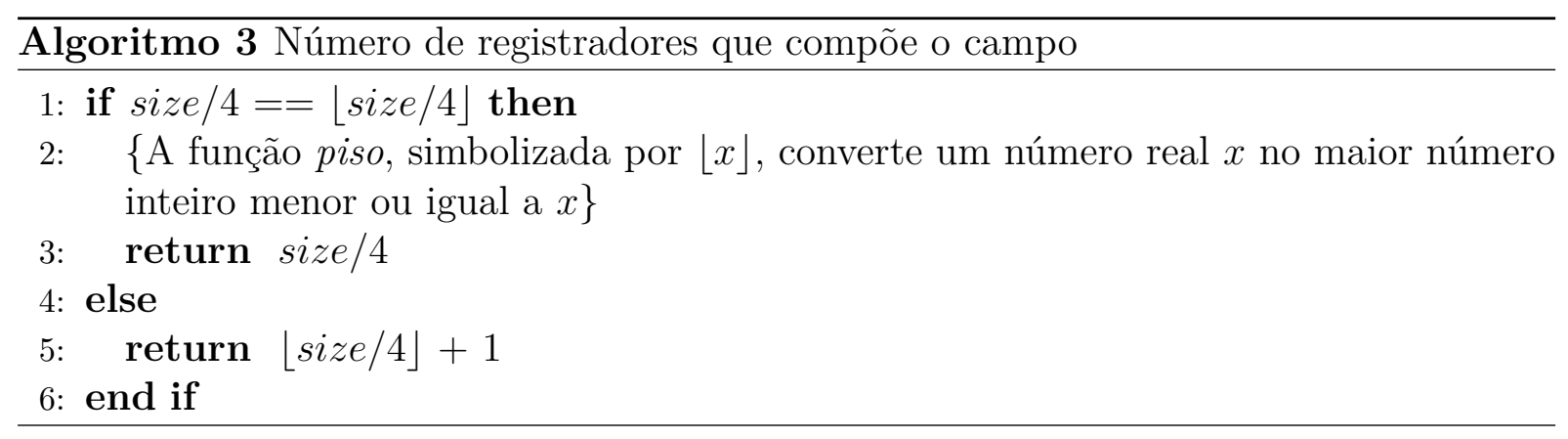

A Figura 49(b) utiliza dados de um IED real para mostrar a formatação completa de uma mensagem GOOSE, com base no modelo proposto. Cabe ressaltar que o número de registradores, que podem ser utilizados na matriz, depende da capacidade lógica da FPGA.

A vantagem da reorganização é que os bytes de um campo não se misturam com outro em um mesmo registrador. Esse processo facilita a utilização de um determinado campo para aplicações em hardware ou software.

Como as mensagens GOOSE apresentam tamanhos distintos, o modelo permite que a função de cada registrador se molde ao tamanho da mensagem. No instante $t_{1}$, um determinado registrador pode estar armazenando bytes do campo datSet e, no instante $t_{2}$, os bytes armazenados podem ser do campo timeAllowtoLive, goID dentre outros.

\subsection{Fluxo de Dados do Modelo}

A troca inteligível de mensagens entre IEDs, utilizando o modelo, exige uma coordenação na troca de dados. A Figura 50 mostra o fluxo de dados de 8 quadros, que são indicados por retângulos inclinados, e a altura do retângulo define a diferença no tempo de transmissão entre o primeiro e o último byte e, por conseguinte, o seu tamanho (ex: 128B, 512B e 1024B). A cor ou o hachurado diferenciam 4 quadros, que representam mensagens GOOSE distintas.

Na Figura 50, o primeiro quadro é recebido na $\mathrm{P}_{0}\left(\right.$ ou $\left.\mathrm{P}_{1}\right)$ - Linha \#1. Depois da serialização dos dados pela fila de entrada, o quadro é encaminhado para o módulo GFIXED e, posteriormente, para o GPDU. Depois de reordenados na matriz de registradores, os dados são encaminhados para a fila de saída e, por conseguinte, para $\mathrm{P}_{1}$ (ou $\left.\mathrm{P}_{0}\right)$.

A chegada do segundo quadro ocorre após o término da decodificação e transmissão do primeiro (Linha \#2). Assim, é possível perceber um intervalo entre o término da transmissão e a recepção do segundo quadro.

O mesmo fluxo de dados ocorre com o segundo quadro, porém não existe o intervalo de tempo entre o segundo e o terceiro (Linha \#3). Entre os quadros 3 e 5, 6 e 8, o intervalo é o menor possível ${ }^{8}$. Como os quadros 3, 4 e 5 têm o mesmo tamanho, o fluxo de dados

\footnotetext{
${ }^{8}$ Para interfaces Gigabit o intervalo é $0,096 \mu$ s - Linha \#4
} 


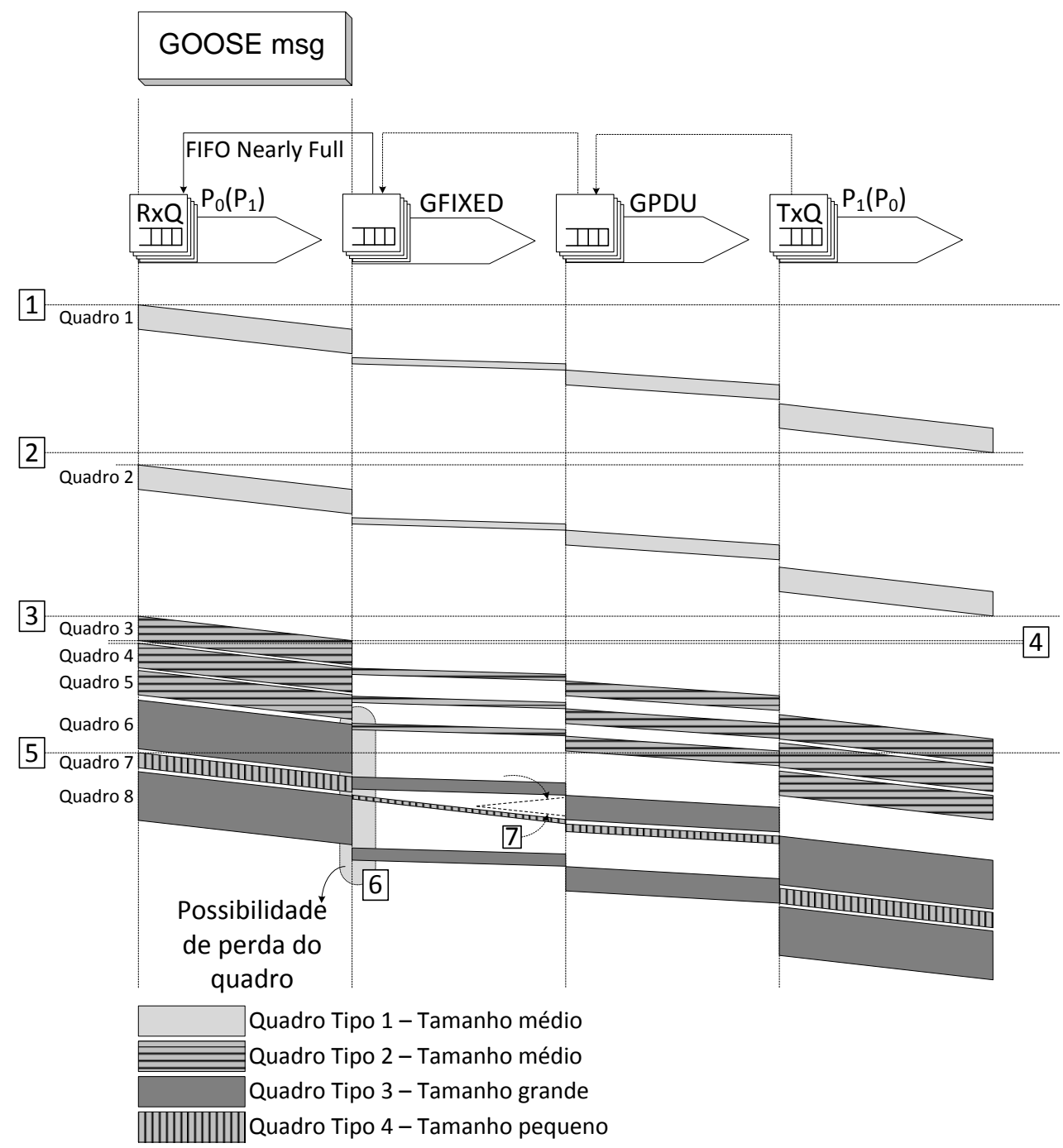

Figura 50: Diagrama do fluxo de dados do modelo

ocorre sem congestionamento.

A possibilidade de quadros serem perdidos ocorre na região \#6, sendo que a fila de entrada tem um poder de armazenamento finito. O padrão IEC 61850 não prevê a retransmissão de quadros perdidos, mas a publicação do mesmo quadro em intervalos discretos. Nesse contexto, o mesmo quadro pode ser recebido em espaço de tempo conciso.

Para que não ocorra a mescla de dados pertinentes a quadros distintos, o módulo GPDU só inicia a decodificação dos campos flexíveis após o processamento do quadro anterior. Isso ocorre entre os quadros 6 e 7 e pode ser observado na região \# ${ }^{\natural}$. Cabe ressaltar que este caso só pode ocorrer no processamento de quadros com tamanhos distintos ( Linha \#5).

O sinal que permitiu o controle deste fluxo de dados foi o FIFO Nearly Full (fornecido pelas FIFOs), que pode ser encaminhado através do módulo $n+1$ para o módulo $n$ da NetFPGA, e permite a interrupção momentaneamente do fluxo de dados entre dois módulos, até que seja possível receber mais quadros. 


\subsection{O Design dos Módulos}

A Figura 51 mostra o design dos módulos GFIXED e GPDU, com a utilização de duas FIFOs, uma FSM (Finite State Machine), registradores e fios para a conexão de sinais.

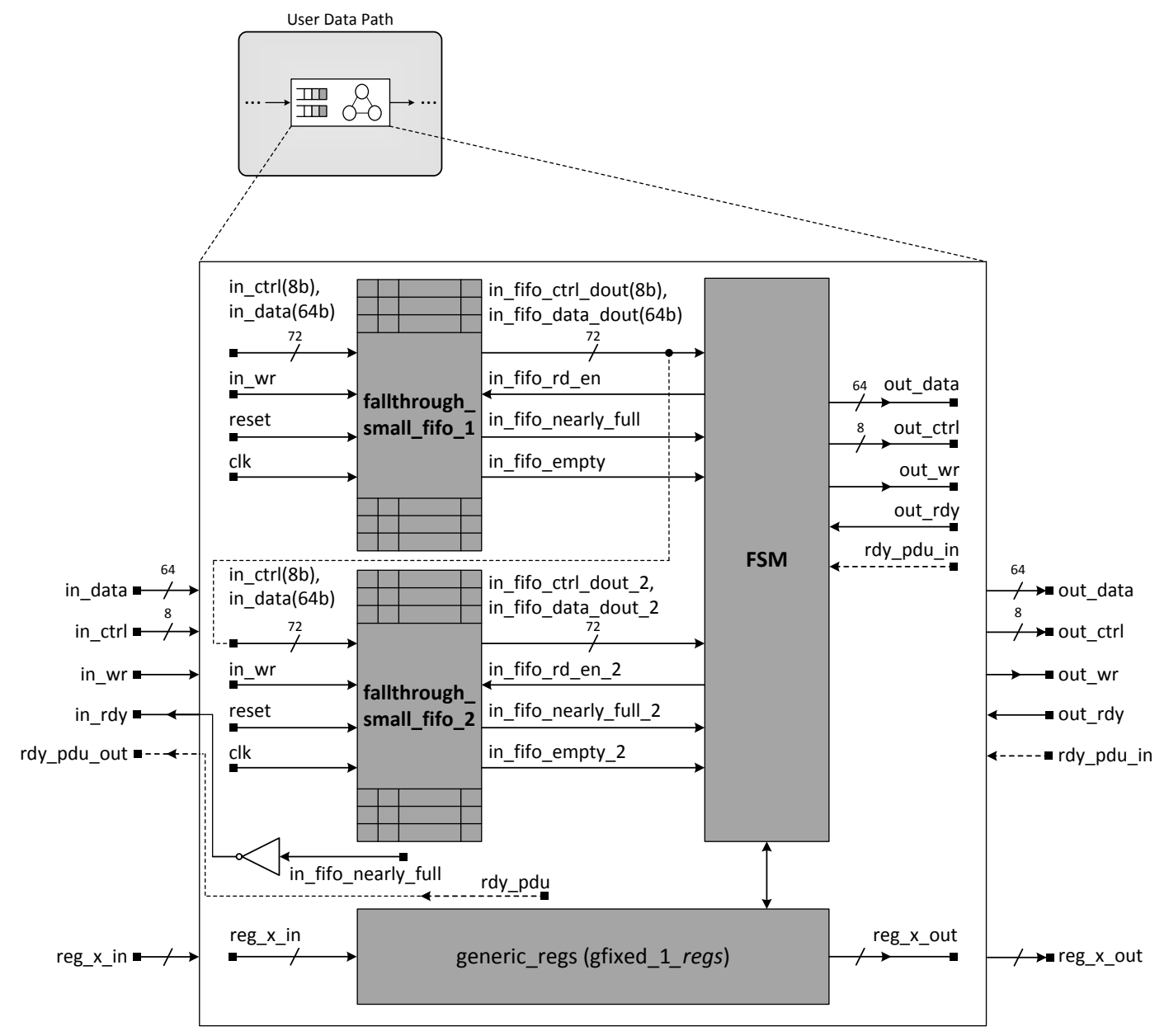

Figura 51: Design dos módulos GFIXED e GPDU (As linhas pontilhadas são exclusivas do módulo GPDU)

No GFIXED, a primeira FIFO tem uma profundidade de 14 bits por 72 bits de largura (64 bits do barramento de dados e 8 bits do barramento de controle), a segunda FIFO tem profundidade de 3 bits por 72 bits de largura. No GPDU, as profundidades são de 8 bits. Enquanto a $\mathrm{FIFO}_{1}$ é utilizada para armazenar as fatias que serão decodificadas, a $\mathrm{FIFO}_{2}$ executa o controle para envio do quadro para o próximo módulo.

\subsubsection{A FSM do Módulo GFIXED}

A FSM, pertinente à Figura 52, apresenta quatro estados e define a operação do módulo GFIXED:

- O estado inicial DA $\mathbf{A}_{s a}$ torna-se ativo quando a placa NetFPGA-V2 é energizada e, posteriormente, o sinal reset adquire nível lógico zero (0). A função deste estado é 


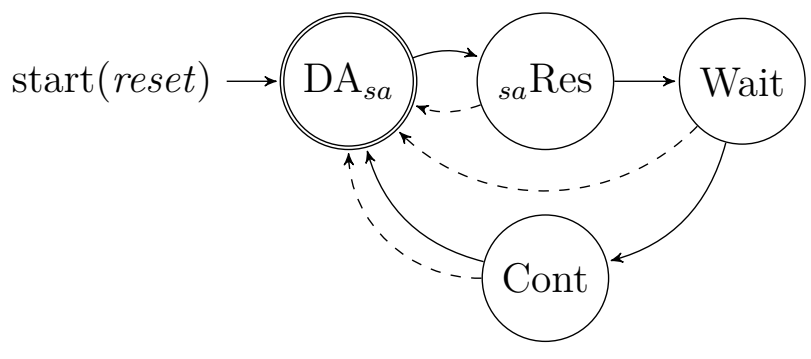

-- reset

Figura 52: FSM do módulo goose_fixed

inicializar alguns dos registradores presentes no módulo, efetuar a captura do campo Destination Address e dois bytes do campo Source Address, caso a fila não esteja vazia e o controle seja $0 \mathrm{x} 00$;

- O estado ${ }_{s a}$ Res finaliza a captura do campo Source Address. Em seguida, ocorre a busca pelos campos TPID e TCI e, caso eles estejam presentes na mensagem GOOSE, os valores são capturados e inicia-se o rastreio pelos campos Ethertype, APPID, Lenght, Reserved 1 e Reserved 2. Se não forem encontrados os campos TPID e TCI, será atribuído valor zero (0) aos registradores de armazenamento deles, e a busca pelos demais campos fixos prossegue;

- O estado Wait é responsável por efetuar um atraso no processamento para atualização dos registradores;

- Posteriormente, o estado Cont, Continue, atualiza a primeira fatia (cabeçalho da NetFPGA, controle 0xFF), indicando, por meio dos bits [59:56], se o quadro tem os campos TPID e TCI:

- Valor 0x0f, se os campos estiverem presentes no quadro;

- Valor 0x00, em caso contrário.

- Se o quadro é uma mensagem GOOSE, os bits [63:60] da primeira fatia recebem o valor 0x00 e caso contrário, o valor 0x0f. O estado Cont também identifica o fim do quadro, encaminha as fatias do quadro atual para o módulo GPDU e retoma o estado $\mathbf{D} \mathbf{A}_{s a}$, quando o valor do controle for diferente de 0x00 e 0xFF.

De acordo com a Figura 53, após a FSM concretizar cada iteração os campos fixos do quadro ficam disponíveis em registradores de 32 bits $^{9}$, que podem ser utilizados via software ou hardware: DA_01, DA_02, SA_01, SA_02, TPID, TCI, Ethertype, APPID, Reserved_1 e Reserved_2.

\footnotetext{
${ }^{9}$ Os campos que utilizam mais de 32 bits foram divididos em dois registradores: \#_01 (os bytes mais significativos) e \#_02 (os bytes menos significativos).
} 


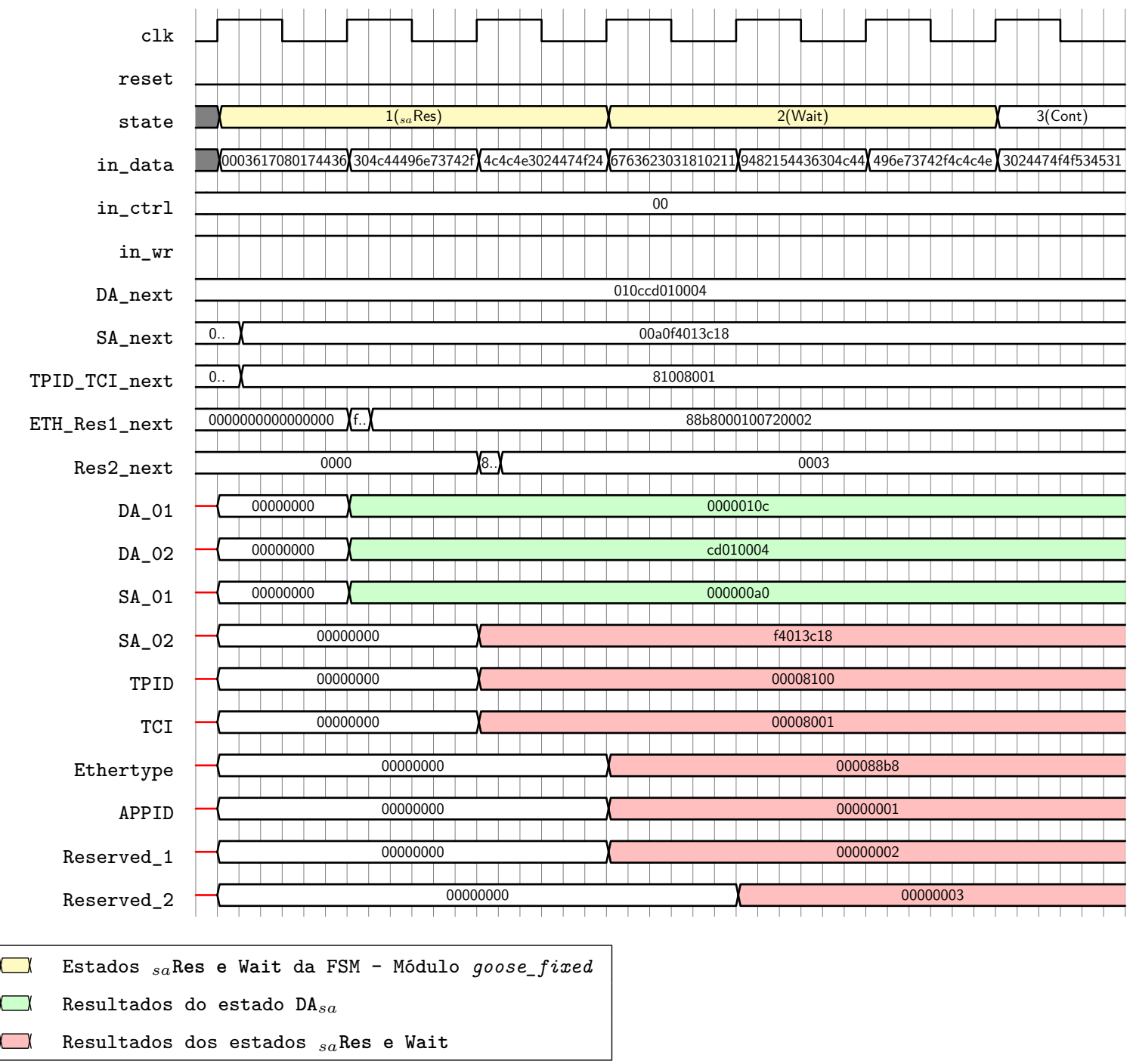

Figura 53: Simulação de captura dos campos Destination Address até o Reserved 2, para a mensagem GOOSE que compõe a Figura 49(b)

\subsubsection{A FSM do Módulo GPDU}

Com os campos fixos capturados, o quadro passa para o módulo GPDU, que apresenta uma FSM com nove estados, conforme ilustra a Figura 54:

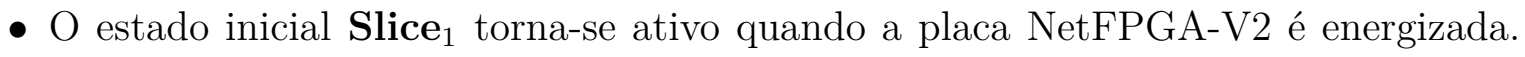
A função deste estado é verificar na primeira fatia, com o byte de controle igual a 0xFF, se o quadro possui os campos TPID e TCI enviados pelo módulo GFIXED; se o quadro é pertinente a uma mensagem GOOSE. O referido estado também tem a função de inicializar diversos registradores, inclusive a matriz. Caso o quadro não seja uma mensagem GOOSE, a FSM é direcionada para o estado Send, responsável por transmitir o quadro para a porta de saída;

- O tamanho (em bytes) dos campos que formam a APDU de uma mensagem GOOSE, sem os campos TPID e TCI, é armazenado pelo estado $\mathbf{P D U} \mathbf{U}_{1}$; 
- O tamanho (em bytes) dos campos que formam a APDU de uma mensagem GOOSE, com os campos TPID e TCI, é armazenado pelo estado $\mathbf{P D U}_{2}$;

- A reordenação dos campos flexíveis, Figura 49(a), é executada pelo estado Fields, que utiliza funções auxiliares pertinentes aos estados Swap, Clear, Data e Cont;

- O estado de Swap auxilia o estado Fields com deslocamentos e alocação de um byte no registrador que atualiza a matriz;

- O estado Clear atualiza alguns sinais de controle;

- Para pular as informações de identificação e de tamanho para os tipos a1 (array) e a2 (structure) da ASN.1, é utilizado o estado Data;

- Se o contador de campos já apresenta o tamanho da matriz ou se todos os campos já foram avaliados, o estado Cont (Continue) é utilizado para repassar as fatias;

- O estado Send, por sua vez, é responsável pelo envio do quadro, seja de uma mensagem GOOSE encaminhada por meio do estado Cont, ou não GOOSE por meio do estado Slice 1 .

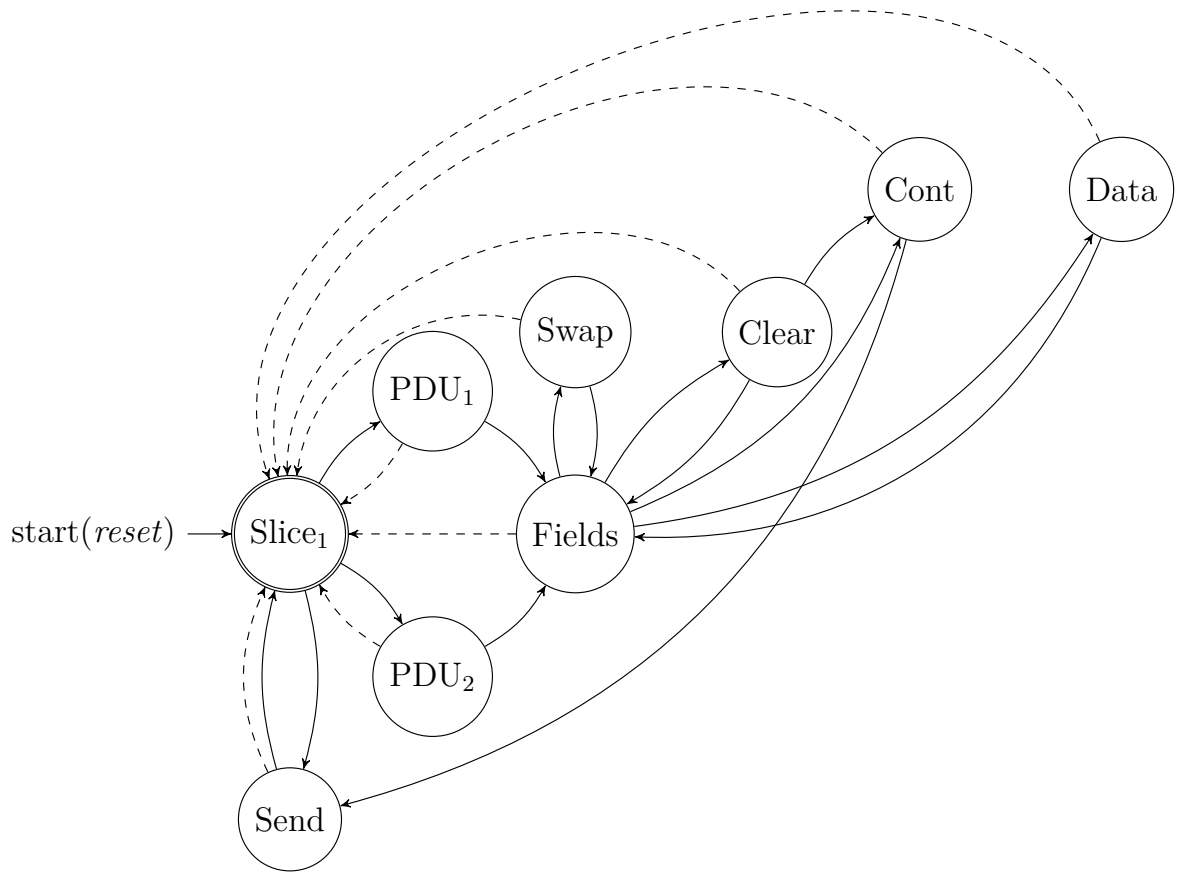

- - reset

Figura 54: FSM do módulo goose_PDU 


\subsubsection{Captura do Campo gocbRef}

Nesta subseção, será descrita a captura do campo flexível gocbRef, como forma de sumarizar o funcionamento da FSM. A Figura 55 ilustra o processo de captura do campo.

Considerando que os campos flexíveis já foram capturados, o registrador de trabalho getALL recebe o valor 0x6170801744360000. Na sequência, desloca-se o byte com o tipo ASN.1 0x61 que identifica o início dos campos flexíveis, ou seja, o começo da PDU GOOSE.

Após o deslocamento do identificador de tipo, o primeiro byte do registrador getALL passa a ser o tamanho do campo que, neste caso, utiliza a forma curta de codificação, apenas 1 byte. O tamanho é armazenado e, posteriormente, deslocado.

$\mathrm{O}$ valor do primeiro byte do registrador get $A L L$ é atualizado para 0x80, que representa o campo gocbRef. O identificador de tipo é deslocado e o tamanho deste campo, além de ser armazenado e deslocado, é utilizado como o tamanho do primeiro campo da PDU GOOSE, dentro da matriz.

Cabe ressaltar que o estado Clear, não identificado na Figura 55, é acionado para verificar se a matriz ainda tem espaço para armazenamento de dados, e para se certificar de que a PDU GOOSE ainda não foi totalmente analisada. Retornando ao estado Fields, o valor do registrador $f$ field é utilizado para preencher a matriz com a identificação e o tamanho do campo gocbRef.

- $\mathrm{ID}_{0}=f$ field $[31: 16]$, neste caso: $\mathrm{ID}_{0}=0 \mathrm{x} 0000$;

- Tamanho $\mathrm{ID}_{0}=f$ field $[15: 0]$, neste caso: Tamanho $\mathrm{ID}_{0}=0 \mathrm{x} 0017$.

O primeiro byte de informação do campo gocbRef (0x44) é capturado e, posteriormente, irá compor o próximo trecho da matriz com o último byte da fatia em avaliação $(0 \times 36)$.

Após o exame completo do registrador get $A L L$, é necessário efetuar uma nova leitura da FIFO para dar prosseguimento ao processo de captura do quadro. Cabe ressaltar que, a cada 4 bytes capturados, uma nova fatia da matriz é inicializada. Isso é necessário para que as informações não sejam sobrescritas. O procedimento de captura prossegue até que todos os bytes do campo tenham sido analisados.

A forma de captura do campo gocbRef é a mesma utilizada para os demais campos da PDU GOOSE.

\subsubsection{Captura do Campo allData}

A análise da estrutura allData tem início quando o primeiro byte do registrador getALL detém o identificador de tipo 0xab.

- $\mathrm{ID}_{B}=0 \mathrm{x} 000 \mathrm{~b}$ 
- Tamanho $\mathrm{ID}_{B}=$ size_field, neste caso: Tamanho $\mathrm{ID}_{B}=0 \mathrm{x} 000 \mathrm{e}$.

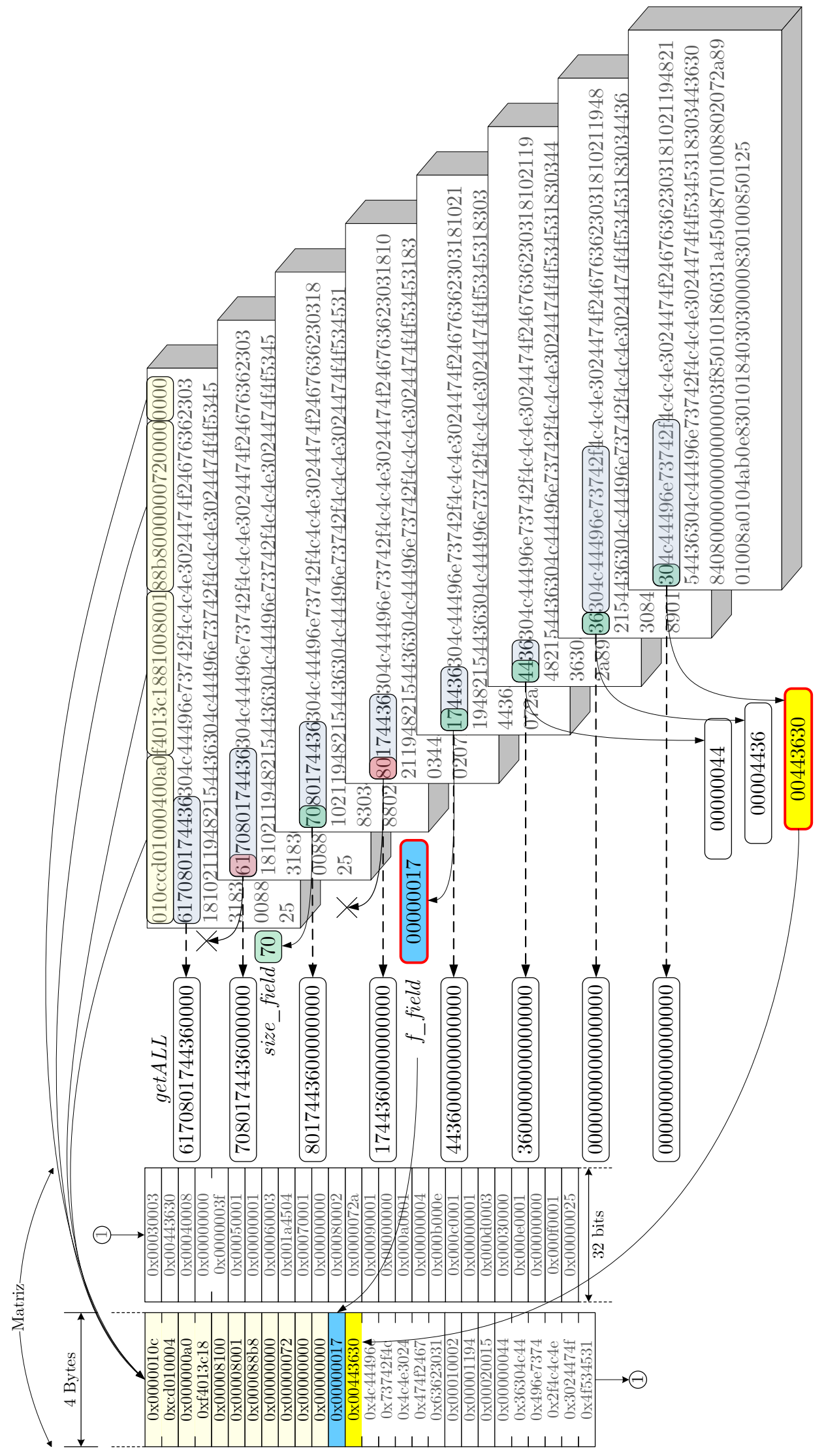

Figura 55: Exemplo da captura de um trecho do campo flexível gocbRef 
A forma de captura do campo allData é a mesma utilizada pelo campo gocbRef, porém, faz-se necessário eliminar os tipos de dados identificados com as tags a1 (array) e a2(structure), descritos na MMS (ZURAWSKI, 2014) e utilizados na composição do campo de dados da mensagem GOOSE.

\subsubsection{Leitura de Dados da Matriz}

Com os valores de cada campo flexível da mensagem GOOSE, alocados na matriz, e com os valores dos campos fixos em registradores individuais, torna-se possível o desenvolvimento de aplicações de supervisão e controle da mensagem.

Uma opção para a leitura dos valores armazenados na matriz é a correspondência direta entre registradores, como ocorre com os valores fixos, disponibilizando o valor de cada posição para um registrador específico, que possa ser lido via software ou hardware.

Embora esta alternativa possibilite a leitura de mais informações de forma simultânea, a ocupação lógica da FPGA é penalizada.

Nesta circunstância, pode-se optar por uma comunicação serial, para a leitura de informações que formam a matriz, conforme a Figura 56.

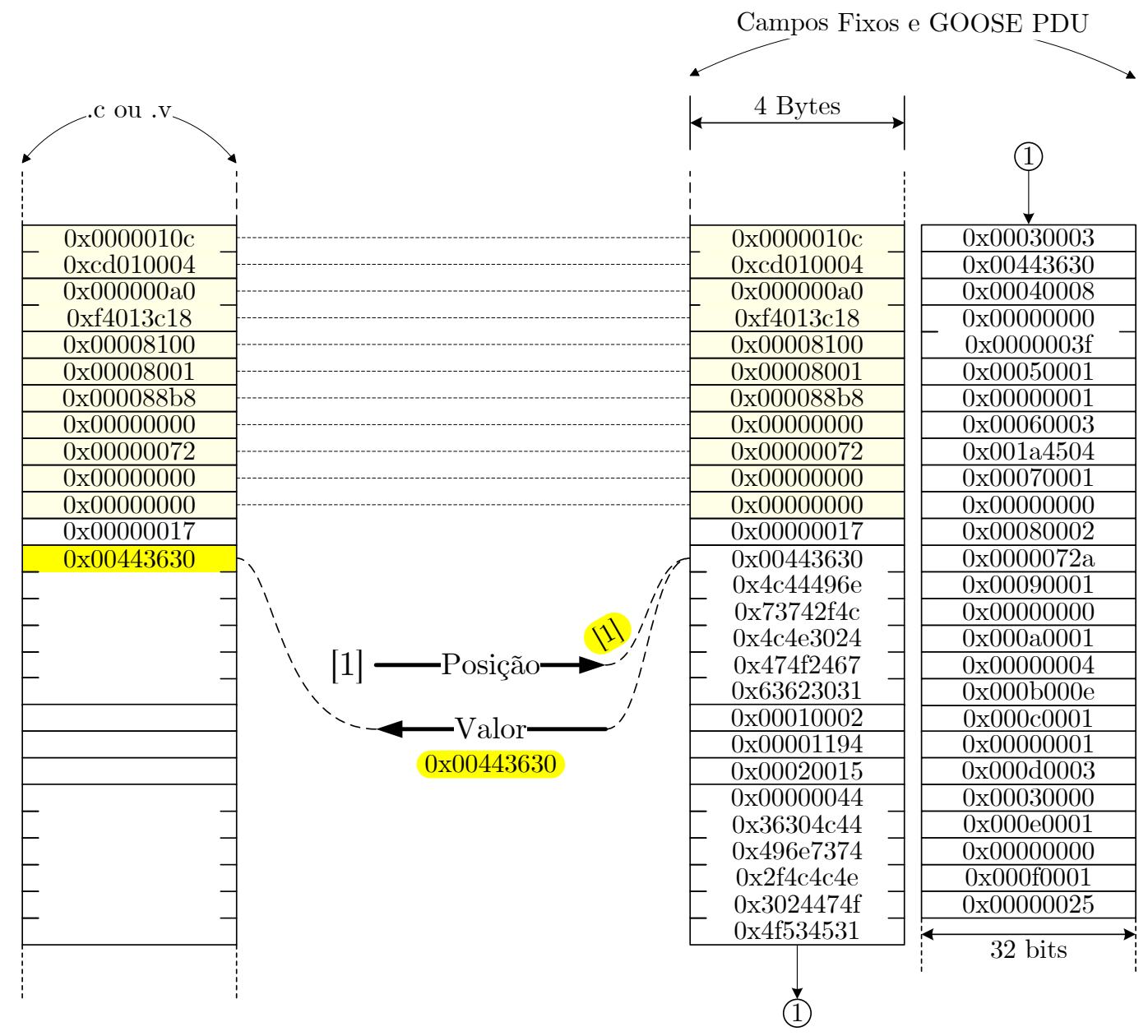

Figura 56: Leitura dos campos da matriz 
Na leitura serial, um aplicativo em software ou uma solicitação de sinal em hardware envia uma posição, que deve ser lida, e a matriz de campos flexíveis retorna o valor da mesma. Utilizando um laço de repetição é possível ler todos os pontos da matriz.

A frequência de aquisição será dependente da interface entre o computador hospedeiro e a NetFPGA, no caso de uma leitura via software ou do clock utilizado pelo hardware (caso a solicitação seja de um módulo adjacente).

\subsection{Ocupação do Hardware - Módulo ASN.1/BER GOOSE}

A Figura 57 explicita informações do chip FPGA Virtex II PRO e um sumário de utilização e distribuição lógica do design. Observando a ocupação do hardware e presumindo a incorporação futura de um módulo para controle das mensagens GOOSE, que se beneficie da matriz fornecida pelo módulo decodificador ASN.1/BER GOOSE, o número de registradores para armazenar o campo allData foi limitado em 130.

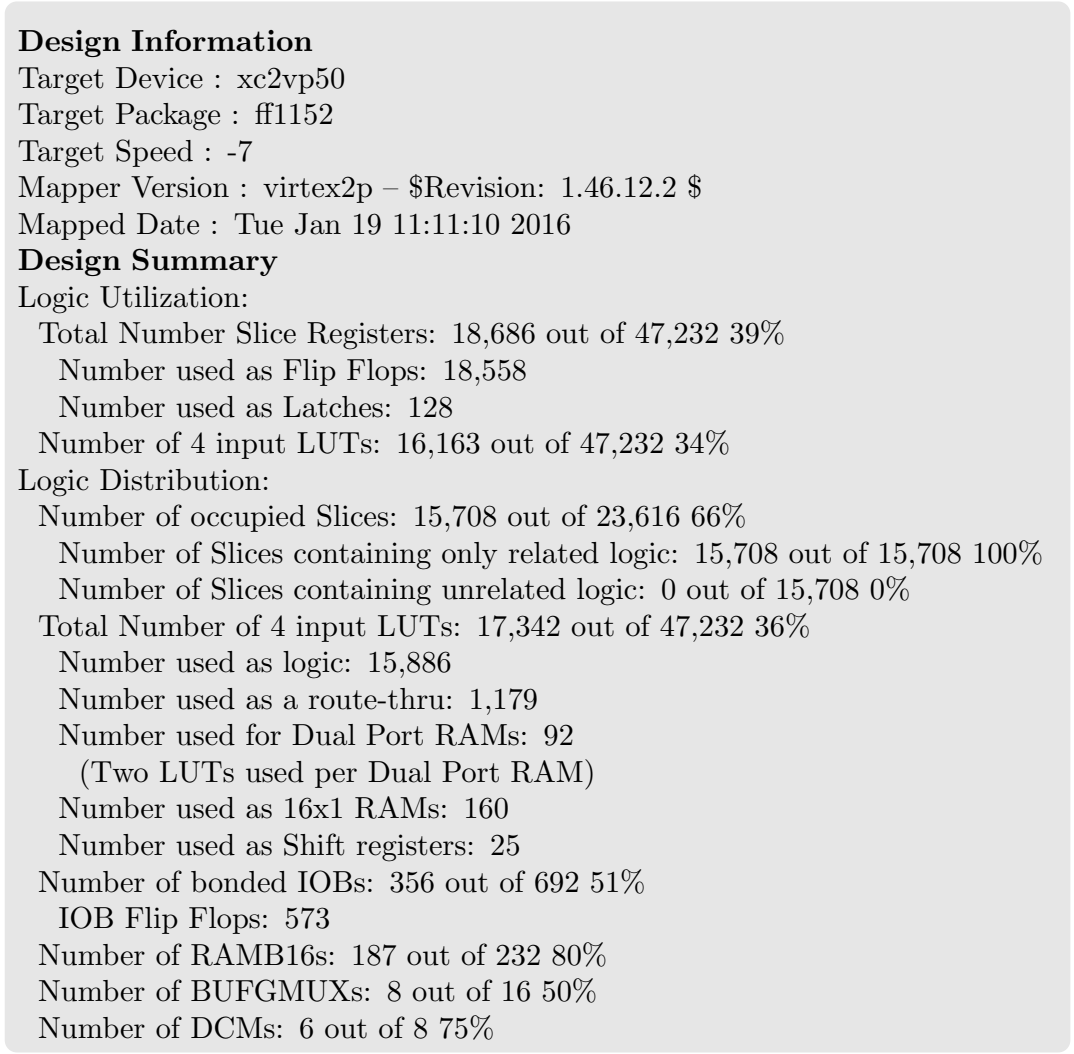

Figura 57: Sumário de utilização e distribuição lógica do design - Projeto ASN.1/BER GOOSE (Route 1 e 2)

Os percentuais de Slices, Flip-Flops e LUTs (Look-up Table) utilizados pelos módulos GFIXED e GPDU, em relação ao total utilizado no design do módulo, podem ser observados na Figura 57. 


\subsection{Sistema de Ensaio ASN.1/BER GOOSE}

A Figura 58 sintetiza os componentes de hardware e software utilizados para validar a decodificação das mensagens GOOSE. Foi utilizado um computador do tipo IBM/PC com uma placa de rede Dual Port Gigabit, duas placas NetFPGA-V2, cabos do tipo par trançado Cat. 6 e componentes de software que foram desenvolvidos ou utilizados para:

- Gerar mensagens GOOSE aleatórias;

- Verificar se as mensagens percorrem o caminho de dados;

- Validar as mensagens GOOSE capturadas pela NetFPGA;

- Replicar as mensagens em tempo real; e

- Verificar o número de quadros que foram perdidos.

Para análise dos sinais e medição dos tempos de processamento, foi utilizado um osciloscópio com 16 canais digitais. A Figura 59 mostra os dispositivos reais utilizados para os ensaios.

\subsubsection{Softwares Utilizados pelo ASN.1/BER GOOSE}

Nesta subseção, serão descritos o conjunto de softwares implementados e um dos aplicativos escolhidos para a validação e teste de desempenho do módulo.

RGGM-61850 O RGGM é um gerador de mensagens GOOSE, detalhado no Capítulo 2 .

DBM-61850 O DBM (Debugger of the Message) é um script, com base no Scapy, que foi elaborado para identificar as mensagens GOOSE que não conseguiam transpor o módulo ASN.1/BER GOOSE. O DBM envia o bitfile para configurar a plataforma NetFPGA, verifica em uma lista o quadro que deve ser transmitido, envia-o por meio de uma das interfaces de rede da placa Dual Port Gigabit, e verifica se ele retornou. São gerados três arquivos de log: quadros que transpassaram pelo módulo; quadros que foram perdidos; quadros não GOOSE.

Caso o quadro não seja recebido após algumas tentativas, o bitfile é reenviado antes da transmissão de um novo quadro. O DBM ajudou a depurar o módulo ASN.1/BER GOOSE durante a fase de desenvolvimento. Cabe ressaltar que o aplicativo não verifica se os campos da mensagem GOOSE foram capturados corretamente. 


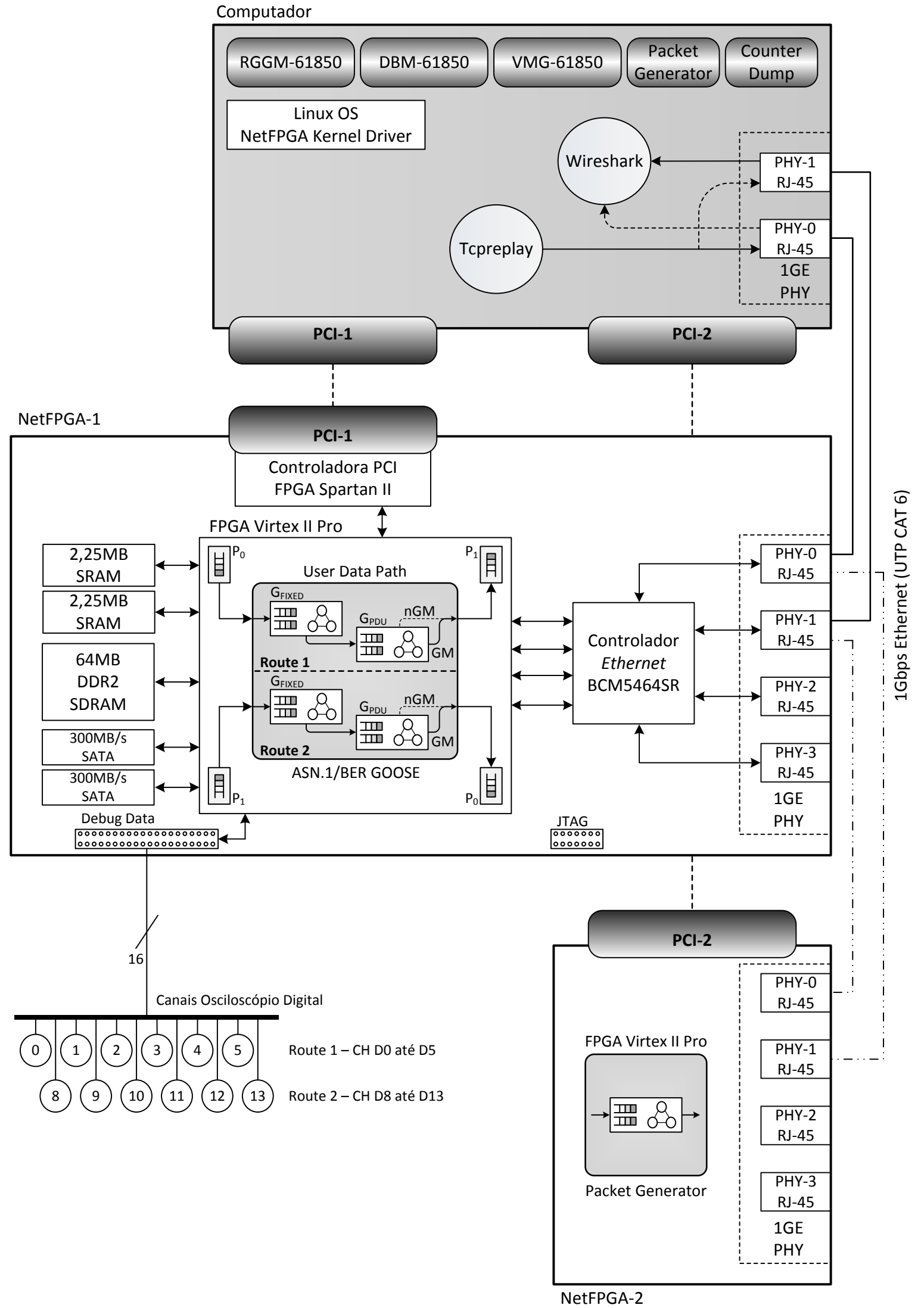

Figura 58: Topologia de ensaio - Estrutura laboratorial 


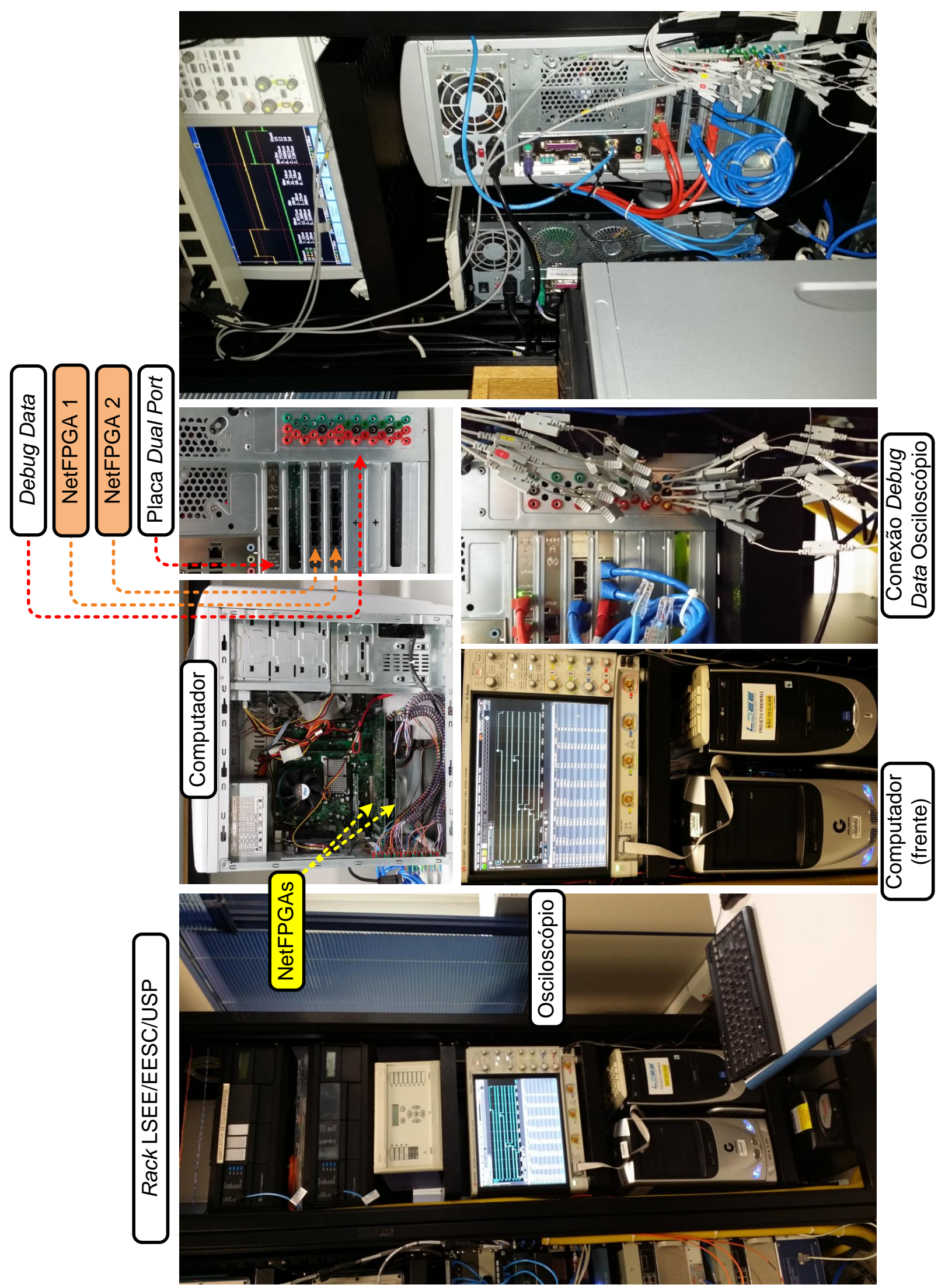

Figura 59: Dispositivos reais da topologia de ensaio - LSEE/EESC/USP (\#1) 
VMG-61850 Com o objetivo de validar as mensagens GOOSE capturadas pelo módulo ASN.1/BER GOOSE, o VMG (Validator GOOSE Messages) é um software que foi desenvolvido em linguagem Java para permitir: a transmissão de mensagens GOOSE; a leitura dos campos pertencentes aos quadros transmitidos e recebidos via interface de rede e, também, a matriz de registradores gerada na plataforma NetFPGA (Figura 49); a comparação dos campos dos quadros transmitidos, recebidos e capturados pela NetFPGA.

O VMG é composto de duas interfaces (Figura 60):

- NetFPGA: permite ao usuário configurar informações para o acesso à placa NetFPGA; o repasse de arquivos (.txt) com a lista de quadros que serão transmitidos e dos registradores utilizados na captura dos campos; a seleção do caminho de dados (Route 1 e/ou Route 2); a interface de rede para transmissão dos quadros; o início da transmissão; o monitoramento do percentual de mensagens transmitidas; e a geração de arquivos .xml com o detalhamento dos quadros.

- Validação: este modo permite carregar os arquivos .xml com todos os quadros transmitidos, recebidos e capturados pela NetFPGA; a configuração do número total de registradores utilizados na matriz (pertinentes a GPDU); e a comparação entre os campos dos quadros transmitidos, recebidos e capturados pela NetFPGA.

O VMG gera uma tela com o detalhamento de todos os quadros e informa se cada campo capturado pelo módulo ASN.1/BER GOOSE corresponde ao da mensagem original. Um arquivo de $\log$ detalha as informações, como, por exemplo, o número total de quadros comparados, quadros e campos corretos/incorretos.

Packet Generator Este projeto foi disponibilizado pelos desenvolvedores da plataforma NetFPGA, e dispõe de um mecanismo de playback - uma sequência de quadros Ethernet podem ser carregados a partir de um arquivo .pcap e, posteriormente, transmitidos. Por meio de um script em Perl é possível verificar o número de quadros e bytes transmitidos, o tempo entre o primeiro e o último bit de dados recebido, e a taxa de transmissão em Mega bits por segundo. Essas informações foram utilizadas para verificar a performance do módulo ASN.1/BER GOOSE. Utilizando o Packet Generator, é possível garantir que o atraso entre quadros e a taxa de envio seja a mesma cada vez que um experimento é executado (COVINGTON et al., 2009a).

Counter Dump É um script em linguagem C que permite a verificação do número de pacotes e bytes, transmitidos e recebidos, e o número de pacotes perdidos em cada interface da NetFPGA. 


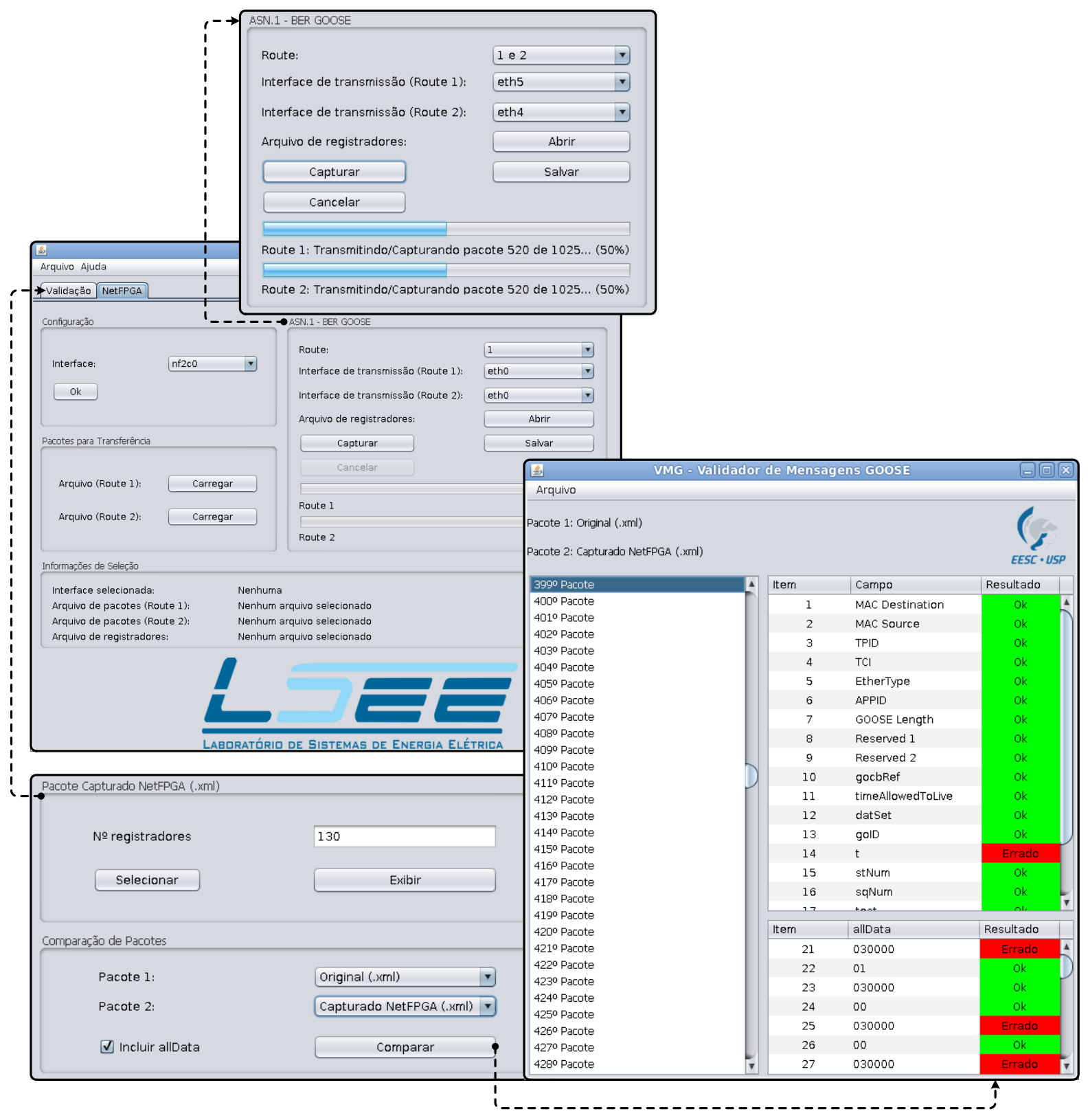

Figura 60: Trechos das telas do VMG

\subsubsection{Ensaios Realizados ASN.1/BER GOOSE}

Considerando que cada interface da placa de rede Dual Port Gigabit (Figura 58) representa um IED do SEP, que transmite e recebe mensagens GOOSE representativas de uma situação de proteção do sistema elétrico, o módulo ASN.1/BER GOOSE foi utilizado para decodificá-las.

Para garantir que o módulo capture e disponibilize de forma correta os campos de qualquer mensagem GOOSE, foram gerados por meio do RGGM 10 conjuntos de testes com 10.000 mensagens aleatórias em cada conjunto. Eles foram carregados no VMG, que utilizou o aplicativo de software Tcpreplay (TCPREPLAY, 2016), para transmitir as mensagens com um intervalo aproximado de 1s entre os envios. 
Cada mensagem foi enviada por meio da interface PHY-0 da placa Dual Port para a NetFPGA-1, que também recebeu as mensagens na PHY-0 $\left(\mathrm{P}_{0}\right)$. Após passar pelo módulo de decodificação, Route 1, cada mensagem foi redirecionada via $P H Y-1\left(\mathrm{P}_{1}\right)$ da NetFPGA-1 para a PHY-1 da placa Dual Port. O sniffer de rede Wireshark ${ }^{\circledR}$ foi utilizado para capturar as mensagens no período de transmissão e recepção. Após a transmissão de cada conjunto de testes, foram salvos os arquivos .xml gerados pelo Wireshark ${ }^{\circledR}$ e pelo módulo decodificador para posterior validação.

Para completar os ensaios, 15.000 mensagens GOOSE pertencentes a 15 IEDs comerciais distintos foram submetidas ao mesmo processo. O ensaio foi realizado no Route 1 e Route 2.

\subsubsection{Resultados ASN.1/BER GOOSE}

Nos testes realizados, o módulo ASN.1/BER GOOSE conseguiu capturar corretamente os campos de todas as mensagens GOOSE aleatórias, e das mensagens geradas por IEDs comerciais. Nenhum erro de quadro ou campo foi detectado. 


\section{Firewall em Hardware Reconfigurável}

O objetivo do presente trabalho é o desenvolvimento de um firewall em hardware reconfigurável, por meio da plataforma NetFPGA, de modo que o incremento no tempo de propagação de uma mensagem GOOSE, Tipo 1A, ao transpor o dispositivo de segurança, não ultrapasse 1ms. Neste contexto, o firewall de filtragem de quadros foi adotado, pois tem como habilidade selecionar no nível dos bits, o formato e o conteúdo de um quadro. Esta característica condiz com sua implementação, utilizando a plataforma NetFPGA-V2 e, portanto, viabiliza que este dispositivo de segurança cibernética atenda aos requisitos de tempo exigidos.

Além da filtragem de conteúdo, este capítulo descreve outros serviços de segurança que foram desenvolvidos e avaliados como módulos do firewall: dois algoritmos de criptografia e um algoritmo para autenticação da mensagem GOOSE.

\subsection{O Módulo Filter}

O módulo de filtragem de quadros utiliza o componente de hardware formado pela interconexão dos módulos ASN.1/BER GOOSE e Filter, conforme mostra a Figura 61.

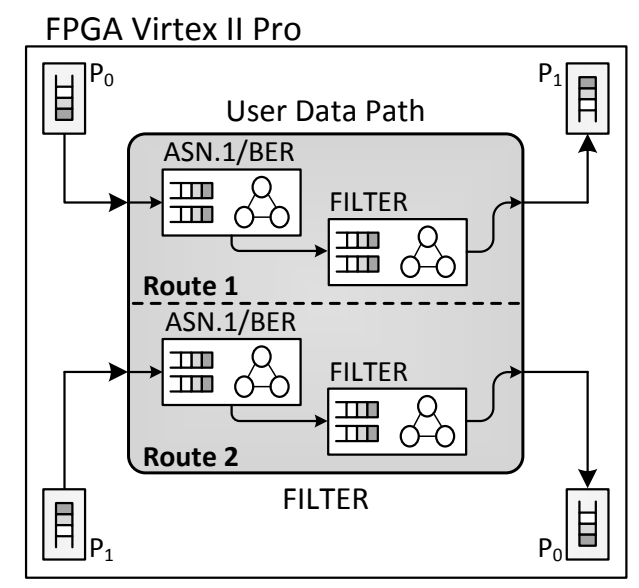

Figura 61: User Data Path Módulo Filter 
Quando um quadro ISO/IEC 8802-3 chega à Porta $0\left(\mathrm{P}_{0}\right)$, é direcionado para o módulo ASN.1/BER GOOSE, que tem a função de aquisição e armazenamento dos campos fixos e flexíveis. Posteriormente, o quadro é direcionado para o módulo Filter. Por intermédio de uma ACL (Access Control List), ocorre a tomada de decisão, entre bloquear ou encaminhar a mensagem para a $\mathrm{P}_{1}$.

A utilização simultânea dos Routes 1 e 2 permite a interligação de dois segmentos de rede com filtros iguais ou diferentes.

\subsubsection{Modelo do Filtro}

O Filter utiliza, para as decisões de filtragem, os bytes capturados pelo módulo ASN.1/ BER GOOSE e uma lista fornecida pelo usuário com os valores esperados para cada campo do quadro ISO/IEC 8802-3, conforme mostra a Figura 62.

Caso todos os campos comparados sejam iguais, a mensagem GOOSE é encaminhada entre as portas do Filter. Porém, se qualquer um dos campos comparados for diferente, a mensagem é bloqueada.

A lista para o controle dos quadros que têm permissão de acesso à rede de comunicação é formada por um arquivo de texto com Filtros de 1 até $n$, conforme mostra a Figura 63. A composição dos filtros segue as seguintes regras:

- Os campos que serão utilizados para filtragem devem estar dispostos em grupos de 4 bytes;

- Os filtros devem ser iniciados com os valores dos campos fixos (11 grupos com 4 bytes);

- Os campos fixos devem ser dispostos na mesma ordem em que aparecem na formação do quadro ISO/IEC 8802-3;

- Mesmo que não se deseje utilizar os campos fixos, estes devem ser inseridos com valor zero (0x00000000);

- Os campos flexíveis, utilizados para filtragem, devem aparecer um após o outro, mesmo que estejam fora de ordem em relação à formação do quadro ISO/IEC 88023

- Embora possam aparecer fora de ordem, os campos flexíveis devem informar e obedecer à sequência: identificador, tamanho e valor do campo;

- A capacidade de campos em cada filtro é dependente da FPGA. Nesse trabalho, são destinados 22 registadores de 32 bits para os campos fixos, e 260 registradores para os campos flexíveis. Estes valores possibilitam configurar 2 filtros com todos os campos; 


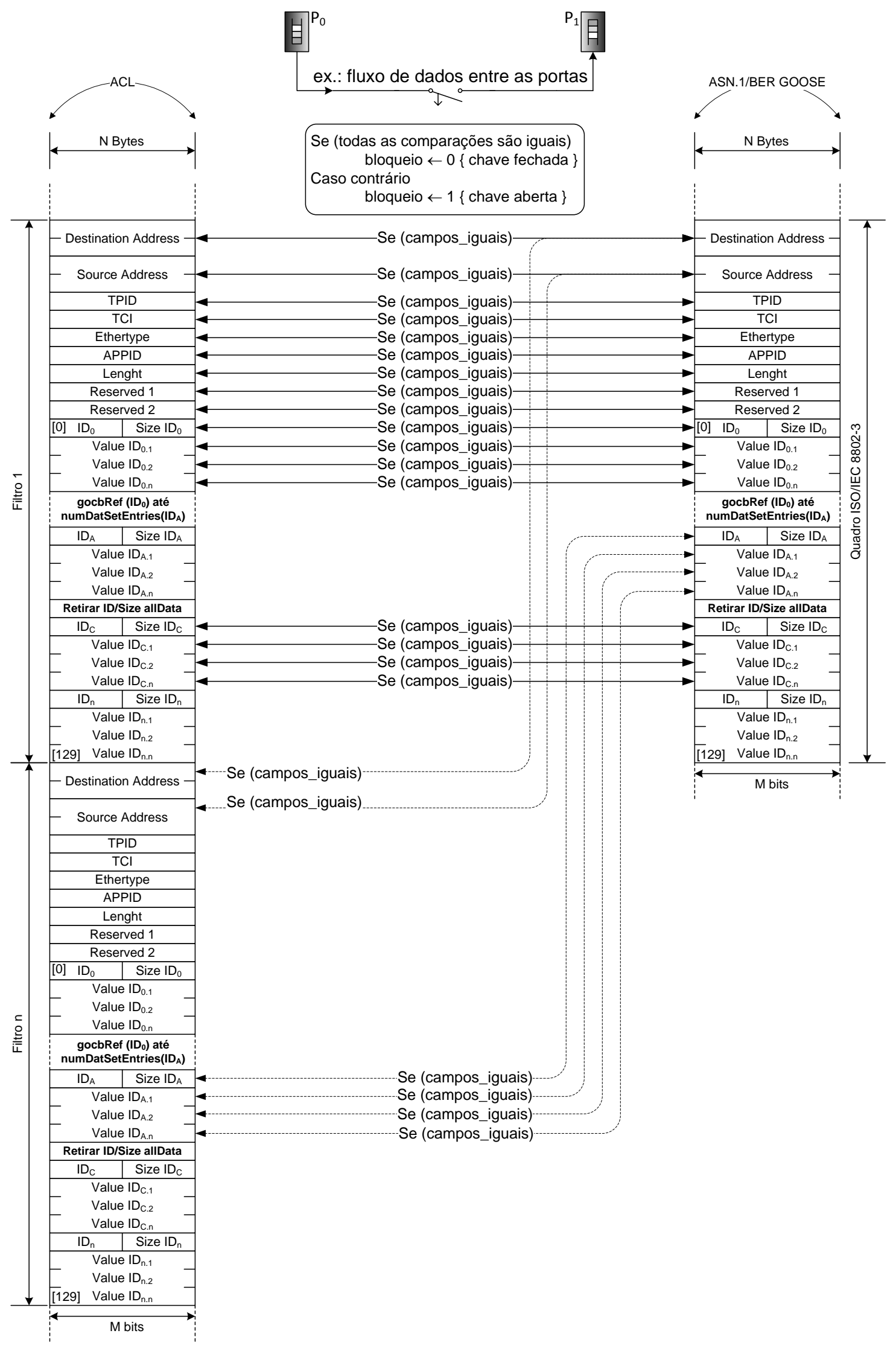

Figura 62: Modelo de filtragem do quadro ISO/IEC 8802-3 
- Se o usuário deseja utilizar apenas um filtro, os mesmos valores devem ser espelhados para o filtro 2.

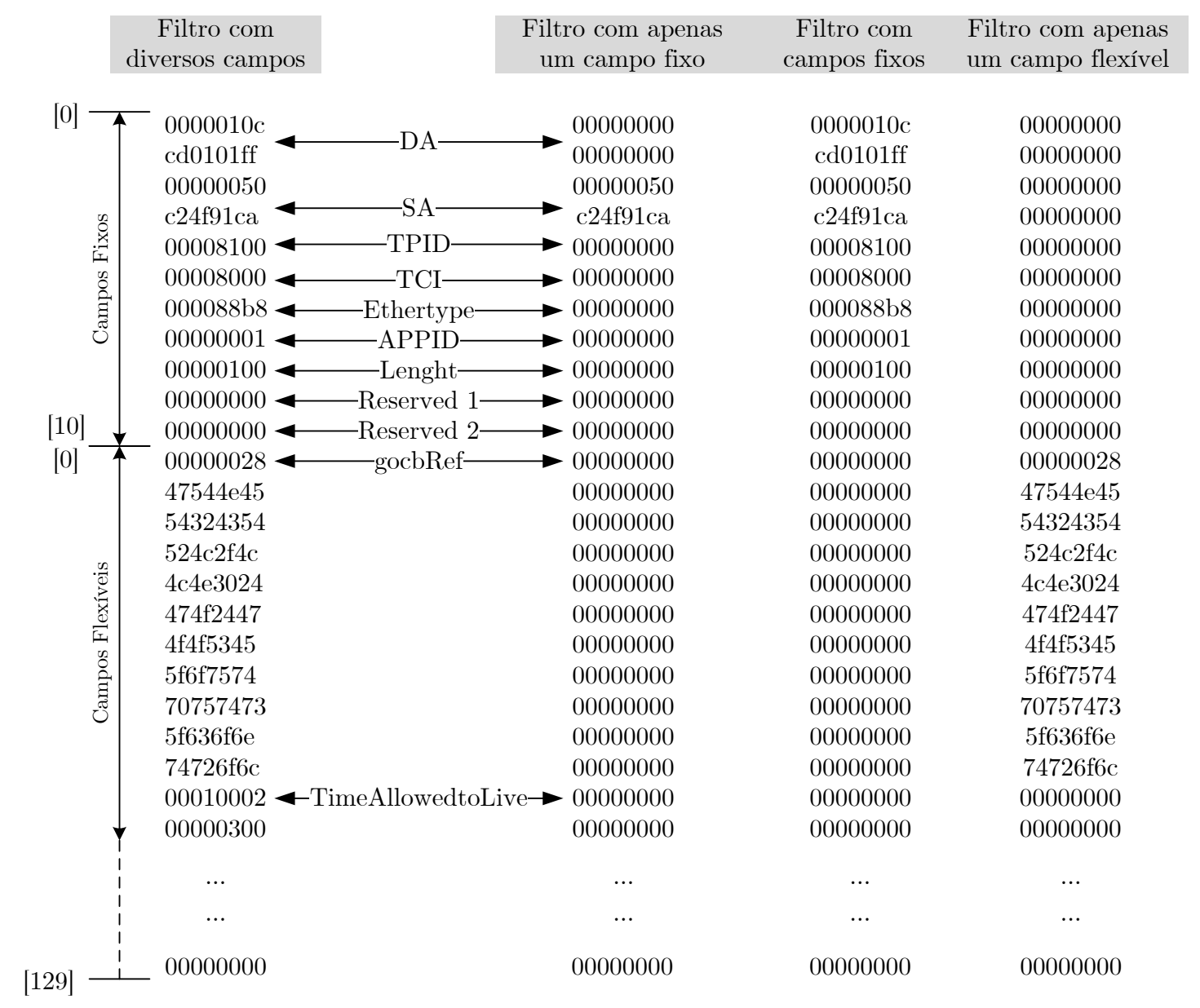

Figura 63: Exemplos de filtros que podem ser configurados

\subsubsection{O Design do Filter}

O módulo Filter foi implementado por intermédio da plataforma NetFPGA-V2, com o mesmo design do módulo ASN1/BER GOOSE. Porém, o design do módulo Filter utiliza apenas uma FIFO (a fallthrough_small_fifo_1), com 8 bits de profundidade.

A FSM, que define a operação do módulo, possui oito estados, como mostra a Figura 64. Destacam-se, a seguir, as funções de cada estado:

- O estado Fixed_Field (Fixed) é responsável por executar a comparação dos valores informados pelo usuário e os dados presentes na parte fixa da matriz (comparação dos primeiros 11 registradores), conforme mostra a Figura 65. Se alguma das comparações não for verdadeira, seja em relação ao Filtro 1 ou ao Filtro 2, o registrador de bloqueio recebe nível lógico 1 e barra a passagem da mensagem GOOSE entre as 


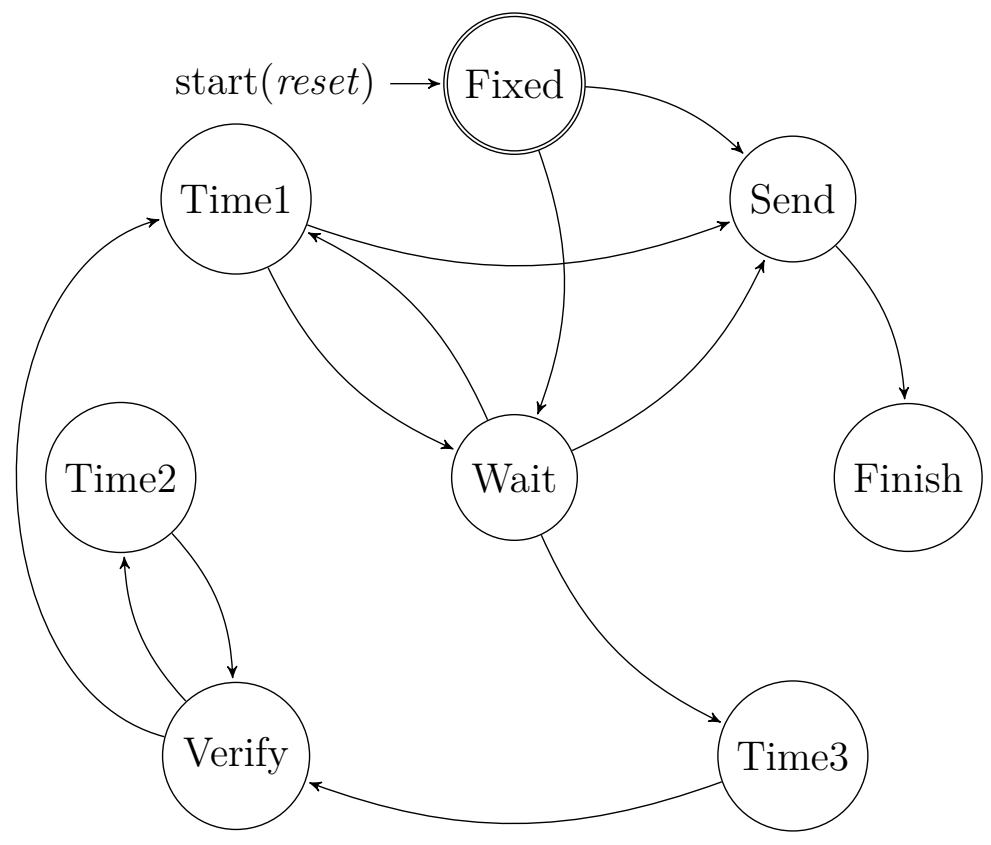

Figura 64: FSM do módulo Filter

portas do firewall. Na Figura 65, o programa em linguagem C está no computador hospedeiro, os demais blocos estão na FPGA;

- A principal função do estado Wait é analisar se a posição da matriz que está selecionada, será analisada ou ignorada, conforme ilustra a Figura 66. Se algum dos filtros possuir o mesmo identificador (ID), que é pertinente à seleção momentânea de um registrador da matriz, o processo de análise do campo terá início. Caso contrário, o campo será ignorado por inteiro. Em destaque na cor vermelha, Figura 66, o último ID da matriz é armazenado para indicar qual será o último ID a ser observado em cada filtro;

- O estado Verify compara os valores de uma posição do filtro, com os valores selecionados pelo registrador da matriz, conforme mostra a Figura 67. Alternando com o estado auxiliar Time2. A comparação é encerrada quando todas as posições de um determinado campo forem verificadas, ou uma delas for falsa. Cabe ressaltar que uma comparação só gera resultado verdadeiro, se todos os campos forem iguais;

- A função de verificar se a matriz está zerada ou se a mensagem GOOSE já passou pelo módulo é de responsabilidade do estado Finish.

- O estado Send permite o direcionamento dos dados de saída da FIFO para a saída do módulo, quando pelo menos um dos filtros for completamente verdadeiro;

- Os estados Timer2 e Timer3 executam funções auxiliares, como: incrementar uma posição para análise da matriz, aguardar alguns ciclos de clock e alternar entre os 
estados.

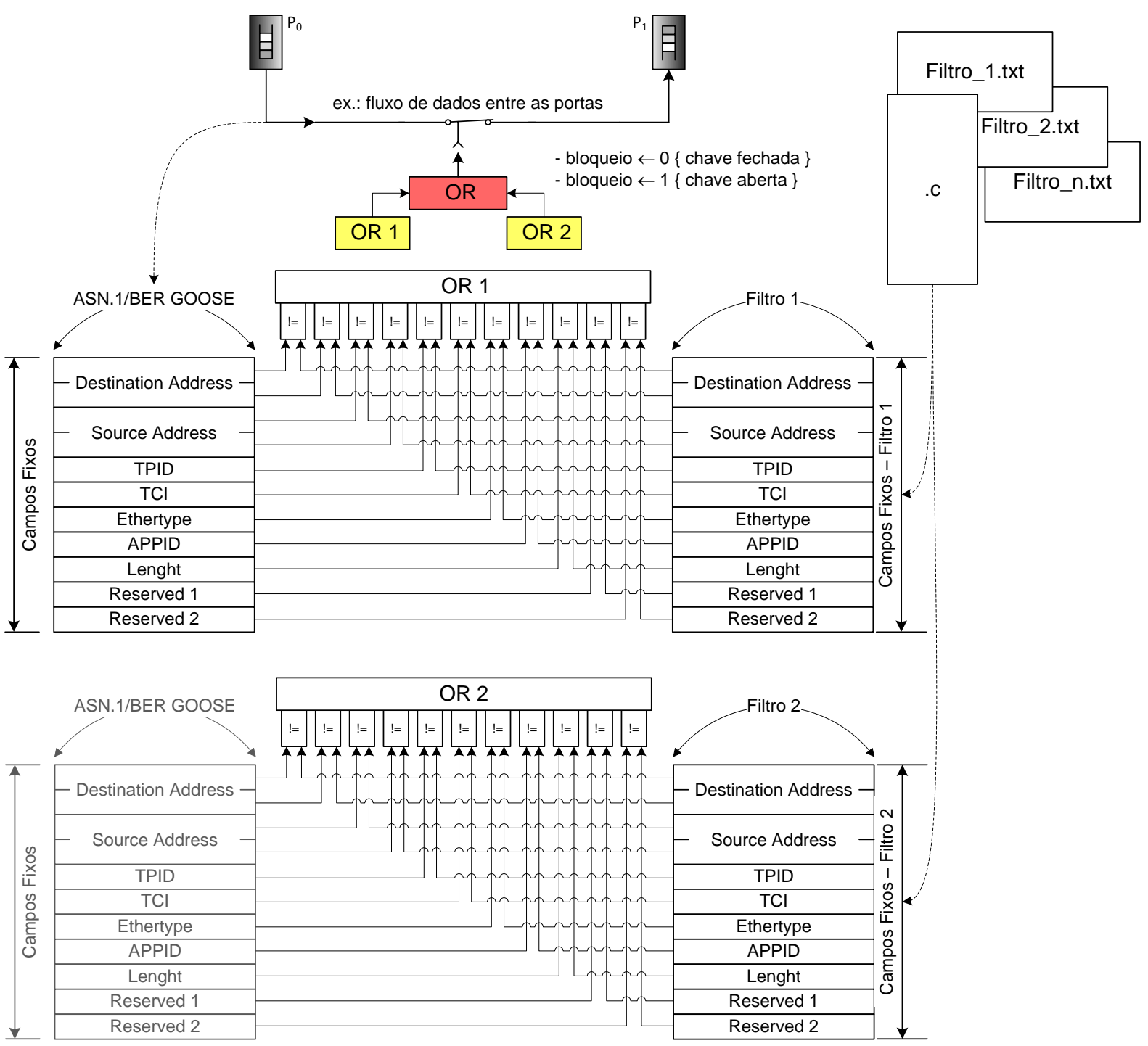

Figura 65: Lógica de atuação do estado Fixed_Field para 2 filtros

\subsubsection{Ensaios Realizados com o Filter}

Considerando que cada interface da placa de rede Dual Port Gigabit representa um IED do SEP (Figura 58, Seção 4.10), ou os switches instalados entre duas subestações, o módulo Filter foi utilizado para filtrar as mensagens GOOSE encaminhadas.

Para comprovar o funcionamento correto do modelo de filtragem do quadro ISO/IEC 8802-3 (Figura 62), foram criados 1002 filtros distintos, por intermédio de 21 mensagens GOOSE, 11 mensagens de IEDs comerciais e 10 mensagens aleatórias geradas pelo RGGM. Para cada mensagem, foram criados os seguintes filtros:

- 1 com todos os campos da mensagem; 


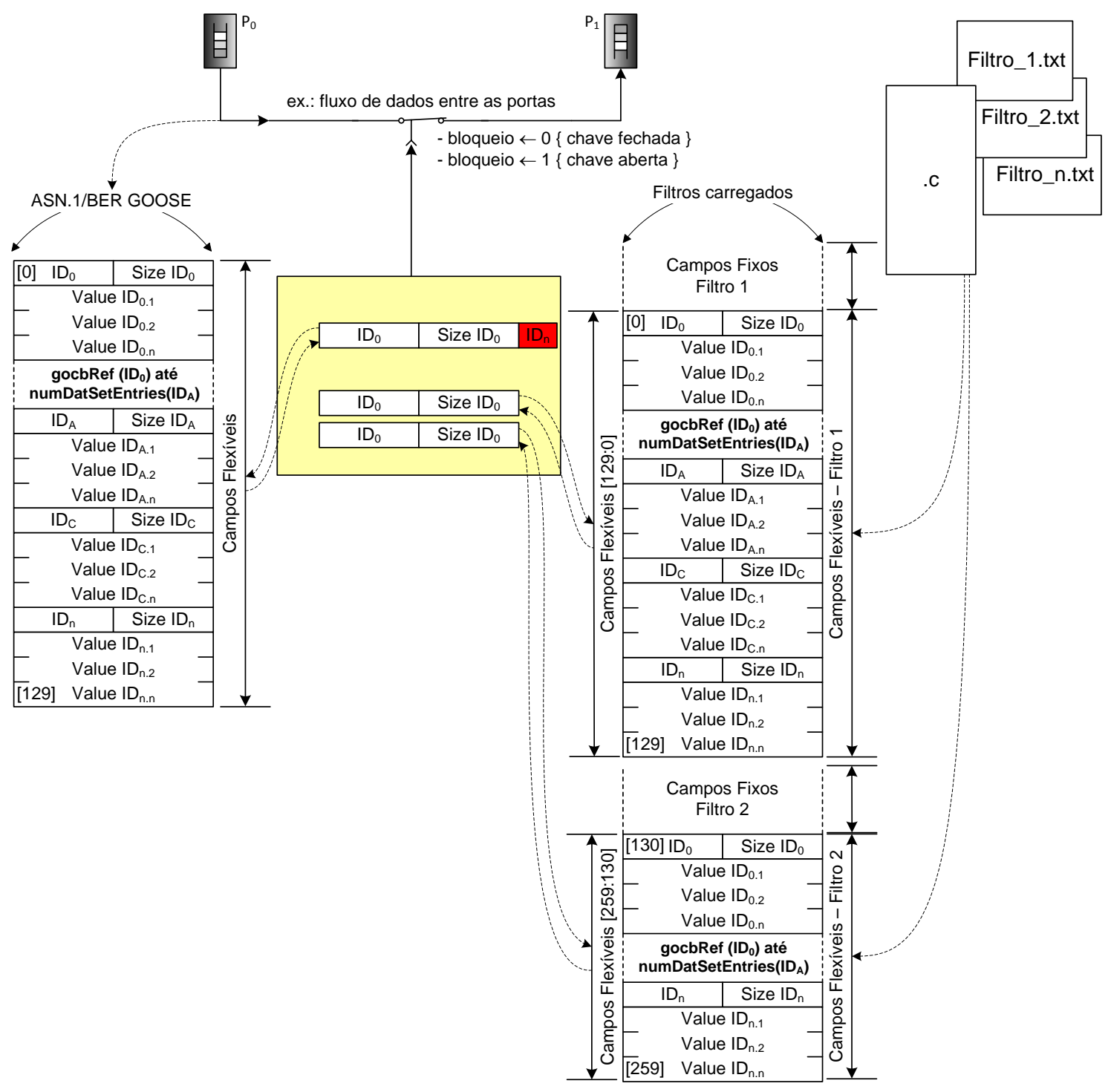

Figura 66: Lógica de atuação do estado Wait para 2 filtros

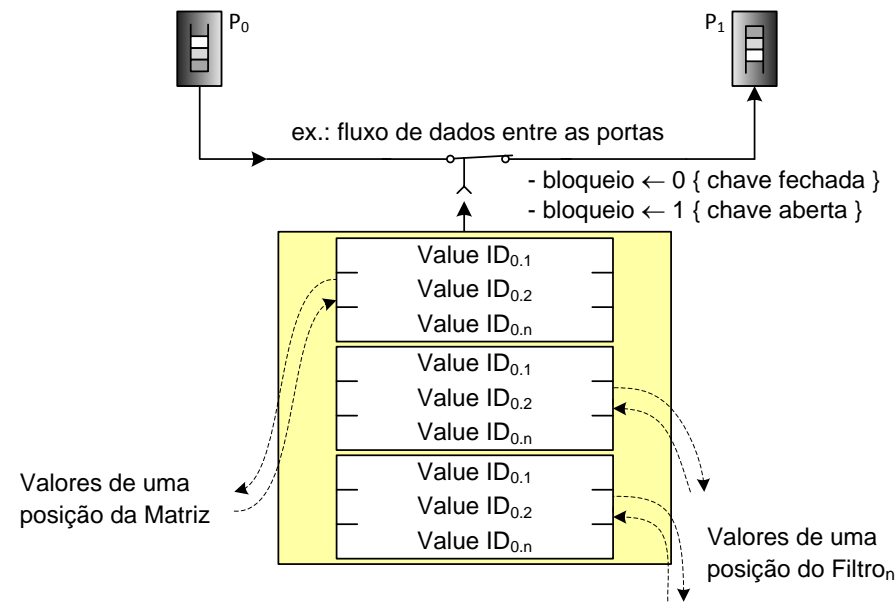

Figura 67: Lógica de atuação do estado Verify para 2 filtros 
- 1 para cada campo da mensagem;

- 1 considerando apenas os campos fixos;

- 1 considerando apenas os campos entre o gocbRef e o numDatSetEntries;

- 1 considerando apenas os campos do allData;

- 1 com os campos fixos (sem VLAN) e os campos gocbRef, datSet e goID;

- 1 com os campos fixos e os campos gocbRef, datSet e goID;

- 1 com os campos fixos e os campos gocbRef, datSet, goID, test, confRev e numDatSetEntries.

Dos 1002 filtros, 301 mesclam campos de mensagens diferentes.

Para testar cada um dos filtros, foi desenvolvido um script em Python, com base no Algoritmo 4.

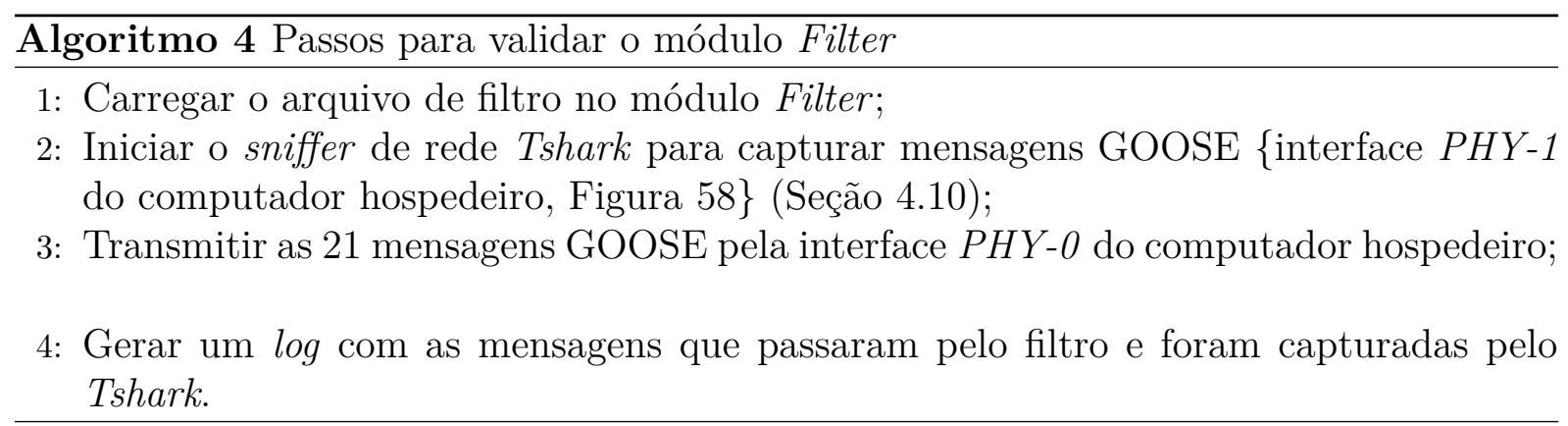

A Figura 68 mostra o resultado da atuação de um filtro para o campo Destination Address. Observa-se que das 21 mensagens GOOSE, transmitidas por meio da interface PHY-O da placa Dual Port, apenas 2 mensagens com o mesmo Destination Address, 01:0c:cd:01:01:ff, foram recebidas na interface $P H Y$-1, após transpor a NetFPGA-1.

\subsubsection{Resultados com o Filter}

Nos testes realizados, o módulo Filter conseguiu filtrar corretamente todas as mensagens que estavam declaradas na ACL. Um total de 10.000 mensagens não GOOSE também foram encaminhadas para o módulo Filter (com diversos protocolos da pilha TCP/IP). Em 100\% dos casos, as mensagens não GOOSE foram bloqueadas pelo módulo.

\subsubsection{Ocupação da FPGA - Módulo Filter}

A Figura 69 mostra as informações do chip FPGA Virtex II PRO e um sumário da utilização e distribuição lógica do design. Os percentuais de Slices, Flip-Flops e LTUs, utilizados pelo módulo Filter, permitem presumir a incorporação de novas funcionalidades. 


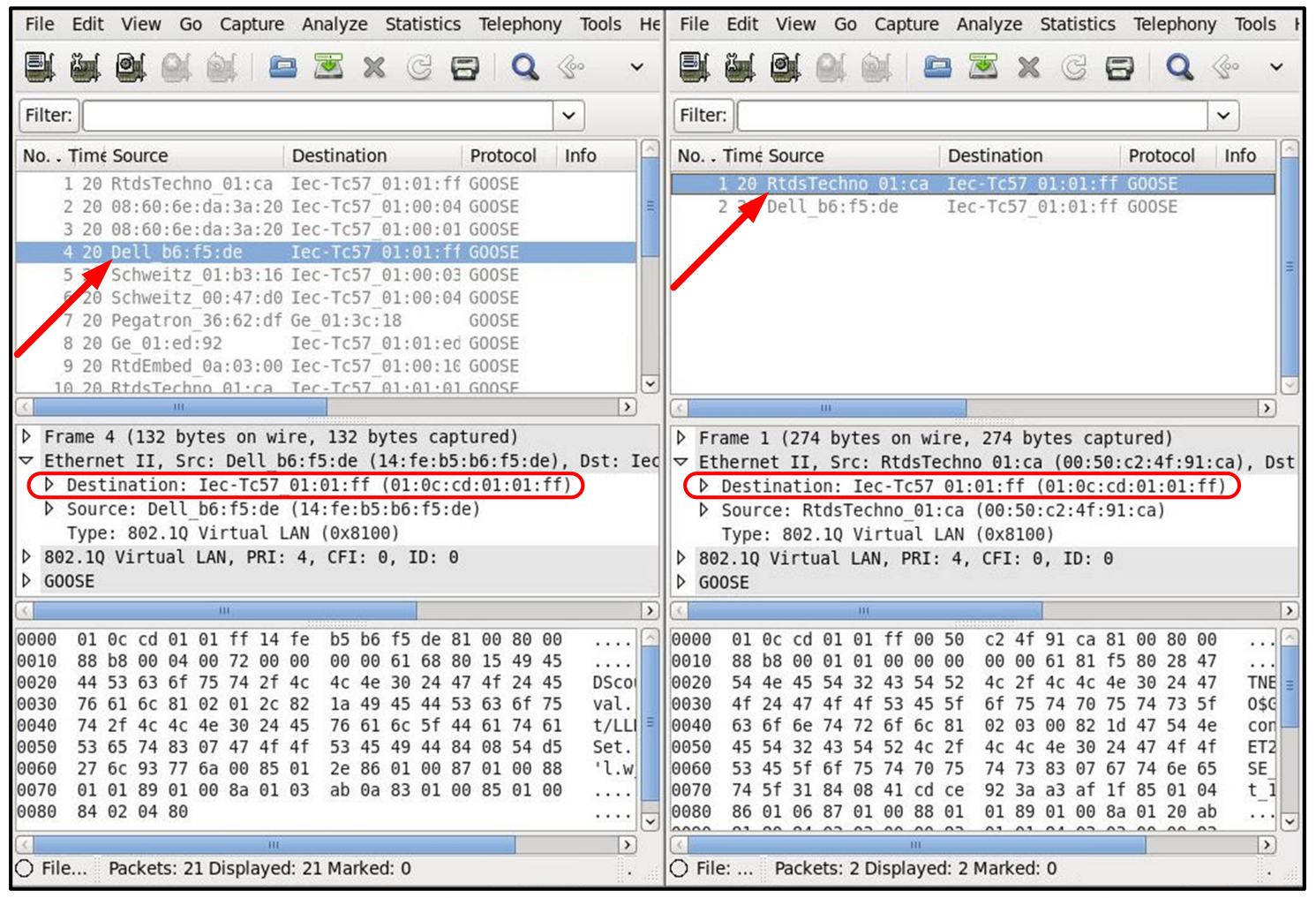

Emissor (PHY-0)

Receptor (PHY-1)

Figura 68: Exemplo de um Filtro para o campo Destination Address

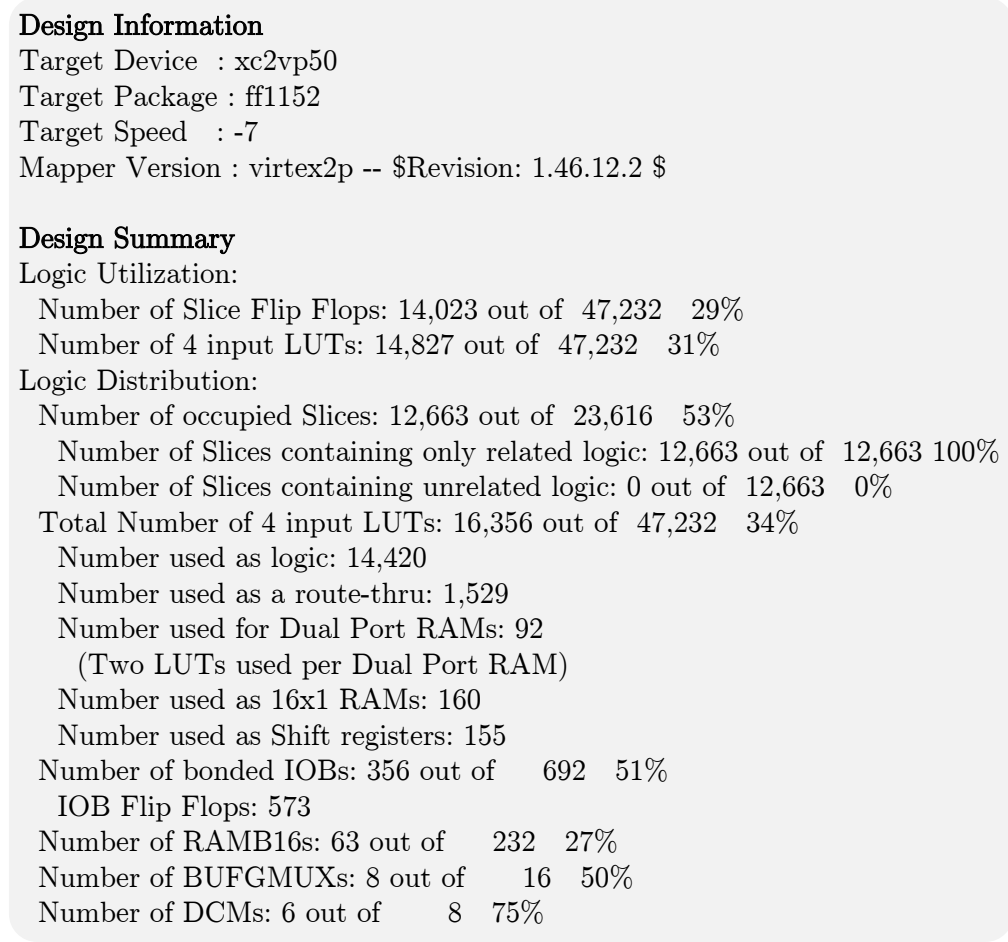

Figura 69: Sumário de utilização e distribuição lógica do design - Projeto Filter (Route 1 e 2$)$ 


\subsection{O Módulo Crypto}

A IEC/TS-62351-6 (2007) orienta que a criptografia não deve ser incluída como uma medida de segurança para as mensagens GOOSE, pois adiciona muitos bytes à mensagem. Porém, deixa uma possibilidade para sua utilização quando menciona que:

No futuro, algumas criptografias em hardware poderão ser adicionadas (IEC/TS-62351-6, 2007).

Nesse contexto, foram implementados dois algoritmos clássicos de criptografia para compor as ferramentas de segurança cibernética do Firewall.

\subsubsection{A Cifra XOR}

As cifras modernas são formadas por um conjunto de cifras simples. A primeira delas, segundo Forouzan e Fegan (2007), é chamada cifra XOR, pois utiliza uma operação ouexclusivo. A Figura 70 mostra que uma operação XOR precisa de duas entradas de dados, a primeira em forma de texto claro, por exemplo, uma mensagem GOOSE; e a segunda, como uma chave. O resultado é um bloco criptografado.

Em uma cifra XOR, o tamanho do texto claro da chave e o texto cifrado são iguais. Cabe ressaltar que a criptografia e a decriptografia utilizam o mesmo algoritmo.

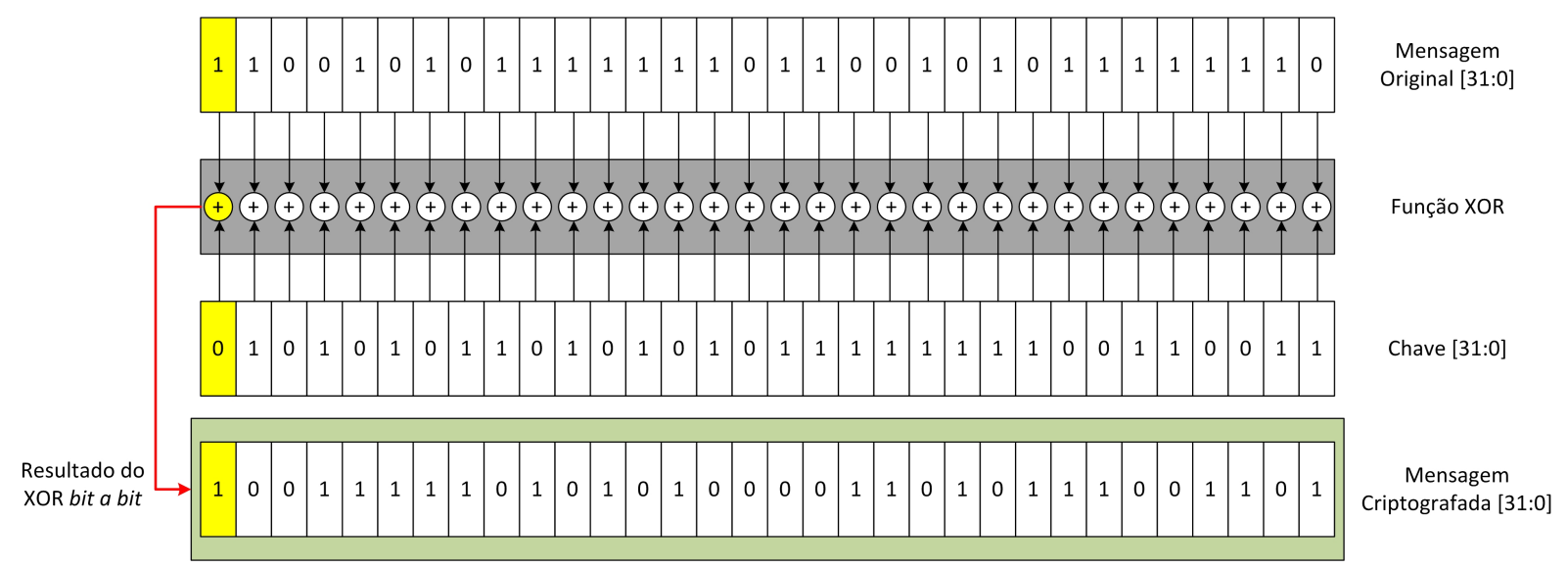

Figura 70: Operação XOR para criptografia de um texto claro

Neste projeto, o algoritmo XOR, junto ao algoritmo DES (Data Encryption Standard), foi utilizado como prova de conceito para validar a utilização da criptografia e decriptografia, na troca de mensagens GOOSE entre IEDs locais ou remotos. Cabe ressaltar que a implementação básica do algoritmo XOR é um projeto de referência da plataforma NetFPGA. 


\subsubsection{A Cifra DES}

Nesta subseção, é introduzida a cifra cíclica de chave simétrica DES, que é conhecida como cifra de bloco, uma vez que divide o texto claro em blocos e utiliza a mesma chave para criptografar e decriptografá-los (FOROUZAN; FEGAN, 2007).

O DES foi projetado pela IBM e publicado pelo NBS (National Bureau of Standards), em 1977, para ser adotado pelo governo dos EUA como método-padrão de criptografia para informações comerciais. Segundo Terada (2000), "o DES foi especialmente projetado para ser implementável em circuitos integrados e não é adequado para implementações em software devido, principalmente, à ocorrência de diversas permutações e sequências longas de bits".

Na Figura 71, tem-se um esquema geral para a criptografia DES. O algoritmo criptografa blocos de 64 bits de extensão, texto claro, e retorna blocos cifrados do mesmo tamanho utilizando uma chave com 56 bits de extensão.

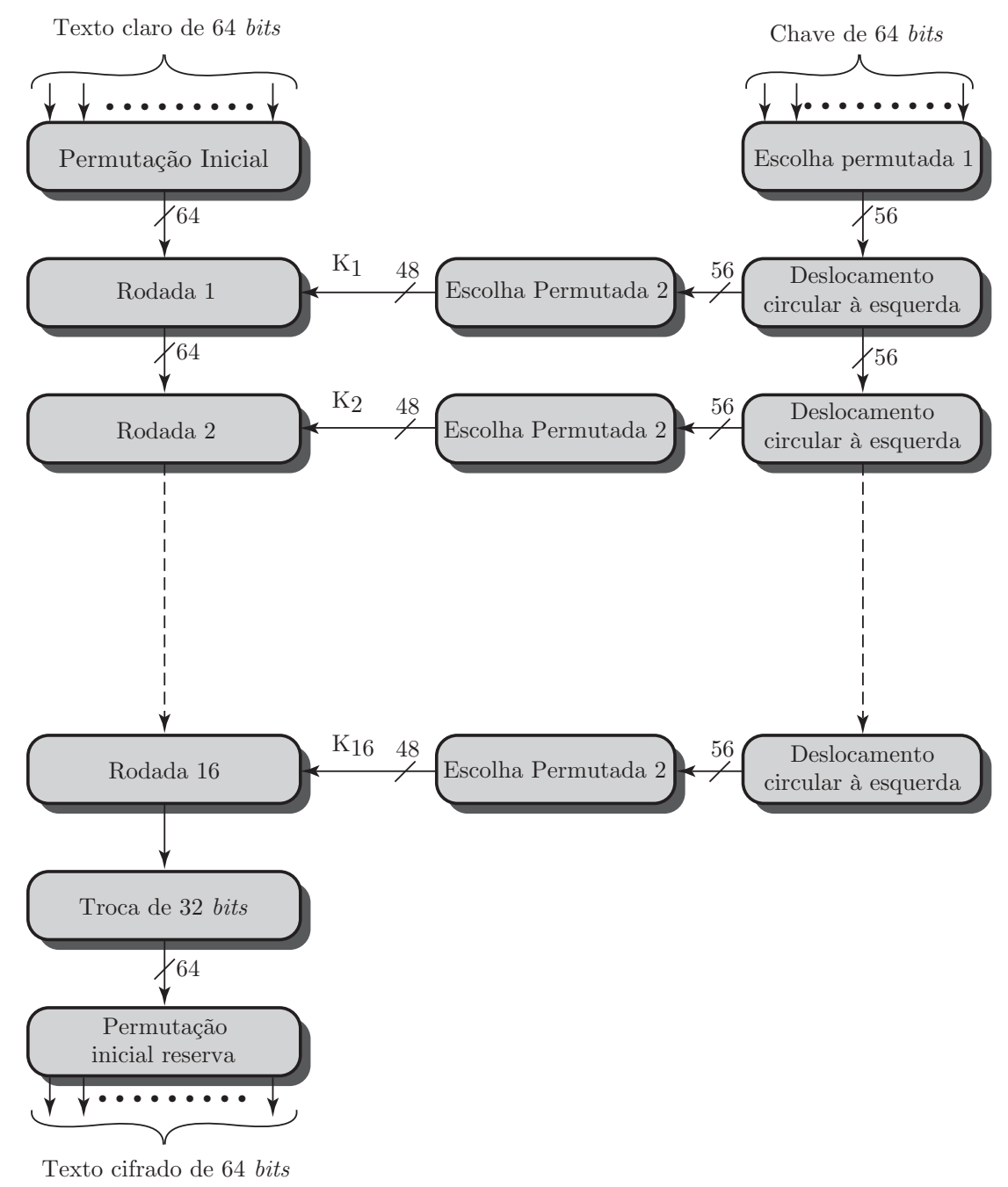

Figura 71: Representação geral do algoritmo de encriptação DES

Fonte: Stallings (2013) 
A decriptografia utiliza o mesmo algoritmo de criptografia, exceto pela inversão da aplicação das subchaves. Além disso, as permutações inicial e final são invertidas.

Uma descrição minuciosa dos algoritmos de criptografia e decriptogria DES é fornecida por Stallings (2013) e Terada (2000).

\subsubsection{O Módulo Crypto}

O módulo Crypto utiliza os bytes dos campos fixos para verificar se a mensagem é GOOSE, conforme ilustra a Figura 72. Caso a mensagem não o seja, existem duas possibilidades, configuráveis via software:

- A mensagem não GOOSE, nGM, é encaminha para a porta de saída sem ser criptografada;

- A mensagem não GOOSE é descartada.

FPGA Virtex II Pro

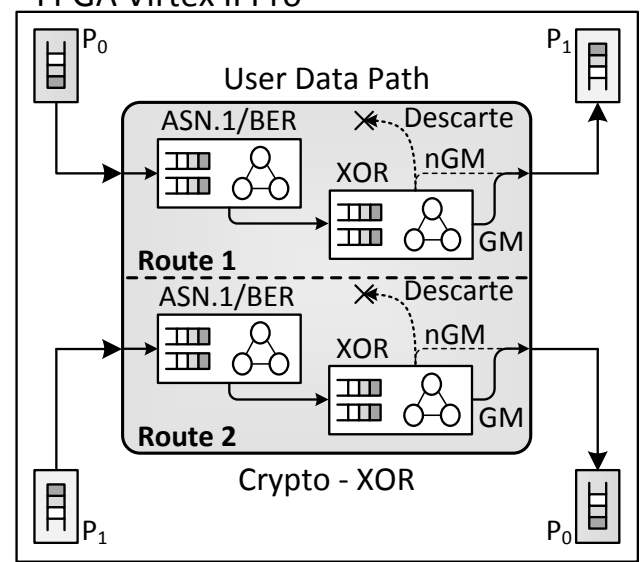

FPGA Virtex II Pro

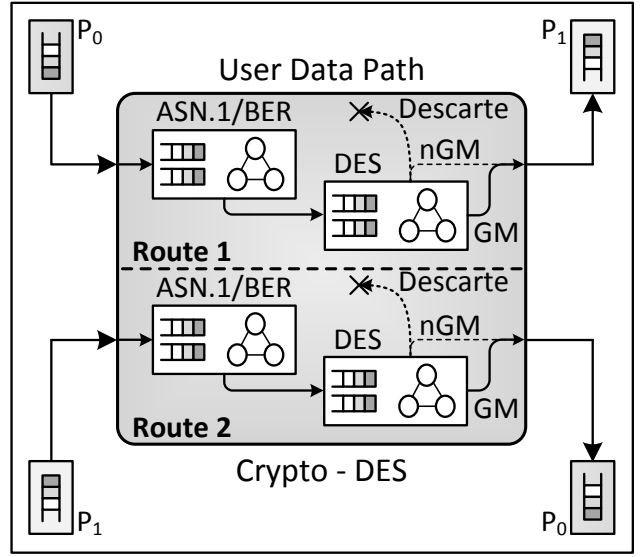

Figura 72: User Data Path Módulo Crypto

Já nos quadros ISO/IEC 8802-3, quando ingressam no barramento de pacotes da NetFPGA-V2, a criptografia ocorre nos campos Ethertype, APPID, Length, Reserved 1, Reserved 2 e $A P D U$, conforme mostra a Figura 73.

Os campos destinados à identificação e à prioridade da mensagem GOOSE foram preservados da criptografia: Destination Address, Source Address, TPID e TCI.

\subsubsection{O Design da Crypto}

O módulo Crypto foi implementado com o trecho do design, pertinente ao módulo ASN1/BER GOOSE, que trata dos campos fixos. O design do módulo utiliza apenas uma FIFO (a fallthrough_small_fifo_1). O design da criptografia XOR utiliza 14 bits 


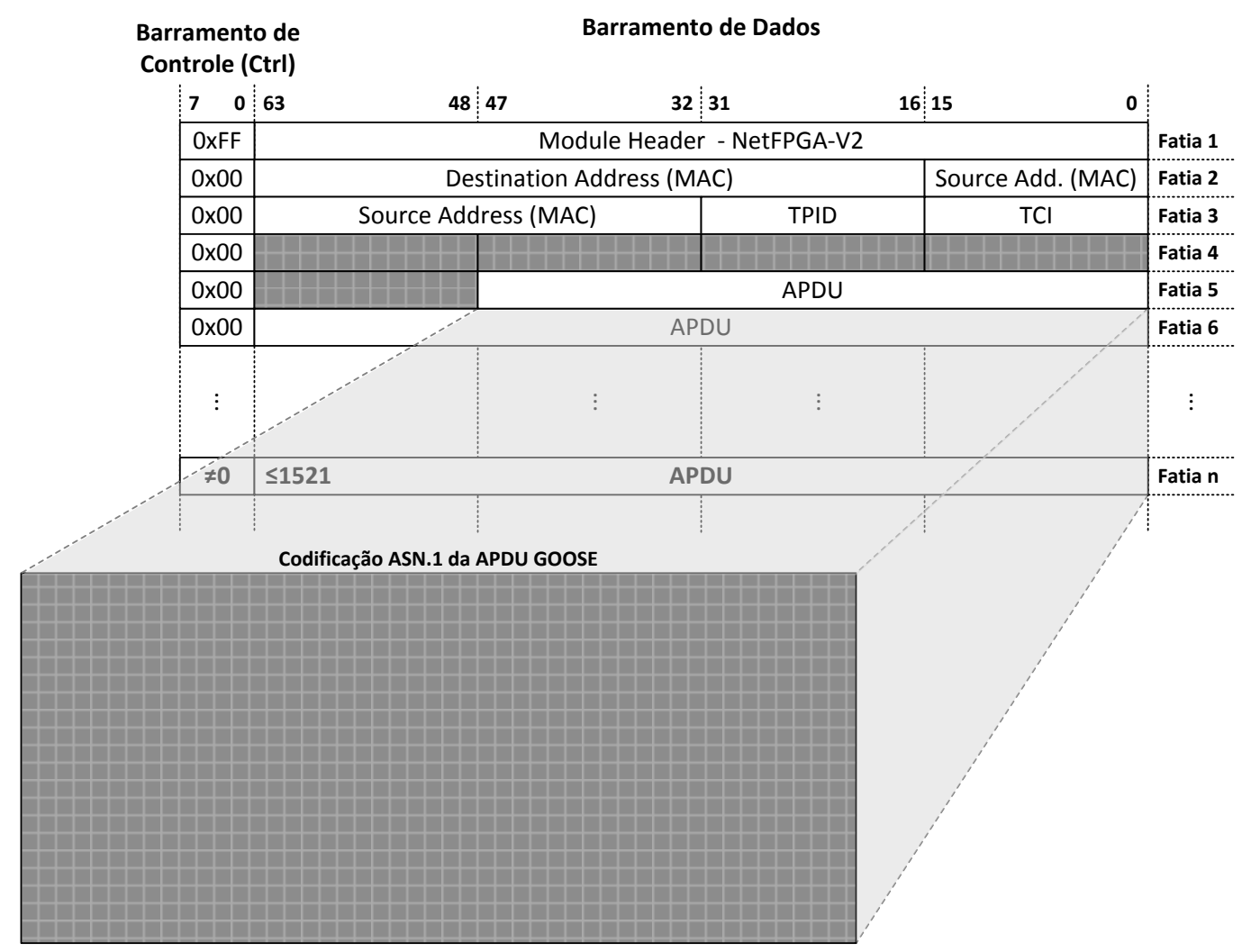

Figura 73: Formato do quadro ISO/IEC 8802-3 criptografado

de profundidade na FIFO, o mesmo acontece para o design da decriptografia XOR. Para a criptografia DES, são 13 bits de profundidade e 14 bits para a decriptografia.

A FSM que define a operação geral do sistema, apresenta oito estados, como mostra a Figura 74. Destacam-se, a seguir, as funções de cada estado:

- O estado Fixed captura o campo Ethertype para verificar se a mensagem é GOOSE;

- O estado Decision (Dec) verifica a opção do usuário entre deixar as mensagens não GOOSE serem descartadas ou, simplesmente, serem transmitidas pela rede;

- Os estados Crypto (cry) ou Decrypto (decry) definem a função, e os estados XOR e DES, o algoritmo que será utilizado;

- O estado Send transmite a mensagem para a saída; e

- O estado End aguarda o fim da mensagem.

Para simplificar a explanação, a Figura 74 apresenta as cifras XOR e DES na mesma FSM. Porém, cada cifra possui uma FSM exclusiva, ou seja, dois módulos distintos (Crypto XOR e Crypto DES). 


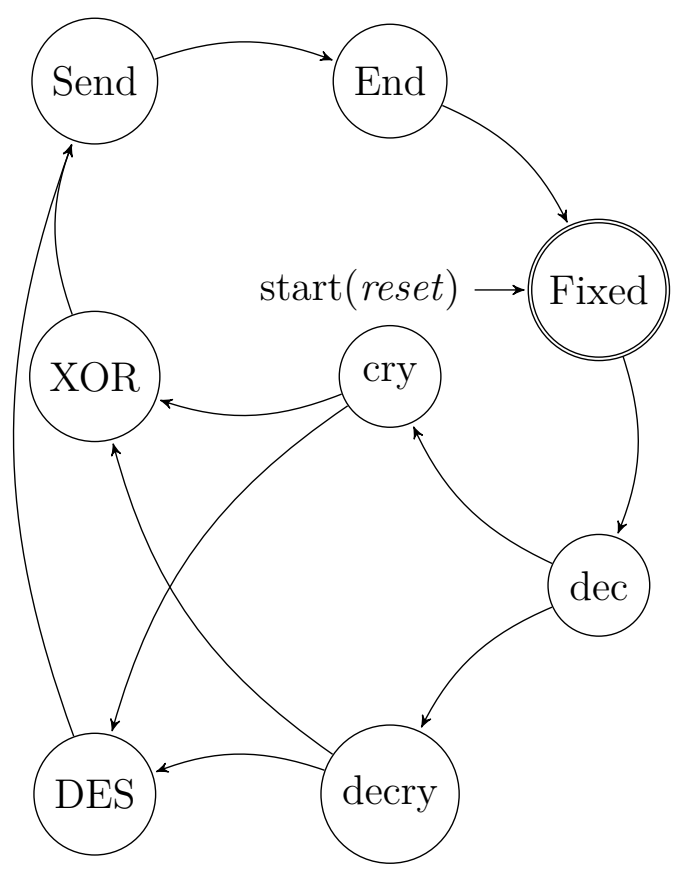

Figura 74: FSM geral do sistema Crypto

\subsubsection{Ensaios Realizados com a Crypto}

Para assegurar o correto funcionamento do módulo, foram utilizadas 10.000 mensagens GOOSE, geradas pelo RGGM e 15.000 mensagens de IEDs comerciais. Os testes foram realizados de acordo com o Algoritmo 5, para as cifras XOR e DES.

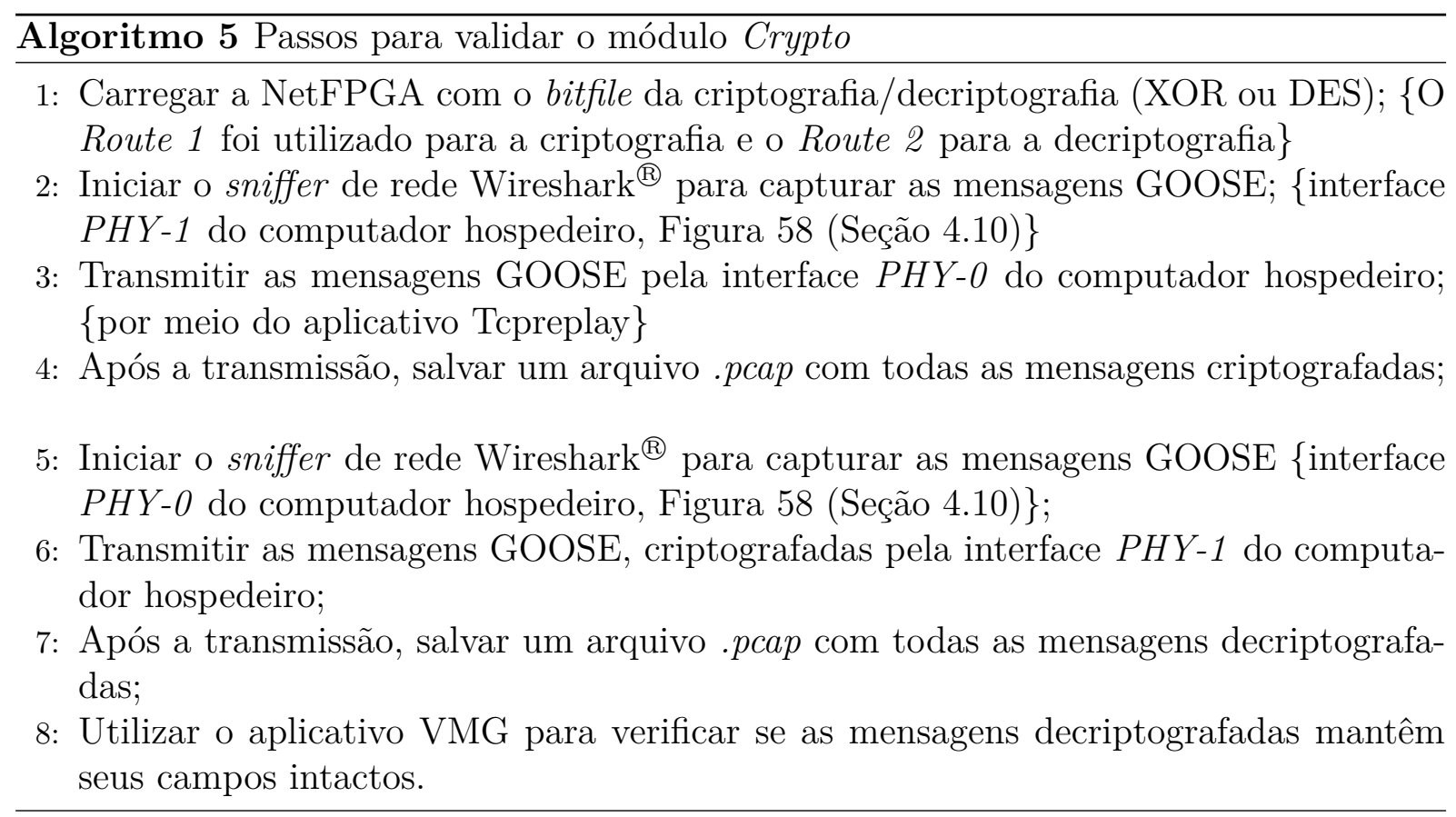

A Figura 75 mostra o resultado da atuação do módulo Crypto XOR. Observa-se a criptografia XOR de uma das mensagens GOOSE, transmitidas por meio da interface 
PHY-0 da placa Dual Port e recebidas na interface PHY-1, após transpor a NetFPGA-1. A criptografia ocorre a partir da linha \#0010.

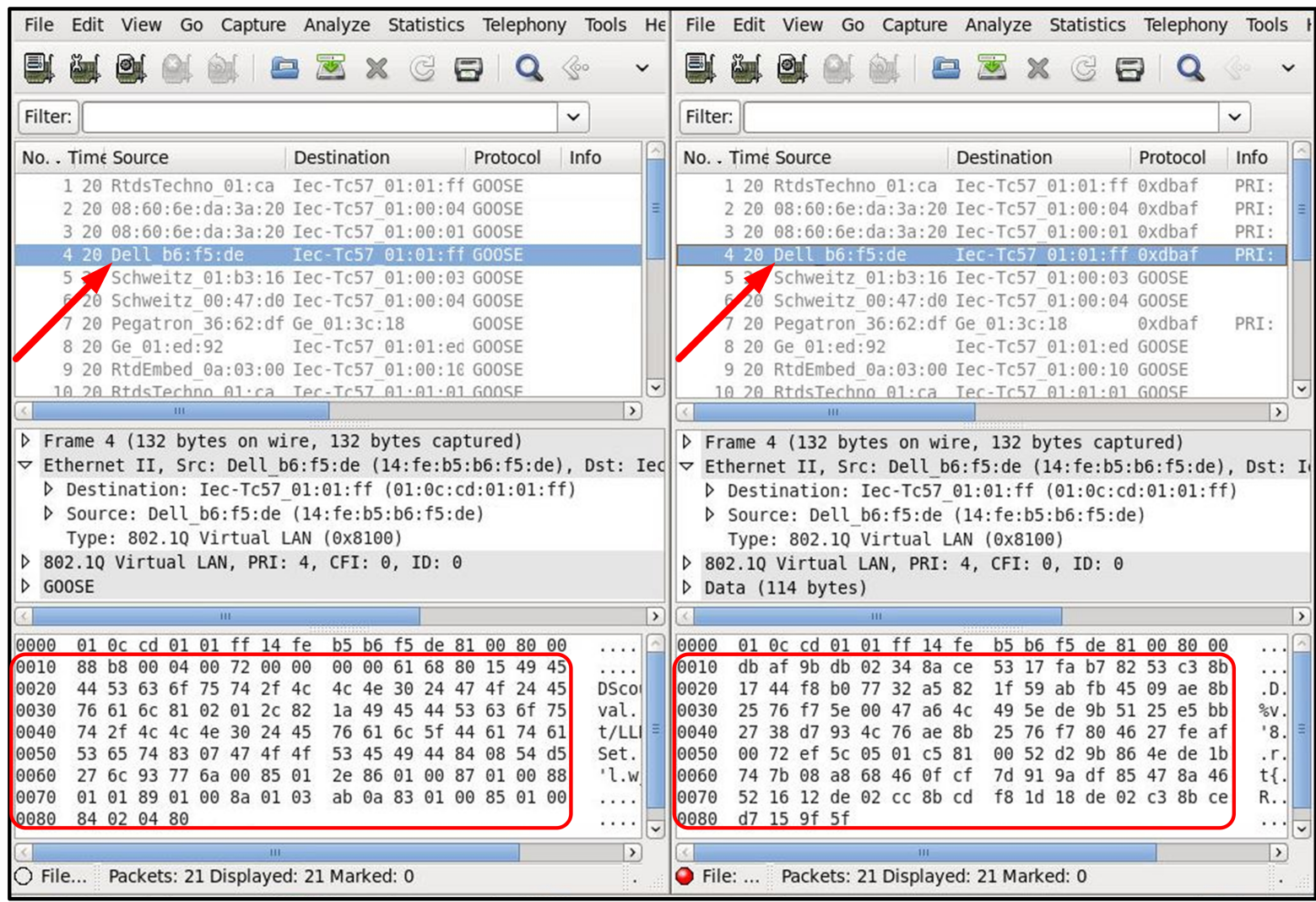

Emissor (PHY-0)

Receptor (PHY-1)

Figura 75: Exemplo da criptografia XOR - Chave 0x53179bdf02468ace

Já a Figura 76 apresenta o resultado da atuação do módulo Crypto DES. Nota-se a criptografia DES de uma das mensagens GOOSE, transmitidas por meio da interface $P H Y-0$ e recebidas na interface $P H Y-1$. A criptografia ocorre a partir da linha \#0010.

Como o algoritmo DES necessita de blocos com 64 bits, a linha \#0080 do emissor recebe um complemento que, posteriormente, é retirado no processo de decriptografia.

Para definir a chave de criptografia/decriptografia, se as mensagens não GOOSE serão descartadas ou encaminhadas para a porta de saída e, também, o número de mensagens criptografadas/decriptografadas, dentre outras informações, foi utilizado um aplicativo em linguagem C, como ilustra a Figura 77.

\subsubsection{Resultados com a Crypto}

As mensagens criptografadas foram retransmitidas e capturadas pelo aplicativo Wireshark ${ }^{\circledR}$. Posteriormente, foi utilizado o VMG para verificar se a decriptografia ocorreu de forma correta. Em 100\% dos casos, as mensagens foram reconstituídas corretamente. 


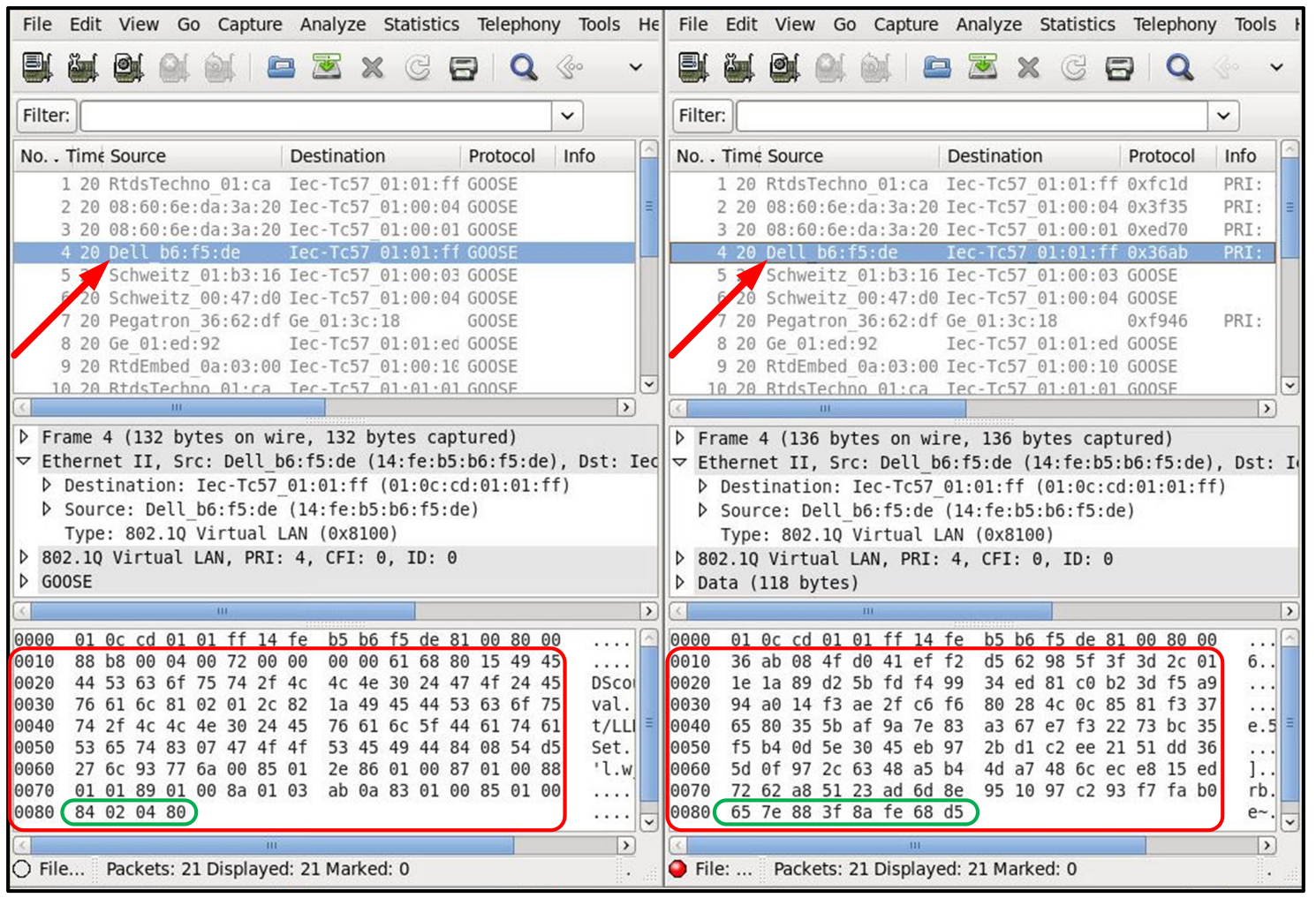

Emissor (PHY-0)

Receptor (PHY-1)

Figura 76: Exemplo da criptografia DES - Chave 0x53179bdf02468ace

Chave: 0x53179bdf02468ace
Algoritmo selecionado: DES
Nova chave definida para o Route 1.
Crypto - Route 1
---------------------
1 - Definir chave
2 - Definir o caminho da msg NÃO GOOSE para Crypto
3 - Verificar configurações do projeto
4 - Informações sobre mensagens
5 - Exibir subchaves (DES)
6 - Voltar
Opção:

Figura 77: Tela de configuração do módulo Crypto

\subsubsection{Ocupação do Hardware - Módulo Crypto}

A Figura 78 e a Figura 79 mostram as informações do chip FPGA Virtex II PRO e um sumário da utilização e distribuição lógica dos designs para os módulos XOR e DES, respectivamente. 


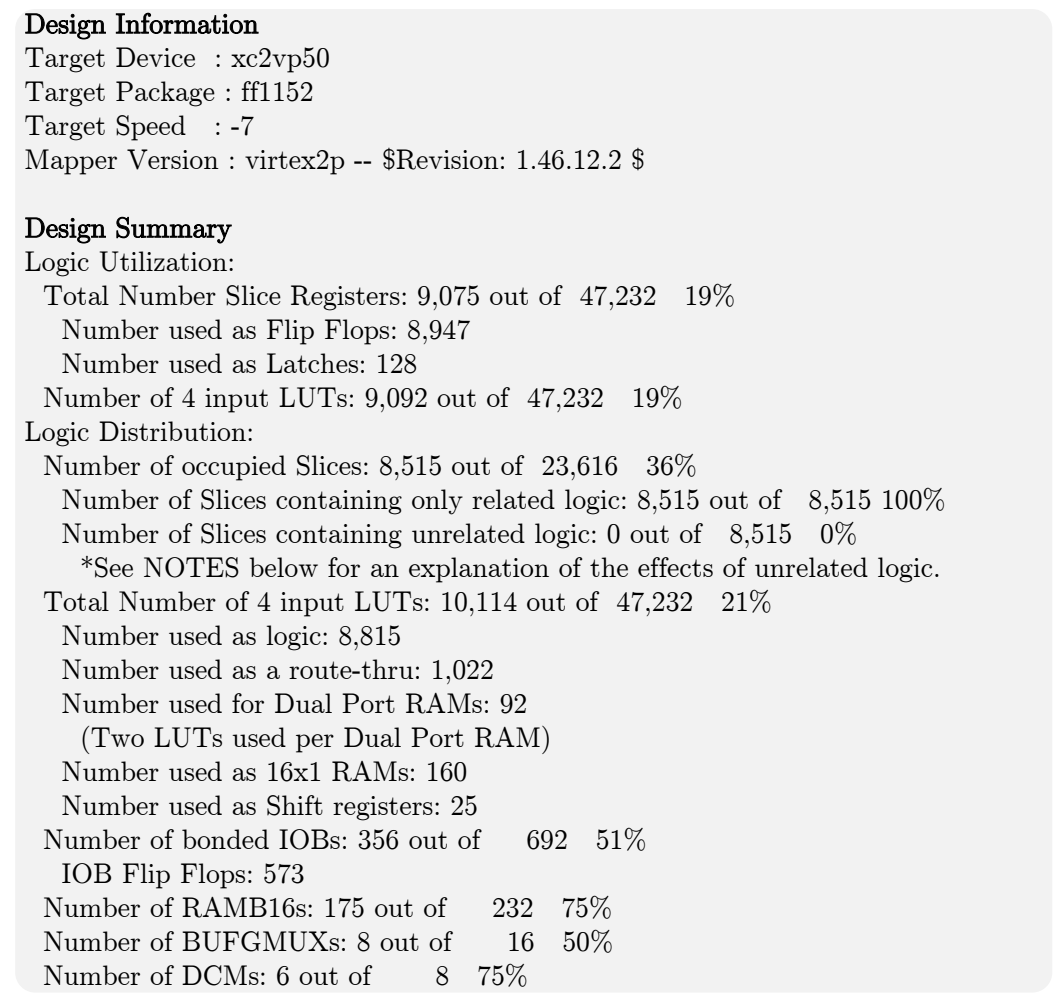

Figura 78: Sumário de utilização e distribuição lógica do design - Projeto XOR (Route 1 e 2)

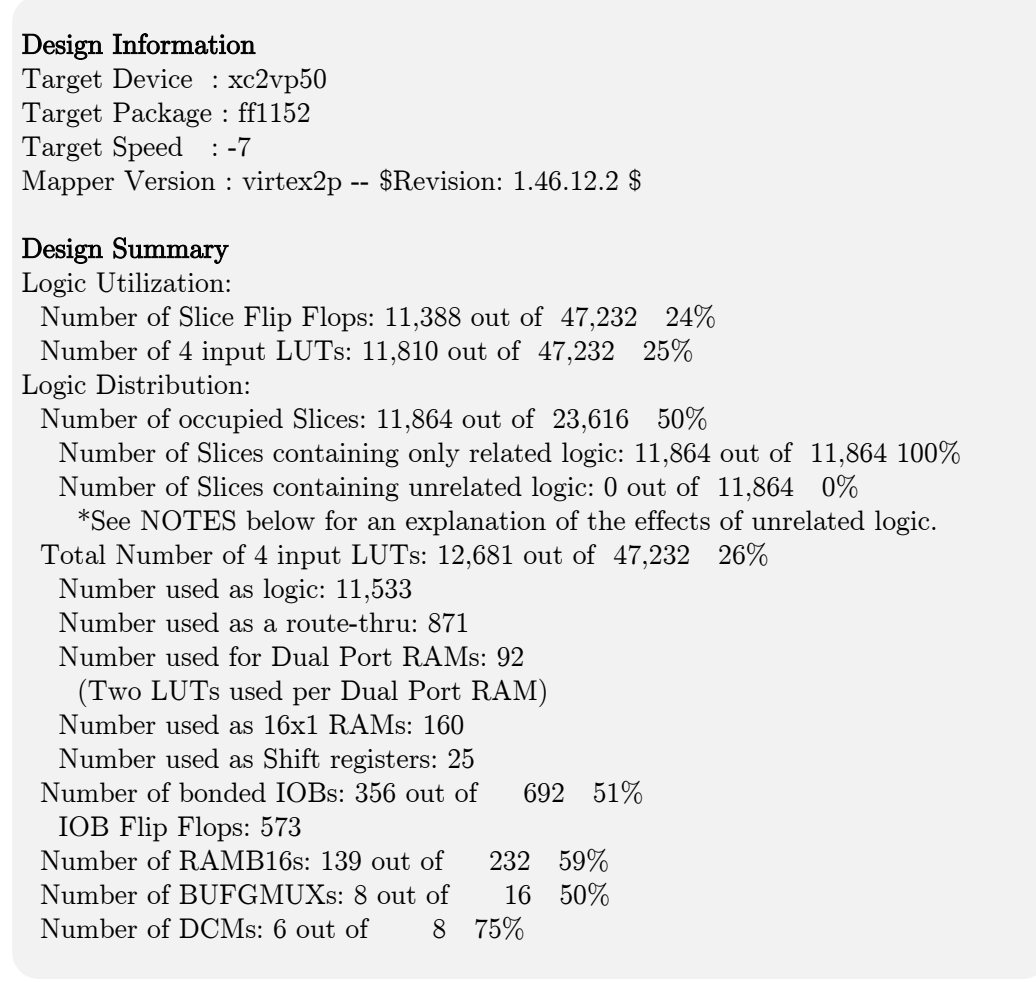

Figura 79: Sumário de utilização e distribuição lógica do design - Projeto DES (Route 1 e 2) 


\subsection{O Módulo Authentication}

Uma das principais áreas, focalizadas pela IEC 62351, é a autenticação, que é chave de três dos principais serviços de segurança: confidencialidade, integridade e não repúdio (IEC/TS-62351-1, 2007).

A IEC 62351, parte 6, sugere que, para a autenticação de uma mensagem GOOSE, deve-se criar um MsAC (Message Authentication Code) por meio do cálculo de um Hash SHA-256, de acordo com a RFC 4634, Society (2006), que deve conter todos os bytes da PDU e o valor do Hash, em seguida, deve receber uma assinatura digital.

Nesta seção serão expostos os resultados, pertinentes à primeira parte desta autenticação, ou seja, a utilização de uma função Hash para gerar o MsAC.

\subsubsection{Função Hash}

Segundo Stallings (2013), um valor de Hash é gerado por uma função H na forma:

$$
h=H(M)
$$

Na qual: $M$ é uma mensagem de comprimento variável, e $H(M)$ é o valor de Hash de comprimento fixo. O valor de Hash é anexado à mensagem na origem. O receptor autentica essa mensagem recalculando o valor do Hash.

A SHA-3, originalmente conhecida como Keccak, é uma função Hash criptográfica, escolhida em 2012, como a vencedora de uma competição do NIST, para estabelecer um novo padrão de Hash. A estrutura básica do SHA-3 é um esquema denominado de construção em esponja, que "recebe uma mensagem de entrada e a divide em blocos de tamanho fixo. Cada bloco é processado por sua vez com a saída de cada iteração alimentada na próxima, produzindo, finalmente, um bloco de saída"(STALLINGS, 2016).

Neste contexto, foi utilizado, para os testes com o módulo ASN.1/BER GOOSE, o IP Core $^{1}$ SHA3 (Keccak) desenvolvido por HSING (2013). O código fornecido em Verilog foi instanciado com os módulos Authentication_TX e Authentication_RX.

Os detalhes do algoritmo SHA-3 podem ser encontrados em Bertoni et al. (2011), Stallings (2016) e NIST (2015).

\subsubsection{Authentication_TX e Authentication_RX}

Os módulos, para autenticação da mensagem GOOSE, utilizam os componentes de hardware formados pela interconexão dos módulos (Figura 80):

- ASN.1/BER GOOSE e Authentication_TX: para inserir o valor da função Hash em anexo à mensagem GOOSE;

\footnotetext{
${ }^{1}$ IP (Intellectual Property) Core são blocos reusáveis de lógica, células ou layout de projetos de circuitos, licenciados, e que podem ser utilizados em projetos de ASIC ou FPGA (AYALA, 2011).
} 
- ASN.1/BER GOOSE e Authentication_RX: para gerar o valor da função Hash, que será comparado com o Hash, que chega em anexo à mensagem.

FPGA Virtex II Pro

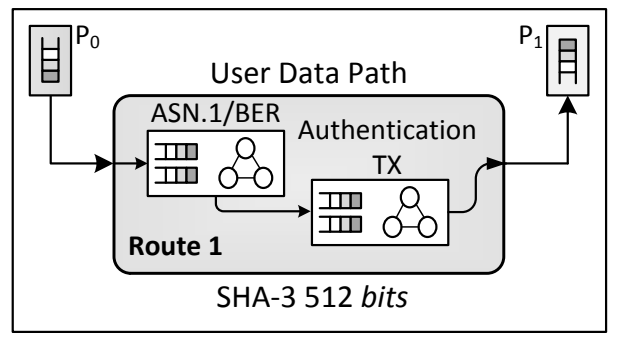

FPGA Virtex II Pro

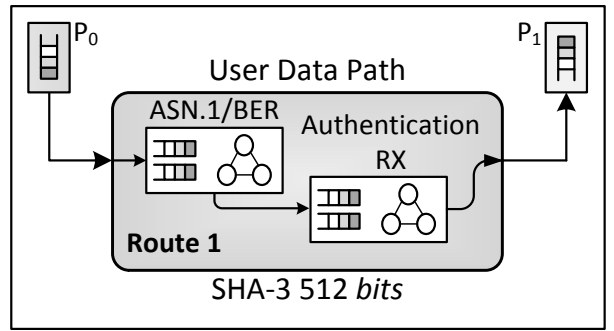

Figura 80: User Data Path módulo Authentication $T X$ e $R X$, respectivamente

Quando um quadro ISO/IEC 8802-3 chega à Porta $0\left(\mathrm{P}_{0}\right)$, é encaminhado para o módulo ASN.1/BER GOOSE, que tem a função de aquisição e armazenamento dos campos fixos e flexíveis. Posteriormente, o quadro é direcionado para o módulo Authentication_ TX. Os registradores da matriz, com os campos fixos e flexíveis, passam pela função Keccak-f, utilizada para processar cada bloco sucessivo da mensagem GOOSE de entrada. A função gera uma mensagem de 512 bits (64 bytes) que será anexada à mensagem original para transmissão por meio da $\mathrm{P}_{1}$.

Como o tamanho gerado pelo Hash será sempre 512 bits (0x40), o quadro ISO/IEC 8802-3 será acrescido de 66 bytes: a tag 0x8c (ASN.1 security[12] $]^{2}$ ), o tamanho 0x40, e o valor resultante da função Hash.

Quando um quadro chega na $\mathrm{P}_{0}$ do Módulo Authentication_RX, os registradores da matriz, com os campos fixos e flexíveis, passam pela função Keccak-f, utilizada para processar cada bloco sucessivo da mensagem GOOSE. A função gera uma mensagem de 512 bits (64 bytes), que será comparada com o campo Security, tag 0x8c. Se os campos forem iguais, o quadro é encaminhado para a $\mathrm{P}_{1}$ do Módulo Authentication_ $R X$ e pode ser entregue para o receptor.

\subsubsection{O Design do Módulo Authentication}

O design do módulo Authentication_TX utiliza o mesmo design do módulo ASN.1/BER GOOSE, com apenas uma FIFO e 8 bits de profundidade. Já o design do módulo Authentication_RX utiliza o mesmo design com duas FIFOs e 8 bits de profundidade.

No módulo Authentication_ $R X$, a primeira FIFO é utilizada para transmitir o quadro, caso o Hash esteja correto; já a segunda FIFO é utilizada para retirar o valor de Hash do

\footnotetext{
${ }^{2}$ Sato et al. (2015) citam um tipo de dado definido para completar a codificação ASN.1 do IECGoosePdu (Algoritmo 1): security[12] ANY OPTIONAL.
} 
quadro recebido pelo módulo. Neste ponto da pesquisa, os módulos Authentication_TX e Authentication_RX utilizam o Route 1 de NetFPGAs distintas.

\subsubsection{A FSM do Módulo Authentication_TX}

A Figura 81 mostra a FSM que define a operação geral do módulo Authentication_TX. Os estados da FSM são:

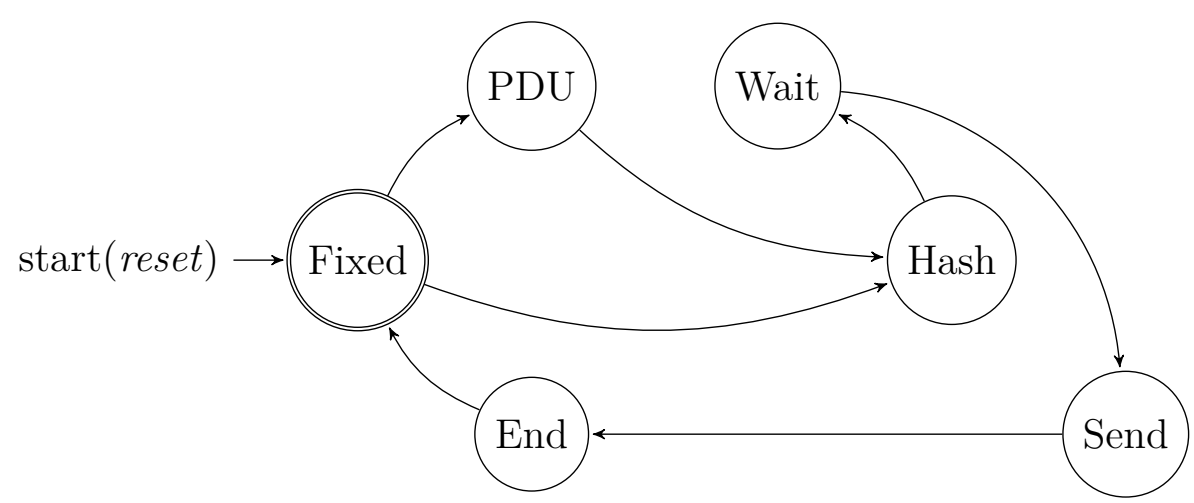

Figura 81: FSM sumarizada do módulo Authentication_TX

- O estado Fixed_Fields (Fixed) captura os campos fixos que serão enviados para a função Hash;

- O estado PDU_Field (PDU) envia os campos da matriz para a função Hash;

- O estado Wait aguarda que a função Hash retorne à flag out_Hash_rdy, informando que o MsAC está pronto;

- A inserção do valor calculado pela função Keccak-f, precedida do identificador 0x8c, e o tamanho 0x40 é de responsabilidade do estado Insert_Hash (Hash). Cabe ressaltar que o quadro ISO/IEC 8802-3 terá o seu tamanho acrescido em 66 bytes, conforme mostra a Figura 82;

- O estado Send transmite a mensagem para a saída do módulo; e

- O estado End aguarda o fim do quadro para iniciar uma nova avaliação.

\subsubsection{A FSM do Módulo Authentication_RX}

A Figura 83 mostra a FSM que define a operação do módulo Authentication_RX. Os estados da FSM são:

- O estado Fixed_Fields (Fixed) captura os campos fixos que serão enviados para a função Hash; 
Mensagem GOOSE (.hex) Quadro ISO/IEC 8802-3

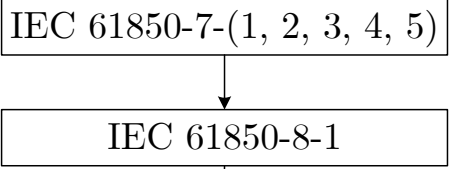

010ccd01000408606eda3a208100e00288b800020078000000006 $16 \mathrm{e} 80174436304 \mathrm{c} 44496 \mathrm{e} 73742 \mathrm{f} 4 \mathrm{c} 4 \mathrm{c} 4 \mathrm{e} 3024474 \mathrm{f} 2467636230318$ $102078082154436304 \mathrm{c} 44496 \mathrm{e} 73742 \mathrm{f} 4 \mathrm{c} 4 \mathrm{c} 4 \mathrm{e} 3024474 \mathrm{f} 4 \mathrm{f} 5345318$ 30a474f4f53454f75745f318408554bc807b47ae50085012c86010 68701008801258901008a0104ab10840303a1d0830101840303a $1 \mathrm{~d} 0830101$

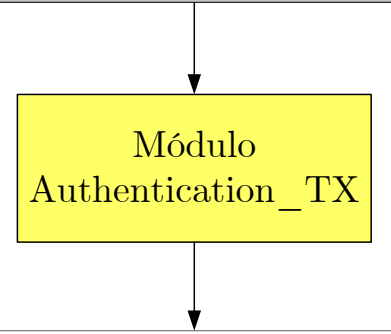

010ccd01000408606eda3a208100e00288b800020078000000006 $16 \mathrm{e} 80174436304 \mathrm{c} 44496 \mathrm{e} 73742 \mathrm{f} 4 \mathrm{c} 4 \mathrm{c} 4 \mathrm{e} 3024474 \mathrm{f} 2467636230318$ $102078082154436304 \mathrm{c} 44496 \mathrm{e} 73742 \mathrm{f} 4 \mathrm{c} 4 \mathrm{c} 4 \mathrm{e} 3024474 \mathrm{f} 4 \mathrm{f} 5345318$ 30a474f4f53454f75745f318408554bc807b47ae50085012c86010 68701008801258901008a0104ab10840303a1d0830101840303a 1d08301018c40c396dd744c96aef743eae3756f438f8cd69701a6 9d9cf915158b613f44096a9ec716bdc11639ffc00f1e71c6bd12ef4 6fc04e88f57a0cf763c05440ea539f8d1

Figura 82: Resultado da autenticação com SHA-3 512 bits

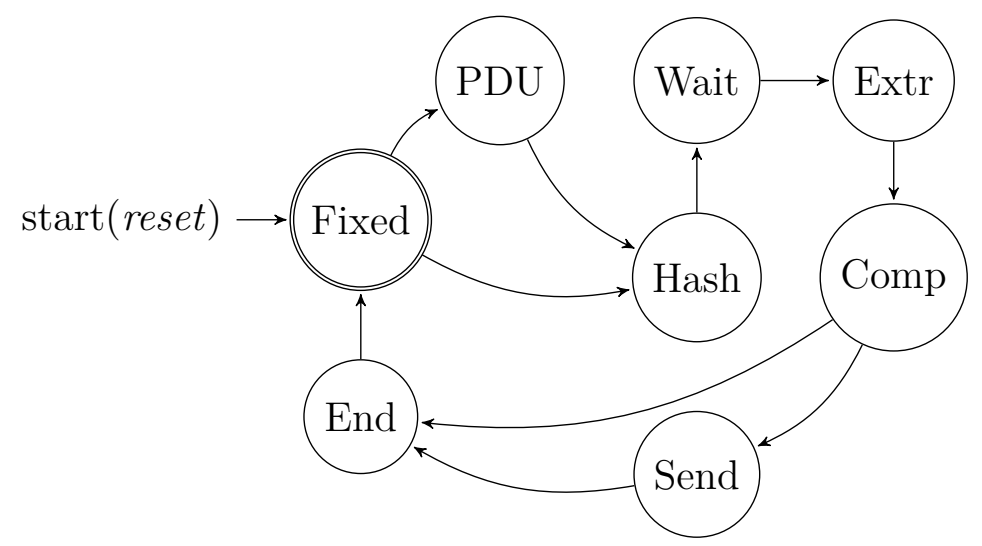

Figura 83: FSM sumarizada do módulo Authentication_RX

- O estado PDU_Field (PDU) envia os campos da matriz para a função Hash;

- O cálculo da função Keccak-f é de responsabilidade do estado Hash.

- O estado Wait aguarda que a função Hash retorne à flag out_Hash_rdy, informando que o MsAC está pronto; 
- A captura do campo Security, tag 0x8c é responsabilidade do estado Extract_Hash (Extr);

- A comparação entre o MsAC, retirado no quadro recebido, e o gerado na recepção, acontece no estado Compare_Hash (Comp). Caso os MsACs sejam iguais, o quadro será direcionado para o estado Send; caso contrário, o quadro será descartado;

- O estado Send transmite o quadro para a saída do módulo; e

- O estado End aguarda o fim do quadro para iniciar uma nova avaliação.

\subsubsection{Ensaios Realizados com o Authentication}

Por intermédio da topologia de ensaio, descrita na Figura 58 (Seção 4.10), foram transmitidas à interface PHY-0, da placa Dual Port, 10.000 mensagens GOOSE, geradas pelo RGGM e 15.000 mensagens de IEDs comerciais. Após transpor a NetFPGA-1 e, por conseguinte, o módulo Authentication_TX, as mensagens foram capturadas pelo aplicativo Wireshark ${ }^{\circledR}$ e as mensagens orignais também foram capturadas.

Posteriormente, a NetFPGA-1 foi configurada com o módulo Authentication_RX. Por meio da interface PHY-0, as 25.000 mensagens, com o campo Security tag 0x8c, foram encaminhadas para a interface $P H Y-1$. Após transpor a NetFPGA, as mensagens foram capturadas pelo sniffer de rede.

\subsubsection{Resultados com o Authentication}

O aplicativo VMG foi utilizado para comparar as mensagens originais com as mensagens GOOSE que passaram pelo módulo Authentication_RX. Em 100\% dos casos, elas foram reconstituídas corretamente.

\subsubsection{Ocupação do Hardware - Módulo Authentication}

A Figura 84 e a Figura 85 mostram informações do chip FPGA Virtex II PRO e um sumário da utilização e da distribuição lógica dos designs para os módulos Authentication_TX e Authentication_RX, respectivamente.

\subsubsection{Bloqueando um Ataque}

Para o processo de autenticação, foi realizado um ataque envolvendo os dois módulos: Authentication TX e Authentication RX, conforme ilustra a Figura 86. 


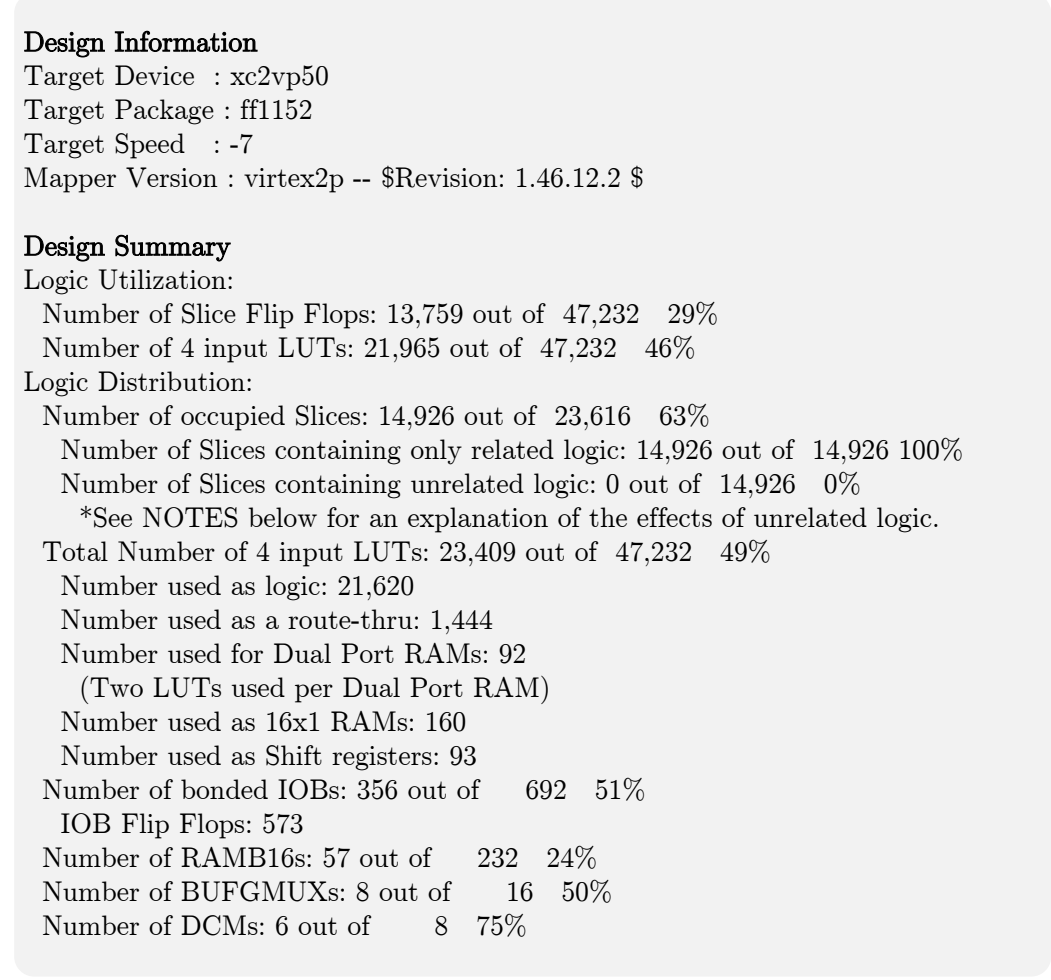

Figura 84: Sumário de utilização e distribuição lógica do design - Projeto Authentication_TX (Route 1)

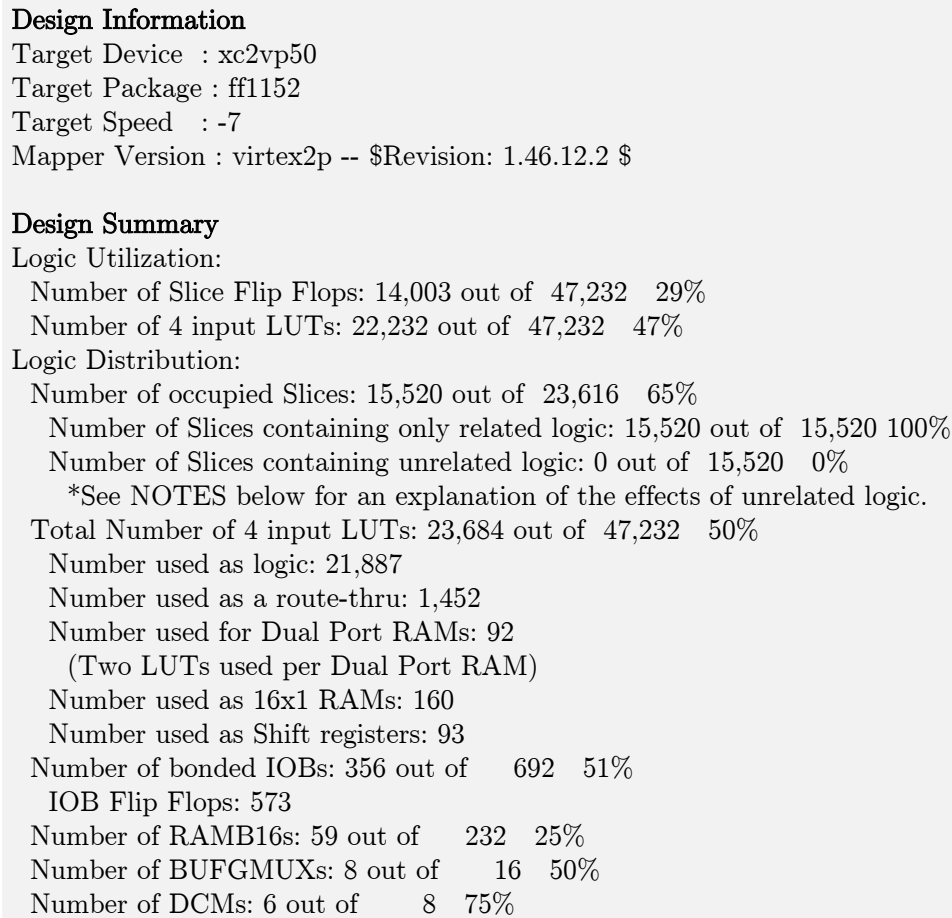

Figura 85: Sumário de utilização e distribuição lógica do design - Projeto Authentication_RX (Route 1) 


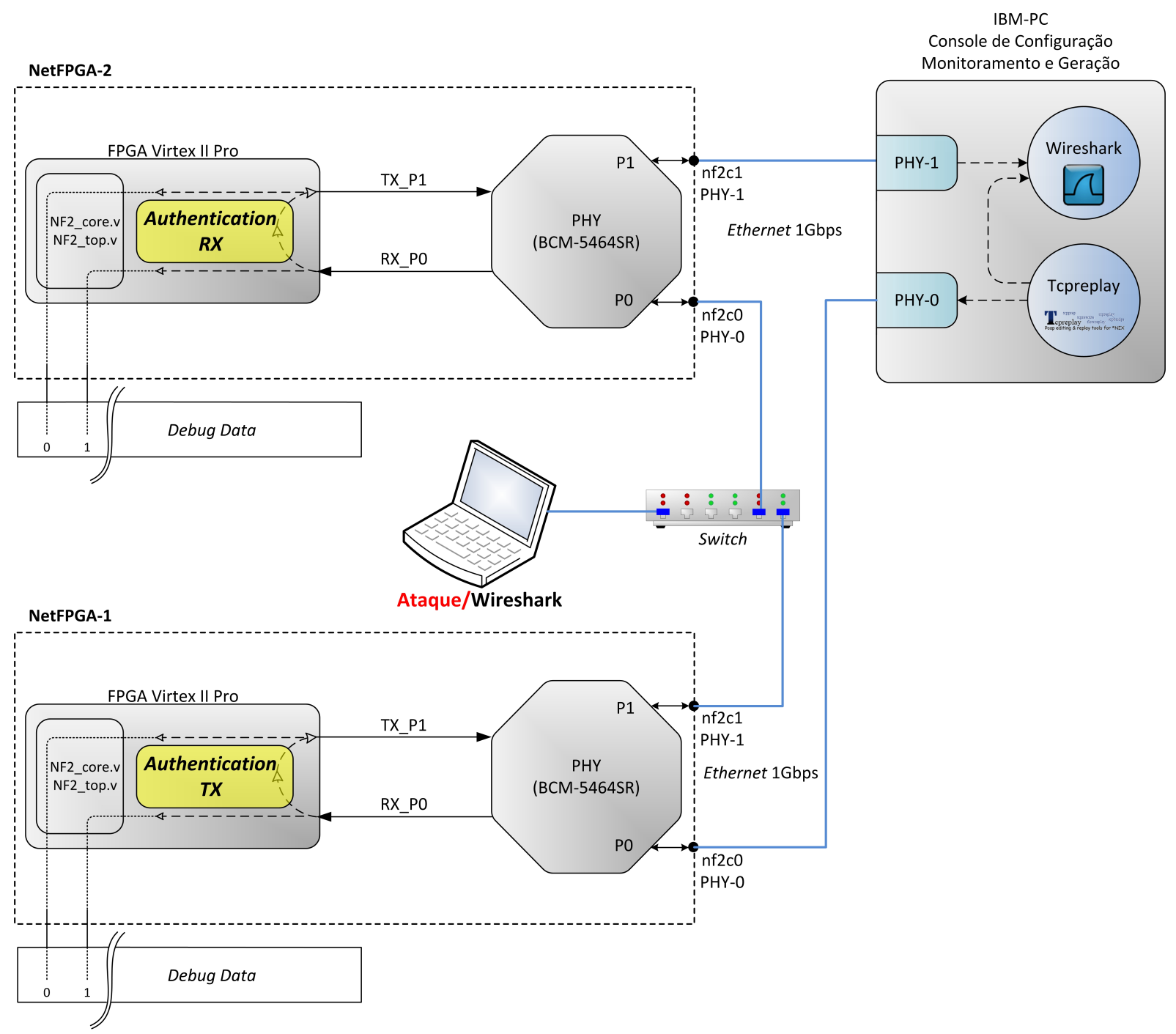

Figura 86: Arranjo do ensaio com os módulos Authentication $T X$ e $R X$

Por meio de um computador do tipo IBM PC (interface $P H Y-0$ ), as mensagens GOOSE foram replicadas, de um arquivo .pcap, para a porta P0 da NetFPGA-1. O módulo Authentication TX executou o algoritmo de autenticação do emissor e transmitiu as mensagens GOOSE, autenticadas para a NetFPGA-2. Estas mensagens, geradas pelo aplicativo de software Tcpreplay no emissor, receberam as alterações pelo algoritmo do módulo Authentication $R X$ e foram repassadas para a interface $P H Y-1$ do computador. Posteriormente, foram capturadas pelo sniffer de rede Wireshark ${ }^{\circledR}$ para comprovar sua transmissão, recepção e execução correta da funcionalidade dos módulos. As NetFPGAs foram conectadas por meio de um switch Ethernet Gigabit, formado por outra NetFPGA.

Um segundo computador do tipo IBM PC foi conectado no switch para enviar as mesmas mensagens transmitidas pelo Tcpreplay, como forma de um ataque, na tentativa de se passar pelo emissor real. Como emissor e receptor foram compostos por um computador, não ocorreu nenhum controle dos campos como stNum, sqNum, dentre outros.

Em um dos conjuntos de testes realizados, foram transmitidas 10.000 mensagens ver- 
dadeiras e 10.000 falsas, originadas pelo emissor real e pelo atacante, respectivamente. Na Figura 87, observa-se que a tela do atacante apresenta 20.000 mensagens, capturadas pelo sniffer de rede Wireshark ${ }^{\circledR}$, e a tela da interface $P H Y-1$ apresenta 10.000 mensagens GOOSE. Analisando as mensagens recebidas, nenhuma delas teve origem no atacante, em cuja interface, observa-se que as mensagens recebidas do emissor real são compostas pelo campo Security (0x8c).

A Figura 88 mostra os dispositivos reais utilizados para os ensaios. 


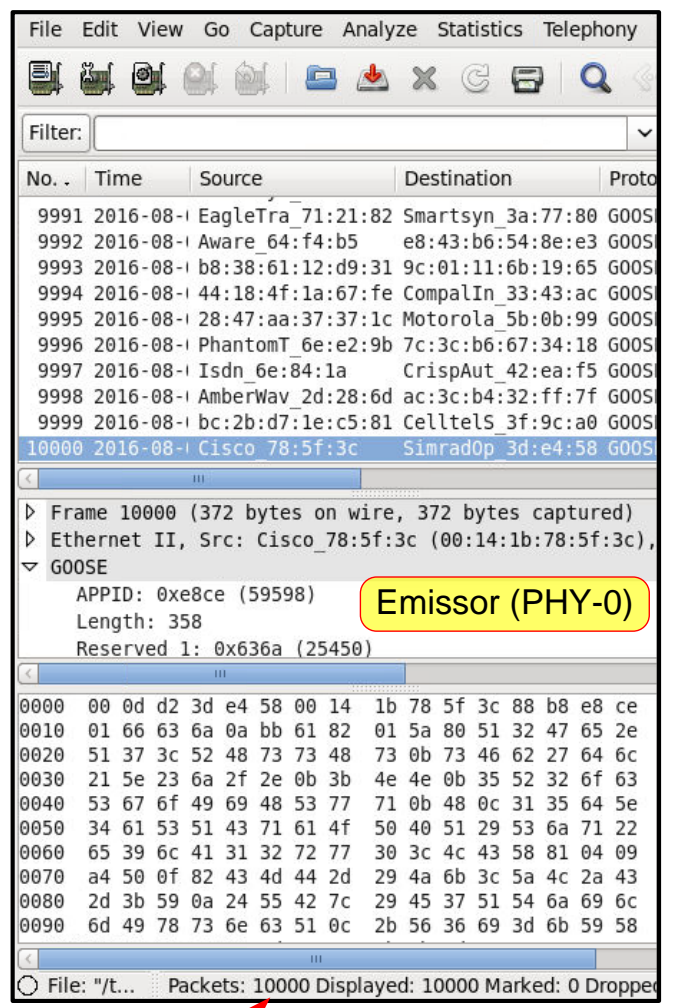

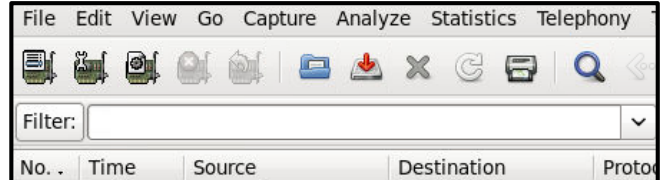

9991 2016-08-1 EagleTra-71:21:82 Smartsyn 3a:77:80 G00S

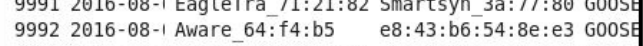
9993 2016-08-1 b8:38:61:12:d9:31 9c:01:11:6b:19:65 G00S 9994 2016-08-1 44:18:4f:1a:67:fe CompalIn 33:43:ac G00S 9995 2016-08-1 28:47:aa:37:37:1c Motorola 5b:0b:99 G00S 9996 2016-08-1 PhantomT_6e:e2:9b 7c:3c:b6:67:34:18 G00S 9997 2016-08-1 Isdn 6e:84:1a CrispAut 42:ea:f5 G00SB 9998 2016-08-1 AmberWav 2d:28:6d ac:3c:b4:32:ff: $7 f$ G00S 9999 2016-08-1 bc:2b:d7:1e:c5:81 Celltels $3 f: 9 c: a 0$ G00S $\frac{99992016-08-1 \text { bc:2b:d7:1e:c5:81 Celltels_3f:9c:a0 G00S }}{10000 \text { 2016-08-1 cisco 78:5f:3c Simradop 3d:e4:58 G00St }}$ 10000 2016-08-1 Cisco 78:5f:3

$D$ Frame 10000 (372 bytes on wire, 372 bytes captured) $D$ Ethernet II, Src: Cisco_78:5f:3c $(00: 14: 1 b: 78: 5 f: 3 c)$, GOOSE

APPID: 0xe8ce (59598) Receptor (PHY-1)

Reserved 1: Ox636a (25450)

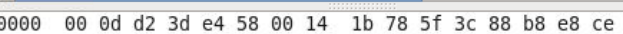

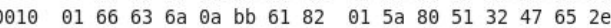
$\begin{array}{lllllllllllllllll}0020 & 51 & 37 & 3 \mathrm{c} & 52 & 48 & 73 & 73 & 48 & 73 & 0 b & 73 & 46 & 62 & 27 & 64 & 6 \mathrm{c}\end{array}$ $0030 \quad 215 e \quad 23$ 6a $2 f \quad 2 e$ ob $3 b \quad 4 e \quad 4 e$ ob $35 \quad 52 \quad 32$ 6f 63

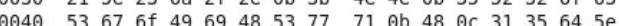

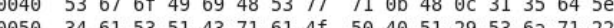

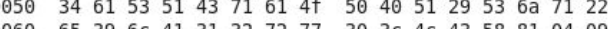

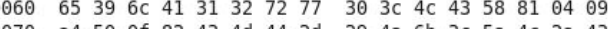

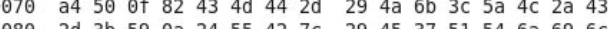
$\begin{array}{llllllllllllllllll}090 & 6 d & 49 & 78 & 73 & 6 e & 63 & 51 & 0 \mathrm{c} & 2 \mathrm{~b} & 56 & 36 & 69 & 3 \mathrm{~d} & 6 \mathrm{~b} & 59 & 58\end{array}$

F File: "/t... Packets: 10000 Displayed: 10000 Marked: 0 Dropped 0 File: "/t... Packets: 10000 Displayed: 10000 Marked: 0 Dropped

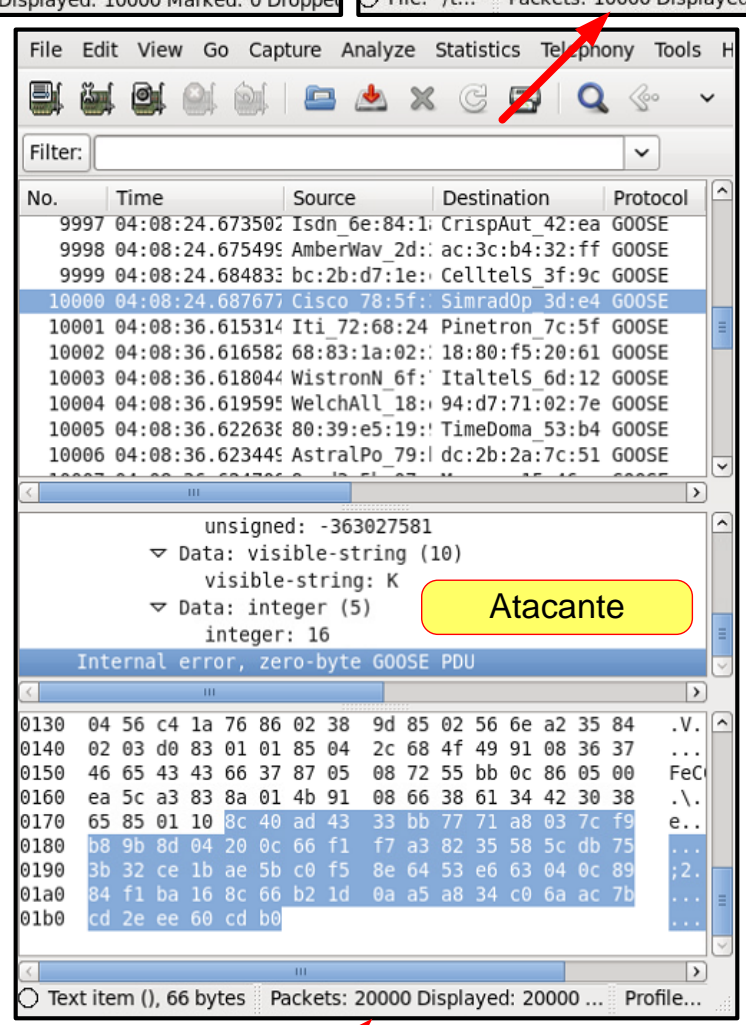

Figura 87: Resultado da autenticação e do ataque 


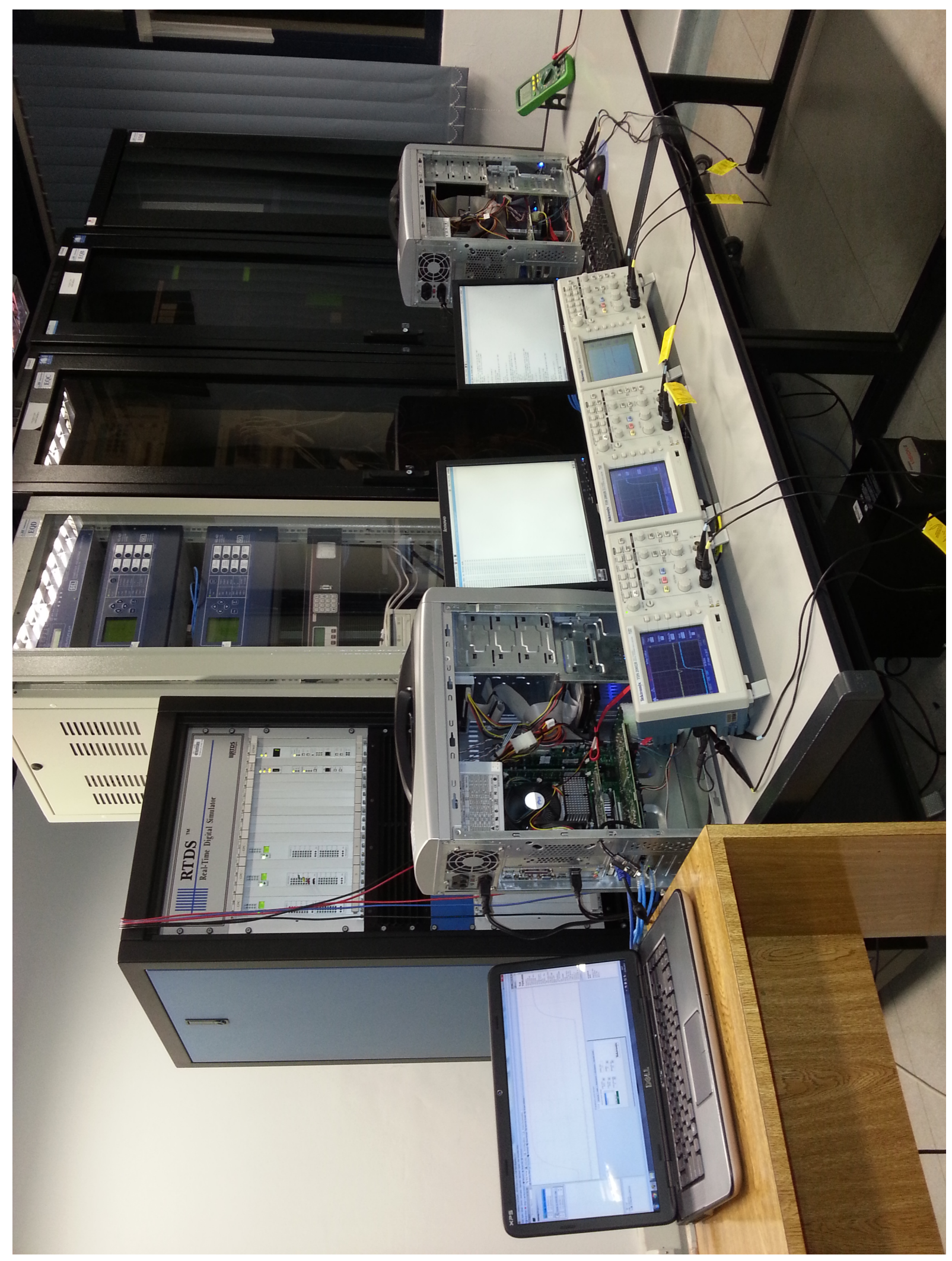

Figura 88: Dispositivos reais da topologia de ensaio - LSEE/EESC/USP (\#2) 


\section{Resultados e Discussões}

No Capítulo 1, foi estabelecida a seguinte questão: é possivel utilizar um firewall como um encaminhador de mensagens, capaz de auxiliar contra ameaças à segurança da rede de uma subestação de energia elétrica, sem depreciar demasiadamente o tempo de transferência das mensagens GOOSE? O Capítulo 5 mostrou que o firewall é capaz de auxiliar contra ameaças à segurança da rede de uma subestação. E, para averiguar o impacto dos módulos, no que tange ao tempo de transferência (TT) da mensagem GOOSE, foram executadas 10.000 transmissões de mensagem GOOSE para cada módulo, variando o tamanho da mensagem a cada 1000 transmissões $^{1}$. Os tamanhos estabelecidos foram os seguintes: 69B (bytes), 128B, 256B, 409B, 512B, 768B, 1024B, 1280B, 1500B e 1518B. Este capítulo apresenta os resultados de um estudo estatístico para responder ao questionamento inicial. Esse estudo foi realizado por meio do software R (versão 3.1.3) com apoio da empresa ABG Consultoria Estatística Ltda ${ }^{2}$.

\subsection{A Metodologia para Medição}

Os componentes principais da plataforma NetFPGA para executar as medições do tempo de transferência foram: o chip FPGA Virtex-II PRO da Xilinx ${ }^{\circledR}$, que permite o acesso à indicação de transmissão e recepção de quadros Ethernet por meio dos sinais da interface RGMII (Reduced Gigabit Media Independent Interface); e o controlador Ethernet BCM5464SR da Broadcom ${ }^{\circledR}$, conforme ilustra o diagrama da Figura 89.

Os sinais digitais RGMII_TX_CTL e RGMII_RX_CTL (Figura 89) são habilitados, em nível lógico 1, enquanto houver bits de dados para serem transmitidos ou recebidos, respectivamente. Estes sinais são encaminhados para a interface denominada Debug Data, que permite o acesso direto de um osciloscópio aos pinos da FPGA, como mostra a Figura 58 (Seção 4.10).

\footnotetext{
${ }^{1} \mathrm{O}$ cálculo do número de amostras pode ser observado no Apêndice B.

${ }^{2}$ Registrada no Conselho Regional de Estatística da $6^{\mathrm{a}}$ região sob o número 099.
} 


\section{Módulo RGMII}

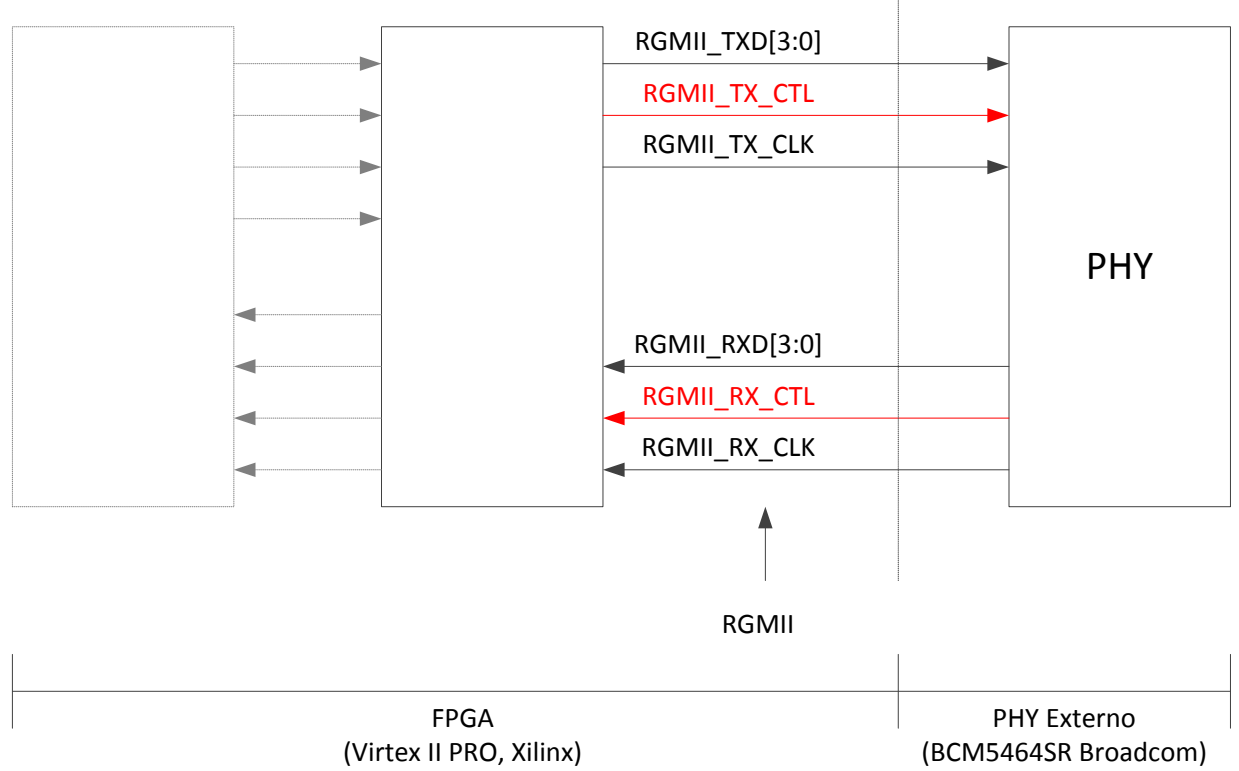

Figura 89: Diagrama de blocos em alto nível dos sinais RGMII - PHY

Fonte: Low (2006)

A medição do tempo de transferência realizada foi do tipo LIFO (Last-In First-Out), definido na RFC 1242 (YANG, 2012), como a medida de latência, que começa assim que o último bit do quadro ISO/IEC 8802-3 entra na NetFPGA e para quando o primeiro bit do quadro deixa a NetFPGA, como ilustra a Figura 90.

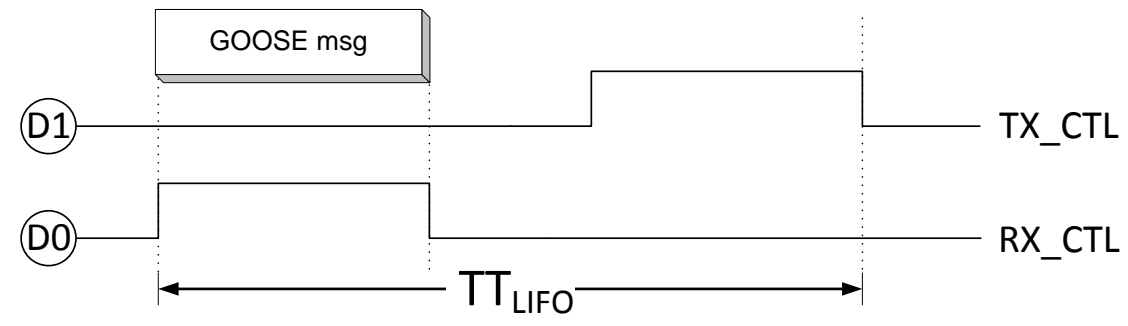

Figura 90: Medida do tempo de transferência/latência (LIFO)

Na medição cada quadro foi enviado por meio da interface PHY-O da placa Dual Port para a NetFPGA-1 (Figura 58, Seção 4.10), que também recebeu o quadro na $P H Y-0\left(\mathrm{P}_{0}\right)$ e habilitou o sinal RGMII_RX_CTL. Após passar pelo módulo, Route 1, cada quadro foi redirecionado via $P H Y-1\left(\mathrm{P}_{1}\right)$ da NetFPGA-1 para a $P H Y-1$ da placa Dual Port, e habilitou o sinal RGMII_TX_CTL.

As medições realizadas pelo osciloscópio, com o valor do $\mathrm{TT}_{L I F O}$, foram obtidas por meio de comandos SCPI (Standard Commands for Programmable Instruments) e armazenadas em arquivo texto para posterior avaliação. 


\subsection{Os Módulos Utilizados}

Os módulos considerados para os testes do tempo de transferência foram os seguintes:

- Módulo 1 (M1): como módulo base, foi criado um projeto considerando os módulos Route 1 e Route 2, sem qualquer processamento interno, apenas uma ponte entre a porta 0 e a porta 1 da NetFPGA;

- Módulo 2 (M2): o Módulo ASN.1/BER GOOSE;

- Módulo 3 (M3): o Módulo Filter, configurado com um filtro, utilizando todos os campos da mensagem GOOSE;

- Módulo 4 (M4): o Módulo Filter, configurado com um filtro, utilizando todos os campos da mensagem GOOSE (2 mensagens diferentes);

- Módulo 5 (M5): o Módulo Filter, configurado com um filtro, utilizando apenas um campo da mensagem GOOSE;

- Módulo 6 (M6): o Módulo Crypto, configurado com o algoritmo XOR;

- Módulo 7 (M7): o Módulo Crypto, configurado com o algoritmo DES (criptografia);

- Módulo 8 (M8): o Módulo Crypto, configurado com o algoritmo DES (decriptografia);

- Módulo 9 (M9): o Módulo Authentication_TX, configurado com o algoritmo SHA-3;

- Módulo 10 (M10): o Módulo Authentication_RX, configurado com o algoritmo SHA-3.

\subsection{A Metodologia Estatística}

A metodologia para descrever o tempo de transferência entre os tamanhos da mensagem GOOSE, considerando todos os módulos, estratificando por módulo e estratificando pela soma dos módulos; assim como para descrever o tempo de transferência entre os módulos, considerando todos os tamanhos da mensagem e estratificando por tamanho, utilizou medidas de tendência central, posição e dispersão. Para verificar se existia diferença do tempo de transferência entre os tamanhos da mensagem e entre os módulos, considerando ou não as estratificações, foi utilizado o teste de Kruskal-Wallis (HOLLANDER; WOLFE; CHICKEN, 2013), sendo que para as comparações múltiplas, foi utilizado o teste de Nemenyi (1962). Para analisar o crescimento do tempo de transferência quando se aumenta o tamanho da mensagem, foi ajustada uma Regressão Gama (MCCULLAGH; NELDER, 1989).

Seguem algumas definições utilizadas nesse estudo: 
Amplitude - É a diferença entre o maior e o menor valor do conjunto de $n$ observações;

C.V. - Coeficiente de Variação. É uma medida adimensional, geralmente expressa em porcentagem e indica que percentual o desvio padrão representa em relação à média.

D.P. - Desvio Padrão. É uma das principais medidas de dispersão dos dados. Pode ser definida como a raiz quadrada da variância. Sua medida representa o quanto os dados se afastam da média;

E.P. - Erro Padrão. O erro padrão é uma medida da precisão da média amostral. O erro padrão é obtido, dividindo o desvio padrão pela raiz quadrada do tamanho da amostra;

I.C. - 95\% - Intervalo de 95\% de Confiança. É estimado para um parâmetro estatístico. Em vez de se estimar o parâmetro por um único valor, é dado um intervalo de estimativas prováveis. Um intervalo de $95 \%$ de confiança garante que o parâmetro pontual, estimado com $95 \%$ de confiança, estará dentro do intervalo estimado em outras amostras da mesma população;

Outlier - Pontos extremos que apresentam um grande afastamento dos demais da série;

TT - Tempo de Transferência da mensagem GOOSE;

TM - Tamanho da Mensagem GOOSE;

Valor-p (ou p-Valor) - É uma estatística utilizada para sintetizar o resultado de um teste de hipóteses. Formalmente, o p-valor é definido como a probabilidade de se obter uma estatística de teste igual ou mais extrema que aquela observada em uma amostra, assumindo como verdadeira a hipótese nula. Como geralmente se define o nível de significância em 5\%, um p-valor menor que 0,05 gera evidências para a rejeição da hipótese nula do teste;

$\mathbf{1}^{\mathrm{o}} \mathbf{Q}-1^{\mathrm{o}}$ Quartil. O primeiro quartil é uma medida de posição que representa que, pelo menos, $25 \%$ das respostas são menores que ele;

$2^{\mathbf{o}} \mathbf{Q}-2^{\mathrm{o}}$ Quartil. O segundo quartil, também conhecido como mediana, é uma medida de posição que representa que, pelo menos, $50 \%$ das respostas são menores que ele;

$3^{\mathbf{o}} \mathbf{Q}-3^{\circ}$ Quartil. O terceiro quartil é uma medida de posição que representa que, pelo menos, $75 \%$ das respostas são menores que ele; 
$\beta$ - São os coeficientes da regressão.

\subsection{Comparação do TT entre os TMs}

A Tabela 19 apresenta a descrição do tempo de transferência entre os tamanhos da mensagem GOOSE, considerando todos os módulos. A partir dela, pode-se concluir que:

- Ao realizar-se o teste de Kruskal-Wallis foi possível inferir que houve diferença significativa (Valor-p $=0,000$ ) do tempo de transferência entre os tamanhos da mensagem. As comparações múltiplas feitas pelo teste de Nemenyi encontram-se na Tabela 20, na qual se pode verificar que houve diferença significativa (Valor-p = 0,000) do tempo de transferência entre todos os tamanhos da mensagem, sendo que, na medida em que se aumentou o tamanho da mensagem, houve um aumento no tempo de transferência médio;

- O maior valor foi de $0,07739 \mathrm{~ms}$ referente ao tamanho da mensagem 1518B, sendo menor que o tamanho desejado de $1 \mathrm{~ms}$. Além disso, a maior amplitude também foi dessa mensagem, sendo igual a 0,05120ms;

- O tamanho da mensagem 1518B foi o que apresentou o maior desvio padrão, seguido pelo tamanho 1500B. Esses dois tamanhos foram também os que apresentaram os maiores coeficientes de variação, sendo que, os desvios relativos à média atingiram, respectivamente, 40,63\% e 40,38\% do valor desta; e

- Também foi observada uma tendência crescente no tempo de transferência nas medidas de mínimo, primeiro quartil, segundo quartil, terceiro quartil, máximo e amplitude.

Tabela 19: Descrição do tempo de transferência (ms) entre os tamanhos da mensagem, considerando todos os módulos

\begin{tabular}{cccccccccc}
\hline TM & Média & D.P. & C.V.(\%) & Mín. & $\mathbf{1}^{\mathbf{o}} \mathbf{Q}$ & $\mathbf{2}^{\mathbf{o}} \mathbf{Q}$ & $\mathbf{3}^{\mathbf{o}} \mathbf{Q}$ & Máx. & Amplitude \\
\hline 69 & 0,00318 & 0,00105 & 33,01887 & 0,00155 & 0,00247 & 0,00351 & 0,00371 & 0,00472 & 0,00317 \\
128 & 0,00546 & 0,00169 & 30,95238 & 0,00255 & 0,00454 & 0,00639 & 0,0065 & 0,00735 & 0,0048 \\
256 & 0,01027 & 0,00309 & 30,08763 & 0,00473 & 0,00902 & 0,01193 & 0,01278 & 0,01294 & 0,00821 \\
409 & 0,01609 & 0,00484 & 30,0808 & 0,00734 & 0,01468 & 0,01793 & 0,0195 & 0,02103 & 0,01369 \\
512 & 0,01906 & 0,00578 & 30,32529 & 0,00908 & 0,01668 & 0,02149 & 0,02211 & 0,02598 & 0,0169 \\
768 & 0,02362 & 0,00862 & 36,4945 & 0,01343 & 0,01811 & 0,02346 & 0,02401 & 0,03904 & 0,02561 \\
1024 & 0,03125 & 0,01142 & 36,544 & 0,01779 & 0,02523 & 0,0305 & 0,03066 & 0,05209 & 0,0343 \\
1280 & 0,03769 & 0,01456 & 38,63094 & 0,02214 & 0,03034 & 0,03511 & 0,03578 & 0,06515 & 0,04301 \\
1500 & 0,04313 & 0,01742 & 40,38952 & 0,02588 & 0,03438 & 0,03898 & 0,03999 & 0,07654 & 0,05066 \\
1518 & 0,04346 & 0,01766 & 40,63507 & 0,02619 & 0,0344 & 0,03948 & 0,04002 & 0,07739 & 0,0512 \\
\hline
\end{tabular}


Tabela 20: Comparação do tempo de transferência (ms) entre os tamanhos da mensagem, considerando todos os módulos

\begin{tabular}{|c|c|c|c|c|c|c|c|c|c|c|c|c|}
\hline \multirow{2}{*}{ TM } & \multirow{2}{*}{$2^{\circ} \mathrm{Q}$} & \multirow{2}{*}{$1^{\circ} \mathrm{Q}$} & \multirow{2}{*}{$3^{\circ} \mathrm{Q}$} & \multicolumn{9}{|c|}{ Valor-p das Comparações Múltiplas } \\
\hline & & & & 69 & 128 & 256 & 409 & 512 & 768 & 1024 & 1280 & 1500 \\
\hline 69 & 0,00351 & 0,00247 & 0,00371 & & & & & & & & & \\
\hline 128 & 0,00639 & 0,00454 & 0,0065 & 0 & & & & & & & & \\
\hline 256 & 0,01193 & 0,00902 & 0,01278 & 0 & 0 & & & & & & & \\
\hline 409 & 0,01793 & 0,01468 & 0,0195 & 0 & 0 & 0 & & & & & & \\
\hline 512 & 0,02149 & 0,01668 & 0,02211 & 0 & 0 & 0 & 0 & & & & & \\
\hline 768 & 0,02346 & 0,01811 & 0,02401 & 0 & 0 & 0 & 0 & 0 & & & & \\
\hline 1024 & 0,0305 & 0,02523 & 0,03066 & 0 & 0 & 0 & 0 & 0 & 0 & & & \\
\hline 1280 & 0,03511 & 0,03034 & 0,03578 & 0 & 0 & 0 & 0 & 0 & 0 & 0 & & \\
\hline 1500 & 0,03898 & 0,03438 & 0,03999 & 0 & 0 & 0 & 0 & 0 & 0 & 0 & 0 & \\
\hline 1518 & 0,03948 & 0,0344 & 0,04002 & 0 & 0 & 0 & 0 & 0 & 0 & 0 & 0 & 0 \\
\hline
\end{tabular}

A Figura 91 apresenta o boxplot do tempo de transferência por tamanho da mensagem, enquanto a Figura 92 apresenta um gráfico de barras representando a média do tempo de transferência por tamanho da mensagem, com barras de erro representando o mínimo e o máximo. Na Figura 91, também foram encontrados 2000 outliers no tamanho 409B, 2000 no tamanho 768B, 2000 no tamanho 1024B, 4000 no tamanho 1280B, 4000 no tamanho 1500B e 2000 no tamanho 1518B.

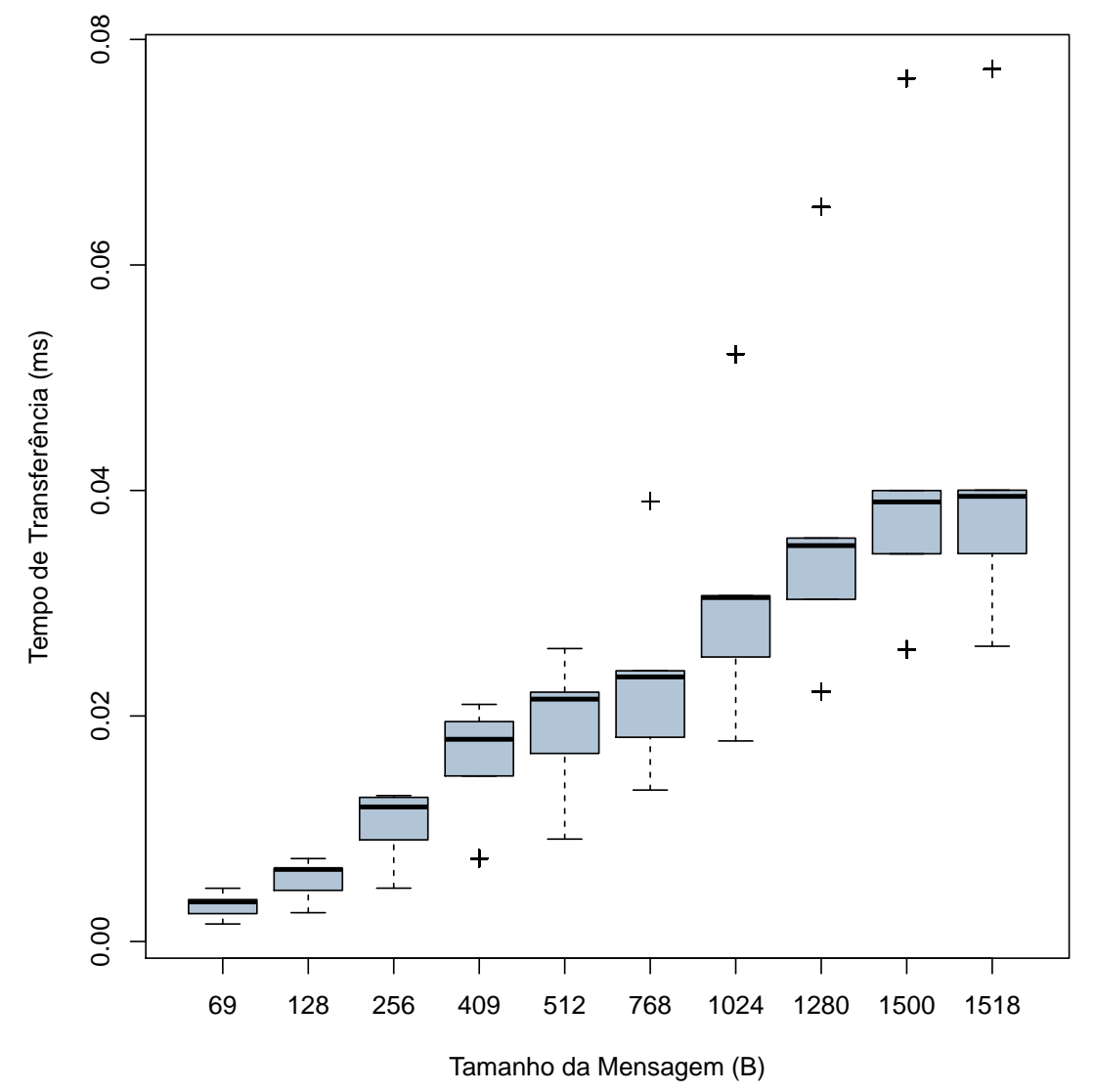

Figura 91: Boxplot do tempo de transferência por tamanho da mensagem, considerando todos os módulos 


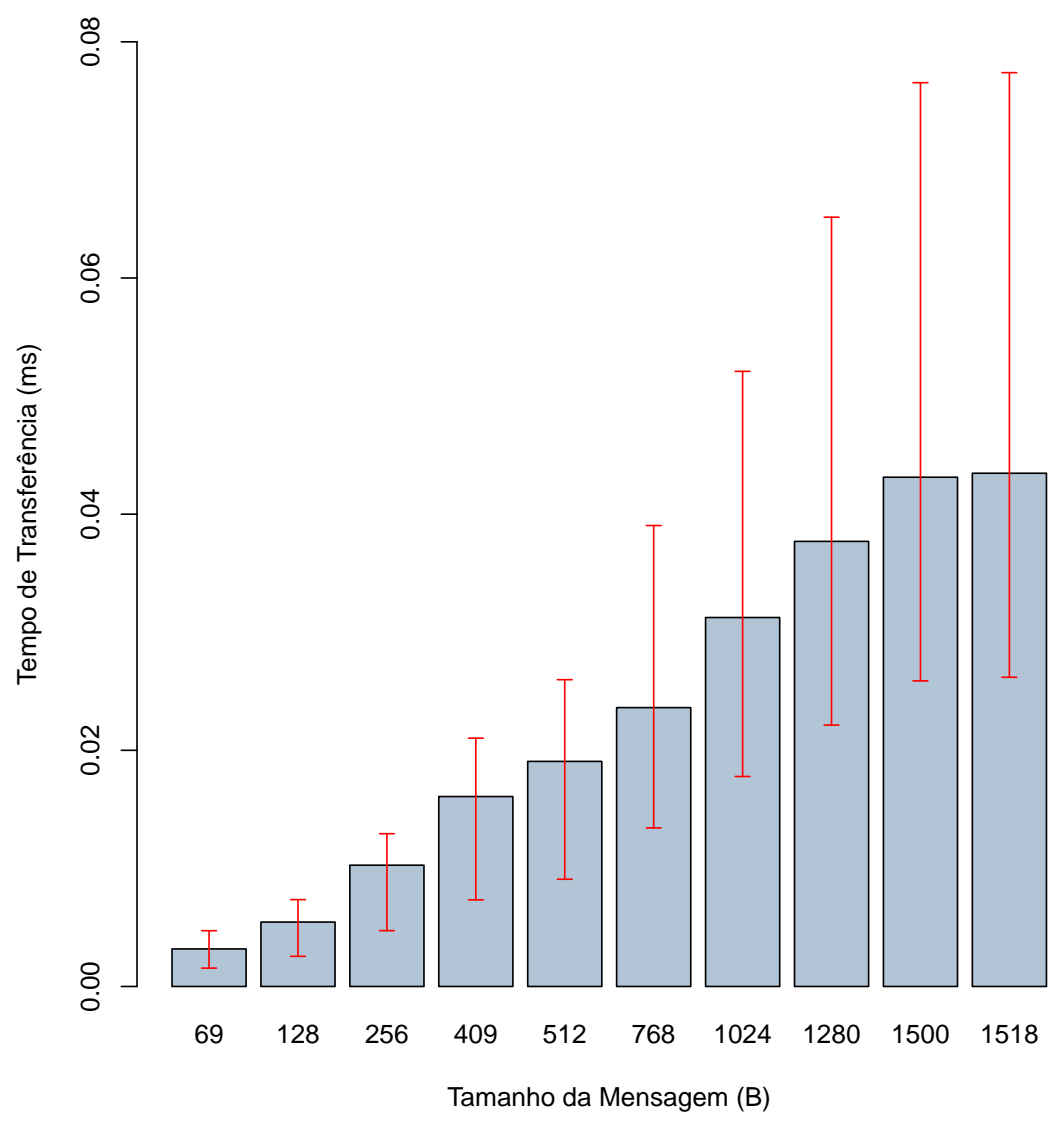

Figura 92: Gráfico de barras do tempo de transferência médio por tamanho da mensagem, com barras de erro representando o mínimo e o máximo, considerando todos os módulos

\subsection{Comparação do TT entre os Módulos}

A Tabela 21 apresenta a descrição do tempo de transferência entre os módulos, considerando todos os tamanhos da mensagem. A partir dela, pode-se concluir que: o maior valor foi de $0,07739 \mathrm{~ms}$ referente ao módulo 8, sendo menor que o tamanho desejado de 1ms. Além disso, a maior amplitude também foi desse módulo, sendo igual a 0,07388ms. Ao interpretar o segundo quartil (mediana), tem-se que nos módulos 7 e 8, pelo menos $50 \%$ das observações apresentaram tempo de transferência menores que 0,03250ms, enquanto nos módulos 1 e 6 , pelo menos $50 \%$ das observações apresentaram tempos de transferência menores que 0,01126 e 0,01130ms, respectivamente. Os módulos 1 e 6 apresentaram os menores valores nas medidas média, desvio padrão, mínimo, primeiro quartil, segundo quartil, terceiro quartil, máximo e amplitude. Os módulos 7 e 8 apresentaram os maiores valores nas medidas média, desvio padrão, coeficiente de variação, primeiro quartil, segundo quartil, terceiro quartil, máximo e amplitude. Os módulos 9 e 10 apresentaram os menores valores no coeficiente de variação e os maiores valores no mínimo.

Ao realizar-se o teste de Kruskal-Wallis, foi possível concluir que houve diferença significativa (Valor-p $=0,000$ ) do tempo de transferência entre os módulos. As comparações múltiplas, feitas pelo teste de Nemenyi, encontram-se na Tabela 22, na qual se pode verificar que não houve diferença significativa do tempo de transferência, apenas entre os 
Tabela 21: Descrição do tempo de transferência (ms) entre os módulos, considerando todos os tamanhos da mensagem

\begin{tabular}{cccccccccc}
\hline Módulo & Média & D.P. & C.V.(\%) & Mín. & $\mathbf{1}^{\mathbf{0}} \mathbf{Q}$ & $\mathbf{2}^{\mathbf{0}} \mathbf{Q}$ & $\mathbf{3}^{\mathbf{o}} \mathbf{Q}$ & Máx. & Amplitude \\
\hline 1 & 0,01307 & 0,00896 & 68,55394 & 0,00155 & 0,00473 & 0,01126 & 0,02214 & 0,02619 & 0,02464 \\
2 & 0,01898 & 0,01117 & 58,85142 & 0,00247 & 0,00902 & 0,01739 & 0,03034 & 0,0344 & 0,03193 \\
3 & 0,02296 & 0,01235 & 53,7892 & 0,00371 & 0,01193 & 0,02275 & 0,03511 & 0,03948 & 0,03577 \\
4 & 0,02296 & 0,01235 & 53,7892 & 0,0037 & 0,01193 & 0,02275 & 0,03511 & 0,03948 & 0,03578 \\
5 & 0,01902 & 0,01117 & 58,72766 & 0,0025 & 0,00905 & 0,01743 & 0,03038 & 0,03444 & 0,03194 \\
6 & 0,01311 & 0,00896 & 68,34477 & 0,00159 & 0,00478 & 0,0113 & 0,02218 & 0,02624 & 0,02465 \\
7 & 0,03800 & 0,02687 & 70,71053 & 0,00351 & 0,01293 & 0,0325 & 0,06514 & 0,07738 & 0,07387 \\
8 & 0,03800 & 0,02688 & 70,73684 & 0,00351 & 0,01294 & 0,0325 & 0,06514 & 0,07739 & 0,07388 \\
9 & 0,02343 & 0,01218 & 51,98464 & 0,0045 & 0,01261 & 0,02267 & 0,03562 & 0,03965 & 0,03515 \\
10 & 0,02365 & 0,01222 & 51,67019 & 0,00471 & 0,01278 & 0,02283 & 0,03578 & 0,04003 & 0,03532 \\
\hline
\end{tabular}

módulos 1 e 6 (Valor-p =0,176), 2 e 5 (Valor-p =0,095), 3 e 4 (Valor-p =1,000) e 7 e 8 (Valor-p $=0,999)$. Tal comportamento é ocasionado pelo processamento similar de alguns módulos.

Tabela 22: Comparação do tempo de transferência (ms) entre os módulos, considerando todos os tamanhos da mensagem

\begin{tabular}{|c|c|c|c|c|c|c|c|c|c|c|c|c|}
\hline \multirow{2}{*}{ Mód. } & \multirow{2}{*}{$2^{\mathrm{o}} \mathrm{Q}$} & \multirow{2}{*}{$1^{\circ} \mathrm{Q}$} & \multirow{2}{*}{$3^{\circ} \mathrm{Q}$} & \multicolumn{9}{|c|}{ Valor-p das Comparações Múltiplas } \\
\hline & & & & 1 & 2 & 3 & 4 & 5 & 6 & 7 & 8 & 9 \\
\hline 1 & 0,01126 & 0,00473 & 0,02214 & & & & & & & & & \\
\hline 2 & 0,01739 & 0,00902 & 0,03034 & 0 & & & & & & & & \\
\hline 3 & 0,02275 & 0,01193 & 0,03511 & 0 & 0 & & & & & & & \\
\hline 4 & 0,02275 & 0,01193 & 0,03511 & 0 & 0 & 1 & & & & & & \\
\hline 5 & 0,01743 & 0,00905 & 0,03038 & 0 & 0,095 & 0 & 0 & & & & & \\
\hline 6 & 0,01130 & 0,00478 & 0,02218 & 0,176 & 0 & 0 & 0 & 0 & & & & \\
\hline 7 & 0,03250 & 0,01293 & 0,06514 & 0 & 0 & 0 & 0 & 0 & 0 & & & \\
\hline 8 & 0,03250 & 0,01294 & 0,06514 & 0 & 0 & 0 & 0 & 0 & 0 & 0,999 & & \\
\hline 9 & 0,02267 & 0,01261 & 0,03562 & 0 & 0 & 0,001 & 0,001 & 0 & 0 & 0 & 0 & \\
\hline 10 & 0,02283 & 0,01278 & 0,03578 & 0 & 0 & 0 & 0 & 0 & 0 & 0 & 0 & 0,005 \\
\hline
\end{tabular}

A Figura 93 apresenta o boxplot do tempo de transferência por módulo, enquanto a Figura 94 apresenta um gráfico de barras, representando a média do tempo de transferência por módulo, com barras de erro, representando o mínimo e o máximo. Não foram encontrados outliers na Figura 93.

\subsection{Comparação do TT entre os TMs Estratificada por Módulo}

A Tabela 28, no Apêndice C, apresenta a descrição do tempo de transferência entre os tamanhos da mensagem estratificada por módulo. A partir dela, pode-se concluir que: 


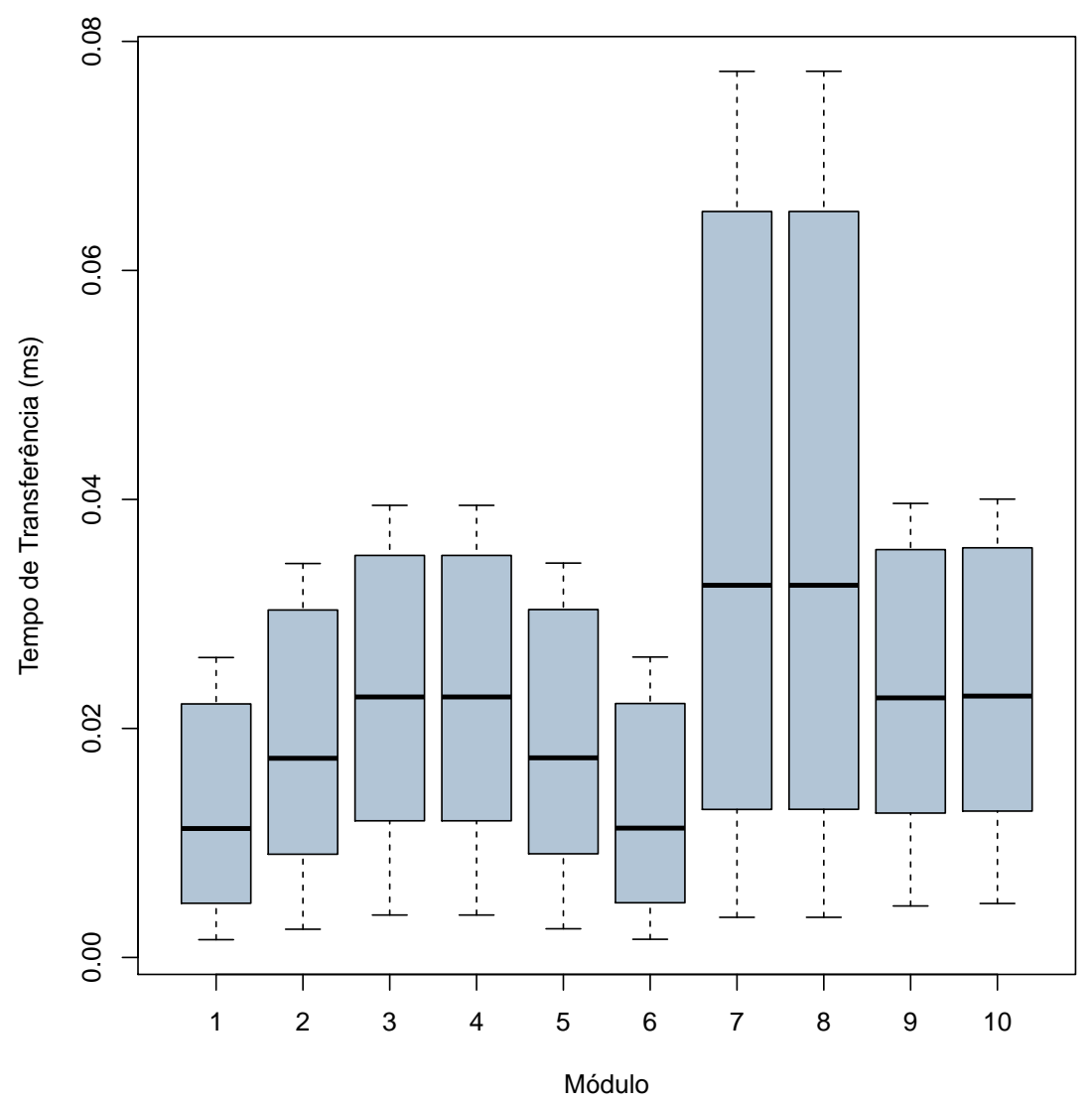

Figura 93: Boxplot do tempo de transferência por módulo, considerando todos os tamanhos da mensagem

- Em todos os módulos, ao se realizar o teste de Kruskal-Wallis, foi possível constatar que houve diferença significativa (Valor-p $=0,000$ ) do tempo de transferência entre os tamanhos da mensagem. As comparações múltiplas feitas pelo teste de Nemenyi, encontram-se na Tabela 29, no Apêndice C, na qual se pode verificar que houve diferença significativa (Valor-p $=0,000$ ) do tempo de transferência entre todos os tamanhos da mensagem, sendo que, na medida que se aumentou o tamanho da mensagem, houve um aumento no tempo médio de transferência; e

- O maior valor foi de 0,07739ms referente ao tamanho da mensagem 1518B no módulo 8, sendo menor que o tamanho desejado de $1 \mathrm{~ms}$. Além disso, a maior amplitude foi de 9,40ns, no módulo 10, nos tamanhos 256B, 409B, 512B e 1500B. Cabe ressaltar que todas as amplitudes ficaram próximas de 8ns, o que indica que a NetFFPGA responde de forma equivalente, independentemente do módulo e do tamanho das mensagens. Essas informações também podem ser vistas nas Figuras 96 a 105, que serão apresentadas posteriormente.

A Tabela 29, no Apêndice C, apresenta as comparações múltiplas feitas pelo teste de Nemenyi. 


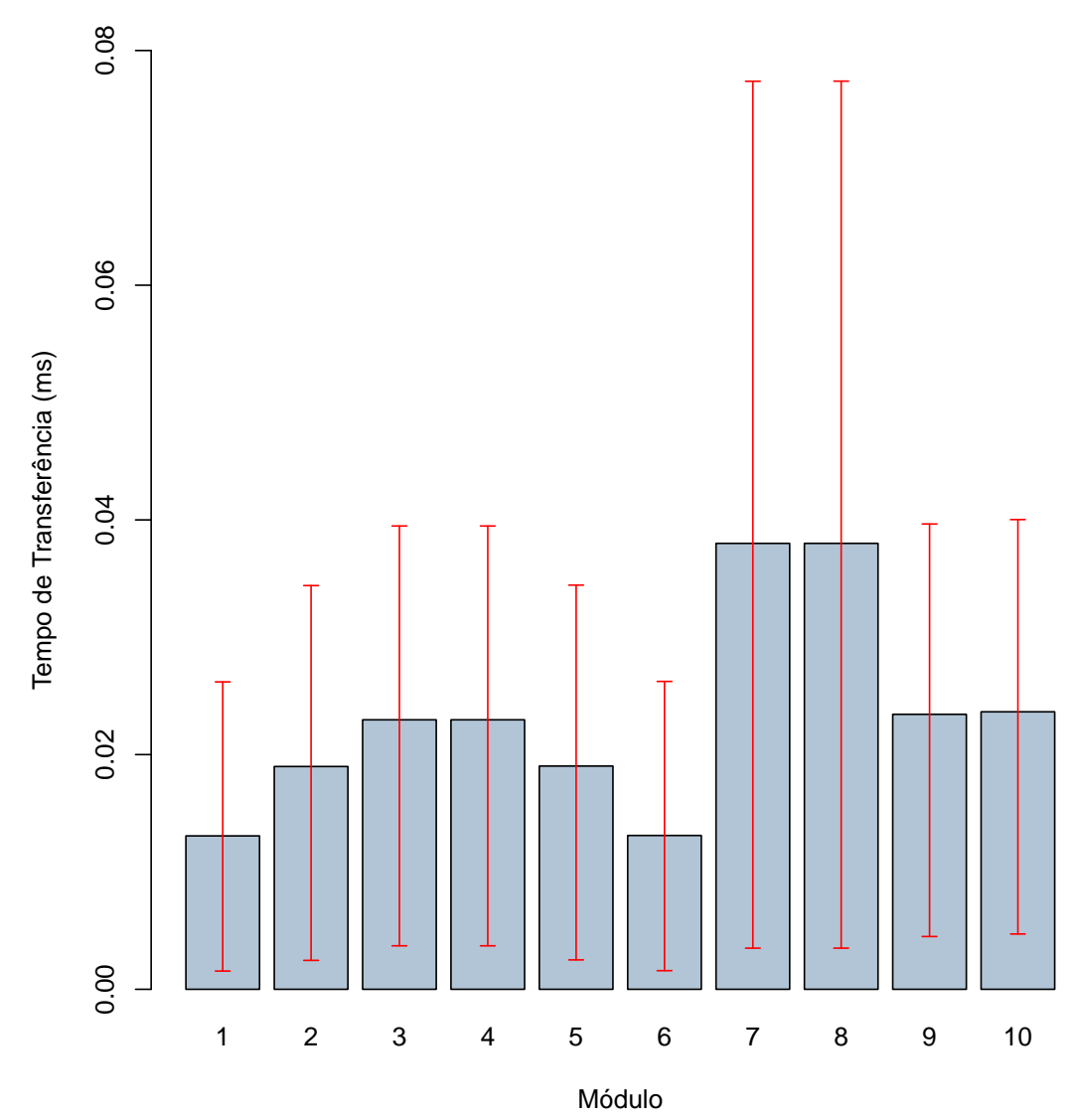

Figura 94: Gráfico de barras, representando a média do tempo de transferência por módulo, com barras de erro representando o mínimo e o máximo, considerando todos os tamanhos da mensagem

A Figura 95 apresenta o gráfico de linhas das médias do tempo de transferência entre os tamanhos da mensagem e os módulos.

As Figuras 96 a 105 apresentam os gráficos de barras do valor máximo e da amplitude do tempo de transferência, por tamanho da mensagem estratificada por módulo. 


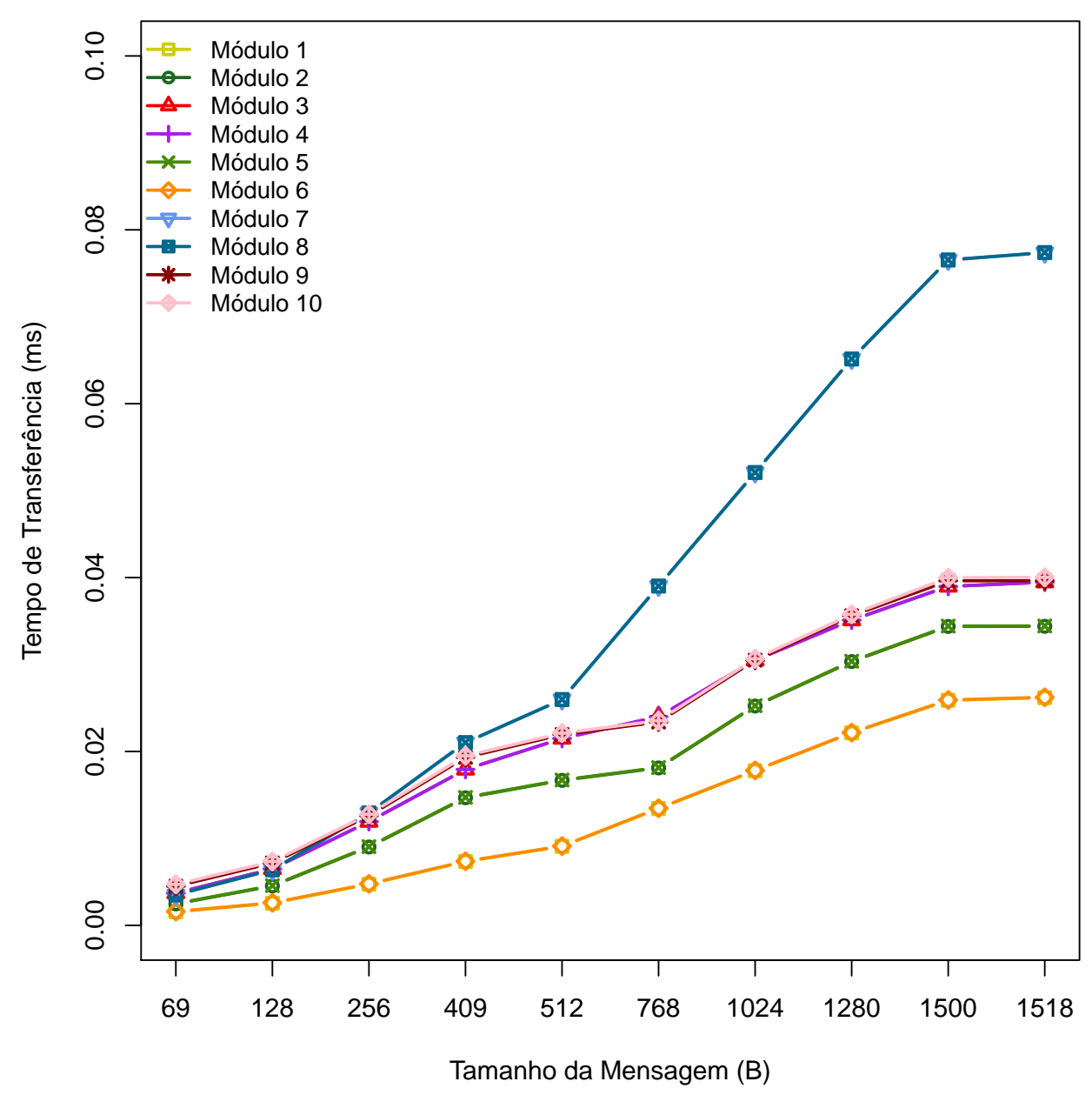

Figura 95: Gráfico de linhas das médias do tempo de transferência entre os tamanhos da mensagem e os módulos

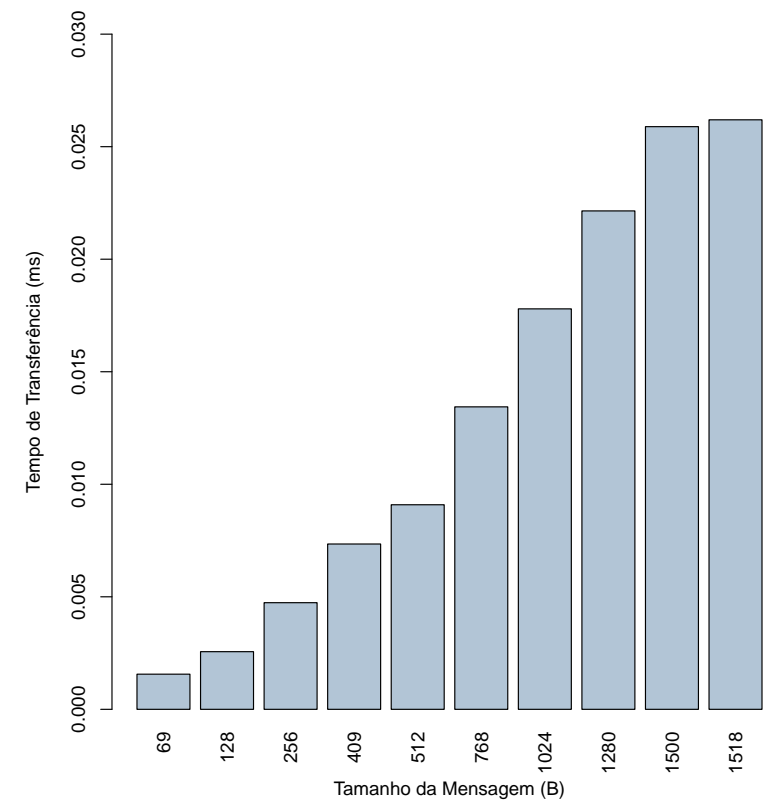

(a)

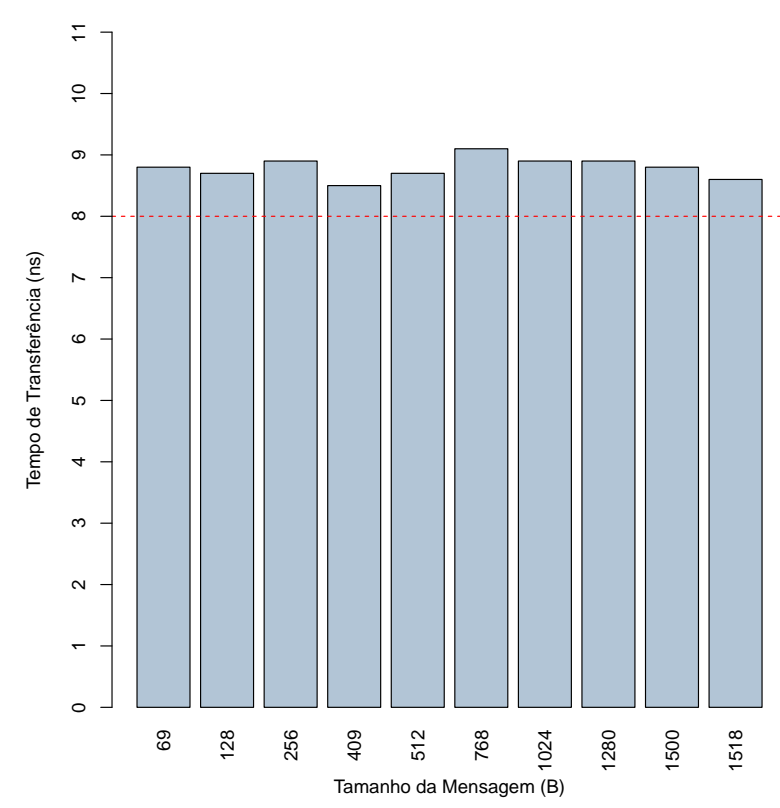

(b)

Figura 96: Gráficos de barras do valor máximo (a) e da amplitude (b) do tempo de transferência, por tamanho da mensagem estratificada para o módulo 1 


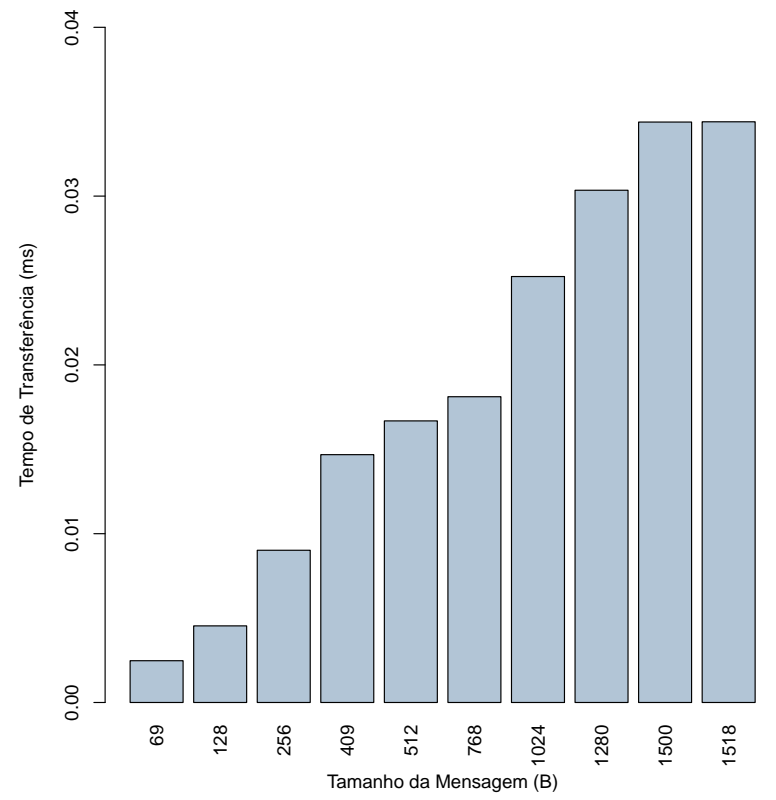

(a)

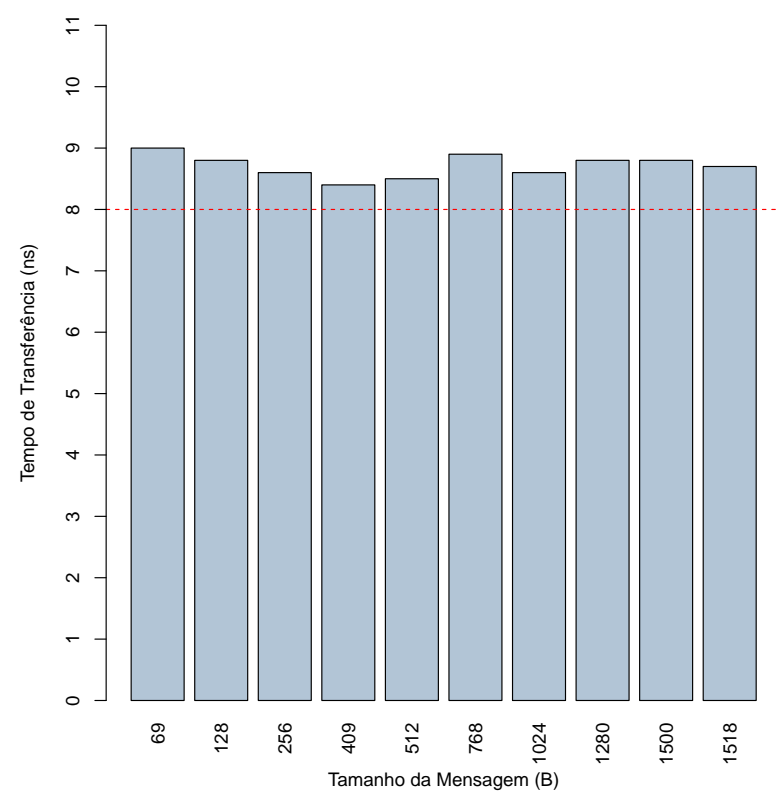

(b)

Figura 97: Gráficos de barras do valor máximo (a) e da amplitude (b) do tempo de transferência, por tamanho da mensagem estratificada para o módulo 2

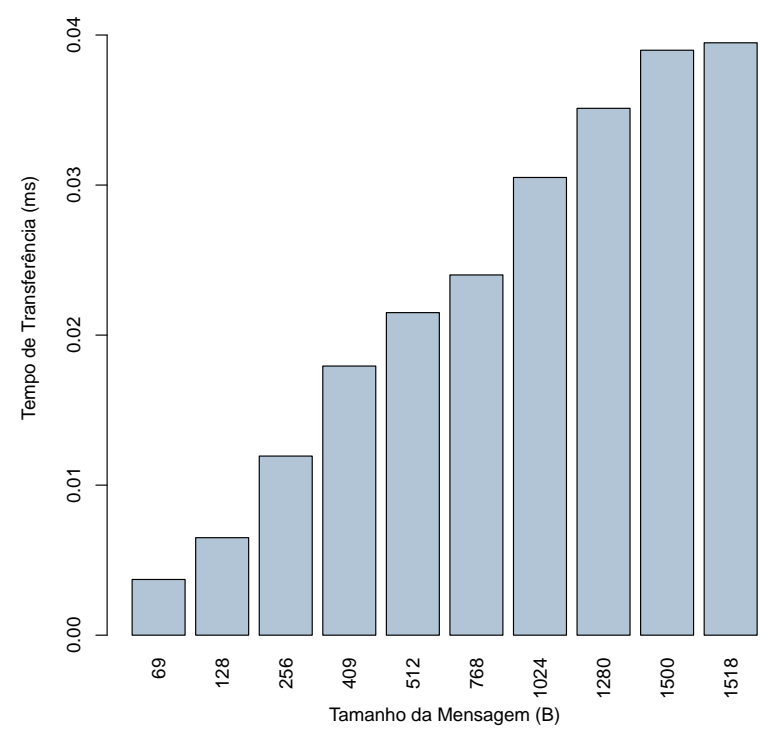

(a)

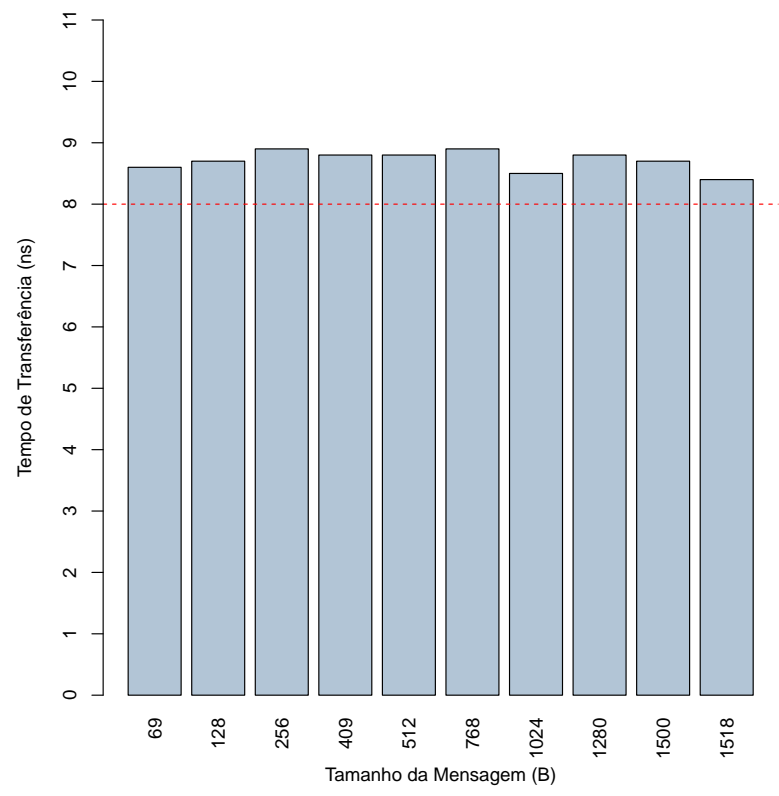

(b)

Figura 98: Gráficos de barras do valor máximo (a) e da amplitude (b) do tempo de transferência por, tamanho da mensagem estratificada para o módulo 3 


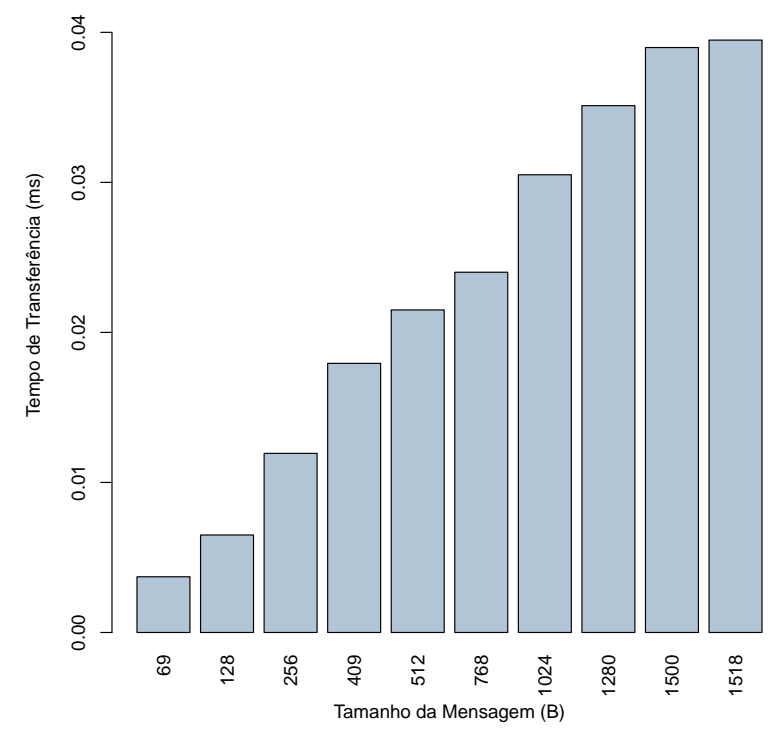

(a)

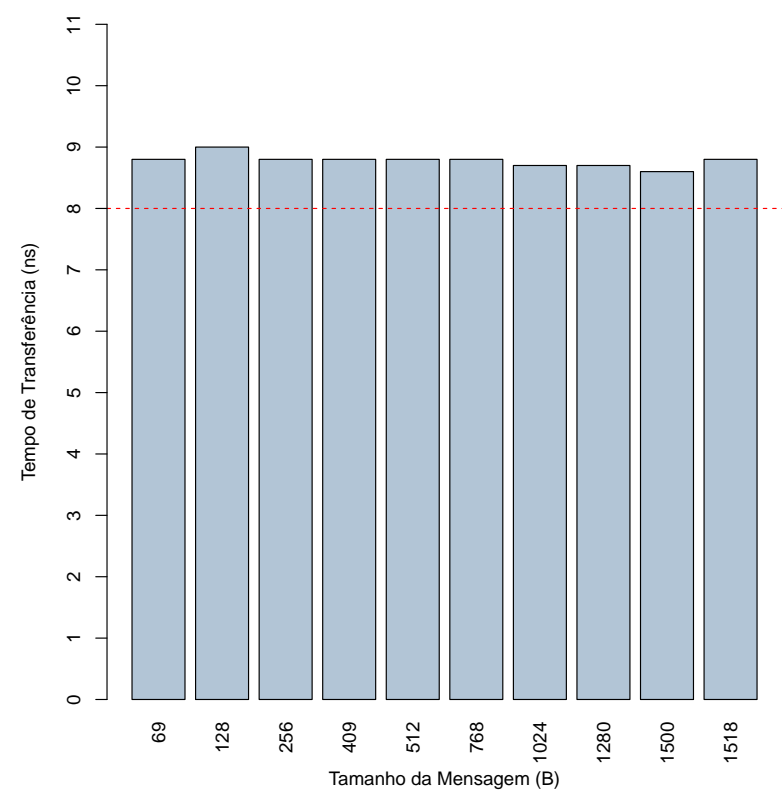

(b)

Figura 99: Gráficos de barras do valor máximo (a) e da amplitude (b) do tempo de transferência por, tamanho da mensagem estratificada para o módulo 4

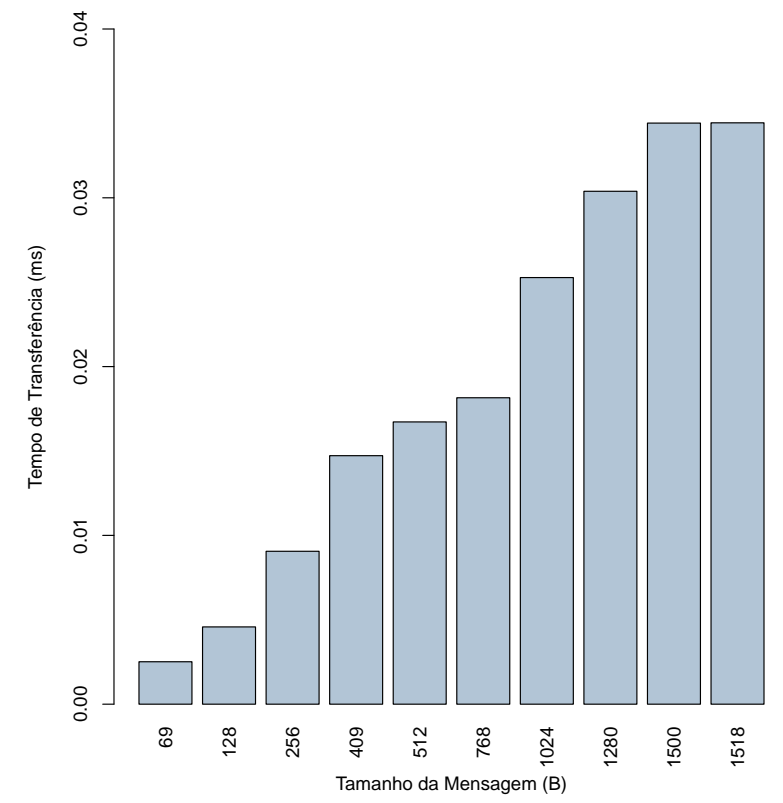

(a)

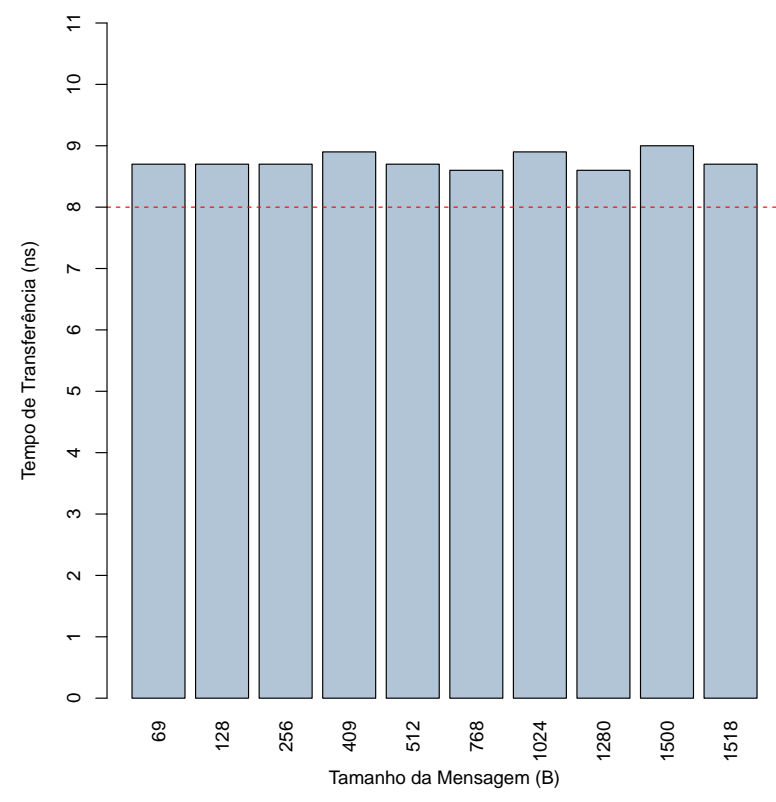

(b)

Figura 100: Gráficos de barras do valor máximo (a) e da amplitude (b) do tempo de transferência por, tamanho da mensagem estratificada para o módulo 5 


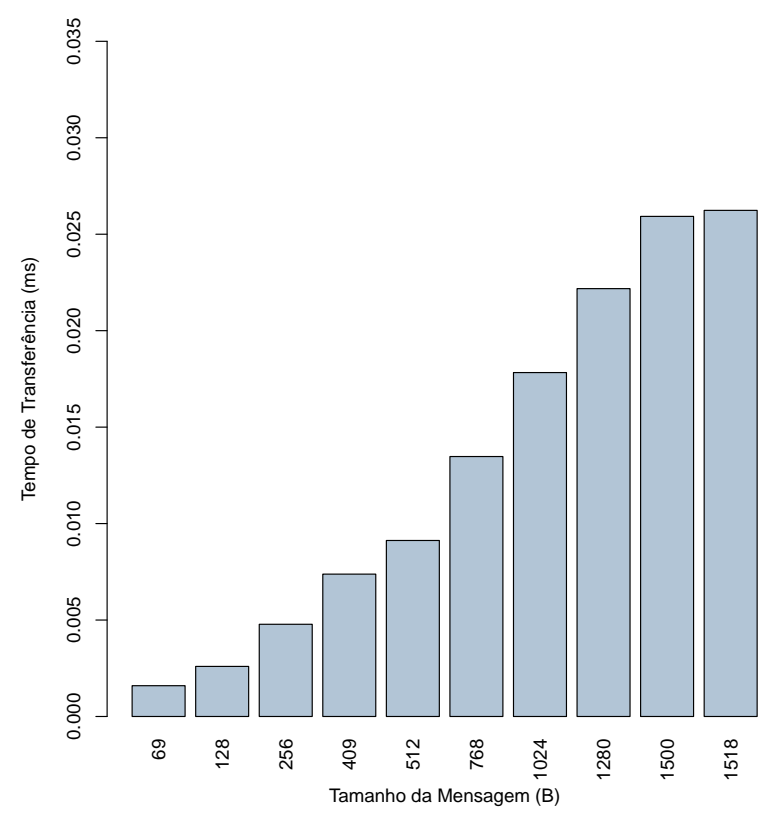

(a)

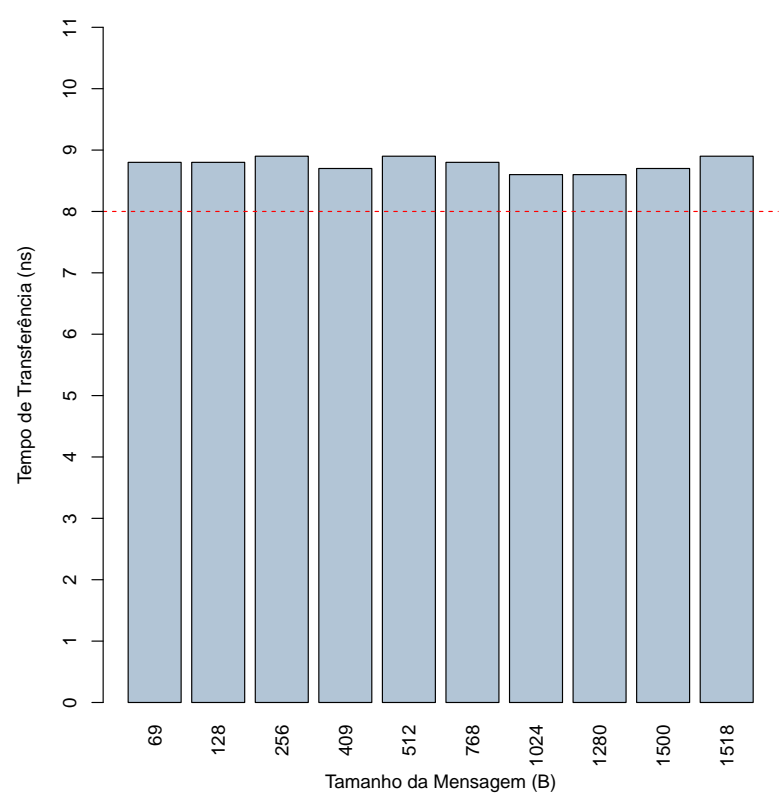

(b)

Figura 101: Gráficos de barras do valor máximo (a) e da amplitude (b) do tempo de transferência por, tamanho da mensagem estratificada para o módulo 6

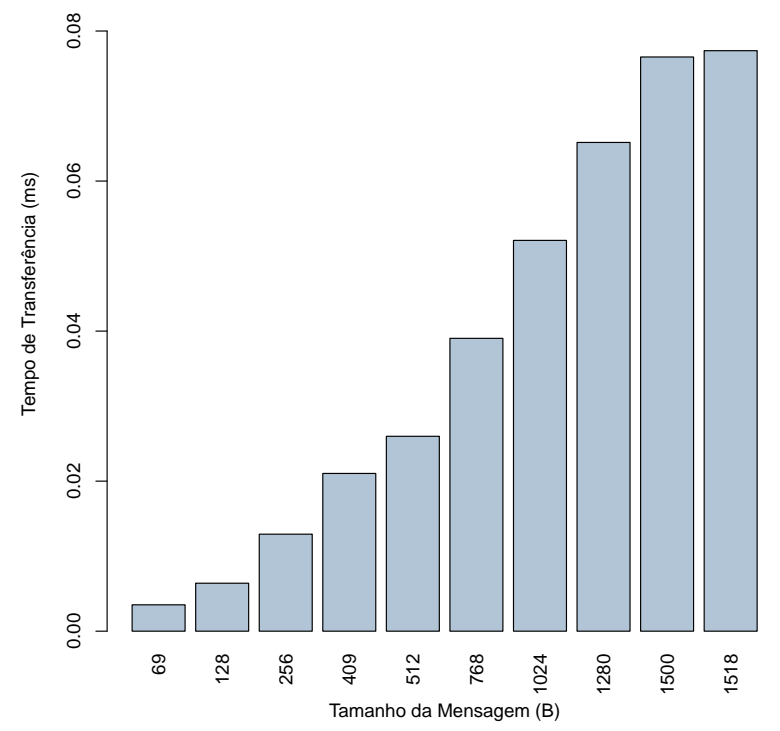

(a)

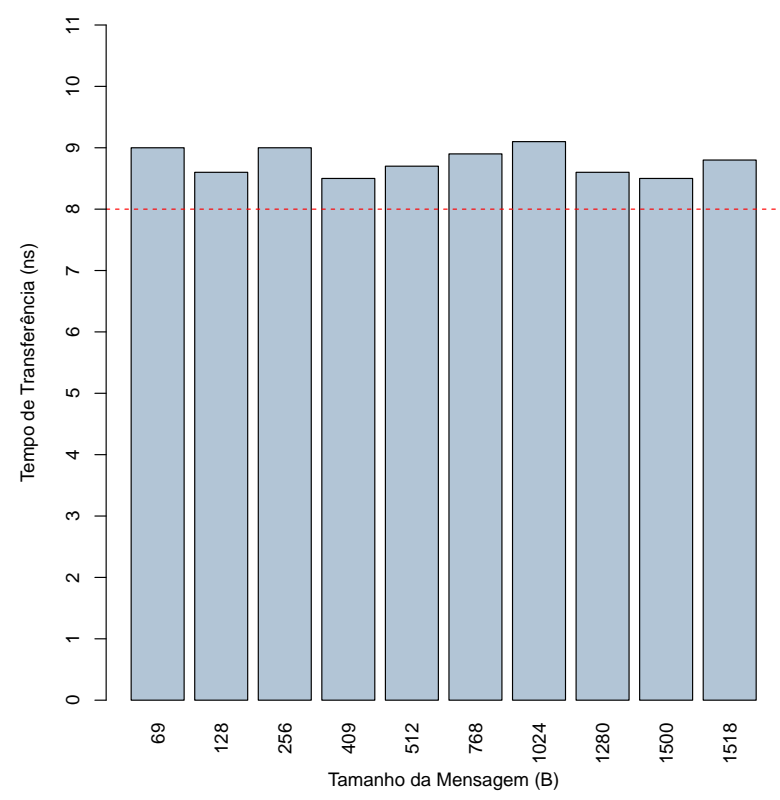

(b)

Figura 102: Gráficos de barras do valor máximo (a) e da amplitude (b) do tempo de transferência por, tamanho da mensagem estratificada para o módulo 7 


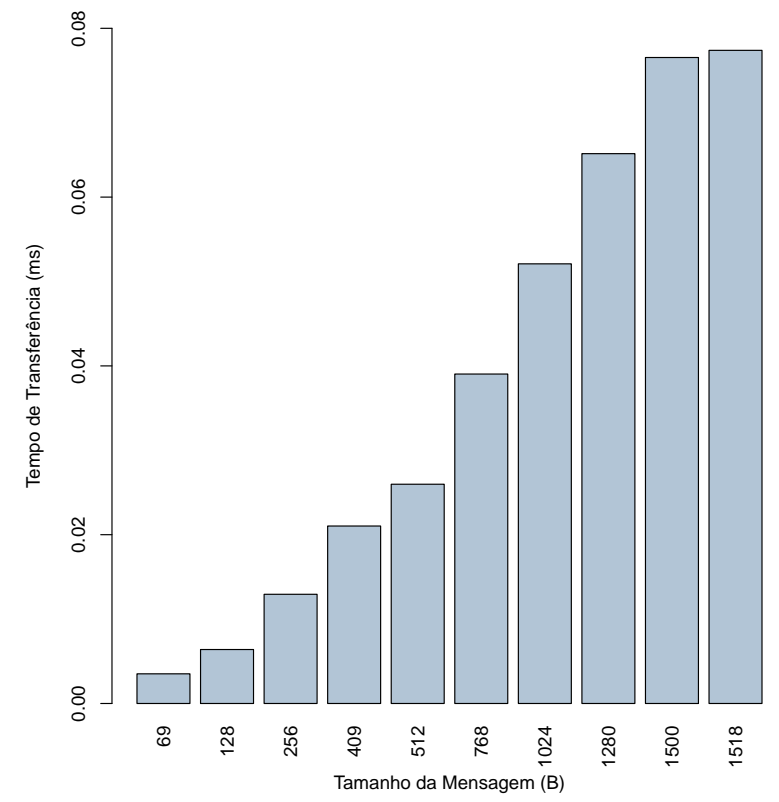

(a)

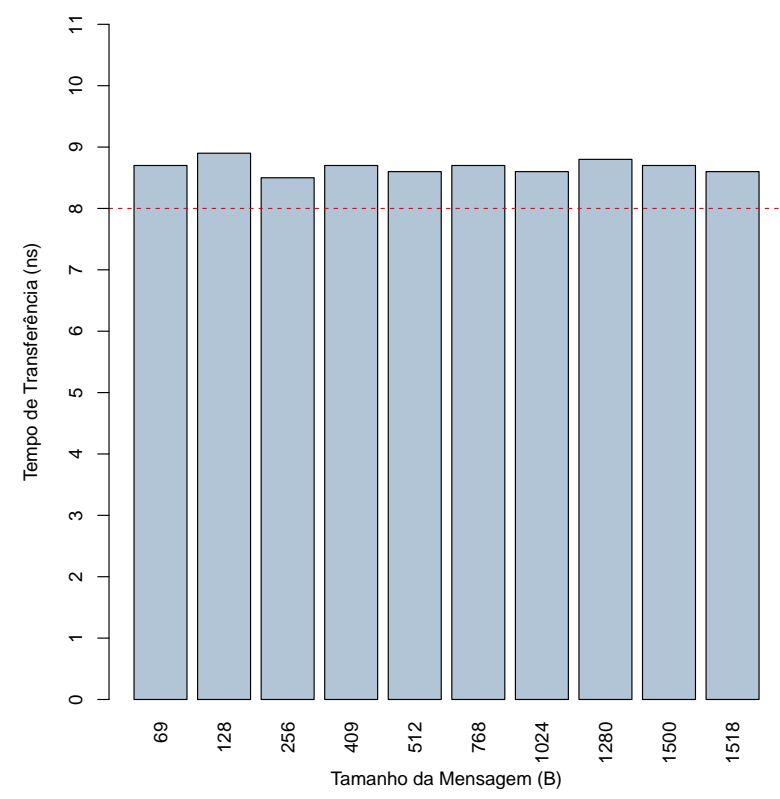

(b)

Figura 103: Gráficos de barras do valor máximo (a) e da amplitude (b) do tempo de transferência por, tamanho da mensagem estratificada para o módulo 8

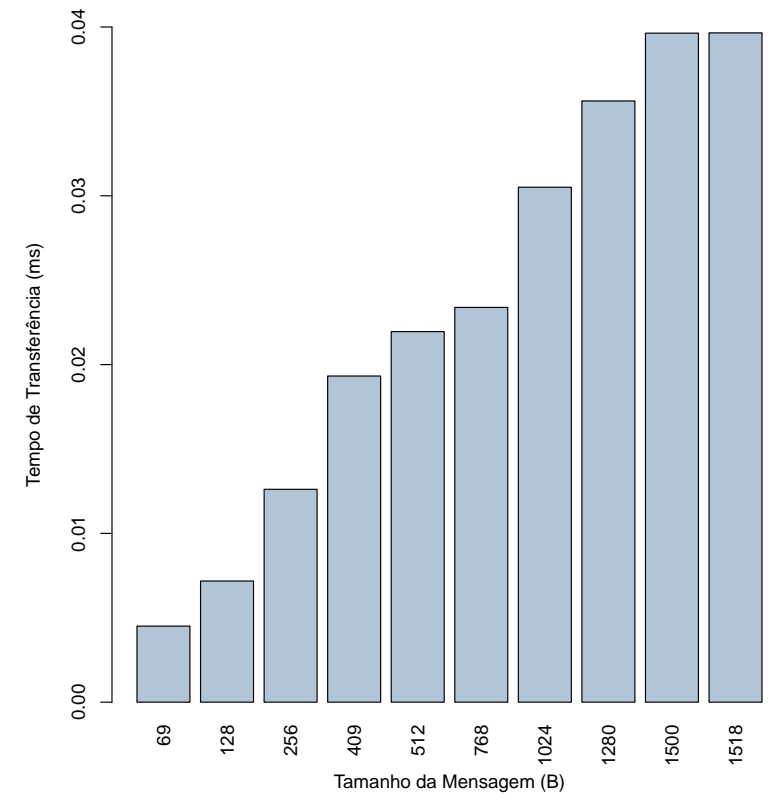

(a)

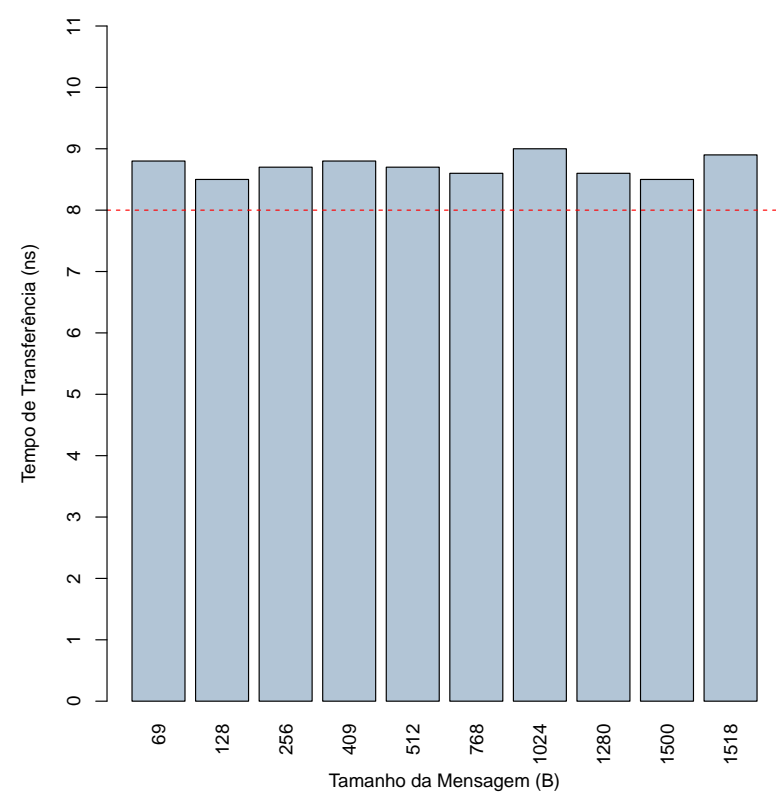

(b)

Figura 104: Gráficos de barras do valor máximo (a) e da amplitude (b) do tempo de transferência por, tamanho da mensagem estratificada para o módulo 9 


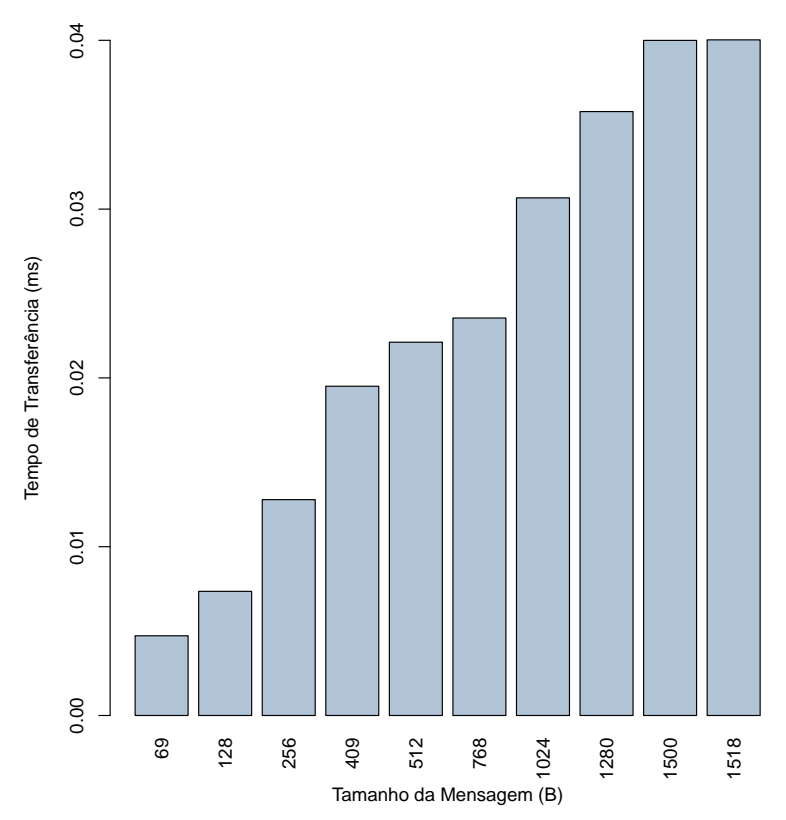

(a)

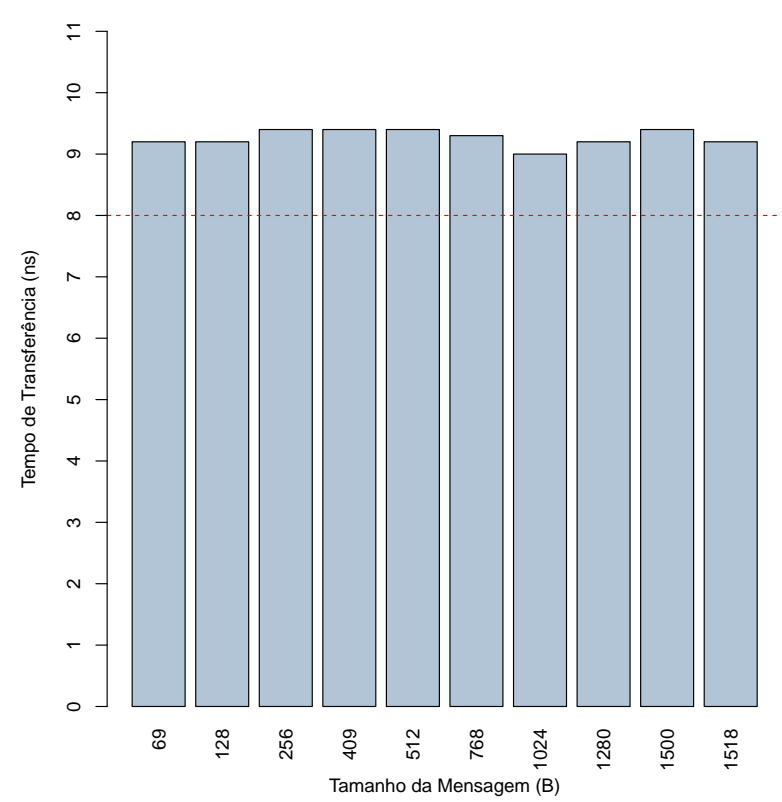

(b)

Figura 105: Gráficos de barras do valor máximo (a) e da amplitude (b) do tempo de transferência por, tamanho da mensagem estratificada para o módulo 10 


\subsection{Comparação do TT entre os Módulos Estratifi- cados por TM}

A Tabela 30, no Apêndice D, apresenta a descrição do tempo de transferência entre os módulos estratificados por tamanho da mensagem. A partir dela, pode-se concluir que:

- O maior valor foi de 0,07739ms referente ao módulo 8 e o tamanho da mensagem, de 1518B, sendo menor que o tamanho desejado de 1ms. Além disso, a maior amplitude foi de 9,40ns, no módulo 10, nos tamanhos 256B, 409B, 512B e 1500B. Cabe ressaltar que todas as amplitudes ficaram próximas de 8ns, o que indica que a NetFPGA responde de forma equivalente, independentemente do módulo e do tamanho das mensagens. Essas informações também podem ser vistas nas Figuras 107 a 116, que serão apresentadas posteriormente.

Ao se realizar o teste de Kruskal-Wallis, foi possível concluir que houve diferença significativa (Valor-p $=0,000$ ) do tempo de transferência entre os módulos em todos os tamanhos da mensagem. As comparações múltiplas, feitas pelo teste de Nemenyi, encontram-se na Tabela 31, no Apêndice D, na qual se pode verificar que não houve diferença significativa do tempo de transferência, apenas entre os módulos 3 e 4 em todos os tamanhos (Valor-p $=1,00)$ e 7 e 8 nos tamanhos 69B (Valor-p =0,997), 128B (Valor-p =0,999), 409B $($ Valor-p $=0,989), 512 \mathrm{~B}($ Valor-p $=0,991), 768 \mathrm{~B}($ Valor-p $=0,954), 1024 \mathrm{~B}($ Valor-p $=0,940), 1280 \mathrm{~B}($ Valor-p $=0,932)$ e 1500B (Valor-p =0,975).

A Figura 106 apresenta o gráfico de linhas das médias do tempo de transferência entre os módulos e os tamanhos da mensagem. 


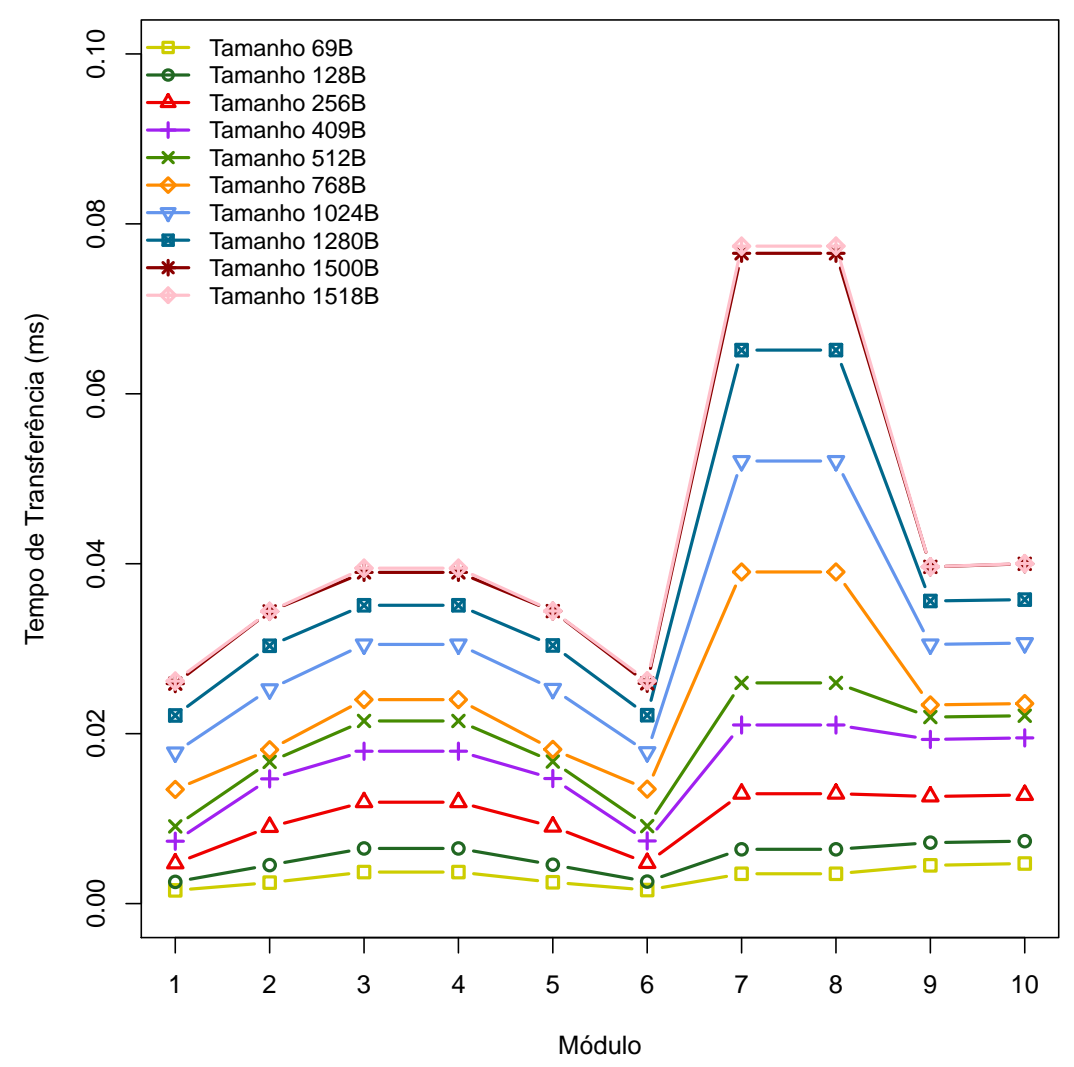

Figura 106: Gráfico de linhas das médias do tempo de transferência entre os módulos e os tamanhos da mensagem

As Figuras 107 a 116 apresentam os gráficos de barras do valor máximo e da amplitude do tempo de transferência, por módulo estratificado por tamanho da mensagem.

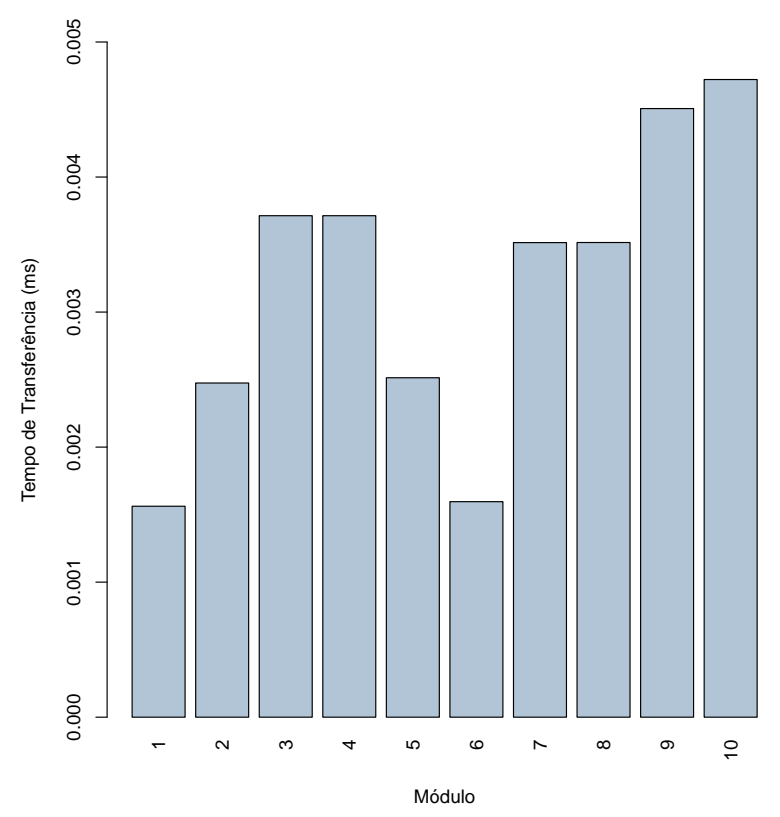

(a)

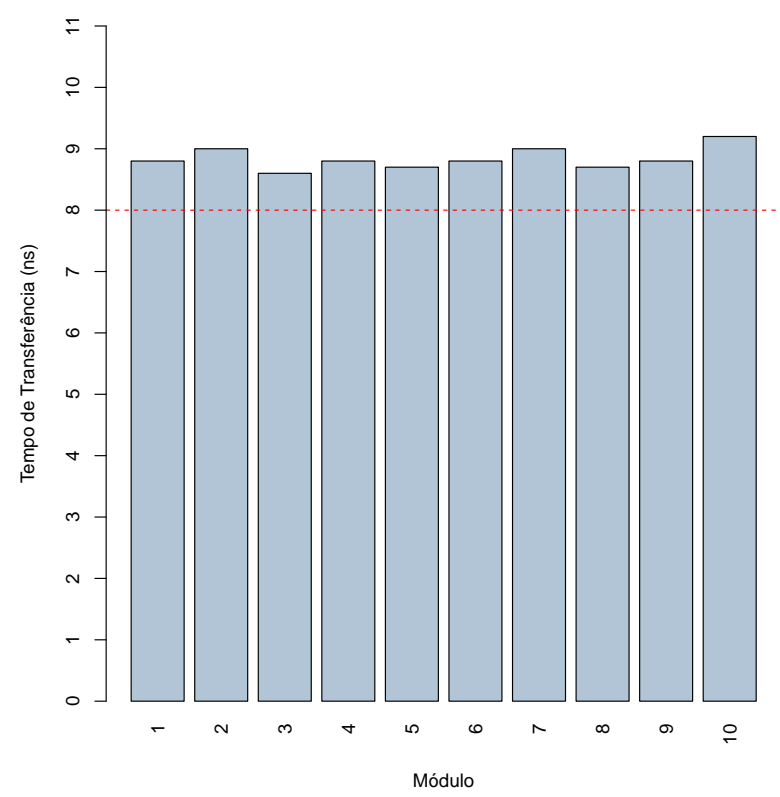

(b)

Figura 107: Gráficos de barras do valor máximo (a) e da amplitude (b) do tempo de transferência, por módulo estratificado para o tamanho da mensagem de 69B 


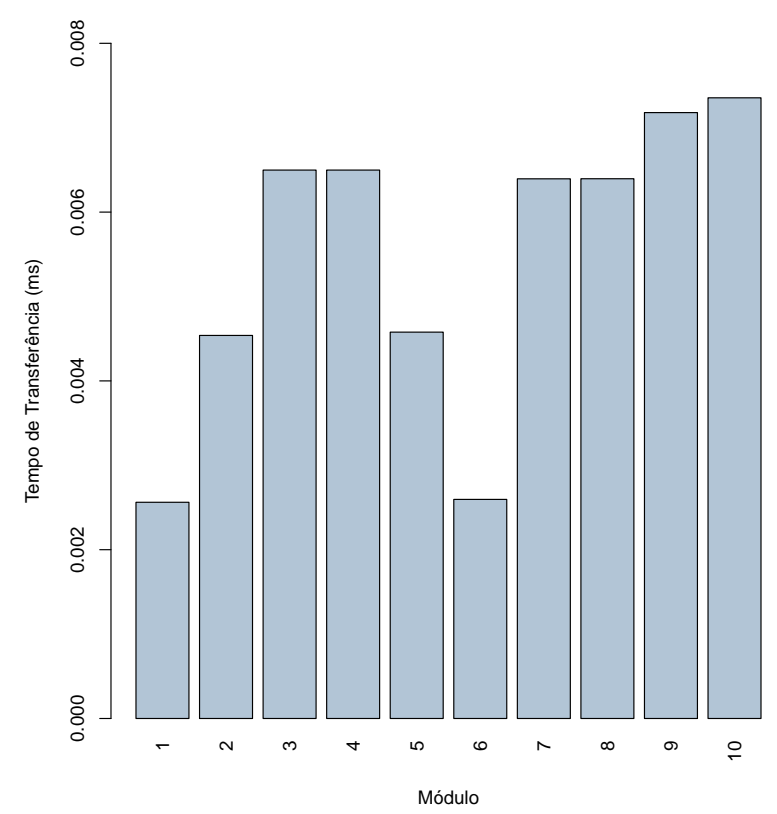

(a)

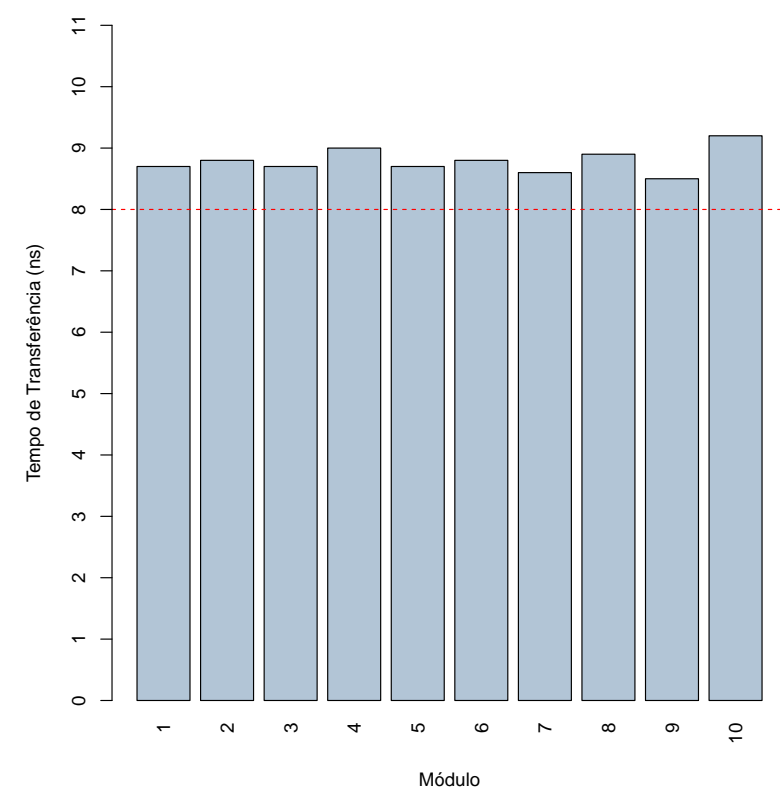

(b)

Figura 108: Gráficos de barras do valor máximo (a) e da amplitude (b) do tempo de transferência, por módulo estratificado para o tamanho da mensagem de 128B

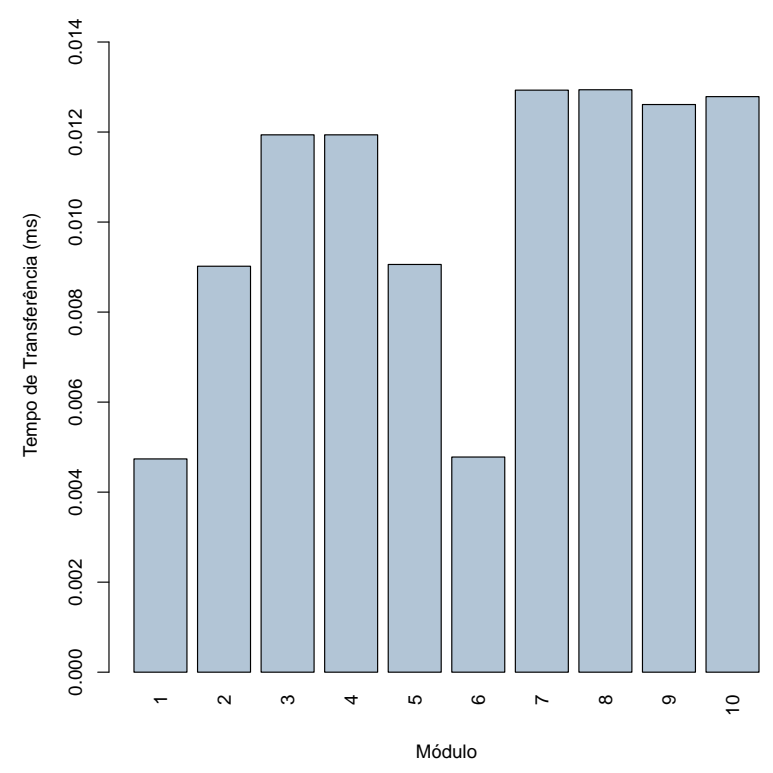

(a)

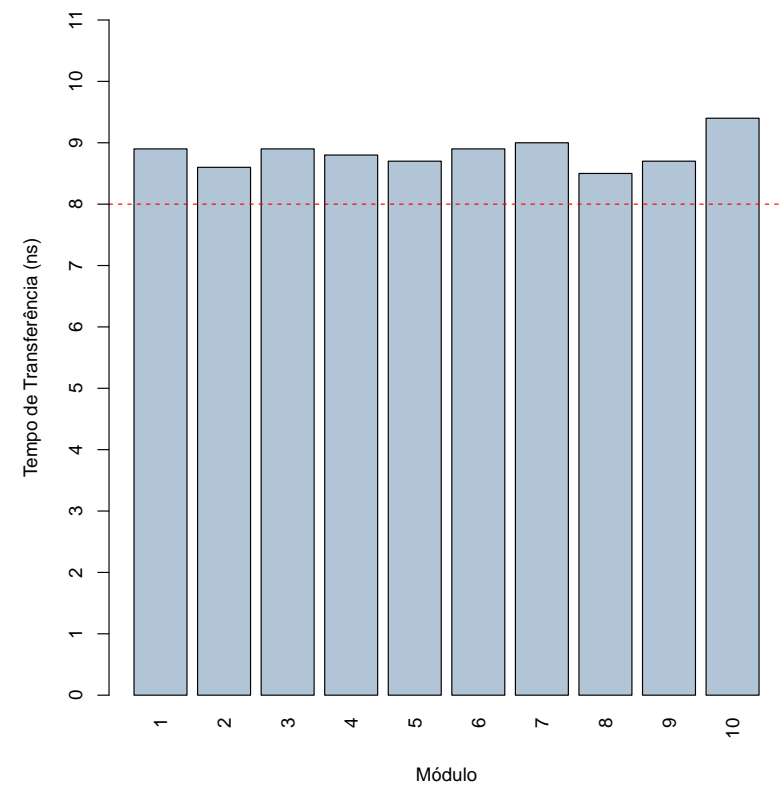

(b)

Figura 109: Gráficos de barras do valor máximo (a) e da amplitude (b) do tempo de transferência, por módulo estratificado para o tamanho da mensagem de 256B 


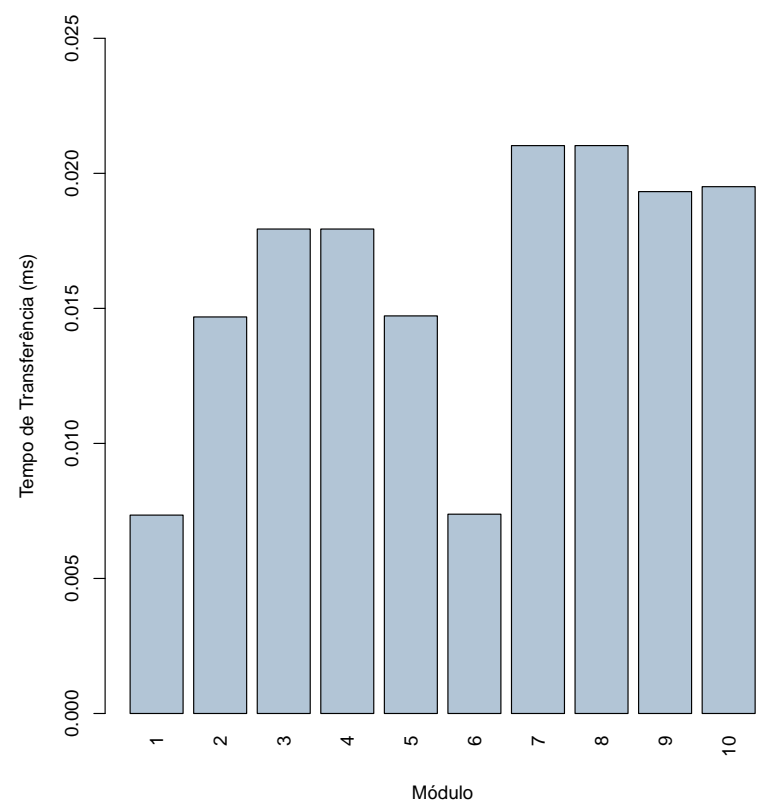

(a)

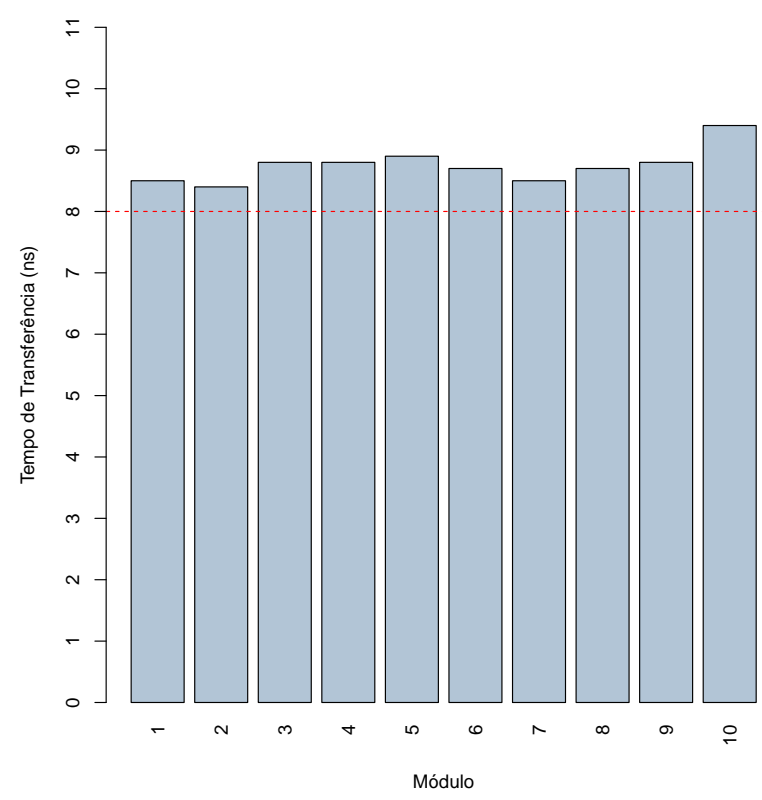

(b)

Figura 110: Gráficos de barras do valor máximo (a) e da amplitude (b) do tempo de transferência, por módulo estratificado para o tamanho da mensagem de 409B

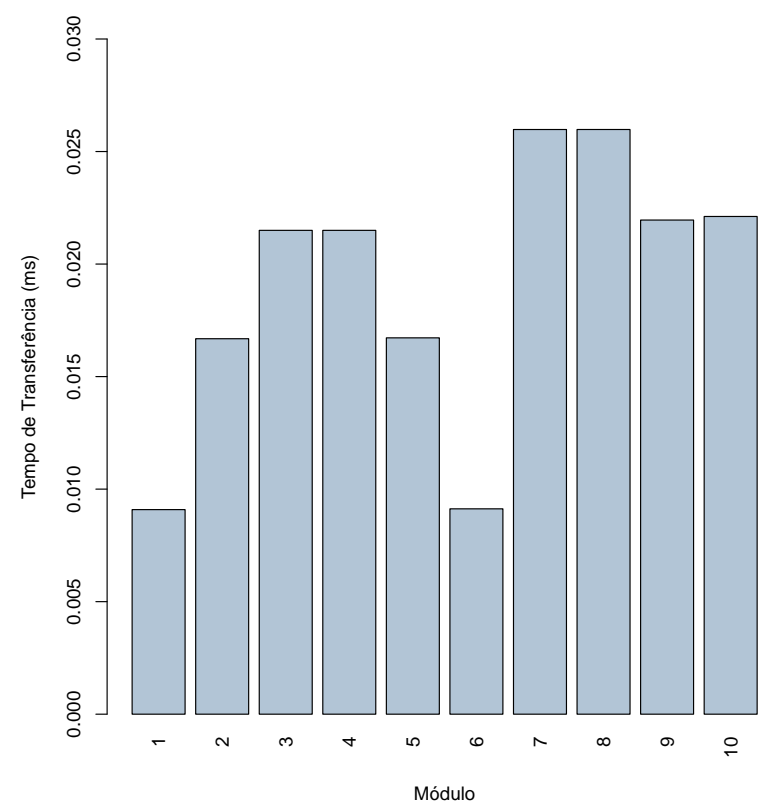

(a)

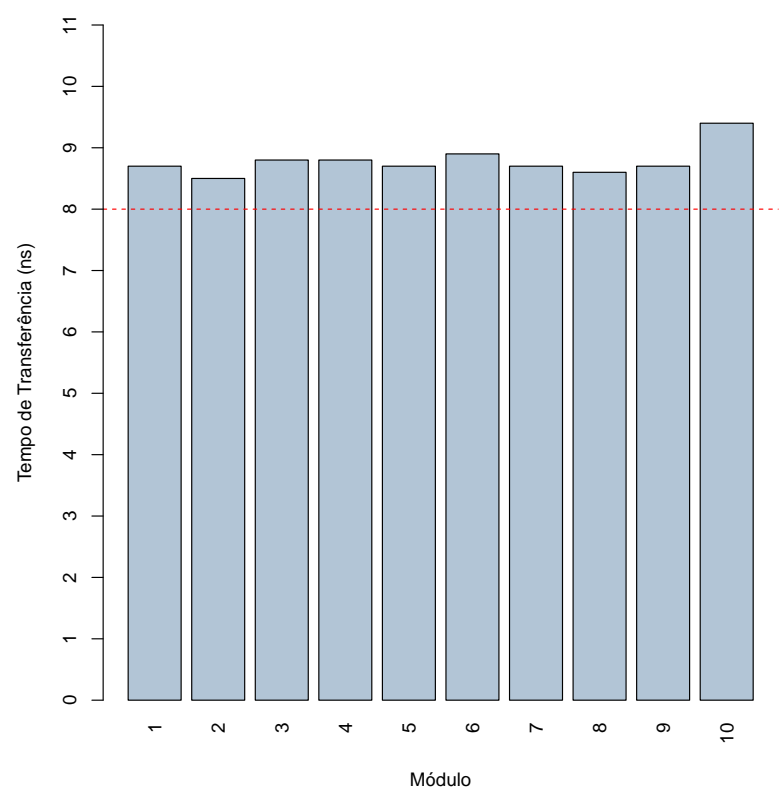

(b)

Figura 111: Gráficos de barras do valor máximo (a) e da amplitude (b) do tempo de transferência, por módulo estratificado para o tamanho da mensagem de 512B 


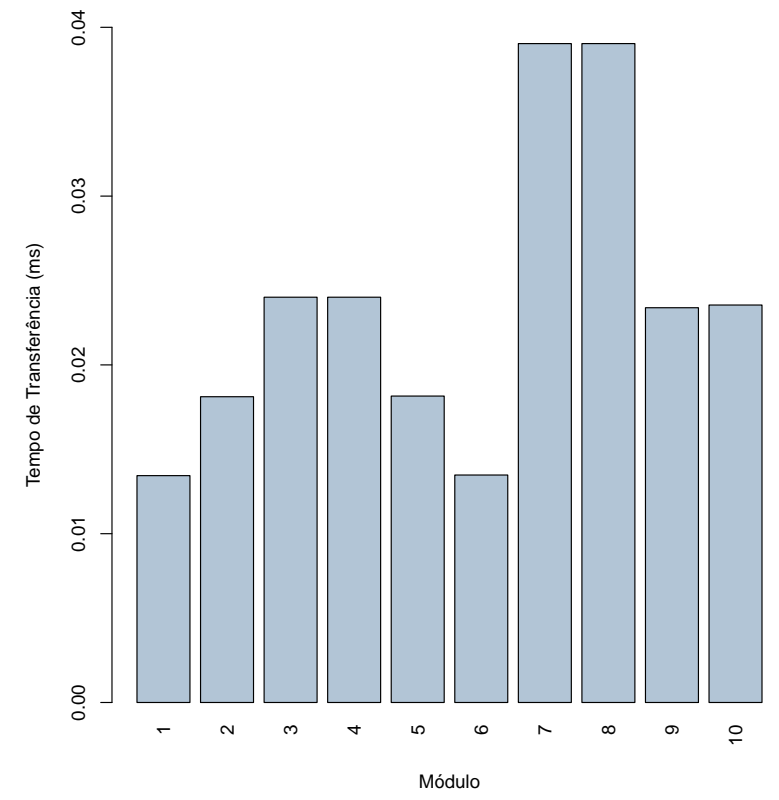

(a)

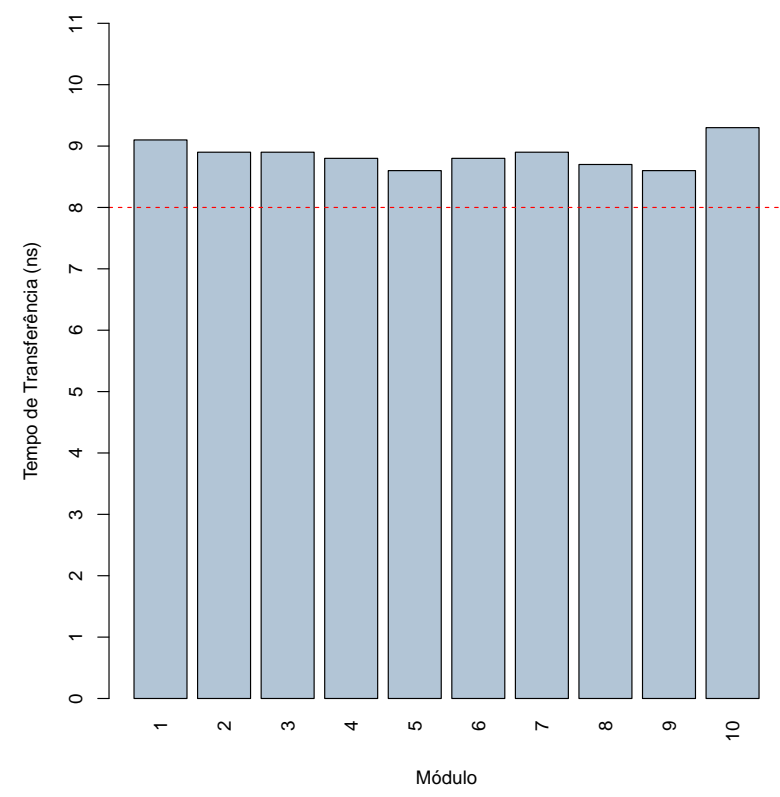

(b)

Figura 112: Gráficos de barras do valor máximo (a) e da amplitude (b) do tempo de transferência, por módulo estratificado para o tamanho da mensagem de 768B

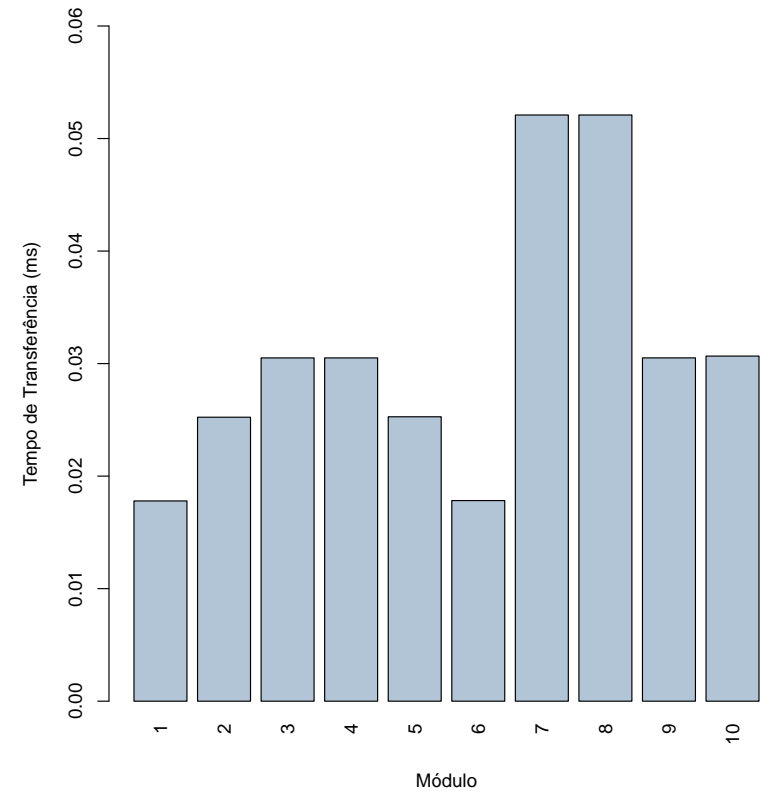

(a)

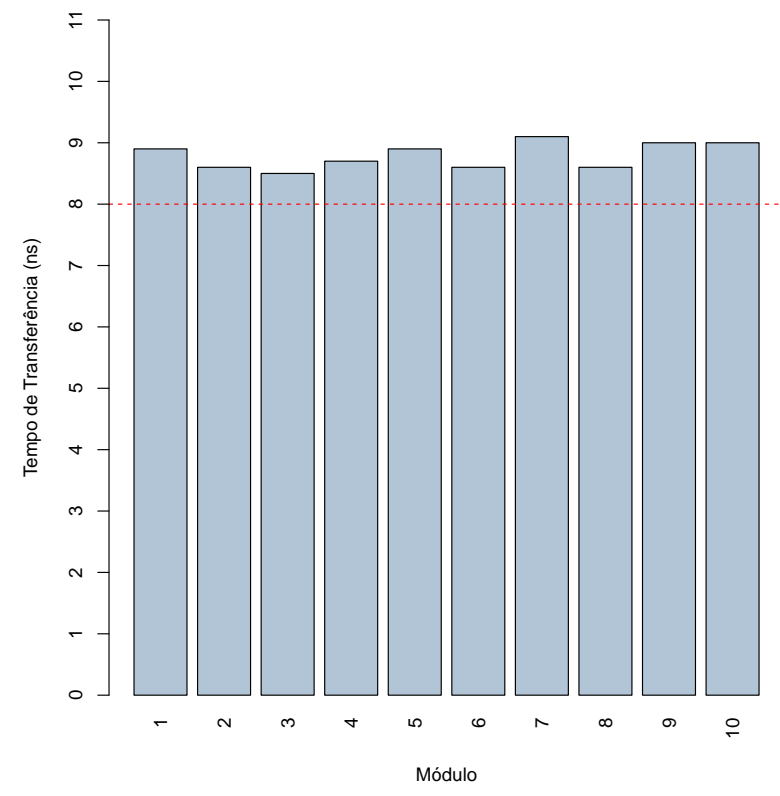

(b)

Figura 113: Gráficos de barras do valor máximo (a) e da amplitude (b) do tempo de transferência, por módulo estratificado para o tamanho da mensagem de 1024B 


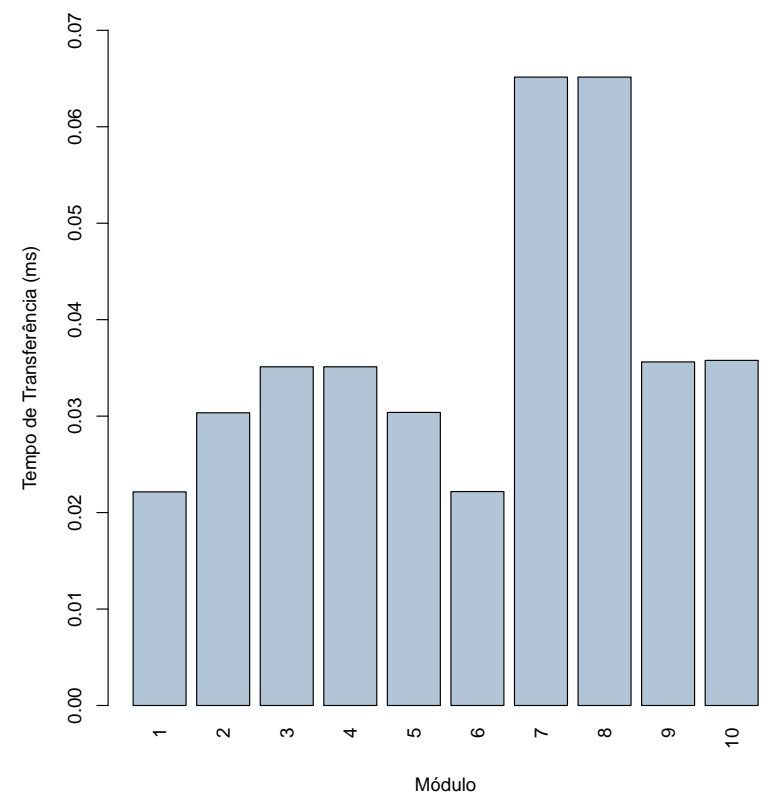

(a)

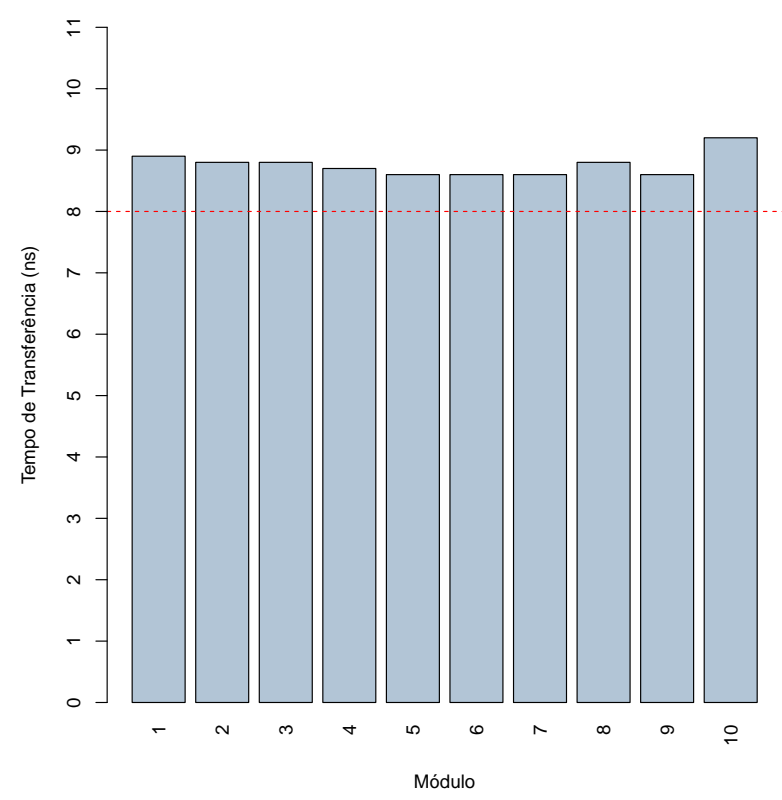

(b)

Figura 114: Gráficos de barras do valor máximo (a) e da amplitude (b) do tempo de transferência, por módulo estratificado para o tamanho da mensagem de 1280B

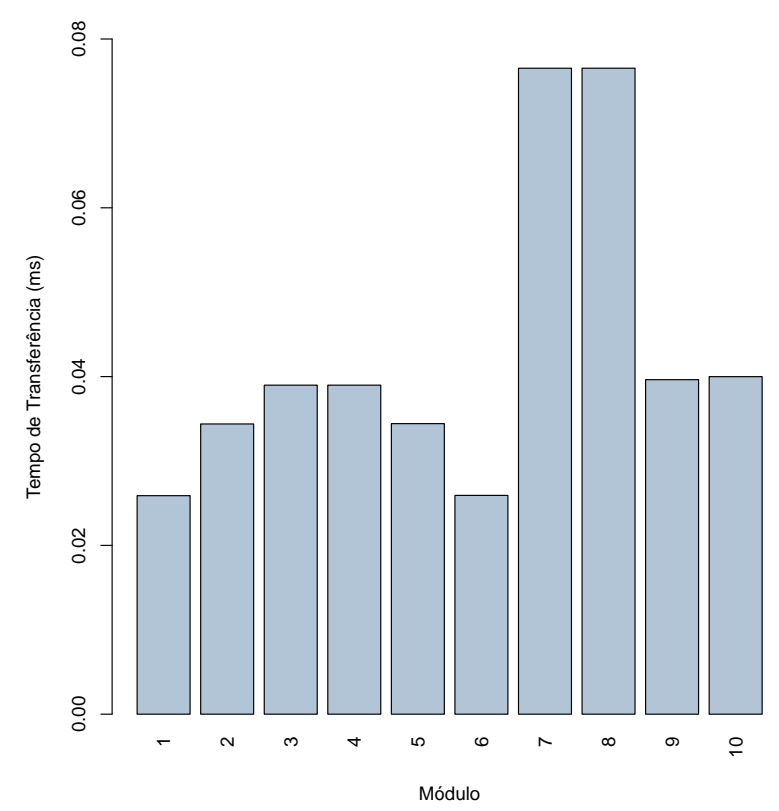

(a)

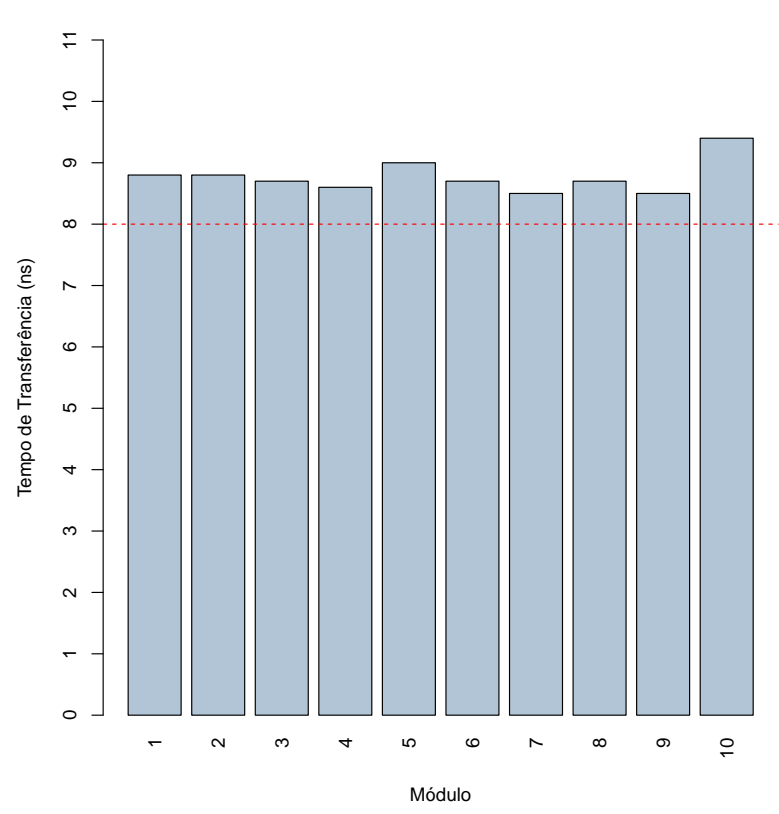

(b)

Figura 115: Gráficos de barras do valor máximo (a) e da amplitude (b) do tempo de transferência, por módulo estratificado para o tamanho da mensagem de 1500B 


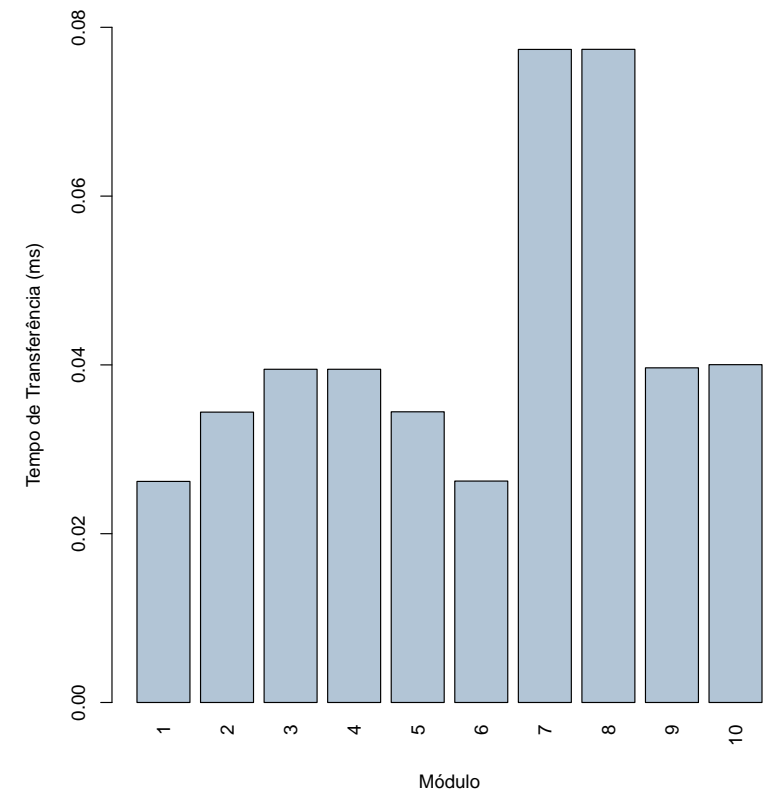

(a)

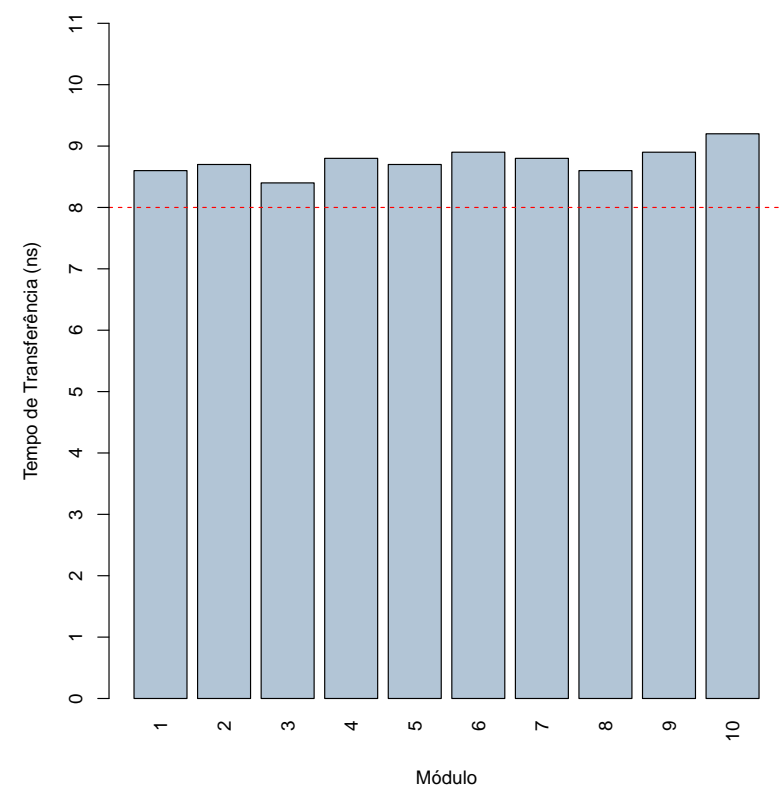

(b)

Figura 116: Gráficos de barras do valor máximo (a) e da amplitude (b) do tempo de transferência, por módulo estratificado para o tamanho da mensagem de 1518B 


\subsection{Análise do Crescimento do TT, quando se Au- menta o TM}

A Tabela 23 apresenta a regressão gama para o tempo de transferência. A partir dela, pode-se destacar que os módulos 7 e 8 foram os que apresentaram o maior crescimento do tempo de transferência, uma vez que, nos módulos 7 e 8, a cada 100B que se aumenta no tamanho da mensagem, o tempo de transferência aumenta em 18,7\%.

Tabela 23: Regressão Gama para o tempo de transferência, a partir da interação entre o tamanho da mensagem e os módulos

\begin{tabular}{cccccc}
\hline Módulos & $\beta$ & E.P. $(\beta)$ & $\operatorname{Exp}(\beta)$ & I.C. $-95 \%$ & Valor-p \\
\hline Módulo 1 & 0,162 & 0,001 & 1,176 & {$[1,174 ; 1,177]$} & 0 \\
Módulo 2 & 0,133 & 0,001 & 1,143 & {$[1,141 ; 1,144]$} & 0 \\
Módulo 3 & 0,12 & 0,001 & 1,128 & {$[1,126 ; 1,129]$} & 0 \\
Módulo 4 & 0,12 & 0,001 & 1,128 & {$[1,126 ; 1,129]$} & 0 \\
Módulo 5 & 0,133 & 0,001 & 1,142 & {$[1,141 ; 1,143]$} & 0 \\
Módulo 6 & 0,161 & 0,001 & 1,175 & {$[1,173 ; 1,176]$} & 0 \\
Módulo 7 & 0,171 & 0,001 & 1,187 & {$[1,186 ; 1,188]$} & 0 \\
Módulo 8 & 0,171 & 0,001 & 1,187 & {$[1,186 ; 1,188]$} & 0 \\
Módulo 9 & 0,113 & 0,001 & 1,12 & {$[1,119 ; 1,121]$} & 0 \\
Módulo 10 & 0,112 & 0,001 & 1,119 & {$[1,117 ; 1,120]$} & 0 \\
\hline
\end{tabular}

Já os módulos 9 e 10 foram os que apresentaram os menores crescimentos, uma vez que, a cada 100B que se aumenta no tamanho da mensagem, o tempo de transferência aumenta em 12,0\% e 11,9\%, respectivamente. Cabe ressaltar que, em todos os módulos, o aumento do tempo de transferência, devido ao aumento da mensagem, foi significativo (Valor-p $=0,000)$.

Para a estimação dos coeficientes da regressão, e demais parâmetros, utilizou-se a função glm e Contrast do software R.

O $\beta$ representa o coeficiente do efeito do tamanho da mensagem, para cada módulo, sendo que a interpretação da regressão acontece, ao se aplicar a função exponencial no $\beta$.

O intervalo de confiança representa um intervalo de estimativas prováveis para o $\exp (\beta)$, sendo que, se esse estudo fosse executado em 100 amostras diferentes, em 95 das amostras, o $\exp (\beta)$ estaria dentro desse intervalo. O erro padrão estima a variabilidade entre os $\beta$ amostrais que seriam obtidos, se fossem coletadas várias amostras diferentes da mesma população. 


\subsection{Comparação do TT entre os TMs Estratificada pela soma dos Módulos 2 a 2}

A Tabela 32, no Apêndice E, apresenta a descrição do tempo de transferência entre os tamanhos da mensagem estratificada pela soma dos módulos 2 a 2. A finalidade desta comparação é averiguar o tempo de transferência de dois módulos em sequência, relativamente ao tempo de $1 \mathrm{~ms}$, considerando cada módulo em uma NetFPGA. A partir dela, pode-se concluir que:

- Em todas as somas dos módulos, ao se realizar o teste de Kruskal-Wallis, foi possível averiguar que houve diferença significativa (Valor-p $=0,000$ ) do tempo de transferência entre os tamanhos da mensagem. As comparações múltiplas, feitas pelo teste de Nemenyi, encontram-se na Tabela 33, no Apêndice E, na qual se pode verificar que houve diferença significativa (Valor-p $=0,000$ ) do tempo de transferência entre todos os tamanhos da mensagem, sendo que, na medida em que se aumentou o tamanho da mensagem, houve um aumento no tempo de transferência médio; e

- O maior valor foi de 0,15477ms, referente ao tamanho da mensagem $1518 \mathrm{~B}$, na soma módulo $7+$ módulo 8, sendo menor que o tamanho desejado de $1 \mathrm{~ms}$. Além disso, a maior amplitude foi de 18,2ns, na soma módulo $1+$ módulo 1 , no tamanho 768B. Cabe ressaltar que todas as amplitudes ficaram acima de 8ns.

A Tabela 33, no Apêndice E, apresenta as comparações múltiplas feitas pelo teste de Nemenyi.

As Figuras 117 a 124 apresentam os gráficos de barras do valor máximo e da amplitude do tempo de transferência, por tamanho da mensagem estratificada pela soma dos módulos 2 a 2. 


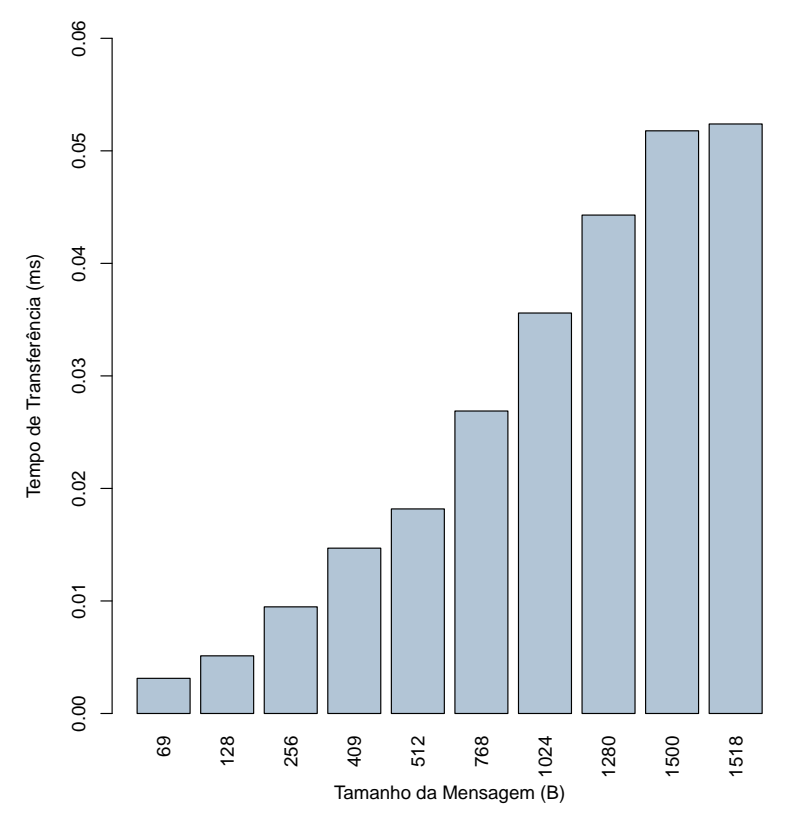

(a)

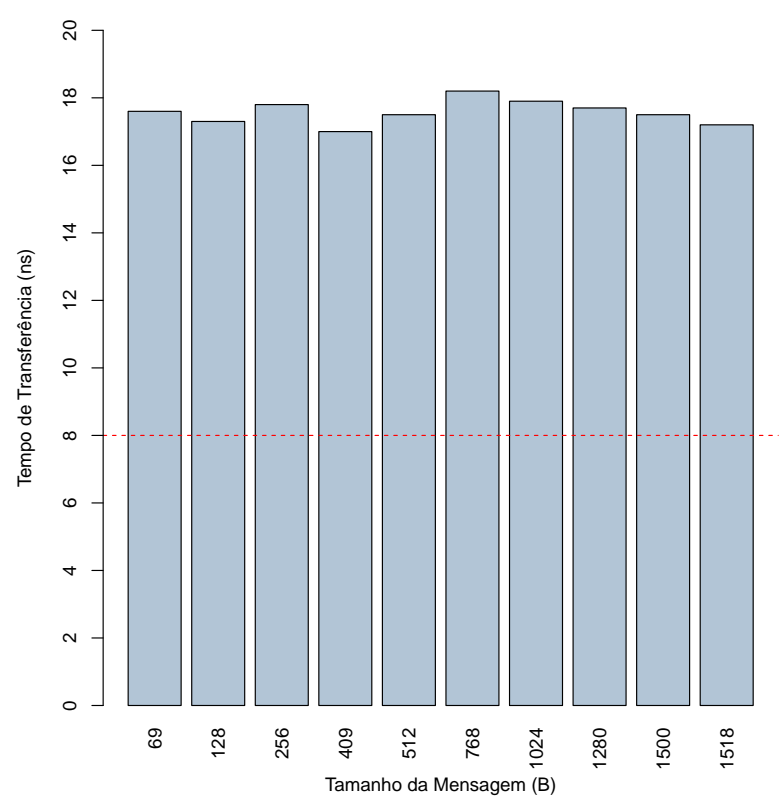

(b)

Figura 117: Gráficos de barras do valor máximo (a) e da amplitude (b) do tempo de transferência, por tamanho da mensagem estratificada pela soma dos módulos M1 e M1

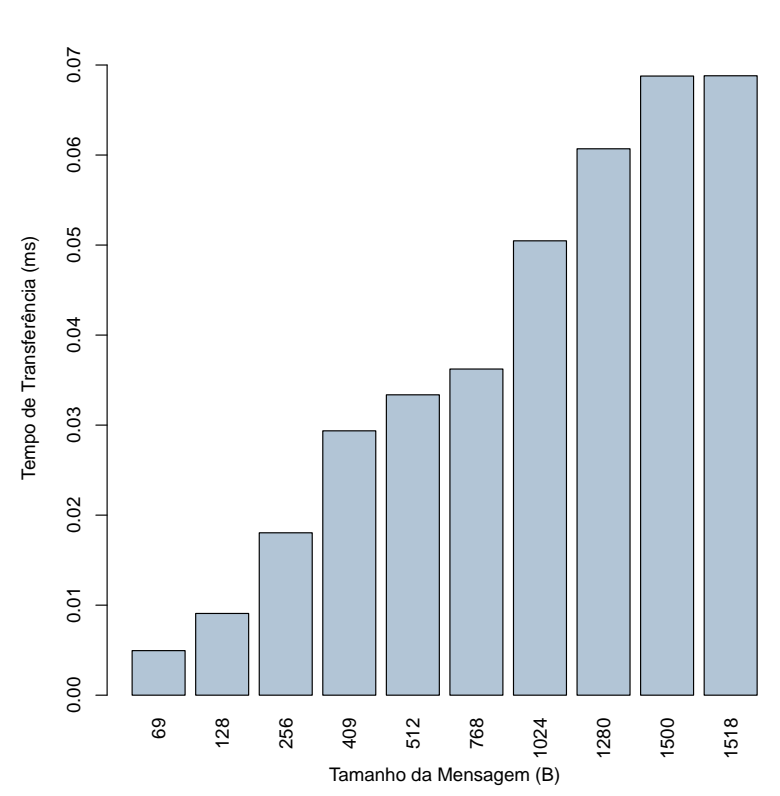

(a)

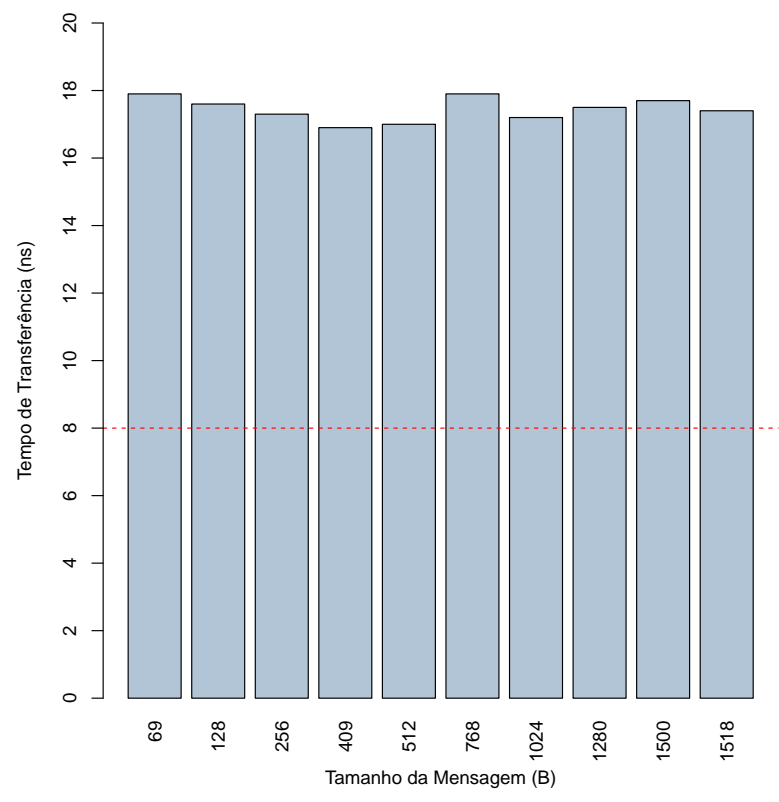

(b)

Figura 118: Gráficos de barras do valor máximo (a) e da amplitude (b) do tempo de transferência, por tamanho da mensagem estratificada pela soma dos módulos M2 e M2 


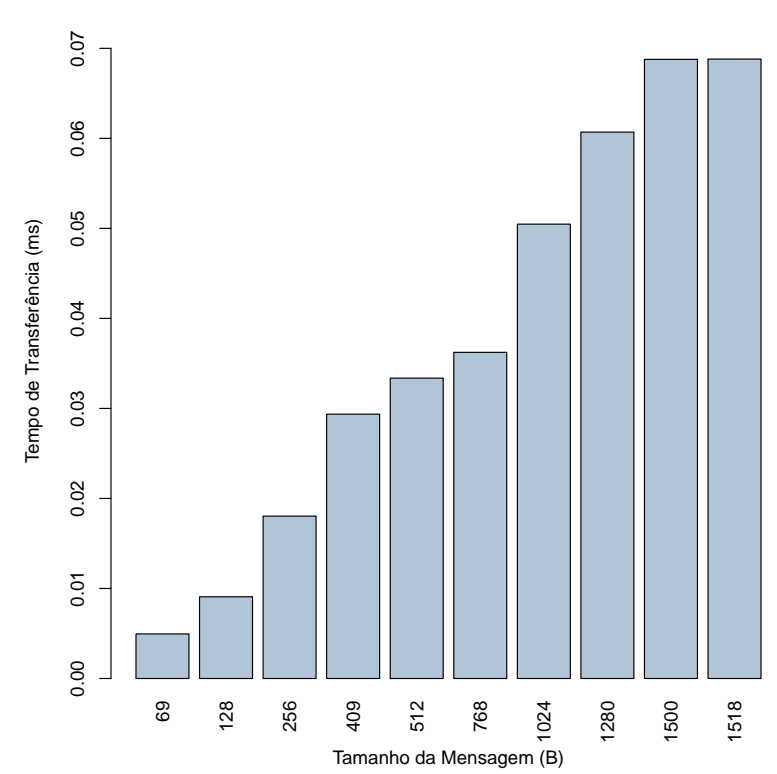

(a)

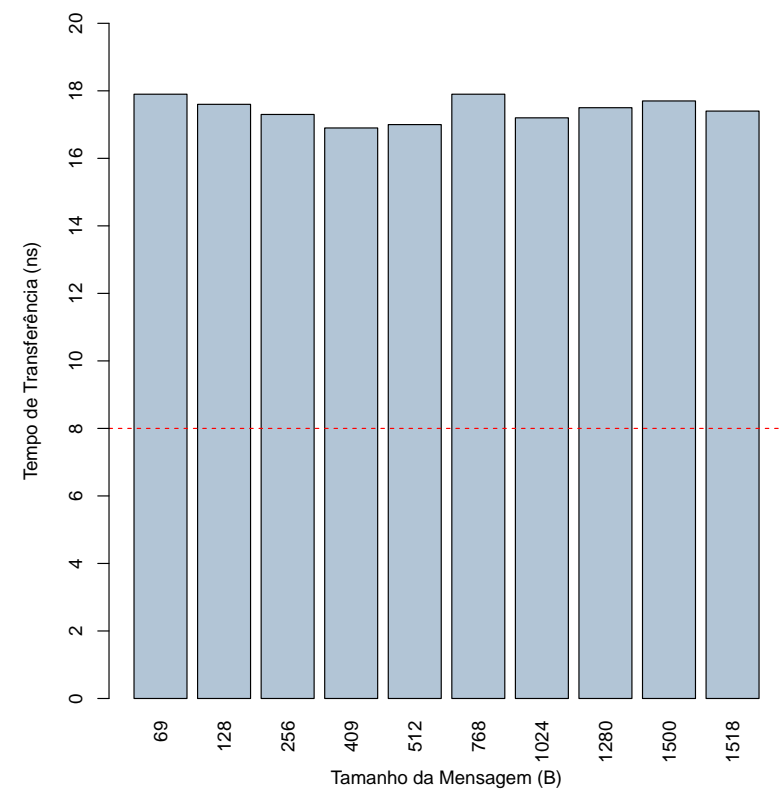

(b)

Figura 119: Gráficos de barras do valor máximo (a) e da amplitude (b) do tempo de transferência, por tamanho da mensagem estratificada pela soma dos módulos M3 e M3

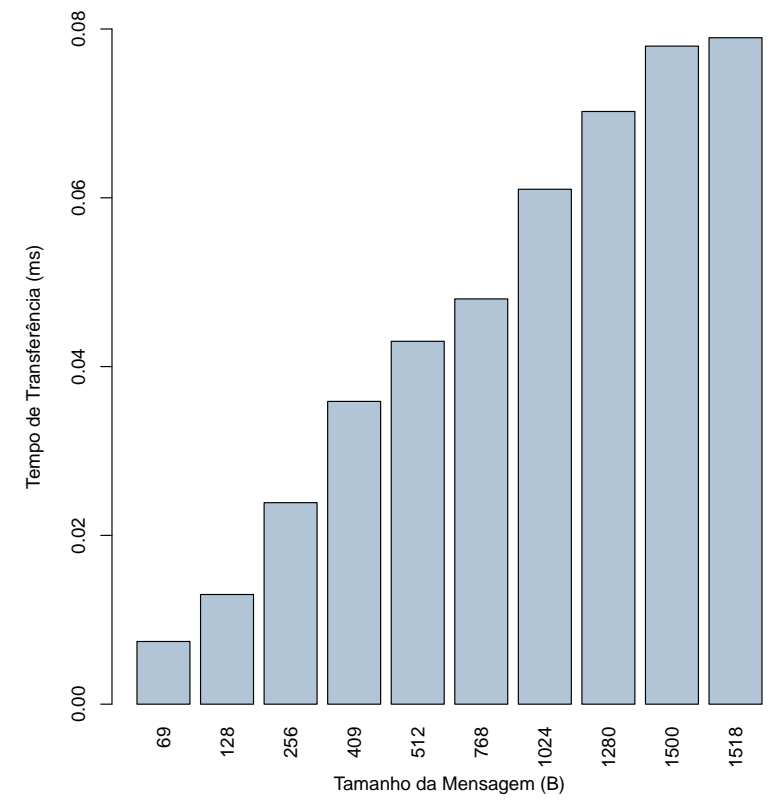

(a)

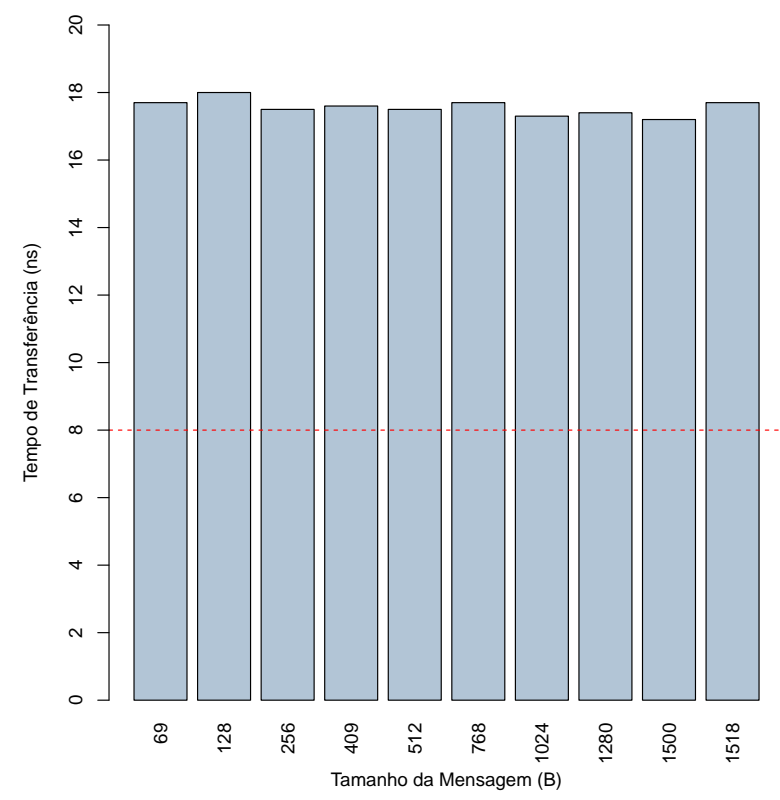

(b)

Figura 120: Gráficos de barras do valor máximo (a) e da amplitude (b) do tempo de transferência, por tamanho da mensagem estratificada pela soma dos módulos M4 e M4 


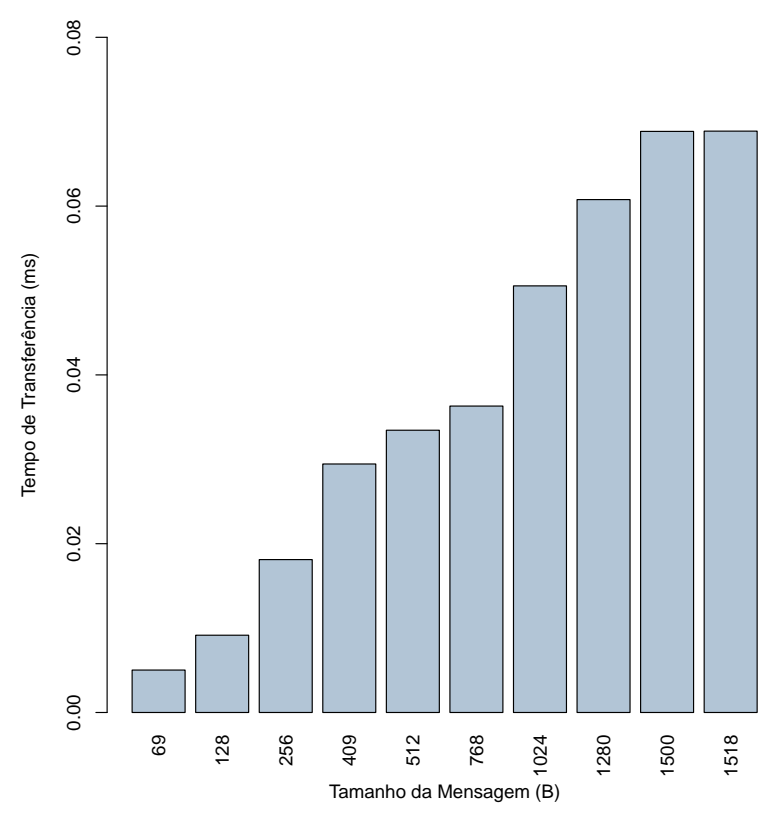

(a)

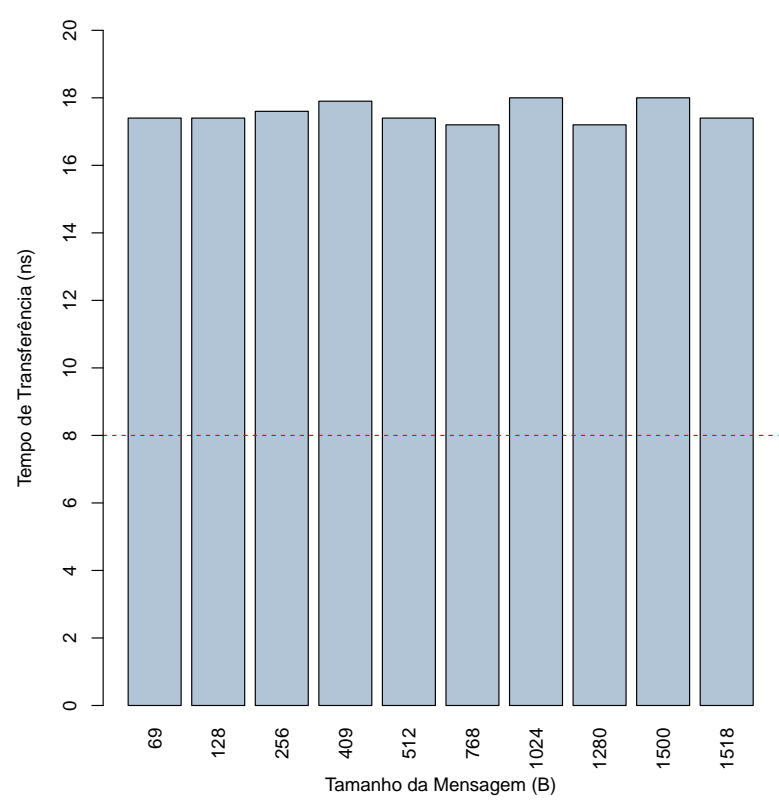

(b)

Figura 121: Gráficos de barras do valor máximo (a) e da amplitude (b) do tempo de transferência, por tamanho da mensagem estratificada pela soma dos módulos M5 e M5

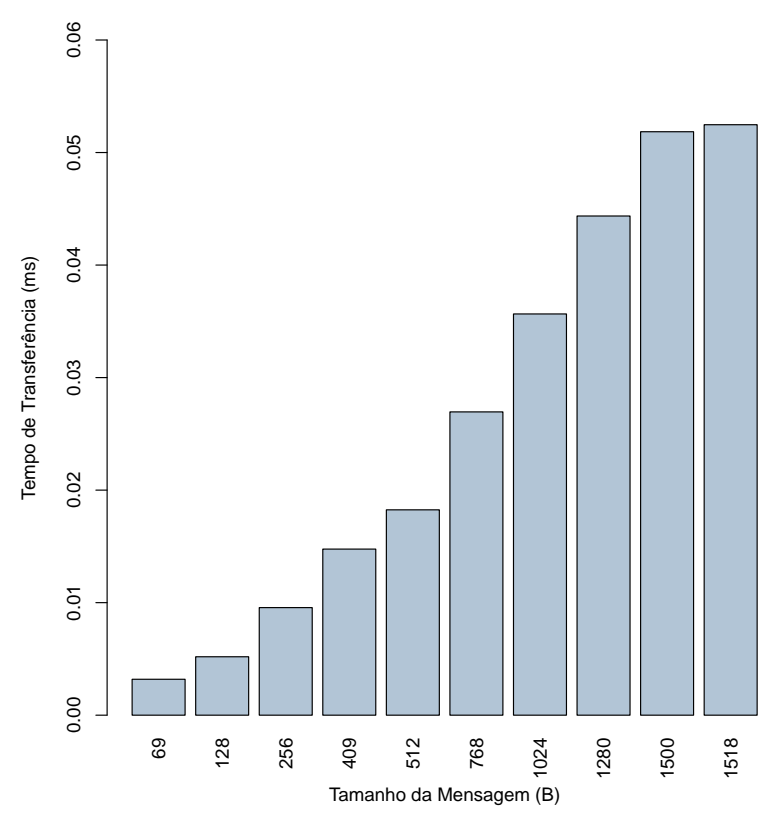

(a)

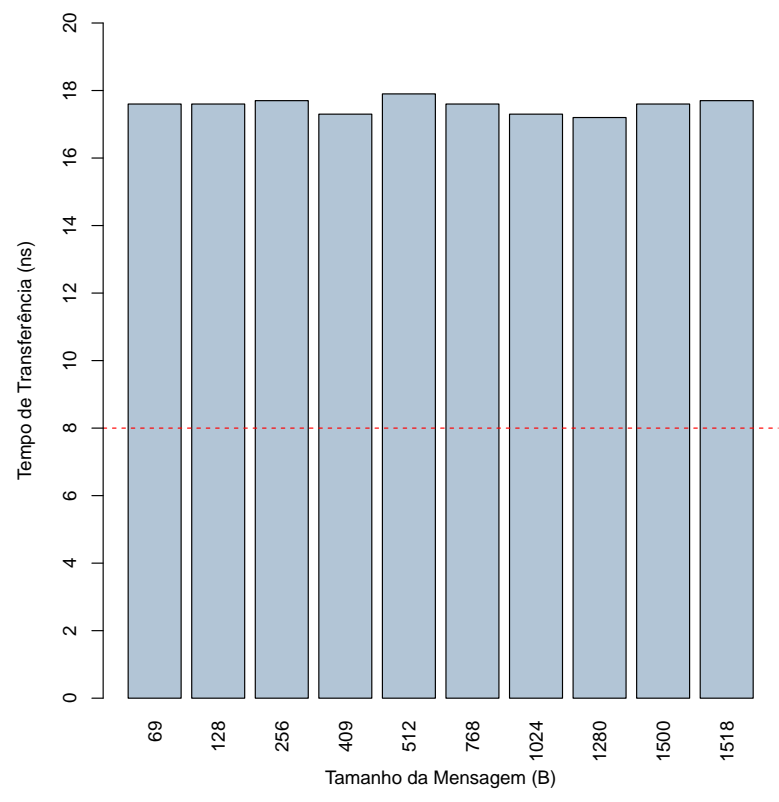

(b)

Figura 122: Gráficos de barras do valor máximo (a) e da amplitude (b) do tempo de transferência, por tamanho da mensagem estratificada pela soma dos módulos M6 e M6 


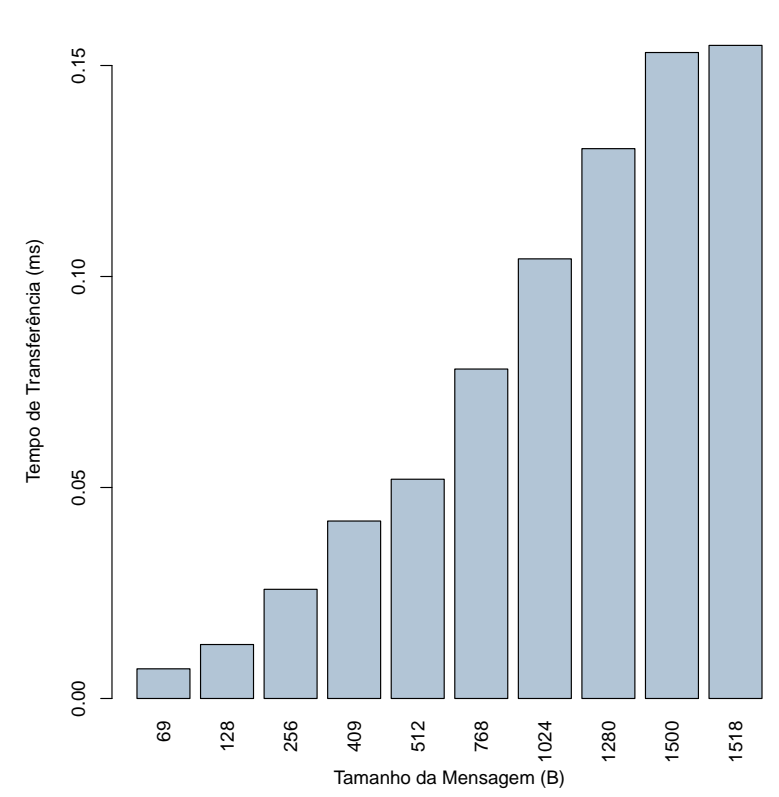

(a)

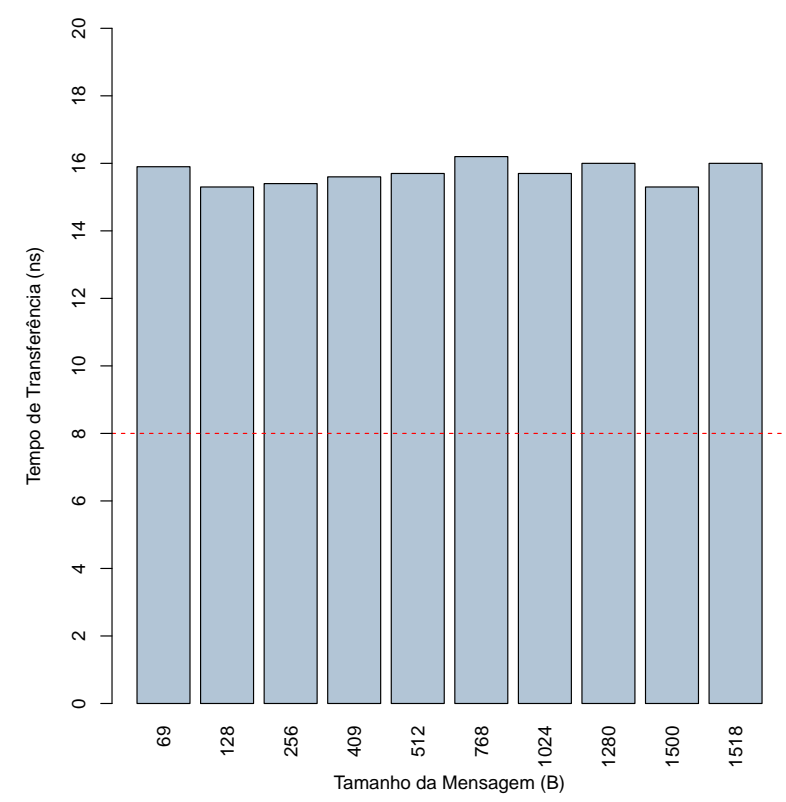

(b)

Figura 123: Gráficos de barras do valor máximo (a) e da amplitude (b) do tempo de transferência, por tamanho da mensagem estratificada pela soma dos módulos M7 e M8

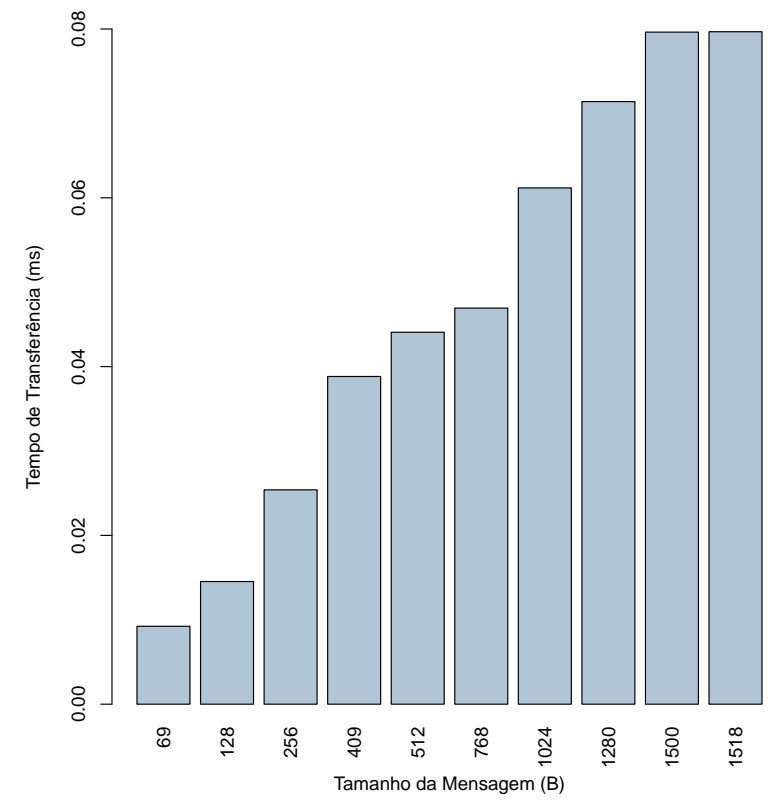

(a)

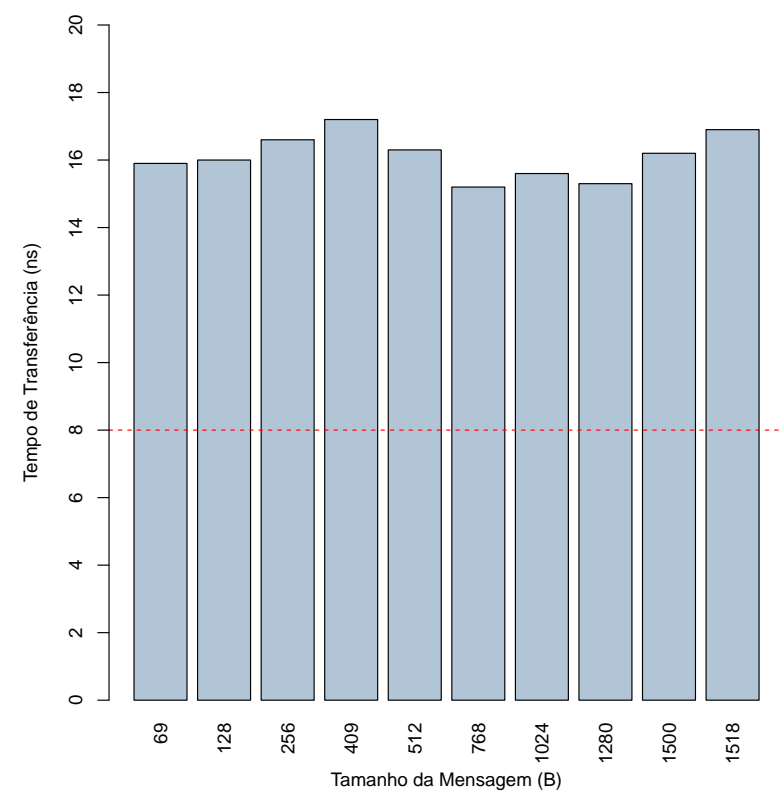

(b)

Figura 124: Gráficos de barras do valor máximo (a) e da amplitude (b) do tempo de transferência, por tamanho da mensagem estratificada pela soma dos módulos M9 e M10 


\subsection{Comparação do TT entre os TMs Estratificada pela Soma dos Módulos 3 a 3}

A Tabela 34, no Apêndice F, apresenta a descrição do tempo de transferência entre os tamanhos da mensagem estratificada pela soma dos módulos 3 a 3. A partir dela, pode-se concluir que:

- Em todas as somas dos módulos, ao se realizar o teste de Kruskal-Wallis, foi possível averiguar que houve diferença significativa (Valor-p $=0,000$ ) do tempo de transferência entre os tamanhos da mensagem. As comparações múltiplas, feitas pelo teste de Nemenyi, encontram-se na Tabela 35, no Apêndice F, na qual se pode verificar que houve diferença significativa (Valor- $\mathrm{p}=0,000$ ) do tempo de transferência entre todos os tamanhos da mensagem, sendo que, na medida que se aumenta o tamanho da mensagem, houve um aumento no tempo de transferência médio; e

- O maior valor foi de 0,15689ms, referente ao tamanho da mensagem 1518B, nas somas M3 + M8 + M10 e M4 + M8 + M10, sendo menor que o tamanho desejado de $1 \mathrm{~ms}$. Além disso, a maior amplitude foi de 24,2ns, na soma M4 + M8 + M10, no tamanho 409B. Cabe ressaltar que todas as amplitudes ficaram acima de 8 ns.

A Tabela 35, no Apêndice F, apresenta as comparações múltiplas, feitas pelo teste de Nemenyi.

As Figuras 125 a 136 apresentam os gráficos de barras do valor máximo e da amplitude do tempo de transferência, por tamanho da mensagem estratificada pela soma dos módulos 3 a 3. 


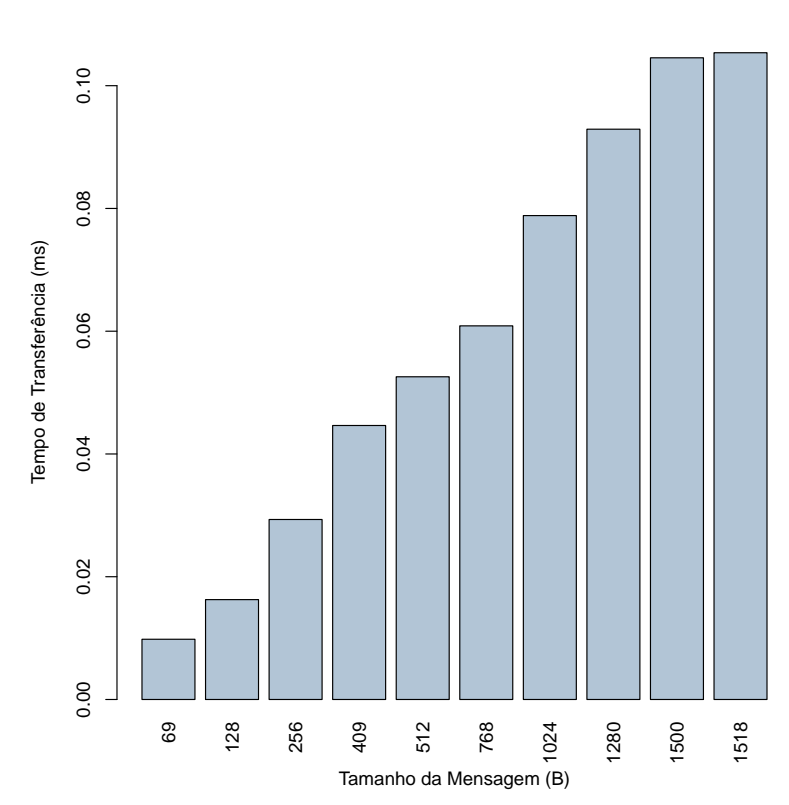

(a)

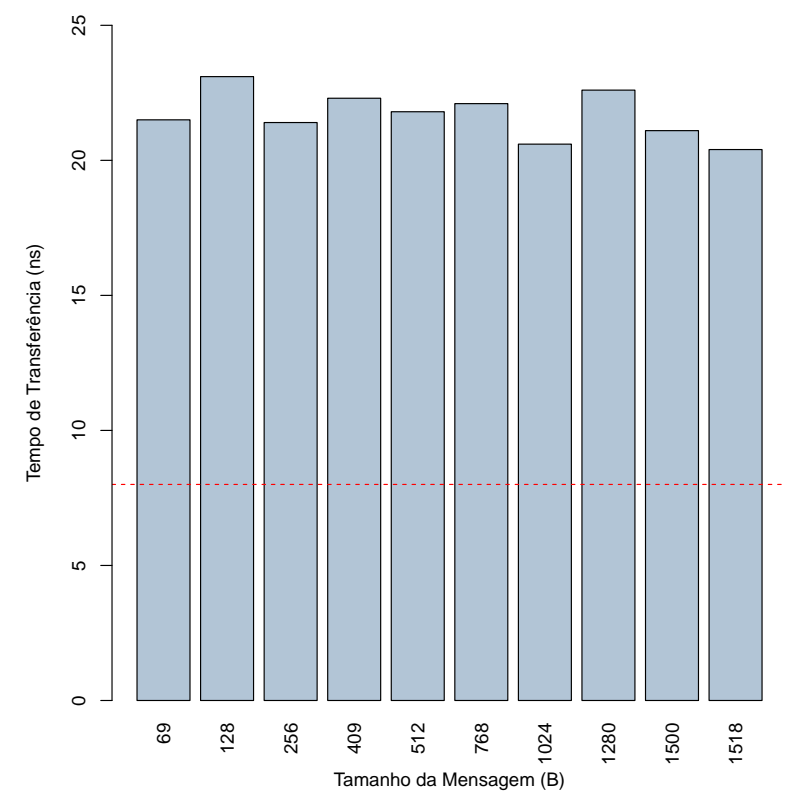

(b)

Figura 125: Gráficos de barras do valor máximo (a) e da amplitude (b) do tempo de transferência, por tamanho da mensagem estratificada pela soma dos módulos M3, M6 e M9

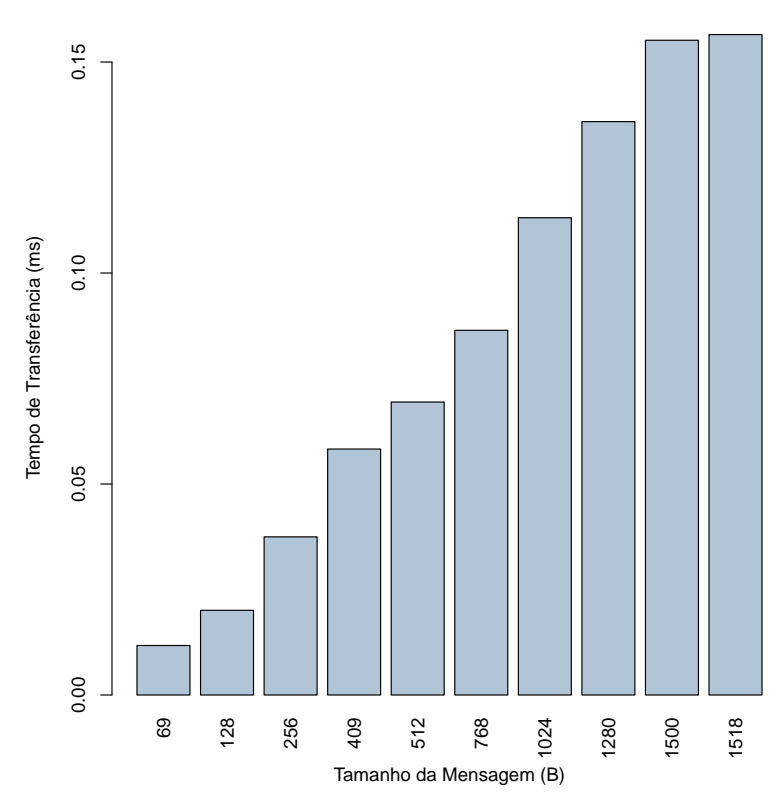

(a)

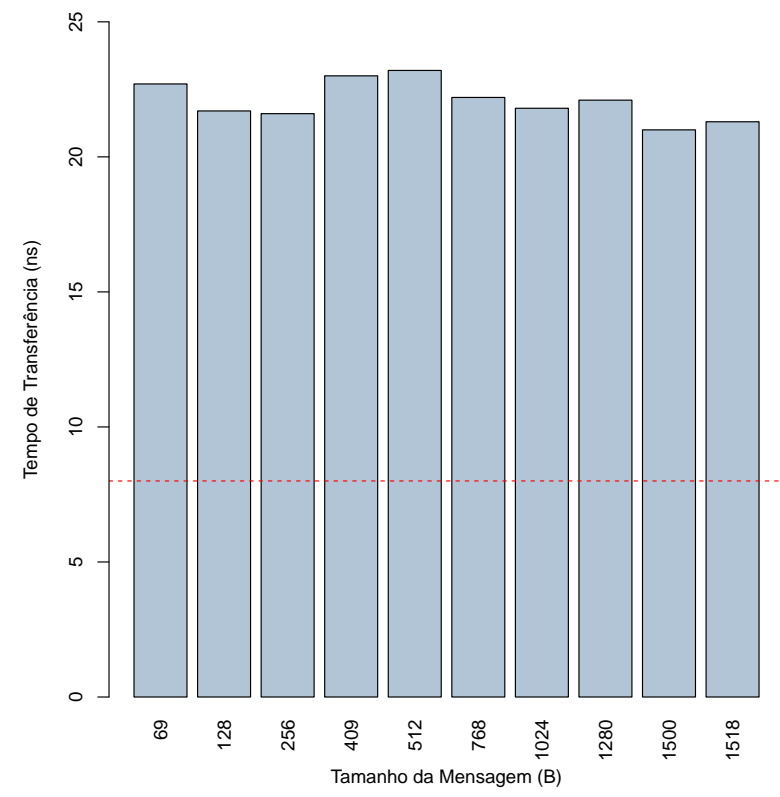

(b)

Figura 126: Gráficos de barras do valor máximo (a) e da amplitude (b) do tempo de transferência, por tamanho da mensagem estratificada pela soma dos módulos M3, M7 e M9 


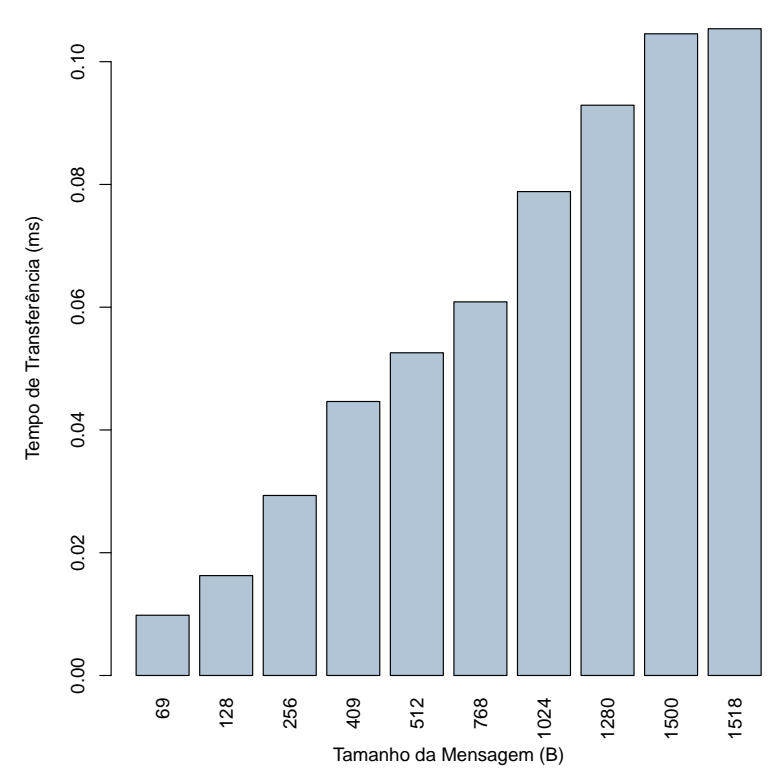

(a)

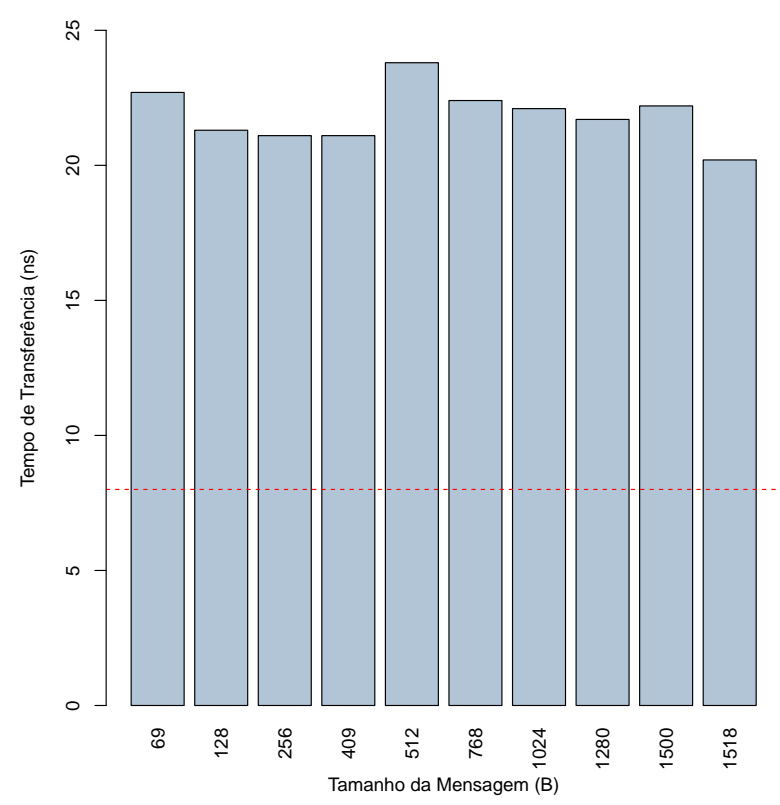

(b)

Figura 127: Gráficos de barras do valor máximo (a) e da amplitude (b) do tempo de transferência, por tamanho da mensagem estratificada pela soma dos módulos M4, M6 e M9

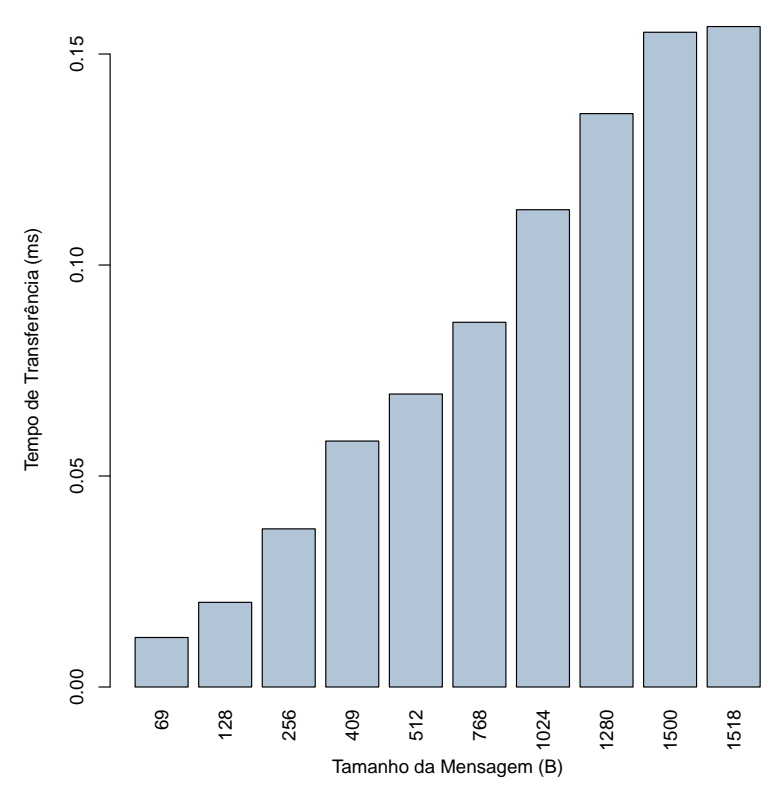

(a)

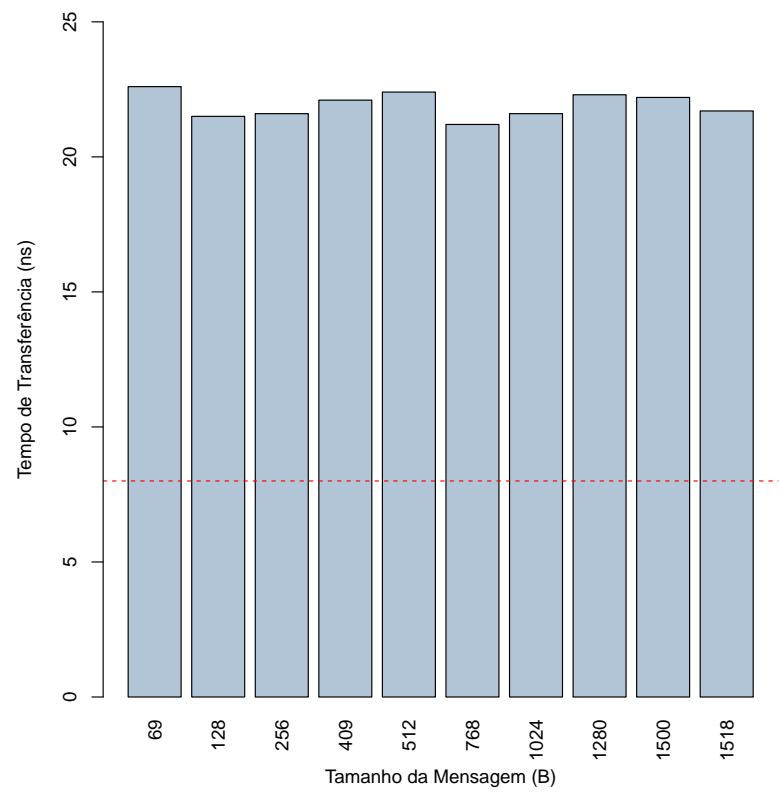

(b)

Figura 128: Gráficos de barras do valor máximo (a) e da amplitude (b) do tempo de transferência, por tamanho da mensagem estratificada pela soma dos módulos M4, M7 e M9 


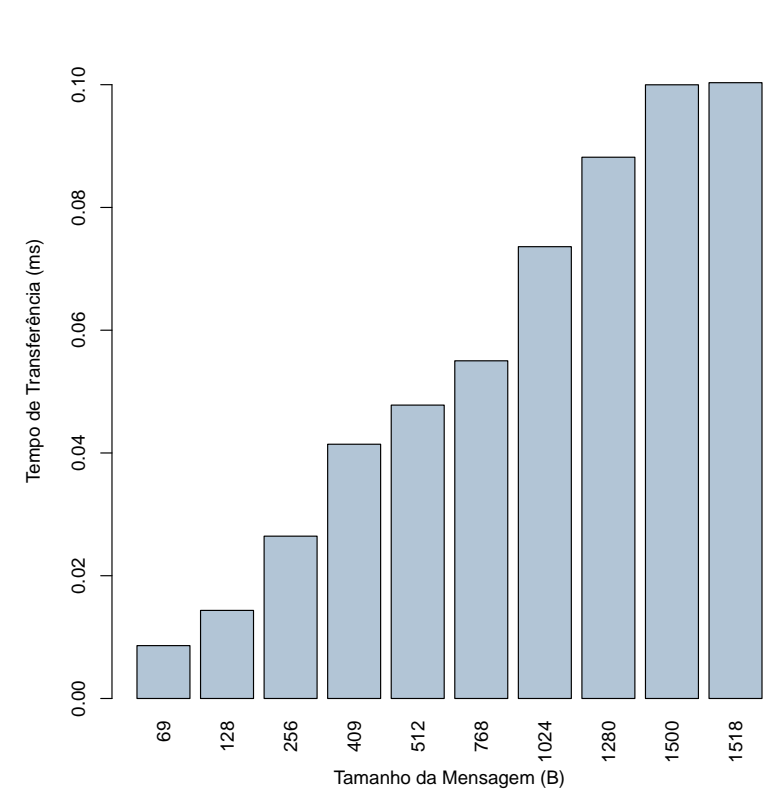

(a)

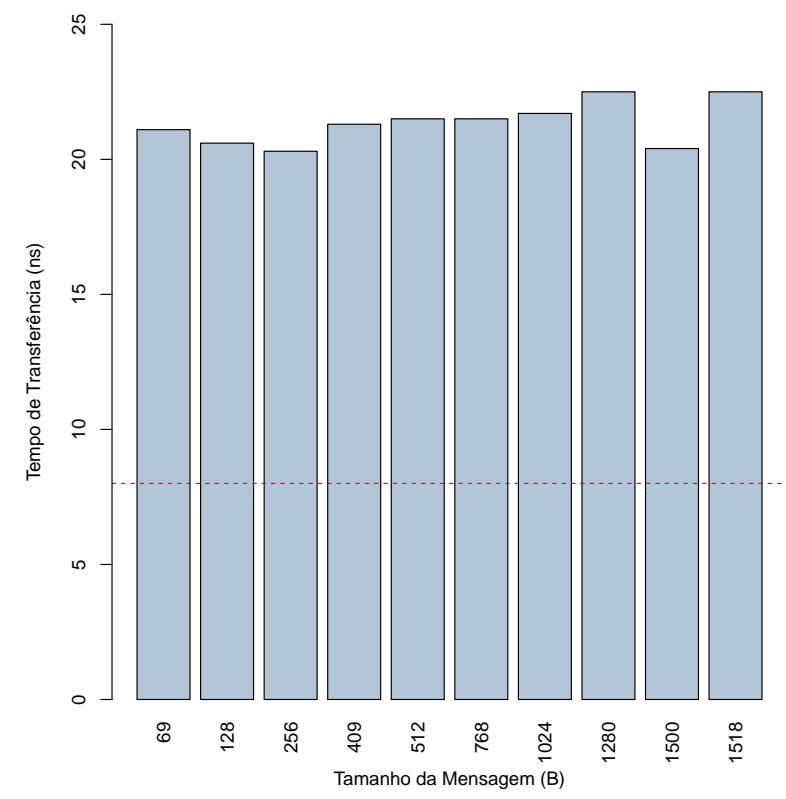

(b)

Figura 129: Gráficos de barras do valor máximo (a) e da amplitude (b) do tempo de transferência, por tamanho da mensagem estratificada pela soma dos módulos M5, M6 e M9

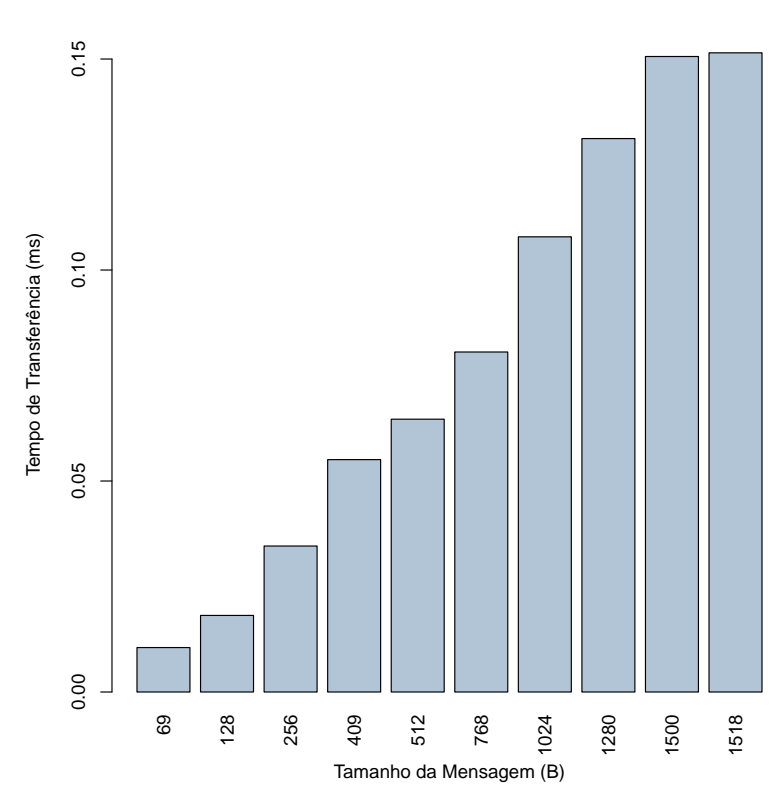

(a)

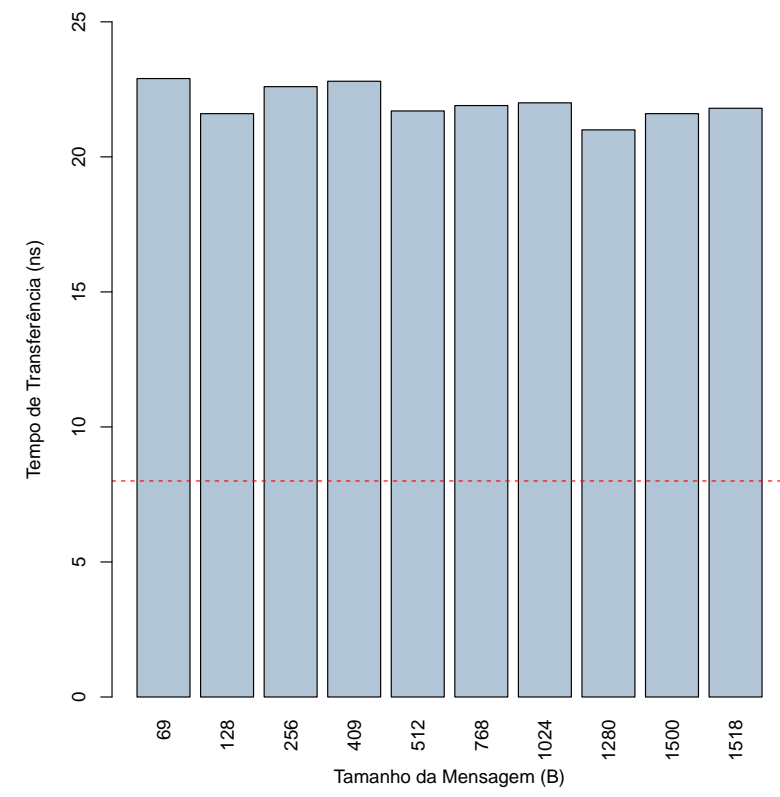

(b)

Figura 130: Gráficos de barras do valor máximo (a) e da amplitude (b) do tempo de transferência, por tamanho da mensagem estratificada pela soma dos módulos M5, M7 e M9 


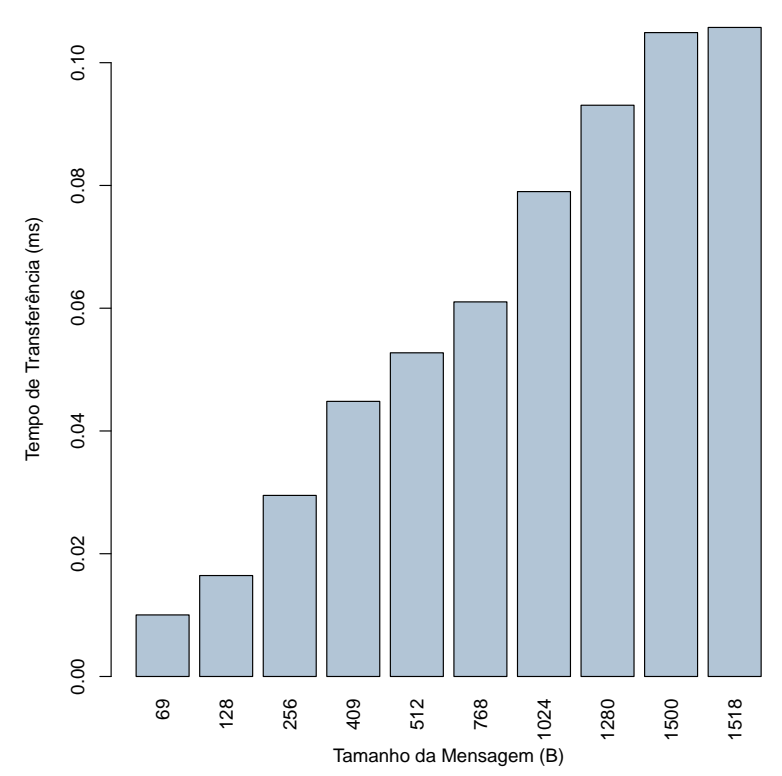

(a)

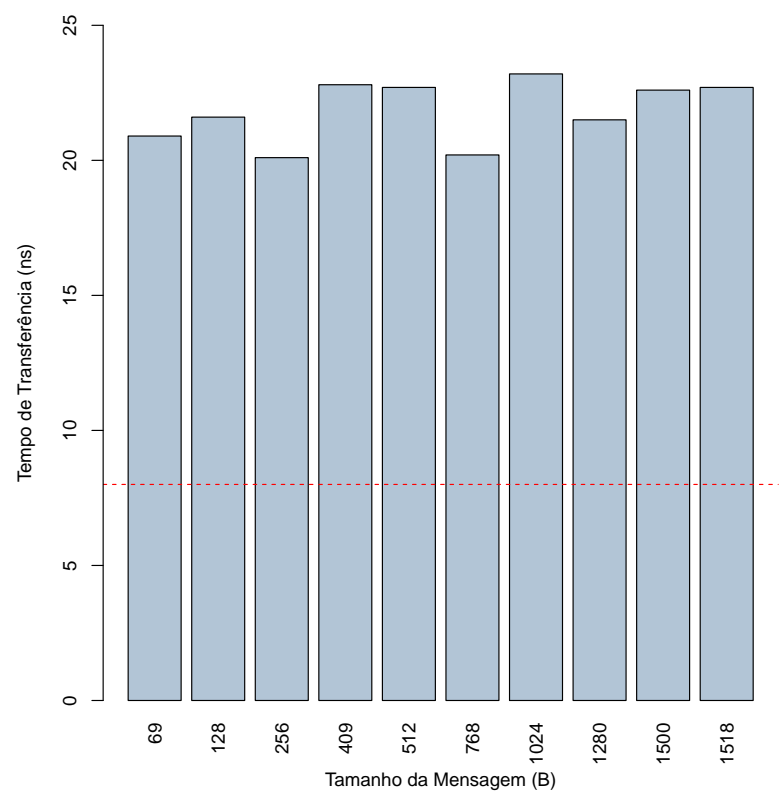

(b)

Figura 131: Gráficos de barras do valor máximo (a) e da amplitude (b) do tempo de transferência, por tamanho da mensagem estratificada pela soma dos módulos M3, M6 e M10

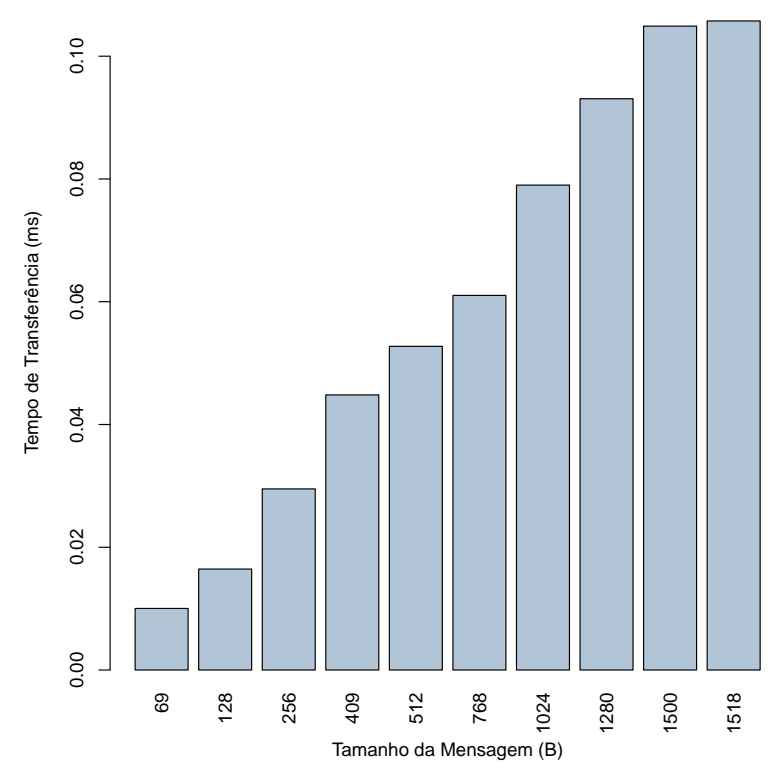

(a)

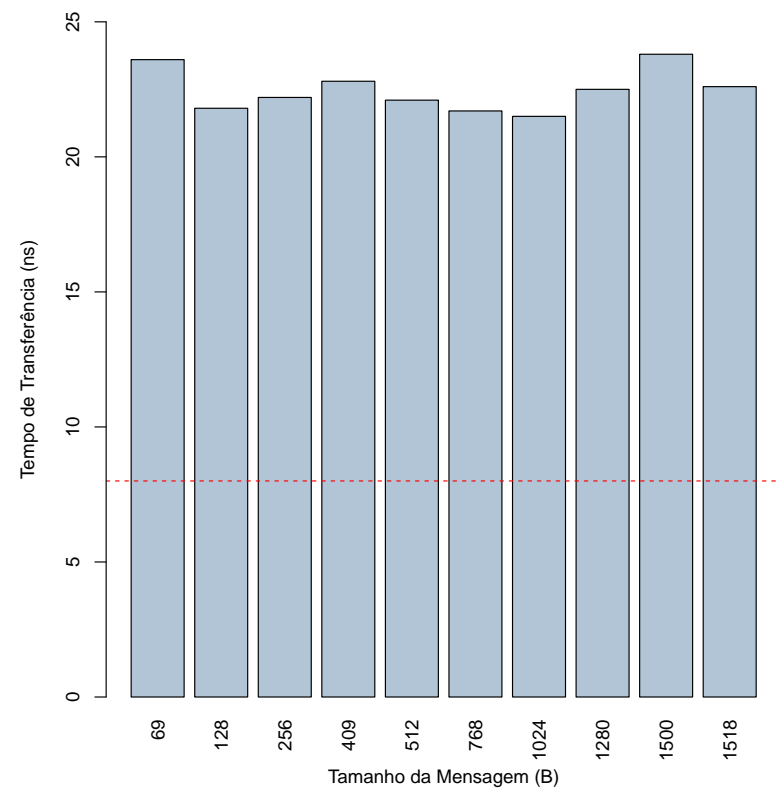

(b)

Figura 132: Gráficos de barras do valor máximo (a) e da amplitude (b) do tempo de transferência, por tamanho da mensagem estratificada pela soma dos módulos M4, M6 e M10 


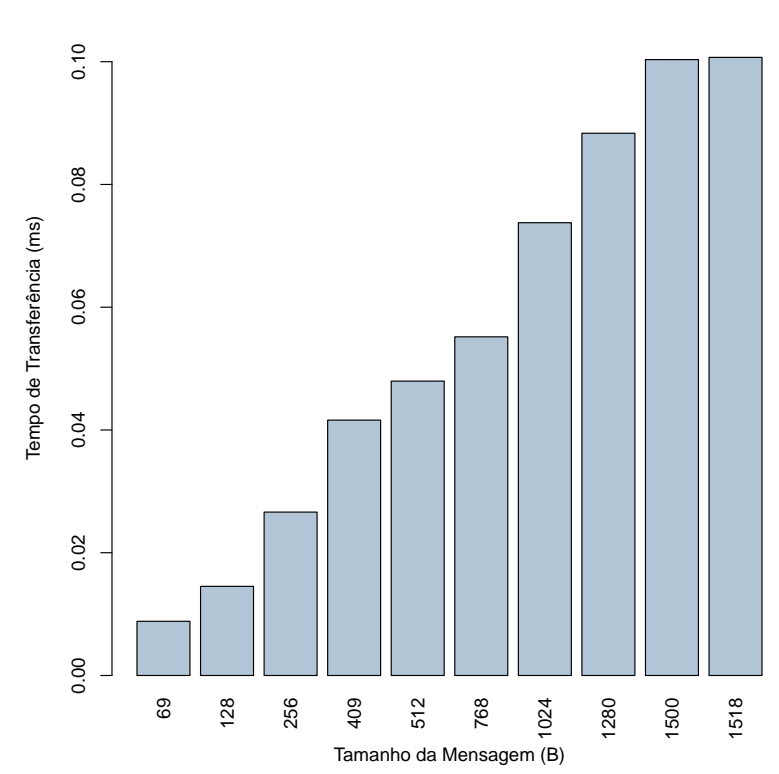

(a)

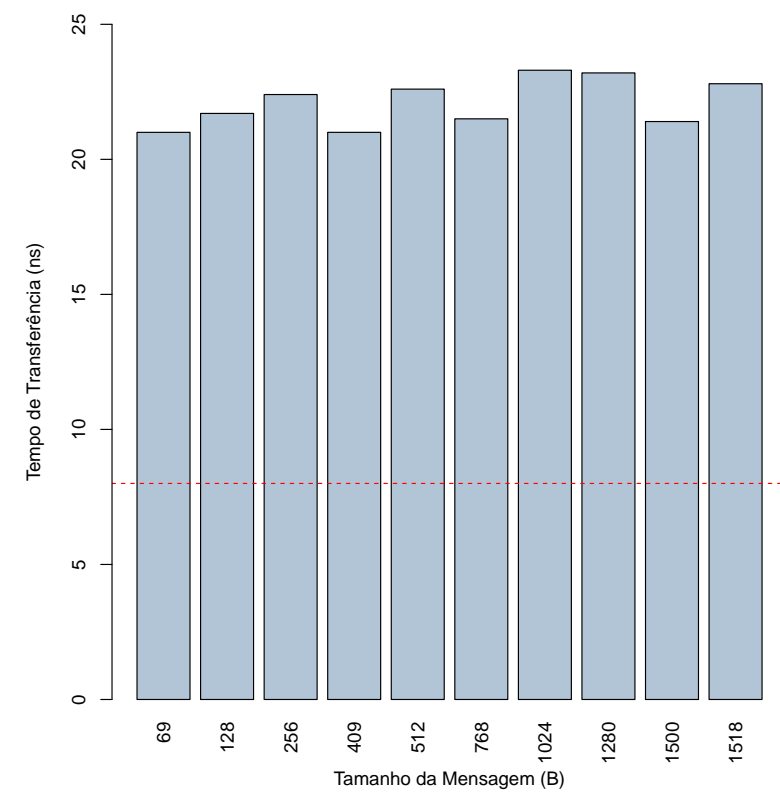

(b)

Figura 133: Gráficos de barras do valor máximo (a) e da amplitude (b) do tempo de transferência, por tamanho da mensagem estratificada pela soma dos módulos M5, M6 e M10

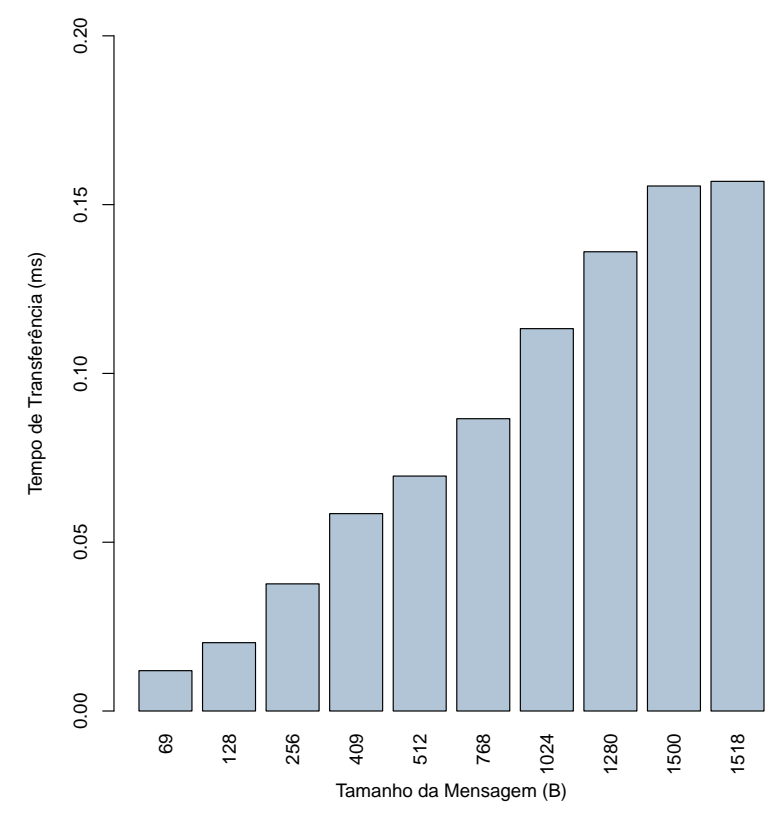

(a)

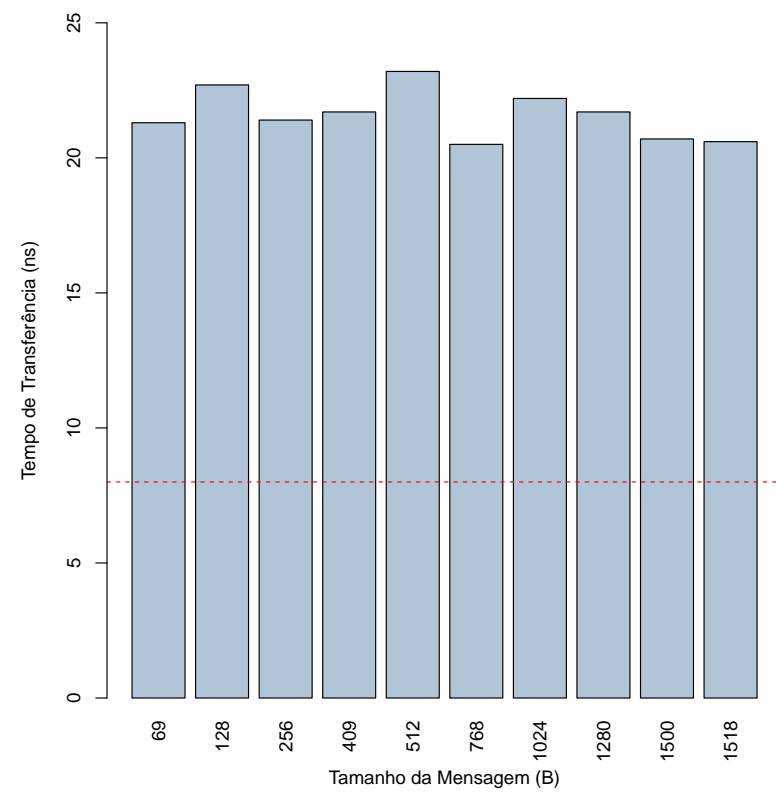

(b)

Figura 134: Gráficos de barras do valor máximo (a) e da amplitude (b) do tempo de transferência, por tamanho da mensagem estratificada pela soma dos módulos M3, M8 e M10 


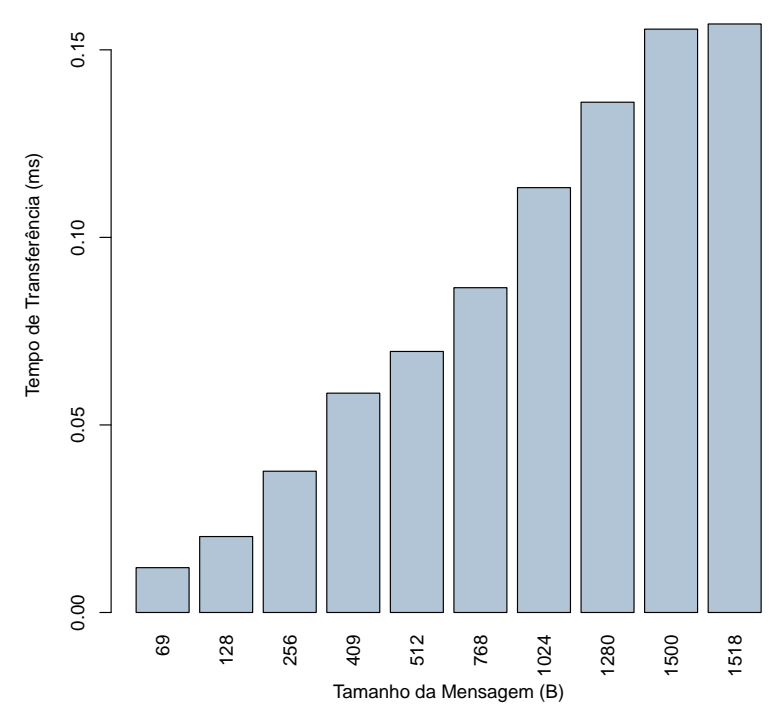

(a)

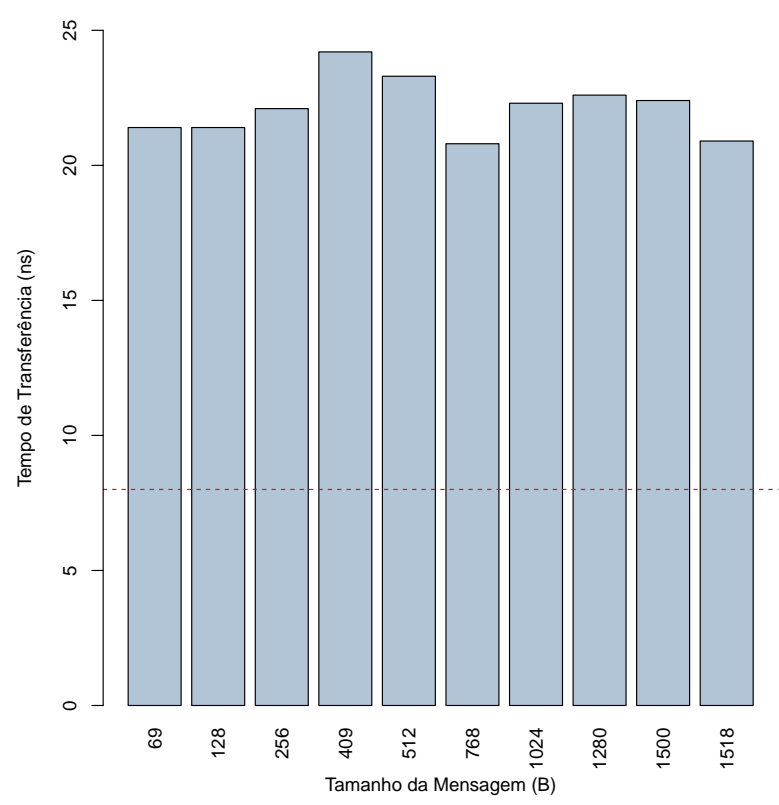

(b)

Figura 135: Gráficos de barras do valor máximo (a) e da amplitude (b) do tempo de transferência, por tamanho da mensagem estratificada pela soma dos módulos M4, M8 e M10

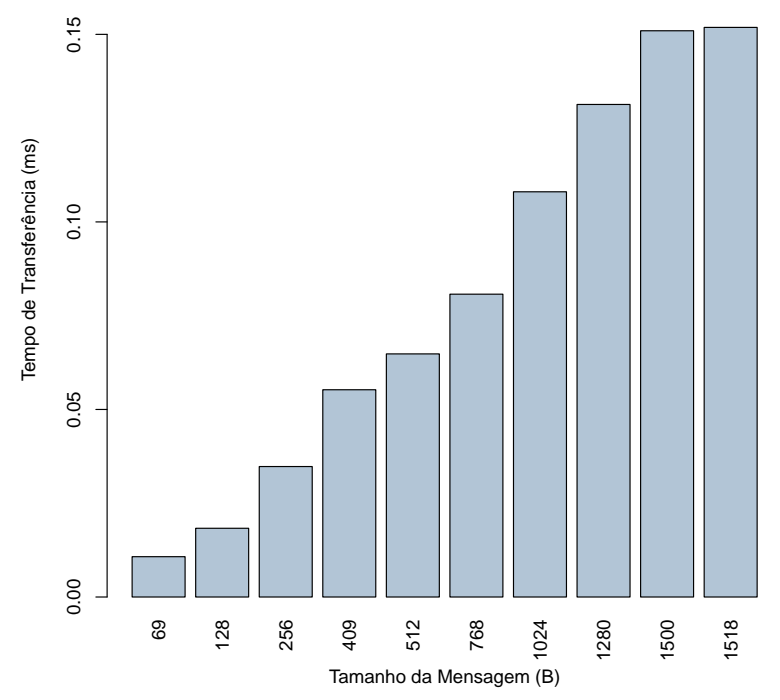

(a)

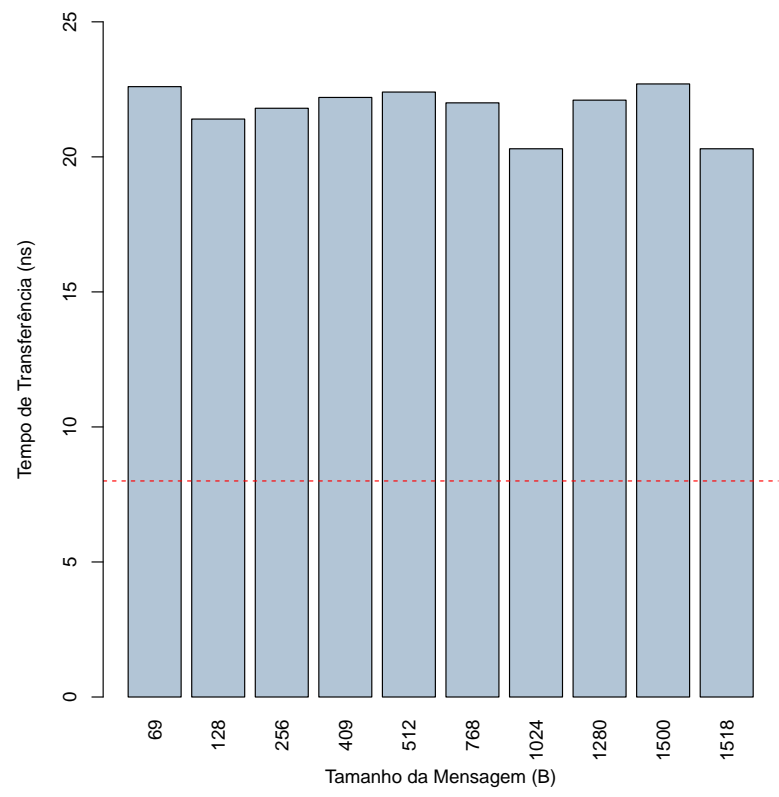

(b)

Figura 136: Gráficos de barras do valor máximo (a) e da amplitude (b) do tempo de transferência, por tamanho da mensagem estratificada pela soma dos módulos M5, M8 e M10 


\subsection{Throughput entre Módulos Estratificado por TM}

Considerando os recursos de hardware da plataforma NetFPGA-V2, o processamento decorrente de cada módulo, o tamanho das FIFOs, a serialização dos dados e a propagação dos bits, a Figura 137 mostra o número de megabits/s que podem ser transferidos por cada módulo, de acordo com o tamanho da mensagem. Para medir o throughput de cada módulo, estratificado por tamanho da mensagem, foi utilizado o aplicativo Packet Generator, descrito na Figura 58, Subseção 4.10.1 (NetFPGA-2).

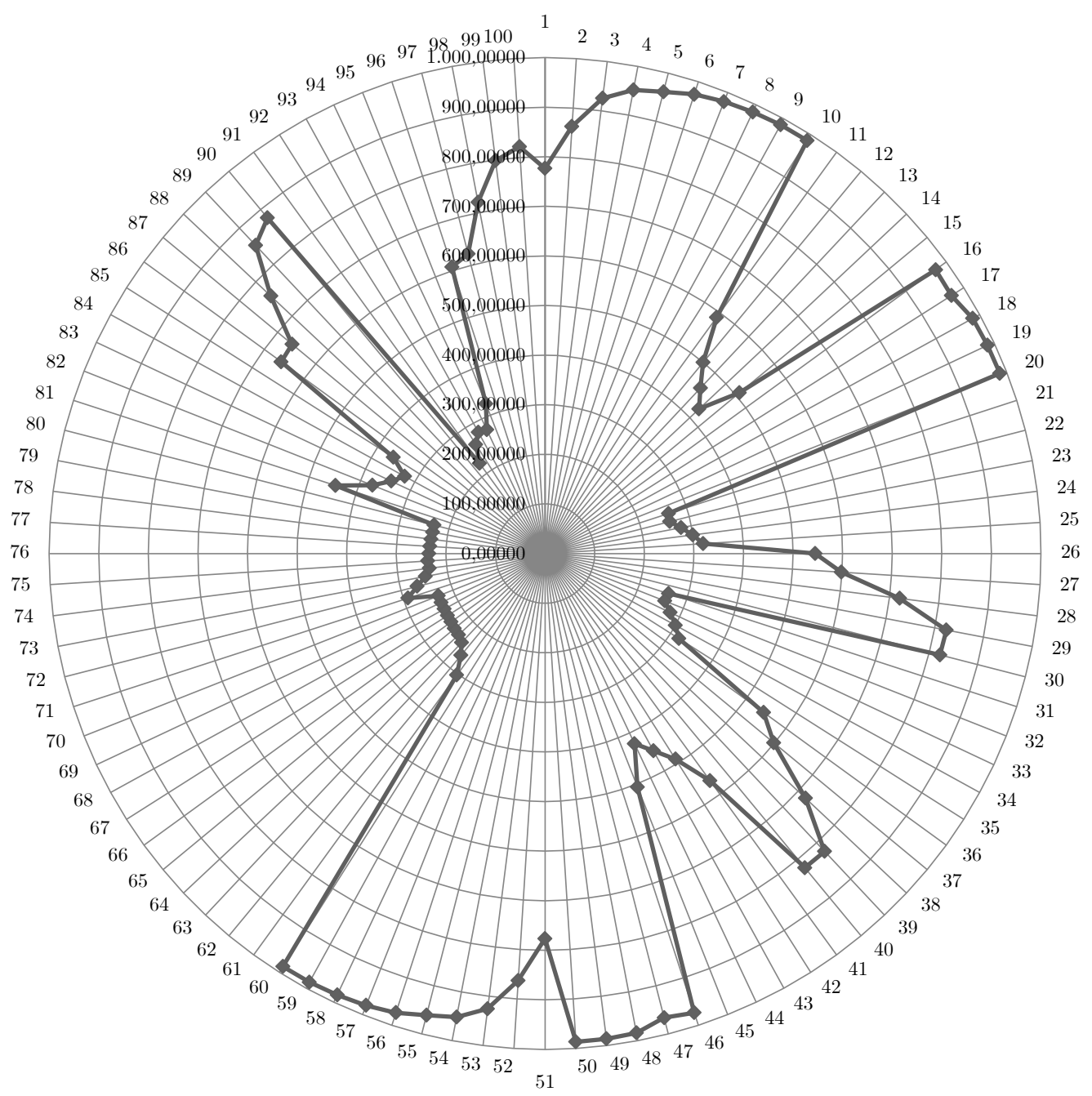

Figura 137: Medida do Throughput entre módulos estratificado por TM

Na Figura 137, os itens de 1 a 10 equivalem às mensagens de 69B a 1518B do módulo 1, os itens de 11 a 20 equivalem às mensagens de $69 \mathrm{~B}$ a $1518 \mathrm{~B}$ do módulo 2, e assim por diante. Nesse ínterim, pode-se verificar que os módulos 1, 2, 5 e 6 apresentam as maiores taxas de transferência de bits, 986,388Mbps, para as mensagens com tamanho de 1518B. A menor taxa é referente ao módulo Authentication_RX, com 224,65Mbps, para a mensagem com 69B. Os valores medidos equivalem às taxas de transferência sem perda de mensagem. 


\section{Conclusões}

Com o propósito de contribuir para a melhoria da segurança cibernética pertinente ao padrão IEC 61850 e, por conseguinte, à troca de mensagens GOOSE entre IEDs, este trabalho propôs um firewall em hardware reconfigurável para restringir o tráfego de mensagens GOOSE para a proteção do SEP.

O encapsulamento e tráfego de quadros de dados no ambiente da subestação, utilizando, por exemplo, o serviço de mensagens GOOSE, leva a uma preocupação quanto à segurança do referido tráfego. Mensagens GOOSE falsas podem ocasionar consequências devastadoras sobre a confiabilidade da rede e afetar a capacidade do sistema de proteção de atenuar condições anormais no sistema elétrico e de assegurar a continuidade no fornecimento de energia.

Primeiramente, este trabalho apresentou um modelo para decodificação de mensagens GOOSE, denominado ASN.1/BER GOOSE, que fornece uma matriz de registradores com todos os campos fixos e flexíveis do quadro ISO/IEC 8802-3. Uma das principais vantagens do modelo é não mesclar em um mesmo registrador campos distintos. Nesse contexto, uma aplicação que faça uso da matriz só precisa identificar o campo de interesse, verificar o número de registradores que serão utilizados e empregar o valor fornecido. Outro benefício é para o campo allData, que tem armazenado na matriz apenas as informações de dados e não as das estruturas pertinentes aos campos.

No que tange aos aplicativos de software concebidos, o RGGM (Random Generator GOOSE Messages) e o VMG (Validator GOOSE Messages) foram fundamentais para corroborar a correta decodificação de mensagens GOOSE, utilizando todas as estruturas e dados pertinentes ao modelo abstrato e às regras básicas de codificação, descritas pelo padrão IEC 61850. O módulo ASN.1/BER GOOSE conseguiu capturar corretamente os campos de 115.000 mensagens.

A avaliação de desempenho mostrou que a implementação em hardware reconfigurável permite a decodificação das mensagens GOOSE com baixa latência, condição fundamental para não incrementar excessivamente o tempo de transferência de uma mensagem no âmbito do SEP. Além disso, o throughput do módulo permite a decodificação de milhares 
de quadros por segundo em modo full-duplex.

Como as mensagens GOOSE podem afetar o sistema elétrico, conclui-se que o modelo proposto pode facultar o desenvolvimento de sistemas com a capacidade de monitorar e controlar a interatividade entre dispositivos que processam mensagens GOOSE.

As mensagens GOOSE são normalmente enviadas em multicast. Se não existe nenhuma restrição de fluxo, elas são distribuídas por switches dentro de todo o segmento Ethernet da subestação. Os meios mais comuns para estabelecer restrições de fluxo é configurar LANs Virtuais (VLANs) entre todos os IEDs que necessitem de uma determinada mensagem ou pertençam a um determinado grupo de trabalho. O relatório técnico TR 61850-90-1 menciona que outra possibilidade é a filtragem por endereços MAC. Porém, o padrão salienta que isto pode ser mais difícil de se definir em um ambiente de redes de longa distância.

Nesse contexto, o referido trabalho de pesquisa também apresentou como contribuição a formação de algoritmos em hardware que podem compor dispositivos de filtragem, não só do endereço MAC, mas de qualquer parte do quadro ISO/IEC 8802-3. Cabe ressaltar que o filtro para mensagens GOOSE é parte de um conjunto de soluções que compõem a segurança cibernética de ativos pertinentes ao sistema elétrico de potência. É importante salientar que, para o maior quadro, com 1518 bytes, o tempo de transferência máximo

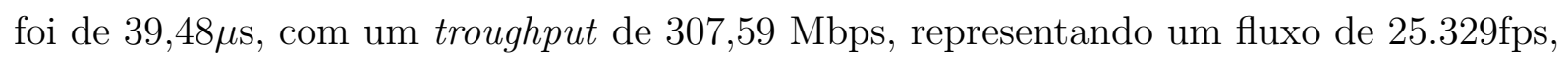
quadros por segundo.

A especificação técnica TS 62351-6 não recomenda a utilização de criptografia para a troca de mensagens GOOSE entre IEDs. Nos testes realizados com a criptografia e decriptografia DES, é possível perceber uma sobrecarga no tempo de transferência. Porém, mesmo com o maior quadro, 1518 bytes, o maior tempo de transferência foi de $77,39 \mu \mathrm{s}$, sendo menor que o tempo de transferência desejado de $1 \mathrm{~ms}$, e representando um fluxo de 12.921fps.

Embora a TS 62351-6 oriente a utilização de um algoritmo SHA-256 Hash, foi utilizado como prova de conceito o algoritmo SHA-3 KECCAK com chave de 512 bits, como forma de intensificar a segurança para as mensagens GOOSE. Com o quadro de 1518 bytes, o maior tempo de transferência foi de $40,03 \mu \mathrm{s}$, no processo de retirada do código de autenticação da mensagem, o que refletiu em um fluxo de 24.981fps. Com o uso do SHA256, o tempo de transferência será menor, pois o número de bytes adicionados à mensagem será menor.

Ressalta-se que, na comparação do tempo de transferência estratificada pela soma dos módulos 3 a 3, o maior valor foi de $0,15689 \mathrm{~ms}$, referente ao tamanho da mensagem de 1518 bytes. E, considerando a utilização simultânea do módulo Filter (com todos os campos sendo utilizados para filtragem), a execução da decriptografia DES e do módulo de autenticação na recepção (com o algoritmo SHA-3), o tempo de transferência ficou abaixo do $1 \mathrm{~ms}$, descrito no objetivo da pesquisa. 
O tempo de transferência, estratificado pela soma dos módulos 2 a 2 e 3 a 3, considera o uso dos módulos em NetFPGAs distintas. A sintetização dos módulos em uma única FPGA deve proporcionar tempos mais baixos.

Os testes realizados e a avaliação estatística demostraram que é factível a utilização de firewalls nas bordas das subestações. Porém, o sistema proposto não é viável para restringir o tráfego de mensagens GOOSE, entre diversos equipamentos, dentro da subestação. Neste ínterim, um estudo pode ser realizado para implementar os módulos desenvolvidos diretamente na placa de rede dos IEDs. Assim, é possível que um relé digital envie para a rede local da subestação mensagens GOOSE criptografadas e autenticadas, e que apenas os pares de interesse possam identificar a mensagem. A segurança não seria limitada às bordas da subestação e cada elemento dela poderia contribuir com a segurança cibernética.

Outro quesito que deve ser considerado é o sincronismo temporal. Com a inserção do barramento de processo baseado no padrão IEC 61850, as medições e funções de proteção pertinentes aos diferentes equipamentos do SEP são conectadas por meio de uma rede Ethernet. Segundo Guo e Crossley (2016), muitas empresas do setor elétrico cogitam a adoção do protocolo PTP (Precision Time Protocol), que é normalizado pelo IEEE 1588, para garantir a exatidão do sincronismo quando se utiliza uma rede Ethernet.

Para que os módulos de filtragem, criptografia e autenticação possam ser utilizados em uma rede que utilize o PTP, será preciso estampar os tempos de transferência de cada módulo para que, assim, o protocolo PTP possa compensar os atrasos.

Embora a plataforma NetFPGA-V2 seja uma das primeiras versões, o que implica uma capacidade reduzida de recursos para a síntese lógica, os resultados apontam para a eficiência da plataforma, uma vez que a variação da amplitude estatística ficou próxima de 8ns, independentemente do módulo e do tamanho das mensagens GOOSE que passaram pelos módulos.

\subsection{Pontos de Continuidade da Pesquisa}

As sugestões propostas para a continuidade da pesquisa são:

- Aprofundar o estudo sobre as vulnerabilidades das mensagens GOOSE e os testes de intrusão que possam ser realizados no ambiente de automação da subestação;

- Desenvolver outras estruturas, em vez da matriz, para acesso aos campos do quadro ISO/IEC 8802-3;

- Explorar a composição dos filtros versus o tempo de transferência necessário;

- Averigar a utilização de outros algoritmos de criptografia para as mensagens GOOSE, por exemplo, triploDES e AES (Advanced Encryption Standard); 
- Acrescentar o módulo Authentication_RX no Route 2;

- Examinar a possibilidade de utilizar outros algoritmos de autenticação;

- Explorar algoritmos de assinatura digital;

- Identificar e resolver os pontos de vulnerabilidade dos módulos;

- Tratar em profundidade os quadros malformados;

- Desenvolver um ASIC (Application Specific Integrated Circuit) dedicado, com o sistema de filtragem, criptografia e autenticação, para o quadro ISO/IEC 8802-3;

- Acrescentar, nos módulos desenvolvidos, suporte ao protocolo de sincronismo temporal PTP;

- Investigar as perdas temporais devido à utilização das memórias externas, pertinentes à plataforma NetFPGA. 


\section{Referências}

AHMAD, D. R. M.; DUBRAWSKY, I.; FLYNN, H.; GRAND, J. K.; GRAHAM, R.; JOHNSON, N. L.; JR.; K2; KAMINSKY, D. E.; LYNCH, F. W.; MANZUIK, S. W.; PERMEH, R.; PFEIL, K.; PUPPY, R. F.; RUSSELL, R. Hack Proofing Your Network 2E. [S.l.]: Elsevier Science, 2002. ISBN 9780080478166.

ALI, I.; THOMAS, M.; GUPTA, S. Methodology amp; tools for performance evaluation of iec 61850 goose based protection schemes. In: Power India Conference, 2012 IEEE Fifth. [S.l.: s.n.], 2012. p. 1-6.

AMIN, S.; GIACOMONI, A. Smart grid, safe grid. Power and Energy Magazine, IEEE, 2012. v. 10, n. 1, p. 33-40, 2012. ISSN 1540-7977.

ANDERSON, D.; KIPP, N. Implementing Firewalls for Modern Substation Cybersecurity. [S.l.], 2010. 20100224 - TP6427-01.

ANDRÉN, F.; BRÜNDLINGER, R.; STRASSER, T. Iec 61850/61499 control of distributed energy resources: Concept, guidelines, and implementation. IEEE Transactions on Energy Conversion, 2014. v. 29, n. 4, p. 1008-1017, Dec 2014. ISSN 0885-8969.

APOSTOLOV, A.; THOLOMIER, D. Impact of iec 61850 on power system protection. In: Power Systems Conference and Exposition, 2006. PSCE '06. 2006 IEEE PES. [S.l.: s.n.], 2006. p. 1053-1058.

AYALA, J. Communication Architectures for Systems-on-Chip. [S.l.]: CRC Press, 2011. ISBN 9781439841716.

BASTOS, M. R.; CASTRO, E. A evolução dos sistemas de proteção e controle com a iec 61850. 2005. Eletricidade Moderna, São Paulo, n. 374, p. 168-177, 2005.

BERTONI, G.; DAEMEN, J.; PEETERS, M.; ASSCHE, G. V. The Keccak sponge function family. 2011. Disponível em: <http://keccak.noekeon.org/>. Acesso em: 0107-2016.

BLUM, R. Network Performance Open Source Toolkit: Using Netperf, tcptrace, NISTnet, and SSFNet. [S.l.]: Wiley, 2003. ISBN 9780471481140.

BRANQUINHO, M. A.; MORAES, L. C.; SEIDL, J.; JUNIOR, J. A.; BRANQUINHO, B. T. Segurança da Automação e SCADA. [S.l.]: Elsevier, 2014. ISBN 9788535277333. 
CARISSIMI, A. da S.; ROCHOL, J.; GRANVILLE, L. Redes de Computadores: Volume 20 da Série Livros didáticos informática UFRGS. [S.1.]: Bookman, 2009. ISBN 9788577805303.

CARvalho, T. C. M. d. B. Arquiteturas de Redes de Computadores OSI e TCP/IP. 2. ed. [S.1.]: Brisa, 1997. ISBN 853460694-3.

CASADO, M.; WATSON, G.; MCKEOWN, N. Reconfigurable networking hardware: A classroom tool. In: IEEE Comp Soc; Xilinx; Intel; GlobalVelocity. HOT INTERCONNECTS 13. 10662 LOS VAQUEROS CIRCLE, PO BOX 3014, LOS ALAMITOS, CA 90720-1264 USA: IEEE COMPUTER SOC, 2005. p. 151-157. ISBN 0-7695-2449-4. 13th Symposium on High Performance Interconnects, Stanford Univ, Stanford, CA, AUG 1719, 2005.

CAVALIERI, S.; REGALBUTO, A. Integration of iec $61850 \mathrm{scl}$ and opc ua to improve interoperability in smart grid environment. Computer Standards \& Interfaces, 2016. v. 47 , p. $77-99,2016$. ISSN 0920-5489.

CERT.BR. CERT.br Stats (janeiro a dezembro de 2015). 2016. Disponível em: <http://www.cert.br/stats/incidentes/2015-jan-dec/tipos-ataque.html>. Acesso em: 2507-2016.

Estatísticas do CERT.br - Incidentes. 2016. Disponível em: <http://www.cert.br/stats/incidentes/>. Acesso em: 25-07-2016.

CHESWICK, W. R.; BELLOVIN, S. M.; RUBIN, A. D. Repelling the Wily Hacker. [S.l.]: Addison-Wesley, 1994.

CILETTI, M. D. Modeling, Synthesis and Rapid Prototypingwith the Verilog HDL. [S.l.]: Prentice Hall, 1999.

CLAVEL, F.; SAVARY, E.; ANGAYS, P.; VIEUX-MELCHIOR, A. Integration of a new standard: A network simulator of iec 61850 architectures for electrical substations. IEEE Industry Applications Magazine, 2015. v. 21, n. 1, p. 41-48, Jan 2015. ISSN 10772618.

COOPERSTEIN, J. Writing Linux Device Drivers: a guide with exercises. [S.l.]: Jerry Cooperstein, 2009.

COSTA, C. da; MESQUITA, L.; PINHEIRO, E. Elementos de Lógica Programável com VHDL e DSP: Teoria e Prática. São Paulo: Érica, 2011.

COSTA, M. da. Setor Elétrico quer verba contra ataque virtual. [S.l.], 2016. P. A2 - Mercado.

COURY, D. V.; OLESKOVICZ, M.; GIOVAnINI, R. Proteção Digital de Sistemas Elétricos de Potência: dos relés eletromecânicos aos microprocessados inteligentes. [S.l.]: EESC-USP, 2007.

COVInGTON, G.; GIBB, G.; LOCKWOOD, J.; MCKEOWN, N. A packet generator on the netfpga platform. In: Field Programmable Custom Computing Machines, 2009. FCCM '09. 17th IEEE Symposium on. [S.l.: s.n.], 2009. p. 235-238. 
COVInGtON, G.; GIBB, G.; NAOUS, J.; LOCKWOOD, J.; MCKEOWN, N. Encouraging reusable network hardware design. In: Microelectronic Systems Education, 2009. MSE '09. IEEE International Conference on. [S.l.: s.n.], 2009. p. 29-32.

CSWG. Introduction to NISTIR 7628 Guidelines for Smart Grid Cyber Security. [S.l.], 2010.

DU, L.; LIU, Q. ying. The design of communication system on the real-time relay protection based on goose. In: Power and Energy Engineering Conference (APPEEC), 2012 Asia-Pacific. [S.l.: s.n.], 2012. p. 1-5. ISSN 2157-4839.

DUBUISSON, O. ASN.1: Communication Between Heterogeneous Systems. [S.l.]: Morgan Kaufmann, 2001. ISBN 9780126333619.

FAY, E.; ECKL, M. J. Subestações integradas: como obter benefícios do protocolo iec 61850 hoje. In: Simpósio de Automação de Sistemas Elétricos, V SIMPASE. Recife: [s.n.], 2003.

FLEISS, J. L. Balanced incomplete block designs for inter-rater reliability studies. Applied Psychological Measurement, 1981. Sage Publications, v. 5, n. 1, p. 105-112, 1981.

FOROUZAN, B.; FEGAN, S. Data Communications and Networking. [S.1.]: McGraw-Hill Higher Education, 2007. (McGraw-Hill Forouzan networking series).

GALLO, M. A.; HANCOCK, W. M. Computer Communications and Networking Technologies. [S.1.]: Course Technology, 2001.

GEORG, H.; DORSCH, N.; PUTZKE, M.; WIETFELD, C. Performance evaluation of time-critical communication networks for smart grids based on iec 61850. In: Computer Communications Workshops (INFOCOM WKSHPS), 2013 IEEE Conference on. [S.l.: s.n.], 2013. p. 43-48.

GIBB, G.; LOCKWOOD, J.; NAOUS, J.; HARTKE, P.; MCKEOWN, N. Netfpga an open platform for teaching how to build gigabit-rate network switches and routers. Education, IEEE Transactions on, 2008. v. 51, n. 3, p. 364-369, 2008. ISSN 00189359.

GIUSTINA, D. D.; DEDÉ, A.; INVERNIZZI, G.; VALLE, D. P.; FRANZONI, F.; PEGOIANI, A.; CREMASCHINI, L. Smart grid automation based on iec 61850: An experimental characterization. IEEE Transactions on Instrumentation and Measurement, 2015. v. 64, n. 8, p. 2055-2063, Aug 2015. ISSN 0018-9456.

GIUSTINA, D. D.; FERRARI, P.; FlAMmini, A.; RINALDI, S.; SISINNI, E. Automation of distribution grids with iec 61850: A first approach using broadband power line communication. Instrumentation and Measurement, IEEE Transactions on, 2013. v. 62, n. 9, p. 2372-2383, 2013. ISSN 0018-9456.

GONZALEZ-REDONDO, M. J.; MORENO-MUNOZ, A.; PALLARES-LOPEZ, V.; REAL-CALVO, R. J. Influence of data-related factors on the use of IEC 61850 for power utility automation. Electric Power Systems Research, 2016. v. 133, p. 269 - 280, 2016. ISSN 0378-7796. 
GORDON, L. A.; LOEB, M. P.; LUCYSHYN, W.; RICHARDSON, R. Computer Crime and Security Survey. [S.1.], 2006.

GUO, F.; ORMOND, O.; FIALHO, L.; COLLIER, M.; WANG, X. Power consumption analysis of a netfpga based router. The Journal of China Universities of Posts and Telecommunications, 2012. v. 19, Supplement 1, n. 0, p. $94-99$, 2012. ISSN 1005-8885.

GUO, H.; CROSSLEY, P. Design of a time synchronization system based on gps and ieee 1588 for transmission substations. IEEE Transactions on Power Delivery, 2016. PP, n. 99 , p. 1-1, 2016. ISSN 0885-8977.

GUO, Q.; BAO, X.; FENG, G. Proceedings of international conference on soft computing techniques and engineering application: Icsctea 2013, september 25-27, 2013, kunming, china. In: New Delhi: Springer India, 2014. cap. Power Data Network Dynamic Simulation Platform, p. 33-41. ISBN 978-81-322-1695-7.

GURJÃO, E. C.; CARMO, U. A.; SOUZA, B. A. Aspectos de comunicação da norma iec 61850. In: Simpósio Brasileiro de Sistemas Elétricos, SBSE. Campina Grande: [s.n.], 2006.

GURJÃO, E. C.; SOUZA, B. A.; CARMO, U. A. A comunicação entre equipamentos de proteção na norma iec 61850. 2007. Eletricidade Moderna, São Paulo, n. 397, p. 148-157, 2007.

HAUCK, S.; DEHON, A. Reconfigurable Computing: The Theory and Practice of FPGA-Based Computation. [S.l.]: Elsevier Science, 2010. (Systems on Silicon). ISBN 9780080556017.

HOGA, C.; WONG, G. Iec 61850: open communication in practice in substations. In: Power Systems Conference and Exposition, 2004. IEEE PES. [S.l.: s.n.], 2004. p. 618-623 vol.2.

HOLLANDER, M.; WOLFE, D. A.; CHICKEN, E. Nonparametric statistical methods. [S.l.]: John Wiley \& Sons, 2013.

HONG, J.; LIU, C. C.; GOVINDARASU, M. Detection of cyber intrusions using networkbased multicast messages for substation automation. In: Innovative Smart Grid Technologies Conference (ISGT), 2014 IEEE PES. [S.l.: s.n.], 2014. p. 1-5.

Integrated anomaly detection for cyber security of the substations. IEEE Transactions on Smart Grid, 2014. v. 5, n. 4, p. 1643-1653, July 2014. ISSN 1949-3053.

HOSSENLOPP, L. Engineering perspectives on iec 61850. Power and Energy Magazine, IEEE, 2007. v. 5, n. 3, p. 45-50, 2007. ISSN 1540-7977.

HOYOS, J.; DEHUS, M.; BROWN, T. Exploiting the goose protocol: A practical attack on cyber-infrastructure. In: Globecom Workshops (GC Wkshps), 2012 IEEE. [S.l.: s.n.], 2012. p. 1508-1513.

HSING, H. SHA3 Core Specification. OpenCores, 2013. Disponível em: <http://opencores.org/project,sha3>. Acesso em: 01-07-2016. 
HULL, J.; KHURANA, H.; MARKHAM, T.; STAGGS, K. Staying in control: Cybersecurity and the modern electric grid. Power and Energy Magazine, IEEE, 2012. v. 10, n. 1, p. 41-48, 2012. ISSN 1540-7977.

IEC-62439-3. IEC 62439-3: Industrial Communication Networks : High Availability Automation Networks. Parallel Redundancy Protocol (PRP) and High availability Seamless Redundancy (HSR). [S.l.], 2016. IEC 62493-3:2016-03.

IEC/TR-61850-1. IEC-61850 - Part 1: Introduction and Overview. [S.l.], 2013. IEC/TR 61850-1:2013(E).

IEC/TR-61850-5. IEC-61850 - Part 5: Communication Requirements for Functions and Device Models. [S.l.], 2013. IEC/TR 61850-5:2013(E).

IEC/TR-61850-6. IEC-61850 - Part 6: Configuration description language for communication in electrical substations related to IEDs. [S.l.], 2009. IEC/TR 61850-6:2009(E).

IEC/TR-61850-7-1. IEC-61850 - Part 7-1: Basic Communication Structure for Substation and Feeder Equipment - Principles and Models. [S.l.], 2011. IEC/TR 61850-7-1:2011(E).

IEC/TR-61850-7-2. IEC-61850 - Part 7-2: Basic Communication Structure for Substation and Feeder Equipment - Abstract Communication Service Interface (ACSI). [S.1.], 2010. IEC/TR 61850-7-2:2010(E).

IEC/TR-61850-7-3. IEC-61850 - Part 7-3: Basic Communication Structure for Substation and Feeder Equipment - Common Data Classes (CDC). [S.l.], 2010. IEC/TR 61850-7-3:2010(E).

IEC/TR-61850-7-4. IEC-61850 - Part 7-4: Basic Communication Structure for Substation and Feeder Equipment - Compatible Logical Node Classes and Data Classes. [S.1.], 2010. IEC/TR 61850-7-4:2010(E).

IEC/TR-61850-8-1. IEC-61850 - Part 8-1: Specific communication service mapping (SCSM) - Mappings to MMS (ISO 9506-1 and ISO 9506-2) and to ISO/IEC 8802-3. [S.l.], 2011. IEC/TR 61850-8-1:2011(E).

IEC/TR-61850-90-1. IEC-61850 - Part 90-1: Use of IEC 61850 for the communication between substations. [S.l.], 2010. IEC/TR 61850-90-1:2010(E).

IEC/TR-62351-10. IEC-62351 - Part 10: Security architecture guidelines. 1. ed. [S.l.], 2012. IEC/TR 62351-10:2012(E).

IEC/TS-62351-1. IEC-62351 - Part 1: Introduction to security issues. 1. ed. [S.1.], 2007. IEC/TS 62351-1:2007(E).

IEC/TS-62351-6. IEC-62351 - Part 6: Security for IEC 61850. 1. ed. [S.1.], 2007. IEC/TS 62351-6:2007(E).

IEEE, P. E. S. IEEE Standard 1402-2000: IEEE Guide for Electric Power Substation Physical and Electronic Security. New York, NY, 2000. 
ISA. ISA99, Industrial Automation and Control Systems Security. ISA, 2013. Disponível em: <http://isa99.isa.org/ISA99\%20Wiki/Home.aspx>. Acesso em: 13-092013.

KANG, D.; LEE, J.; KIM, B.; HUR, D. Proposal strategies of key management for data encryption in SCADA network of electric power systems. International Journal of Electrical Power \& Energy Systems, 2011. v. 33, n. 9, p. 1521 - 1526, 2011. ISSN 0142-0615. Disponível em: <http://www.sciencedirect.com/science/article/pii/S0142061509000313>.

KInDERmann, G. Proteção de Sistemas Elétricos de Potência. [S.l.]: Edição do Autor, 2014. ISBN 9788591087556.

KOSTIC, T.; PREISS, O.; FREI, C. Understanding and using the IEC 61850: a case for meta-modelling. Computer Standards \& Interfaces, 2005. v. 27, n. 6, p. 679 - 695, 2005. ISSN 0920-5489. Disponível em: <http://www.sciencedirect.com/science/article/pii/S0920548904001023>.

KRIGER, C.; BEHARDIEN, S.; RETONDA-MODIYA, J.-C. A detailed analysis of the goose message structure in an iec 61850 standard-based substation automation system. International Journal of Computers Communications \& Control, 2013. v. 8, n. 5, p. 708-721, 2013.

KUROSE, J. F.; ROSS, K. W. Computer Networking: A Top-Down Approach. [S.l.]: Pearson, 2012.

LARMOUTH, J. ASN.1 Complete. [S.l.]: Academic Press, 2000. ISBN 9780122334351.

LEHMANN, E. L.; D'ABRERA, H. Nonparametrics: statistical methods based on ranks. [S.l.]: Holden-Day, 1975.

LIU, C.-C.; STEFANOV, A.; HONG, J.; PANCIATICI, P. Intruders in the grid. Power and Energy Magazine, IEEE, 2012. v. 10, n. 1, p. 58-66, 2012. ISSN 1540-7977.

LOCKWOOD, J.; MCKEOWN, N.; WATSON, G.; GIBB, G.; HARTKE, P.; NAOUS, J.; RAGHURAMAN, R.; LUO, J. Netfpga-an open platform for gigabit-rate network switching and routing. In: Microelectronic Systems Education, 2007. MSE '07. IEEE International Conference on. [S.l.: s.n.], 2007. p. 160-161.

LOW, M. Using the RGMI to Interface with the Gigabit Ethernet MAC. [S.l.], 2006. XAPP692(v1.0.1).

LU, X.; WANG, W.; LU, Z.; MA, J. From security to vulnerability: Data authentication undermines message delivery in smart grid. In: MILITARY COMMUNICATIONS CONFERENCE, 2011 - MILCOM 2011. [S.l.: s.n.], 2011. p. 1183-1188. ISSN 21557578.

MACKIEWICZ, R. Overview of iec 61850 and benefits. In: Power Engineering Society General Meeting, 2006. IEEE. [S.l.: s.n.], 2006. p. 8 pp.--.

MARÇULA, M.; FILHO, P. Informática: conceitos e aplicações. [S.l.]: Érica, 2005.

MARDEGAN, C. Dispositivos de proteção parte 1. O Setor Elétrico, 2010. p. 28-39, mar 2010. 
MARTINHO, E. Distúrbios da Energia Elétrica. São Paulo: Érica, 2007.

MAXIMUM Security: a hacker's guide to protecting your computer systems and network. Indianópolis: Sams, 2003. ISBN 9780672324598.

MAZUR, D. C.; ENTZMINGER, R. A.; KAY, J. A. Enhancing traditional process scada and historians for industrial and commercial power systems with energy (via iec 61850). IEEE Transactions on Industry Applications, 2016. v. 52, n. 1, p. 76-82, Jan 2016. ISSN 0093-9994.

MCAFEE. Global Energy Cyberattacks: Night Dragon. [S.l.], 2011. 21401wp nightdragon 0211.

MCCULLAGH, P.; NELDER, J. A. Generalized linear models. [S.l.]: CRC press, 1989.

MCKEOWN, N.; LOCKWOOD, J.; NAOUS, J.; GIBB, G.; COVINGTON, A. Hands-on with the netfpga to build a gigabit-rate router. In: High-Performance Interconnects, 2007. HOTI 2007. 15th Annual IEEE Symposium on. [S.l.: s.n.], 2007. p. 7-10. ISSN 1550-4794.

MELO, E. B. B. Reducing the Obscurity in Cyber Security - Trends, Challenges and Advances in Brazil. 2010. Disponível em: <http://www.cigre.org.br/zpublisher/paginas/bienal2010.asp>. Acesso em: 29-08-2013.

MILLER, R. G. J. Simultaneous statistical inference. Springer-Verlag, 1991. 1991.

MORAES, A. F. de. Segurança em Redes: fundamentos. São Paulo: Érica, 2010.

MOURA, J. A. B.; SAUvé, J. P.; GIOZZA, W. F.; ARAÚJO, J. F. M. d. Redes e Computadores: Protocolos de Alto Nível e Avaliação de Desempenho. [S.l.]: McGraw-Hill, 1986.

NAKAMURA, E. T.; GEUS, P. L. de. Segurança de Redes em Ambientes Cooperativos. [S.l.]: Novatec, 2007.

NAOUS, J.; BOLOUKI, S. Netfpga: reusable router architecture for experimental research. In: In PRESTO 08: Proceedings of the ACM workshop on Programmable routers for extensible services of tomorrow. [S.l.]: ACM, 2008. p. 1-7.

NCCIC/ICS-CERT. IR-ALERT-H-16-043-01AP Cyber-Attack Against Ukrainian Critical Infrastructure. [S.l.], 2016. IR-ALERT-H-16-043-01AP.

NEMENYI, P. Distribution-free multiple comparisons. In: INTERNATIONAL BIOMETRIC SOC 1441 I ST, NW, SUITE 700, WASHINGTON, DC 20005-2210. Biometrics. [S.l.], 1962. v. 18, n. 2, p. 263.

NERC. Critical Infrastructure Protection Committee (CIPC). NERC, 2013. Disponível em: <http://www.nerc.com/comm/CIPC/Pages/default.aspx>. Acesso em: 1309-2013.

NETFPGA. 1G Specs - NetFPGA - NetFPGA. 2016. Disponível em: <http://netfpga.org/1G_specs.html>. Acesso em: 01-07-2016. 
ApplicationsProjects - NetFPGA. 2016. Disponível em: <http://netfpga.org/project_table.html>. Acesso em: 01-07-2016.

Guide - NetFPGA/netfpga Wiki - GitHub. 2016. Disponível em: < https://github.com/NetFPGA/netfpga/wiki/Guide>. Acesso em: 01-07-2016.

NICANFAR, H.; JOKAR, P.; LEUNG, V. Smart grid authentication and key management for unicast and multicast communications. In: Innovative Smart Grid Technologies Asia (ISGT), 2011 IEEE PES. [S.l.: s.n.], 2011. p. 1-8.

NIST. Cryptographic HASH and SHA-3 Standard Development. Computer Security Division, 2015. Disponível em: <http://csrc.nist.gov/groups/ST/hash/index.html>. Acesso em: 01-07-2016.

OLIFER, N.; OLIFER, V. Computer networks: principles, technologies and protocols for network design. [S.l.]: John Wiley \& Sons, 2006. ISBN 9780470869826.

OLIVEIRA, J. C. de; SANHUEZA, S. M. R. Behavior of air conditioners under voltage sags and interruptions using computional models. 2006. XVI Congresso Brasileiro de Automática, Salvador, p. 1-6, 2006.

OLIVEIRA, P. R. P.; JARDINI, J. A.; MAGRINI, L. C.; CRISPINO, F.; VILLACORTA, C. A.; KIYOHARA, H. K. Sistemas abertos de supervisão e controle e subestações de energia. In: Congresso de Inovação Tecnológica em Energia Elétrica. Salvador: II CITENEL, 2003. p. 1047-1052.

OMAN, P.; SCHWEITZER, E. O.; ROBERTS, J. Safeguarding IEDs, substations, and SCADA systems against electronic intrusions. Pullman, WA, 2001.

OZANSOY, C. Modelling and Object Oriented Implementation of IEC 61850: The New International Standard on Substation Communications and Automation. [S.1.]: LAP Lambert Acad. Publ., 2010. ISBN 9783838358482.

OZANSOY, C.; ZAYEGH, A.; KALAM, A. The application-view model of the international standard iec 61850. Power Delivery, IEEE Transactions on, 2009. v. 24, n. 3, p. 1132-1139, 2009. ISSN 0885-8977.

Object modeling of data and datasets in the international standard iec 61850. Power Delivery, IEEE Transactions on, 2009. v. 24, n. 3, p. 1140-1147, 2009. ISSN 0885-8977.

PATEL, N. IEC 61850 Horizontal Goose Communication and Overview: IEC 61850 Horizontal Communication, Goose Messaging And Documentation. IEC 61850 Standard Overview And Understanding. [S.l.]: LAP Lambert Academic Publishing, 2011. ISBN 9783846546321.

PATNAIK, S.; XIAOLONG, L. Proceedings of International Conference on Soft Computing Techniques and Engineering Application: ICSCTEA 2013, September 25-27, 2013, Kunming, China. [S.l.]: Springer India, 2013. (Advances in Intelligent Systems and Computing). ISBN 9788132216957.

PAULINO, M. E. de C. Teste de IEDs baseados na iec 61850. In: Simpósio Brasileiro de Sistemas Elétricos, SBSE. Campina Grande: [s.n.], 2006. 
PEREIRA, A. C.; ORDACGI FILHO, J. M.; CORREIA, J. R. G.; CÁCERES, D.; PELLIZZONI, R. Automação de subestações e usinas: estado da arte e tendências utilizando a norma iec 61850. In: Simpósio de Automação de Sistemas Elétricos. Salvador: VII SIMPASE, 2007.

PES, I. Power Systems Relay Committee - WG H13. IEEE PES, 2013. Disponível em: <http://www.pes-psrc.org/h/>. Acesso em: 13-09-2013.

PREISS, O.; WEGMANN, A. Towards a composition model problem based on IEC61850. Journal of Systems and Software, 2003. v. 65, n. 3, p. $227-236$, 2003. ISSN 0164-1212. Disponível em: <http://www.sciencedirect.com/science/article/pii/S016412120200047X>.

PREMARATNE, U. K.; SAMARABANDU, J.; SIDHU, T. S.; BERESH, R.; TAN, J. C. An intrusion detection system for iec61850 automated substations. IEEE Transactions on Power Delivery, 2010. v. 25, n. 4, p. 2376-2383, Oct 2010. ISSN 0885-8977.

RASHID, M. T. A.; YUSSOF, S.; YUSOFF, Y.; ISMAIL, R. A review of security attacks on iec61850 substation automation system network. In: Information Technology and Multimedia (ICIMU), 2014 International Conference on. [S.l.: s.n.], 2014. p. 5-10.

REFORGIATO, D.; BATTAGLIA, F. NetFPGA Architecture and Hardware Description: An insight of the NetFPGA platform. [S.l.]: LAP, 2012.

REFORGIATO, D.; REITANO, A.; TORRISI, M. A Traffic Monitor on NetFPGA platform: Comparisons against a Software Implementation on the Click Modular Router. [S.l.]: LAP, 2011.

REIN JR., O. Um modelo de integração entre os padrões IEC-61850 e IEC61970 (CIM/XML). Dissertação (Mestrado) - Universidade de São Paulo, São Paulo, 2006. Dissertação de Mestrado, Engenharia Elétrica.

RODRIGUES, J. R. M. Primeira subestação em funcionamento com iec 61850. In: Simpósio de Automação de Sistemas Elétricos. São Paulo: VI SIMPASE, 2005.

SALAH, K.; ELBADAWI, K.; BOUTABA, R. Performance modeling and analysis of network firewalls. Network and Service Management, IEEE Transactions on, 2012. v. 9, n. 1, p. 12-21, 2012. ISSN 1932-4537.

SANTOS, A. A. dos; TEIXEIRA, B. M.; SAMPAIO, F. M.; ALVES, R. B. Automação elétrica com a IEC-61850. Rio de Janeiro: Universidade do Estado do Rio de Janeiro, 2007. Monografia de Conclusão de Curso, Automação Industrial.

SATO, T.; KAMMEN, D.; MACUHA, M.; DUAN, B.; ZHOU, Z.; WU, J.; TARIQ, M.; ASFAW, S. Smart Grid Standards: Specifications, Requirements, and Technologies. [S.1.]: Wiley, 2015. ISBN 9781118653692.

SCHUBERT, H.; WONG, G. Iec 61850 - the future global standard for seamless and vendor-independent communication within substations. In: Advances in Power System Control, Operation and Management, 2003. ASDCOM 2003. Sixth International Conference on (Conf. Publ. No. 497). [S.l.: s.n.], 2003. v. 2, p. 462-466.

SCHWARZ, K. Offene Kommunikation nach IEC 61850 für die Schutz- und Stationsleittechnik. [S.l.]: VDE-Verlag, 2004. (ETZ / ETZ-Report). ISBN 9783800727889. 
SCHWEITZER, E. L. Segurança em redes de computadores aplicadas a subestações de energia elétrica. O Setor Elétrico, 2010. p. 72-77, jun 2010.

Schweitzer Engineering Laboratories. Sua subestação está protegida contra ataques cibernéticos? 2013. Disponível em: <http://www.selinc.com.br/press_releases/Proteja_sua_subestacao_contra_ataques_ciberneticos.aspx>. Acesso em: 06-09-2013.

SECLEN, J. L. T. Projeto, Verificação Funcional e Síntese de Módulos Funcionais para um Comutador Gigabit Ethernet. Dissertação (Mestrado) - Universidade Federal do Rio Grande do Sul, Porto Alegre, 2011. Dissertação de Mestrado, Microeletrônica.

SHEPHARD, B.; JANSSEN, M. C.; SCHUBERT, M. Standardised communications in substations. In: Developments in Power System Protection, 2001, Seventh International Conference on (IEE). [S.l.: s.n.], 2001. p. 270-274. ISSN 0537-9989.

SHINN, M.; SHINN, S. Troubleshooting Linux Firewalls. [S.l.]: Addison - Wesley, 2005.

SINGH, A.; SINGH, B.; JOSEPH, H. Vulnerability Analysis and Defense for the Internet. [S.1.]: Springer US, 2008. (Advances in Information Security). ISBN 9780387743905 .

SOCIETY, T. I. US Secure Hash Algorithms (SHA and HMAC-SHA). Network Working Group, 2006. Disponível em: <https://tools.ietf.org/html/rfc4634>. Acesso em: 02-07-2016.

STALLINGS, W. Cryptography and Network Security: Principles and Practice. [S.l.]: Prentice Hall, 2013.

Cryptography and Network Security: Principles and Practice. [S.l.]: Pearson Education, 2016. ISBN 9780134484525.

STALLINGS, W.; BROWN, L. Computer Security. [S.l.]: Pearson Prentice Hall, 2008.

STATO FILHO, A. Linux Controle de Redes. Florianópolis: Visual Books, 2009.

SUN, X.; REDFERN, M. An investigation into the design of an iec 61850 based protection relay. In: Universities Power Engineering Conference (UPEC), 2009 Proceedings of the 44th International. [S.l.: s.n.], 2009. p. 1-5.

TANENBAUM, A. S. Computer Networks. [S.l.]: Prentice Hall, 1996.

Computer Networks. [S.l.]: Pearson, 2011.

TCPREPLAY. Tcpreplay. 2016. Disponível em: <http://tcpreplay.synfin.net>. Acesso em: 01-07-2016.

TERADA, R. Segurança de dados: criptografia em redes de computador. [S.l.]: Edgard Blucher, 2000. ISBN 9788521204398.

VAHID, F. Digital Design. [S.l.]: John Wiley \& Sons, 2007. ISBN 9780470100134. 
VAIDYA, B.; MAKRAKIS, D.; MOUFTAH, H. Authentication and authorization mechanisms for substation automation in smart grid network. Network, IEEE, 2013. v. 27, n. 1, p. 5-11, 2013. ISSN 0890-8044.

WATSON, G.; MCKEOWN, N.; CASADO, M. Netfpga: A tool for network research and education. In: 2nd Workshop on Architecture Research using FPGA Platforms (WARFP). [S.l.: s.n.], 2006.

WEISS, J.; DELSON, M. Cyber security of substation control and diagnostic systems. In: _. Electric power substations engineering. 2nd. ed. [S.l.]: CRC Press, 2007. cap. 17.

WENGE, C.; PELZER, A.; NAUMANN, A.; KOMARNICKI, P.; RABE, S.; RICHTER, M. Wide area synchronized hvdc measurement using iec 61850 communication. In: 2014 IEEE PES General Meeting | Conference Exposition. [S.l.: s.n.], 2014. p. 1-5. ISSN 1932-5517.

WGC1. IEEE SA - P1686 - IEEE Draft Standard for Intelligent Electronic Devices (IEDs) Cyber Security Capabilities. IEEE, 2013. Disponível em: <http://standards.ieee.org/develop/project/1686.html>. Acesso em: 13-09-2013.

WGE7. 1402-2000 - IEEE Guide for Electric Power Substation Physical and Electronic Security. IEEE, 2013. Disponível em: <http://standards.ieee.org/findstds/standard/1402-2000.html >. Acesso em: 13-09-2013.

WIRESHARK. Wireshark - Go Deep. 2016. Disponível em: <http://www.wireshark.org >. Acesso em: 01-07-2016.

XIAO, Y. Security and Privacy in Smart Grids. [S.l.]: CRC Press, 2013. ISBN 9781439877845.

YAN, W.; WU, J.; LI, S. Realization of fpga-based iec61850-goose messages decoder for digital substation. 2015. Modern Eletronics Technique, Sichuan University, n. 18, p. $151-154,2015$.

YANG, Y. Understanding Switch Latency. [S.l.], 2012. C11-661939-01.

ZHANG, Y.; WANG, L.; XIANG, Y.; TEN, C.-W. Power System Reliability Evaluation With SCADA Cybersecurity Considerations. IEEE TRANSACTIONS ON SMART GRID, 2015. 6, n. 4, p. 1707-1721, JUL 2015. ISSN 1949-3053.

ZHU, L.; SHI, D.; DUAN, X. Standard function blocks for flexible ied in iec 61850-based substation automation. Power Delivery, IEEE Transactions on, 2011. v. 26, n. 2, p. 1101-1110, 2011. ISSN 0885-8977.

ZURAWSKI, R. Industrial Communication Technology Handbook, Second Edition. [S.1.]: CRC Press, 2014. (Industrial Information Technology). ISBN 9781482207330.

ZWICKY, E. D.; COOPER, S.; CHAPMAN, D. B. Building Internet Firewalls. [S.l.]: O'Reilly Media, 2000. 
Apêndices 


\section{APÊNDICE}

\section{Pseudocódigo do RGGM}

Este apêndice trata do RGGM (Random Generator GOOSE Messages), um gerador de mensagens GOOSE, que utiliza os cabeçalhos e tipos de dados descritos pelo padrão IEC 61850, parte 8.1, e também o formato de codificação dos bytes do quadro ISO/IEC 8802-3. O Algoritmo 6 apresenta o pseudocódigo do RGGM (versão 1.0).

Para avaliação do algoritmo, é necessário estabelecer as seguintes premissas:

- O "dado_1", que aparece a primeira vez na linha 30 do Algoritmo 6, é uma informação do campo allData e deve estar em conformidade com os tipos de dados e tamanhos informados na Tabela 11. A Tabela 24 mostra 7 itens de um campo allData que são considerados, pelo Algoritmo 6, como "dado_1" (visible-string, integer,bitstring, utc-time, boolean, floating-point e unsigned).

Tabela 24: Exemplo de 7 itens do allData com o tipo "dado_1"

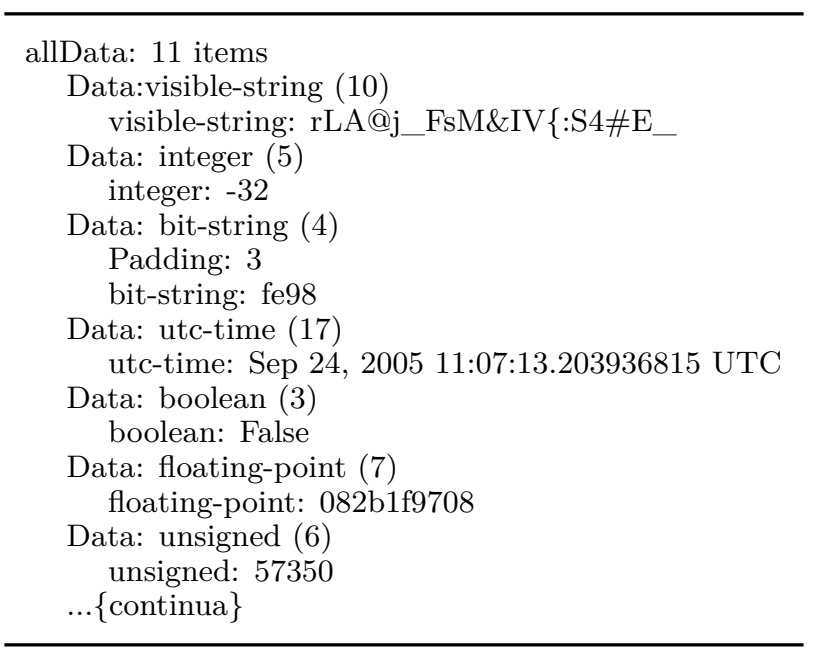

- O "dado_2" é uma lista (structure, tag 0xa2, presente no Algoritmo 2) que contém entre 1 e 20 informações aleatórias do tipo "dado_1". A Tabela 25 mostra 2 listas. A primeira lista contém 6 itens de dados e a segunda lista 11 itens. 


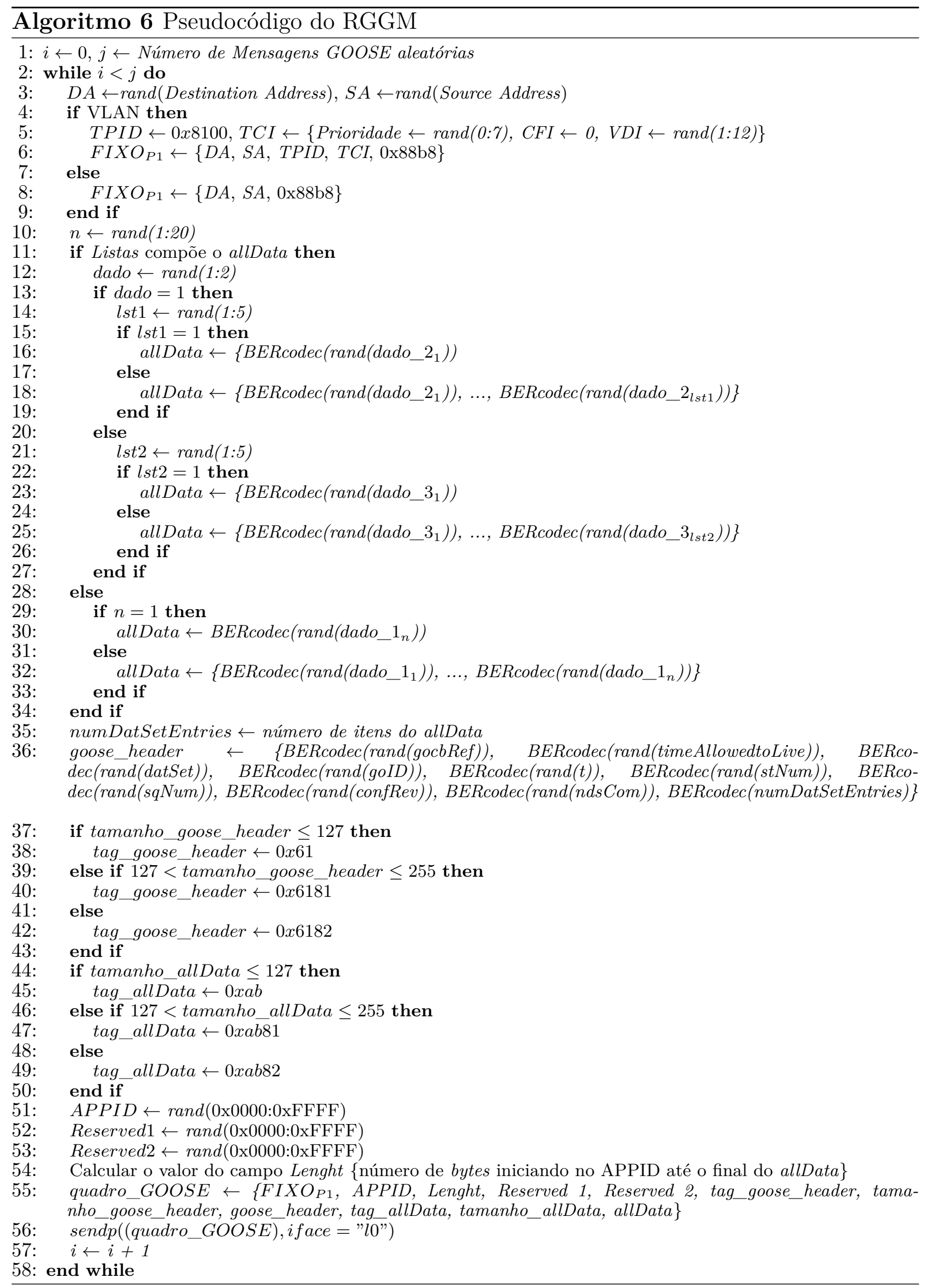


Tabela 25: Exemplo de itens do allData com o tipo "dado_2"

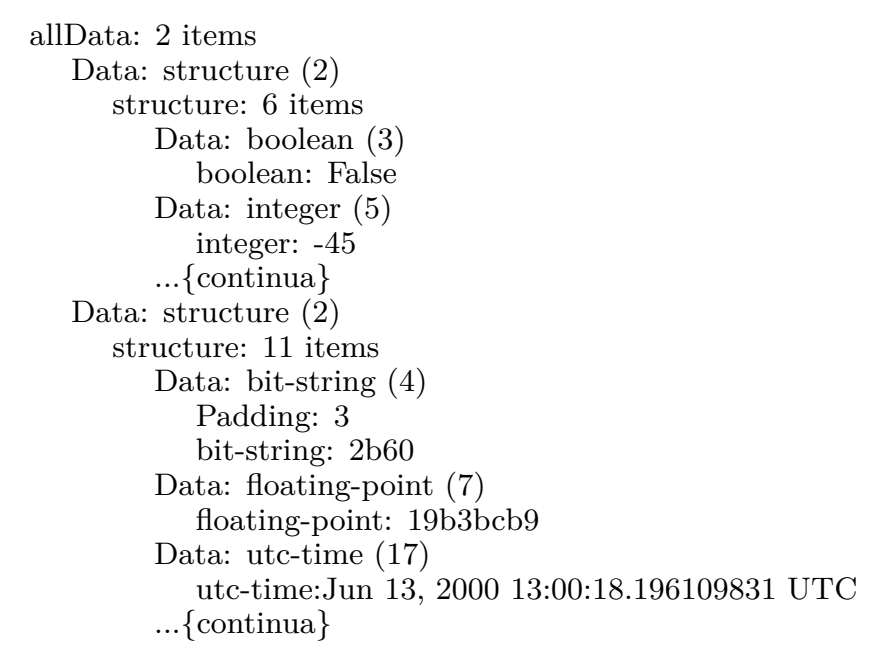

- $\mathrm{O}$ "dado_3" é uma lista dentro de outra, com informações aleatórias do tipo "dado_1" dispostas em paralelo com a primeira lista e, também, presentes na segunda lista, conforme ilustra a Tabela 26.

Tabela 26: Exemplo de itens do allData com o tipo "dado_3"

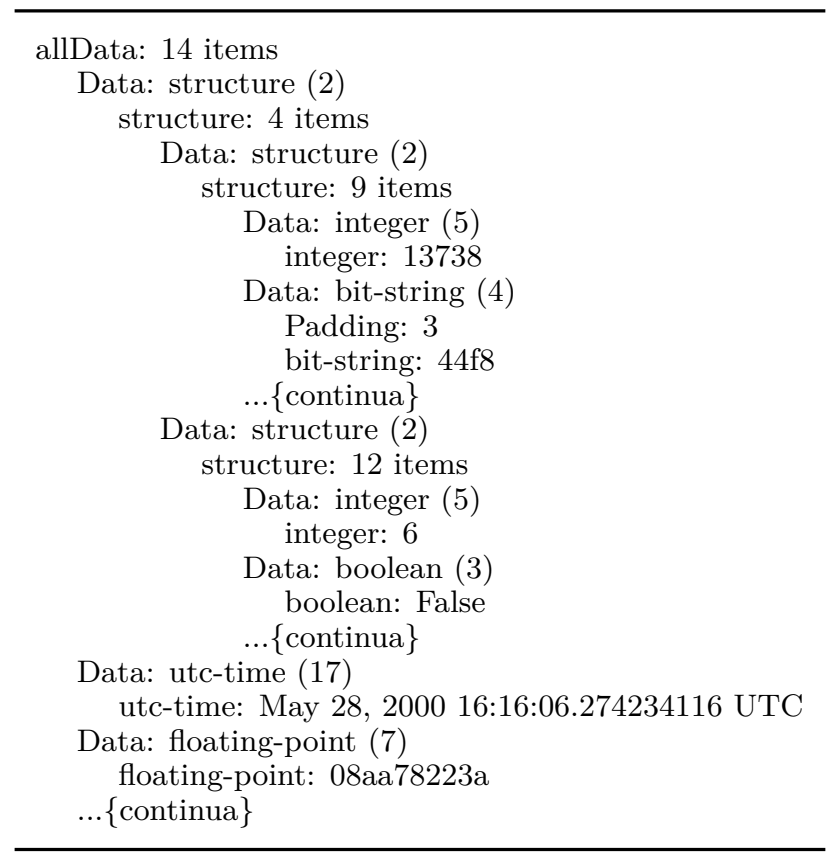

O pseudocódigo pode ser analisado em 6 blocos principais:

- Entre as linhas 3 e 8 do Algoritmo 6, ocorre a formação dos primeiros campos fixos, com a possibilidade de inclusão (ou não) das informações da VLAN; 
- O campo allData é formado entre as linhas 10 e 34, obedecendo às premissas em destaque na Tabela 24, Tabela 25 e Tabela 26. Com a definição dos campos que formam o allData, é atribuído o número de itens de dados ao campo numDatSetEntries;

- Os campos flexíveis (gocbRef até ndsCom) são criados na linha 36;

- As tags para o cabeçalho da PDU GOOSE e para o campo allData são criadas entre as linhas 37 e 50;

- Na sequência, são criados os campos fixos (APPID, Reserved 1 e Reserved 2) e, por último, o campo Length, que é o número de bytes do quadro, com início no campo APPID (linha 54).

- O quadro fica completo na linha 55 e é transmitido por meio da função sendp() linha 56. 


\section{Tamanho da Amostra para os Testes Estatísticos Realizados}

\section{B.1 Definições}

\section{B.1.1 Poder do Teste}

Os testes estatísticos procuram evidências para rejeitar a hipótese nula e concluir que existe diferença entre os módulos. No entanto, há sempre a possibilidade de se encontrar uma diferença entre os módulos, quando, na verdade, não existe. Isso é chamado de erro de tipo I. Da mesma forma, é possível existir uma diferença e o teste não ser capaz de identificá-la. Este tipo de erro é chamado de erro do tipo II. O poder do teste é a probabilidade de se encontrar uma diferença significativa, quando, realmente, essa diferença existe. Em outras palavras, o poder é a probabilidade de se rejeitar a hipótese nula, quando, realmente deve-se rejeitá-la. É geralmente aceito que o poder do teste seja igual ou maior que 0,8 .

\section{B.1.2 Nível de Significância}

O nível de significância é o que conhecemos como erro tipo I. Geralmente, adota-se um $\alpha=0,05$.

\section{B.1.3 Tamanho do Efeito}

O tamanho do efeito é dado por:

$$
d=\frac{\mu_{i}-\mu_{j}}{\sigma}
$$

Sendo que $\mu_{i}$ é a média do módulo $i, \mu_{j}$ é a média do módulo $j$ e $\sigma$ é o desvio padrão, comum entre os módulos. Pode-se definir os efeitos como pequeno $(d=0,2)$; médio $(d=0,5)$ e grande $(d=0,8)$. 


\section{B.2 Método para Calcular o Número de Amostras}

Para calcular o tamanho necessário da amostra para comparar os módulos, em cada tamanho de mensagem, foi utilizada a metodologia proposta por Fleiss (1981) para comparações de dois grupos em relação a respostas contínuas. Dessa forma, a quantidade total de amostras por módulo pode ser dada pela equação:

$$
n=\frac{2\left(z_{\alpha}+z_{\beta}\right)^{2}}{\left(\frac{\mu_{i}-\mu_{j}}{\sigma}\right)^{2}}
$$

Na qual: $z_{\alpha}$ é o percentil da distribuição normal correspondente ao nível de significância; $z_{\beta}$ é o percentil da distribuição normal correspondente ao poder do teste; $\mu_{i}$ é a média do tempo de transferência no módulo $i ; \mu_{j}$ é a média do tempo de transferência no módulo j; e $\sigma$ é o desvio padrão do tempo de transferência, comum entre os módulos comparados.

De forma a garantir o poder de teste adequado, mesmo na realização de testes não paramétricos, utilizou-se a relação proposta por Lehmann e D'abrera (1975):

$$
n^{*}=\frac{n}{0,955}
$$

O software utilizado, para calcular o tamanho amostral, foi o $\mathrm{R}$ versão 3.1.3.

\section{B.3 Cálculo do Número de Amostras Ideal}

Considerando um tamanho de efeito pequeno e as devidas correções de Bonferroni (MILLER, 1991) para comparação dois a dois entre os módulos, pode-se verificar na Tabela 27 que ao nível de 1\% de significância e com um poder de 95\%, o tamanho de amostra necessário por módulo, em cada tamanho de mensagem, é de 746. Dessa forma, conforme a Tabela 27, observa-se que, mesmo considerando os parâmetros ótimos (1\% de significância, tamanho do efeito pequeno e poder de teste de 95\%), o tamanho da amostra exigido fica, consideravelmente menor que o realizado $n=1000$.

Tabela 27: Tamanho da amostra por módulo, em cada tamanho de mensagem, variando o nível de significância e o poder do teste

\begin{tabular}{cccc}
\hline Poder do Teste & \multicolumn{3}{c}{ Nível de Significância } \\
\cline { 2 - 4 } & $1 \%$ & $5 \%$ & $10 \%$ \\
\hline $80 \%$ & 537 & 440 & 398 \\
$90 \%$ & 647 & 539 & 493 \\
$95 \%$ & 746 & 629 & 579 \\
\hline
\end{tabular}




\section{Tabelas Referentes ao TT entre os TM, Estratificadas por Módulo}

Tabela 28: Descrição do tempo de transferência (ms) entre os tamanhos da mensagem, estratificada por módulo

\begin{tabular}{|c|c|c|c|c|c|c|c|c|c|c|}
\hline \multicolumn{2}{|c|}{ Mód./7 } & Iédia & D.P. & C.V. & Mín. & $1^{\circ} \mathrm{Q}$ & $2^{\circ} \mathrm{Q}$ & $3^{\circ} \mathrm{Q}$ & Máx. & \\
\hline & 69 & 0,00156 & $2,20 \times 10-6$ & 0,14121 & 00155 & 0,00156 & 0,00156 & 0,00156 & 00156 & \\
\hline & 128 & & & & & & & & & \\
\hline & 256 & 73 & -6 & & & & & & & \\
\hline & 409 & & & & & & & & & \\
\hline & 512 & 0,00909 & $0-6$ & 0,02421 & 00908 & 0,00908 & 0,0 & & 0,00909 & \\
\hline & 768 & 4 & -6 & & & & & & 344 & \\
\hline & 1024 & 0,01779 & $30 \mathrm{x}$ & 0,01293 & 0,01779 & 0,01779 & 0,0 & & 0,01779 & \\
\hline & 1280 & 0,02 & -6 & & & & & & & \\
\hline & 1500 & 0,02589 & $2,20 \times 10-6$ & 0,0085 & 0,02588 & 0,02 & & & 589 & $0-6$ \\
\hline & 18 & 19 & & 0084 & & & & & 619 & \\
\hline & & & & & & & & & & \\
\hline & & & & & & & & & & \\
\hline & 2 & 0,00 & 2,40 & & & & & & 902 & \\
\hline & & & & & & & & & & \\
\hline & 512 & 0,01668 & $2,50 \times 10-6$ & 0,01499 & 0,01667 & 0,01668 & 0,0 & & 0,01668 & $0-6$ \\
\hline & & 0,018 & -6 & & 0,01 & & & & & \\
\hline & 1024 & 0,02 & $2,40 \mathrm{x}$ & & & & & & 523 & \\
\hline & 80 & 0,03 & -6 & & 0,030 & & & & 3035 & $10-6$ \\
\hline & & 0,03 & & & & 0,03438 & & & 439 & \\
\hline & 1518 & 0,0344 & $2,40 \times 10-6$ & 0,00698 & 0,03439 & 0,0344 & 0,0344 & 0,0344 & 0,0344 & $10-6$ \\
\hline & & & & & & & & & & \\
\hline & 128 & 0,00 & $2,60 \mathrm{x}$ & & 0,00649 & 0,00649 & & 0,0065 & 0,0065 & $10-6$ \\
\hline & 256 & & $2,60 \times 10$ & & & 0,01193 & & & 0,01194 & \\
\hline & 4( & 0,01 & & & 1793 & 0,01793 & 0,01793 & 0,0 & 0,01794 & $8,80 \times 10-6$ \\
\hline & & & & & & & & & 0,0215 & \\
\hline
\end{tabular}


Tabela 28 - Continuação da página anterior

\begin{tabular}{|c|c|c|c|c|c|c|c|c|c|c|}
\hline \multicolumn{2}{|r|}{ d./TM } & Média & D.P. & C.V. & Mín. & $1^{\circ} \mathrm{Q}$ & $2^{\circ} \mathrm{Q}$ & $3^{\circ} \mathrm{Q}$ & Máx. & \\
\hline & 768 & 0,02401 & $2,50 \times 10-6$ & 0,01041 & 0,024 & 0,024 & 0,02401 & 0,02401 & 0,02401 & x $10-6$ \\
\hline & 1024 & 05 &, $50 \times 10-6$ & & & & & & & \\
\hline & 1280 & 11 & $2,60 \times 10-6$ & & & & & & & \\
\hline & 1500 & 0,038 & $2,60 \times 10-6$ & & & & & & 0,03 & $10-6$ \\
\hline & 1518 & 0,03948 & $2,60 \times 10-6$ & 0,00659 & 0,03947 & 948 & 948 & 948 & 0,03948 & $10-6$ \\
\hline & 69 & & $2,60 \times 10-6$ & & & & & & & $10-6$ \\
\hline & 128 & & $2,50 \mathrm{x}$ & & & & & & & $0-6$ \\
\hline & 256 & 0,011 & $2,50 \times$ & 0,02095 & 0,011 & & 193 & 194 & & \\
\hline & 409 & 3 & $0-6$ & 45 & & & & & & $0-6$ \\
\hline & 512 & 0,021 & $2,50 \mathrm{x}$ & 0,01163 & 0,02149 & & & & & \\
\hline & 768 & 0,02401 & $2,60 \times 10-6$ & & 0,024 & 24 & & & & $10-6$ \\
\hline & 1024 & 5 & $2,60 \mathrm{x}$ & & 0,0305 & & & & & $10-6$ \\
\hline & 1280 & & $2,60 \mathrm{x}$ & & & & & & & $10-6$ \\
\hline & 1500 & 0,03898 & $2,50 \times$ & & 0,0 & & & & 899 & $10-6$ \\
\hline & 1518 & & $2,60 \times$ & & & & & & & $10-6$ \\
\hline & & & & & & & & & & \\
\hline & 128 & 0,0 & $2,60 \mathrm{x}$ & & & & & & & $0-6$ \\
\hline & 256 & & 2,50 & & & & & & & $0-6$ \\
\hline & 409 & 0,01472 & $2,50 \mathrm{x}$ & & 0,01 & & & & & $0-6$ \\
\hline & 512 &, 01672 & $2,50 \times 1$ & 0,01 & & & & & & $0-6$ \\
\hline & 768 & 0,01 & $2,60 \mathrm{x}$ & & & & & & & \\
\hline & 1024 & 7 & $2,50 \mathrm{x}$ & & 0,0 & & 0 & & & $0-6$ \\
\hline & 1280 & & $2,60 \times$ & & & & & & & \\
\hline & 1500 & 0,03442 & $2,60 \times 10-6$ & 0,00755 & 0,03442 & 3442 & 0,0 & 0, & 0,0 & $10-6$ \\
\hline & 1518 & & $2,50 \times 10-6$ & & & & & & & \\
\hline & 69 & & & & & & & & & \\
\hline & 128 & & $2,20 \mathrm{x}$ & 0,08488 & 0259 & & 0 & 259 & & $0-6$ \\
\hline & 56 & & & & & & & & & \\
\hline & 409 & 0,00738 & $2,20 \times 10-6$ & 0,02983 & 0,00737 & 737 & 0,0 & 738 & & $0-6$ \\
\hline & 512 & $0,00 s$ & $2,20 \times 10-6$ & & & & & & & \\
\hline & 68 &, 01347 & $2,20 \times 10-6$ & 0,01633 & 0,01347 & 0,01347 & & & 0,0 & $0-6$ \\
\hline & 1024 & 0,017 & $2,20 \mathrm{x}$ & & & & & & & \\
\hline & 1280 & & $2,30 \times 1$ & & & & & & & \\
\hline & 1500 & 0,02 & $2,20 \mathrm{x}$ & & & 592 & & & 0,0 & $10-6$ \\
\hline & 1518 & 0,02623 & $2,20 \times 10-6$ & & & & & & & $10-6$ \\
\hline & 6 & & & & & & & & & \\
\hline & 128 & & $2,10 \mathrm{x}$ & & & & & & & $0-6$ \\
\hline & 256 & 0,01293 & $2,10 \times 10-6$ & & & & & & & \\
\hline & 409 & 0,021 & $2,10 \times 10-6$ & 0,00999 & 0,02102 & 0,02102 & 0,02102 & 0,02102 & 0,02103 & $10-6$ \\
\hline & 512 & 0,025 & $2,10 \times 10-6$ & 0,00808 & 0,02597 & 0,02597 & 0,02598 & 0,02598 & 0,02598 & $10-6$ \\
\hline & 768 & & $2,10 \times 1$ & & & & & & & \\
\hline & 1024 & 0,052 & $2,20 \times 1$ & 0,00422 & 0,05208 & 5209 & 0,0 & 0,0 & 0,05209 & $10-6$ \\
\hline & 1280 & 0,06514 & $2,10 \times 10-6$ & 0,00322 & 0,06514 & & & 0,0 & 0,06515 & $8,60 \times 10-6$ \\
\hline
\end{tabular}


Tabela 28 - Continuação da página anterior

\begin{tabular}{|c|c|c|c|c|c|c|c|c|c|c|}
\hline \multicolumn{2}{|c|}{ Mód./TM } & Média & D.P. & C.V. & Mín. & $1^{\circ} \mathrm{Q}$ & $2^{\circ} \mathrm{Q}$ & $3^{\circ} \mathrm{Q}$ & Máx. & Amplitude \\
\hline & 1500 & 0,07654 & $2,20 \times 10-6$ & 0,00287 & 0,07653 & 0,07653 & 0,07654 & 0,07654 & 0,07654 & $8,50 \times 10-6$ \\
\hline & 1518 & 0,07738 & $2,20 \times 10-6$ & 0,00284 & 0,07737 & 0,07737 & 0,07738 & 0,07738 & 0,07738 & $8,80 \times 10-6$ \\
\hline \multirow{10}{*}{8} & 69 & 0,00351 & $2,30 \times 10-6$ & 0,06551 & 0,00351 & 0,00351 & 0,00351 & 0,00351 & 0,00352 & $8,70 \times 10-6$ \\
\hline & 128 & 0,00639 & $2,30 \times 10-6$ & 0,03599 & 0,00639 & 0,00639 & 0,00639 & 0,00639 & 0,0064 & $8,90 \times 10-6$ \\
\hline & 256 & 0,01294 & $2,30 \times 10-6$ & 0,01778 & 0,01293 & 0,01293 & 0,01294 & 0,01294 & 0,01294 & $8,50 \times 10-6$ \\
\hline & 409 & 0,02102 & $2,20 \times 10-6$ & 0,01046 & 0,02102 & 0,02102 & 0,02102 & 0,02103 & 0,02103 & $8,70 \times 10-6$ \\
\hline & 512 & 0,02598 & $2,30 \times 10-6$ & 0,00885 & 0,02597 & 0,02597 & 0,02598 & 0,02598 & 0,02598 & $8,60 \times 10-6$ \\
\hline & 768 & 0,03903 & $2,30 \times 10-6$ & 0,00589 & 0,03903 & 0,03903 & 0,03903 & 0,03903 & 0,03904 & $8,70 \times 10-6$ \\
\hline & 1024 & 0,05209 & $2,30 \times 10-6$ & 0,00442 & 0,05208 & 0,05209 & 0,05209 & 0,05209 & 0,05209 & $8,60 \times 10-6$ \\
\hline & 1280 & 0,06514 & $2,20 \times 10-6$ & 0,00338 & 0,06514 & 0,06514 & 0,06514 & 0,06515 & 0,06515 & $8,80 \times 10-6$ \\
\hline & 1500 & 0,07654 & $2,30 \times 10-6$ & 0,00301 & 0,07653 & 0,07653 & 0,07654 & 0,07654 & 0,07654 & $8,70 \times 10-6$ \\
\hline & 1518 & 0,07738 & $2,20 \times 10-6$ & 0,00284 & 0,07738 & 0,07738 & 0,07738 & 0,07739 & 0,07739 & $8,60 \times 10-6$ \\
\hline \multirow{10}{*}{9} & 69 & 0,0045 & $2,20 \times 10-6$ & 0,04885 & 0,0045 & 0,0045 & 0,0045 & 0,00451 & 0,00451 & $8,80 \times 10-6$ \\
\hline & 128 & 0,00718 & $2,20 \times 10-6$ & 0,03066 & 0,00717 & 0,00717 & 0,00718 & 0,00718 & 0,00718 & $8,50 \times 10-6$ \\
\hline & 256 & 0,01261 & $2,20 \times 10-6$ & 0,01745 & 0,0126 & 0,01261 & 0,01261 & 0,01261 & 0,01261 & $8,70 \times 10-6$ \\
\hline & 409 & 0,01932 & $2,20 \times 10-6$ & 0,01139 & 0,01931 & 0,01932 & 0,01932 & 0,01932 & 0,01932 & $8,80 \times 10-6$ \\
\hline & 512 & 0,02195 & $2,30 \times 10-6$ & 0,01048 & 0,02195 & 0,02195 & 0,02195 & 0,02195 & 0,02196 & $8,70 \times 10-6$ \\
\hline & 768 & 0,02338 & $2,20 \times 10-6$ & 0,00941 & 0,02338 & 0,02338 & 0,02338 & 0,02339 & 0,02339 & $8,60 \times 10-6$ \\
\hline & 1024 & 0,0305 & $2,20 \times 10-6$ & 0,00721 & 0,0305 & 0,0305 & 0,0305 & 0,03051 & 0,03051 & $9,00 \times 10-6$ \\
\hline & 1280 & 0,03562 & $2,20 \times 10-6$ & 0,00618 & 0,03561 & 0,03561 & 0,03562 & 0,03562 & 0,03562 & $8,60 \times 10-6$ \\
\hline & 1500 & 0,03963 & $2,20 \times 10-6$ & 0,00555 & 0,03963 & 0,03963 & 0,03963 & 0,03963 & 0,03964 & $8,50 \times 10-6$ \\
\hline & 1518 & 0,03965 & $2,20 \times 10-6$ & 0,00555 & 0,03964 & 0,03965 & 0,03965 & 0,03965 & 0,03965 & $8,90 \times 10-6$ \\
\hline \multirow{10}{*}{10} & 69 & 0,00472 & $2,30 \times 10-6$ & 0,04875 & 0,00471 & 0,00472 & 0,00472 & 0,00472 & 0,00472 & $9,20 \times 10-6$ \\
\hline & 128 & 0,00735 & $2,20 \times 10-6$ & 0,02993 & 0,00735 & 0,00735 & 0,00735 & 0,00735 & 0,00735 & $9,20 \times 10-6$ \\
\hline & 256 & 0,01278 & $2,30 \times 10-6$ & 0,01799 & 0,01278 & 0,01278 & 0,01278 & 0,01278 & 0,01279 & $9,40 \times 10-6$ \\
\hline & 409 & 0,0195 & $2,20 \times 10-6$ & 0,01128 & 0,0195 & 0,0195 & 0,0195 & 0,0195 & 0,01951 & $9,40 \times 10-6$ \\
\hline & 512 & 0,02211 & $2,30 \times 10-6$ & 0,0104 & 0,02211 & 0,02211 & 0,02211 & 0,02211 & 0,02211 & $9,40 \times 10-6$ \\
\hline & 768 & 0,02354 & $2,20 \times 10-6$ & 0,00934 & 0,02354 & 0,02354 & 0,02354 & 0,02354 & 0,02355 & $9,30 \times 10-6$ \\
\hline & 1024 & 0,03066 & $2,30 \times 10-6$ & 0,0075 & 0,03066 & 0,03066 & 0,03066 & 0,03066 & 0,03067 & $9,00 \times 10-6$ \\
\hline & 1280 & 0,03577 & $2,30 \times 10-6$ & 0,00643 & 0,03577 & 0,03577 & 0,03578 & 0,03578 & 0,03578 & $9,20 \times 10-6$ \\
\hline & 1500 & 0,03999 & $2,30 \times 10-6$ & 0,00575 & 0,03999 & 0,03999 & 0,03999 & 0,03999 & 0,04 & $9,40 \times 10-6$ \\
\hline & 1518 & 0,04002 & $2,30 \times 10-6$ & 0,00575 & 0,04002 & 0,04002 & 0,04002 & 0,04002 & 0,04003 & $9,20 \times 10-6$ \\
\hline
\end{tabular}


Tabela 29: Comparação do tempo de transferência (ms) entre os tamanhos da mensagem estratificada por módulo

\begin{tabular}{|c|c|c|c|c|c|c|c|c|c|c|c|c|c|}
\hline \multirow{2}{*}{\multicolumn{2}{|c|}{ Mód./TM }} & \multirow{2}{*}{$2^{\mathrm{o}} \mathrm{Q}$} & \multirow{2}{*}{$1^{\mathrm{o}} \mathrm{Q}$} & \multirow{2}{*}{$3^{\circ} \mathrm{Q}$} & \multicolumn{9}{|c|}{ Valor-p das Comparações Múltiplas } \\
\hline & & & & & 69 & 128 & 256 & 409 & 512 & 768 & 1024 & 1280 & 1500 \\
\hline \multirow{10}{*}{1} & 69 & 0,00156 & 0,00156 & 0,00156 & & & & & & & & & \\
\hline & 128 & 0,00256 & 0,00256 & 0,00256 & 0 & & & & & & & & \\
\hline & 256 & 0,00473 & 0,00473 & 0,00474 & 0 & 0 & & & & & & & \\
\hline & 409 & 0,00734 & 0,00734 & 0,00734 & 0 & 0 & 0 & & & & & & \\
\hline & 512 & 0,00909 & 0,00908 & 0,00909 & 0 & 0 & 0 & 0 & & & & & \\
\hline & 768 & 0,01344 & 0,01343 & 0,01344 & 0 & 0 & 0 & 0 & 0 & & & & \\
\hline & 1024 & 0,01779 & 0,01779 & 0,01779 & 0 & 0 & 0 & 0 & 0 & 0 & & & \\
\hline & 1280 & 0,02214 & 0,02214 & 0,02214 & 0 & 0 & 0 & 0 & 0 & 0 & 0 & & \\
\hline & 1500 & 0,02589 & 0,02588 & 0,02589 & 0 & 0 & 0 & 0 & 0 & 0 & 0 & 0 & \\
\hline & 1518 & 0,02619 & 0,02619 & 0,02619 & 0 & 0 & 0 & 0 & 0 & 0 & 0 & 0 & 0 \\
\hline \multirow{10}{*}{2} & 69 & 0,00247 & 0,00247 & 0,00247 & & & & & & & & & \\
\hline & 128 & 0,00454 & 0,00453 & 0,00454 & 0 & & & & & & & & \\
\hline & 256 & 0,00902 & 0,00901 & 0,00902 & 0 & 0 & & & & & & & \\
\hline & 409 & 0,01468 & 0,01468 & 0,01468 & 0 & 0 & 0 & & & & & & \\
\hline & 512 & 0,01668 & 0,01668 & 0,01668 & 0 & 0 & 0 & 0 & & & & & \\
\hline & 768 & 0,01811 & 0,01811 & 0,01811 & 0 & 0 & 0 & 0 & 0 & & & & \\
\hline & 1024 & 0,02523 & 0,02523 & 0,02523 & 0 & 0 & 0 & 0 & 0 & 0 & & & \\
\hline & 1280 & 0,03034 & 0,03034 & 0,03035 & 0 & 0 & 0 & 0 & 0 & 0 & 0 & & \\
\hline & 1500 & 0,03438 & 0,03438 & 0,03439 & 0 & 0 & 0 & 0 & 0 & 0 & 0 & 0 & \\
\hline & 1518 & 0,0344 & 0,0344 & 0,0344 & 0 & 0 & 0 & 0 & 0 & 0 & 0 & 0 & 0 \\
\hline \multirow{10}{*}{3} & 69 & 0,00371 & 0,00371 & 0,00371 & & & & & & & & & \\
\hline & 128 & 0,00649 & 0,00649 & 0,0065 & 0 & & & & & & & & \\
\hline & 256 & 0,01193 & 0,01193 & 0,01194 & 0 & 0 & & & & & & & \\
\hline & 409 & 0,01793 & 0,01793 & 0,01794 & 0 & 0 & 0 & & & & & & \\
\hline & 512 & 0,02149 & 0,02149 & 0,0215 & 0 & 0 & 0 & 0 & & & & & \\
\hline & 768 & 0,02401 & 0,024 & 0,02401 & 0 & 0 & 0 & 0 & 0 & & & & \\
\hline & 1024 & 0,0305 & 0,0305 & 0,0305 & 0 & 0 & 0 & 0 & 0 & 0 & & & \\
\hline & 1280 & 0,03511 & 0,03511 & 0,03511 & 0 & 0 & 0 & 0 & 0 & 0 & 0 & & \\
\hline & 1500 & 0,03898 & 0,03898 & 0,03898 & 0 & 0 & 0 & 0 & 0 & 0 & 0 & 0 & \\
\hline & 1518 & 0,03948 & 0,03948 & 0,03948 & 0 & 0 & 0 & 0 & 0 & 0 & 0 & 0 & 0 \\
\hline \multirow{10}{*}{4} & 69 & 0,00371 & 0,00371 & 0,00371 & & & & & & & & & \\
\hline & 128 & 0,00649 & 0,00649 & 0,0065 & 0 & & & & & & & & \\
\hline & 256 & 0,01193 & 0,01193 & 0,01194 & 0 & 0 & & & & & & & \\
\hline & 409 & 0,01793 & 0,01793 & 0,01794 & 0 & 0 & 0 & & & & & & \\
\hline & 512 & 0,02149 & 0,02149 & 0,0215 & 0 & 0 & 0 & 0 & & & & & \\
\hline & 768 & 0,02401 & 0,024 & 0,02401 & 0 & 0 & 0 & 0 & 0 & & & & \\
\hline & 1024 & 0,0305 & 0,0305 & 0,0305 & 0 & 0 & 0 & 0 & 0 & 0 & & & \\
\hline & 1280 & 0,03511 & 0,03511 & 0,03511 & 0 & 0 & 0 & 0 & 0 & 0 & 0 & & \\
\hline & 1500 & 0,03898 & 0,03898 & 0,03898 & 0 & 0 & 0 & 0 & 0 & 0 & 0 & 0 & \\
\hline & 1518 & 0,03948 & 0,03948 & 0,03948 & 0 & 0 & 0 & 0 & 0 & 0 & 0 & 0 & 0 \\
\hline
\end{tabular}


Tabela 29 - Continuação da página anterior

\begin{tabular}{|c|c|c|c|c|c|c|c|c|c|c|c|c|c|}
\hline \multirow{2}{*}{\multicolumn{2}{|c|}{ Mód./TM }} & \multirow{2}{*}{$2^{\mathrm{o}} \mathrm{Q}$} & \multirow{2}{*}{$1^{\mathrm{o}} \mathrm{Q}$} & \multirow{2}{*}{$3^{\mathrm{o}} \mathrm{Q}$} & \multicolumn{9}{|c|}{ Valor-p das Comparações Múltiplas } \\
\hline & & & & & 69 & 128 & 256 & 409 & 512 & 768 & 1024 & 1280 & 1500 \\
\hline \multirow{10}{*}{5} & 69 & 0,00251 & 0,00251 & 0,00251 & & & & & & & & & \\
\hline & 128 & 0,00457 & 0,00457 & 0,00458 & 0 & & & & & & & & \\
\hline & 256 & 0,00905 & 0,00905 & 0,00906 & 0 & 0 & & & & & & & \\
\hline & 409 & 0,01472 & 0,01472 & 0,01472 & 0 & 0 & 0 & & & & & & \\
\hline & 512 & 0,01672 & 0,01672 & 0,01672 & 0 & 0 & 0 & 0 & & & & & \\
\hline & 768 & 0,01815 & 0,01815 & 0,01815 & 0 & 0 & 0 & 0 & 0 & & & & \\
\hline & 1024 & 0,02527 & 0,02527 & 0,02527 & 0 & 0 & 0 & 0 & 0 & 0 & & & \\
\hline & 1280 & 0,03038 & 0,03038 & 0,03038 & 0 & 0 & 0 & 0 & 0 & 0 & 0 & & \\
\hline & 1500 & 0,03442 & 0,03442 & 0,03442 & 0 & 0 & 0 & 0 & 0 & 0 & 0 & 0 & \\
\hline & 1518 & 0,03444 & 0,03444 & 0,03444 & 0 & 0 & 0 & 0 & 0 & 0 & 0 & 0 & 0 \\
\hline \multirow{10}{*}{6} & 69 & 0,00159 & 0,00159 & 0,00159 & & & & & & & & & \\
\hline & 128 & 0,00259 & 0,00259 & 0,00259 & 0 & & & & & & & & \\
\hline & 256 & 0,00478 & 0,00477 & 0,00478 & 0 & 0 & & & & & & & \\
\hline & 409 & 0,00738 & 0,00737 & 0,00738 & 0 & 0 & 0 & & & & & & \\
\hline & 512 & 0,00912 & 0,00912 & 0,00912 & 0 & 0 & 0 & 0 & & & & & \\
\hline & 768 & 0,01347 & 0,01347 & 0,01347 & 0 & 0 & 0 & 0 & 0 & & & & \\
\hline & 1024 & 0,01782 & 0,01782 & 0,01783 & 0 & 0 & 0 & 0 & 0 & 0 & & & \\
\hline & 1280 & 0,02218 & 0,02217 & 0,02218 & 0 & 0 & 0 & 0 & 0 & 0 & 0 & & \\
\hline & 1500 & 0,02592 & 0,02592 & 0,02592 & 0 & 0 & 0 & 0 & 0 & 0 & 0 & 0 & \\
\hline & 1518 & 0,02623 & 0,02623 & 0,02623 & 0 & 0 & 0 & 0 & 0 & 0 & 0 & 0 & 0 \\
\hline \multirow{10}{*}{7} & 69 & 0,00351 & 0,00351 & 0,00351 & & & & & & & & & \\
\hline & 128 & 0,00639 & 0,00639 & 0,00639 & 0 & & & & & & & & \\
\hline & 256 & 0,01293 & 0,01293 & 0,01293 & 0 & 0 & & & & & & & \\
\hline & 409 & 0,02102 & 0,02102 & 0,02102 & 0 & 0 & 0 & & & & & & \\
\hline & 512 & 0,02598 & 0,02597 & 0,02598 & 0 & 0 & 0 & 0 & & & & & \\
\hline & 768 & 0,03903 & 0,03903 & 0,03903 & 0 & 0 & 0 & 0 & 0 & & & & \\
\hline & 1024 & 0,05209 & 0,05209 & 0,05209 & 0 & 0 & 0 & 0 & 0 & 0 & & & \\
\hline & 1280 & 0,06514 & 0,06514 & 0,06514 & 0 & 0 & 0 & 0 & 0 & 0 & 0 & & \\
\hline & 1500 & 0,07654 & 0,07653 & 0,07654 & 0 & 0 & 0 & 0 & 0 & 0 & 0 & 0 & \\
\hline & 1518 & 0,07738 & 0,07737 & 0,07738 & 0 & 0 & 0 & 0 & 0 & 0 & 0 & 0 & 0 \\
\hline \multirow{10}{*}{8} & 69 & 0,00351 & 0,00351 & 0,00351 & & & & & & & & & \\
\hline & 128 & 0,00639 & 0,00639 & 0,00639 & 0 & & & & & & & & \\
\hline & 256 & 0,01294 & 0,01293 & 0,01294 & 0 & 0 & & & & & & & \\
\hline & 409 & 0,02102 & 0,02102 & 0,02103 & 0 & 0 & 0 & & & & & & \\
\hline & 512 & 0,02598 & 0,02597 & 0,02598 & 0 & 0 & 0 & 0 & & & & & \\
\hline & 768 & 0,03903 & 0,03903 & 0,03903 & 0 & 0 & 0 & 0 & 0 & & & & \\
\hline & 1024 & 0,05209 & 0,05209 & 0,05209 & 0 & 0 & 0 & 0 & 0 & 0 & & & \\
\hline & 1280 & 0,06514 & 0,06514 & 0,06515 & 0 & 0 & 0 & 0 & 0 & 0 & 0 & & \\
\hline & 1500 & 0,07654 & 0,07653 & 0,07654 & 0 & 0 & 0 & 0 & 0 & 0 & 0 & 0 & \\
\hline & 1518 & 0,07738 & 0,07738 & 0,07739 & 0 & 0 & 0 & 0 & 0 & 0 & 0 & 0 & 0 \\
\hline \multirow{2}{*}{9} & 69 & 0,0045 & 0,0045 & 0,00451 & & & & & & & & & \\
\hline & 128 & 0,00718 & 0,00717 & 0,00718 & 0 & & & & & & & & \\
\hline
\end{tabular}


Tabela 29 - Continuação da página anterior

\begin{tabular}{|c|c|c|c|c|c|c|c|c|c|c|c|c|}
\hline \multirow{2}{*}{ Mód./TM } & \multirow{2}{*}{$2^{\mathrm{o}} \mathrm{Q}$} & \multirow{2}{*}{$1^{\circ} \mathrm{Q}$} & \multirow{2}{*}{$3^{\circ} \mathrm{Q}$} & \multicolumn{9}{|c|}{ Valor-p das Comparações Múltiplas } \\
\hline & & & & 69 & 128 & 256 & 409 & 512 & 768 & 1024 & 41280 & 1500 \\
\hline 256 & 0,01261 & 0,01261 & 0,01261 & 0 & 0 & & & & & & & \\
\hline 409 & 0,01932 & 0,01932 & 0,01932 & 0 & 0 & 0 & & & & & & \\
\hline 512 & 0,02195 & 0,02195 & 0,02195 & 0 & 0 & 0 & 0 & & & & & \\
\hline 768 & 0,02338 & 0,02338 & 0,02339 & 0 & 0 & 0 & 0 & 0 & & & & \\
\hline 1024 & 0,0305 & 0,0305 & 0,03051 & 0 & 0 & 0 & 0 & 0 & 0 & & & \\
\hline 1280 & 0,03562 & 0,03561 & 0,03562 & 0 & 0 & 0 & 0 & 0 & 0 & 0 & & \\
\hline 1500 & 0,03963 & 0,03963 & 0,03963 & 0 & 0 & 0 & 0 & 0 & 0 & 0 & 0 & \\
\hline 1518 & 0,03965 & 0,03965 & 0,03965 & 0 & 0 & 0 & 0 & 0 & 0 & 0 & 0 & 0 \\
\hline 69 & 0,00472 & 0,00472 & 0,00472 & & & & & & & & & \\
\hline 128 & 0,00735 & 0,00735 & 0,00735 & 0 & & & & & & & & \\
\hline 256 & 0,01278 & 0,01278 & 0,01278 & 0 & 0 & & & & & & & \\
\hline 409 & 0,0195 & 0,0195 & 0,0195 & 0 & 0 & 0 & & & & & & \\
\hline 512 & 0,02211 & 0,02211 & 0,02211 & 0 & 0 & 0 & 0 & & & & & \\
\hline 768 & 0,02354 & 0,02354 & 0,02354 & 0 & 0 & 0 & 0 & 0 & & & & \\
\hline 1024 & 0,03066 & 0,03066 & 0,03066 & 0 & 0 & 0 & 0 & 0 & 0 & & & \\
\hline 1280 & 0,03578 & 0,03577 & 0,03578 & 0 & 0 & 0 & 0 & 0 & 0 & 0 & & \\
\hline 1500 & 0,03999 & 0,03999 & 0,03999 & 0 & 0 & 0 & 0 & 0 & 0 & 0 & 0 & \\
\hline 1518 & 0,04002 & 0,04002 & 0,04002 & 0 & 0 & 0 & 0 & 0 & 0 & 0 & 0 & 0 \\
\hline
\end{tabular}




\section{Tabelas Referentes ao TT entre os Módulos, Estratificados por TM}

Tabela 30: Descrição do tempo de transferência (ms) entre os módulos, estratificados por tamanho da mensagem.

\begin{tabular}{ccccccccccc}
\hline TM/Mód. Média & D.P. & C.V. & Mín. & $\mathbf{1}^{\mathbf{o}} \mathbf{Q}$ & $\mathbf{2}^{\mathbf{o}} \mathbf{Q}$ & $\mathbf{3}^{\mathbf{o}} \mathbf{Q}$ & Máx. & Amplitude \\
\hline 1 & 0,00156 & $2,20 \times 10-6$ & 0,14121 & 0,00155 & 0,00156 & 0,00156 & 0,00156 & 0,00156 & $8,80 \times 10-6$ \\
2 & 0,00247 & $2,50 \times 10-6$ & 0,10119 & 0,00247 & 0,00247 & 0,00247 & 0,00247 & 0,00247 & $9,00 \times 10-6$ \\
3 & 0,00371 & $2,50 \times 10-6$ & 0,06739 & 0,00371 & 0,00371 & 0,00371 & 0,00371 & 0,00371 & $8,60 \times 10-6$ \\
69 & 0,00371 & $2,60 \times 10-6$ & 0,07009 & 0,0037 & 0,00371 & 0,00371 & 0,00371 & 0,00371 & $8,80 \times 10-6$ \\
& 5 & 0,00251 & $2,50 \times 10-6$ & 0,09962 & 0,00251 & 0,00251 & 0,00251 & 0,00251 & 0,00251 & $8,70 \times 10-6$ \\
6 & 0,00159 & $2,20 \times 10-6$ & 0,13818 & 0,00159 & 0,00159 & 0,00159 & 0,00159 & 0,0016 & $8,80 \times 10-6$ \\
7 & 0,00351 & $2,10 \times 10-6$ & 0,05982 & 0,00351 & 0,00351 & 0,00351 & 0,00351 & 0,00351 & $9,00 \times 10-6$ \\
8 & 0,00351 & $2,30 \times 10-6$ & 0,06551 & 0,00351 & 0,00351 & 0,00351 & 0,00351 & 0,00352 & $8,70 \times 10-6$ \\
9 & 0,0045 & $2,20 \times 10-6$ & 0,04885 & 0,0045 & 0,0045 & 0,0045 & 0,00451 & 0,00451 & $8,80 \times 10-6$ \\
10 & 0,00472 & $2,30 \times 10-6$ & 0,04875 & 0,00471 & 0,00472 & 0,00472 & 0,00472 & 0,00472 & $9,20 \times 10-6$ \\
\hline 6 & 1 & 0,00256 & $2,30 \times 10-6$ & 0,08992 & 0,00255 & 0,00256 & 0,00256 & 0,00256 & 0,00256 & $8,70 \times 10-6$ \\
2 & 0,00453 & $2,50 \times 10-6$ & 0,05513 & 0,00453 & 0,00453 & 0,00454 & 0,00454 & 0,00454 & $8,80 \times 10-6$ \\
3 & 0,00649 & $2,60 \times 10-6$ & 0,04004 & 0,00649 & 0,00649 & 0,00649 & 0,0065 & 0,0065 & $8,70 \times 10-6$ \\
4 & 0,00649 & $2,50 \times 10-6$ & 0,03850 & 0,00649 & 0,00649 & 0,00649 & 0,0065 & 0,0065 & $9,00 \times 10-6$ \\
5 & 0,00457 & $2,60 \times 10-6$ & 0,05685 & 0,00457 & 0,00457 & 0,00457 & 0,00458 & 0,00458 & $8,70 \times 10-6$ \\
6 & 0,00259 & $2,20 \times 10-6$ & 0,08488 & 0,00259 & 0,00259 & 0,00259 & 0,00259 & 0,0026 & $8,80 \times 10-6$ \\
7 & 0,00639 & $2,10 \times 10-6$ & 0,03286 & 0,00639 & 0,00639 & 0,00639 & 0,00639 & 0,00639 & $8,60 \times 10-6$ \\
8 & 0,00639 & $2,30 \times 10-6$ & 0,03599 & 0,00639 & 0,00639 & 0,00639 & 0,00639 & 0,0064 & $8,90 \times 10-6$ \\
9 & 0,00718 & $2,20 \times 10-6$ & 0,03066 & 0,00717 & 0,00717 & 0,00718 & 0,00718 & 0,00718 & $8,50 \times 10-6$ \\
10 & 0,00735 & $2,20 \times 10-6$ & 0,02993 & 0,00735 & 0,00735 & 0,00735 & 0,00735 & 0,00735 & $9,20 \times 10-6$ \\
\hline
\end{tabular}


Tabela 30 - Continuação da página anterior

TM/Mód. Média D.P. $\quad$ C.V. Mín. $1^{\circ} \mathrm{Q} \quad 2^{\circ} \mathrm{Q} \quad 3^{\circ} \mathrm{Q}$ Máx. Amplitude

$6 \quad 0,00478 \quad 2,20 \times 10-6 \quad 0,04606 \quad 0,00477 \quad 0,00477 \quad 0,00478 \quad 0,00478 \quad 0,00478 \quad 8,90 \times 10-6$

$7 \quad 0,012932,10 \times 10-6 \quad 0,01625 \quad 0,01292 \quad 0,01293 \quad 0,01293 \quad 0,01293 \quad 0,01293 \quad 9,00 \times 10-6$

$8 \quad 0,012942,30 \times 10-6 \quad 0,01778 \quad 0,01293 \quad 0,01293 \quad 0,01294 \quad 0,01294 \quad 0,01294 \quad 8,50 \times 10-6$

$9 \quad 0,012612,20 \times 10-6 \quad 0,01745 \quad 0,0126 \quad 0,01261 \quad 0,01261 \quad 0,01261 \quad 0,01261 \quad 8,70 \times 10-6$

$10 \quad 0,01278 \quad 2,30 \times 10-6 \quad 0,01799 \quad 0,01278 \quad 0,01278 \quad 0,01278 \quad 0,01278 \quad 0,01279 \quad 9,40 \times 10-6$

$1 \quad 0,007342,10 \times 10-6 \quad 0,02860 \quad 0,00734 \quad 0,00734 \quad 0,00734 \quad 0,00734 \quad 0,00735 \quad 8,50 \times 10-6$

$2 \quad 0,01468 \quad 2,50 \times 10-6 \quad 0,01703 \quad 0,01467 \quad 0,01468 \quad 0,01468 \quad 0,01468 \quad 0,01468 \quad 8,40 \times 10-6$

$3 \quad 0,017932,50 \times 10-6 \quad 0,01394 \quad 0,01793 \quad 0,01793 \quad 0,01793 \quad 0,01794 \quad 0,01794 \quad 8,80 \times 10-6$

$4 \quad 0,017932,60 \times 10-6 \quad 0,01450 \quad 0,01793 \quad 0,01793 \quad 0,01793 \quad 0,01794 \quad 0,01794 \quad 8,80 \times 10-6$

$409 \quad 5 \quad 0,01472 \quad 2,50 \times 10-6 \quad 0,01699 \quad 0,01471 \quad 0,01472 \quad 0,01472 \quad 0,01472 \quad 0,01472 \quad 8,90 \times 10-6$

$6 \quad 0,00738 \quad 2,20 \times 10-6 \quad 0,02983 \quad 0,00737 \quad 0,00737 \quad 0,00738 \quad 0,00738 \quad 0,00738 \quad 8,70 \times 10-6$

$7 \quad 0,021022,10 \times 10-6 \quad 0,00999 \quad 0,02102 \quad 0,02102 \quad 0,02102 \quad 0,02102 \quad 0,02103 \quad 8,50 \times 10-6$

$8 \quad 0,021022,20 \times 10-6 \quad 0,010460,02102 \quad 0,021020,02102 \quad 0,02103 \quad 0,02103 \quad 8,70 \times 10-6$

$9 \quad 0,019322,20 \times 10-6 \quad 0,011390,019310,019320,019320,01932 \quad 0,01932 \quad 8,80 \times 10-6$

$10 \quad 0,0195 \quad 2,20 \times 10-6 \quad 0,01128 \quad 0,0195 \quad 0,0195 \quad 0,0195 \quad 0,0195 \quad 0,01951 \quad 9,40 \times 10-6$

$10,009092,20 \times 10-6 \quad 0,024210,00908 \quad 0,00908 \quad 0,009090,00909 \quad 0,00909 \quad 8,70 \times 10-6$

$2 \quad 0,016682,50 \times 10-6 \quad 0,01499 \quad 0,01667 \quad 0,01668 \quad 0,01668 \quad 0,01668 \quad 0,01668 \quad 8,50 \times 10-6$

$3 \quad 0,021492,60 \times 10-6 \quad 0,01210 \quad 0,021490,02149 \quad 0,02149 \quad 0,0215 \quad 0,0215 \quad 8,80 \times 10-6$

$4 \quad 0,021492,50 \times 10-6 \quad 0,01163 \quad 0,02149 \quad 0,02149 \quad 0,02149 \quad 0,0215 \quad 0,0215 \quad 8,80 \times 10-6$

$5 \quad 0,016722,50 \times 10-6 \quad 0,01495 \quad 0,016710,016720,01672 \quad 0,01672 \quad 0,01672 \quad 8,70 \times 10-6$

$6 \quad 0,009122,20 \times 10-6 \quad 0,024120,00912 \quad 0,009120,009120,00912 \quad 0,00912 \quad 8,90 \times 10-6$

$7 \quad 0,02597 \quad 2,10 \times 10-6 \quad 0,00808 \quad 0,02597 \quad 0,02597 \quad 0,02598 \quad 0,02598 \quad 0,02598 \quad 8,70 \times 10-6$

$8 \quad 0,02598 \quad 2,30 \times 10-6 \quad 0,00885 \quad 0,02597 \quad 0,02597 \quad 0,02598 \quad 0,02598 \quad 0,02598 \quad 8,60 \times 10-6$

$9 \quad 0,021952,30 \times 10-6 \quad 0,01048 \quad 0,02195 \quad 0,02195 \quad 0,02195 \quad 0,02195 \quad 0,02196 \quad 8,70 \times 10-6$

$10 \quad 0,022112,30 \times 10-6 \quad 0,01040 \quad 0,02211 \quad 0,02211 \quad 0,02211 \quad 0,02211 \quad 0,02211 \quad 9,40 \times 10-6$

$10,013442,20 \times 10-6 \quad 0,01637 \quad 0,01343 \quad 0,01343 \quad 0,01344 \quad 0,01344 \quad 0,01344 \quad 9,10 \times 10-6$

$2 \quad 0,018112,40 \times 10-6 \quad 0,01325 \quad 0,018110,018110,01811 \quad 0,018110,01812 \quad 8,90 \times 10-6$

$3 \quad 0,024012,50 \times 10-6 \quad 0,01041 \quad 0,024 \quad 0,024 \quad 0,02401 \quad 0,02401 \quad 0,02401 \quad 8,90 \times 10-6$

$4 \quad 0,024012,60 \times 10-6 \quad 0,01083 \quad 0,024 \quad 0,024 \quad 0,02401 \quad 0,02401 \quad 0,02401 \quad 8,80 \times 10-6$

$\begin{array}{llllllllllll}768 & 5 & 0,01815 & 2,60 \times 10-6 & 0,01433 & 0,01815 & 0,01815 & 0,01815 & 0,01815 & 0,01815 & 8,60 \times 10-6\end{array}$

$6 \quad 0,01347 \quad 2,20 \times 10-6 \quad 0,01633 \quad 0,01347 \quad 0,01347 \quad 0,01347 \quad 0,01347 \quad 0,01348 \quad 8,80 \times 10-6$

$7 \quad 0,039032,10 \times 10-6 \quad 0,00538 \quad 0,03903 \quad 0,03903 \quad 0,03903 \quad 0,03903 \quad 0,03904 \quad 8,90 \times 10-6$

$8 \quad 0,039032,30 \times 10-6 \quad 0,00589 \quad 0,03903 \quad 0,03903 \quad 0,03903 \quad 0,03903 \quad 0,03904 \quad 8,70 \times 10-6$

$9 \quad 0,02338 \quad 2,20 \times 10-6 \quad 0,00941 \quad 0,02338 \quad 0,02338 \quad 0,02338 \quad 0,02339 \quad 0,02339 \quad 8,60 \times 10-6$

$10 \quad 0,02354 \quad 2,20 \times 10-6 \quad 0,00934 \quad 0,02354 \quad 0,02354 \quad 0,02354 \quad 0,02354 \quad 0,02355 \quad 9,30 \times 10-6$

$1 \quad 0,017792,30 \times 10-6 \quad 0,01293 \quad 0,017790,017790,017790,017790,01779 \quad 8,90 \times 10-6$

$2 \quad 0,025232,40 \times 10-6 \quad 0,00951 \quad 0,02523 \quad 0,02523 \quad 0,02523 \quad 0,02523 \quad 0,02523 \quad 8,60 \times 10-6$

$3 \quad 0,0305 \quad 2,50 \times 10-6 \quad 0,00820 \quad 0,0305 \quad 0,0305 \quad 0,0305 \quad 0,0305 \quad 0,03051 \quad 8,50 \times 10-6$

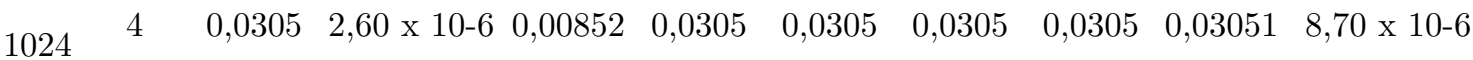

$5 \quad 0,02527 \quad 2,50 \times 10-6 \quad 0,00989 \quad 0,02527 \quad 0,02527 \quad 0,02527 \quad 0,02527 \quad 0,02527 \quad 8,90 \times 10-6$

$6 \quad 0,017822,20 \times 10-6 \quad 0,01234 \quad 0,01782 \quad 0,01782 \quad 0,01782 \quad 0,01783 \quad 0,01783 \quad 8,60 \times 10-6$

$7 \quad 0,052092,20 \times 10-6 \quad 0,00422 \quad 0,05208 \quad 0,05209 \quad 0,05209 \quad 0,052090,05209 \quad 9,10 \times 10-6$

$8 \quad 0,052092,30 \times 10-6 \quad 0,00442 \quad 0,05208 \quad 0,05209 \quad 0,05209 \quad 0,05209 \quad 0,05209 \quad 8,60 \times 10-6$ 
Tabela 30 - Continuação da página anterior

TM/Mód. Média D.P. $\quad$ C.V. Mín. $1^{\circ} \mathrm{Q} 2^{\circ} \mathrm{Q} \quad 3^{\mathrm{o}} \mathrm{Q}$ Máx. Amplitude

$90,0305 \quad 2,20 \times 10-6 \quad 0,00721 \quad 0,0305 \quad 0,0305 \quad 0,0305 \quad 0,03051 \quad 0,03051 \quad 9,00 \times 10-6$

$10 \quad 0,03066 \quad 2,30 \times 10-6 \quad 0,00750 \quad 0,03066 \quad 0,03066 \quad 0,03066 \quad 0,03066 \quad 0,03067 \quad 9,00 \times 10-6$

\begin{tabular}{|c|c|c|c|c|c|c|c|c|c|c|}
\hline \multirow{10}{*}{1280} & 1 & 0,02214 & $2,10 \times 10-6$ & 0,00948 & 0,02214 & 0,02214 & 0,02214 & 0,02214 & 0,02215 & $8,90 \times 10-6$ \\
\hline & 2 & 0,03034 & $2,40 \times 10-6$ & 0,00791 & 0,03034 & 0,03034 & 0,03034 & 0,03035 & 0,03035 & $8,80 \times 10-6$ \\
\hline & 3 & 0,03511 & $2,60 \times 10-6$ & 0,00741 & 0,03511 & 0,03511 & 0,03511 & 0,03511 & 0,03511 & $8,80 \times 10-6$ \\
\hline & 4 & 0,03511 & $2,60 \times 10-6$ & 0,00741 & 0,03511 & 0,03511 & 0,03511 & 0,03511 & 0,03511 & $8,70 \times 10-6$ \\
\hline & 5 & 0,03038 & $2,60 \times 10-6$ & 0,00856 & 0,03038 & 0,03038 & 0,03038 & 0,03038 & 0,03039 & $8,60 \times 10-6$ \\
\hline & 6 & 0,02218 & $2,30 \times 10-6$ & 0,01037 & 0,02217 & 0,02217 & 0,02218 & 0,02218 & 0,02218 & $8,60 \times 10-6$ \\
\hline & 7 & 0,06514 & $2,10 \times 10-6$ & 0,00322 & 0,06514 & 0,06514 & 0,06514 & 0,06514 & 0,06515 & $8,60 \times 10-6$ \\
\hline & 8 & 0,06514 & $2,20 \times 10-6$ & 0,00338 & 0,06514 & 0,06514 & 0,06514 & 0,06515 & 0,06515 & $8,80 \times 10-6$ \\
\hline & 9 & 0,03562 & $2,20 \times 10-6$ & 0,00618 & 0,03561 & 0,03561 & 0,03562 & 0,03562 & 0,03562 & $8,60 \times 10-6$ \\
\hline & 10 & 0,03577 & $2,30 \times 10-6$ & 0,00643 & 0,03577 & 0,03577 & 0,03578 & 0,03578 & 0,03578 & $9,20 \times 10-6$ \\
\hline \multirow{10}{*}{1500} & 1 & 0,02589 & $2,20 \times 10-6$ & 0,00850 & 0,02588 & 0,02588 & 0,02589 & 0,02589 & 0,02589 & $8,80 \times 10-6$ \\
\hline & 2 & 0,03438 & $2,50 \times 10-6$ & 0,00727 & 0,03438 & 0,03438 & 0,03438 & 0,03439 & 0,03439 & $8,80 \times 10-6$ \\
\hline & 3 & 0,03898 & $2,60 \times 10-6$ & 0,00667 & 0,03898 & 0,03898 & 0,03898 & 0,03898 & 0,03899 & $8,70 \times 10-6$ \\
\hline & 4 & 0,03898 & $2,50 \times 10-6$ & 0,00641 & 0,03898 & 0,03898 & 0,03898 & 0,03898 & 0,03899 & $8,60 \times 10-6$ \\
\hline & 5 & 0,03442 & $2,60 \times 10-6$ & 0,00755 & 0,03442 & 0,03442 & 0,03442 & 0,03442 & 0,03443 & $9,00 \times 10-6$ \\
\hline & 6 & 0,02592 & $2,20 \times 10-6$ & 0,00849 & 0,02592 & 0,02592 & 0,02592 & 0,02592 & 0,02592 & $8,70 \times 10-6$ \\
\hline & 7 & 0,07654 & $2,20 \times 10-6$ & 0,00287 & 0,07653 & 0,07653 & 0,07654 & 0,07654 & 0,07654 & $8,50 \times 10-6$ \\
\hline & 8 & 0,07654 & $2,30 \times 10-6$ & 0,00301 & 0,07653 & 0,07653 & 0,07654 & 0,07654 & 0,07654 & $8,70 \times 10-6$ \\
\hline & 9 & 0,03963 & $2,20 \times 10-6$ & 0,00555 & 0,03963 & 0,03963 & 0,03963 & 0,03963 & 0,03964 & $8,50 \times 10-6$ \\
\hline & 10 & 0,03999 & $2,30 \times 10-6$ & 0,00575 & 0,03999 & 0,03999 & 0,03999 & 0,03999 & 0,04 & $9,40 \times 10-6$ \\
\hline \multirow{10}{*}{1518} & 1 & 0,02619 & $2,20 \times 10-6$ & 0,00840 & 0,02619 & 0,02619 & 0,02619 & 0,02619 & 0,02619 & $8,60 \times 10-6$ \\
\hline & 2 & 0,0344 & $2,40 \times 10-6$ & 0,00698 & 0,03439 & 0,0344 & 0,0344 & 0,0344 & 0,0344 & $8,70 \times 10-6$ \\
\hline & 3 & 0,03948 & $2,60 \times 10-6$ & 0,00659 & 0,03947 & 0,03948 & 0,03948 & 0,03948 & 0,03948 & $8,40 \times 10-6$ \\
\hline & 4 & 0,03948 & $2,60 \times 10-6$ & 0,00659 & 0,03947 & 0,03948 & 0,03948 & 0,03948 & 0,03948 & $8,80 \times 10-6$ \\
\hline & 5 & 0,03444 & $2,50 \times 10-6$ & 0,00726 & 0,03443 & 0,03444 & 0,03444 & 0,03444 & 0,03444 & $8,70 \times 10-6$ \\
\hline & 6 & 0,02623 & $2,20 \times 10-6$ & 0,00839 & 0,02623 & 0,02623 & 0,02623 & 0,02623 & 0,02624 & $8,90 \times 10-6$ \\
\hline & 7 & 0,07738 & $2,20 \times 10-6$ & 0,00284 & 0,07737 & 0,07737 & 0,07738 & 0,07738 & 0,07738 & $8,80 \times 10-6$ \\
\hline & 8 & 0,07738 & $2,20 \times 10-6$ & 0,00284 & 0,07738 & 0,07738 & 0,07738 & 0,07739 & 0,07739 & $8,60 \times 10-6$ \\
\hline & 9 & 0,03965 & $2,20 \times 10-6$ & 0,00555 & 0,03964 & 0,03965 & 0,03965 & 0,03965 & 0,03965 & $8,90 \times 10-6$ \\
\hline & 10 & 0,04002 & $2,30 \times 10-6$ & 0,00575 & 0,04002 & 0,04002 & 0,04002 & 0,04002 & 0,04003 & $9,20 \times 10-6$ \\
\hline
\end{tabular}

Tabela 31: Comparação do tempo de transferência (ms) entre os módulos, estratificados por tamanho da mensagem

\begin{tabular}{|c|c|c|c|c|c|c|c|c|c|c|c|c|c|}
\hline \multirow{2}{*}{\multicolumn{2}{|c|}{ TM/Mód. }} & \multirow{2}{*}{$2^{\mathrm{o}} \mathrm{Q}$} & \multirow{2}{*}{$1^{\circ} \mathrm{Q}$} & \multirow{2}{*}{$3^{\mathrm{o}} \mathrm{Q}$} & \multicolumn{9}{|c|}{ Valor-p das Comparações Múltiplas } \\
\hline & & & & & 69 & 128 & 256 & 409 & 512 & 768 & 1024 & 1280 & 1500 \\
\hline \multirow{5}{*}{69} & 1 & 0,00156 & 0,00156 & 0,00156 & & & & & & & & & \\
\hline & 2 & 0,00247 & 0,00247 & 0,00247 & 0 & & & & & & & & \\
\hline & 3 & 0,00371 & 0,00371 & 0,00371 & 0 & 0 & & & & & & & \\
\hline & 4 & 0,00371 & 0,00371 & 0,00371 & 0 & 0 & 1 & & & & & & \\
\hline & 5 & 0,00251 & 0,00251 & 0,00251 & 0 & 0 & 0 & 0 & & & & & \\
\hline
\end{tabular}


Tabela 31 - Continuação da página anterior

TM/Mód. $\quad 2^{\mathrm{o}} \mathrm{Q} \quad \mathbf{1}^{\mathrm{o}} \mathrm{Q} \quad 3^{\mathrm{o}} \mathrm{Q}$

Valor-p das Comparações Múltiplas

$\begin{array}{lllllllll}69 & 128 & 256 & 409 & 512 & 768 & 1024 & 1280 & 1500\end{array}$

\begin{tabular}{|c|c|c|c|c|c|c|c|c|c|c|c|c|c|}
\hline & 6 & 0,00159 & 0,00159 & 0,00159 & 0 & 0 & 0 & 0 & 0 & & & & \\
\hline & 7 & 0,00351 & 0,00351 & 0,00351 & 0 & 0 & 0 & 0 & 0 & 0 & & & \\
\hline & 8 & 0,00351 & 0,00351 & 0,00351 & 0 & 0 & 0 & 0 & 0 & 0 & 0,997 & & \\
\hline & 9 & 0,0045 & 0,0045 & 0,00451 & 0 & 0 & 0 & 0 & 0 & 0 & 0 & 0 & \\
\hline & 10 & 0,00472 & 0,00472 & 0,00472 & 0 & 0 & 0 & 0 & 0 & 0 & 0 & 0 & 0 \\
\hline \multirow{10}{*}{128} & 1 & 0,00256 & 0,00256 & 0,00256 & & & & & & & & & \\
\hline & 2 & 0,00454 & 0,00453 & 0,00454 & 0 & & & & & & & & \\
\hline & 3 & 0,00649 & 0,00649 & 0,0065 & 0 & 0 & & & & & & & \\
\hline & 4 & 0,00649 & 0,00649 & 0,0065 & 0 & 0 & 1 & & & & & & \\
\hline & 5 & 0,00457 & 0,00457 & 0,00458 & 0 & 0 & 0 & 0 & & & & & \\
\hline & 6 & 0,00259 & 0,00259 & 0,00259 & 0 & 0 & 0 & 0 & 0 & & & & \\
\hline & 7 & 0,00639 & 0,00639 & 0,00639 & 0 & 0 & 0 & 0 & 0 & 0 & & & \\
\hline & 8 & 0,00639 & 0,00639 & 0,00639 & 0 & 0 & 0 & 0 & 0 & 0 & 0,999 & & \\
\hline & 9 & 0,00718 & 0,00717 & 0,00718 & 0 & 0 & 0 & 0 & 0 & 0 & 0 & 0 & \\
\hline & 10 & 0,00735 & 0,00735 & 0,00735 & 0 & 0 & 0 & 0 & 0 & 0 & 0 & 0 & 0 \\
\hline \multirow{10}{*}{256} & 1 & 0,00473 & 0,00473 & 0,00474 & & & & & & & & & \\
\hline & 2 & 0,00902 & 0,00901 & 0,00902 & 0 & & & & & & & & \\
\hline & 3 & 0,01193 & 0,01193 & 0,01194 & 0 & 0 & & & & & & & \\
\hline & 4 & 0,01193 & 0,01193 & 0,01194 & 0 & 0 & 1 & & & & & & \\
\hline & 5 & 0,00905 & 0,00905 & 0,00906 & 0 & 0 & 0 & 0 & & & & & \\
\hline & 6 & 0,00478 & 0,00477 & 0,00478 & 0 & 0 & 0 & 0 & 0 & & & & \\
\hline & 7 & 0,01293 & 0,01293 & 0,01293 & 0 & 0 & 0 & 0 & 0 & 0 & & & \\
\hline & 8 & 0,01294 & 0,01293 & 0,01294 & 0 & 0 & 0 & 0 & 0 & 0 & 0 & & \\
\hline & 9 & 0,01261 & 0,01261 & 0,01261 & 0 & 0 & 0 & 0 & 0 & 0 & 0 & 0 & \\
\hline & 10 & 0,01278 & 0,01278 & 0,01278 & 0 & 0 & 0 & 0 & 0 & 0 & 0 & 0 & 0 \\
\hline \multirow{10}{*}{409} & 1 & 0,00734 & 0,00734 & 0,00734 & & & & & & & & & \\
\hline & 2 & 0,01468 & 0,01468 & 0,01468 & 0 & & & & & & & & \\
\hline & 3 & 0,01793 & 0,01793 & 0,01794 & 0 & 0 & & & & & & & \\
\hline & 4 & 0,01793 & 0,01793 & 0,01794 & 0 & 0 & 1 & & & & & & \\
\hline & 5 & 0,01472 & 0,01472 & 0,01472 & 0 & 0 & 0 & 0 & & & & & \\
\hline & 6 & 0,00738 & 0,00737 & 0,00738 & 0 & 0 & 0 & 0 & 0 & & & & \\
\hline & 7 & 0,02102 & 0,02102 & 0,02102 & 0 & 0 & 0 & 0 & 0 & 0 & & & \\
\hline & 8 & 0,02102 & 0,02102 & 0,02103 & 0 & 0 & 0 & 0 & 0 & 0 & 0,989 & & \\
\hline & 9 & 0,01932 & 0,01932 & 0,01932 & 0 & 0 & 0 & 0 & 0 & 0 & 0 & 0 & \\
\hline & 10 & 0,0195 & 0,0195 & 0,0195 & 0 & 0 & 0 & 0 & 0 & 0 & 0 & 0 & 0 \\
\hline \multirow{7}{*}{512} & 1 & 0,00909 & 0,00908 & 0,00909 & & & & & & & & & \\
\hline & 2 & 0,01668 & 0,01668 & 0,01668 & 0 & & & & & & & & \\
\hline & 3 & 0,02149 & 0,02149 & 0,0215 & 0 & 0 & & & & & & & \\
\hline & 4 & 0,02149 & 0,02149 & 0,0215 & 0 & 0 & 1 & & & & & & \\
\hline & 5 & 0,01672 & 0,01672 & 0,01672 & 0 & 0 & 0 & 0 & & & & & \\
\hline & 6 & 0,00912 & 0,00912 & 0,00912 & 0 & 0 & 0 & 0 & 0 & & & & \\
\hline & 7 & 0,02598 & 0,02597 & 0,02598 & 0 & 0 & 0 & 0 & 0 & 0 & & & \\
\hline
\end{tabular}

Continua na próxima página 
Tabela 31 - Continuação da página anterior

\begin{tabular}{|c|c|c|c|c|c|c|c|c|c|c|c|c|c|}
\hline \multirow{2}{*}{\multicolumn{2}{|c|}{ TM/Mód. }} & \multirow{2}{*}{$2^{\mathrm{o}} \mathrm{Q}$} & \multirow{2}{*}{$1^{\mathrm{o}} \mathrm{Q}$} & \multirow{2}{*}{$3^{\mathrm{o}} \mathrm{Q}$} & \multicolumn{9}{|c|}{ Valor-p das Comparações Múltiplas } \\
\hline & & & & & 69 & 128 & 256 & 409 & 512 & 768 & 1024 & 1280 & 1500 \\
\hline & 8 & 0,02598 & 0,02597 & 0,02598 & 0 & 0 & 0 & 0 & 0 & 0 & 0,991 & & \\
\hline & 9 & 0,02195 & 0,02195 & 0,02195 & 0 & 0 & 0 & 0 & 0 & 0 & 0 & 0 & \\
\hline & 10 & 0,02211 & 0,02211 & 0,02211 & 0 & 0 & 0 & 0 & 0 & 0 & 0 & 0 & 0 \\
\hline \multirow{10}{*}{768} & 1 & 0,01344 & 0,01343 & 0,01344 & & & & & & & & & \\
\hline & 2 & 0,01811 & 0,01811 & 0,01811 & 0 & & & & & & & & \\
\hline & 3 & 0,02401 & 0,024 & 0,02401 & 0 & 0 & & & & & & & \\
\hline & 4 & 0,02401 & 0,024 & 0,02401 & 0 & 0 & 1 & & & & & & \\
\hline & 5 & 0,01815 & 0,01815 & 0,01815 & 0 & 0 & 0 & 0 & & & & & \\
\hline & 6 & 0,01347 & 0,01347 & 0,01347 & 0 & 0 & 0 & 0 & 0 & & & & \\
\hline & 7 & 0,03903 & 0,03903 & 0,03903 & 0 & 0 & 0 & 0 & 0 & 0 & & & \\
\hline & 8 & 0,03903 & 0,03903 & 0,03903 & 0 & 0 & 0 & 0 & 0 & 0 & 0,954 & & \\
\hline & 9 & 0,02338 & 0,02338 & 0,02339 & 0 & 0 & 0 & 0 & 0 & 0 & 0 & 0 & \\
\hline & 10 & 0,02354 & 0,02354 & 0,02354 & 0 & 0 & 0 & 0 & 0 & 0 & 0 & 0 & 0 \\
\hline \multirow{10}{*}{1024} & 1 & 0,01779 & 0,01779 & 0,01779 & & & & & & & & & \\
\hline & 2 & 0,02523 & 0,02523 & 0,02523 & 0 & & & & & & & & \\
\hline & 3 & 0,0305 & 0,0305 & 0,0305 & 0 & 0 & & & & & & & \\
\hline & 4 & 0,0305 & 0,0305 & 0,0305 & 0 & 0 & 1 & & & & & & \\
\hline & 5 & 0,02527 & 0,02527 & 0,02527 & 0 & 0 & 0 & 0 & & & & & \\
\hline & 6 & 0,01782 & 0,01782 & 0,01783 & 0 & 0 & 0 & 0 & 0 & & & & \\
\hline & 7 & 0,05209 & 0,05209 & 0,05209 & 0 & 0 & 0 & 0 & 0 & 0 & & & \\
\hline & 8 & 0,05209 & 0,05209 & 0,05209 & 0 & 0 & 0 & 0 & 0 & 0 & 0,94 & & \\
\hline & 9 & 0,0305 & 0,0305 & 0,03051 & 0 & 0 & 0 & 0 & 0 & 0 & 0 & 0 & \\
\hline & 10 & 0,03066 & 0,03066 & 0,03066 & 0 & 0 & 0 & 0 & 0 & 0 & 0 & 0 & 0 \\
\hline \multirow{10}{*}{1280} & 1 & 0,02214 & 0,02214 & 0,02214 & & & & & & & & & \\
\hline & 2 & 0,03034 & 0,03034 & 0,03035 & 0 & & & & & & & & \\
\hline & 3 & 0,03511 & 0,03511 & 0,03511 & 0 & 0 & & & & & & & \\
\hline & 4 & 0,03511 & 0,03511 & 0,03511 & 0 & 0 & 1 & & & & & & \\
\hline & 5 & 0,03038 & 0,03038 & 0,03038 & 0 & 0 & 0 & 0 & & & & & \\
\hline & 6 & 0,02218 & 0,02217 & 0,02218 & 0 & 0 & 0 & 0 & 0 & & & & \\
\hline & 7 & 0,06514 & 0,06514 & 0,06514 & 0 & 0 & 0 & 0 & 0 & 0 & & & \\
\hline & 8 & 0,06514 & 0,06514 & 0,06515 & 0 & 0 & 0 & 0 & 0 & 0 & 0,932 & & \\
\hline & 9 & 0,03562 & 0,03561 & 0,03562 & 0 & 0 & 0 & 0 & 0 & 0 & 0 & 0 & \\
\hline & 10 & 0,03578 & 0,03577 & 0,03578 & 0 & 0 & 0 & 0 & 0 & 0 & 0 & 0 & 0 \\
\hline \multirow{9}{*}{1500} & 1 & 0,02589 & 0,02588 & 0,02589 & & & & & & & & & \\
\hline & 2 & 0,03438 & 0,03438 & 0,03439 & 0 & & & & & & & & \\
\hline & 3 & 0,03898 & 0,03898 & 0,03898 & 0 & 0 & & & & & & & \\
\hline & 4 & 0,03898 & 0,03898 & 0,03898 & 0 & 0 & 1 & & & & & & \\
\hline & 5 & 0,03442 & 0,03442 & 0,03442 & 0 & 0 & 0 & 0 & & & & & \\
\hline & 6 & 0,02592 & 0,02592 & 0,02592 & 0 & 0 & 0 & 0 & 0 & & & & \\
\hline & 7 & 0,07654 & 0,07653 & 0,07654 & 0 & 0 & 0 & 0 & 0 & 0 & & & \\
\hline & 8 & 0,07654 & 0,07653 & 0,07654 & 0 & 0 & 0 & 0 & 0 & 0 & 0,975 & & \\
\hline & 9 & 0,03963 & 0,03963 & 0,03963 & 0 & 0 & 0 & 0 & 0 & 0 & 0 & 0 & \\
\hline
\end{tabular}


Tabela 31 - Continuação da página anterior

\begin{tabular}{|c|c|c|c|c|c|c|c|c|c|c|c|c|c|}
\hline \multirow{2}{*}{\multicolumn{2}{|c|}{ TM/Mód. }} & \multirow{2}{*}{$2^{\circ} \mathrm{Q}$} & \multirow{2}{*}{$1^{\circ} \mathrm{Q}$} & \multirow{2}{*}{$3^{\circ} \mathrm{Q}$} & \multicolumn{9}{|c|}{ Valor-p das Comparações Múltiplas } \\
\hline & & & & & 69 & 128 & 256 & 409 & 512 & 768 & 1024 & 1280 & 1500 \\
\hline & 10 & 0,03999 & 0,03999 & 0,03999 & 0 & 0 & 0 & 0 & 0 & 0 & 0 & 0 & 0 \\
\hline \multirow{10}{*}{1518} & 1 & 0,02619 & 0,02619 & 0,02619 & & & & & & & & & \\
\hline & 2 & 0,0344 & 0,0344 & 0,0344 & 0 & & & & & & & & \\
\hline & 3 & 0,03948 & 0,03948 & 0,03948 & 0 & 0 & & & & & & & \\
\hline & 4 & 0,03948 & 0,03948 & 0,03948 & 0 & 0 & 1 & & & & & & \\
\hline & 5 & 0,03444 & 0,03444 & 0,03444 & 0 & 0 & 0 & 0 & & & & & \\
\hline & 6 & 0,02623 & 0,02623 & 0,02623 & 0 & 0 & 0 & 0 & 0 & & & & \\
\hline & 7 & 0,07738 & 0,07737 & 0,07738 & 0 & 0 & 0 & 0 & 0 & 0 & & & \\
\hline & 8 & 0,07738 & 0,07738 & 0,07739 & 0 & 0 & 0 & 0 & 0 & 0 & 0 & & \\
\hline & 9 & 0,03965 & 0,03965 & 0,03965 & 0 & 0 & 0 & 0 & 0 & 0 & 0 & 0 & \\
\hline & 10 & 0,04002 & 0,04002 & 0,04002 & 0 & 0 & 0 & 0 & 0 & 0 & 0 & 0 & 0 \\
\hline
\end{tabular}




\section{Tabelas Referentes ao TT entre os TM, Estratificadas pela Soma dos Módulos 2}

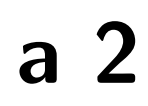

Tabela 32: Descrição do tempo de transferência (ms) entre os tamanhos da mensagem estratificada pela soma dos módulos 2 a 2

\begin{tabular}{ccccccccccc}
\hline Módulos/TM & Média & D.P. & C.V. & Mín. & $\mathbf{1}^{\mathbf{o}} \mathbf{Q}$ & $\mathbf{2}^{\mathbf{o}} \mathbf{Q}$ & $\mathbf{3}^{\mathbf{o}} \mathbf{Q}$ & Máx. & Amplitude \\
\hline 69 & 0,00312 & $4,40 \times 10-6$ & 0,14121 & 0,00311 & 0,00311 & 0,00312 & 0,00312 & 0,00312 & $1,76 \times 10-5$ \\
& 128 & 0,00512 & $4,50 \times 10-6$ & 0,08796 & 0,00511 & 0,00511 & 0,00512 & 0,00512 & 0,00512 & $1,73 \times 10-5$ \\
& 256 & 0,00947 & $4,30 \times 10-6$ & 0,04542 & 0,00946 & 0,00946 & 0,00947 & 0,00947 & 0,00948 & $1,78 \times 10-5$ \\
& 409 & 0,01468 & $4,30 \times 10-6$ & 0,02928 & 0,01467 & 0,01468 & 0,01468 & 0,01469 & 0,01469 & $1,70 \times 10-5$ \\
M1 + M1 & 512 & 0,01817 & $4,30 \times 10-6$ & 0,02366 & 0,01816 & 0,01817 & 0,01817 & 0,01818 & 0,01818 & $1,75 \times 10-5$ \\
& 768 & 0,02687 & $4,40 \times 10-6$ & 0,01637 & 0,02686 & 0,02687 & 0,02687 & 0,02687 & 0,02688 & $1,82 \times 10-5$ \\
& 1024 & 0,03558 & $4,50 \times 10-6$ & 0,01265 & 0,03557 & 0,03558 & 0,03558 & 0,03558 & 0,03559 & $1,79 \times 10-5$ \\
& 1280 & 0,04428 & $4,20 \times 10-6$ & 0,00948 & 0,04427 & 0,04428 & 0,04429 & 0,04429 & 0,04429 & $1,77 \times 10-5$ \\
& 1500 & 0,05177 & $4,40 \times 10-6$ & 0,0085 & 0,05176 & 0,05177 & 0,05177 & 0,05178 & 0,05178 & $1,75 \times 10-5$ \\
& 1518 & 0,05238 & $4,40 \times 10-6$ & 0,0084 & 0,05237 & 0,05238 & 0,05238 & 0,05238 & 0,05239 & $1,72 \times 10-5$ \\
\hline \multirow{5}{*}{ M2 + M2 } & 512 & 0,00494 & $4,90 \times 10-6$ & 0,09917 & 0,00493 & 0,00494 & 0,00494 & 0,00495 & 0,00495 & $1,79 \times 10-5$ \\
& 128 & 0,00907 & $4,90 \times 10-6$ & 0,05403 & 0,00906 & 0,00907 & 0,00907 & 0,00907 & 0,00908 & $1,76 \times 10-5$ \\
& 256 & 0,01803 & $4,90 \times 10-6$ & 0,02718 & 0,01802 & 0,01803 & 0,01803 & 0,01803 & 0,01804 & $1,73 \times 10-5$ \\
& 409 & 0,02936 & $4,90 \times 10-6$ & 0,01669 & 0,02935 & 0,02935 & 0,02936 & 0,02936 & 0,02937 & $1,69 \times 10-5$ \\
& 1024 & 0,05046 & $4,90 \times 10-6$ & 0,00971 & 0,05045 & 0,05046 & 0,05046 & 0,05047 & 0,05047 & $1,72 \times 10-5$ \\
& 1280 & 0,06069 & $4,90 \times 10-6$ & 0,00807 & 0,06068 & 0,06068 & 0,06069 & 0,06069 & 0,06069 & $1,75 \times 10-5$ \\
& 1500 & 0,06877 & $5,10 \times 10-6$ & 0,00742 & 0,06876 & 0,06876 & 0,06877 & 0,06877 & 0,06877 & $1,77 \times 10-5$ \\
& 1518 & 0,0688 & $4,80 \times 10-6$ & 0,00698 & 0,06879 & 0,06879 & 0,0688 & 0,0688 & 0,06881 & $1,74 \times 10-5$ \\
\hline \multirow{4}{*}{ M3 + M3 } & 69 & 0,00742 & $5,00 \times 10-6$ & 0,06739 & 0,00741 & 0,00741 & 0,00742 & 0,00742 & 0,00743 & $1,73 \times 10-5$ \\
& 128 & 0,01299 & $5,20 \times 10-6$ & 0,04004 & 0,01298 & 0,01298 & 0,01299 & 0,01299 & 0,013 & $1,75 \times 10-5$ \\
& 256 & 0,02387 & $5,20 \times 10-6$ & 0,02179 & 0,02386 & 0,02386 & 0,02387 & 0,02387 & 0,02388 & $1,78 \times 10-5$ \\
\hline
\end{tabular}


Tabela 32 - Continuação da página anterior

\begin{tabular}{|c|c|c|c|c|c|c|c|c|c|c|}
\hline Módulos & $/ \mathrm{TM}$ & Média & D.P. & C.V. & Mín. & $1^{\circ} \mathrm{Q}$ & $2^{\circ} \mathrm{Q}$ & $3^{\circ} \mathrm{Q}$ & Máx. & Amplitude \\
\hline & 409 & 0,03587 & $5,00 \times 10-6$ & 0,01394 & 0,03586 & 0,03586 & 0,03587 & 0,03587 & 0,03588 & $1,77 \times 10-5$ \\
\hline & 512 & 0,04299 & $5,20 \times 10-6$ & 0,0121 & 0,04298 & 0,04298 & 0,04299 & 0,04299 & 0,043 & $1,77 \times 10-5$ \\
\hline & 768 & 0,04801 & $5,00 \times 10-6$ & 0,01041 & 0,048 & 0,04801 & 0,04801 & 0,04802 & 0,04802 & $1,78 \times 10-5$ \\
\hline & 1024 & 0,061 & $5,10 \times 10-6$ & 0,00836 & 0,06099 & 0,061 & 0,061 & 0,06101 & 0,06101 & $1,70 \times 10-5$ \\
\hline & 1280 & 0,07022 & $5,20 \times 10-6$ & 0,00741 & 0,07021 & 0,07021 & 0,07022 & 0,07022 & 0,07023 & $1,77 \times 10-5$ \\
\hline & 1500 & 0,07796 & $5,10 \times 10-6$ & 0,00654 & 0,07795 & 0,07796 & 0,07796 & 0,07797 & 0,07797 & $1,74 \times 10-5$ \\
\hline & 1518 & 0,07896 & $5,10 \times 10-6$ & 0,00646 & 0,07895 & 0,07895 & 0,07896 & 0,07896 & 0,07896 & $1,68 \times 10-5$ \\
\hline \multirow{10}{*}{$\mathrm{M} 4+\mathrm{M} 4$} & 69 & 0,00742 & $5,10 \times 10-6$ & 0,06874 & 0,00741 & 0,00741 & 0,00742 & 0,00742 & 0,00743 & $1,77 \times 10-5$ \\
\hline & 128 & 0,01299 & $5,10 \times 10-6$ & 0,03927 & 0,01298 & 0,01298 & 0,01299 & 0,01299 & 0,013 & $1,80 \times 10-5$ \\
\hline & 256 & 0,02387 & $5,10 \times 10-6$ & 0,02137 & 0,02386 & 0,02386 & 0,02387 & 0,02387 & 0,02388 & $1,75 \times 10-5$ \\
\hline & 409 & 0,03587 & $5,10 \times 10-6$ & 0,01422 & 0,03586 & 0,03586 & 0,03587 & 0,03587 & 0,03588 & $1,76 \times 10-5$ \\
\hline & 512 & 0,04299 & $5,10 \times 10-6$ & 0,01186 & 0,04298 & 0,04298 & 0,04299 & 0,04299 & 0,043 & $1,75 \times 10-5$ \\
\hline & 768 & 0,04801 & $5,20 \times 10-6$ & 0,01083 & 0,048 & 0,04801 & 0,04801 & 0,04802 & 0,04802 & $1,77 \times 10-5$ \\
\hline & 1024 & 0,061 & $5,10 \times 10-6$ & 0,00836 & 0,06099 & 0,061 & 0,061 & 0,06101 & 0,06101 & $1,73 \times 10-5$ \\
\hline & 1280 & 0,07022 & $5,10 \times 10-6$ & 0,00726 & 0,07021 & 0,07021 & 0,07022 & 0,07022 & 0,07023 & $1,74 \times 10-5$ \\
\hline & 1500 & 0,07796 & $5,00 \times 10-6$ & 0,00641 & 0,07795 & 0,07796 & 0,07796 & 0,07797 & 0,07797 & $1,72 \times 10-5$ \\
\hline & 1518 & 0,07896 & $5, \times 10-6$ & 0,00646 & 0,07895 & 0,07895 & 0,07896 & 0,07896 & 0,07896 & $1,77 \times 10-5$ \\
\hline \multirow{10}{*}{$\mathrm{M} 5+\mathrm{M} 5$} & 69 & 0,00502 & $5,00 \times 10-6$ & 0,09962 & 0,00501 & 0,00501 & 0,00502 & 0,00502 & 0,00503 & $1,74 \times 10-5$ \\
\hline & 128 & 0,00915 & $5,20 \times 10-6$ & 0,05685 & 0,00914 & 0,00914 & 0,00915 & 0,00915 & 0,00916 & $1,74 \times 10-5$ \\
\hline & 256 & 0,01811 & $5,10 \times 10-6$ & 0,02816 & 0,0181 & 0,0181 & 0,01811 & 0,01811 & 0,01812 & $1,76 \times 10-5$ \\
\hline & 409 & 0,02944 & $5,00 \times 10-6$ & 0,01699 & 0,02943 & 0,02943 & 0,02944 & 0,02944 & 0,02944 & $1,79 \times 10-5$ \\
\hline & 512 & 0,03344 & $5,10 \times 10-6$ & 0,01525 & 0,03343 & 0,03343 & 0,03344 & 0,03344 & 0,03344 & $1,74 \times 10-5$ \\
\hline & 768 & 0,0363 & $5,20 \times 10-6$ & 0,01433 & 0,03629 & 0,03629 & 0,0363 & 0,0363 & 0,03631 & $1,72 \times 10-5$ \\
\hline & 1024 & 0,05054 & $5,10 \times 10-6$ & 0,01009 & 0,05053 & 0,05054 & 0,05054 & 0,05054 & 0,05055 & $1,80 \times 10-5$ \\
\hline & 1280 & 0,06076 & $5,20 \times 10-6$ & 0,00856 & 0,06075 & 0,06076 & 0,06076 & 0,06077 & 0,06077 & $1,72 \times 10-5$ \\
\hline & 1500 & 0,06884 & $5,10 \times 10-6$ & 0,00741 & 0,06883 & 0,06884 & 0,06884 & 0,06885 & 0,06885 & $1,80 \times 10-5$ \\
\hline & 1518 & 0,06888 & $5,10 \times 10-6$ & 0,0074 & 0,06887 & 0,06887 & 0,06888 & 0,06888 & 0,06888 & $1,74 \times 10-5$ \\
\hline \multirow{10}{*}{$\mathrm{M} 6+\mathrm{M} 6$} & 69 & 0,00318 & $4,40 \times 10-6$ & 0,13819 & 0,00317 & 0,00318 & 0,00319 & 0,00319 & 0,00319 & $1,76 \times 10-5$ \\
\hline & 128 & 0,00518 & $4,40 \times 10-6$ & 0,08487 & 0,00517 & 0,00518 & 0,00518 & 0,00519 & 0,00519 & $1,76 \times 10-5$ \\
\hline & 256 & 0,00955 & $4,40 \times 10-6$ & 0,04606 & 0,00954 & 0,00955 & 0,00955 & 0,00956 & 0,00956 & $1,77 \times 10-5$ \\
\hline & 409 & 0,01475 & $4,40 \times 10-6$ & 0,02983 & 0,01474 & 0,01475 & 0,01475 & 0,01476 & 0,01476 & $1,73 \times 10-5$ \\
\hline & 512 & 0,01824 & $4,50 \times 10-6$ & 0,02467 & 0,01823 & 0,01824 & 0,01824 & 0,01824 & 0,01825 & $1,79 \times 10-5$ \\
\hline & 768 & 0,02694 & $4,40 \times 10-6$ & 0,01633 & 0,02693 & 0,02694 & 0,02695 & 0,02695 & 0,02695 & $1,76 \times 10-5$ \\
\hline & 1024 & 0,03565 & $4,40 \times 10-6$ & 0,01234 & 0,03564 & 0,03565 & 0,03565 & 0,03565 & 0,03566 & $1,73 \times 10-5$ \\
\hline & 1280 & 0,04435 & $4,50 \times 10-6$ & 0,01015 & 0,04434 & 0,04435 & 0,04435 & 0,04436 & 0,04436 & $1,72 \times 10-5$ \\
\hline & 1500 & 0,05184 & $4,50 \times 10-6$ & 0,00868 & 0,05183 & 0,05184 & 0,05184 & 0,0184 & 0,05185 & $1,76 \times 10-5$ \\
\hline & 1518 & 0,05246 & $4,50 \times 10-6$ & 0,00858 & 0,05245 & 0,05246 & 0,05247 & 0,05247 & 0,05247 & $1,77 \times 10-5$ \\
\hline \multirow{6}{*}{$\mathrm{M} 7+\mathrm{M} 8$} & 69 & 0,00702 & $3,10 \times 10-6$ & 0,04415 & 0,00701 & 0,00702 & 0,00702 & 0,00702 & 0,00703 & $1,59 \times 10-5$ \\
\hline & 128 & 0,01278 & $3,20 \times 10-6$ & 0,02504 & 0,01277 & 0,01278 & 0,01278 & 0,01278 & 0,01279 & $1,53 \times 10-5$ \\
\hline & 256 & 0,02586 & $3,10 \times 10-6$ & 0,01199 & 0,02585 & 0,02586 & 0,02586 & 0,02586 & 0,02587 & $1,54 \times 10-5$ \\
\hline & 409 & 0,04205 & $3,20 \times 10-6$ & 0,00761 & 0,04204 & 0,04204 & 0,04205 & 0,04205 & 0,04205 & $1,56 \times 10-5$ \\
\hline & 512 & 0,05195 & $3,10 \times 10-6$ & 0,00597 & 0,05194 & 0,05195 & 0,05195 & 0,05195 & 0,05196 & $1,57 \times 10-5$ \\
\hline & 768 & 0,07806 & $3,10 \times 10-6$ & 0,00397 & 0,07805 & 0,07806 & 0,07806 & 0,07806 & 0,07807 & $1,62 \times 10-5$ \\
\hline
\end{tabular}


Tabela 32 - Continuação da página anterior

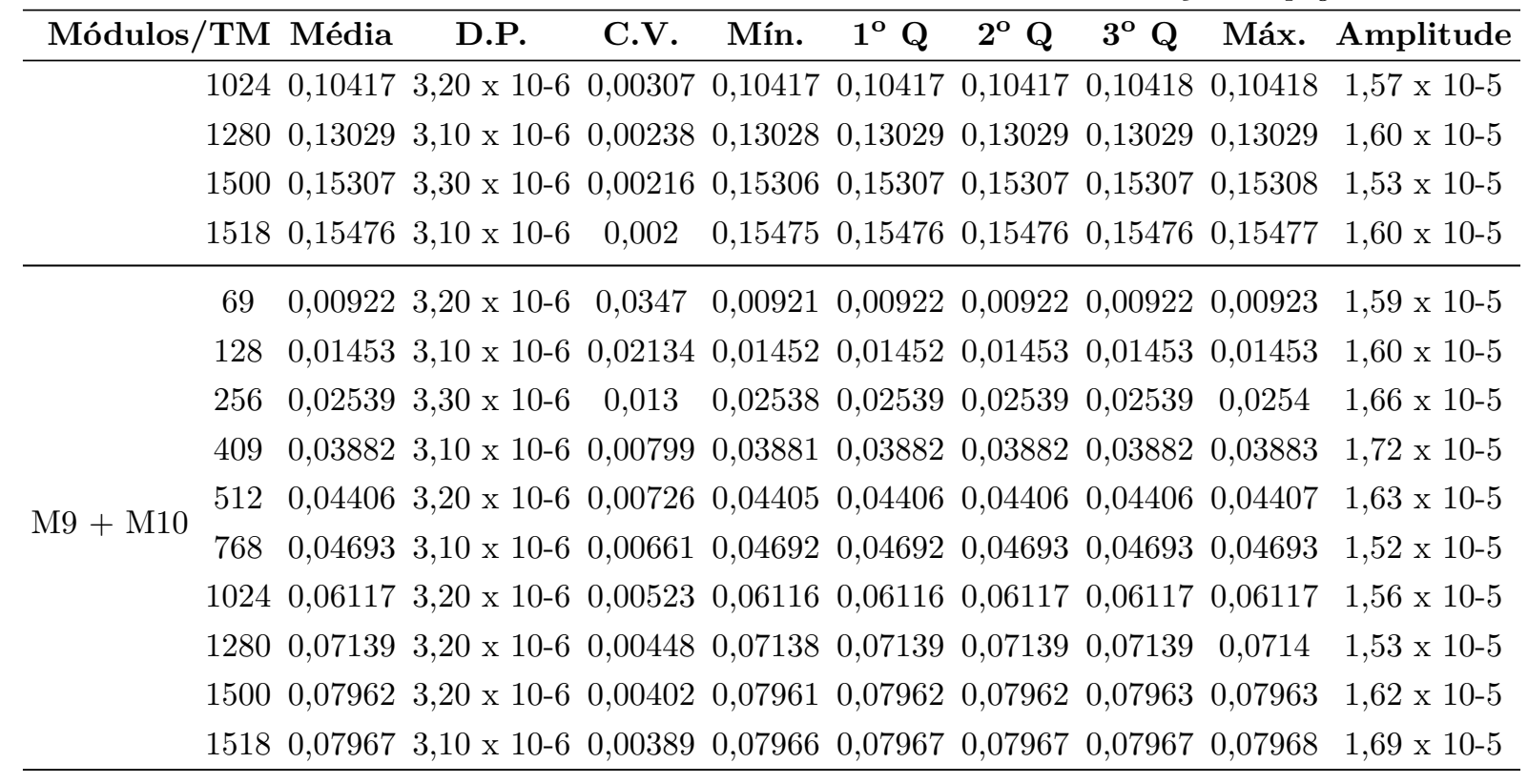

Tabela 33: Comparação do tempo de transferência entre os tamanhos da mensagem, estratificada pela soma dos módulos 2 a 2

\begin{tabular}{|c|c|c|c|c|c|c|c|c|c|c|c|c|c|}
\hline \multirow{2}{*}{ Módulos/ } & \multirow{2}{*}{ /TM } & \multirow{2}{*}{$2^{\mathrm{o}} \mathrm{Q}$} & \multirow{2}{*}{$1^{\circ} \mathrm{Q}$} & \multirow{2}{*}{$3^{\circ} \mathrm{Q}$} & \multicolumn{9}{|c|}{ Valor-p das Comparações Múltiplas } \\
\hline & & & & & 69 & 128 & 256 & 409 & 512 & 768 & 1024 & 1280 & 1500 \\
\hline \multirow{10}{*}{$\mathrm{M} 1+\mathrm{M} 1$} & 69 & 0,00312 & 0,00311 & 0,00312 & & & & & & & & & \\
\hline & 128 & 0,00512 & 0,00511 & 0,00512 & 0 & & & & & & & & \\
\hline & 256 & 0,00947 & 0,00946 & 0,00947 & 0 & 0 & & & & & & & \\
\hline & 409 & 0,01468 & 0,01468 & 0,01469 & 0 & 0 & 0 & & & & & & \\
\hline & 512 & 0,01817 & 0,01817 & 0,01818 & 0 & 0 & 0 & 0 & & & & & \\
\hline & 768 & 0,02687 & 0,02687 & 0,02687 & 0 & 0 & 0 & 0 & 0 & & & & \\
\hline & 1024 & 0,03558 & 0,03558 & 0,03558 & 0 & 0 & 0 & 0 & 0 & 0 & & & \\
\hline & 1280 & 0,04429 & 0,04428 & 0,04429 & 0 & 0 & 0 & 0 & 0 & 0 & 0 & & \\
\hline & 1500 & 0,05177 & 0,05177 & 0,05178 & 0 & 0 & 0 & 0 & 0 & 0 & 0 & 0 & \\
\hline & 1518 & 0,05238 & 0,05238 & 0,05238 & 0 & 0 & 0 & 0 & 0 & 0 & 0 & 0 & 0 \\
\hline \multirow{10}{*}{$\mathrm{M} 2+\mathrm{M} 2$} & 69 & 0,00494 & 0,00494 & 0,00495 & & & & & & & & & \\
\hline & 128 & 0,00907 & 0,00907 & 0,00907 & 0 & & & & & & & & \\
\hline & 256 & 0,01803 & 0,01803 & 0,01803 & 0 & 0 & & & & & & & \\
\hline & 409 & 0,02936 & 0,02935 & 0,02936 & 0 & 0 & 0 & & & & & & \\
\hline & 512 & 0,03336 & 0,03335 & 0,03336 & 0 & 0 & 0 & 0 & & & & & \\
\hline & 768 & 0,03622 & 0,03622 & 0,03623 & 0 & 0 & 0 & 0 & 0 & & & & \\
\hline & 1024 & 0,05046 & 0,05046 & 0,05047 & 0 & 0 & 0 & 0 & 0 & 0 & & & \\
\hline & 1280 & 0,06069 & 0,06068 & 0,06069 & 0 & 0 & 0 & 0 & 0 & 0 & 0 & & \\
\hline & 1500 & 0,06877 & 0,06876 & 0,06877 & 0 & 0 & 0 & 0 & 0 & 0 & 0 & 0 & \\
\hline & 1518 & 0,0688 & 0,06879 & 0,0688 & 0 & 0 & 0 & 0 & 0 & 0 & 0 & 0 & 0 \\
\hline \multirow{3}{*}{$\mathrm{M} 3+\mathrm{M} 3$} & 69 & 0,00742 & 0,00741 & 0,00742 & & & & & & & & & \\
\hline & 128 & 0,01299 & 0,01298 & 0,01299 & 0 & & & & & & & & \\
\hline & 256 & 0,02387 & 0,02386 & 0,02387 & 0 & 0 & & & & & & & \\
\hline
\end{tabular}


Tabela 33 - Continuação da página anterior

\begin{tabular}{|c|c|c|c|c|c|c|c|c|c|c|c|c|}
\hline \multirow{2}{*}{ Módulos/TM } & \multirow{2}{*}{$2^{\mathrm{O}} \mathrm{Q}$} & \multirow{2}{*}{$1^{\circ} \mathrm{Q}$} & \multirow{2}{*}{$3^{\circ} \mathrm{Q}$} & \multicolumn{9}{|c|}{ Valor-p das Comparações Múltiplas } \\
\hline & & & & 69 & 128 & 256 & 409 & 512 & 768 & 1024 & 1280 & 1500 \\
\hline 409 & 0,03587 & 0,03586 & 0,03587 & 0 & 0 & 0 & & & & & & \\
\hline 512 & 0,04299 & 0,04298 & 0,04299 & 0 & 0 & 0 & 0 & & & & & \\
\hline 768 & 0,04801 & 0,04801 & 0,04802 & 0 & 0 & 0 & 0 & 0 & & & & \\
\hline 1024 & 0,061 & 0,061 & 0,06101 & 0 & 0 & 0 & 0 & 0 & 0 & & & \\
\hline 1280 & 0,07022 & 0,07021 & 0,07022 & 0 & 0 & 0 & 0 & 0 & 0 & 0 & & \\
\hline 1500 & 0,07796 & 0,07796 & 0,07797 & 0 & 0 & 0 & 0 & 0 & 0 & 0 & 0 & \\
\hline 1518 & 0,07896 & 0,07895 & 0,07896 & 0 & 0 & 0 & 0 & 0 & 0 & 0 & 0 & 0 \\
\hline
\end{tabular}

\begin{tabular}{|c|c|c|c|c|c|c|c|c|c|c|c|c|c|}
\hline \multirow{10}{*}{$\mathrm{M} 4+\mathrm{M} 4$} & 69 & 0,00742 & 0,00741 & 0,00742 & & & & & & & & & \\
\hline & 128 & 0,01299 & 0,01298 & 0,01299 & 0 & & & & & & & & \\
\hline & 256 & 0,02387 & 0,02386 & 0,02387 & 0 & 0 & & & & & & & \\
\hline & 409 & 0,03587 & 0,03586 & 0,03587 & 0 & 0 & 0 & & & & & & \\
\hline & 512 & 0,04299 & 0,04298 & 0,04299 & 0 & 0 & 0 & 0 & & & & & \\
\hline & 768 & 0,04801 & 0,04801 & 0,04802 & 0 & 0 & 0 & 0 & 0 & & & & \\
\hline & 1024 & 0,061 & 0,061 & 0,06101 & 0 & 0 & 0 & 0 & 0 & 0 & & & \\
\hline & 1280 & 0,07022 & 0,07021 & 0,07022 & 0 & 0 & 0 & 0 & 0 & 0 & 0 & & \\
\hline & 1500 & 0,07796 & 0,07796 & 0,07797 & 0 & 0 & 0 & 0 & 0 & 0 & 0 & 0 & \\
\hline & 1518 & 0,07896 & 0,07895 & 0,07896 & 0 & 0 & 0 & 0 & 0 & 0 & 0 & 0 & 0 \\
\hline \multirow{10}{*}{$\mathrm{M} 5+\mathrm{M} 5$} & 69 & 0,00502 & 0,00501 & 0,00502 & & & & & & & & & \\
\hline & 128 & 0,00915 & 0,00914 & 0,00915 & 0 & & & & & & & & \\
\hline & 256 & 0,01811 & 0,0181 & 0,01811 & 0 & 0 & & & & & & & \\
\hline & 409 & 0,02944 & 0,02943 & 0,02944 & 0 & 0 & 0 & & & & & & \\
\hline & 512 & 0,03344 & 0,03343 & 0,03344 & 0 & 0 & 0 & 0 & & & & & \\
\hline & 768 & 0,0363 & 0,03629 & 0,0363 & 0 & 0 & 0 & 0 & 0 & & & & \\
\hline & 1024 & 0,05054 & 0,05054 & 0,05054 & 0 & 0 & 0 & 0 & 0 & 0 & & & \\
\hline & 1280 & 0,06076 & 0,06076 & 0,06077 & 0 & 0 & 0 & 0 & 0 & 0 & 0 & & \\
\hline & 1500 & 0,06884 & 0,06884 & 0,06885 & 0 & 0 & 0 & 0 & 0 & 0 & 0 & 0 & \\
\hline & 1518 & 0,06888 & 0,06887 & 0,06888 & 0 & 0 & 0 & 0 & 0 & 0 & 0 & 0 & 0 \\
\hline
\end{tabular}

\begin{tabular}{|c|c|c|c|c|c|c|c|c|c|c|c|c|c|}
\hline \multirow{10}{*}{$\mathrm{M} 6+\mathrm{M} 6$} & 69 & 0,00319 & 0,00318 & 0,00319 & & & & & & & & & \\
\hline & 128 & 0,00518 & 0,00518 & 0,00519 & 0 & & & & & & & & \\
\hline & 256 & 0,00955 & 0,00955 & 0,00956 & 0 & 0 & & & & & & & \\
\hline & 409 & 0,01475 & 0,01475 & 0,01476 & 0 & 0 & 0 & & & & & & \\
\hline & 512 & 0,01824 & 0,01824 & 0,01824 & 0 & 0 & 0 & 0 & & & & & \\
\hline & 768 & 0,02695 & 0,02694 & 0,02695 & 0 & 0 & 0 & 0 & 0 & & & & \\
\hline & 1024 & 0,03565 & 0,03565 & 0,03565 & 0 & 0 & 0 & 0 & 0 & 0 & & & \\
\hline & 1280 & 0,04435 & 0,04435 & 0,04436 & 0 & 0 & 0 & 0 & 0 & 0 & 0 & & \\
\hline & 1500 & 0,05184 & 0,05184 & 0,05184 & 0 & 0 & 0 & 0 & 0 & 0 & 0 & 0 & \\
\hline & 1518 & 0,05247 & 0,05246 & 0,05247 & 0 & 0 & 0 & 0 & 0 & 0 & 0 & 0 & 0 \\
\hline \multirow{5}{*}{$\mathrm{M} 7+\mathrm{M} 8$} & 69 & 0,00702 & 0,00702 & 0,00702 & & & & & & & & & \\
\hline & 128 & 0,01278 & 0,01278 & 0,01278 & 0 & & & & & & & & \\
\hline & 256 & 0,02586 & 0,02586 & 0,02586 & 0 & 0 & & & & & & & \\
\hline & 409 & 0,04205 & 0,04204 & 0,04205 & 0 & 0 & 0 & & & & & & \\
\hline & 512 & 0,05195 & 0,05195 & 0,05195 & 0 & 0 & 0 & 0 & & & & & \\
\hline
\end{tabular}


Tabela 33 - Continuação da página anterior

\begin{tabular}{|c|c|c|c|c|c|c|c|c|c|c|c|c|c|}
\hline \multirow{2}{*}{\multicolumn{2}{|c|}{ Módulos/TM }} & \multirow{2}{*}{$2^{\circ} \mathrm{Q}$} & \multirow{2}{*}{$1^{\circ} \mathrm{Q}$} & \multirow{2}{*}{$3^{\circ} \mathrm{Q}$} & \multicolumn{9}{|c|}{ Valor-p das Comparações Múltiplas } \\
\hline & & & & & 69 & 128 & 256 & 409 & 512 & 768 & 1024 & 1280 & 1500 \\
\hline & 768 & 0,07806 & 0,07806 & 0,07806 & 0 & 0 & 0 & 0 & 0 & & & & \\
\hline & 1024 & 0,10417 & 0,10417 & 0,10418 & 0 & 0 & 0 & 0 & 0 & 0 & & & \\
\hline & 1280 & 0,13029 & 0,13029 & 0,13029 & 0 & 0 & 0 & 0 & 0 & 0 & 0 & & \\
\hline & 1500 & 0,15307 & 0,15307 & 0,15307 & 0 & 0 & 0 & 0 & 0 & 0 & 0 & 0 & \\
\hline & 1518 & 0,15476 & 0,15476 & 0,15476 & 0 & 0 & 0 & 0 & 0 & 0 & 0 & 0 & 0 \\
\hline \multirow{10}{*}{$\mathrm{M} 9+\mathrm{M} 10$} & 69 & 0,00922 & 0,00922 & 0,00922 & & & & & & & & & \\
\hline & 128 & 0,01453 & 0,01452 & 0,01453 & 0 & & & & & & & & \\
\hline & 256 & 0,02539 & 0,02539 & 0,02539 & 0 & 0 & & & & & & & \\
\hline & 409 & 0,03882 & 0,03882 & 0,03882 & 0 & 0 & 0 & & & & & & \\
\hline & 512 & 0,04406 & 0,04406 & 0,04406 & 0 & 0 & 0 & 0 & & & & & \\
\hline & 768 & 0,04693 & 0,04692 & 0,04693 & 0 & 0 & 0 & 0 & 0 & & & & \\
\hline & 1024 & 0,06117 & 0,06116 & 0,06117 & 0 & 0 & 0 & 0 & 0 & 0 & & & \\
\hline & 1280 & 0,07139 & 0,07139 & 0,07139 & 0 & 0 & 0 & 0 & 0 & 0 & 0 & & \\
\hline & 1500 & 0,07962 & 0,07962 & 0,07963 & 0 & 0 & 0 & 0 & 0 & 0 & 0 & 0 & \\
\hline & 1518 & 0,07967 & 0,07967 & 0,07967 & 0 & 0 & 0 & 0 & 0 & 0 & 0 & 0 & 0 \\
\hline
\end{tabular}




\section{Tabelas Referentes ao TT entre os TM, Estratificadas pela Soma dos Módulos 3}

a 3

Tabela 34: Descrição do tempo de transferência (ms) entre os tamanhos da mensagem estratificada, pela soma dos módulos 3 a 3

\begin{tabular}{|c|c|c|c|c|c|c|c|c|c|c|}
\hline Módulos & /TM & Média & D.P. & C.V. & Mín. & $1^{\circ} \mathrm{Q}$ & $2^{\circ} \mathrm{Q}$ & $3^{\circ} \mathrm{Q}$ & Máx. & Amplitude \\
\hline \multirow{10}{*}{$\mathrm{M} 3+\mathrm{M} 6+\mathrm{M} 9$} & 69 & 0,00981 & $4,10 \times 10-6$ & 0,04181 & 0,00979 & 0,0098 & 0,00981 & 0,00981 & 0,00981 & $2,15 \times 10-5$ \\
\hline & 128 & 0,01626 & $4,00 \times 10-6$ & 0,0246 & 0,01625 & 0,01626 & 0,01626 & 0,01626 & 0,01627 & $2,31 \times 10-5$ \\
\hline & 256 & 0,02932 & $4,10 \times 10-6$ & 0,01398 & 0,02931 & 0,02931 & 0,02932 & 0,02932 & 0,02933 & $2,14 \times 10-5$ \\
\hline & 409 & 0,04463 & $4,00 \times 10-6$ & 0,00896 & 0,04462 & 0,04463 & 0,04463 & 0,04463 & 0,04464 & $2,23 \times 10-5$ \\
\hline & 512 & 0,05257 & $4,10 \times 10-6$ & 0,0078 & 0,05255 & 0,05256 & 0,05257 & 0,05257 & 0,05258 & $2,18 \times 10-5$ \\
\hline & 768 & 0,06086 & $4,10 \times 10-6$ & 0,00674 & $=0,06085$ & 0,06086 & 0,06086 & 0,06086 & 0,06087 & $2,21 \times 10-5$ \\
\hline & 1024 & 0,07883 & $4,00 \times 10-6$ & 0,00507 & 0,07882 & 0,07883 & 0,07883 & 0,07883 & 0,07884 & $2,06 \times 10-5$ \\
\hline & 1280 & 0,0929 & $4,10 \times 10-6$ & 0,00 & 0,09289 & 0,0929 & 0,0929 & 0,0929 & 0,09291 & $2,26 \times 10-5$ \\
\hline & 1500 & 0,10453 & $4,10 \times 10-6$ & 0,00392 & 0,10452 & 0,10453 & 0,10 & 0,10454 & 0,10454 & $2,11 \times 10-5$ \\
\hline & 1518 & 0,10536 & $3,90 \times 10-6$ & 0,0037 & 0,10535 & 0,10536 & 0,10536 & 0,10536 & 0,10537 & $2,04 \times 10-5$ \\
\hline \multirow{10}{*}{$\mathrm{M} 3+\mathrm{M} 7+\mathrm{M} 9$} & 69 & 0,01172 & $4,10 \times 10-6$ & 0,03 & 0,01 & 0,01 & & 0,0 & 0,01173 & $2,27 \times 10-5$ \\
\hline & 128 & 0,02006 & $4,00 \times 10-6$ & 0,01994 & 0,02005 & 0,02006 & 0,02006 & 0,02006 & 0,02007 & $2,17 \times 10-5$ \\
\hline & 256 & 0,03747 & $4,00 \times 10-6$ & 0,01068 & 0,03746 & 0,03746 & 0,03747 & 0,03747 & 0,03748 & $2,16 \times 10-5$ \\
\hline & 409 & 0,05828 & $4,00 \times 10-6$ & 0,00686 & 0,05826 & 0,05827 & 0,05828 & 0,05828 & 0,05829 & $2,30 \times 10-5$ \\
\hline & 512 & 0,06942 & $4,10 \times 10-6$ & 0,00591 & 0,06941 & 0,06942 & 0,06942 & 0,06942 & 0,06943 & $2,32 \times 10-5$ \\
\hline & 768 & 0,08642 & $3,90 \times 10-6$ & 0,00451 & 0,08641 & 0,08642 & 0,08642 & 0,08642 & 0,08643 & $2,22 \times 10-5$ \\
\hline & 1024 & 0,11309 & $4,00 \times 10-6$ & 0,00354 & 0,11308 & 0,11309 & 0,11309 & 0,1131 & 0,1131 & $2,18 \times 10-5$ \\
\hline & 1280 & 0,13 & $4,00 \times 10-6$ & 0,0029 & 0,13 & 0,13 & 0,13 & 0,13587 & 0,13588 & $2,21 \times 10-5$ \\
\hline & 1500 & 0,15515 & $4,00 \times 10-6$ & 0,00258 & 0,15514 & 0,15515 & 0,15515 & 0,15515 & 0,15516 & $2,10 \times 10-5$ \\
\hline & 1518 & 0,1565 & $4,00 \times 10-6$ & 0,00256 & 0,15649 & 0,1565 & 0,1565 & 0,1565 & 0,15651 & $2,13 \times 10-5$ \\
\hline \multirow{3}{*}{$\mathrm{M} 4+\mathrm{M} 6+\mathrm{M} 9$} & 69 & 0,00981 & $4,10 \times 10-6$ & 0,04181 & 0,00979 & 0,0098 & 0,00981 & 0,00981 & 0,00982 & $2,27 \times 10-5$ \\
\hline & 128 & 0,01626 & $4,10 \times 10-6$ & 0,02521 & 0,01625 & 0,01626 & 0,01626 & 0,01626 & 0,01627 & $2,13 \times 10-5$ \\
\hline & 256 & 0,02932 & $4,10 \times 10-6$ & 0,01398 & 0,02931 & 0,02931 & 0,02932 & 0,02932 & 0,02933 & $2,11 \times 10-5$ \\
\hline
\end{tabular}


Tabela 34 - Continuação da página anterior

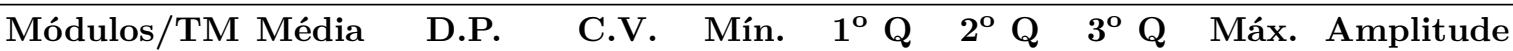
$4090,044634,00 \times 10-60,008960,044620,044630,044630,04463 \quad 0,044642,11 \times 10-5$ $5120,052574,10 \times 10-6 \quad 0,0078 \quad 0,05255 \quad 0,05256 \quad 0,05257 \quad 0,05257 \quad 0,05258 \quad 2,38 \times 10-5$ $768 \quad 0,060864,20 \times 10-6 \quad 0,0069 \quad 0,060850,06086 \quad 0,06086 \quad 0,06086 \quad 0,06087 \quad 2,24 \times 10-5$ $10240,078834,10 \times 10-6 \quad 0,0052 \quad 0,07882 \quad 0,07883 \quad 0,07883 \quad 0,07883 \quad 0,07884 \quad 2,21 \times 10-5$ $1280 \quad 0,0929 \quad 4,10 \times 10-6 \quad 0,00441 \quad 0,09289 \quad 0,0929 \quad 0,0929 \quad 0,0929 \quad 0,09291 \quad 2,17 \times 10-5$ $1500 \quad 0,104534,00 \times 10-60,00383 \quad 0,104520,10453 \quad 0,10453 \quad 0,10454 \quad 0,10454 \quad 2,22 \times 10-5$ $15180,105364,00 \times 10-6 \quad 0,0038 \quad 0,10535 \quad 0,10536 \quad 0,10536 \quad 0,10536 \quad 0,10537 \quad 2,02 \times 10-5$

$690,011724,20 \times 10-60,035830,011710,011720,011720,011730,01173 \quad 2,26 \times 10-5$ $1280,020064,00 \times 10-60,019940,020050,020060,020060,020060,02007 \quad 2,15 \times 10-5$ $2560,037474,10 \times 10-60,010940,037460,03747 \quad 0,03747 \quad 0,03747 \quad 0,03748 \quad 2,16 \times 10-5$ $4090,058284,00 \times 10-60,006860,058260,05827 \quad 0,058280,058280,058292,21 \times 10-5$

$\mathrm{M} 4+\mathrm{M} 7+\mathrm{M} 9$ $5120,069424,00 \times 10-60,005760,069410,069420,069420,06942 \quad 0,06943 \quad 2,24 \times 10-5$ $7680,086424,00 \times 10-60,004630,086410,086420,08642 \quad 0,08642 \quad 0,086432,12 \times 10-5$ $10240,113094,00 \times 10-6 \quad 0,00354 \quad 0,11308 \quad 0,11309 \quad 0,11309 \quad 0,1131 \quad 0,1131 \quad 2,16 \times 10-5$ $12800,135873,90 \times 10-60,002870,135860,13587 \quad 0,13587 \quad 0,13587 \quad 0,13588 \quad 2,23 \times 10-5$ $1500 \quad 0,155154,00 \times 10-60,00258 \quad 0,15514 \quad 0,15515 \quad 0,155150,155150,15516 \quad 2,22 \times 10-5$ $1518 \quad 0,1565 \quad 4,10 \times 10-6 \quad 0,00262 \quad 0,15649 \quad 0,1565 \quad 0,1565 \quad 0,1565 \quad 0,15651 \quad 2,17 \times 10-5$

$69 \quad 0,0086 \quad 4,10 \times 10-6 \quad 0,04765 \quad 0,00859 \quad 0,0086 \quad 0,00861 \quad 0,00861 \quad 0,00861 \quad 2,11 \times 10-5$ $1280,014344,00 \times 10-60,027890,01433 \quad 0,01434 \quad 0,01434 \quad 0,01434 \quad 0,01435 \quad 2,06 \times 10-5$ $2560,026444,00 \times 10-60,015130,026430,02643 \quad 0,02644 \quad 0,02644 \quad 0,02645 \quad 2,03 \times 10-5$ $409 \quad 0,041414,10 \times 10-6 \quad 0,0099 \quad 0,0414 \quad 0,04141 \quad 0,04141 \quad 0,04142 \quad 0,04142 \quad 2,13 \times 10-5$ M5+M6+M9 $512 \quad 0,047794,10 \times 10-6 \quad 0,00858 \quad 0,04778 \quad 0,04779 \quad 0,04779 \quad 0,04779 \quad 0,0478 \quad 2,15 \times 10-5$ $768 \quad 0,055014,20 \times 10-6 \quad 0,00764 \quad 0,05499 \quad 0,055 \quad 0,05501 \quad 0,05501 \quad 0,05501 \quad 2,15 \times 10-5$ $1024 \quad 0,0736 \quad 4,10 \times 10-6 \quad 0,00557 \quad 0,073590,07359 \quad 0,0736 \quad 0,0736 \quad 0,07361 \quad 2,17 \times 10-5$ $12800,088174,20 \times 10-60,004760,088160,08817 \quad 0,08817 \quad 0,088180,08818 \quad 2,25 \times 10-5$ $15000,099974,10 \times 10-6 \quad 0,00410,099960,09997 \quad 0,09997 \quad 0,09998 \quad 0,09998 \quad 2,04 \times 10-5$ $15180,100324,00 \times 10-60,003990,100310,100310,10032 \quad 0,10032 \quad 0,10033 \quad 2,25 \times 10-5$

$690,010524,10 \times 10-60,038960,010510,010520,01052 \quad 0,01053 \quad 0,01053 \quad 2,29 \times 10-5$ $1280,018144,00 \times 10-60,022050,018130,01814 \quad 0,01814 \quad 0,01814 \quad 0,01815 \quad 2,16 \times 10-5$ $256 \quad 0,034593,90 \times 10-6 \quad 0,011280,03458 \quad 0,03459 \quad 0,034590,03459 \quad 0,0346 \quad 2,26 \times 10-5$ $4090,055064,00 \times 10-60,007260,055050,05506 \quad 0,05506 \quad 0,05506 \quad 0,05507 \quad 2,28 \times 10-5$

$\mathrm{M} 5+\mathrm{M} 7+\mathrm{M} 9$ $5120,064644,00 \times 10-60,006190,064630,06464 \quad 0,06464 \quad 0,06465 \quad 0,06465 \quad 2,17 \times 10-5$ $7680,080564,00 \times 10-60,004960,080550,08056 \quad 0,08056 \quad 0,08057 \quad 0,08057 \quad 2,19 \times 10-5$ $10240,107864,00 \times 10-60,003710,107850,10786 \quad 0,107860,107860,10787 \quad 2,20 \times 10-5$ $12800,131144,00 \times 10-60,003050,131130,131140,131140,131140,13115 \quad 2,10 \times 10-5$ $1500 \quad 0,150594,10 \times 10-6 \quad 0,002720,15058 \quad 0,150590,150590,15059 \quad 0,1506 \quad 2,16 \times 10-5$ $15180,151464,00 \times 10-60,002640,151450,15146 \quad 0,15146 \quad 0,15146 \quad 0,15147 \quad 2,18 \times 10-5$

$690,010024,10 \times 10-60,040920,010010,010020,010020,01002 \quad 0,010032,09 \times 10-5$ $1280,016444,10 \times 10-60,024950,016420,01643 \quad 0,01644 \quad 0,01644 \quad 0,01645 \quad 2,16 \times 10-5$ $256 \quad 0,029494,00 \times 10-6 \quad 0,01356 \quad 0,029480,029490,02949 \quad 0,0295 \quad 0,0295 \quad 2,01 \times 10-5$ $409 \quad 0,044813,90 \times 10-6 \quad 0,0087 \quad 0,0448 \quad 0,04481 \quad 0,04481 \quad 0,04481 \quad 0,04482 \quad 2,28 \times 10-5$ $5120,052724,20 \times 10-60,00797 \quad 0,052710,052720,05272 \quad 0,05273 \quad 0,052732,27 \times 10-5$ $7680,061024,00 \times 10-60,006560,061010,061020,06102 \quad 0,06102 \quad 0,06103 \quad 2,02 \times 10-5$ 
Tabela 34 - Continuação da página anterior

\begin{tabular}{|c|c|c|c|c|c|c|c|c|c|c|}
\hline Módulos & /TM & Média & D.P. & C.V. & Mín. & $1^{\circ} \mathrm{Q}$ & $2^{\circ} \mathrm{Q}$ & $3^{\circ} \mathrm{Q}$ & Máx. & Amplitude \\
\hline & 1024 & 0,07899 & $3,90 \times 10-6$ & 0,00494 & 0,07898 & 0,07899 & 0,07899 & 0,07899 & 0,079 & $2,32 \times 10-5$ \\
\hline & 1280 & 0,09306 & $4,10 \times 10-6$ & 0,00441 & 0,09305 & 0,09306 & 0,09306 & 0,09306 & 0,09307 & $2,15 \times 10-5$ \\
\hline & 1500 & 0,10489 & $4,10 \times 10-6$ & 0,00391 & 0,10488 & 0,10489 & 0,10489 & 0,1049 & 0,1049 & $2,26 \times 10-5$ \\
\hline & 1518 & 0,10573 & $4,10 \times 10-6$ & 0,00388 & 0,10572 & 0,10573 & 0,10573 & 0,10574 & 0,10574 & $2,27 \times 10-5$ \\
\hline \multirow{10}{*}{$\mathrm{M} 4+\mathrm{M} 6+\mathrm{M} 10$} & 69 & 0,01002 & $4,00 \times 10-6$ & 0,03992 & 0,01001 & 0,01002 & 0,01002 & 0,01002 & 0,01003 & $2,36 \times 10-5$ \\
\hline & 128 & 0,01644 & $4,10 \times 10-6$ & 0,02495 & 0,01642 & 0,01643 & 0,01644 & 0,01644 & 0,01645 & $2,18 \times 10-5$ \\
\hline & 256 & 0,02949 & $4,10 \times 10-6$ & 0,0139 & 0,02948 & 0,02949 & 0,02949 & 0,0295 & 0,0295 & $2,22 \times 10-5$ \\
\hline & 409 & 0,04481 & $3,90 \times 10-6$ & 0,0087 & 0,0448 & 0,04481 & 0,04481 & 0,04482 & 0,04482 & $2,28 \times 10-5$ \\
\hline & 512 & 0,05272 & $4,20 \times 10-6$ & 0,00797 & 0,05271 & 0,05272 & 0,05272 & 0,05273 & 0,05273 & $2,21 \times 10-5$ \\
\hline & 768 & 0,06102 & $4,00 \times 10-6$ & 0,00656 & 0,06101 & 0,06102 & 0,06102 & 0,06102 & 0,06103 & $2,17 \times 10-5$ \\
\hline & 1024 & 0,07899 & $4,00 \times 10-6$ & 0,00506 & 0,07898 & 0,07899 & 0,07899 & 0,07899 & 0,079 & $2,15 \times 10-5$ \\
\hline & 1280 & 0,09306 & $4,10 \times 10-6$ & 0,00441 & 0,09305 & 0,09306 & 0,09306 & 0,09306 & 0,09307 & $2,25 \times 10-5$ \\
\hline & 1500 & 0,10489 & $4,10 \times 10-6$ & 0,00391 & 0,10488 & 0,10489 & 0,10489 & 0,1049 & 0,1049 & $2,38 \times 10-5$ \\
\hline & 1518 & 0,10573 & $4,10 \times 10-6$ & 0,00388 & 0,10572 & 0,10573 & 0,10573 & 0,10574 & 0,10574 & $2,26 \times 10-5$ \\
\hline
\end{tabular}

$690,008824,00 \times 10-60,045350,008810,00882 \quad 0,00882 \quad 0,00882 \quad 0,00883 \quad 2,10 \times 10-5$ $128 \quad 0,014524,00 \times 10-6 \quad 0,02756 \quad 0,0145 \quad 0,01451 \quad 0,01452 \quad 0,01452 \quad 0,01453 \quad 2,17 \times 10-5$ $256 \quad 0,026614,10 \times 10-6 \quad 0,01541 \quad 0,0266 \quad 0,02661 \quad 0,02661 \quad 0,02662 \quad 0,02662 \quad 2,24 \times 10-5$ $409 \quad 0,04164,00 \times 10-6 \quad 0,00962 \quad 0,04158 \quad 0,04159 \quad 0,0416 \quad 0,0416 \quad 0,04161 \quad 2, \times 10-5$

M5+M6+M10 $512 \quad 0,04795 \quad 4,20 \times 10-6 \quad 0,00876 \quad 0,04794 \quad 0,04795 \quad 0,04795 \quad 0,04795 \quad 0,04796 \quad 2,26 \times 10-5$ $\begin{array}{lllllllllll}768 & 0,05516 & 4,20 \times 10-6 & 0,00761 & 0,05515 & 0,05516 & 0,05516 & 0,05517 & 0,05517 & 2,15 \times 10-5\end{array}$ $10240,073764,10 \times 10-60,005560,073740,073750,07376 \quad 0,07376 \quad 0,07377 \quad 2,33 \times 10-5$ $12800,088334,20 \times 10-60,004750,088320,088330,08833 \quad 0,08834 \quad 0,08834 \quad 2,32 \times 10-5$ $15000,100334,00 \times 10-60,003990,100320,100330,10033 \quad 0,10034 \quad 0,10034 \quad 2,14 \times 10-5$ $15180,100694,10 \times 10-6 \quad 0,00407 \quad 0,100680,100690,10069 \quad 0,1007 \quad 0,1007 \quad 2,28 \times 10-5$

$690,011944,10 \times 10-60,034340,011930,011940,011940,011940,01195 \quad 2,13 \times 10-5$ $1280,020243,90 \times 10-60,019270,02022 \quad 0,02023 \quad 0,020240,02024 \quad 0,02024 \quad 2,27 \times 10-5$ $2560,037654,10 \times 10-6 \quad 0,010890,03764 \quad 0,03765 \quad 0,03765 \quad 0,03765 \quad 0,03766 \quad 2,14 \times 10-5$ $409 \quad 0,058464,00 \times 10-6 \quad 0,006840,05845 \quad 0,05846 \quad 0,05846 \quad 0,05846 \quad 0,05847 \quad 2,17 \times 10-5$ M3+M8+M10 $512 \quad 0,06958 \quad 4,30 \times 10-6 \quad 0,00618 \quad 0,06957 \quad 0,06958 \quad 0,06958 \quad 0,06958 \quad 0,06959 \quad 2,32 \times 10-5$ $\begin{array}{llllllllllllll}768 & 0,08658 & 4,10 \times 10-6 & 0,00474 & 0,08657 & 0,08658 & 0,08658 & 0,08658 & 0,08659 & 2,05 \times 10-5\end{array}$ $10240,113254,10 \times 10-60,003620,11324 \quad 0,11325 \quad 0,113250,113260,11326 \quad 2,22 \times 10-5$ $12800,136034,10 \times 10-6 \quad 0,00301 \quad 0,136020,13603 \quad 0,13603 \quad 0,13603 \quad 0,13604 \quad 2,17 \times 10-5$ $1500 \quad 0,155514,20 \times 10-6 \quad 0,0027 \quad 0,1555 \quad 0,15551 \quad 0,15551 \quad 0,15551 \quad 0,15552 \quad 2,07 \times 10-5$ $15180,156884,00 \times 10-6 \quad 0,00255 \quad 0,15687 \quad 0,156880,15688 \quad 0,156890,15689 \quad 2,06 \times 10-5$

$690,011944,10 \times 10-6 \quad 0,03434 \quad 0,01193 \quad 0,01194 \quad 0,01194 \quad 0,01194 \quad 0,01195 \quad 2,14 \times 10-5$ $1280,020244,00 \times 10-6 \quad 0,019770,02022 \quad 0,02023 \quad 0,02024 \quad 0,02024 \quad 0,02025 \quad 2,14 \times 10-5$ $256 \quad 0,037654,10 \times 10-6 \quad 0,010890,03764 \quad 0,03765 \quad 0,03765 \quad 0,03765 \quad 0,03766 \quad 2,21 \times 10-5$ $4090,058464,10 \times 10-60,007010,058450,058460,058460,05846 \quad 0,05847 \quad 2,42 \times 10-5$ M4+M8+M10 $512 \quad 0,06958 \quad 4,20 \times 10-6 \quad 0,00604 \quad 0,06957 \quad 0,06958 \quad 0,06958 \quad 0,06958 \quad 0,06959 \quad 2,33 \times 10-5$ $\begin{array}{llllllllllllll}768 & 0,08658 & 4,10 \times 10-6 & 0,00474 & 0,08657 & 0,08658 & 0,08658 & 0,08658 & 0,08659 & 2,08 \times 10-5\end{array}$ $10240,113254,20 \times 10-6 \quad 0,003710,113240,113250,113250,113260,11326 \quad 2,23 \times 10-5$ $12800,136034,10 \times 10-60,003010,136020,136030,13603 \quad 0,13603 \quad 0,136042,26 \times 10-5$ $1500 \quad 0,15551 \quad 4,10 \times 10-6 \quad 0,00264 \quad 0,1555 \quad 0,15551 \quad 0,15551 \quad 0,15551 \quad 0,15552 \quad 2,24 \times 10-5$ 
Tabela 34 - Continuação da página anterior

\begin{tabular}{rcccccccccc}
\hline Módulos & TM Média & D.P. & C.V. & Mín. & $\mathbf{1}^{\mathbf{o}} \mathbf{Q}$ & $\mathbf{2}^{\mathbf{o}} \mathbf{Q}$ & $\mathbf{3}^{\mathbf{o}} \mathbf{Q}$ & Máx. & Amplitude \\
\hline 1518 & 0,15689 & $4,00 \times 10-6$ & 0,00255 & 0,15687 & 0,15688 & 0,15689 & 0,15689 & 0,15689 & $2,09 \times 10-5$ \\
\hline 69 & 0,01074 & $4,10 \times 10-6$ & 0,03818 & 0,01073 & 0,01074 & 0,01074 & 0,01074 & 0,01075 & $2,26 \times 10-5$ \\
128 & 0,01832 & $3,90 \times 10-6$ & 0,02129 & 0,0183 & 0,01831 & 0,01832 & 0,01832 & 0,01832 & $2,14 \times 10-5$ \\
256 & 0,03477 & $4,10 \times 10-6$ & 0,01179 & 0,03476 & 0,03477 & 0,03477 & 0,03477 & 0,03478 & $2,18 \times 10-5$ \\
& 409 & 0,05524 & $3,90 \times 10-6$ & 0,00706 & 0,05523 & 0,05524 & 0,05524 & 0,05525 & 0,05525 & $2,22 \times 10-5$ \\
M5+M8+M10 & 512 & 0,0648 & $4,20 \times 10-6$ & 0,00648 & 0,06479 & 0,0648 & 0,0648 & 0,06481 & 0,06481 & $2,24 \times 10-5$ \\
& 768 & 0,08072 & $4,20 \times 10-6$ & 0,0052 & 0,08071 & 0,08072 & 0,08072 & 0,08073 & 0,08073 & $2,20 \times 10-5$ \\
1024 & 0,10802 & $4,20 \times 10-6$ & 0,00389 & 0,10801 & 0,10802 & 0,10802 & 0,10802 & 0,10803 & $2,03 \times 10-5$ \\
1280 & 0,1313 & $4,10 \times 10-6$ & 0,00312 & 0,13129 & 0,1313 & 0,1313 & 0,1313 & 0,13131 & $2,21 \times 10-5$ \\
1500 & 0,15095 & $4,10 \times 10-6$ & 0,00272 & 0,15094 & 0,15095 & 0,15095 & 0,15095 & 0,15096 & $2,27 \times 10-5$ \\
1518 & 0,15184 & $4,00 \times 10-6$ & 0,00263 & 0,15183 & 0,15184 & 0,15184 & 0,15185 & 0,15185 & $2,03 \times 10-5$ \\
\hline
\end{tabular}

Tabela 35: Comparação do tempo de transferência (ms) entre os tamanhos da mensagem estratificada pela soma dos módulos 3 a 3

\begin{tabular}{|c|c|c|c|c|c|c|c|c|c|c|c|c|c|}
\hline \multirow{2}{*}{\multicolumn{2}{|c|}{ Módulos/TM }} & \multirow{2}{*}{$2^{\circ} \mathrm{Q}$} & \multirow{2}{*}{$1^{\circ} \mathrm{Q}$} & \multirow{2}{*}{$3^{\circ} \mathrm{Q}$} & \multicolumn{9}{|c|}{ Valor-p das Comparações Múltiplas } \\
\hline & & & & & 69 & 128 & 256 & 409 & 512 & 768 & 1024 & 1280 & 1500 \\
\hline \multirow{10}{*}{$\mathrm{M} 3+\mathrm{M} 6+\mathrm{M} 9$} & 69 & 0,00981 & 0,0098 & 0,00981 & & & & & & & & & \\
\hline & 128 & 0,01626 & 0,01626 & 0,01626 & 0 & & & & & & & & \\
\hline & 256 & 0,02932 & 0,02931 & 0,02932 & 0 & 0 & & & & & & & \\
\hline & 409 & 0,04463 & 0,04463 & 0,04463 & 0 & 0 & 0 & & & & & & \\
\hline & 512 & 0,05257 & 0,05256 & 0,05257 & 0 & 0 & 0 & 0 & & & & & \\
\hline & 768 & 0,06086 & 0,06086 & 0,06086 & 0 & 0 & 0 & 0 & 0 & & & & \\
\hline & 1024 & 0,07883 & 0,07883 & 0,07883 & 0 & 0 & 0 & 0 & 0 & 0 & & & \\
\hline & 1280 & 0,0929 & 0,0929 & 0,0929 & 0 & 0 & 0 & 0 & 0 & 0 & 0 & & \\
\hline & 1500 & 0,10453 & 0,10453 & 0,10454 & 0 & 0 & 0 & 0 & 0 & 0 & 0 & 0 & \\
\hline & 1518 & 0,10536 & 0,10536 & 0,10536 & 0 & 0 & 0 & 0 & 0 & 0 & 0 & 0 & 0 \\
\hline \multirow{10}{*}{$\mathrm{M} 3+\mathrm{M} 7+\mathrm{M} 9$} & 69 & 0,01172 & 0,01172 & 0,01173 & & & & & & & & & \\
\hline & 128 & 0,02006 & 0,02006 & 0,02006 & 0 & & & & & & & & \\
\hline & 256 & 0,03747 & 0,03746 & 0,03747 & 0 & 0 & & & & & & & \\
\hline & 409 & 0,05828 & 0,05827 & 0,05828 & 0 & 0 & 0 & & & & & & \\
\hline & 512 & 0,06942 & 0,06942 & 0,06942 & 0 & 0 & 0 & 0 & & & & & \\
\hline & 768 & 0,08642 & 0,08642 & 0,08642 & 0 & 0 & 0 & 0 & 0 & & & & \\
\hline & 1024 & 0,11309 & 0,11309 & 0,1131 & 0 & 0 & 0 & 0 & 0 & 0 & & & \\
\hline & 1280 & 0,13587 & 0,13587 & 0,13587 & 0 & 0 & 0 & 0 & 0 & 0 & 0 & & \\
\hline & 1500 & 0,15515 & 0,15515 & 0,15515 & 0 & 0 & 0 & 0 & 0 & 0 & 0 & 0 & \\
\hline & 1518 & 0,1565 & 0,1565 & 0,1565 & 0 & 0 & 0 & 0 & 0 & 0 & 0 & 0 & 0 \\
\hline \multirow{6}{*}{$\mathrm{M} 4+\mathrm{M} 6+\mathrm{M} 9$} & 69 & 0,00981 & 0,0098 & 0,00981 & & & & & & & & & \\
\hline & 128 & 0,01626 & 0,01626 & 0,01626 & 0 & & & & & & & & \\
\hline & 256 & 0,02932 & 0,02931 & 0,02932 & 0 & 0 & & & & & & & \\
\hline & 409 & 0,04463 & 0,04463 & 0,04463 & 0 & 0 & 0 & & & & & & \\
\hline & 512 & 0,05257 & 0,05256 & 0,05257 & 0 & 0 & 0 & 0 & & & & & \\
\hline & 768 & 0,06086 & 0,06086 & 0,06086 & 0 & 0 & 0 & 0 & 0 & & & & \\
\hline
\end{tabular}


Tabela 35 - Continuação da página anterior

\begin{tabular}{|c|c|c|c|c|c|c|c|c|c|c|c|c|c|}
\hline \multirow{2}{*}{\multicolumn{2}{|c|}{ Módulos/TM }} & \multirow{2}{*}{$2^{\mathrm{o}} \mathrm{Q}$} & \multirow{2}{*}{$1^{\mathrm{o}} \mathrm{Q}$} & \multirow{2}{*}{$3^{\mathrm{o}} \mathrm{Q}$} & \multicolumn{9}{|c|}{ Valor-p das Comparações Múltiplas } \\
\hline & & & & & 69 & 128 & 256 & 409 & 512 & 768 & 1024 & 1280 & 1500 \\
\hline & 1024 & 0,07883 & 0,07883 & 0,07883 & 0 & 0 & 0 & 0 & 0 & 0 & & & \\
\hline & 1280 & 0,0929 & 0,0929 & 0,0929 & 0 & 0 & 0 & 0 & 0 & 0 & 0 & & \\
\hline & 1500 & 0,10453 & 0,10453 & 0,10454 & 0 & 0 & 0 & 0 & 0 & 0 & 0 & 0 & \\
\hline & 1518 & 0,10536 & 0,10536 & 0,10536 & 0 & 0 & 0 & 0 & 0 & 0 & 0 & 0 & 0 \\
\hline \multirow{10}{*}{$\mathrm{M} 4+\mathrm{M} 7+\mathrm{M} 9$} & 69 & 0,01172 & 0,01172 & 0,01173 & & & & & & & & & \\
\hline & 128 & 0,02006 & 0,02006 & 0,02006 & 0 & & & & & & & & \\
\hline & 256 & 0,03747 & 0,03747 & 0,03747 & 0 & 0 & & & & & & & \\
\hline & 409 & 0,05828 & 0,05827 & 0,05828 & 0 & 0 & 0 & & & & & & \\
\hline & 512 & 0,06942 & 0,06942 & 0,06942 & 0 & 0 & 0 & 0 & & & & & \\
\hline & 768 & 0,08642 & 0,08642 & 0,08642 & 0 & 0 & 0 & 0 & 0 & & & & \\
\hline & 1024 & 0,11309 & 0,11309 & 0,1131 & 0 & 0 & 0 & 0 & 0 & 0 & & & \\
\hline & 1280 & 0,13587 & 0,13587 & 0,13587 & 0 & 0 & 0 & 0 & 0 & 0 & 0 & & \\
\hline & 1500 & 0,15515 & 0,15515 & 0,15515 & 0 & 0 & 0 & 0 & 0 & 0 & 0 & 0 & \\
\hline & 1518 & 0,1565 & 0,1565 & 0,1565 & 0 & 0 & 0 & 0 & 0 & 0 & 0 & 0 & 0 \\
\hline \multirow{10}{*}{$\mathrm{M} 5+\mathrm{M} 6+\mathrm{M} 9$} & 69 & 0,00861 & 0,0086 & 0,00861 & & & & & & & & & \\
\hline & 128 & 0,01434 & 0,01434 & 0,01434 & 0 & & & & & & & & \\
\hline & 256 & 0,02644 & 0,02643 & 0,02644 & 0 & 0 & & & & & & & \\
\hline & 409 & 0,04141 & 0,04141 & 0,04142 & 0 & 0 & 0 & & & & & & \\
\hline & 512 & 0,04779 & 0,04779 & 0,04779 & 0 & 0 & 0 & 0 & & & & & \\
\hline & 768 & 0,05501 & 0,055 & 0,05501 & 0 & 0 & 0 & 0 & 0 & & & & \\
\hline & 1024 & 0,0736 & 0,07359 & 0,0736 & 0 & 0 & 0 & 0 & 0 & 0 & & & \\
\hline & 1280 & 0,08817 & 0,08817 & 0,08818 & 0 & 0 & 0 & 0 & 0 & 0 & 0 & & \\
\hline & 1500 & 0,09997 & 0,09997 & 0,09998 & 0 & 0 & 0 & 0 & 0 & 0 & 0 & 0 & \\
\hline & 1518 & 0,10032 & 0,10031 & 0,10032 & 0 & 0 & 0 & 0 & 0 & 0 & 0 & 0 & 0 \\
\hline \multirow{10}{*}{$\mathrm{M} 5+\mathrm{M} 7+\mathrm{M} 9$} & 69 & 0,01052 & 0,01052 & 0,01053 & & & & & & & & & \\
\hline & 128 & 0,01814 & 0,01814 & 0,01814 & 0 & & & & & & & & \\
\hline & 256 & 0,03459 & 0,03459 & 0,03459 & 0 & 0 & & & & & & & \\
\hline & 409 & 0,05506 & 0,05506 & 0,05506 & 0 & 0 & 0 & & & & & & \\
\hline & 512 & 0,06464 & 0,06464 & 0,06465 & 0 & 0 & 0 & 0 & & & & & \\
\hline & 768 & 0,08056 & 0,08056 & 0,08057 & 0 & 0 & 0 & 0 & 0 & & & & \\
\hline & 1024 & 0,10786 & 0,10786 & 0,10786 & 0 & 0 & 0 & 0 & 0 & 0 & & & \\
\hline & 1280 & 0,13114 & 0,13114 & 0,13114 & 0 & 0 & 0 & 0 & 0 & 0 & 0 & & \\
\hline & 1500 & 0,15059 & 0,15059 & 0,15059 & 0 & 0 & 0 & 0 & 0 & 0 & 0 & 0 & \\
\hline & 1518 & 0,15146 & 0,15146 & 0,15146 & 0 & 0 & 0 & 0 & 0 & 0 & 0 & 0 & 0 \\
\hline \multirow{8}{*}{$\mathrm{M} 3+\mathrm{M} 6+\mathrm{M} 10$} & 69 & 0,01002 & 0,01002 & 0,01002 & & & & & & & & & \\
\hline & 128 & 0,01644 & 0,01643 & 0,01644 & 0 & & & & & & & & \\
\hline & 256 & 0,02949 & 0,02949 & 0,0295 & 0 & 0 & & & & & & & \\
\hline & 409 & 0,04481 & 0,04481 & 0,04481 & 0 & 0 & 0 & & & & & & \\
\hline & 512 & 0,05272 & 0,05272 & 0,05273 & 0 & 0 & 0 & 0 & & & & & \\
\hline & 768 & 0,06102 & 0,06102 & 0,06102 & 0 & 0 & 0 & 0 & 0 & & & & \\
\hline & 1024 & 0,07899 & 0,07899 & 0,07899 & 0 & 0 & 0 & 0 & 0 & 0 & & & \\
\hline & 1280 & 0,09306 & 0,09306 & 0,09306 & 0 & 0 & 0 & 0 & 0 & 0 & 0 & & \\
\hline
\end{tabular}


Tabela 35 - Continuação da página anterior

\begin{tabular}{|c|c|c|c|c|c|c|c|c|c|c|c|c|c|}
\hline \multirow{2}{*}{\multicolumn{2}{|c|}{ Módulos/TM }} & \multirow{2}{*}{$2^{\circ} \mathrm{Q}$} & \multirow{2}{*}{$1^{\mathrm{o}} \mathrm{Q}$} & \multirow{2}{*}{$3^{\mathrm{o}} \mathrm{Q}$} & \multicolumn{9}{|c|}{ Valor-p das Comparações Múltiplas } \\
\hline & & & & & 69 & 128 & 256 & 409 & 512 & 768 & 1024 & 1280 & 1500 \\
\hline & 1500 & 0,10489 & 0,10489 & 0,1049 & 0 & 0 & 0 & 0 & 0 & 0 & 0 & 0 & \\
\hline & 1518 & 0,10573 & 0,10573 & 0,10574 & 0 & 0 & 0 & 0 & 0 & 0 & 0 & 0 & 0 \\
\hline \multirow{10}{*}{$\mathrm{M} 4+\mathrm{M} 6+\mathrm{M} 10$} & 69 & 0,01002 & 0,01002 & 0,01002 & & & & & & & & & \\
\hline & 128 & 0,01644 & 0,01643 & 0,01644 & 0 & & & & & & & & \\
\hline & 256 & 0,02949 & 0,02949 & 0,0295 & 0 & 0 & & & & & & & \\
\hline & 409 & 0,04481 & 0,04481 & 0,04482 & 0 & 0 & 0 & & & & & & \\
\hline & 512 & 0,05272 & 0,05272 & 0,05273 & 0 & 0 & 0 & 0 & & & & & \\
\hline & 768 & 0,06102 & 0,06102 & 0,06102 & 0 & 0 & 0 & 0 & 0 & & & & \\
\hline & 1024 & 0,07899 & 0,07899 & 0,07899 & 0 & 0 & 0 & 0 & 0 & 0 & & & \\
\hline & 1280 & 0,09306 & 0,09306 & 0,09306 & 0 & 0 & 0 & 0 & 0 & 0 & 0 & & \\
\hline & 1500 & 0,10489 & 0,10489 & 0,1049 & 0 & 0 & 0 & 0 & 0 & 0 & 0 & 0 & \\
\hline & 1518 & 0,10573 & 0,10573 & 0,10574 & 0 & 0 & 0 & 0 & 0 & 0 & 0 & 0 & 0 \\
\hline \multirow{10}{*}{$\mathrm{M} 5+\mathrm{M} 6+\mathrm{M} 10$} & 69 & 0,00882 & 0,00882 & 0,00882 & & & & & & & & & \\
\hline & 128 & 0,01452 & 0,01451 & 0,01452 & 0 & & & & & & & & \\
\hline & 256 & 0,02661 & 0,02661 & 0,02662 & 0 & 0 & & & & & & & \\
\hline & 409 & 0,0416 & 0,04159 & 0,0416 & 0 & 0 & 0 & & & & & & \\
\hline & 512 & 0,04795 & 0,04795 & 0,04795 & 0 & 0 & 0 & 0 & & & & & \\
\hline & 768 & 0,05516 & 0,05516 & 0,05517 & 0 & 0 & 0 & 0 & 0 & & & & \\
\hline & 1024 & 0,07376 & 0,07375 & 0,07376 & 0 & 0 & 0 & 0 & 0 & 0 & & & \\
\hline & 1280 & 0,08833 & 0,08833 & 0,08834 & 0 & 0 & 0 & 0 & 0 & 0 & 0 & & \\
\hline & 1500 & 0,10033 & 0,10033 & 0,10034 & 0 & 0 & 0 & 0 & 0 & 0 & 0 & 0 & \\
\hline & 1518 & 0,10069 & 0,10069 & 0,1007 & 0 & 0 & 0 & 0 & 0 & 0 & 0 & 0 & 0 \\
\hline \multirow{10}{*}{$\mathrm{M} 3+\mathrm{M} 8+\mathrm{M} 10$} & 69 & 0,01194 & 0,01194 & 0,01194 & & & & & & & & & \\
\hline & 128 & 0,02024 & 0,02023 & 0,02024 & 0 & & & & & & & & \\
\hline & 256 & 0,03765 & 0,03765 & 0,03765 & 0 & 0 & & & & & & & \\
\hline & 409 & 0,05846 & 0,05846 & 0,05846 & 0 & 0 & 0 & & & & & & \\
\hline & 512 & 0,06958 & 0,06958 & 0,06958 & 0 & 0 & 0 & 0 & & & & & \\
\hline & 768 & 0,08658 & 0,08658 & 0,08658 & 0 & 0 & 0 & 0 & 0 & & & & \\
\hline & 1024 & 0,11325 & 0,11325 & 0,11326 & 0 & 0 & 0 & 0 & 0 & 0 & & & \\
\hline & 1280 & 0,13603 & 0,13603 & 0,13603 & 0 & 0 & 0 & 0 & 0 & 0 & 0 & & \\
\hline & 1500 & 0,15551 & 0,15551 & 0,15551 & 0 & 0 & 0 & 0 & 0 & 0 & 0 & 0 & \\
\hline & 1518 & 0,15688 & 0,15688 & 0,15689 & 0 & 0 & 0 & 0 & 0 & 0 & 0 & 0 & 0 \\
\hline
\end{tabular}

\begin{tabular}{|c|c|c|c|c|c|c|c|c|c|c|c|c|c|}
\hline \multirow{10}{*}{$\mathrm{M} 4+\mathrm{M} 8+\mathrm{M} 10$} & 69 & 0,01194 & 0,01194 & 0,01194 & & & & & & & & & \\
\hline & 128 & 0,02024 & 0,02023 & 0,02024 & 0 & & & & & & & & \\
\hline & 256 & 0,03765 & 0,03765 & 0,03765 & 0 & 0 & & & & & & & \\
\hline & 409 & 0,05846 & 0,05846 & 0,05846 & 0 & 0 & 0 & & & & & & \\
\hline & 512 & 0,06958 & 0,06958 & 0,06958 & 0 & 0 & 0 & 0 & & & & & \\
\hline & 768 & 0,08658 & 0,08658 & 0,08658 & 0 & 0 & 0 & 0 & 0 & & & & \\
\hline & 1024 & 0,11325 & 0,11325 & 0,11326 & 0 & 0 & 0 & 0 & 0 & 0 & & & \\
\hline & 1280 & 0,13603 & 0,13603 & 0,13603 & 0 & 0 & 0 & 0 & 0 & 0 & 0 & & \\
\hline & 1500 & 0,15551 & 0,15551 & 0,15551 & 0 & 0 & 0 & 0 & 0 & 0 & 0 & 0 & \\
\hline & 1518 & 0,15689 & 0,15688 & 0,15689 & 0 & 0 & 0 & 0 & 0 & 0 & 0 & 0 & 0 \\
\hline
\end{tabular}


Tabela 35 - Continuação da página anterior

\begin{tabular}{|c|c|c|c|c|c|c|c|c|c|c|c|c|c|}
\hline \multirow{2}{*}{\multicolumn{2}{|c|}{ Módulos/TM }} & \multirow{2}{*}{$2^{\circ} \mathrm{Q}$} & \multirow{2}{*}{$1^{\circ} \mathrm{Q}$} & \multirow{2}{*}{$3^{\mathrm{o}} \mathrm{Q}$} & \multicolumn{9}{|c|}{ Valor-p das Comparações Múltiplas } \\
\hline & & & & & 69 & 128 & 256 & 409 & 512 & 768 & 1024 & 1280 & 1500 \\
\hline \multirow{10}{*}{$\mathrm{M} 5+\mathrm{M} 8+\mathrm{M} 10$} & 69 & 0,01074 & 0,01074 & 0,01074 & & & & & & & & & \\
\hline & 128 & 0,01832 & 0,01831 & 0,01832 & 0 & & & & & & & & \\
\hline & 256 & 0,03477 & 0,03477 & 0,03477 & 0 & 0 & & & & & & & \\
\hline & 409 & 0,05524 & 0,05524 & 0,05525 & 0 & 0 & 0 & & & & & & \\
\hline & 512 & 0,0648 & 0,0648 & 0,06481 & 0 & 0 & 0 & 0 & & & & & \\
\hline & 768 & 0,08072 & 0,08072 & 0,08073 & 0 & 0 & 0 & 0 & 0 & & & & \\
\hline & 1024 & 0,10802 & 0,10802 & 0,10802 & 0 & 0 & 0 & 0 & 0 & 0 & & & \\
\hline & 1280 & 0,1313 & 0,1313 & 0,1313 & 0 & 0 & 0 & 0 & 0 & 0 & 0 & & \\
\hline & 1500 & 0,15095 & 0,15095 & 0,15095 & 0 & 0 & 0 & 0 & 0 & 0 & 0 & 0 & \\
\hline & 1518 & 0,15184 & 0,15184 & 0,15185 & 0 & 0 & 0 & 0 & 0 & 0 & 0 & 0 & 0 \\
\hline
\end{tabular}

